$\gamma$

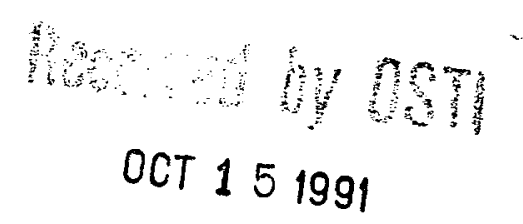

NUREG/CR-5768 PNL-7765

\title{
Ice-Condenser Aerosol Tests
}

Prepared by

M. W. Ligotke, E. J. Eschbach, W. K. Winegardner

Pacific Northwest Laboratory

Operated by

Battelle Memorial Institute

Prepared for

U.S. Nuclear Regulatory Commission 


\section{DISCLAIMER}

This report was prepared as an account of work sponsored by an agency of the United States Government. Neither the United States Government nor any agency Thereof, nor any of their employees, makes any warranty, express or implied, or assumes any legal liability or responsibility for the accuracy, completeness, or usefulness of any information, apparatus, product, or process disclosed, or represents that its use would not infringe privately owned rights. Reference herein to any specific commercial product, process, or service by trade name, trademark, manufacturer, or otherwise does not necessarily constitute or imply its endorsement, recommendation, or favoring by the United States Government or any agency thereof. The views and opinions of authors expressed herein do not necessarily state or reflect those of the United States Government or any agency thereof. 


\section{DISCLAIMER}

Portions of this document may be illegible in electronic image products. Images are produced from the best available original document. 


\section{AVAILABILITY NOTICE}

Availability of Reference Materials Cited in NRC Publications

Most documents cited in NRC publications will be avallable from one of the following sources:

1. The NRC Public Document Room, 2120 L Street. NW., Lower Level, Washington, DC 20555

2. The Superintendent of Documents, U.S. Government Printing Office, P.O. Box 37082, Washington, DC 20013-7082

3. The National Technical Information Service, Springfield, VA 22161

Although the listing that follows represents the majority of documents clted in NRC publications. It is not Intended to be exhaustive.

Referenced documents available for inspection and copying for a fee from the NRC Public Document Room include NRC correspondence and internal NRC memoranda: NRC bulletins, circulars, information notices, inspection and investigation notices: licensee event reports; vendor reports and correspondence; Commisslon papers; and applicant and licensee documents and correspondence.

The following documents in the NUREG serles are available for purchase from the GPO Sales Program: formal NRC staff and contractor reports, NRC-sponsored conference proceedings, international agreement reports, grant publications, and NRC booklets and brochures. Aiso available are regulatory guides, NRC regulations in the Code of Federal Regulations, and Nuclear Regulatory Commission Issuances.

Documents available from the National Technical Information Service include NUREG-series reports and technical reports prepared by other Federal agencies and reports prepared by the Atomic Energy Commission, forerunner agency to the Nuclear Regulatory Commission.

Documents available from public and special technical libraries include all open literature items, such as books, journal articles, and transactions. Federal Register notices, Federal and State legislation, and congressional reports can usually be obtained from these libraries.

Documents such as theses, dissertations, foreign reports and translations, and non-NRC conference proceedings are available for purchase from the organization sponsoring the publication cited.

Single copies of NRC draft reports are available free, to the extent of supply, upon written request to the Office of Administration, Distribution and Mail Services Section, U.S. Nuclear Regulatory Commission, Washington, DC 20555.

Coples of Industry codes and standards used in a substantive manner in the NRC regulatory process are maintained at the NRC Library, 7920 Norfolk Avenue. Bethesda, Maryland, for use by the publlc. Codes and standards are usually copyrighted and may be purchased from the originating organization or, If they are American National Standards, from the American National Standards Institute, 1430 Broadway, New York, NY 10018.

\section{DISCLAIMER NOTICE}

This report was prepared as an account of work sponsored by an agency of the United States Government. Neither the United States Government nor any agency thereof, or any of their employees, makes any warranty, expressed or implied, or assumes any legal liability of responsibility for any third party's use, or the results of such use, of any information, apparatus, product or process disclosed in this report, or represents that its use by such third party would not infringe privately owned rights. 


\section{Ice-Condenser Aerosol Tests}

Manuscript Completed: July 1991

Date Published: September 1991

Prepared by

M. W. Ligotke, E. J. Eschbach, W. K. Winegardner

Pacific Northwest Laboratory

Richland, WA 99352

\section{Prepared for}

Division of Regulatory Applications

Office of Nuclear Regulatory Research

U.S. Nuclear Regulatory Commission

Washington, DC 20555

NRC FIN B2444

This document is
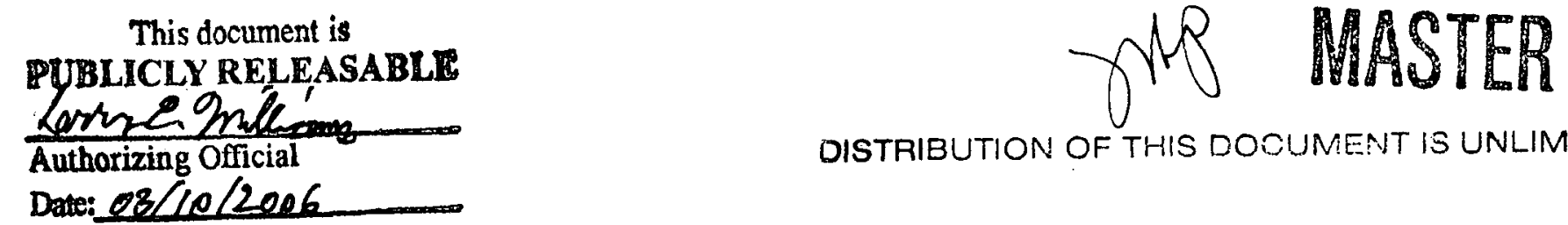


$$
\begin{array}{lll}
\cdots & \cdots \\
\ddots \quad & \cdots
\end{array}
$$




\section{ABSTRACT}

This report presents the results of an experimental investigation of aerosol particle transport and capture using a full-scale height and reduced-scale cross section test facility based on the design of the ice compartment of a pressurized water reactor (PWR) ice-condenser containment system. Results of 38 tests included thermal-hydraulic as well as aerosol particle data. Particle retention in the test section was greatly influenced by thermal-hydraulic and aerosol test parameters. Test-average decontamination factor (DF) ranged between 1.0 and 36 (retentions between 0 and $97.2 \%$ ). The measured test-average particle retentions for tests without and with ice and steam ranged between $D F=1.0$ and 2.2 and $D F=2.4$ and 36 , respectively. In order of apparent importance, parameters that caused particle retention in the test section in the presence of ice were steam mole fraction (SMF), noncondensible gas flow rate (residence time), particle solubility, and inlet particle size. Ice-basket section noncondensible flows greater than $0.1 \mathrm{~m}^{3} / \mathrm{s}$ resulted in stable thermal stratification whereas flows less than $0.1 \mathrm{~m}^{3} / \mathrm{s}$ resulted in thermal behavior termed meandering with frequent temperature crossovers between flow channels. 

SUMMARY

This report presents the results of an experimental investigation of aerosol particle transport and capture using a test. facility based on the design of the ice compartment of a pressurized water reactor (PWR)

ice-condenser containment system. Suspensions of fine particles in steam and/or heated air were directed past ice inventories held in perforated metal baskets.

The original focus of the investigation was to obtain aerosol data, primarily for use in the validation of a computer code (ICEDF). The code was developed to estimate the extent of particle retention in ice compartments during severe nuclear reactor accidents. However, the validation effort was hindered by temperature measurements that revealed the need to reassess the assumptions and analytical models that had been used in development of the code.

Test results provided information about thermal-hydraulic conditions and aerosol particle characteristics and retention in a test section constructed to represent full-scale height and reduced-scale cross section of an ice compartment. A total of 38 tests were performed, including 35 tests with aerosols. Thermal-hydraulic data included inlet gas flow characteristics and temperature profiles, and provided information on flow stratification within the test section. Aerosol data included information about the retention of particles within the test section for tests with and without ice and steam, and for a variety of inlet gas flow and aerosol characteristics. Particle retention was determined as decontamination factor (DF), the ratio of particle mass flow in to that out of the test section, and $R$, the mass percentage of particles retained in the test section. Test-average DF and $R$ were determined for each test using the average results of particle mass flow rate measurements at the inlet and outlet. Other aerosol information included particle size at the inlet and outlet and the distribution of aerosol mass concentration within the ice-basket region of the test section. Additionally, a mass balance analysis was performed for three tests to determine the ability to recover generated aerosol material and to provide a secondary method of determining particle retention results.

Thermal-hydraulic test results indicated that the inlet diffuser thermal behavior was related most strongly to the total volume flow rate. It was deduced that the coldest inlet diffuser region exhibited reverse flow when the diffuser was thermally stratified. Ice-basket region thermal behavior was related to noncondensible flow rate. Ice-basket section noncondensible flows greater than $0.1 \mathrm{~m}^{3} / \mathrm{s}$ resulted in stable thermal stratification whereas flows less than $0.1 \mathrm{~m}^{3} / \mathrm{s}$ resulted in thermal behavior described as meandering with frequent temperature crossovers between flow channels.

Particle retention in the test section was greatly influenced by thermal-hydraulic and aerosol test parameters. Test-average DF ranged between 1.0 and 36 ( $R$ between $\sim$ and $97.2 \%$ ). For inlet aerodynamic mass median 
diameters (AMMD) less than $12 \mu \mathrm{m}$, all tests performed with ice and steam (complex case) resulted in greater particle retention than tests performed without ice and steam (simple case). The measured test-average particle retentions for the simple case ranged between $D F=1.0$ and $2.2(R=\sim 0$ to $55 \%$ ), and those for the complex case ranged between $D F=2.4$ and 36 ( $R=58$ and $97.2 \%$ ). In order of apparent importance, parameters that caused particle retention in the test section in the presence of ice were steam mole fraction (SMF), noncondensible gas flow rate (residence time), particle solubility, and inlet particle size. Particle retention was shown to increase with increasing SMF, decreasing noncondensible gas flow rate, and increasing inlet particle size. In addition, greater particle retention was measured during tests of soluble-particle aerosols when compared to tests of insoluble-particle aerosols.

The use of a specific model or tradename in this document was for research accountability only and does not imply Pacific Northwest Laboratory's endorsement of this item. 


\section{ACKNOWLEDGMENTS}

Selection of test parameters and design of the facility began in 1985 . Many contributors were involved over the years including the following Pacific Northwest Laboratory staff members. Landis Kannberg, Brad Ross, Jim Bates, and $\mathrm{Cliff}$ Haines were vital members of the design and operation teams. Landis directed the design effort. Brad directed installation of the test facility. $\mathrm{Jim}$ and $\mathrm{Cliff}$ directed the procurement of flow instrumentation and the data acquisition system, respectively. Design drawings for the test facility were prepared by Walt Jackson, and structural analysis of components was provided by Tom Gates. Greg Piepel directed development of the statistically-based experimental design. Bill Hanf, Jr., and Ken Hinkle provided valuable assistance in completing aerosol- and facility-related tasks, respectively. Donald Klopfer, Peter Owczarski, Kris Northy, Gary Dennis, Judith Bamberger, Sharon Bailey, and Janet Roberts also provided valuable assistance in the laboratory and during tests. Sue Arey provided project support and greatly aided in preparation of reports.

The authors would also like to gratefully acknowledge the significant contributions made to the project by Charles Nilsen, USNRC/RES in his position as Project Manager in the Divisions and Branches that sponsored this work. As part of peer review teams, Arlin Postma, Benton City Technology; Jim Gieseke and Ken Lee, Battelle Columbus Laboratories; Jerry McCormack and Bob Hilliard, Westinghouse Hanford Company; and Owen Moss and Don Trent, Battelle, provided valuable recommendations regarding the facility design and experimental approach. Finally, the perforated metal basket used to construct the fullsize center column of the test facility was graciously provided by the Duke Power Company. 
. 


\section{CONTENTS}

ABSTRACT .............................

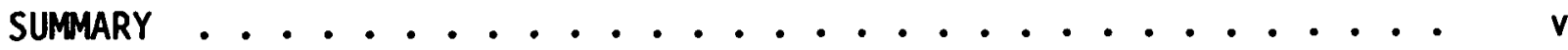
ACKNOWLEDGMENTS ................................. vi

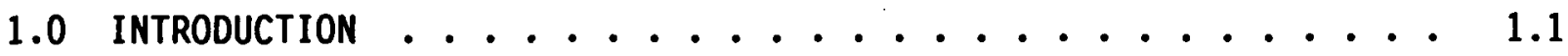

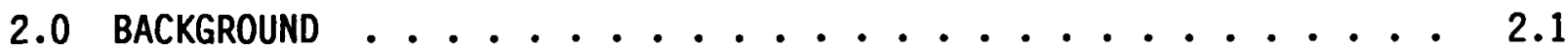

3.0 MATERIALS AND METHODS . . . . . . . . . . . . 3.1

3.1 FACILITY DESCRIPTION . . . . . . . . . . . 3.1

3.1.1 Test Facility Building .................. 3.1

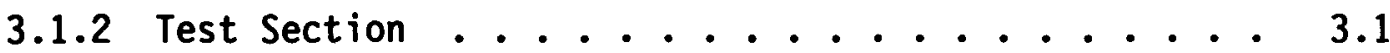

3.1 .3 Refrigeration System ........... 3.6

3.1 .4 Influent Systems . . . . . . . . . 3.6

3.1.5 Effluent Systems ............ 3.8

3.1.6 Data Acquisition System . . . . . . . 3.9

3.2 NON-AEROSOL SYSTEMS . . . . . . . . . . 3.10

3.2.1 Condensate and Meltwater Measurement Systems ... 3.10

3.2.2 Process and Control Instrumentation ....... 3.14

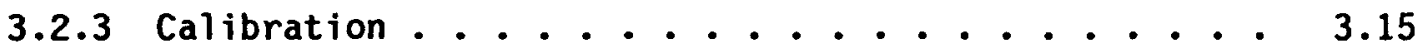

3.3 TEST SECTION THERMAL MEASUREMENT . . . . . . . . . 3.15

3.3.1 Description of Thermocouples ........ 3.15

3.3.2 Diffuser Temperature Measurement ...... 3.15

3.3.3 Ice-Basket Section Temperature Measurement . . . 3.16

3.3.4 Calibration..................... 3.22

3.4 AEROSOL GENERATION . . . . . . . . . . . . 3.22 
3.5 AEROSOL CHARACTERIZATION . . . . . . . . . . 3.27

3.5.1 Aerosol Sampling Stations........... 3.27

3.5.2 Critical Orifice Flow-Rate Controllers ...... 3.31

3.5.3 Aerosol Mass Concentration ......... 3.32

3.5.4 Particle Size Distribution and Morphology ..... 3.33

3.5.5 Probe and Sampler Calibration Tests....... 3.34

3.5.6 Aerosol Material Mass Balance ......... 3.37

3.5.7 Aerosol Data Analysis Procedures ........ . 3.40

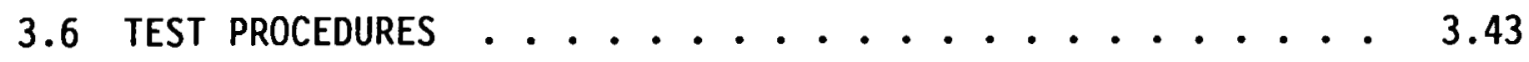

3.6.1 Ice Loading and Test System Preparation ...... 3.43

3.6.2 Thermal-Hydraulic Test Procedures ....... 3.44

3.6.3 Aerosol Generation .............. 3.47

3.6.4 Aerosol Characterization ......... 3.48

4.0 TEST RESULTS AND DISCUSSION . . . . . . . . . . . 4.1

4.1 MEASURED TEST CONDITIONS ...................... 4.1

4.2 THERMAL-HYDRAULIC RESULTS . . . . . . . . . 4.5

4.2 .1 Tests 1 through $7 \ldots \ldots . . . . . . . .4 .5$

4.2.2 Velocity Profile Measurements .......... 4.20

4.2 .3 Tests 8 through $14 \ldots \ldots . \ldots . \ldots 4 . \ldots . \ldots$

4.2 .4 Tests 12,13 , and $14 \ldots \ldots . \ldots . . . \ldots 49$

4.2.5 Thermal-Hydraulic Observation Summary ....... 4.46

4.3 PARTICLE RETENTION . . . . . . . . . . . . 4.47

4.3.1 Steam Mole Fraction ............. 4.47

4.3.2 Sample Analyses: Mass and Chemistry ...... 4.48

4.3.3 Particle Size Distribution and Morphology . . . . 4.51 
4.3.4 Particle Mass Concentration .......... 4.58

4.3.5 Particle Mass Flow Rate ............. 4.60

4.3.6 Particle Retention: Decontamination Factor .... 4.61

4.3.7 Aerosol Material Mass Balance .......... 4.78

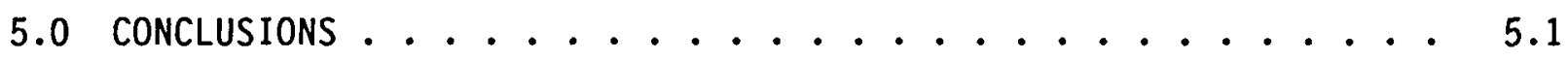

5.1 THERMAL-HYDRAULIC CONCLUSIONS ................ 5.1

5.2 AEROSOL CONCLUSIONS ...................... 5.1

5.3 CODE VAlidation ......................... 5.4

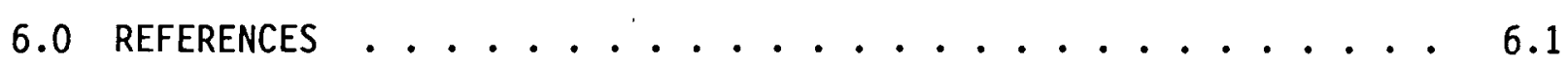

APPENDIX A - EXPERIMENTAL STRATEGY . . . . . . . . . . A. A

APPENDIX B - THERMAL-HYDRAULIC GENERAL DATA REDUCTION PROCEDURES . . B B.1

APPENDIX C - STEAM MOLE FRACTION DATA REDUCTION WORKSHEETS . . . . . C.1

APPENDIX D - AEROSOL PARTICLE SIZE DISTRIBUTION . . . . . . . D.

APPENDIX E - PARTICLE CONCENTRATION AND MASS FLOW RATE WORKSHEETS . . E.1

APPENDIX F - ICE-BASKET REGION PARTICLE MASS CONCENTRATION . . . . . F.1

APPENDIX G - INLET AND OUTLET PARTICLE MASS FLOW RATES . . . . . . G.1 


\section{FIGURES}

2.1 Test Section Thermal-Hydraulic and Aerosol Processes . . . . 2.2

3.1 Schematic of Ice-Condenser Test Facility ........ 3.2

3.2 Elevation View of the West Face of the Test Section . . . . 3.3

3.3 Test Section Cross Section .............. 3.5

3.4 Elevation View of the West Face of the Test Section with Identification of Penetration Locations .......... 3.7

3.5 Diffuser Rake Locations . . . . . . . . . . . . . 3.17

3.6 Diffuser Rake Element Distribution for Each Rake Location . . . 3.18

3.7 Typical Cross Section of the Test Section with Quadrants Identified .............. 3.19

3.8 Flow-Channel Temperature Measurement Locations . . . . . . 3.19

3.9 Test Section Skin Thermocouple Locations at Each Leve1 . . . 3.21

3.10 Sketch of a Trost Model TX Energy Mill Used to Generate Aerosols for Ice-Condenser Tests ............ 3.24

3.11 Sketch of a Heat Systems Model 600-1 Ultrasonic Nozzle Used to Generate CSI Aerosol for Ice-Condenser Test $7 \ldots \ldots$

3.12 Sketch of a Vibrating Orifice Aerosol Generator (VOAG) Used to Generate Aerosols for Ice-Condenser Tests . . . . . . 3.26

3.13 Sketch of a Typical Ice-Condenser Aerosol Sampling Station . . 3.29

3.14 Comparison of Critical Orifice (CO) Flow Rate Calibration Results (using a Dry Test Meter) to Two Methods of Calculating Flow Rate [(CEH) = Chemical Engineer's Handbook (1973), $($ SHP $)=$ Shapiro (1953)] at Standard Temperature and Pressure . . 3.31

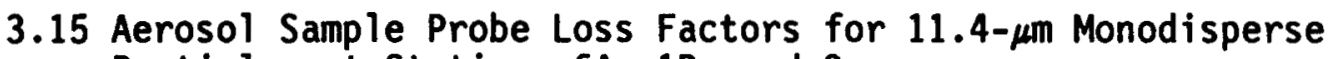

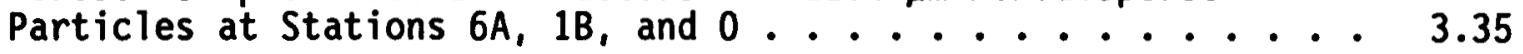

3.16 Results of a Calibration of Andersen Ambient Cascade Impactors Operated at Nominal (28 $\mathrm{lpm})$ and Less-Than-Nominal $(7,14,18$, and $21 \mathrm{lpm})$ Flow Rates .................... 36

3.17 Aerosol Mass Balance Procedure Influent and Effluent Streams . 3.38 
3.18 Example Aerosol Sampling Test Protocol - Station 6A, Test 13 . 3.50

3.19 Example Data Sheet - Station 6A, Test 13a . . . . . . . 3.51

4.1 Ice-Basket Section Thermal Profiles, Test 1 . . . . . . 4 4.7

4.2 Ice-Basket Section Thermal Profiles, Test $4 \ldots . . . . . .4 .8$

4.3 Ice-Basket Section Thermal Profiles, Test 2 ........ 4.9

4.4 Diffuser Rake Locations . . . . . . . . . . . . . . 4 4.11

4.5 Ice-Basket Section Thermal Profiles, Test 5 . . . . . . 4 4.12

4.6 Diffuser Thermal Profiles, Test 5 . . . . . . . . . 4.13

4.7 Ice-Basket Section Thermal Profiles, Test 6, Levels 1 and 5 . . 4.15

4.8 Ice-Basket Section Thermal Profiles, Test 6, Level 3 . . . . 4.16

4.9 Diffuser Thermal Profiles, Test 6 . . . . . . . . . 4.17

4.10 Ice-Basket Section Thermal Profiles, Test 7 . . . . . . 4.18

4.11 Diffuser Thermal Profiles, Test 7 . . . . . . . . 4.19

4.12 Velocity Profiles.................. 4.21

4.13 Available Flow Cross-Sectional Area . . . . . . . . . 4. 4.23

4.14 Velocity Profiles at Levels 5 and 1 for V-1 . . . . . . . 4.24

4.15 Velocity Profiles at Levels 5 and 1 for V-2 . . . . . . . 4.25

4.16 Velocity Profiles at Levels 5 and 1 for V-3 . . . . . . . 4.26

4.17 Revised Velocity Profile for V-1 Level 5 and the Diffuser . . . 4.29

4.18 Revised Version of the Diffuser Velocity Profile for V-2 . . . 4.30

4.19 Ice-Basket Section Thermal Profiles, Test 8 . . . . . . . 4.33

4.20 Diffuser Thermal Profiles, Test $8 \ldots . . . . . . . . . . .34$

4.21 Diffuser Thermal Profiles, Test 9 . . . . . . . . 4.35

4.22 Diffuser Thermal Profiles, Test 11 . . . . . . . . 4.36 
4.23 Ice-Basket Section Thermal Profiles, Test 9 . . . . . . . 4.37

4.24 Ice-Basket Section Thermal Profiles, Test $11 \ldots . . . . . .4 .38$

4.25 Diffuser Thermal Profiles, Test 12 . . . . . . . 4.40

4.26 Diffuser Thermal Profiles, Test $13 \ldots . . . . . . .4 .41$

4:27 Diffuser Thermal Profiles, Test $14 \ldots . . . . . . . .44 .42$

4.28 Ice-Basket Section Thermal Profiles, Test $12 \ldots . . \ldots 4.4 . . .43$

4.29 Ice-Basket Section Thermal Profiles, Test $13 \ldots . . . . . .4 .44$

4.30 Ice-Basket Section Thermal Profiles, Test $14 \ldots . . . . . .4 .45$

4.31 Steam Mole Fraction Versus Time for the Test Section Inlet (Station 6A) and the Outlet (Station 0) During Tests 13b, 8, and $11 \ldots \ldots \ldots \ldots \ldots$

4.32 Scanning Electron Micrographs of CsI Particles Collected Near the Ultrasonic Nozzle Aerosol Generator on Glass Slide (Top) and Millipore Membrane Substrate (Bottom) ...........

4.33 Scanning Electron Micrographs of ZnS Particles Generated by the Energy Mill and Collected on Deposition Inserts in the Ice-Basket

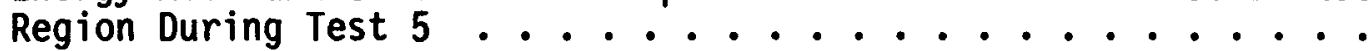

4.34 Scanning Electron Micrographs of ZnS Particles Generated by the Energy Mill and Collected on Nucleopore Filters at the Inlet (Lower Micrograph) and Upper Ice-Basket Region (Upper Micrograph) During Test 6..............

4.35 Decontamination Factor and Particle Retention Results for Tests 1,2 , and $3 \ldots \ldots \ldots \ldots$

4.36 Decontamination Factor and Particle Retention Results for Tests

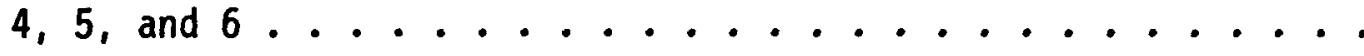

4.37 Decontamination Factor and Particle Retention Results for Tests 7 and $8 \ldots \ldots \ldots \ldots \ldots \ldots$

4.38 Decontamination Factor and Particle Retention Results for Test 8 (contd) and Test $9 \ldots \ldots \ldots \ldots$

4.39 Decontamination Factor and Particle Retention Results for Tests 10,11 , and $12 \mathrm{a} \ldots \ldots \ldots \ldots \ldots$

4.40 Decontamination Factor and Particle Retention Results for Tests $12 \mathrm{~b}, 12 \mathrm{c}$, and $12 \mathrm{~d} \ldots \ldots \ldots \ldots \ldots$ 
4.41 Decontamination Factor and Particle Retention Results for Tests $13 \mathrm{a}$ and 13b............................. 4.70

4.42 Decontamination Factor and Particle Retention Results for Test 13b (contd) ...................... 4.71

4.43 Decontamination Factor and Particle Retention Results for Test

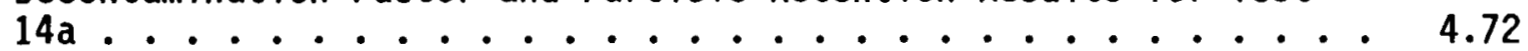

4.44 Decontamination Factor and Particle Retention Results for Test $14 a$ (contd) .....................

4.45 Decontamination Factor and Particle Retention Results for Test

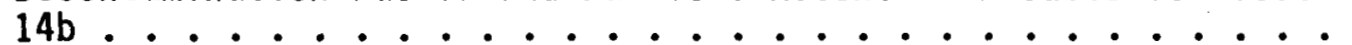

4.46 Decontamination Factor and Particle Retention Results for Test $14 b$ (contd) ..................... 


\section{TABLES}

3.1 Facility Instrumentation ....................... 3.11

3.2 Test Section Skin Thermocouple Locations . . . . . . . 3.20

3.3 Ice Loading Summary . . . . . . . . . . . . . . 3.44

4.1 Measured Inlet Test Conditions ............. 4.2

4.2 Instrumentation Available for Each Test . . . . . . . . 4.5

4.3 Estimated Volumetric Flow Rates for V-1 .......... 4.27

4.4 Est imated Volumetric flow Rates for V-2 . . . . . . . 4.30

4.5 Estimated Volumetric flow Rates for V-3 ..........4 4.31

4.6 Thermal-Hydraulic Observations ............ . . 4.46

4.7 Comparisons of Chemical Analyses of Aerosol Samples Analyzed for Two Ions ................ 4.50

4.8 Comparisons of Chemical Analyses and Gravimetric Analyses of Aerosol Samples ............... 4.50

4.9 Aerosol Particle Size Distribution Results of Cascade Impactor

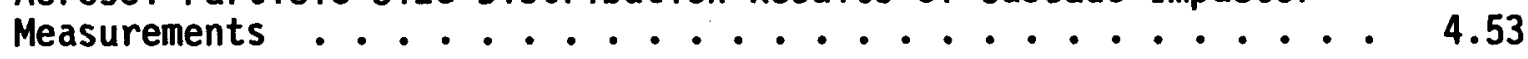

4.10 Distribution of Aerosol Mass Concentration in the Ice-Basket

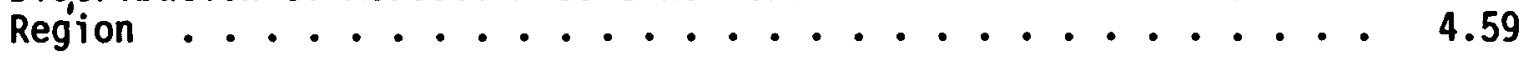

4.11 Results of DF Measurements: Simple Case (No Steam) . . . . . 4.62

4.12 Results of DF Measurements: Complex Case (Both Ice and Steam

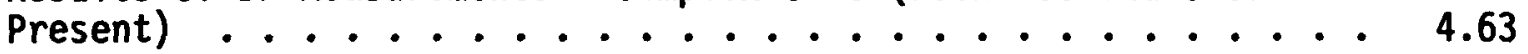

4.13 Aerosol Material Recovery and Estimated Particle Retention Based on an Aerosol Material Mass Balance .......... 4.79

A.1 Percentage of Time Accident Conditions are Encompassed by

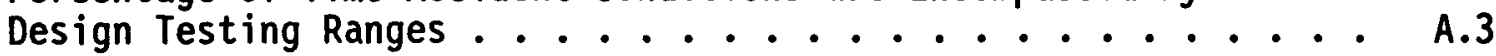

A.2 Test Matrix .................. A.6 


\subsection{INTRODUCTION}

This report presents the results of an experimental investigation of aerosol particle transport and capture using a test facility based on the design of the ice compartment of a pressurized water reactor (PWR) icecondenser containment system. The test conditions selected for this study included evaluation of the effects of ice load, steam condensation, fluid flow velocity, and particle size. Suspensions of fine particles in steam and/or heated air were directed past ice inventories that had been manually loaded into perforated metal baskets. The baskets were stacked in columns in a geometry equivalent to four full-length $(14.6-\mathrm{m})$ ice-compartment columns. An arrangement of one full-size 30.5-cm-diameter cylindrical central column surrounded by four quarter or corner and four half or side columns provided four cross-shaped flow channels for routing the aerosols past the melting ice. Almost from the onset of testing it appeared likely that the introduction of hot gases into the cold air was causing the formation of complex, buoyancyinduced flow fields. Temperature data and gas velocity measurements obtained to gain insights into these patterns are also presented.

The original focus of the investigation was to obtain aerosol data, primarily for use in the validation of a computer code (ICEDF). The code was developed to estimate the extent of particle retention in ice compartments during severe nuclear reactor accidents (Owczarski, Schreck, and Winegardner 1985). A large amount of information concerning fine particle behavior was obtained despite the many problems that are inherent in sampling from a condensing steam environment. However, the validation effort was hindered by temperature measurements that revealed the need to reassess the assumptions and analytical models that had been used in development of the code.

Specifically, results indicated that models used to represent material balances (assuming well-mixed volumes) should be replaced by those that would more adequately depict the stratified and bidirectional patterns that were being suggested by the measurements. In addition, temperature data indicated that improved representations of the transient ice geometry might also be needed. The test results can, of course, be used to aid in the development of such models, especially in the case of flow field definition. However, results are being published at this time because they may have a significantly broader application, namely for use in generating model-data comparisons using other codes that have been developed to provide best-estimates of flow patterns, heat transfer, and/or particle behavior in environments involving the mixing of hot and cold gases and/or transient steam condensation in the presence of noncondensibles.

The work was performed by Pacific Northwest Laboratory (a) (PNL) as part of a U.S. Nuclear Regulatory Commission (NRC) sponsored project to investigate the fission product removal effectiveness of light water reactor engineered safety feature (ESF) systems considering postulated severe accident conditions.

(a) Operated for the U.S. Department of Energy by Battelle Memorial Institute under Contract DE-ACO6-76RLO 1830. 


\subsection{BACKGROUND}

The geometry of the vertical ice-basket regiun of the facility test section was based on the configuration of the ice compartment of a pressurized water reactor ice-condenser containment system. This type of containment system has been described by Liparulo, Tinkler, and George (1976). Briefly, the system "... is designed to suppress the rise' in pressure within the reactor containment that would result from a rupture in the reactor coolant system. The ice-condenser concept is based on the use of a suitable quantity of ice as a low-temperature, passive heat sink to condense the steam and thus absorb the energy released to the containment atmosphere following a postulated pipe rupture... The ice-condenser is essentially a cold-storage room, which in plan $v$ iew extends as a partial annulus around approximately $300^{\circ}$ of the periphery of the reactor containment building... The ice (more than 1.1 million $\mathrm{kg}$ )... is contained in (cylindrical) perforated-metal baskets...stacked in columns to provide suitable flow channels through and between them for passage of steam and air... The ice-condenser (compartment) consists of 24 identical modules or bays, each of which holds 81 basket columns in an array of 9 radial and 9 circumferential rows...". Information presented in the following section will reveal that the vertical ice-basket region of the facility test section contained the equivalent of four of these basket columns.

As additional background information, it should be emphasized that the test facility was designed for use in an experimental investigation of aerosol particle transport and capture, i.e., an aspect of reactor accidents other than pressure suppression. Computer-generated estimates of the conditions associated with severe accidents indicate that large quantities of aerosol particles can be generated following pipe rupture, loss of coolant, primary system blowdown, and pressure suppression. Progressive thermal degradation of the reactor core can lead to particle formation by volatilization and condensation of structural material as well as irradiated fuel elements and fission products. Fine particles can also be formed external to the failed reactor vessel as a result of interactions between molten core debris and concrete. In either case, the aerosols that are generated may then pass through the ice compartment. The test facility discussed in this report was designed to investigate the extent of particle capture during this passage. Selected transient thermal-hydraulic and aerosol processes associated with the condensing steam environment of the test section are shown in Figure 2.1. As shown in this figure, mechanisms identified as being potentially important to the capture of aerosol particles include settling on upward facing horizontal basket surfaces, impaction and interception by basket surfaces, diffusiophoresis (or more appropriately Stefan flow), thermophoresis, and particle grow'th. 


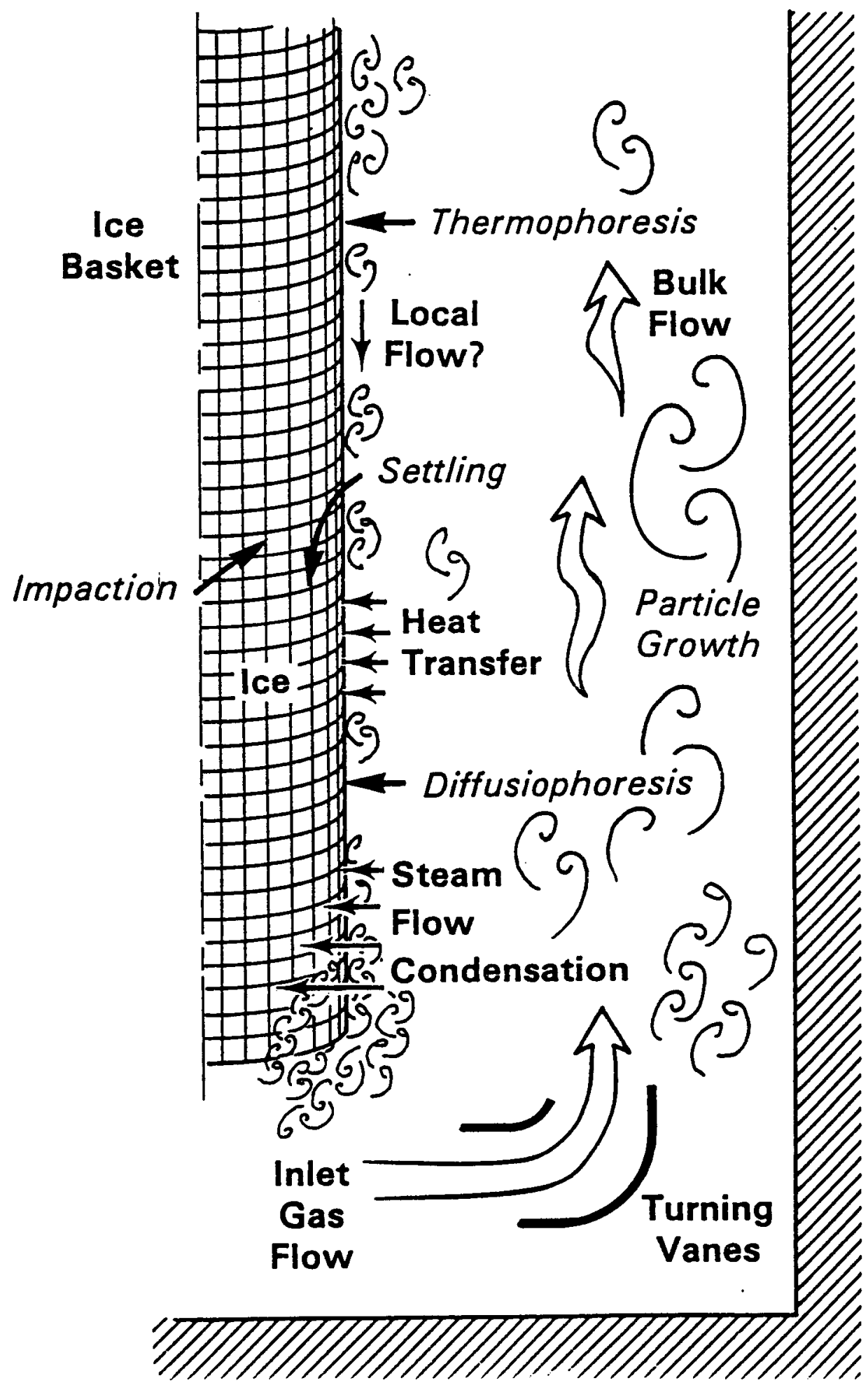

FIGURE 2.1. Test Section Thermal-Hydraulic and Aerosol Processes 


\subsection{MATERIALS AND METHODS}

A series of aerosol particle retention tests was performed in a test section constructed to provide full height and reduced cross-section replication of the ice compartments of ice-condenser containment systems. Suspensions of fine particles in heated air or steam and heated air were directed past ice inventories that had been manually loaded into perforated sheet-metal baskets. Particle retention was determined by sampling the mixed stream at the inlet and outlet regions and at several locations with in the ice-basket region of the test section. Descriptions of the facility, thermal measurements, and aerosol generation and characterization techniques are presented in this section, along with test procedures.

\subsection{FACILITY DESCRIPTION}

The test facility is located in the High Bay Test Facility (HBTF), Building 336 in the 300 Area of the Hanford Reser ation, Richland, Washington. The test facility, illustrated in Figure 3.1, was designed to investigate aerosol particle retention in the ice compartment of PWR ice-condenser containment systems. The primary features of the test facility and systems are described in the following subsections.

\subsubsection{Test Facility Building}

The HBTF has a 24.4-m high ceiling and a 6.1-m diameter pit that extends $15.2 \mathrm{~m}$ below grade. A one-story control room is located at Level 1 in the northeast corner of the building. This control room, with a separate heating, ventilation, and air conditioning (HVAC) system and conditioned power supply, housed the computer-based data acquisition system and is the center of operations for the facility. A U-shaped platform was installed $2.4 \mathrm{~m}$ above grade to facilitate ice loading into the test section and other necessary operations at the top of the test section and bypass line. Standard stairs provided access to the platform and Level 2; spiral stairs were installed to access the lower levels of the pit. A large rolling metal door at the south side of the building allowed a truck to back into the building so that ice could be unloaded directly onto the ice loading platform. The entire building is both heated and air conditioned. An independent ventilation system assures air supply to the pit. A 4.5-metric-ton overhead crane is available for removal and installation of test section ice-basket columns, as well as general hoisting.

\subsubsection{Test Section}

The entire test section, shown in Figure 3.2, was 17.1-m high; the $14.6-\mathrm{m}$ ice columns were centered between the turning vane assemblies located at the inlet and outlet of the ice-basket region of the test section. Access doors for ice loading and removal were located at the out let of the ice-basket region and at Level 6 of the pit. Ten other access doors were located at various levels on the north side of the test section. Eleven sight windows, $10.2 \mathrm{~cm}$ in diameter with internal wipers, were located on the north side at' 


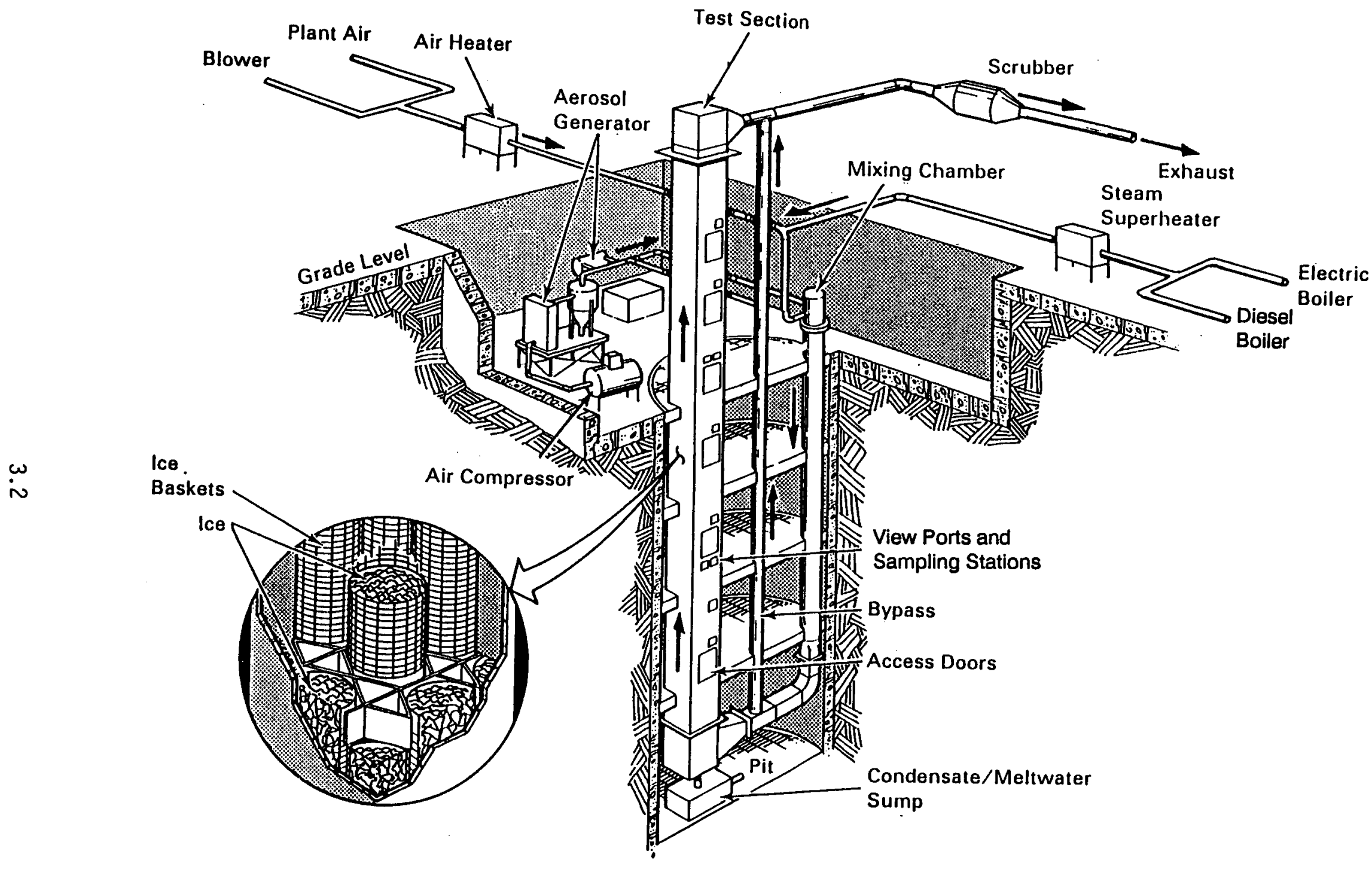

FIGURE 3.1. Schematic of Ice-Condenser Test Facility 


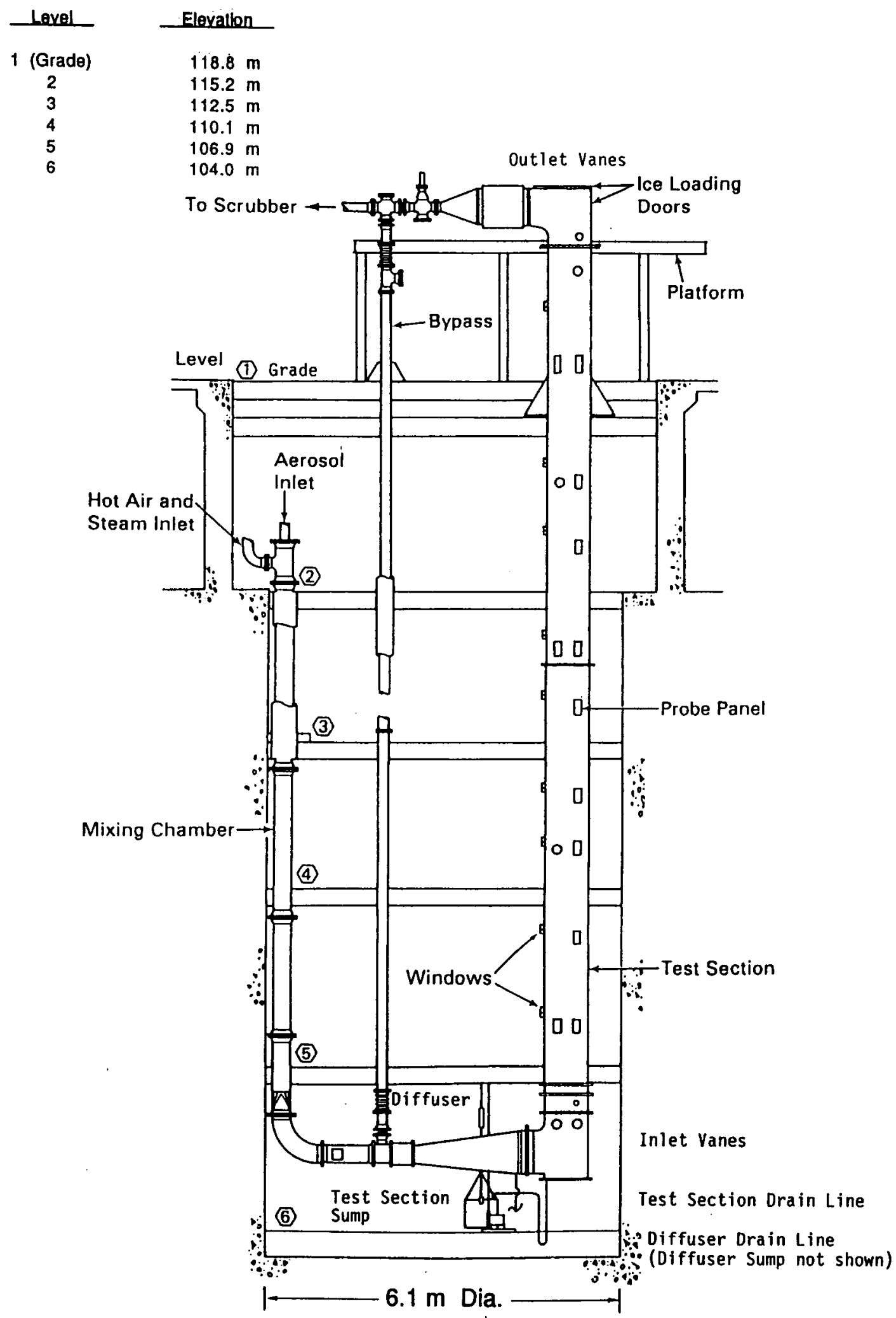

FIGURE 3.2. Elevation View of the West Face of the Test Section 
various levels of the test section and enabled observation of the flow and the ice when conditions permitted. The original 12 probe panels, on the west side of the test section at various elevations, provided multiple penetrations for the installation of instruments. Distribution of the west face probe panels is shown in Figure 3.2. Within the pit, there was limited access to the south side of the test section. The design pressure of the test section was $103 \mathrm{kPa}$ gage. The normal operating test section pressure, however, did not exceed $13.8 \mathrm{kPa}$ gage. The maximum test section operating temperature was $200^{\circ} \mathrm{C}$.

The test section was made up of three major subsections: the diffuser inlet, ice-basket section, and the outlet. Typically, the diffuser inlet is referred to simply as the diffuser. Each subsection of the test section is described below in more detail.

\subsubsection{Diffuser Inlet Section}

The diffuser section was the final horizontal transition from the downcomer to the ice-basket section inlet. As implied by the name, the diffuser increased in cross-sectional area in the direction of flow. Over a length of $1.74 \mathrm{~m}$, the cross section increased from a $30.5-\mathrm{cm}$ square at the inlet to a $72.4-\mathrm{cm}$ square at the exit. The angle of expansion was approximately $7.3^{\circ}$ from horizontal. Just downstream from the diffuser outlet were inlet turning vanes that directed the flow upward into the vertical icebasket section.

\subsubsection{Ice-Basket Section}

The ice-basket section was $14.6-\mathrm{m}$ tall with a $72.4-\mathrm{cm}$ square cross section and was made of one whole, four half, and four quarter ice baskets; in sum, equivalent to four complete ice-basket columns, as shown in Figure 3.3. Four primary open flow channels (typically referred to as quadrants) were formed by the ice-fijled baskets. A prototypic center-basket was borrowed from Duke Power Company . Partial baskets, half and quarter sections, were specifically fabricated for the test section and had sheet-metal backings for structural integrity. Ice-basket lattice supports, similar to those found in the containment system, were installed in the ice-basket section. Nine lattice supports, at the prototypic $1.8-\mathrm{m}$ intervals starting at the base and ending at the top of the ice-basket column, were installed in the ice-basket section. The ice-basket section replicated full basket column height and nominal fully loaded ice-basket column weight. The ice inventory of the unit cell was approximately $0.2 \%$ of a full-scale ice-condenser: 2400 to $2500 \mathrm{~kg}$ of plain water ice versus 1.1 million $\mathrm{kg}$ of borated ice.

\subsubsection{Additional Ice-Basket Section Access}

Ice-basket section instrumentation access (provided by the original 12 probe panels distributed over the west face of the test section mentioned in Section 3.1.2) was augmented by additional single penetrations. Combined,

(a) Duke Power Company, Charlotte, North Carolina. 


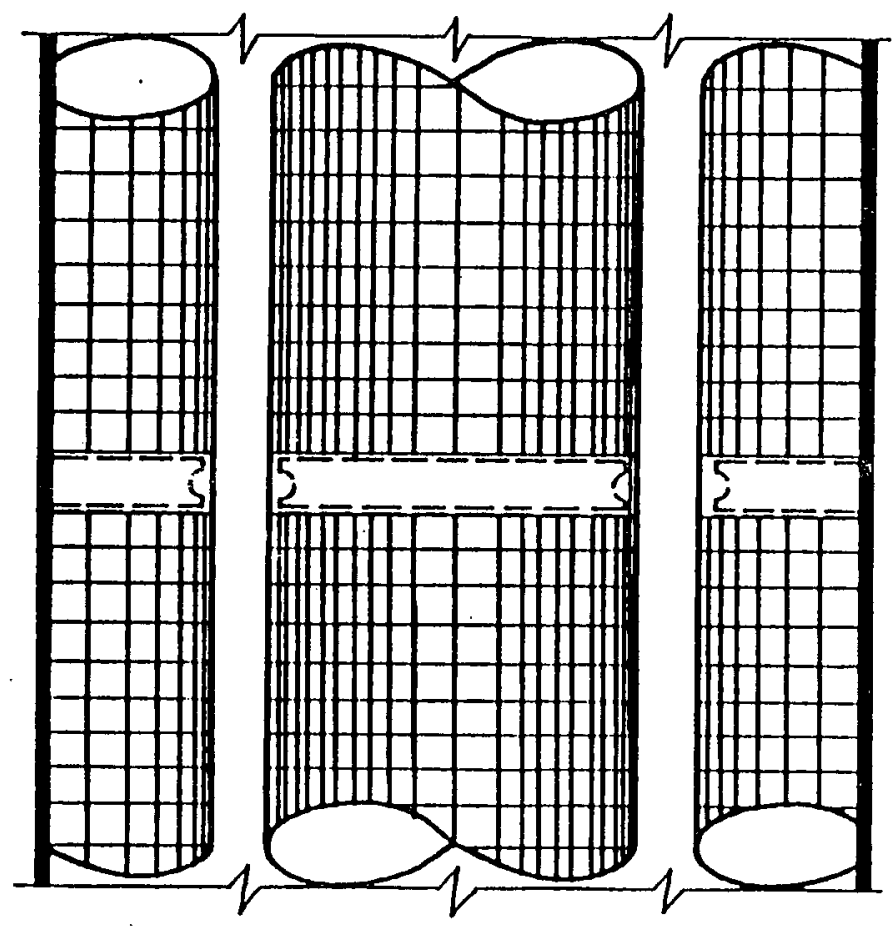

Elevation View

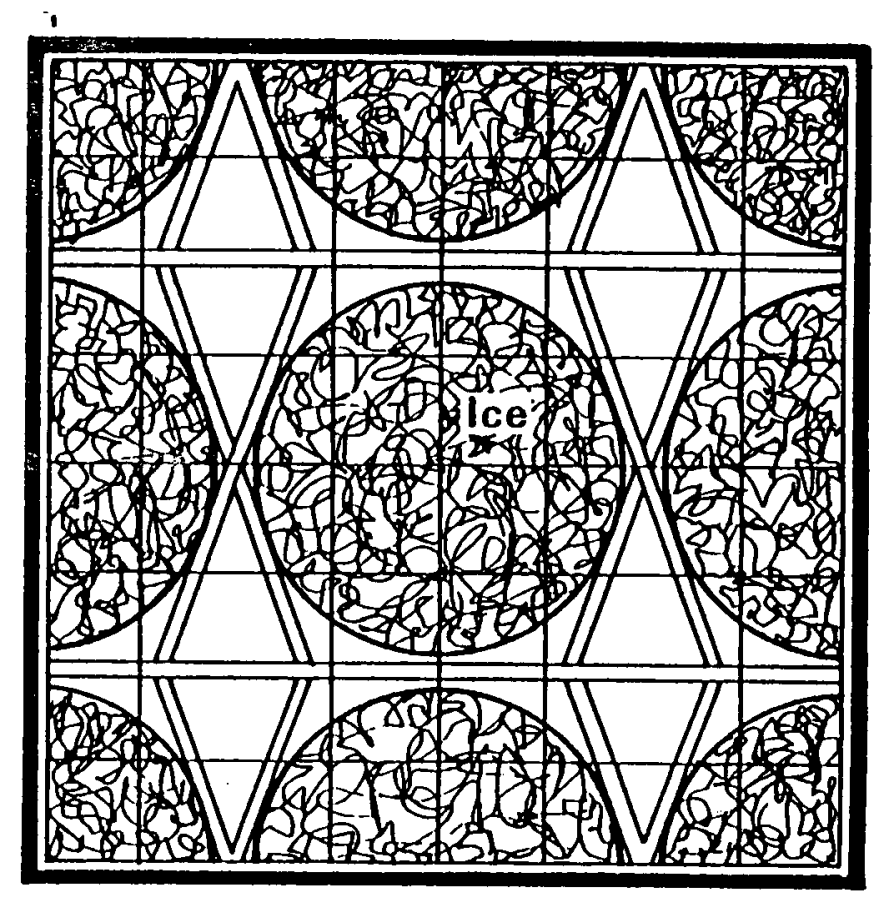

Plan View

(at lattice supports with location grid)

FIGURE 3.3. Test Section Cross Section 
the original probe panels and the additional single penetrations allowed independent access to each primary flow quadrant at Levels 1 and 5 , as well as access to both north and south halves of the test section from the west face at Levels 2, 3, and 4. The location and labels of the probe panels, single penetrations, and other sampling stations are shown in Figure 3.4. Typically, each single penetration/sampling station was either a 3.2- or $3.8-\mathrm{cm}$ ( $1 \frac{1}{4}$ or $1 \frac{1}{2}$ in. NPT) coupling.

At Levels 1 and 5 in the pit, the individual penetrations (not complete probe panels), which had been added on the east face of the test section, allowed all four primary flow quadrants of the test section to be independently accessed. Sampling stations at Levels 1 and 5 having independent access to all four flow quadrants are typically referred to as "quad" stations.

\subsubsection{Ice-Basket Modifications}

It was determined that cruciforms, internal structural support members, were missing in three locations of the center-basket (middle of three of the six 2.4-m basket sections). The additional cruciforms were obtained and installed during the summer of 1989.

\subsubsection{Outlet Section}

The outlet section consisted of the turning vanes that directed the flow into the horizontal exhaust duct system. The exhaust duct system consisted of a reducer and a 15.2-cm-diameter exhaust pipe. The exhaust pipe optionally discharged to a scrubber or directly to atmosphere. Typically, all aerosol tests utilized the scrubber prior to discharging the exhaust stream to atmosphere.

\subsubsection{Refrigeration System}

A water-cooled, 5-ton air chiller was used to pre-chill the test section before ice loading and to maintain the ice inventory after loading. The system typically reduced the test section temperature to $-6.7^{\circ} \mathrm{C}$. When in use, the test section and refrigeration unit were configured as a closed loop by connecting 15.2-cm flanges at the top of the bypass and the test section exhaust. The bypass was utilized as the cold air supply to the test section, and the discharge from the test section served as the supply to the chiller.

\subsubsection{Influent Systems}

Saturated steam at $586 \mathrm{kPa}$ gage was supplied by either the dedicated $150-\mathrm{kW}$ electric boiler $(250 \mathrm{~kg} / \mathrm{hr}$ ) or the temporary diesel-fired boiler (2722 $\mathrm{kg} / \mathrm{hr}$ capacity). From either source, steam traveled through insulated pipes to the 20-kW superheater, located on Level 2. The superheated steam then passed through the steam control system, which included separate high- and low-range metering components. Manual valves were installed for each flowrate range, and on both sides of variable area rotameters. Typically, the pressure dropped from $586 \mathrm{kPa}$ gage to $241 \mathrm{kPa}$ gage across the first manual 


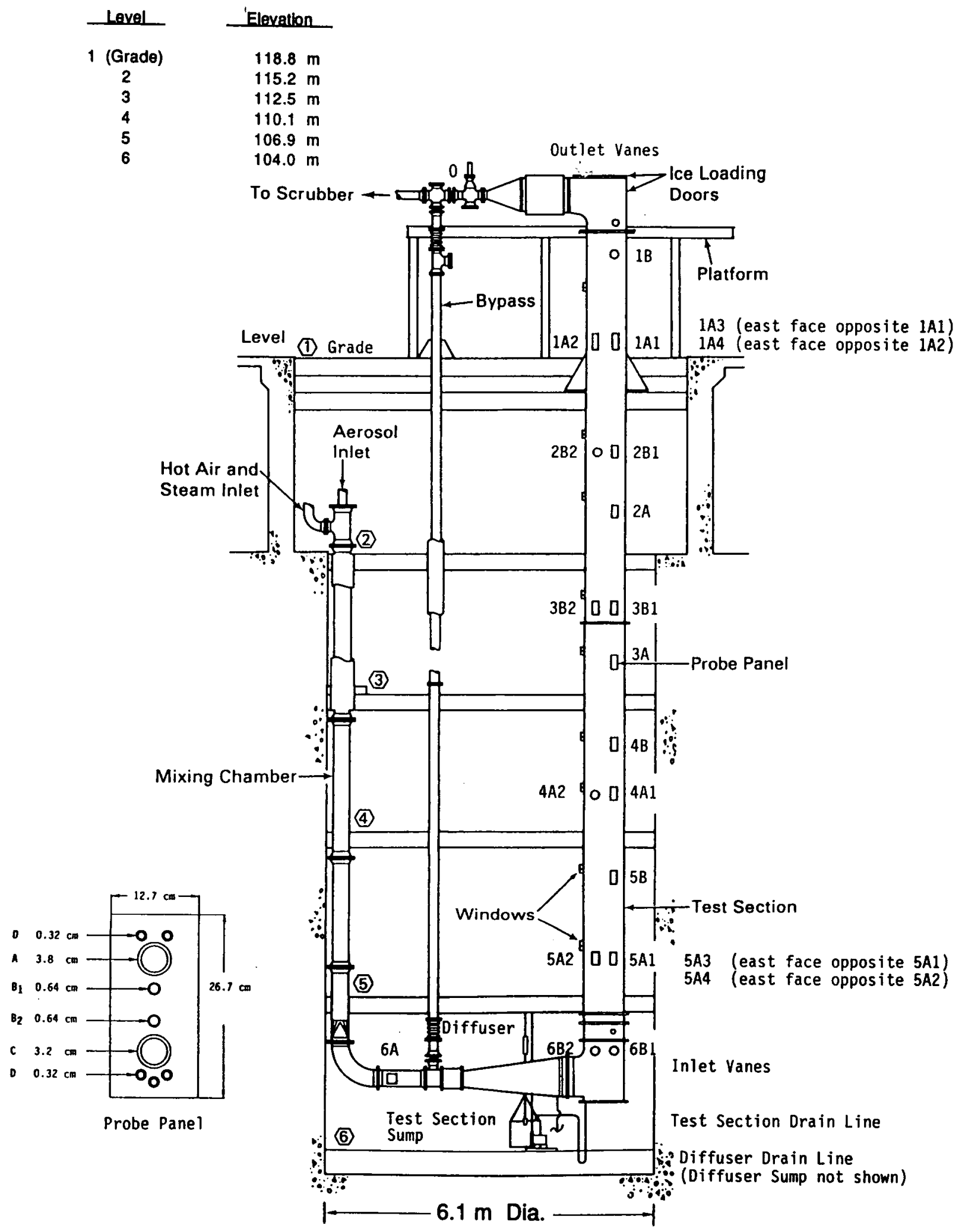

FIGURE 3.4. Elevation View of the West Face of the Test Section with Identification of Penetration Locations 
valve and from $241 \mathrm{kPa}$ gage to less than $6.9 \mathrm{kPa}$ gage across the second manual valve. The reduced pressure steam then continued through insulated pipe to the mixing tee, also at Level 2. (See Section 3.4 for a description of the mixing tee.)

Inlet air was supplied from either a blower or the plant air system. Plant air was filtered to remove oil and water droplets. The plant air flow was limited by the two variable area flowmeters, although they could be used in parallel. The larger flowmeter measured flow to $2.27 \mathrm{~kg} / \mathrm{min}$, while the smaller flowmeter, typically used for aerosol injection, mesasured flow to $0.91 \mathrm{~kg} / \mathrm{min}$. The $45-\mathrm{kW}$ blower supplied from 2.8 to $19.8 \mathrm{~m} / \mathrm{min}$ of air. Flow rate of the blower was measured with a vortex element and flow computer system. The supply air to the blower was filtered through a HEPA filter. Discharge of both the blower and the large plant air flowmeter were directed to the $100-\mathrm{kW}$ air heater, which was capable of heating the air to $199^{\circ} \mathrm{C}$. Air exhausted from the heater continued through an insulated $15.2-\mathrm{cm}$ pipe to the mixing tee at Level 2. Air from the small plant air flowmeter was injected directly into the mixing tee (aerosol injection location).

The air and steam inlet streams were combined in the mixing tee and entered the 10.7-m long, 30.5-cm diameter, heat-traced stainless-steel downcomer installed along the north side of the pit. At the lowest level of the pit, the cross section of the duct changed from a 30.5-cm-diameter circle to a $30.5-\mathrm{cm}$ per side square and passed through a long radius turn directed horizontally southward. At this point, the flow could either be directed up the 15.2-cm-diameter bypass or straight toward the ice-basket region. Continuing toward the inlet of the ice-basket region, the gas streams passed through the inlet diffuser. The inlet diffuser was square in cross section and expanded gradually from a $30.5-\mathrm{cm}$ square duct to a $72.4-\mathrm{cm}$ square duct. The final transition to the ice-basket region was made as the flow was turned upward by the inlet turning vanes.

Installation of the temporary diesel-fired boiler for testing performed in 1989 required preparation of a stable support surface. A temporary pad consisting of railroad ties and gravel was constructed on the east side of the HBTF exterior. Once the boiler was set in place, water and electrical power were routed to the container, and lines were installed between the diesel fuel storage tank and the boiler container. The 5.1-cm out let steam line was connected to the existing piping through the use of two additional support columns and two expansion joints. The outlet steam line was insulated and covered with a weatherproof skin. Tests utilizing the diesel-fired boiler required manual adjustment of the valve upstream of the steam flowmeter to accommodate boiler pressure fluctuations and to maintain a fairly constant steam supply.

\subsubsection{Effluent Systems}

Downstream of the vertical ice-basket region the upward flow was changed to northward horizontal flow as it passed through the outlet turning vanes. The cross section of the flow then reduced to that of the $15.2-\mathrm{cm}$ exhaust duct system. Prior to release to the environment, exhaust streams containing 
injected particles were routed through the scrubber. Finally, the gaseous effluent was discharged outside of the north wall of the 336 Building. Condensate and meltwater collection systems are discussed later in Section 3.2.1.

\subsubsection{Data Acquisition System}

Data acquisition at the facility was accomplished using two systems. The pripary data acquisition system was computer-based ${ }^{(2)}$ and consisted of an IBM personal computer with a hard card and IBM DOS 2.0 (which was later updategd, to 3.3); a Keithley data (acquisition hardware system; and an Epson printer. LabTech Notebook version 4.11 was the data acquisition software. The computer-based data acquisition system (DAS) supported 95 thermocouple channels and, 18 analog channels (flowmeters and pressure transmitters). A Fluke Model 2240B data logger equippeg with remote programming capabilities and coupled to a Columbia $300 \mathrm{D}(9)$ data cartridge recorder was used to collect data from additional instrumentation, such as the diffuser thermocouple rakes. Hereafter, DAS refers only to the computerbased data acquisition system and data logger refers to the Fluke data logger.

Flowmeter and pressure instrument readings logged by the DAS were converted to English units by the DAS software package. The conversion to engineering units from voltage or amperage was accomplished using linear fits derived from current instrument and channel calibration information. Higher order fits could not be accommodated by the data acquisition software. The form of the conversion available was derived from the equation of a line:

$$
y=m x+b=m(x+b / m) \text {. }
$$

The equation was utilized as:

engineering units $=$ scale value(instrument reading + offset value) .

(a) IBM, Boca Raton, Florida.

(b) IBM, Boca Raton, Florida.

(c) Keithley Data Acquisition and Control Inc., Cleveland, Ohio.

(d) Epson Corporation, Nagano, Japan.

(e) Laboratory Technologies Corporation, Wilmington, Massachusetts.

(f) John Fluke Manufacturing Company, Inc., Everett, Washington.

(g) Columbia Data Products, Columbia, Maryland. 
Thermocouple channels were input directly to a compensating junction having an isothermal input block. As is common practice, the emf of the thermocouples was converted to degrees by the readout instruments. No additional corrections were made to the thermocouple readings prior to being written (recorded) to file.

\subsection{NON-AEROSOL SYSTEMS}

Facility process and control systems are discussed in the following sections. A brief description of the instrumentation calibration controls and frequency are also presented. Table 3.1 provides specific information including model, serial number, range, the data acquisition label as appropriate, and estimated uncertainty for the instruments used in this test program.

\subsubsection{Condensate and Meltwater Measurement Systems}

The initial test section design and fabrication included a monitored test section liquid collection system. Observations made during low flow rate aerosol retention tests led to the design and installation of a monitored diffuser liquid collection system. Each liquid collection system is described below.

\subsubsection{Test Section Liquid Collection System}

Water from steam condensation and ice melting was directed out the bottom of the test section through a 3.8-cm-diameter pipe and water leg to a collection sump tank located on the east side of the pit. Thermocouples were installed in the water leg to monitor the temperature of the condensate and meltwater going into the tank. The weight of the water in the tank, up to approximately $136 \mathrm{~kg}$ net, was monitored by a precision load cell. A $98 \mathrm{l} / \mathrm{min}$ pump, activated by load cell controlled limit switches, pumped water up to the drain at grade level where it entered the sanitary drain system. Typically, the test section sump tank high/low limit switches were set at approximately $136 \mathrm{~kg}$ and $0.5 \mathrm{~kg}$, respectively. The signals from the thermocouples and the load cell were connected to the computer-based data acquisition system and were monitored throughout the test, thereby providing a time history of the drain line temperature and sump tank inventory.

\subsubsection{Diffuser Condensate Collection System}

A significant amount of steam condensation was suspected to occur in the diffuser section during the performance of low flow rate aerosol retention tests. In the summer of 1989, a separate sump system for the diffuser was installed. The lower, downstream edge (i.e., near the diffuser exit) of the diffuser was slotted and a sloped-bottom trough was welded around the slot. Outlet piping was directed from the low edge of the trough to a water leg, then over to the suspended tank on the west side of the pit. Thermocouples were installed to monitor the temperature in the water leg. The sump tank 


\section{TABLE 3.1. Facility Instrumentation}

\begin{tabular}{|c|c|c|c|c|c|c|}
\hline INSTRUMENT & MOOE & IDENTIFICATION & $\begin{array}{l}\text { NOMINAL } \\
\text { RANGE/CAPACITY }\end{array}$ & DAS LABEL & $\begin{array}{l}\text { SENGOR } \\
\text { ESTIMATED UNCERTAINTY }\end{array}$ & $\begin{array}{l}\text { INSTALLLED ESTIMATED } \\
\text { UNCERTAINTY }\end{array}$ \\
\hline Blower meler & $\begin{array}{l}\text { Eastech in-line vortex } \\
\text { meter and flow compuler }\end{array}$ & $\begin{array}{l}\text { sn } 86315 \\
\text { Eastech }\end{array}$ & $82-800$ scim & F101 & $\begin{array}{l}0.5 \% \text { llow element } \\
\text { reading }\end{array}$ & $\begin{array}{l}+/-3 \% \text { reading, based } \\
\text { on limited analysis. }\end{array}$ \\
\hline High range air meler & $\begin{array}{l}\text { Wallace \& Tiernan } \\
\text { metal tube vareameter }\end{array}$ & $\begin{array}{l}\text { ALN-2913 } \\
\text { Wallace\& Tiernan }\end{array}$ & $\begin{array}{l}5 \mathrm{lb} / \mathrm{min} \text { air } \\
70 \mathrm{~F} .45 \mathrm{psig}\end{array}$ & $F_{102}$ & $\begin{array}{ll}+/- & 0.05 \mathrm{lb} / \mathrm{min} \\
+/- & 0.275 \mathrm{lb} / \mathrm{min} 1990^{\circ}\end{array}$ & $+1-0.07 \mathrm{lb} / \mathrm{min}$ \\
\hline Low range air meter & $\begin{array}{l}\text { Wallace \& Tiernan } \\
\text { metal tube vareameter }\end{array}$ & $\begin{array}{l}\text { ALN-2914 } \\
\text { Wallace\& Tiernan }\end{array}$ & $\begin{array}{l}2 \mathrm{ib} / \mathrm{min} \text { air } \\
70 \mathrm{~F}, 45 \mathrm{psig}\end{array}$ & F205 & $\begin{array}{l}+1-0.02 \mathrm{lb} / \min \\
+1-0.06 \mathrm{lb} / \mathrm{min} 1990^{\circ}\end{array}$ & $+0.04 \mathrm{lb} / \mathrm{min}$ \\
\hline High range sleam meler & $\begin{array}{l}\text { Wallace \& Tiernan } \\
\text { metal tube vareameter }\end{array}$ & $\begin{array}{l}\text { ALN-2911 } \\
\text { Wallace\& Tiernan }\end{array}$ & $\begin{array}{l}2000 \mathrm{lb} / \mathrm{hr} \mathrm{slm} \\
400 \mathrm{~F}, 35 \mathrm{psig}\end{array}$ & $\mathrm{F} 203$ & $\begin{array}{l}+1-20.5 \mathrm{lb} / \mathrm{hr} \\
+1-20.5 \mathrm{lb} / \mathrm{hr} 1990^{*}\end{array}$ & $+1-31 \mathrm{lb} / \mathrm{hr}$ \\
\hline Low range sleam meter & $\begin{array}{l}\text { Wallace \& Tiernan } \\
\text { metal tube vareameter }\end{array}$ & $\begin{array}{l}\text { ALN-2912 } \\
\text { Wallace\&Tiernan }\end{array}$ & $\begin{array}{l}175 \mathrm{lb} / \mathrm{hr} \mathrm{sim} \\
400 \mathrm{~F}, 35 \mathrm{psig}\end{array}$ & F204 & $\begin{array}{lll}+1 . & 1.8 \mathrm{lb} / \mathrm{hr} \\
+1- & 1.8 \mathrm{lb} / \mathrm{hr} \quad 1990^{\circ}\end{array}$ & $+/-2.2 \mathrm{lb} / \mathrm{hr}$ \\
\hline Exit llow rale & $\begin{array}{l}\text { Pitot probe with del P } \\
\text { pressure Iransducer }\end{array}$ & $\begin{array}{l}\text { sn } 46719-1-1 \\
\text { MKS Baratron }\end{array}$ & $\begin{array}{l}\text { Dilfntl Press } \\
1 \text { torr }\end{array}$ & F150 & $\begin{array}{l}+/-2.5 \% \text { reading } \\
\text { (difintl press only) }\end{array}$ & $\begin{array}{l}+1-2.6 \% \text { reading } \\
\text { (diffntl press only) }\end{array}$ \\
\hline Sump discharge meter & $\begin{array}{l}\text { Wallace \& Thernan } \\
\text { metal tube vareameter }\end{array}$ & $\begin{array}{l}\text { ALN-2915 } \\
\text { Wallace\& Tiernan }\end{array}$ & $\begin{array}{l}5 \text { to } 45 \mathrm{gpm} \\
\text { water }\end{array}$ & F246 & $\begin{array}{l}\text { t/ } 0.45 \mathrm{gpm} \\
+/ 0.45 \mathrm{gpm} \quad 1990^{*}\end{array}$ & $+1-0.7 \mathrm{gpm}$ \\
\hline $\begin{array}{l}\text { High range air meler } \\
\text { pressure }\end{array}$ & $\begin{array}{l}\text { Schaevitz pressure } \\
\text { transmiller }\end{array}$ & $\begin{array}{l}\text { Sn } 11570 \\
\text { Schaevitz }\end{array}$ & 100 psig & P102 & $+1-0.5$ psig & $+1-1$ psig \\
\hline Blower alr pressure & $\begin{array}{l}\text { Schaevilz pressure } \\
\text { transmitter }\end{array}$ & $\begin{array}{l}\text { sn } 9740 \\
\text { Schaevitz }\end{array}$ & 50 psig & P101 & $+/-0.25$ psig & +1.0 .3 psig \\
\hline Steam meter pressure & $\begin{array}{l}\text { Schaevitz pressure } \\
\text { iransmitler }\end{array}$ & $\begin{array}{l}\text { sn } 9831 \\
\text { Schaevitz }\end{array}$ & 100 psig & $P 203 / 4$ & $+/-0.5$ psig & +/- 1.1 psig \\
\hline $\begin{array}{l}\text { Low range air meter } \\
\text { pressure }\end{array}$ & $\begin{array}{l}\text { Sensolec pressure } \\
\text { transducer }\end{array}$ & $\begin{array}{l}\text { sn } 112638 \\
\text { Sensolec }\end{array}$ & 1000 psig\# & P205 & $\begin{array}{l}+1-2 \text { psig } 1987.1988 \\
+/-0.33 \text { psig } 1990\end{array}$ & 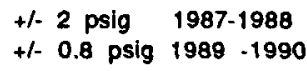 \\
\hline $\begin{array}{l}\text { Test section inlet } \\
\text { pressure }\end{array}$ & $\begin{array}{l}\text { Honeywell pressure } \\
\text { Iransducer }\end{array}$ & $\begin{array}{l}\text { sn } 6847753001 \\
\text { Honeywell }\end{array}$ & $\begin{array}{l}+/-10 \text { in. water } \\
\text { gage }\end{array}$ & P630 & $\begin{array}{l}+/-0.05 \text { in. wir } \\
1989-1990\end{array}$ & +1.0 .06 in. wir." \\
\hline $\begin{array}{l}\text { Test section inlet } \\
\text { pressure }\end{array}$ & $\begin{array}{l}\text { Schaevitz pressure } \\
\text { Iransmitter }\end{array}$ & $\begin{array}{l}\text { Sn } 11680 \\
\text { Sensotec }\end{array}$ & $\begin{array}{l}50 \text { in. water } \\
\text { gage }\end{array}$ & P630 & $\begin{array}{l}+/ \cdot 0.25 \text { in. WIr } \\
1987-1988\end{array}$ & $+/-0.5$ in. wir \\
\hline $\begin{array}{l}\text { Test section exit } \\
\text { pressure }\end{array}$ & $\begin{array}{l}\text { Honeywell pressure } \\
\text { Iransducer }\end{array}$ & $\begin{array}{l}\text { sn } 6847753004 \\
\text { Honeywell }\end{array}$ & $\begin{array}{l}+1-10 \text { in. water } \\
\text { gage }\end{array}$ & P150 & $\begin{array}{l}+1.0 .1 \text { in. wir } 1987 \\
+1-0.05 \text { in. wir 1988-90 }\end{array}$ & $\begin{array}{l}+1-0.07 \text { in. wtr. } 1988 \\
1990 \% \\
+1.0 .1 \text { in. wtr. } 1989^{\circ}\end{array}$ \\
\hline
\end{tabular}


TABLE 3.1. contd

\begin{tabular}{|c|c|c|c|c|c|c|}
\hline NSTRUMENT & MOOB & IDENTIFICATION & $\begin{array}{l}\text { NOMINAL } \\
\text { RANGE/CAPACITY }\end{array}$ & DAS LABEL & $\begin{array}{l}\text { SENOOR } \\
\text { ESTIMATED UNCERTAINTY }\end{array}$ & $\begin{array}{l}\text { INSTALLED ESTIMATED } \\
\text { UNCERTAINTY }\end{array}$ \\
\hline Test section sump weight & $\begin{array}{l}\text { Suspended tank with } \\
\text { tensile load cell }\end{array}$ & $\begin{array}{l}\text { Sn A0130 } \\
\text { DI Load Cell }\end{array}$ & $\begin{array}{l}500 \mathrm{lb} \\
\text { gross full scale }\end{array}$ & L646 & $+1.0 .75 \mathrm{lb}$ & $+1.4 .8 \mathrm{lb}$ \\
\hline Ditluser sump weighı & $\begin{array}{l}\text { Suspended tank with } \\
\text { tensile load cell }\end{array}$ & $\begin{array}{l}\text { sn } 223601 \\
\text { Sensolec Load Cell }\end{array}$ & $\begin{array}{l}100 \mathrm{lb} \\
\text { gross full scale }\end{array}$ & L648 & $+1-0.2 \mathrm{lb}$ & $+/-0.9 \mathrm{lb}$ \\
\hline Exit humidity sensor & Capacitive film sensor & $\begin{array}{l}\text { sn } 11399 \\
\text { Rotronic HT250D }\end{array}$ & $\begin{array}{l}0-100 \% \text { relative } \\
\text { humidty } \\
-50-150 \mathrm{C}\end{array}$ & $\begin{array}{l}\text { H151 \& } \\
\text { T151 }\end{array}$ & $\begin{array}{l}+/-2 \% \text { relative humidity } \\
+/-0.6 \mathrm{C}\end{array}$ & $\begin{array}{l}+/-5 \% \text { relative } \\
\text { humidity } \cdots \\
+/-3.5 \mathrm{C} \text { limited } \\
\text { calibration range } 1.50 \mathrm{C}\end{array}$ \\
\hline $\begin{array}{l}\text { High range steam meler } \\
\text { temperature }\end{array}$ & $\begin{array}{l}\text { Sheathed, grounded, } 0.16 \mathrm{~cm} \\
\text { type J thermocouple }\end{array}$ & $\begin{array}{l}1 / 6 / 3 \\
6848\end{array}$ & $0-750 \mathrm{C}$ & T203 & $\begin{array}{l}+1-2.2 \mathrm{C} \\
\text { thermocouple only }\end{array}$ & $+1-2.6 C$ \\
\hline $\begin{array}{l}\text { Low range steam meter } \\
\text { temperalure }\end{array}$ & $\begin{array}{l}\text { Sheathed, grounded, } 0.16 \mathrm{~cm} \\
\text { type J thermocouple }\end{array}$ & $\begin{array}{l}1 / 6 / 4 \\
6849\end{array}$ & $0-750 \mathrm{C}$ & T204 & $\begin{array}{l}+/-2.2 \text { C } \\
\text { thermocouple only }\end{array}$ & $+1-2.6 \mathrm{C}$ \\
\hline $\begin{array}{l}\text { Low range air meter } \\
\text { temperature }\end{array}$ & $\begin{array}{l}\text { Sheathed, grounded, } 0.16 \mathrm{~cm} \\
\text { type J thermocouple }\end{array}$ & $\begin{array}{l}1 / 6 / 5 \\
6846\end{array}$ & $0-750 \mathrm{C}$ & T205 & $\begin{array}{l}\text { +1- } 2.2 \mathrm{C} \\
\text { thermocouple only }\end{array}$ & $+1-2.6 \mathrm{C}$ \\
\hline $\begin{array}{l}\text { Test section sump } \\
\text { temperture }\end{array}$ & $\begin{array}{l}\text { Sheathed, grounded, } 0.16 \mathrm{~cm} \\
\text { type J thermocouple }\end{array}$ & $\begin{array}{l}1 / 6 / 8 \\
6843\end{array}$ & $0-750 \mathrm{C}$ & T646 & $\begin{array}{l}+/-2.2 \mathrm{C} \\
\text { thermocouple only }\end{array}$ & $+1-2.6 \mathrm{C}$ \\
\hline Exit temperature & $\begin{array}{l}\text { Sheathed, grounded, } 0.16 \mathrm{~cm} \\
\text { type J thermocouple }\end{array}$ & $\begin{array}{l}1 / 6 / 9 \\
6844\end{array}$ & $0-750 \mathrm{C}$ & T150 & $\begin{array}{l}+/-2.2 \mathrm{C} \\
\text { thermocouple only }\end{array}$ & $+1-2.6 \mathrm{C}$ \\
\hline $\begin{array}{l}\text { Temperature of steam to } \\
\text { the mixing chamber }\end{array}$ & $\begin{array}{l}\text { Sheathed, grounded, } 0.16 \mathrm{~cm} \\
\text { Iype J thermocouple }\end{array}$ & $1 / 12 / 10$ & $0.750 \mathrm{C}$ & T223 & $\begin{array}{l}+1-2.2 \mathrm{C} \\
\text { thermocouple only }\end{array}$ & $+1.2 .6 \mathrm{C}$ \\
\hline $\begin{array}{l}\text { Temperature of air } 10 \\
\text { the mixing chamber }\end{array}$ & $\begin{array}{l}\text { Sheathed, grounded, } 0.16 \mathrm{~cm} \\
\text { type J thermocouple }\end{array}$ & $1 / 12 / 13$ & $0.750 \mathrm{C}$ & T221 & $\begin{array}{l}+1-2.2 \text { C } \\
\text { thermocouple only }\end{array}$ & $+1-2.6 \mathrm{C}$ \\
\hline $\begin{array}{l}\text { Sump moter } \\
\text { temperalure }\end{array}$ & $\begin{array}{l}\text { Sheathed, grounded, } 0.16 \mathrm{~cm} \\
\text { type J thermocouple }\end{array}$ & $1 / 12 / 31$ & $0-750 \mathrm{C}$ & T246 & $\begin{array}{l}+/-2.2 \text { C } \\
\text { thermocouple only }\end{array}$ & $+1-2.6 \mathrm{C}$ \\
\hline $\begin{array}{l}\text { Large alr meler } \\
\text { temperature }\end{array}$ & $\begin{array}{l}\text { Sheathed, grounded, } 0.16 \mathrm{~cm} \\
\text { type J thermocouple }\end{array}$ & $\begin{array}{l}1 / 12 / 39 \\
6842\end{array}$ & $0.750 \mathrm{C}$ & $\mathrm{T} 102$ & $\begin{array}{l}+1-2.2 \mathrm{C} \\
\text { thermocouple only }\end{array}$ & $+1-2.6 \mathrm{C}$ \\
\hline $\begin{array}{l}\text { Blower meler } \\
\text { lemperature }\end{array}$ & $\begin{array}{l}\text { Sheathed, grounded, } 0.16 \mathrm{~cm} \\
\text { type J thermocouple with } \\
\text { TX52J1 Transmtr, Omega }\end{array}$ & & $0-750 \mathrm{C}$ & T101 & $+1-3.0 \mathrm{C}$ & $+1-3 \mathrm{C}$ \\
\hline
\end{tabular}




\section{TABLE 3.1. contd}

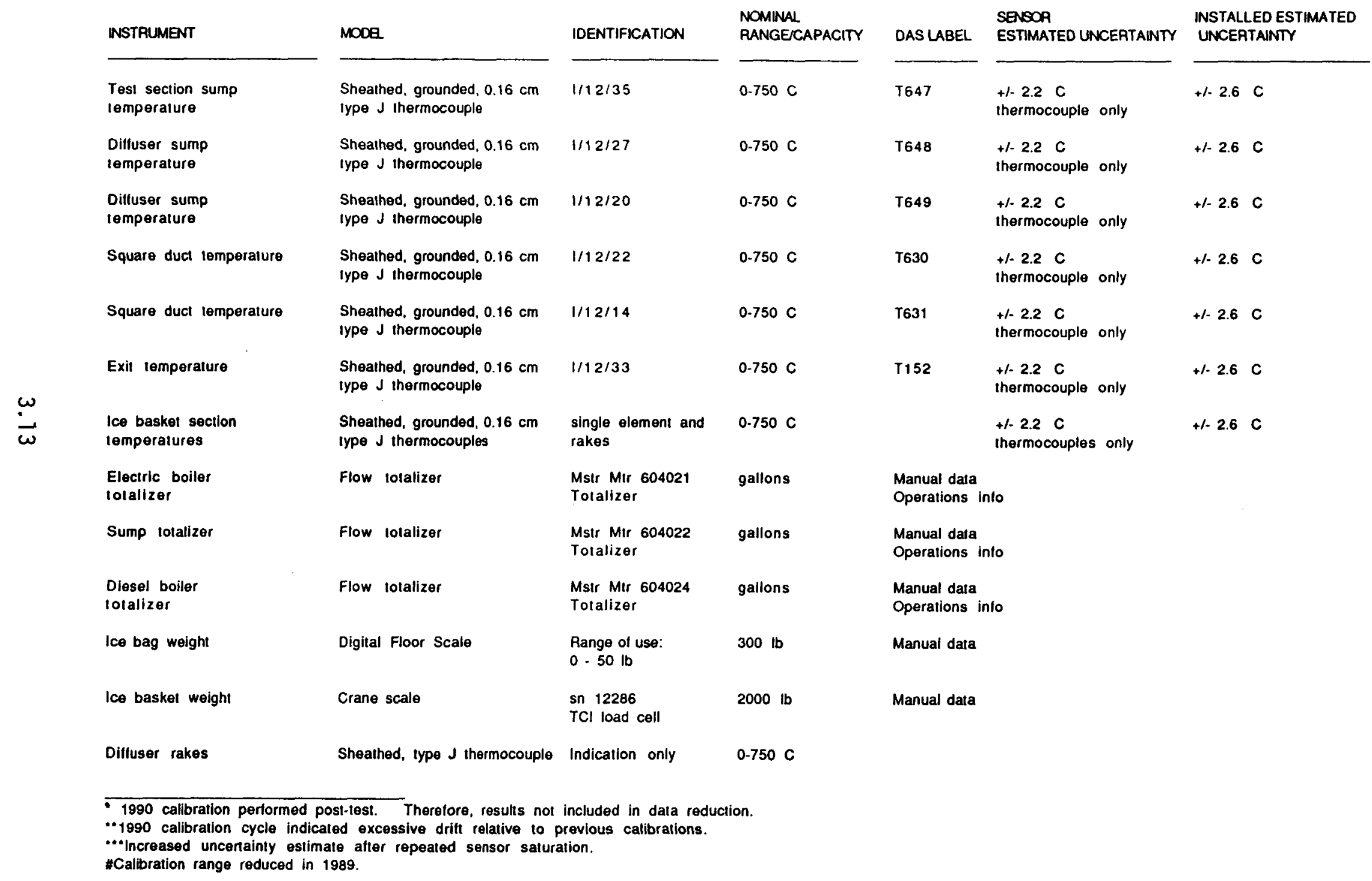


weight was monitored by a load cell, whose signal was also used to control a pump to transfer condensate from the diffuser sump tank to the test section sump tank. Operation of the transfer pump was initiated at the high level limit setting, approximately $18 \mathrm{~kg}$ net. The pump transferred the inventory of the small sump tank until the lower limit setpoint was reached, generally less than $2.3 \mathrm{~kg}$ net. The signal wires from the thermocouples and the load cell were connected to the computer-based data acquisition system and were monitored throughout the test, thereby providing time histories of the water leg temperature and sump tank inventory.

\subsubsection{Process and Control Instrumentation}

Process and control instrumentation consisted of the equipment required to meter unmixed inlet component streams, as well as outlet streams. In general, metering of primary supply and effluent streams, which took place upstream of the inlet turning vanes" and downstream of the outlet turning vanes, is termed process and control instrumentation. Measurements made between the inlet and outlet turning vanes were generally made using test section instrumentation. Both test section and diffuser sump tank load cells were included in the process and control instrumentation category.

Standard practice of measuring fluid temperature (liquid and gas) and pressure (gas) with flow measurements was applied to the process instrumentation. In addition, the individual component (air and steam) temperatures were measured just prior to the mixing tee. Downstream of the test section inlet and outlet turning vanes, the combined stream temperatures and pressures were measured. Efforts were made to measure the exhaust stream flow rate and humidity. As mentioned earlier, the sump inventories were controlled by independent level control switches. The load cells provided control input to the pump switches, and by connection to the computer-based data acquisition system, provided time histories of the sump tank inventories.

Efforts were made to measure the humidity in the exit duct. First, an available chilled mirror psychrometer was installed in the exit duct. However, particulate matter tended to foul the chilled mirror, which rendered the unit unreliable. Second, a capacitive film humidity sensor was installed. Typically, the exit stream was so heavily laden with water droplets that the humidity sensor was quickly saturated and rendered useless.

Early in the facility design phase, it was recognized that measurement of the flow rate in the exit pipe would be difficult. Estimated design exhaust flow rates (the noncondensible portion of the design inlet stream) ranged between approximately $0.71 \mathrm{~m}^{3} / \mathrm{min}$ and $2.3 \mathrm{~m}^{3} / \mathrm{min}$ (approximate velocity range of 0.61 to $2.1 \mathrm{~m} / \mathrm{s}$ ). In addition to the relatively low flow rates, the phase and composition of the exhaust flow stream was of some concern. It was postulated that the exhaust stream could be a mixture of noncondensible gas (air) and water vapor with possible droplet entrainment. Despite the measurability concerns associated with low flow rate, composition, and mixed phases; an effort was made to measure exit stream flow by an affordable method. 
Based on the expected noncondensible flow rates, velocity measurements were attempted using a pitot probe. However, given the low flow rates, the potential of the exit stream to have a relatively high condensible fraction and/or entrained droplets, and the propensity for the suspended aerosols to foul the pitot probe, data proved difficult to reduce and interpret.

The process and control portion of Table 3.1 provides specific information on the instruments used in this test program. Generally, not all of the process and control instruments listed in Table 3.1 were used during a given test. Instrumentation locations are identified in Figure 3.4 with their data acquisition system label.

\subsubsection{Calibration}

Measurement and test equipment (hereafter called M\&TE), utilized as data sources for process and control were calibrated traceable to the National Institute of Standards and Technology (NIST) on an annual basis.

Services of offsite metrology organizations were procured as needed. The bulk of the procured calibrations (process thermocouples, specific pressure transducers, data loggers, and other instruments) were performed onsite by the Westinghouse Hanford Company (WHC) Electrical and Physical Standards Laboratory. The WHC Electrical and Physical Standards Laboratory provides calibration support to the Hanford Site.

Calibrations that were more effectively performed in-place and those involving unique instrument arrays, such as sump tank load cells and certain pressure transmitters, were performed by project personnel in accordance with formally reviewed and approved internal technical procedures. Reports for in-place calibrations were generated by the cognizant engineer.

\subsection{TEST SECTION THERMAL MEASUREMENT}

The type of thermocouples used to monitor diffuser and ice-basket section temperatures are described below. Other temperature measurements such as flowmeter and single inlet and outlet temperature measurements are described in Table 3.1 .

\subsubsection{Description of Thermocouples}

All thermocouples used in support of this test program were standard limits of error, type $J$ elements. Type $J$ elements are useful over a range of $0^{\circ}$ to $750^{\circ} \mathrm{C}$ with standard limits of error being the larger of $\pm 2.2^{\circ} \mathrm{C}$ or $0.75 \%$ of the reading.

\subsubsection{Diffuser Temperature Measurement}

Observation of stable thermal stratification in the ice-basket section during testing led to the installation of thermocouple rakes in the diffuser section after the fourth test. The objective of the rake installation was to 
assess the thermal uniformity in the diffuser. Thermocouple rakes were subsequently installed in the diffuser section upstream of the inlet turning vanes. The rakes were monitored as information only. The nominal locations of the rakes are shown in Figure 3.5. Extreme elements were located approximately $2.5 \mathrm{~cm}$ from the top and bottom of the diffuser duct. Intermediate elements were equally spaced across the remaining area. It should be noted that the rake installed at position (a) in Figure 3.5 was generally installed approximately $7.6 \mathrm{~cm}$ west of the duct centerline so that the inlet thermocouple could be installed along the duct centerline. The symbols in Figure 3.6 (a) through (d), indicate thermocouple element location. Diffuser instrumentation was very useful in the interpretation of thermal-hydraulic data as well as in the assessment of the inlet stream conditions prior to test initiation.

\subsubsection{Ice-Basket Section Temperature Measurement}

Methods of ice-basket flow-channel and skin temperature measurements are described in the following sections.

\subsubsection{Flow-Channel Temperature Measurement}

Single, $0.32-\mathrm{cm}$ penetrations of the probe panels were used for thermocouple installation during the first seven tests. Initially, the locations of these penetrations enabled temperature measurements along westeast lines and the west-side gap between the center- and west half-baskets. The combined effect of thermal cycling and settling of the ice baskets within the test section during early aerosol retention testing resulted in a number of the $0.32-\mathrm{cm}$ penetrations being blocked by the sheet metal backing of the partial baskets. At the end of September 1988, one-third of the $0.32-\mathrm{cm}$ penetrations were unusable because of ice-basket shifting. Prompted by the limited access to the test section from the penetrations, the desire to improve the accuracy of locating the thermocouple elements in the flow channels, and the desire to improve the detail of test section temperature profiles, thermocouple rakes were designed and fabricated for the test section flowchannel temperature measurements.

A typical cross section of the test section (exclusive of the support lattice members) is shown in Figure 3.7. Two types of rakes, three and five elements each, were fabricated. Elements of the five-element rake were distributed as follows: elements 1 and 5 were $2.5 \mathrm{~cm}$ from the test section wall; elements 2 and 4 at the center of the flow channels; element 3 along the centerline of the test section, between the center-and half-baskets. The three-element rakes were identical to the five-element rakes except that the two extreme thermocouples were omitted. The resulting rake flow-channel temperature measurements locations are shown in Figure 3.8 .

Flow-channel rakes were installed through and secured in the $3.8-\mathrm{cm}-$ diameter penetrations of the probe panels (penetration "A", Figure 3.4 insert) and the same size single penetrations. Installation of the flow-channel rakes was accomplished using $1.3-$ by $0.64-\mathrm{cm}\left(\frac{1}{2}-\right.$ by $t-i n$. NPT) single probe sealing 


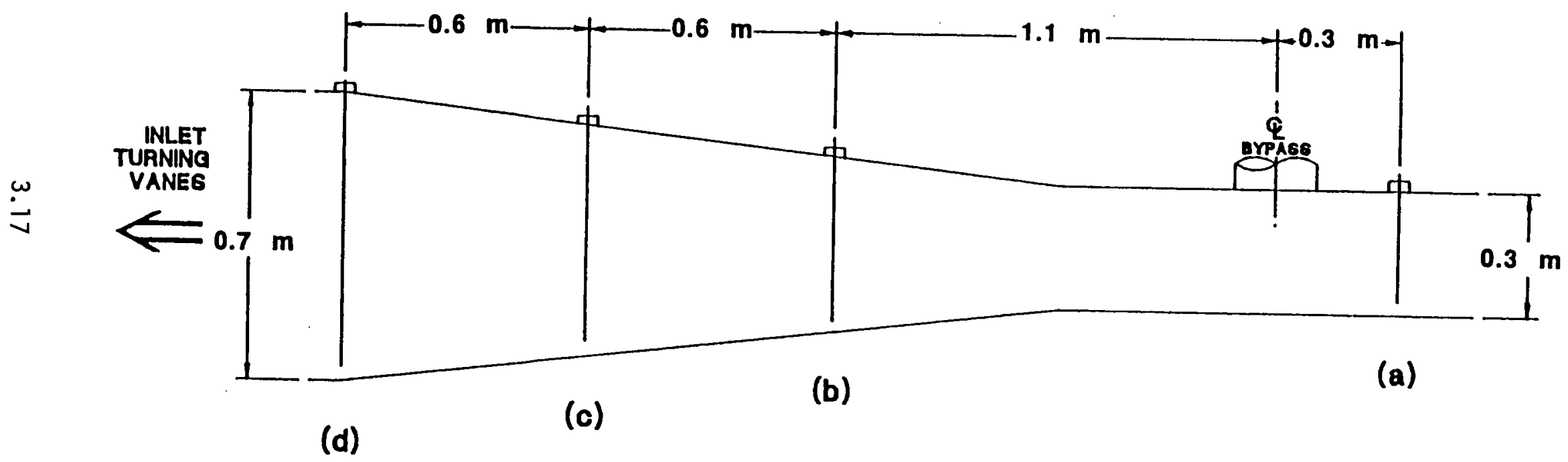

FIGURE 3.5. Diffuser Rake Locations 


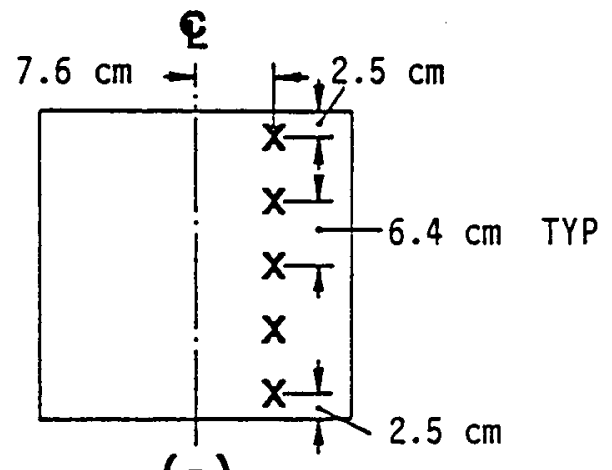

(a)

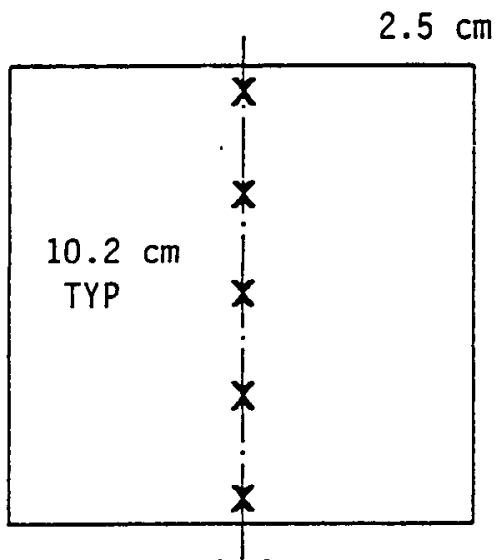

(b)
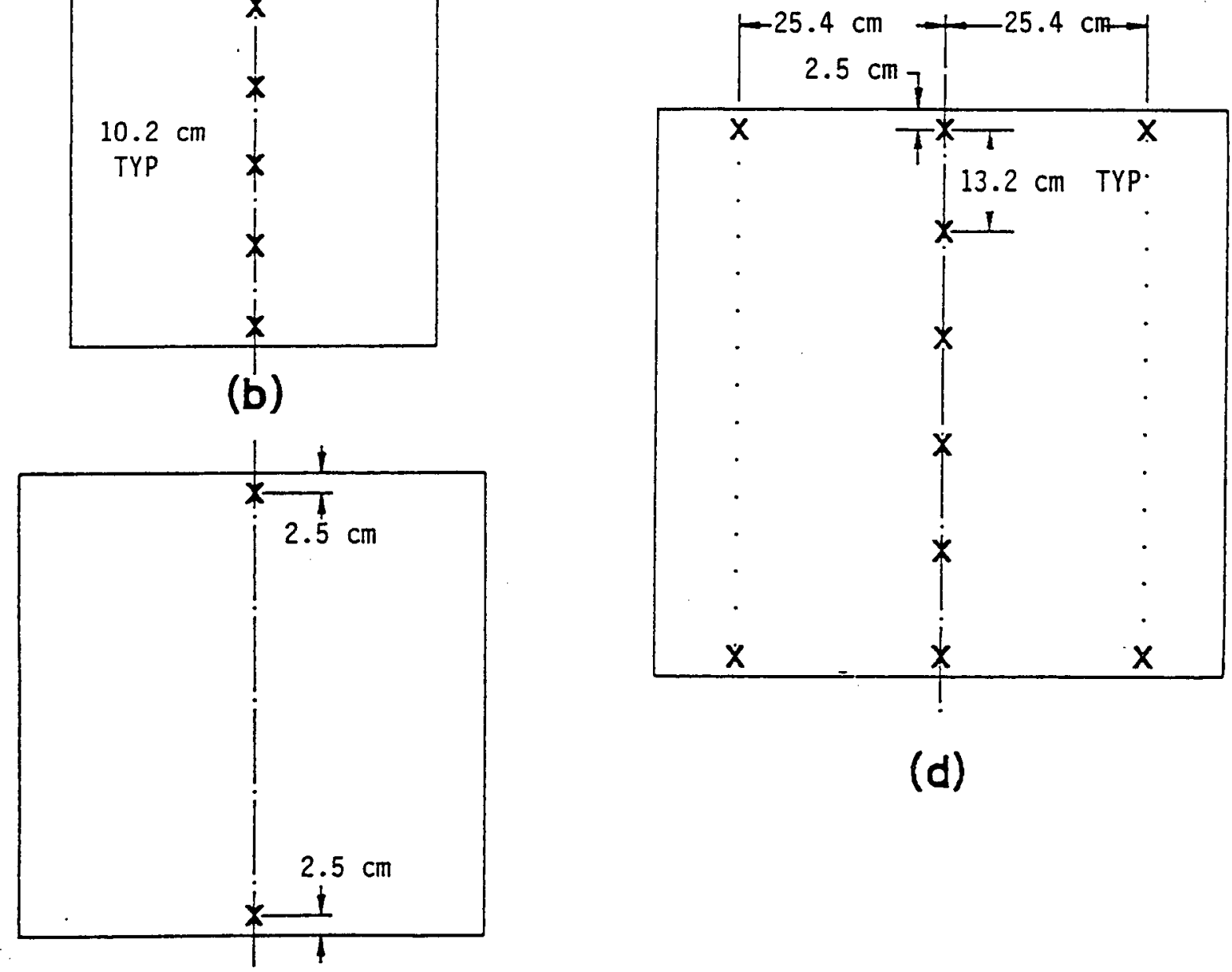

(d)

(c)

FIGURE 3.6. Diffuser Rake Element Distribution for Each Rake Location 


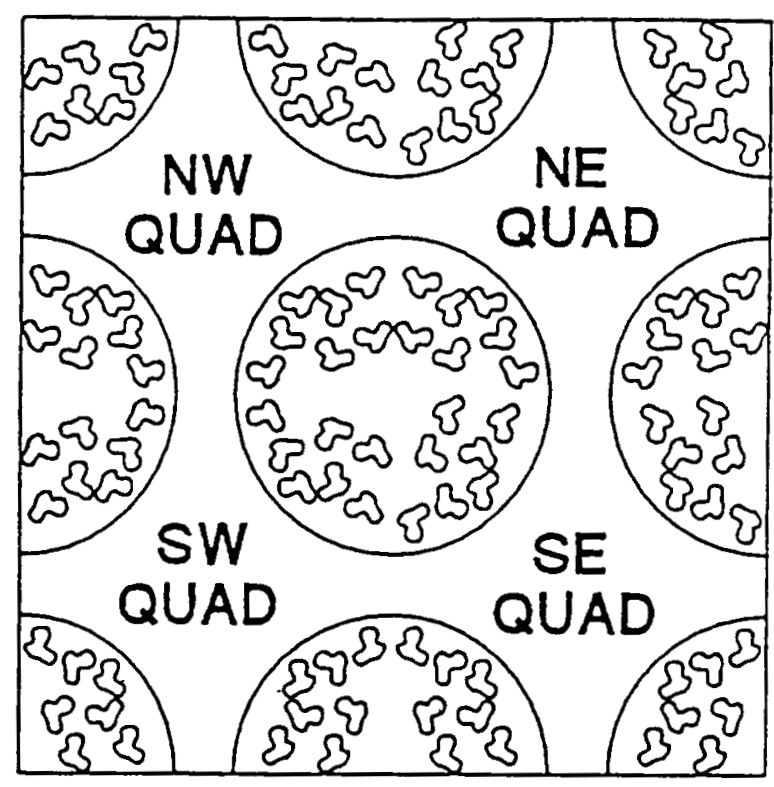

FIGURE 3.7. Typical Cross Section of the Test Section with Quadrants Identified

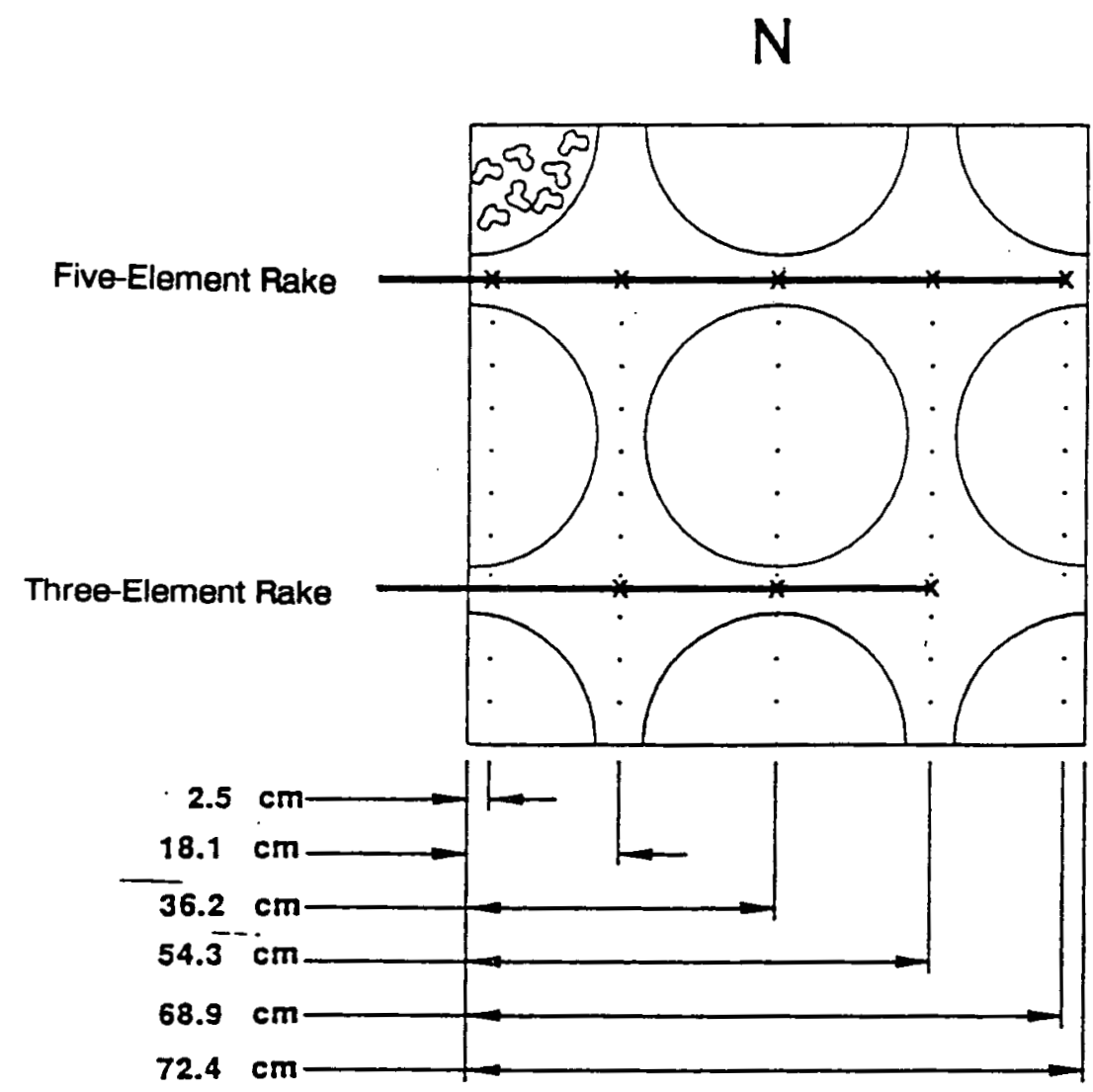

FIGURE 3.8. Flow-Channel Temperature Measurement Locations 
gland and $3.8-$ by $0.64-\mathrm{cm}$ ( $1 \frac{1}{2}-$ by $\frac{1}{2}-\mathrm{in}$. NPT) bushing. The thermocouple end plugs had to be installed through a probe gland after the rake was assembled. Wire clamps were utilized to provide additional support to the thermocouple plug junction.

\subsubsection{Skin Temperature Measurements}

As part of the ice-basket section fabrication, thermocouples were installed at specific locations on the test section skin. The number of skin thermocouples was limited by data acquisition system capacity and the monitoring requirements of the process and test section instrumentation. Ten $0.32-\mathrm{cm}$, sheathed, type $J$ thermocouples were installed. Nominally, the skin thermocouples were centered behind half- and quarter-baskets. Thermocouples centered behind half-baskets were located at the center of the test section face. Thermocouples centered behind quarter-baskets were located $7.6 \mathrm{~cm}$ from the appropriate corner of the test section. For example, at Level 4 the skin thermocouple T4SB was installed on the west face, $7.6 \mathrm{~cm}$ from the southwest corner of the test section. Table 3.2 lists the nominal locations of the skin thermocouples. Figure 3.9 (a through e) summarizes the locations schematically. The readings of the skin thermocouples have not been

TABLE 3.2. Test Section Skin Thermocouple Locations

Skin Thermocouple Location(a), m
Level 5 - N center, elevation 1.2
Level 5 - SE corner, elevation 1.2
Level 4 - E center, elevation 4.0
Level 4 - WS corner, elevation 4.0
Level 3 - NW corner, elevation 7.0
Level 3 - S center, elevation 7.0
Level 2 - EN corner, elevation 10.1
Level 2 - W center, elevation 10.1
Level 1 - N center, elevation 13.4
Level 1 - SW corner, elevation 13.4

Data Acquisition System Label

T5SA

T5SB

T4SA

T4SB

T3SA

T3SB

T2SA

T2SB

T1SA

T1SB

(a) Single letter location designations indicate the test section face on which the thermocouple is located: north $(N)$, south $(S)$, east $(E)$, west $(W)$. For two-letter locations, the leading letter indicates the test section face and the second letter indicates the secondary area of installation. Elevation designations relative to the base of the ice basket: $0-m$ elevation at bottom of ice basket, and the 14.6-m elevation at top of ice basket. 


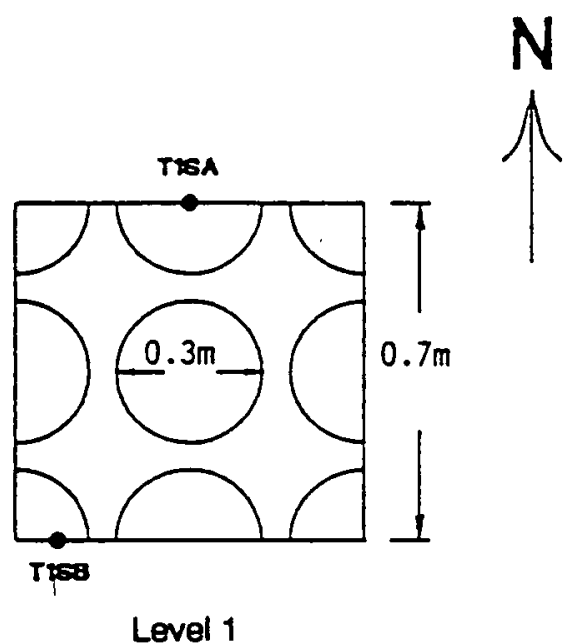

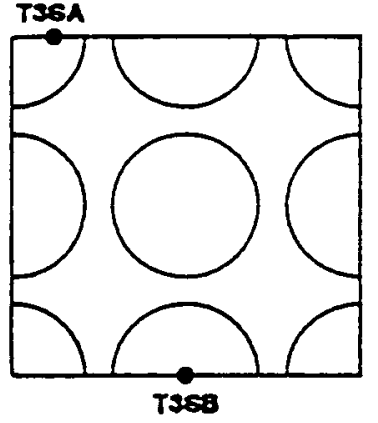

Level 3

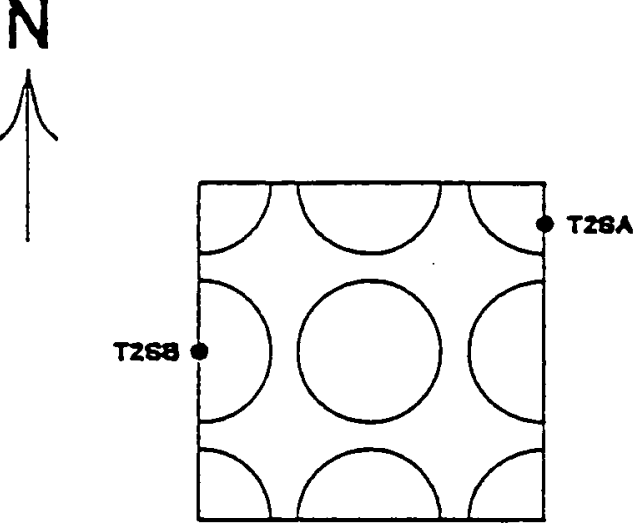

Level 2

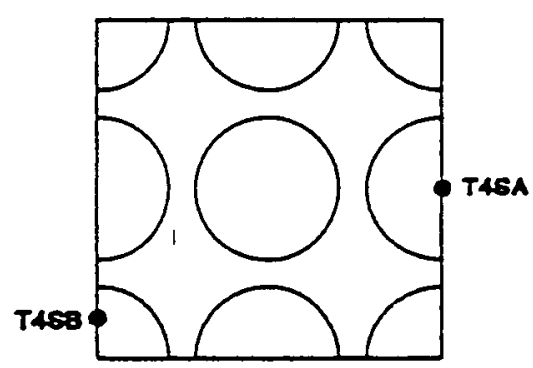

Level 4

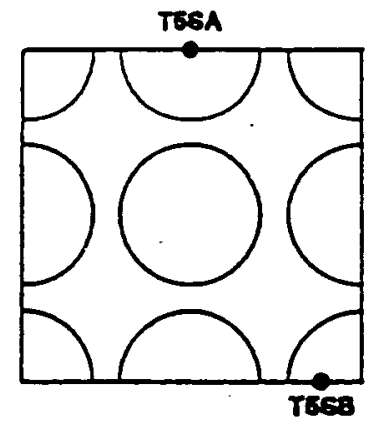

Lovel 5

FIGURE 3.9. Test Section Skin Thermocouple Locations at Each Level 
utilized because of installation uncertainty. During the summer of 1989, the junctions of the skin thermocouples were exposed and packed with a conductive paste to enhance contact with the test section. The junctions were then recovered with insulation and protective sheet metal.

\subsubsection{Calibration}

The majority of thermocouples used as data sources were verified to be within specification by methods traceable to the National Institute of Standards and Technology on an annual basis. No corrections to measurements were made, hence, the use of the term verification. Exceptions to the verification were the diffuser rake thermocouples and skin thermocouples, which were monitored as indication only.

\subsection{AEROSOL GENERATION}

Three devices were used to produce aerosols during the series of tests: an energy mill, an ultrasonic nozzle, and a vibrating orifice aerosol generator. Source materials from which aerosols were generated for particle retention tests were selected based on physical properties and characteristics including density, solubility, and thermal stability. Analytical requirements were also considered. The primary aerosol characteristics measured at the test section inlet, however, were particle size and concentration. As a result of experience gained during early tests and trials, most tests were performed using soluble potassium chloride (KCl) or insoluble zinc sulfide ( $\mathrm{ZnS})$. The energy mill aerosol generator was used to disperse powders during most of the tests, but an ultrasonic nozzle was used during one test, and a vibrating orifice aerosol generator was used during a four-part test to provide monodisperse particles of different sizes. Feed rates of aerosol materials were selected based on the test conditions associated with the original test matrix (Appendix A), determination of analytical requirements, and practical limits on the operation of the generators. Feed rates were further modified by estimates of losses within the generators, the aerosol charge neutralizer, and the aerosol mixing duct.

Aerosols were produced on Level 2 of the ice-condenser facility (Figure 3.4). Aerosol generators were operated using air supplied from either the normal building compressed air or a small air compressor. Air flow rates were measured using a flowmeter connected to the facility's computer data acquisition system, or by observation of other flowmeter systems. Aerosols were passed via 2.5- and 12.5-cm-diameter stainless-steel tubing to the top of the aerosol mixing duct. An in-line $10-\mathrm{mCi} \mathrm{Kr}^{85}$ charge neutralizer was used to produce bipolar air ions that in turn acted to reduce the charge on generated particles to a Boltzmann equilibrium charge distribution. The generation rate of air ions by the radioactive source was calculated to be sufficient following the method described by Liu and Pui (1974).

A vertical mixing duct was used to transport particles, air, and steam from the location of the aerosol generators at Level 2 to the test section inlet at Level 6 , a distance of about $11 \mathrm{~m}$. The stream from the aerosol generator was injected into the flow of heated air and steam at the top of the 
30.5-cm-diameter vertical mixing duct in a manner to facilitate mixing. The aerosol component was injected via a vertical $5-\mathrm{cm}$-diameter tube that extended about $60 \mathrm{~cm}$ downward along the centerline of the mixing duct from a flange plate on top of the duct. The air and steam components were mixed prior to entering the top of the mixing duct via a 2-cm-wide annular region centered around the aerosol injection tube and positioned about $5 \mathrm{~cm}$ above the exit end of the tube. Aerosol was injected into the center, of what was during most tests, an annular region of turbulent gas flow (heated air mixed with steam). The mixing duct terminated in a $90^{\circ}$ bend to horizontal and a round-to-square transition, followed immediately by the inlet aerosol sampling station (Station 6A) located at Level 6.

A Trost ${ }^{(a)}$ Model TX air impact pulverizer, or fluid energy mill, was selected to generate aerosols for most tests. The device uses fluid energy in the form of opposed jets of compressed air to mill and disperse materials as aerosols. Some degree of control over the resultant particle size distribution was obtained by controlling jet pressure, angular velocities, and the presence or absence of a cyclone on the exhaust of the device. A Model TX energy mill is shown in Figure 3.10. Source powder or granular material was introduced via a funnel over the $P$ jet and drawn into the impact chamber by a flow of air created by the aspiration of the air jet. Particle milling occurred in the impact chamber at the region of contact between the two air jets, and was accomplished primarily by particle-particle interactions in the shear zone. Particle classification and re-entrainment into the impact zone occurred in the cyclonic region centered around the discharge. Particles too large to follow the spiraling-inward streamlines were returned to the impact chamber via the downstack for additional milling. Internal components were made of urethane, which was found to provide superior wear resistance (compared to metal) to the abrading stress of milled particles. The mill was modified slightly to allow use of the flow of very fine particles from the top of the discharge cyclone as the primary product (during tests when the cyclone was used). This varied from typical mill operation procedure because milled material trapped in the cyclone is generally the principle product in most energy mill applications, and the fine fraction exiting the cyclone is collected in bag filters. The cyclone was not used when coarse or large particle flow rate aerosols were required; all material exiting the discharge orifice was then directed to the test section. Powder milling rates of more than $50 \mathrm{~g} / \mathrm{min}$ were achievable for most source materials, and tests were typically performed at rates between 1 and $50 \mathrm{~g} / \mathrm{min}$. Powdered ( $\mathrm{ZnS}$ ) or granular ( $\mathrm{KCl}$ ) source materials were fed to the mill manually, with and without the aid of a vibrating trough during Tests 1 through 6 . An AccuRate ${ }^{\text {M }}$ Model 302 dry chemical feeder was used during subsequent tests. The total mass of source material used during each test was quantified, and feed rates were measured before and after each test as part of an effort to obtain an aerosol material mass balance.
(a) Garlock Inc., Newton, Pennsylvania.
(b) AccuRate Inc., Whitewater, Wisconsin. 


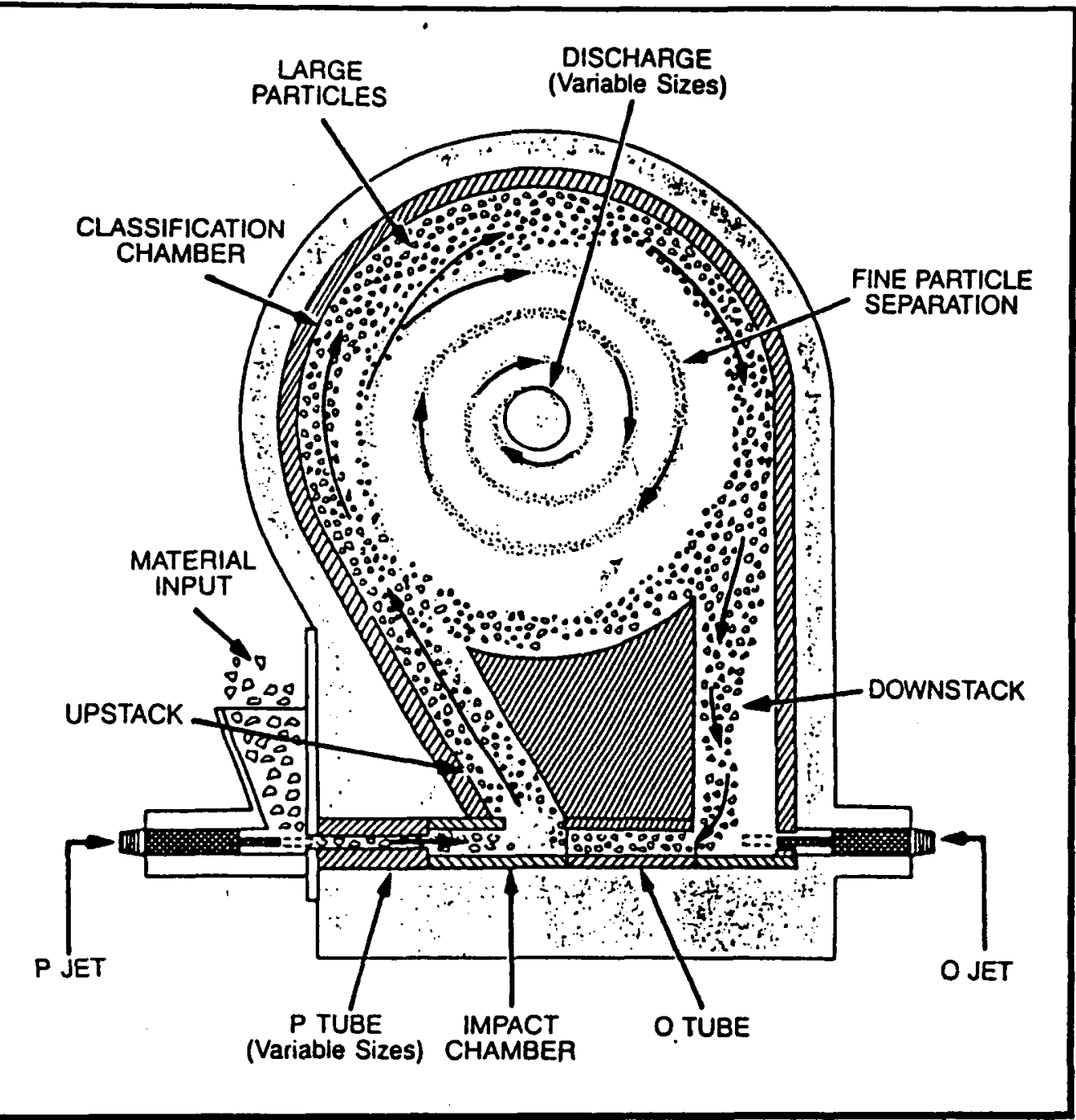

FIGURE 3.10. Sketch of a Trost Model TX Energy Mill Used to Generate Aerosols for Ice-Condenser Tests

A Heat Systems (a) Model 600-1 ultrasonic nozzle, shown in Figure 3.11, was used to generate an aerosol of soluble cesium iodide (CSI) during Test 7 . A dilute solution of CSI was sprayed into a barrel and transported via a carrier air flow through the charge neutralizer and into the mixing duct. The nozzle was selected for its capacity to produce droplets about $3 \mu \mathrm{m}$ in diameter at feed rates of 0.5 to $5 \mathrm{ml} / \mathrm{min}$. A very fine mist was obtained by atomizing a jet of CSI solution using shock waves generated by the expansion of compressed air in and near an annular gap around the liquid jet. The advantage of generating small droplets was that the required dilution of CsI in distilled water was relatively great at $0.023 \mathrm{~g} / \mathrm{ml}$, a concentration that was not

(a) Heat Systems, Inc., Farmingdale, New York. 


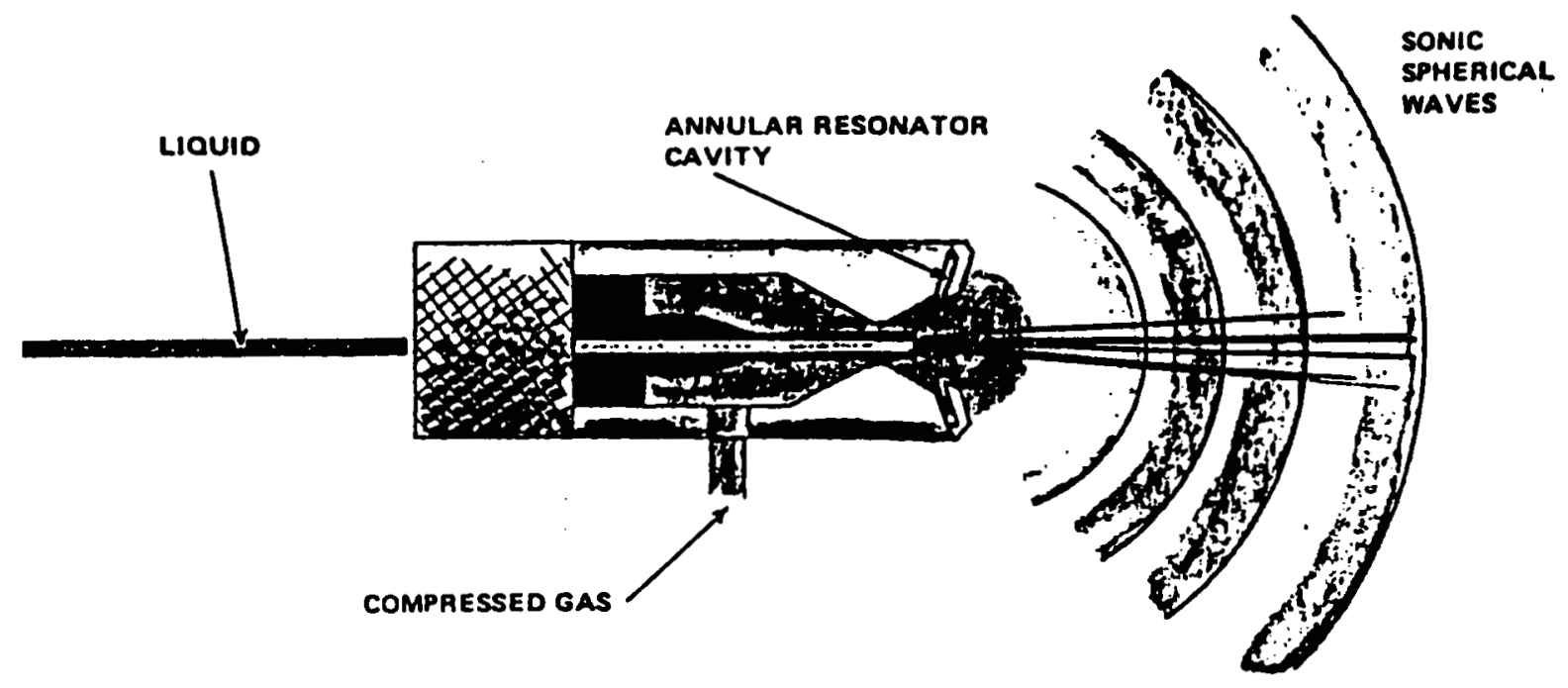

FIGURE 3.11. Sketch of a Heat Systems Model 600-1 Ultrasonic Nozzle Used to Generate CSI Aerosol for Ice-Condenser Test 7

difficult to prepare at the required solution purity. Generation of a similar aerosol using a conventional nozzle that produced larger droplets would have required solution purities about 100 times greater than were actually required. (Nonvolatile contaminant material present in impure solutions will remain with the generated particles after evaporation of the solvent and can potentially cause an increase of the resultant particle size.)

A vibrating orifice aerosol generator (VOAG) similar to that described by Berglund and Liu (1973), modified to include a pressure gauge on the solution supplied to the orifice, was used to produce monodisperse particles for calibration tests, trial tests, and the four parts of Test 12. The VOAG generator is shown schematically in Figure 3.12. Monodisperse particles were generated by passing methanol solutions through a $20-\mu \mathrm{m}$ orifice at a flow rate of $0.19 \mathrm{mi} / \mathrm{min}$. The orifice, attached to a piezoelectric crystal, was displaced along the axis of the liquid jet at controlled frequencies between about 60 and $110 \mathrm{kHz}$ (usually $90 \mathrm{kHz}$ ). The resulting liquid jet was thus disrupted to form droplets having nominal diameters of about $40 \mu \mathrm{m}$. By controlling solute concentrations and evaporation rates, spherical particles ranging from about 1 to $18 \mu \mathrm{m}$ in diameter were produced as the original droplets evaporated. Aerosols produced using this technique consisted of monodisperse particles having geometric standard deviations of about 1.06 . Particles were collected on glass slides coated with Fluorad ${ }^{2}$ and inspected for quality using an optical microscope.

(a) Registered trademark of 3M Commercial Chemical Division, St. Paul, Minnesota. 


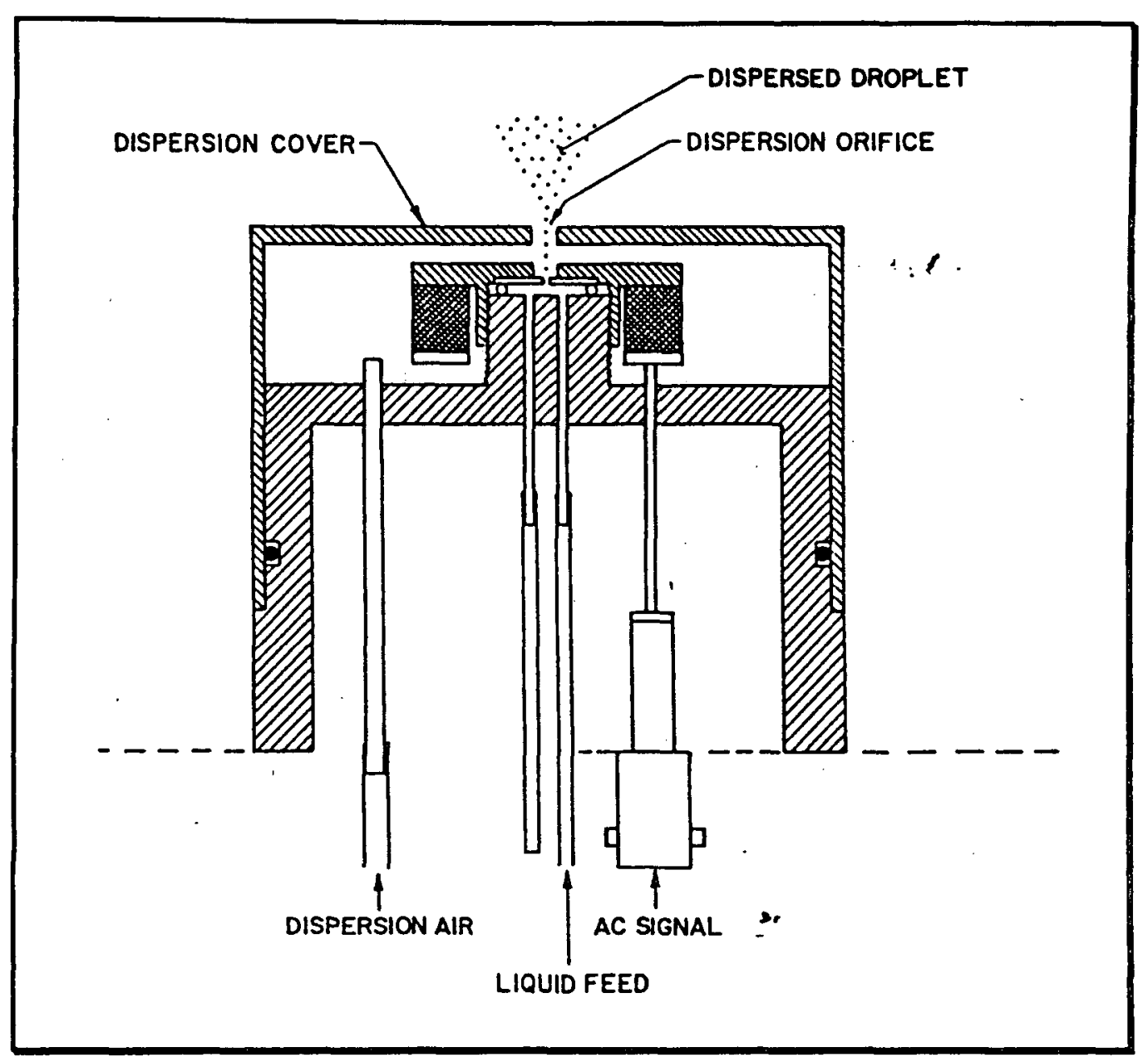

FIGURE 3.12. Sketch of a Vibrating Orifice Aerosol Generator (VOAG) ${ }^{(0)}$ Used to Generate Aerosols for Ice-Condenser Tests

For calibration and trial tests, solutions of oleic acid and fluorescein were prepared in methanol. With one exception, similar mixtures were prepared for Test 12 although dioctyl phthalate (DOP) was used instead of oleic acid because it retained thermal stability in conditions where oleic acid would have degraded.' Only fluorescein was dissolved in methanol for one of the four parts of Test 12 to produce particles about $1 \mu \mathrm{m}$ in diameter. 0leic acid or DOP was used to provide a stable, low-volatility particle. Fluorescein, a fluorescent compound, was used to provide a tracer that was later analyzed to determine aerosol characteristics. Pure fluorescein particles were generated at the smallest particle size $(\sim 1 \mu \mathrm{m})$. Because of solubility limits of fluorescein in methanol, oleic acid and DOP were needed to form the bulk of each particle for generation of particle sizes between about 2 and $18 \mu \mathrm{m}$. Analysis of the fluorescein was accomplished by dissolving collected particles in methanol and determining the fluorescence of the resulting solutions using a Turner ${ }^{(b)}$ Model 111 fluorometer.

(a) Manufactured by TSI, St. Paul, Minnesota.

(b) Unipath, Mountain View, California. 


\subsection{AEROSOL CHARACTERIZATION}

The primary test results were obtained from the determination of inlet conditions and the amount of particle retention between the inlet and outlet of the test section. Secondary results included the determination of aerosol characteristics and thermal-hydraulic conditions at various locations within the test section. Aerosol measurements were made at a series of sampling stations located between Station 6A at the inlet and Station 0 at the outlet (Figure 3.4). Sampling stations were operated during the tests to provide information on steam mole fraction, aerosol concentration, and particle size distribution. Gas flow rates determined by considering inlet flow rates, temperatures, and steam mole fractions, were then used in conjunction with the aerosol concentration results at Stations $6 \mathrm{~A}$ and 0 to determine the aerosol particle mass flow rate at the inlet and outlet, respectively. Particle retention and decontamination factors were then calculated for various time periods during each itest as the ratio of inlet to outlet particle mass flow rate.

A range of aerosol samplers and techniques was considered prior to initiation of the tests. Because of the presence of steam, fog, and a changing particle size distribution and composition, instruments were selected that obtained physical samples of the test aerosols by filtration. Other than in the steady conditions at the test system inlet, the use of optical systems was determined to be impractical because of the influence of changing test conditions on aerosol characteristics. A laser transmissometer was set up at Station 6A, but a real-time output signal related to aerosol mass concentration was not possible because of the difficulty of keeping the windows clear, and because many of the tests were performed at aerosol concentrations outside of the range of the technique.

\subsubsection{Aerosol Sampling Stations}

Aerosol sampling stations were identified by codes that indicated their location within the test section. A list of aerosol sampling stations used at one time or another during the complete series of tests included: 6A, 6B1, $6 B 2,5 A 1,5 A 2,5 A 3,5 A 4,4 B 1,2 B 1,1 A 1,1 A 2,1 A 3,1 A 4,1 B 1$, and 0 (Figure 3.4 ). The first number in each identification code indicated the level at which the station was located. The letter A or B indicated, for facility levels containing stations at two elevations, whether the station was upstream (below), or downstream (above) the other station, respectively. Finally, the second number in each station identification code referred to the flow-channel quadrant in the ice-basket region from which aerosol was sampled (Figure 3.7 ). The numbers $1,2,3$, and 4 in the station identification codes referred to flow-channel quadrants $S W$, NW, SE, and NE, respectively. During early tests, samples were only obtained from Stations $6 \mathrm{~A}$ and those stations on the first quadrant (southwest) of the ice-basket region at Levels 5, 4, 2, and 1. After these tests, it became clear that the characteristics, flow rate, and direction of gas flow were not always similar in each channel, and additional aerosol sampling stations were constructed at Levels $5 \mathrm{~A}$ and $1 \mathrm{~A}$. The new stations were used to obtain aerosol samples from the center of each of the four flow channels between ice baskets. These two quadruple-sample-train stations are 
referred to as "quad" stations.: At the same time, Station 0 was added to ensure that the aerosol characteristics measured at the test system outlet were representative of the bulk flow at that location. Outlet data was obtained from Station 1B1 during the first four tests under the assumption that the upper ice-basket region was well mixed. Stations 6B1 and 6B2 were also added after several tests had been completed and were located about $1 \mathrm{~m}$ below the bottom of the ice baskets. However, their use was discontinued after the identification of recirculation cells centered at or near Station 6B. The presence of the cells prevented the acquisition of representative samples.

A sketch of a typical aerosol sampling station is shown in Figure 3.13 . As shown in the figure, aerosol samples were drawn through the probe, an isolation valve, a filter or impactor where particles were collected, a condensate trap, flowmeter, second isolation valve, and a critical orifice flow-rate controller. Thermometers were installed at each station to provide temperature estimates near the sample probe inlets. Pressure taps were also included at some stations. Most samples were withdrawn via sharp-edged 1.27-cm-diameter, $90^{\circ}$ stainless-steel sampling probes having bend radia of about $15 \mathrm{~cm}$. At Stations $5 \mathrm{~A}$ and $1 \mathrm{~A}$, however, four special probes accessing the first (southwest) and third (southeast) ice-basket quadrants were straight and flared out at the nozzle end. The special probes were installed before Test 9 in the southern two flow channels and used during all subsequent tests. This was done to prevent misorientation between the nozzle and the gas flow direction during periods when suspected flow reversals occurred in the lower turning vane and lower ice-compartment regions of the test system. All aerosol samples were obtained from the centers of ice-basket region quadrants.

Aerosol sampling probes and connecting stainless-steel tubing between the test atmosphere and filter or impactor substrate were designed for a range of flow rates (1 to $25 \mathrm{epm}$ ) and to be optimally efficient in transferring sampled particles ( 1 to $15 \mathrm{~mm}$ ) to the collection substrate. The design limited losses caused by both gravitational settling in the horizontal sections and inertial impaction in curved sections. Particle diffusion losses were also estimated, but were not important for any likely sampling conditions. A 0.95-cm-diameter ball valve was located on the sample tubing immediately outside the test section and was used as a controller to isolate the sample train from the test atmosphere. The sampler, either a filter or an impactor, was connected downstream of the control valve using smooth-wall stainless-steel tubing connections. Temperature-controlled heat tapes and heating mantles were used to maintain the sample stream at a temperature above the dew point. The procedure for initiating flow through a sampling system was to install the collector (filter or impactor), open the test section valve, and then open the valve to the vacuum system. To end a sample, the procedure was completed in reverse order to avoid placing a vacuum on condensers or aerosol samples.

The portions of the aerosol sampling probes extending outside of the test section and the aerosol samplers were heated to prevent condensation of steam and loss of aerosol on internal surfaces. It was also important to maintain the cascade impactors at temperatures above the dew point to provide a known 


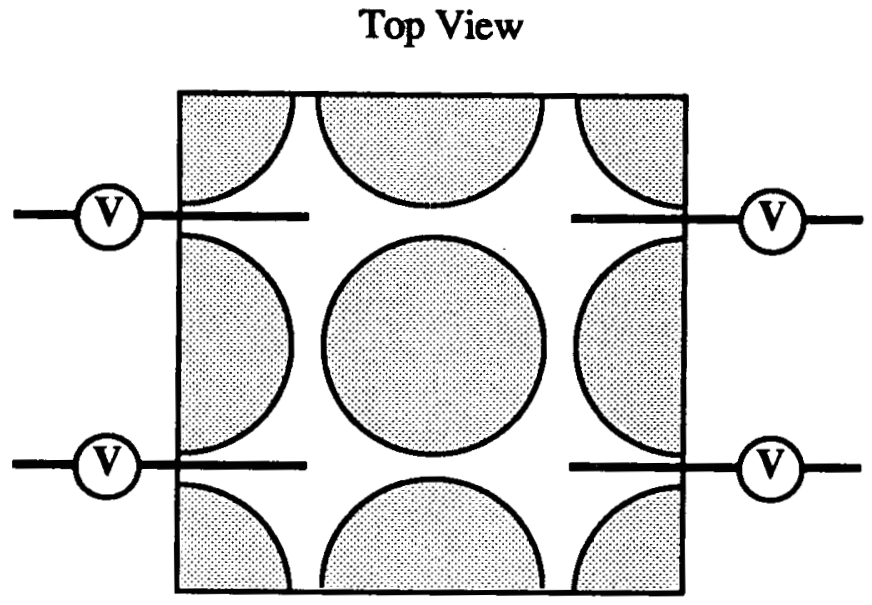

To Vacuum

Pump

$1 /$ Crushed Ice

(V) Sample Isolation Valve

Side View

Critical Orifice

Flow Rate Controller
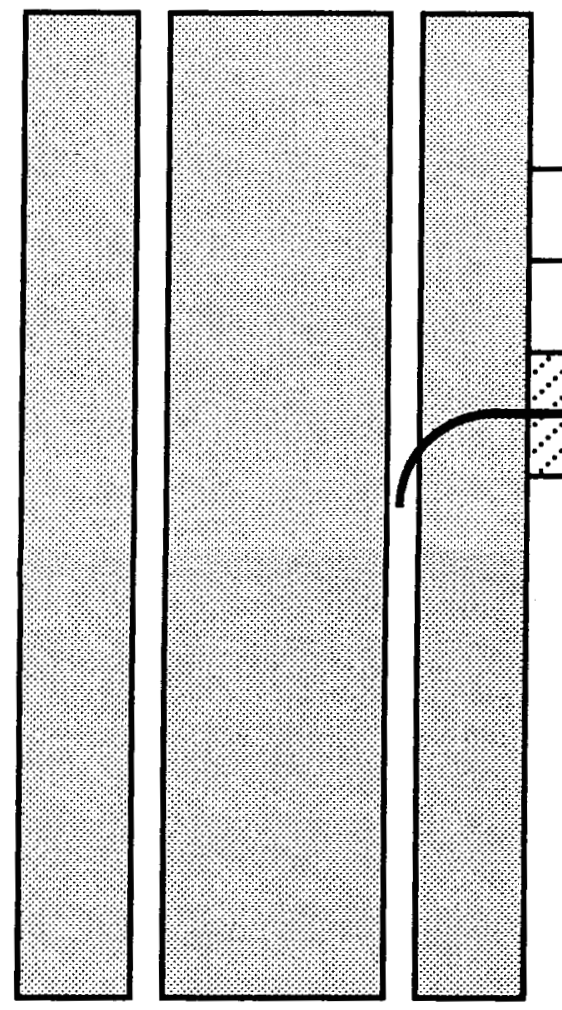

(T)

(P)
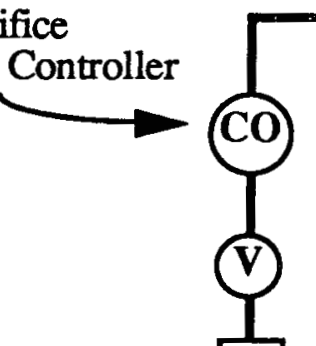

Flowmeter
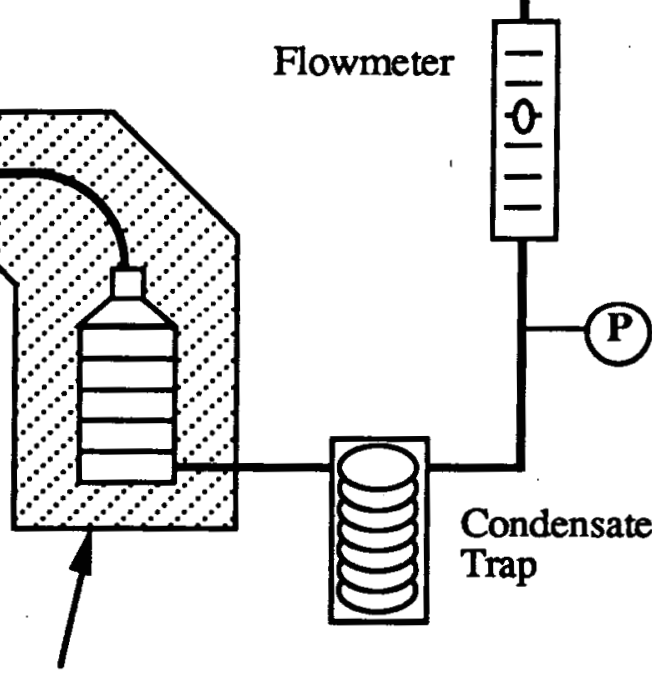

Temperature-Controlled

Filter or Impactor

FIGURE 3.13. Sketch of a Typical Ice-Condenser Aerosol Sampling Station. All samples were obtained from the centerlines of ice-basket region quadrants. 
sample flow rate. This was because segregation of sampled aerosol by particle size on the various stages of the impactors was dependent on sample flow rate. Rubberized heat tapes and glass fiber heating mantles were used to heat the probe and the samplers, respectively. Glas-Col Model 606 HS heating mantles, each modified with a hole and a slit, werg, used to heat the stainless-steel filter holders. Tudor Scientific (B) Model TG-1276-103 heating mantles (soft-shelled with a $2.5-\mathrm{cm}$ zippered slit) were used to heat the aluminum casçade impactors. Probe and sampler temperatures were regulated using Omega $(\varepsilon)$ Model $20 \mathrm{M}$ solid-state temperature controllers modified to provide 15-amp current loads; type $J$ thermocouples were attached under heat tapes or between mantles and impactors. Most filter holders were heated without using a thermocouple because the specific temperature was less important than maintaining the device above the dew point when sampling soluble-particle aerosols. Filter holders were typically preheated before sampling to ensure that all surfaces were hot, and then unplugged some moments after the beginning of the sampling period. A longer, low-energy heat-up period was used to avoid warping the aluminum cascade impactors. The heavy impactors did not cool quickly; as a result, heating was not usually required during the sampling periods, although the mantles were left in place to maintain thermal insulation.

Condensate traps were constructed of 2-1iter Thermos ${ }^{R(d)}$ bottles and coiled stainless-steel tubing. The traps were used to provide data for determining the steam mole fraction (SMF) present at specific locations within the test section, and were operated downstream of the aerosol samplers on all aerosol sampling trains. In addition, condensate traps were operated on sample lines connected directly to the test section atmosphere to provide data that was independent of the period and sample flow requirements of the aerosol samples. Condensate trap and aerosol samples at the various stations, however, were often obtained concurrently. Coiled tubing entered the traps at the top and exited at the bottom, where 90- or 180-ml polyethylene bottles were used to collect condensation. Ice and water were maintained in the condensate traps during sampling. Sample flow rates were controlled using critical orifices. Condensate mass was determined using a semi-micro mass balance.

The noncondensible gas fraction of samples was measured to control sample flow rate. As indicated above, aerosol sample gas streams were drawn through a condensate trap after collection of particulate matter on a filter or impactor. This was done to remove the steam fraction of the sample flow and to cool the sample. The noncondensible fraction of the sample was then passed

(a) Glas-Col, Terre Haute, Indiana.

(b) Tudor Scientific, Belvedere, South Carolina.

(c) Omega Engineering, Inc., Stamford, Connecticut.

(d) Registered trademark of the Thermos Division, Household Manufacturing, Norwich, Connecticut. 
through a flowmeter to provide a check of sample flow rate, a pressure tap, and a critical orifice flow-rate controller.

\subsubsection{Critical Orifice Flow-Rate Controllers}

Critical orifices were used to control aerosol and condensate-trap sample flow rates. This was done to reduce the influence of pressure fluctuations in the sample line on flow rate and to standardize sample flow rates between stations. Brass orifices were used, having nominal drill sizes of 80,77 , $74,69,65,58,55,53$, and 50 . The actual diameters of the orifices were measured and found to be similar to the nominal drill sizes; $0.034,0.041$, $0.054,0.074,0.089,0.102,0.132,0.151$, and $0.178 \mathrm{~cm}$, respectively. The orifices were calibrated by comparison with certified dry test meters and found to have air flow rates of $1.03,1.45,2.47,5.03,6.97,9.14,15.2$, 19.8 , and $27.2 \mathrm{lpm}$, respectively, when operated with a pressure drop greater than one-half atmosphere. In addition to calibrating the orifices, expected flow rates were calculated using two methods; one presented in the Chemical Engineer's Handbook (Perry and Chilton 1973), and one described by Shapiro (1953). The measured flow rates were found to be within about $5 \%$ of those calculated by the two methods, and are shown in Figure 3.14.

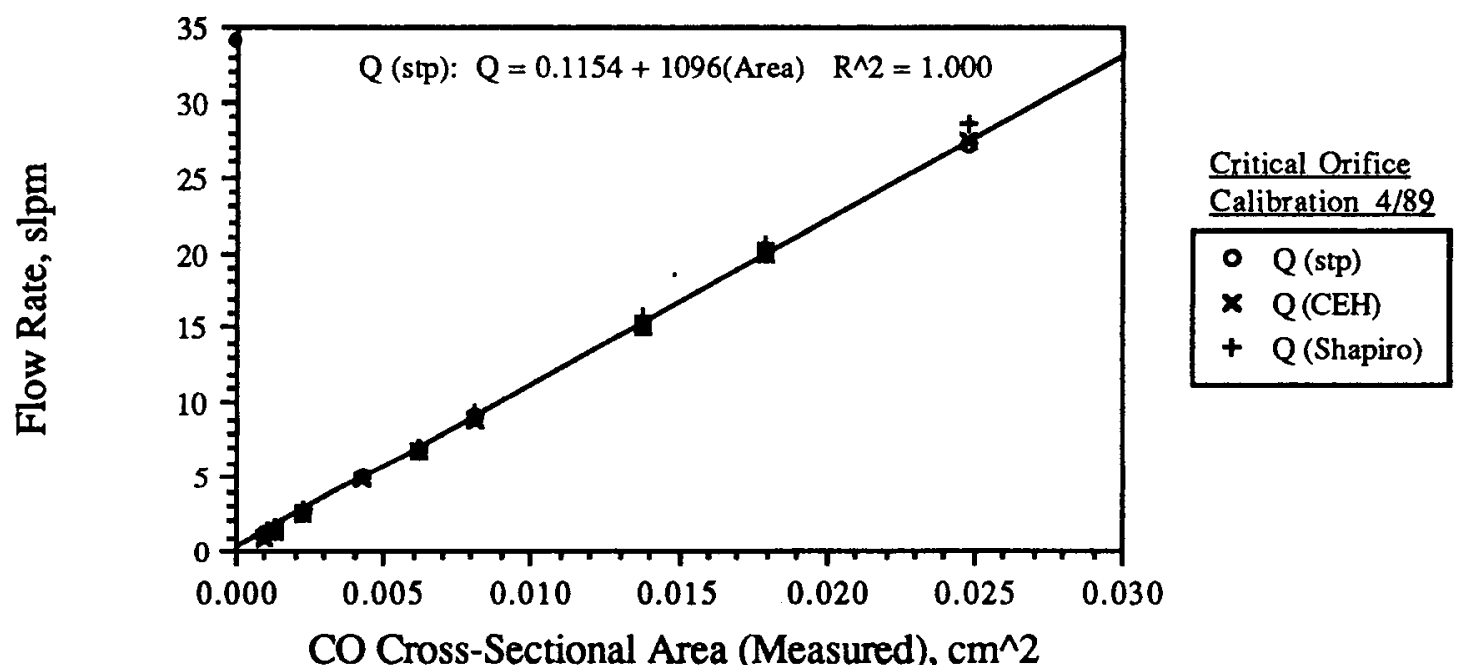

FIGURE 3.14. Comparison of Critical Orifice (CO) Flow Rate Calibration Results (using a Dry Test Meter) to Two Methods of Calculating Flow Rate [(CEH) = Chemical Engineer's Handbook (1973), (SHP) = Shapiro (1953)] at Standard Temperature and Pressure 


\subsubsection{Aerosol Mass Concentration}

Samples of test aerosols were obtained by drawing known volumes through the sampling trains. Aerosol concentration measurements, the mass of suspended particles per volume, were usually obtained by collecting the particulate matter present in each sample on pre-weighed 47-mm Gelman glass fiber filters. (Filters were not preweighed before tests having very dilute aerosol mass concentrations, when particle mass loading was estimated to be less than about $0.5 \mathrm{mg}$. Filters from these tests were analyzed using only chemical or fluoroscopic methods.) Aerosol mass concentration was determined as the ratio of the particulate mass collected on each filter to the total actual gas volume sampled (corrected for test section temperature, pressure, and gas composition). The filters were placed in heated Gelman(a) in-line stainless-steel filter holders. Samples were obtained isokinetically when necessitated by particle inertia, using the sharp-edged nozzles described previously.

Sample flow rates and durations to be used during each test were determined by considering the anticipated aerosol mass concentration, gas flow and temperature conditions, sample probe effectiveness, and the estimated total time available for each test. The specific sampling procedure used at each station and during each sampling period of a particular test depended on the actual gas temperature present in the test system. Thermometers installed near each sampling probe provided this information. Depending on the temperature present at each sample station, samples were obtained using one of two alternate sampling procedures specifically determined for each station (Section 3.6.4). Filters were weighed after most tests, and submitted for analys is of principle chemical or fluoroscopic constituents after selected tests. Chemical analyses performed included chloride analys is for $\mathrm{KCl}$, and inductively-coupled plasma (ICP) analyses for $\mathrm{ZnS}, \mathrm{CSI}$, and $\mathrm{KCl}$. Test 12 and several calibration and trial tests were performed using dioctyl phthalate (DOP) or oleic acid particles with known mass fractions of fluorescein or sodium fluorescein (uranine) tracer. In these (instances, samples were analyzed fluoroscopically for the tracer using a Turner ${ }^{(b)}$ Model 111 fluorometer.

Because it was possible that gravitational settling could have affected the vertical distribution of aerosol mass concentration in the outlet region of the test section, a special multi-probe sampler was used. The probe consisted of five 47-mm in-line filter holders mounted horizontally on a vertical tube. Samples were drawn into each filter via a sharp-edged nozzle. Sample flow rate was controlled using a common critical orifice. The samplers were uniformly spaced, with No. 1 near the top of the test section and No. 5 near the bottom. No. 3 was located at the test section centerline about $1 \mathrm{~m}$ upstream from the probe used at Station 0 . The series of filters provided data on the vertical distribution of aerosol mass concentration and allowed
(a) Gelman Sciences, Ann Arbor, Michigan.
(b) Unipath, Mountain View, California. 
determination of the suitability of samples obtained at Station 0 to accurately represent the average, or bulk aerosol conditions existing at the test section outlet. The possibility of a vertical aerosol concentration gradient at the outlet was originally perceived because of the combined presence of both slow gas flow rates and large particle sizes. The slow gas flow rates were caused by a large cross-sectional area combined with reduced gas flow rate (which was, in turn, caused by upstream condensation of steam). The large particle sizes were caused by particle growth in the condensation zone and the formation of fog droplets.

\subsubsection{Particle Size Distribution and Morphology}

Particle size distribution measurements were performed both to identify the characteristics of aerosols supplied to the inlet of the test section and to determine the resulting distribution of particulate matter in the fog and aerosol mixture present within and at the outlet of the test section. Particle morphology measurements were made to determine the physical nature of particles produced by the aerosol generators, and measurements were also attempted to provide similar information for particles present in the test section.

Particle size distributions were measured using Andersen ${ }^{(a)}$ cascade impactors. Impactor data were used to determine aerodynamic mass median diameter (AMMD) and geometric standard deviation (GSD) of aerosol particles. Measurements were typically performed at the inlet and outlet of the test section, but also occasionally at locations within and immediately below the ice-basket region. Operational considerations such as temperature and flowrate control were described previously (Sections 3.5.1 and 3.5.2), and special calibrations and measurement of internal losses are discussed below (Section 3.5.5). Five identical impactors were used interchangeably throughout the test series. The impactors consisted of eight stacked stages and a back-up filter, with each stage diverting sampled aerosol through a series of jets impacting on a common collection substrate. The impaction velocity provided by each stage was a function of the number and diameter of the jets. This style of particle impactor is called "cascade" because the aerosol sample passes through each stage successively, impacting large particles below the upper stages and small particles below the lower stages. Upper stages consisted of relatively large jet diameters and provided relatively slow impaction velocities. Lower stages provided increasing impaction velocities by using decreasing numbers of jets and decreasing jet diameters. The collection surfaces used were $81-\mathrm{mm}$ glass fiber filter media, placed smooth side up.

When operated at the nominal flow rate of $28 \mathrm{lpm}$, the Andersen(a) cascade impactor size segregates airborne particles having aerodynamic diameters between about 10 and $0.5 \mu \mathrm{m}$. Particles larger than $10 \mu \mathrm{m}$ are collected on the first stage, and particles less than $0.5 \mu \mathrm{m}$ are collected on the back-up

(a) Andersen Instruments, Inc., Atlanta, Georgia. 
filter after the eighth successive impaction substrate. By lowering the flow rate, larger particles were successfully collected (Section 3.5.5) over a greater range of particle sizes, although at the cost of increased internal wall losses.

Particle morphology was not provided by cascade impactor samples because the nature of the sampling process caused the agglomeration of collected particles in piles under the impactor jets. Samples for analys is of particle morphology were obtained using smooth polycarbonate membrane filters or glass slide deposition coupons. These samples were obtained near the aerosol generator, at the inlet, in the ice-basket region, and at the outlet of the test section. However, because of condensing steam, many of the samples collected at locations other than the generator were flooded and not useful. Particle morphologies were observed and micrographs were prepared using a Scanning Electron Microscope (SEM).

\subsubsection{Probe and Sampler Calibration Tests}

Calibration tests were performed in the test facility to determine the effectiveness of particle sampling. Calibration tests were also performed in a wind tunnel to determine the suitability of cascade impactors to measure particle size distributions. Both types of calibration tests were performed using a range of monodisperse particle sizes produced using a vibrating orifice aerosol generator.

Probe loss correction factors relating measured to actual aerosol mass concentration are shown in Figure 3.15. Values are presented for relatively large-diameter particles $(11.4 \mu \mathrm{m})$ and for the three different sampling probe configurations used during ice-condenser tests. Although the geometries of all probes were similar, calibration tests were performed because of differing particle deposition characteristics caused by the orientations of each probe configuration with respect to the force of gravity. For example, sedimentation losses in sample transfer tubes were greater for horizontal than vertical orientations. The configuration of the probe at Station 6A was a horizontal nozzle followed by a vertical, downward-oriented sample transfer tube. The configuration of the probe at Station 0 was similar, but with an upward vertical sample transfer tube. The configuration of the probe at Station 1B was a vertical, downward-oriented nozzle with a horizontal sample transfer tube (as shown in Figure 3.13), and was similar to all stations between 6B and $1 \mathrm{~B}$ with the exception of the straight tubes described previously.

Probe loss correction factors were determined as the inverse of unity minus the fractional percentage of the aerosol (by mass) lost in the sampling tube between the nozzle and the collection filter. All samples were obtained under effectively isokinetic sampling conditions. For sample flow rates less than $15 \mathrm{epm}$ all sampling losses were limited to less than or equal to about $25 \%$. Losses at the greatest sampling rate $(25 \mathrm{lpm})$ ranged between about 20 and $55 \%$. The increase in sampling tube losses with increasing sample flow rate was attributed to increased particle impaction in the curved region of the sampling tubes. Losses measured at Station 1B were slightly greater than 

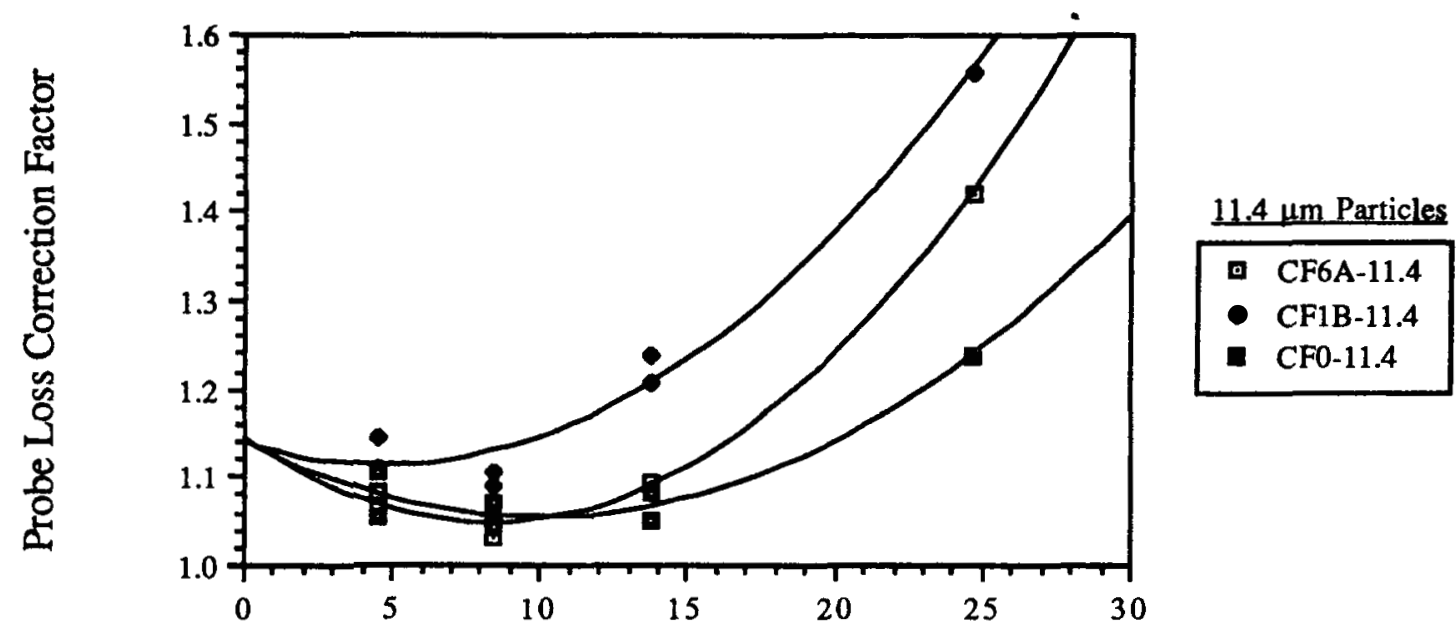

Sample Flow Rate, lpm

FIGURE 3.15. Aerosol Sample Probe Loss Factors for 11.4- $\mu \mathrm{m}$ Monodisperse Particles at Stations 6A, 1B, and 0

those measured at Stations $6 \mathrm{~A}$ and 0 . This was attributed to the horizontal orientation of the sample transfer tube at Station 1B, which potentially contributed to greater sedimentation losses. Data presented in the figure are conservative because most particles in the test section during icecondenser aerosol tests were smaller than $11 \mu \mathrm{m}$. Probe sampling losses for particles less than about $5 \mu \mathrm{m}$ in diameter were typically on the order of $1 \%$. All particle sizes were determined as aerodynamic diameters by considering particle density.

Calibration tests of the cascade impactors were performed both before and after the particle retention tests. The former calibration tests were performed because the impactors were operated at flow rates equal to and less than the nominal $28 \mathrm{epm}$ flow rate recommended by the manufacturer. The result of calibration tests was particle size cutpoints for the individual stages of the device at representative sample flow rates. An in-stack impactor was also tested during the earlier series of tests for comparison with the ambient impactor ultimately selected. Both impactors were found to be suitable for sizing particles. However, wall losses based on particle size and sample flow rate test parameters within the impactors were predictable for the ambient impactor but not for the in-stack impactor. The reason for this difference between the two impactors was thought to be that the in-stack impactor tended to concentrate all internal losses on the top plate of the top stage. Losses in the ambient impactor tended to be distributed around a number of sample stages as a function of particle size and sample flow rate. As a result, correction factors could be developed only for the ambient impactor. The Andersen ambient cascade impactor was, therefore, selected for use during the particle retention tests.

(a) Andersen Instruments, Inc., Atlanta, Georgia. 
Although results of measurements made using cascade impactors were reported in terms of aerodynamic mass median diameter (AMMD) and geometric standard deviation (GSD), calibration tests were performed to verify AMMD only. Results of calibration tests performed before the ice-condenser particle retention tests are shown in Figure 3.16. Measured (impactor) particle size was found to be within $10 \%$ of the actual particle size produced using a vibrating orifice aerosol generator (Section 3.4), when a Stoke's $D_{5}$ g parameter of 0.103 was used (the data in the figure were plotted using 0.102 , an insignificant difference). For 14 and $21 \mathrm{lpm}$ sample flow rates, losses caused by particle deposition to inner walls of the impactor ranged from less than $5 \%$ for particle sizes less than $5 \mu \mathrm{m}$, to 20 and $13 \%$, respectively, for $10-\mu \mathrm{m}$ particles, and 25 and $18 \%$, respectively, for 12- $\mu \mathrm{m}$ particles. Losses at $7 \mathrm{lpm}$ were probably slightly greater than those at $14 \mathrm{lpm}$ because of greater sedimentation, although data were only obtained at $8 \mu \mathrm{m}$ for the $7 \mathrm{lpm}$ flow rate case. Losses at $28 \mathrm{lpm}$ were not measured other than at $5 \mu \mathrm{m}$, at which size they were about $5 \%$. Tests were performed at flow rates of 7 to $28 \mathrm{lpm}$ and using monodisperse particle sizes between 3 and $12 \mu \mathrm{m}$.

Cascade impactor calibration tests performed after the series of icecondenser particle retention tests provided results similar to those obtained before the tests. All four impactors most often used during the particle retention tests were tested during the latter calibration test series. Measured particle size was within about $10 \%$ of actual particle size, except that measured particles greater than about $10 \mu \mathrm{m}$ were typically $10 \%$ smaller than their actual size.

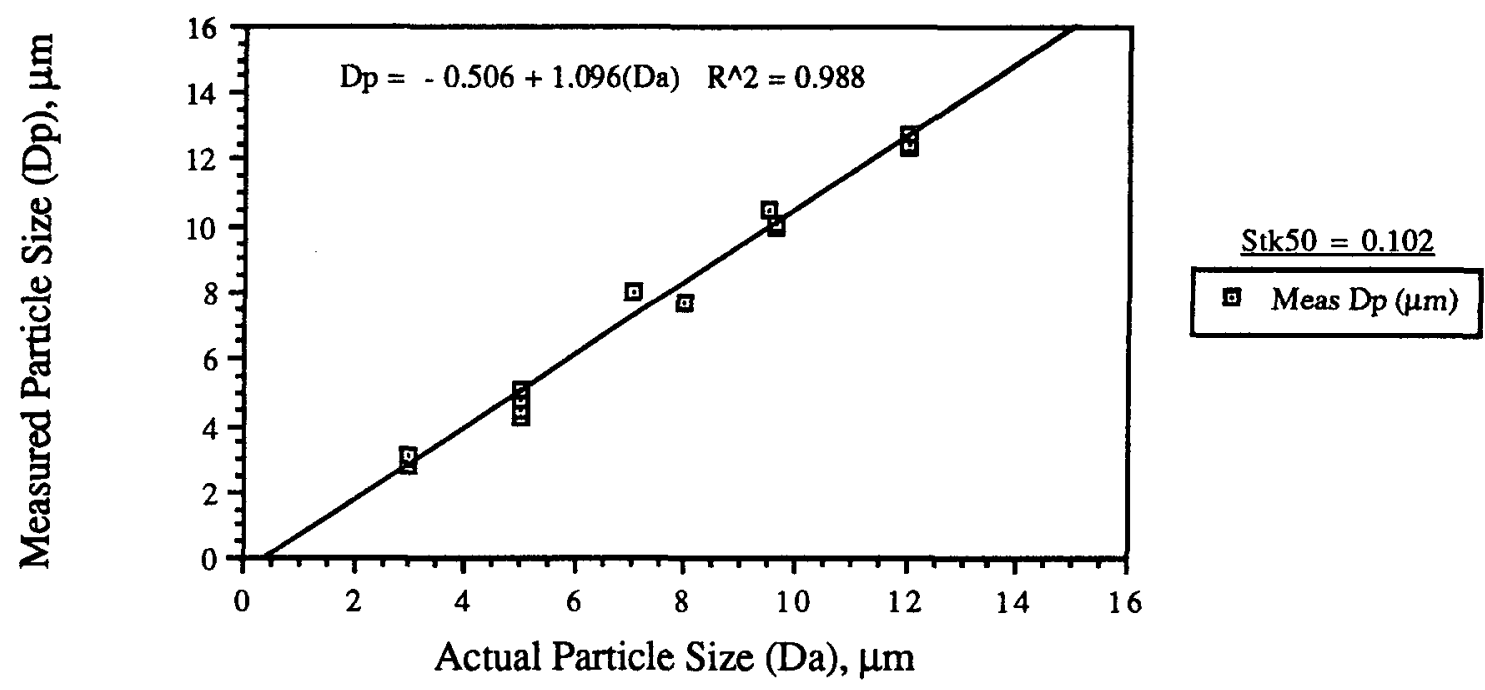

FIGURE 3.16. Results of a Calibration of Andersen Ambient Cascade Impactors Operated at Nominal (28 epm) and Less-Than-Nominal (7, 14, 18, and $21 \mathrm{lpm})$ Flow Rates 


\subsubsection{Aerosol Material Mass Balance}

An independent measure of the distribution of aerosol particle retention in the test section was performed by completing an aerosol particle material mass balance (the primary measurement method used aerosol samples). A mass balance was performed for Tests 4,9 , and 10 by measuring the mass of aerosol source material dispersed into the test system, and by analyzing the concentration of aerosol materials in all effluent streams from the test section and test facility during each test. Influent and effluent streams are identified in Figure 3.17. To determine the percentage of mass recovered, the total aerosol particle mass produced (M1) was compared to the sum of aerosolmaterial masses collected in each effluent stream $(M 2+M 3+M 4+\ldots+M 10)$.

It was only possible to perform a mass balance analysis for tests using soluble-particle aerosols. This was because the method that was developed depended on the ability to rinse residual material from the mixing duct and the test section after the test was completed and the remaining ice had melted. It was also necessary that material collected in the sump tanks and scrubber remain in solution to allow representative grab samples to be obtained. In addition, the procedure was only attempted for tests performed with ice present in the baskets. Although seven such tests were performed using solubleparticle aerosols, four were not suitable for the procedure: Test 1 was performed before the procedure was developed; Test 7 consisted of a dilute CsI aerosol and the concentration of the material in sump and scrubber effluents was insufficient for analysis; Test 8 was disrupted by an intermittent and unsteady aerosol production caused by failure of the energy mill; and effluents were not monitored during Test 13a because soluble-particle aerosol was only generated during the first half of the test (insoluble $\mathrm{ZnS}$ was generated during the second half of the test).

Because the locations of each influent and effluent stream were known, it was possible to estimate the retention of aerosol material within the test section during the tests. This was a secondary result of the mass analys is procedure. Particle retention estimates based on the mass balance analys is were independent of those based on aerosol samples (the primary method) and, thus, could be used to provide a gross comparison. The mass-balance procedure for estimating particle retention is based on the influent and effluent streams (Figure 3.17). Recalling that decontamination factor (DF) $=1-\mathrm{R}^{-1}$. two expressions for DF (DF 1 and $D F_{2}$ ) may be derived using different combinations of the mass parameters shown in the figure:

$$
\begin{aligned}
\mathrm{DF}_{1} & =\frac{\text { Mass Flow Rate Into the Test Section }}{\text { Mass Flow Rate Out of the Test Section }}=\frac{M 1-M 2-M 3-M 8}{M 5+M 6+M 10} \\
\mathrm{DF}_{2} & =\frac{\text { Mass Flow Rate Into the Test Section }}{\text { Mass Flow Rate In - Mass Flow Rate Retained }} \\
& =\frac{M 1-M 2-M 3-M 8}{(M 1-M 2-M 3-M 8)-(M 4+M 7+M 9)}
\end{aligned}
$$




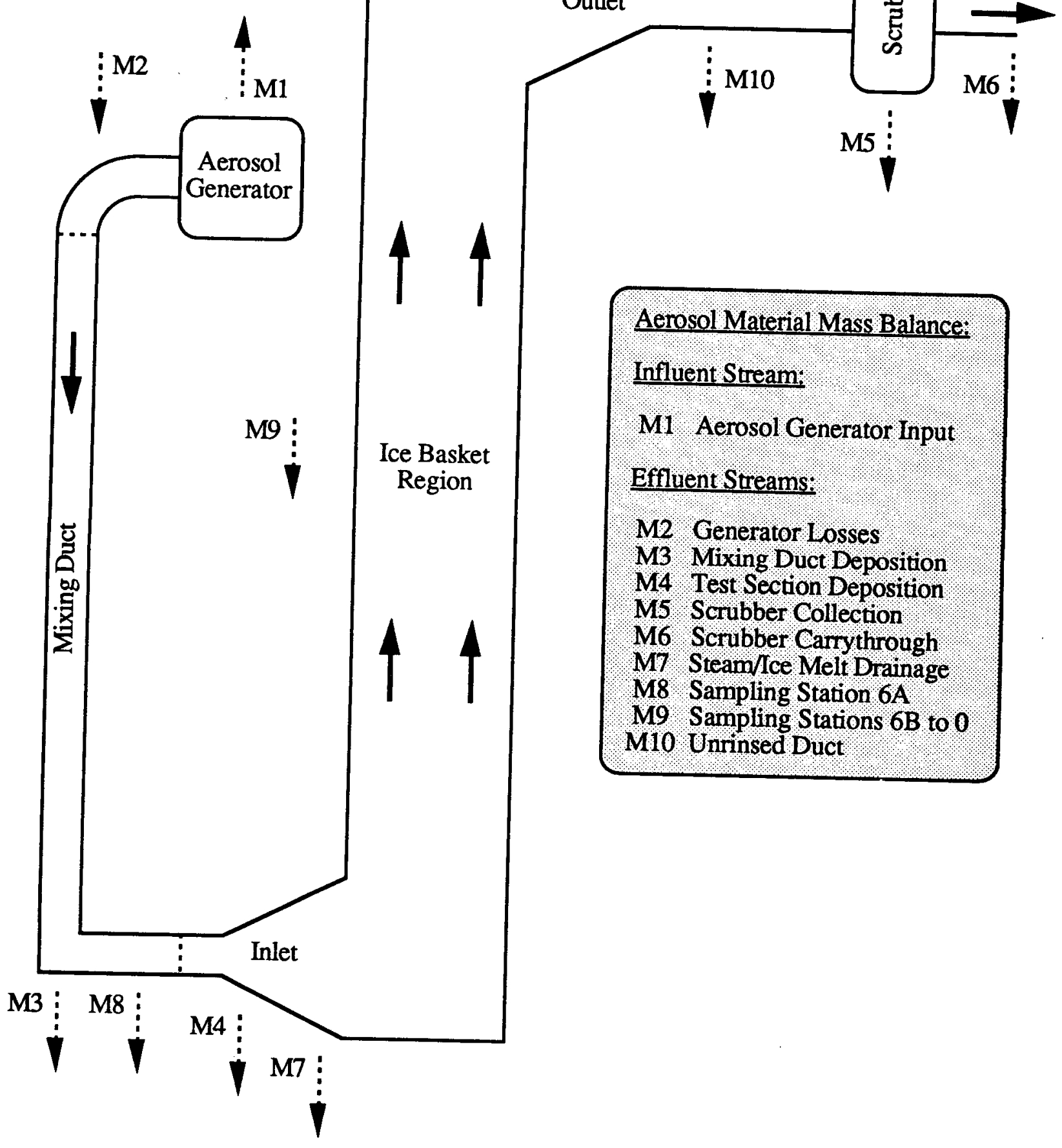

FIGURE 3.17. Aerosol Mass Balance Procedure Influent and Effluent Streams 
Because the magnitude of the masses represented by $M 6, M 8, M 9$, and $M 10$ were very small compared to those of the other effluent streams, they did not influence the estimate of DF and could be disregarded. Each of the disregarded values account for less than $0.1 \%$ of the total aerosol-material mass. The resulting particle retention relationships are shown in Equations (3) and (4).

$$
\begin{aligned}
& \mathrm{DF}_{1}=\frac{M 1-M 2-M 3}{M 5} \\
& \mathrm{DF}_{2}=\frac{M 1-M 2-M 3}{M 1-M 2-M 3-M 4-M 7}
\end{aligned}
$$

Uncertainty in test-average DF determined using the aerosol mass balance procedure was primarily influenced by the difference between the total mass of generated aerosol source material, M1, and the total mass of aerosol material present in the effluent streams, $\Sigma(M 2, M 3, M 4, \ldots, M 10)$. M1 was always greater than the sum of the masses present in the effluent streams, indicating that some of the streams were under-represented in the analyses. Because the total M1 was known with great accuracy, and because of the nature of the various effluent streams, some assumptions could be made about which of the effluent streams may not have been well represented in the analysis. For example, when consecutive rinses of the mixing duct and the ice-basket and inlet regions of the test section were performed and indicated that nearly all of the aerosol material had been removed, the possibility of measurement errors for M3, M4, and M7 was substantially reduced. Thus, material missing from the mass balance would then likely have been associated with either M2 or M5. While pre- and post-test samples of the scrubber tank water allowed accurate measurements of M5, the accuracy of the measurements of M2 was usually less certain. This was because the mass of aerosol material deposited within the energy mill, cyclone, charge neutralizer, and tubing between the generator and the mixing duct was difficult to completely recover.

For the aerosol material mass balance procedure, the mass M1 was determined by direct measurement of the mass of aerosol source material placed into the hopper of the energy mill powder feeder minus that remaining at the end of the test. M2 was determined by measuring the mass of powder present in the various portions of the aerosol generation and delivery system, and as described above, was the most difficult measurement to perform. M3, the mass of material deposited to the mixing duct upstream of the inlet region of the test section, was determined after tests by rinsing the mixing duct from the top and collecting the effluent in the sump. The concentration of aerosol material in the sump liquid was measured using 20-ml sample vials dipped into the sump during each fill and pump cycle. The total mass of aerosol material present in each sump tank of rinse water was then calculated as the concentration multiplied by the total volume present in the sump. The total mass M3 was finally obtained by summing the masses present in each sump. Decreasing concentrations of aerosol material in successive sump loads provided 
an indication of the effectiveness of the rinsing process to remove deposits of soluble-particle aerosols from the mixing duct. M4 was a measure of the mass of aerosol material remaining in the test section after completion of the tests and was determined using a similar procedure to that described for M3. M5 was the total aerosol material mass present in the 250-gal scrubber tank and was determined from results of samples obtained after tests less those of samples obtained before tests. M6 was determined as the theoretical penetration of aerosol particles through the exhaust scrubber. M7 represented the mass of aerosol material removed from the test section during the tests as the sump filled with water from condensed steam and melted $i c e$, and was determined similarly to $M 3$ and $M 4$ using 20-ml vials each time the sump filled. $M 8$ was the mass withdrawn from the test section at Station $6 \mathrm{~A}$, including both condensate and aerosol samples, and $M 9$ was the total of the masses withdrawn from the aerosol sampling stations between $6 \mathrm{~B}$ and 0 . M10 was the mass of material deposited between Station 0 and the scrubber, and was calculated based on pipe geometry, gas velocity, and particle size distribution. Again, M6, M8, M9, and M10 were each less than about $0.1 \%$ of the total mass and were not significant.

\subsubsection{Aerosol Data Analysis Procedures}

Data analysis procedures performed after each test were similar. Changes in sampling station location and operation from test to test did not greatly affect data analysis procedures except that additional procedures were added as new sampling techniques were developed and used (e.g., the addition of a vertical array of aerosol samplers at Station 0 ). Physical samples were analyzed by gravimetric, chemical, or fluoroscopic methods. Filters and impactor substrate were usually weighed using a Mettler AE163 semi-micro balance. Condensate trap lids were removed and the wet and then dry weights were measured using the semi-micro balance or a Mettler ${ }^{(a)}$ PE360 balance. Samples from most tests were chemically analyzed including chloride analysis for $\mathrm{KCl}$, and inductively-coupled plasma (ICP) for $\mathrm{ZnS}, \mathrm{CsI}$, and $\mathrm{KCl}$. Test 12 and several calibration and trial tests were performed using dioctyi phthalate (DOP) or oleic acid particles with known mass fractions of sodium fluorescein (uranine) f tracer. Samples were analyzed fluoroscopically for the tracer using a Turner Model 111 fluorometer. Filter and impactor substrate samples were contacted with distilled water, dilute nitric acid, or methanol prior to analysis. Aqueous samples taken from the drainage sump and the scrubber during tests, and the mixer and test section during cleaning operations were obtained during selected tests for use in mass balance analyses (Section 3.5.6) and submitted for analysis along with the filter and impactor samples. Finally, occasional samples of aerosol particle losses within the sampling probes were obtained and analyzed either chemically or fluoroscopically.

(a) Mettler Instrument Corporation, Hightstown, New Jersey.

(b) Unipath, Mountain View, California. 
Data were analyzed sequentially with the final result being the determination of decontamination factor (DF) values for each test. Although gravimetric data were suitable for immediate analysis, results of chemical and fluoroscopic analyses required additional consideration. Preliminary sample results, usually in $\mathrm{ppm}$ of $\mathrm{Cl}^{-}, \mathrm{K}, \mathrm{Zn}$, or $\mathrm{Cs}$, or in terms of mass or activity of tracer per volume of solvent, were corrected for background levels using control samples, checked for mass ratio of inorganic ions, and converted to total mass based on the molecular composition of the aerosol material.

Using information collected at each station and recorded on data sheets, a spreadsheet for calculating the steam mole fraction at each station during each condensate sample was completed. These spreadsheets are included in Appendix C. Data entered included the time the sample was obtained, sample duration, test section temperature, critical orifice identification number, pressure at inlet to the critical orifice, and mass of condensate. The steam mole fraction present in the test system was calculated using the outline presented at the end of each spreadsheet in the appendix. In addition, the condition of the gas (not saturated, saturated, or superheated water vapor) was determined. For cases when more condensate was collected than could be expected in the sampled air, the residual condensate mass was considered to be present in the air as water droplets and was listed as fog concentration in $\mathrm{mg} / \mathrm{m}^{3}$. This latter calculation was based on the temperature of the air.

The temperature and steam mole fraction present at the time and location of each aerosol sample were next determined using temperatures recorded on station data sheets and steam mole fraction results determined in Appendix $C$. These results were plotted for the inlet and outlet (Stations 6A and 0 ) and for several regions within the ice-basket region to show trends in the penetration of hot moist gas through the test section as each test progressed.

After determining the gas conditions present during each aerosol sample, particle size distributions, aerosol mass concentrations, and particle mass flow rates were calculated. Particle size distributions were determined from cascade jippactor data using a data-reduction program operated on a HewlettPackard 9816 computer. In addition to the mass of particles collected on each stage of the impactor, the temperature, actual sample flow rate, and pressure drop were entered for each sample. The Stokes parameter was 0.103 in all cases, and was based on the results of a series of calibration tests (Section 3.5.5). Results included the aerodynamic cutpoint of each stage based on sample flow rate and gas conditions and a printout of the mass collected on each stage and the cumulative-percentage-less-than present at each cutpoint particle size. Cumulative-percentage-less-than was a measure of the mass fraction of the sampled aerosol having aerodynamic particle sizes less than the cutpoint of each particular stage. These data were used to plot, on log-probability scales, the size distribution of the particles present in the sample between 0.1 and $30 \mu \mathrm{m}$. Using a log-normal best fit curve, and

(a) Hewlett Packard, Palo Alto, California. 
typically including the middle $90 \%$ of the particle size distribution by mass, the aerodynamic mass median diameter (AMMD) and the geometric standard deviation (GSD) were determined. These analyses are presented in Appendix D. on the figures in the appendix, MMAD is equivalent to AMMD.

A second spreadsheet was prepared and used to calculate aerosol mass concentration and particle mass flow rate. Spreadsheets for each test are presented in Appendix E. Data entered included the time of the sample, sample duration, temperature, critical orifice identification number and inlet pressure, steam mole fraction, and sample mass or activity based on gravimetric, chemical, or fluoroscopic analysis. Results based on both mass and either chemical or fluoroscopic analyses were performed together on the same spreadsheet to allow comparison between these independent methods of analysis. Fractional sample masses based on chemical analyses could also be entered and the resultant total sample mass calculated based on the molecular composition of the aerosol material. Sample flow rate was determined using a look-up table value based on critical orifice identification number and converted to actual sample volume based on temperature and sţeam mole fraction. Results were presented as aerosol mass concentration in $\mathrm{mg} / \mathrm{m}^{3}$, particle mass flow rate in $\mathrm{mg} / \mathrm{s}$, and the resultant aerosol material generation rate was determined where appropriate. All concentration and mass flow rate results were based on the mass of suspended particulate matter per actual volume of gas sampled, and did not include the mass of the gas or the mass of associated water droplets.

Aerosol mass concentration results obtained directly from the spreadsheets in Appendix E provided for each test a time history of the aerosol mass concentration present at each sampling station. These data were of most interest for the two quad stations that were first operated during Test 5 and provided aerosol mass concentration data in each of the four open flow quadrants in the ice-basket region of the test section (Figure 3.7). These data were summarized and plotted as aerosol mass concentration versus location and time of exposure, and are shown in Appendix F. It is important to note that the aerosol mass concentration data obtained at intermediate stations within the ice-basket region could not be used to determine intermediate DFs (such as the DF between Stations $6 \mathrm{~A}$ and $5 \mathrm{~A}$, for example). This was because, although the average gas composition and aerosol concentration might be known, especially at the quad stations where samples were obtained from each open flow quadrant between the ice baskets, it was not possible to calculate aerosol mass flow rate. The direction and magnitude of the gas flow in each channel and in the complicated interchannel and inner basket regions were not known.

The final aerosol data analysis procedure was the calculation of decontamination factor (DF), the ratio of aerosol particle mass flow rate in to that out of the ice-condenser (test section). Results are listed as both DF and a related parameter--percentage retention of aerosol particulate mass in the ice-condenser $(R)$. $R$ was determined as the product of 100 and the quantity unity less the reciprocal of $D F\left[R=100\left(1-D F^{-1}\right)\right]$. DF and $R$ values were determined for specific periods during each test (aerosol sampling periods), and then averaged to determine "test average" results. Such 
averaging was possible because of relatively uniform aerosol particle mass flow rates at the test section inlet. A third parameter related to particle removal in an ice-condenser is particle penetration (P), the reciprocal of DF. $P$ can be used to characterize release rather than retention. The retention of aerosol particles in the test section was calculated between Stations $6 \mathrm{~A}$ and 0 except for tests prior to Test 5 for which Station $1 \mathrm{Al}$ was the station closest to the outlet of the test section. These locations were selected because all necessary thermal-hydraulic and aerosol parameters were known. These test parameters included gas temperature, steam mole fraction and flow rate, and aerosol mass concentration. Gas flow rate was determined using inlet conditions corrected for measured local temperature and steam mole fraction. Aerosol mass concentration and actual gas flow rate were used to calculate the aerosol particle mass flow rate at both inlet and outlet (Appendix E).

As described above, the primary method for determining DF and $R$ was based on the results of analysis of aerosol samples. However, for three tests, an aerosol material mass balance procedure (Section 3.5.6) was also performed to provide an independent method of measuring the retention of aerosol particulate matter in the ice-condenser, and the two methods were compared.

\subsection{TEST PROCEDURES}

Four test procedures were necessary for each test involving steam, ice, and aerosol. These procedures included: 1) loading ice baskets and preparing the test section and mechanical devices, 2) thermal-hydraulic testing, 3) aerosol generation, and 4) aerosol characterization. Thermal-hydraulic tests without aerosol, and aerosol calibration tests without ice and steam were performed using fewer test procedures.

\subsubsection{Ice Loading and Test System Preparation}

Custom-made ice was obtained from a local vendor. The ice pieces ranged in size from $2.5 \mathrm{~cm}$ to $7.6 \mathrm{~cm}$ in diameter and were nominally $0.64-\mathrm{cm}$ thick. The ice was not borated because the small concentration of boron was not found to significantly affect the melting characteristics of the ice. A simple comparative melt rate test between borated $(0.2 \%$ sodium tetraborate) and plain tapwater ice was performed. After a period of $30 \mathrm{~min}$., the percent of each sample that had melted agreed within 1\%. Furthermore, the addition of boron would have complicated both the production of the ice and the disposal of the meltwater.

The test section was chilled prior to ice loading. 'Refrigeration of the test section began the evening prior to receipt of the ice. Ice, packed in bags, was delivered to the test facility by truck. Each bag weighed approximately $21.3 \mathrm{~kg}$. A load of ice, typically 137 bägs, was transferred from the truck to the Operating Platform, Level 0 . The air chiller was turned off and aluminum plates were installed above the ice-basket section inlet to prevent spilled ice from packing into the turning vanes. The top south-side access door, with integral outlet turning vanes, was removed so that ice loading could begin! Each bag was weighed, the weight recorded and then the bag of ice loaded into the test section. 
Ice was loaded into the test section in the following sequence: centerbasket followed by the partial (half and quarter) baskets. Initially, all baskets were filled using a funnel and 10.2-cm PVC pipe arrangement. With loading experience, the center- and half-baskets were filled by emptying the bags of ice directly into the basket. Quarter-baskets continued to be filled using a funnel and 10.2-cm PVC pipe arrangement. Once the baskets were full, the ice spillage was removed from the test section and weighed. The aluminum plates above the inlet turning vanes were removed. Ice loading doors and test section access panels were then replaced. Lastly, air chiller operation was resumed. A summary of the ice loads is presented in Table 3.3.

\subsubsection{Thermal-Hydraulic Test Procedures}

Over the course of the test program, 1987 through 1990, flow-channel temperature measurement was achieved by two methods. Tests performed during 1987 and 1988 (Tests 1 through 7) were instrumented with single thermocouples. Tests performed in 1989 and 1990 (Tests 8 through 14b) were instrumented with flow-channel rakes. Rakes were used not only to circumvent the loss of access to the flow channels (described in Section 3.3.3) but also to improve the accuracy of locating the thermocouple elements in the flow channels, and to

TABLE 3.3. Ice Loading Summary

\begin{tabular}{|c|c|c|c|}
\hline Test & $\begin{array}{l}\text { Net Load, } \\
\mathrm{kg} \\
\end{array}$ & $\begin{array}{l}\text { Estimated Test }(\mathrm{a}) \\
\text { Start Load, } \mathrm{kg} \\
\end{array}$ & $\begin{array}{c}\text { Loaded Void } \\
\text { Fraction } \\
\end{array}$ \\
\hline $\begin{array}{r}1 \\
2 \\
3 \\
4 \\
5 \\
6 \\
7 \\
8 \\
9 \\
10 \\
11 \\
12 \\
13 \\
14\end{array}$ & $\begin{array}{l}1963^{(b)} \\
\text { No ice } \\
2410(b) \\
2415 \\
2502 \\
2431 \\
2432 \\
2481 \\
2439 \\
2424 \\
2463 \\
2446 \\
2492 \\
2512\end{array}$ & $\begin{array}{l}1859 \\
1445 \\
1790 \\
1361 \\
1520 \\
1554 \\
2439 \\
2424 \\
2463 \\
2446 \\
2492 \\
2512\end{array}$ & $\begin{array}{l}0.5 \\
0.38 \\
0.38 \\
0.36 \\
0.38 \\
0.38 \\
0.36 \\
0.37 \\
0.38 \\
0.37 \\
0.37 \\
0.36 \\
0.36\end{array}$ \\
\hline Solid ice & 3899 & & 0.0 \\
\hline
\end{tabular}

(a) Sublimation not subtracted.

(b) Estimated. 
improve the detail of ice-basket section flow-channel temperature profiles. In either case (single element or rakes), the flow-channel temperatures were monitored with sheathed, grounded, $0.16-\mathrm{cm}$ type $\mathrm{J}$ thermocouples. The installation of the individual thermocouples and the flow-channel rakes, as well as data acquisition configuration and test time initiation are described in the following subsections.

\subsubsection{Flow-Channel Thermocouple Installation}

Single element thermocouples, typically having the junction end turned slightly up to enhance shedding water, were installed after completion of the ice loading activities. The bent tip location was indicated on the outermost (furthest from the element tip) sheath by a permanent black ink line.

Penetrations labeled "D" on the insert of Figure 3.4 were used to install the single element thermocouples. As evident from the Figure 3.4 insert, the temperature measurements obtained from the single-element thermocouples were not necessarily from the same horizontal or vertical plane. Vertically, the measurements can be displaced by as much as $19 \mathrm{~cm}$. The potential horizontal displacement is much less. Thermocouples installed in the ice-basket flow channels were of three lengths: $0.91 \mathrm{~m}, 0.61 \mathrm{~m}$, or $0.305 \mathrm{~m}$. Use of singleelement thermocouples limited their installation to the probe panels on the west face of the test section. Therefore, except at Levels 1, 3, and 5, measurements could be directly made only in the south flow quadrants. Based on the design of the ice-basket section and probe panels, an insertion length was estimated that would position the single-element thermocouples in the desired position. The longest thermocouples, $0.91 \mathrm{~m}$ and $0.61 \mathrm{~m}$, were utilized to access the east flow quadrants. Centerline temperatures, between the center- and half-baskets, were obtained using thermocouples at least $0.61-\mathrm{m}$ long. West flow channels were accessed by $0.305-\mathrm{m}$ thermocouples. Data gathered during the initial tests indicated that measurement of north-half ice-basket section temperatures was important in the interpretation of stable thermal stratification. Therefore, an effort was made to install thermocouples, judiciously bent, from the south probe panels at Levels 2 and 4 to monitor temperatures in the northeast and west quadrants at those levels. Installation of the bent thermocouples was difficult and their final location was uncertain. All single element thermocouples were secured in the 0.125in. NPT penetrations using probe gland fittings. The installation steps were as follows: insert the thermocouple through the penetration, install the probe gland in the bushing, adjust the outboard length of the thermocouple to match the estimated outboard length, verify that the black line indicating the location of the bent tip was in position, and install the probe gland nut.

The response of each flow-channel thermocouple was verified prior to each test as part of the data acquisition pre-test check. Unusual readings discovered as part of the pre-test check were investigated using a portable digital thermometer. If possible, the problem was corrected. However, if the thermocouple element was determined to be open, either a substitute thermocouple or a thermocouple exposed to the ambient environment ("dummy") was connected in lieu of the dysfunctional thermocouple. "Dummy" thermocouples were substituted for dysfunctional elements because operation of the DAS was found to be compromised by an excessive number of open channels. 


\subsubsection{Flow-Channel Rake Installation}

Flow-channel rakes were installed after completion of the ice loading activities prior to Tests 8 through 14b. The rakes were fabricated with a $1.27-\mathrm{cm}$ tip to allow lateral location of the rake by a tap (on the far wall) and extract method. All flow-channel rakes were installed in $3.8-\mathrm{cm}$ penetrations. The installation steps were as follows: insert the rake through the bushing; install the probe gland in the bushing; insert the rake until the far (east) wall of the test section was contacted; retract the rake the appropriate length to locate the elements in the desired position; start the threads of the probe gland nut; rotate the rake slightly clockwise so that the elements were in the free stream of the flow quadrant; tighten the probe gland nut. After installation, the leads from the flow-channel rake were connected to prescribed jack panel locations.

The response of each flow-channel rake thermocouple element was verified prior to each test as part of the data acquisition pre-test check. Unusual readings discovered as part of the pre-test check were investigated using a portable digital thermometer. If possible, the problem was corrected. However, if the element was determined to be open, a thermocouple exposed to the ambient ("dummy") environment was connected in lieu of the open element. As previously indicated, "dummy" thermocouples were substituted for open rake elements because operation of the DAS was found to be compromised by an excessive number of open channels.

\subsubsection{Data Acquisition Configuration and Pre-Test Operation}

In advance of each test, the computer-based data acquisition system was configured for the specific needs of the test. Each test had its own configuration file. After installation of the flow-channel thermocouples (either individual or rakes), the DAS was operated in the data collection mode for a few minutes. The pre-test data files were printed out and reviewed. Suspicious readings (process as well as test section temperature data) were investigated and resolved prior to performing the test.

The data logger was also verified to be programmed correctly and operational. The printer paper inventory and ribbon quality were checked and replaced as needed. Connections between the data logger and cartridge tape recorder were checked; blank magnetic tape was installed.

\subsubsection{Test Initiation and Test Start Time}

On the morning of the test the chiller was turned off and the facility placed in the bypass configuration, thereby isolating the test section. The facility remained in the bypass configuration while the boiler was coming on-line and the aerosol generation and sampling preparations were made. In general, the data acquisition systems were started as steam began to flow through the steam meter; yielding a substantial record of pre-test conditions. 
The test was started by an audible signal controlled by the test director. At the signal, the timers carried by each staff member operating a sampling station were started. In tests conducted in 1989 and 1990, a timer was also started for the staff member monitoring the computer-based data acquisition system. If inlet condition changes were to be made as part of the test, a timer was also given to the staff member assigned to control the steam and air flow rates so that the adjustments to the flows could be made according to schedule.

The start of the timers was coordinated with flow through the test section. Inevitably, there was a finite time difference between the timer start and the initiation of flow through the test section caused by valve operation time. However, every effort was made to minimize the difference.

\subsubsection{Aerosol Generation}

Guidance for aerosol generation procedures was provided by a list of candidate tests and the results of trial tests. The list of tests indicated aerosol material solubility, particle size, and aerosol mass concentration, as well as gas flow rate, temperature, and steam content. Aerosol mass concentration limits, based on anticipated test conditions and particle residence time in the test section, were applied to preclude significant particle coagulation. Significant coagulation was determined to be that sufficient to cause an increase of more than $10 \%$ in median particle diameter. Limits on aerosol particle concentration were calculated following the procedure for polydisperse particles presented by Hinds (1982, pp. 240-244). Candidate tests of aerosol generation were performed primarily to provide information on operating procedures and aerosol concentration and particle size distribution at the inlet to the test section. The trial tests also provided information on the percentage losses of aerosol material in the generators, neutralizer, and associated tubing and the test facility gas mixing duct. Occasionally, baseline DF information was obtained during trial tests when the system was operated at known air flow rates and aerosol samples were obtained at the test section outlet. DF values determined from these tests were considered baseline because the tests were performed in the absence of both steam and ice (and usually at about $20^{\circ} \mathrm{C}$ ).

Generator operating procedure requirements (e.g., the air pressures for the energy mill and ultrasonic nozzle, the vibrating frequency for the VOAG) were determined with the aid of trial tests as were the feed rates of source aerosol materials. When milling powders or granular material in the energy mill and using the mill's outlet cyclone to trap the largest generated particles, it was possible that more than one-half of the generated aerosol material was not passed to the ice-condenser. These generator losses varied greatly with operating procedures and were important in the production of an aerosol having the desired characteristics.

To generate aerosols, source material feed rates were selected as described above. Next, the dry chemical feeder (energy mill), sonic nozzle 
controller (sonic nozzle), or the infusion pump (VOAG) were calibrated to deliver the needed source feed rates. After the test section was subject to pre-melt (not performed prior to every test, see Table 4.1) operating conditions of the generator were set. Immediately before energizing the generators with compressed air, the isolation valve between the generators and the $\mathrm{Kr}^{\mathrm{B}}$ charge neutralizer (when used) was opened. This was performed quickly and in sequence to prevent steam from entering the aerosol tubing. The pressure in the aerosol tubing was thereafter monitored and maintained slightly greater than that in the mixing duct. The system was then operated without actually feeding aerosol source materials into the generators until the start of each test.

Following diversion of the test system gas flow from the bypass to the test section, the tests were begun and aerosol generation initiated. Grounding cables were used to prevent a charge build-up in the energy mill. The feed rate of granular or powdered material was confirmed before and after the test, and a mass balance was performed on the material in the hopper to provide a secondary check of the total amount of material generated. The operating pressures of both the $P$ and 0 jets were monitored during the tests and the status of the energy mill was checked periodically by observation through a transparent side panel. Compressed air and CsI solution flowmeters were observed periodically during use of the ultrasonic nozzle aerosol generator. The nozzle provided a stable output throughout the test. The stream of aerosol produced by the VOAG was monitored via a transparent section using a bright white light. Frequency of vibration, solution feed via the infusion pump, dispersion air flow rate, and solution pressure upstream of the vibrating orifice were monitored periodically during the test. Aerosol generation was ended in reverse order: the feed of material was stopped and the energizing air flow rates were turned off, followed immediately by closure of the isolation valve.

\subsubsection{Aerosol Characterization}

Written test protocols were prepared describing aerosol characterization and generation procedures for each test. Procedures for each test varied because of test-to-test differences in expected ice melt rates, gas residence times within the test section, aerosol concentrations, and sample quantities required for gravimetric, chemical, or fluoroscopic analyses. Other differences included the addition, removal, or modification of individual aerosol sampling stations. Aerosol sampling procedures were specific for each measurement station and were listed on separate pages of each aerosol test protocol and were distributed to research staff operating each station. In addition, procedures common to all aerosol measurement stations, including safety, schedule, and operations (sampling handling, valve operation, and condenser trap handing), were listed on one page of each protocol and distributed to all staff.

Filter and impactor samples were (usually) pre-weighed and placed into holders and heating mantles before each test. Filter and impactor samples, condensate traps, timers, miscellaneous equipment, test procedures, and data 
sheets were then distributed to each measurement station. Condensate traps were filled with crushed ice and water. Critical orifice sample flow-rate controllers were installed and aerosol and condensate sampling lines were checked for leaks. The leak tests consisted of plugging the end of each sampling line and connecting the line to a 28 - to $30-\mathrm{in}$. $\mathrm{Hg}$ vacuum by opening and then closing the isolation valve near the critical orifice (Figure 3.13 ). A 0 - to 30-in. Hg vacuum gauge on each sampling line revealed any significant leaks. Staff were then instructed in the operation of the measurement stations. Heaters for the cascade impactors required extra time and were usually turned on before other test activities were begun.

The start time for all tests was associated with the initiation of aerosol production and was relayed to the computer system operator for subsequent comparison between data sheets and the computer data log. Timers were started simultaneously at all stations. Aerosol sampling was initiated after a waiting period equal to or greater than the time required for at least five gas exchanges in the test section. The duration of the waiting period was based on inlet conditions and the assumption that all steam condensed in the inlet region. The first samples were connected to the aerosol and condensate sample trains during the waiting period.

Test protocols described the start and stop times and the identification codes associated with each sample. The appropriate critical orifice was also identified for each filter, impactor, and condensate sample. While each type of sample was often obtained repeatedly during tests using the same critical orifice, a second smaller orifice had to be used at stations that were initially relatively cool but that warmed as the test progressed (usually only Station 5A, near the bottom of the ice-basket region). This was done to maintain proper actual gas flow rates through the samplers, especially through the cascade impactors, the samplers that were most affected by flow rate. In addition to flow-rate control, the test protocols described temperature control requirements of each station and specific sample handing requirements.

Figure 3.18 shows an example of a portion of a written test protocol. The example page shown in the figure was prepared for use at Station 6A during Test 13. Note that Test 13 was a two-part test, the first using a $\mathrm{KCl}$ aerosol and the second a $\mathrm{ZnS}$ aerosol.

Sampling activities and other observations were recorded throughout each test by the operators of each aerosol station. One or two data sheets were provided each station, one for aerosol samples and one for condensate trap samples (some operators combined both types of samples on one data sheet). An example data sheet is shown in Figure 3.19. The figure contains data obtained at Station 6A during Test 13a. Station operator entries were made in the shaded regions of the data sheet. Samples having the same number were obtained approximately concurrently. Sample ID numbers referred to coded samples that were checked three times: at the time they were inserted into holders, when they were installed in the station sample lines, and after the test when they were retrieved from the holders. For the example (Figure 3.19), condensate traps (C), filters (F), and one cascade impactor (I) were 


\section{Station $6 \mathrm{~A}$}

Two tests (reset timer between tests)

( 3 filters, 1 impactor, and 5 condensers) $\times 2$ tests

Schedule (test "a" first, then test " $b ")$ :

\begin{tabular}{cccc|cccc} 
No. & Type & Start $(\min )$ & Stop $(\mathrm{min})$ & No & Type & Start (min) & Stop (min) \\
\hline 1 & C1 & 5 & 15 & 6 & C6 & 5 & 15 \\
2 & F2/C2 & 25 & 30 & 7 & F7/C7 & 25 & 30 \\
3 & I18/C3 & 35 & 40 & 8 & I19/C8 & 35 & 40 \\
4 & F4/C4 & 45 & 50 & 9 & F9/C9 & 45 & 50 \\
5 & F5/C5 & 55 & 60 & 10 & F10/C10 & 55 & 60
\end{tabular}

Sample flow rate control:

\begin{tabular}{ccc} 
Type & \# CO & Special Cond \\
\hline Filter & 69 & Always \\
Impactor & 55 & Always \\
Condenser & 69 & Always
\end{tabular}

Temperature control:

Probe: $\quad=125^{\circ} \mathrm{C}$.

Filters: $\quad$ Heat up for $\sim 10$ min on line (110v), leave connected to line power during 1st 1 -min of sample periods.

Impactors: Plan for $105^{\circ} \mathrm{C}$, however, set the temperatures at To or slightly greater. Do not overheat. Pre-heat at $50 \%$ for $15 \mathrm{~min}$ ? Idle at $23 \%$ ?

Condensers: No temperature control.

Sampling handling:

1) Set filters upright (inlet side up) to cool. Cover. Leave holders in mantles after sampling. No need to change filters this test.

2) Set impactor aside when sample is completed. Do not jar prior to sampling.

3) Be sure not to leave a condenser trap open between samples.

4) Also record Po and To. Record Ps for the CO sample line.

5) Maintain ice and water in your condenser(s). The outlet sample tube should be cool.

FIGURE 3.18. Example Aerosol Sampling Test Protocol - Station 6A, Test 13 


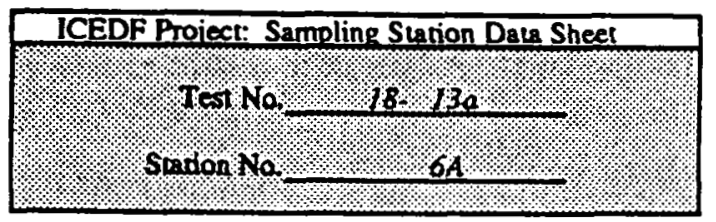

MWL Dals Sheet: 6A \& 0

ICEDF D.Sht S.Sta 10/89

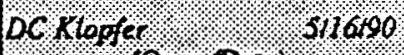

\begin{tabular}{|c|c|c|c|c|c|c|c|c|c|}
\hline $\begin{array}{c}\text { Sample } \\
\text { No. }\end{array}$ & $\begin{array}{c}\text { Sample } \\
\text { ID }\end{array}$ & $\begin{array}{c}\text { Time } \\
\text { Start/End } \\
\text { (h:m:s) }\end{array}$ & $\begin{array}{c}\text { Temp. } \\
\text { System } \\
\left({ }^{\circ} \mathrm{C}\right) \\
\end{array}$ & $\begin{array}{l}\text { Temp. } \\
\text { Probe } \\
\text { (ㅇ) }\end{array}$ & $\begin{array}{c}\text { Temp. } \\
\text { Sampler } \\
\left({ }^{\circ} \mathrm{C}\right)\end{array}$ & $\begin{array}{c}\text { Pressure } \\
\text { System } \\
\left({ }^{n} \mathrm{H} 2 \mathrm{O}\right) \\
\end{array}$ & $\begin{array}{l}\text { Pressure } \\
\text { Sampler } \\
\left({ }^{*} \mathrm{H} 2 \mathrm{O}\right)\end{array}$ & $\begin{array}{c}\text { Flowmeter } \\
\text { Reading } \\
\text { (lpm) }\end{array}$ & $\begin{array}{c}\# \mathrm{CO} \& \\
\text { Vacuum } \\
\text { (" } \mathrm{Hg})^{2}\end{array}$ \\
\hline 8 & $86 A 7$ & $\frac{0.0500}{0.1500}$ & 109 & & & 10005 & 10 & 30 & 3090 \\
\hline
\end{tabular}

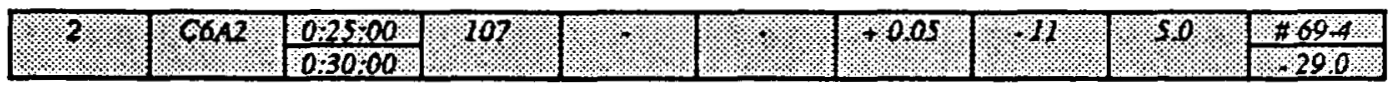

\begin{tabular}{|c|c|c|c|c|c|c|c|c|c|}
\hline 2 & $\mathrm{FSA}^{2}$ & $\frac{0,25,00}{0.30,00}$ & 107 & 126 & $\$$ & 00,05 & 16 & 48 & $\begin{array}{l}\# 698 \\
290\end{array}$ \\
\hline 3 & $\mathrm{COA3}$ & $\frac{0,350,5}{00,40,05}$ & 106 & \% & $\%$ & 10005 & $\%$ & 50 & $\frac{\# 69.4}{28,0}$ \\
\hline
\end{tabular}

1.

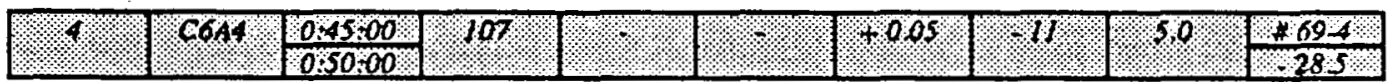

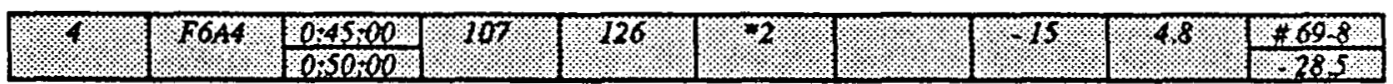

\begin{tabular}{|c|c|c|c|c|c|c|c|c|c|}
\hline 3 & $\mathrm{COAS}$ & $\frac{0.55 .02}{1.00 .02}$ & 107 & 8 & 8 & +005 & 11 & 50 & $\begin{array}{l}8694 \\
\$ 29: 0\end{array}$ \\
\hline 3 & FA' & $\frac{0.55 .02}{1.00 .02}$ & 107 & 126 & 27 & & 15 & 48 & $\frac{469.8}{290}$ \\
\hline
\end{tabular}

\section{ADDITIONAL TEMPERATURE DATA:}

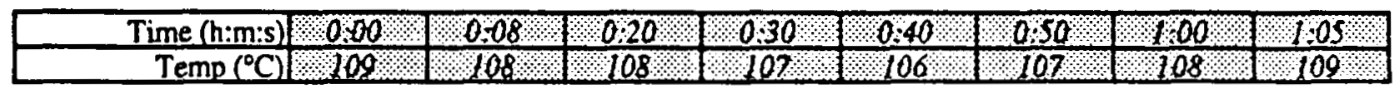

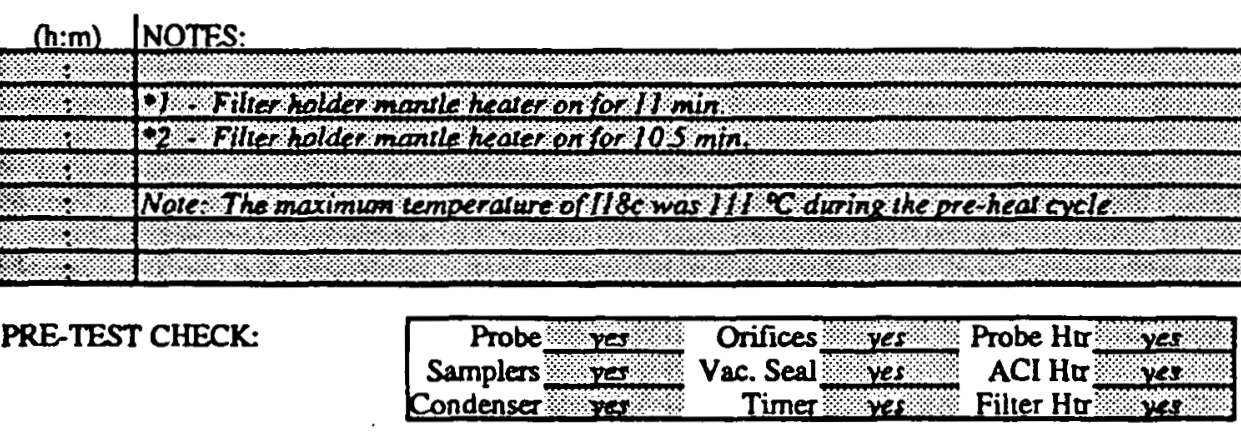

FIGURE 3.19. Example Data Sheet - Station 6A, Test 13a. Entries were made in the shaded areas of the data sheet. 
used to obtain samples from the test section. Sample codes included the sample type, station number, and a numerical or alphabetic sequence. Sample start and end times were recorded and corresponded to the time period that both isolation valves were open (see Figure 3.13). The system temperature was measured using a thermometer inserted into the test section near the sample probe nozzle. Temperatures and pressures were recorded to provide test conditions, quality checks, and information for determining sample flow rate. Both the critical orifice identification number and the pressure drop across the orifice were recorded, and a flowmeter was used to provide a back-up check of sample flow rate. Additional notes included temperature control activities and test section temperatures at regular intervals. 


\subsection{TEST RESULTS AND DISCUSSION}

Aerosol particle retention results were determined based on measured thermal-hydraulic and aerosol characteristics present at the inlet and outlet of the test section. Measurements of gas flow rate and aerosol mass concentration at both locations were used to calculate particle mass flow rates. Decontamination factor (DF) was then calculated as the ratio of particle mass flow rate in to that out of the test section. Particle retention (R) was also determined for each test. DF and $R$ values were determined for specific periods during each test and then averaged to determine "test average" results (Section 3.5.7). To provide intermediate data when possible, and to characterize the complex conditions present at the inlet and within the ice-basket region of the test section, thermal-hydraulic and aerosol characteristics were also measured at locations between the inlet and outlet. These measurements provided information on temperature profiles and gas flow recirculation cells in the inlet and ice-basket regions, and on the distribution of steam mole fraction and aerosol particle mass concentration within the ice-basket region of the test section.

Measured thermal-hydraulic conditions and aerosol characteristics are summarized. Thermal-hydraulic test results including bulk temperatures, thermal profiles, inlet gas steam content, and flow recirculation cells are described. Aerosol results are described beginning with the steam mole fraction present at each measurement station, and including comparisons of mass and chemical analyses of aerosol samples, particle size distribution at the inlet and outlet, particle mass concentration, and particle mass flow rate. DF values for the 35 aerosol tests are presented based on aerosol and thermal-hydraulic data. (A total of 38 tests were performed in the facility; however, 3 tests did not include aerosols.) Results of aerosol material mass balances are used to provide independent estimates of of for three tests.

\subsection{MEASURED TEST CONDITIONS}

A chronological listing of the tests and the associated inlet test conditions are presented in Table 4.1. Underlying reasons for selecting the values shown in this table for test conditions are discussed in Appendix $A$. In review, the sequence of events leading to those investigations of particle retention and involving ice usually consisted of the following steps. The refrigeration system was used overnight to cool the test facility to a temperature below the freezing point of water. On the following morning ice was loaded manually from bags of ice into the tops of the nine basket columns.' Cooling was then re-established to maintain the ice inventory until the next morning when the test was initiated. An average of about $2450 \mathrm{~kg}$ of ice was loaded for each test, corresponding to a void fraction within the columns of about 0.37 . For Tests $1,3,4,5,6,7$ and 8 steam was routed past the ice for about 30 min prior to the introduction of particles. This pretreatment, an attempt to better represent the ice inventory after the blowdown phase of a postulated severe reactor accident, resulted in an approximate one-third reduction in the initial ice inventory. No pretreatment was used in the other investigations involving ice either because of the rapid melt rate associated 
TABLE 4.1. Measured Inlet Test Conditions

Aerosol Characteristics

\begin{tabular}{|c|c|c|c|c|c|c|c|c|c|c|c|c|}
\hline \multirow[b]{3}{*}{$\begin{array}{l}\text { Test } \\
\text { No. }\end{array}$} & \multirow[b]{3}{*}{ Date } & \multicolumn{5}{|c|}{ Aerosol Characteristics } & \multicolumn{3}{|c|}{ Thernal-Hydraulic Conditions } & \multirow{2}{*}{\multicolumn{2}{|c|}{ Ico (a) }} & \multirow[b]{3}{*}{$\begin{array}{l}\text { Alternate } \\
\text { Test No. (d) }\end{array}$} \\
\hline & & \multirow[b]{2}{*}{ Material } & \multirow{2}{*}{ Diamoter $^{(b)}$, } & \multicolumn{2}{|l|}{ Mass } & \multirow[b]{2}{*}{$\begin{array}{l}\text { Soluble/ } \\
\text { Insoluble }\end{array}$} & \multirow[b]{2}{*}{$\begin{array}{c}\text { Teaperature, } \\
\propto\end{array}$} & \multicolumn{2}{|c|}{ Stean } & & & \\
\hline & & & & $\begin{array}{c}\text { Concentration (c) } \\
\mathrm{mg} / \mathrm{m}^{3} \\
\end{array}$ & $\begin{array}{l}\text { Rate, } \\
\pm g / 3\end{array}$ & & & $\begin{array}{c}\text { Wole } \\
\text { Fraction }\end{array}$ & $\begin{array}{l}\text { Flow, } \\
\text { 3/s }\end{array}$ & $\begin{array}{l}\text { Used, } \\
\text { Y or N }\end{array}$ & $\begin{array}{l}\text { Protreat, } \\
\text { Yor } N \\
\end{array}$ & \\
\hline 1 & $6 / 11 / 87$ & $\mathrm{KCl}$ & 3.1 & $1640 \pm 860$ & 340 & $\mathbf{S}$ & 123 & 0.39 & 0.21 & $Y$ & $\mathbf{Y}$ & $10-1$ \\
\hline 2 & $6 / 29 / 87$ & $\mathrm{KCl}$ & 5.8 & $1040 \pm 200$ & 32 & $\mathbf{S}$ & 91 & - & 0.63 & $N$ & & $15-2$ \\
\hline 3 & $8 / 4 / 87$ & $\mathrm{SiO}_{2}$ & $>15$ & $479+28$ & 14 & I & 90 & - & 6.63 & $\mathbf{Y}$ & $\mathbf{Y}$ & $2-3$ \\
\hline 4 & $8 / 25 / 87$ & $\mathrm{KCl}$ & 8,12 & $1790 \pm 320$ & 360 & $\mathbf{S}$ & 125 & 0.41 & 0.22 & $Y$ & $\mathbf{Y}$ & $10-4$ \\
\hline PC4 & $12 / 16 / 87$ & Oleic acid & 15 & (e) & (o) & $I$ & 29 & - & 6.15 & N & & \\
\hline PC5 & $12 / 21 / 87$ & Oleic acid & 15 & (e) & (e) & $I$ & 29 & - & 6.15 & N & & \\
\hline PC3 & $12 / 22 / 87$ & Oloic acid & 11.4 & (e) & (e) & I & 20 & - & 0.15 & $N$ & & \\
\hline PC1 & $12 / 28 / 87$ & Oloic acid & 4.6 & (e) & (e) & I & 20 & - & 0.15 & $N$ & & \\
\hline PC6 & $12 / 30 / 87$ & Oleic acid & 11.4 & (e) & (e) & $I$ & 29 & - & 6.15 & N & & \\
\hline $\mathrm{T} 17$ & $1 / 6 / 88$ & $\operatorname{ZnS}$ & 1.8 & 41 & 6.2 & $I$ & 29 & - & 0.15 & N & & \\
\hline T18 & $1 / 14 / 88$ & ZnS & -8 & 1420 & 260 & I & 20 & - & 6.14 & N & & \\
\hline T19 & $1 / 15 / 88$ & $\mathrm{ZnS}$ & 11 & 1650 & 230 & I & 20 & - & 6.14 & N & & \\
\hline T29 & $1 / 18 / 88$ & ZnS & 6.2 & 665 & 93 & I & 20 & - & 6.14 & N & & \\
\hline 6 & $1 / 27 / 88$ & ZnS & 3.9 & $869 \pm 120$ & 120 & I & 184 & - & 0.15 & $Y$ & $\mathbf{Y}$ & $7-5$ \\
\hline 6 & $3 / 17 / 88$ & ZnS & 3.5 & $60 \pm 1$ & 11 & I & 123 & 6.70 & 0.16 & $Y$ & $\mathbf{Y}$ & $11-6$ \\
\hline T21 & $6 / 3 / 88$ & CsI \& Uranine & 0.9 & -0.77 & -0.623 & $\mathbf{S}$ & 26 & - & -0.03 & $\mathbf{N}$ & & \\
\hline T22 & $6 / 3 / 88$ & CsI & 1.3 & -3.6 & -0.098 & $\mathbf{s}$ & 20 & - & -6.63 & $\mathbf{N}$ & & \\
\hline T23 & $6 / 3 / 88$ & CsI & 1.8 & -5.3 & -0.16 & $\mathbf{S}$ & 20 & - & -6.63 & N & & \\
\hline$v-1$ & $6 / 10 / 88$ & - & - & - & - & - & unheated & - & 0.14 & $Y$ & $N$ & - \\
\hline$v-2$ & $6 / 16 / 88$ & - & - & - & - & - & heated & - & 0.14 & $Y$ & N & - \\
\hline$V-3$ & $6 / 10 / 88$ & - & - & - & - & - & unheated & - & 6.3 & $Y$ & N & - \\
\hline $\begin{array}{l}\text { (a) } \\
\text { (b) } \\
\text { (c) } \\
\text { (c) } \\
\text { (f) } \\
(g) \\
\text { (h) }\end{array}$ & $\begin{array}{l}\text { See Table } \\
\text { Amit. } \\
\text { Using resu } \\
\text { additional } \\
\text { range of } d \\
\text { Ident if ica } \\
\text { Aerosol } f i \\
\text { concentrat } \\
\text { percentage } \\
\text { Cenerator } \\
\text { Fluorescei } \\
\text { AMDs for }\end{array}$ & 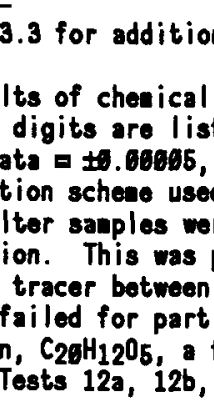 & $\begin{array}{l}\text { Inal details. } \\
\text { analyses when } \\
\text { ited to avoid } t \\
\text { t. } 111 \text {, th. } \\
\text { in Appendixe } \\
\text { poss analyzed us } \\
\text { the inlet and } \\
\text { of test; } 160 \\
\text { fluorescent cor } \\
12 c \text {, and } 12 d\end{array}$ & $\begin{array}{l}\text { available, otherwi } \\
\text { he use of scientifi } \\
3 \text { and } \pm 4.9 \mathrm{~m}^{3} \text {, ro } \\
\mathrm{C} \text { through } \mathrm{G} \text {. } \\
\text { ing a fluoroscopic } \\
\text { he PC (probe calibr } \\
\text { outlot of the test } \\
\mathrm{g} / \mathrm{m}^{3} \text { is for period } \\
\text { apound also used as } \\
\text { are listed as those }\end{array}$ & $\begin{array}{l}\text { using r } \\
\text { notation } \\
\text { spectively } \\
\text { inalysis a } \\
\text { tion) tes } \\
\text { section. } \\
\text { wen gen } \\
\text { a tracer } \\
\text { produced }\end{array}$ & $\begin{array}{l}\text { esults of } g \\
\text { I. Results } \\
\text { ind DF was c } \\
\text { th series be } \\
\text { The tracer } \\
\text { lerator was } \\
\text { in DOP. } \\
\text { by the VOAG }\end{array}$ & $\begin{array}{l}\text { avinetric anal } \\
\text { Tests } 12 a, 1 \\
\text { leulated witho } \\
\text { ause the parti } \\
\text { was uranine (s } \\
\text { orking. } \\
\text { aeasured size }\end{array}$ & $\begin{array}{l}\text { sis. Dats } \\
b, 12 c \text {, an } \\
\text { t converti } \\
\text { les were } \\
\text { diun fluor } \\
\text { were } 0.9 \text {, }\end{array}$ & $\begin{array}{l}\text { ng the d } \\
\text { onodispe } \\
\text { escein). } \\
0.9,3 \text {. }\end{array}$ & $\begin{array}{l}\text { if icant } \\
\text { based } \\
\text { ta to ac } \\
\text { se and d } \\
\text {, and } 12\end{array}$ & $\begin{array}{l}\text { o about two } \\
\text { n two sämpl } \\
\text { ual aerosol } \\
\text { o not chang } \\
\text { m, respect }\end{array}$ & $\begin{array}{l}\text { digits, } \\
\text { on only; } \\
\text { mass } \\
\text { size or } \\
\text { vely. }\end{array}$ \\
\hline
\end{tabular}


TABLE 4.1. contd

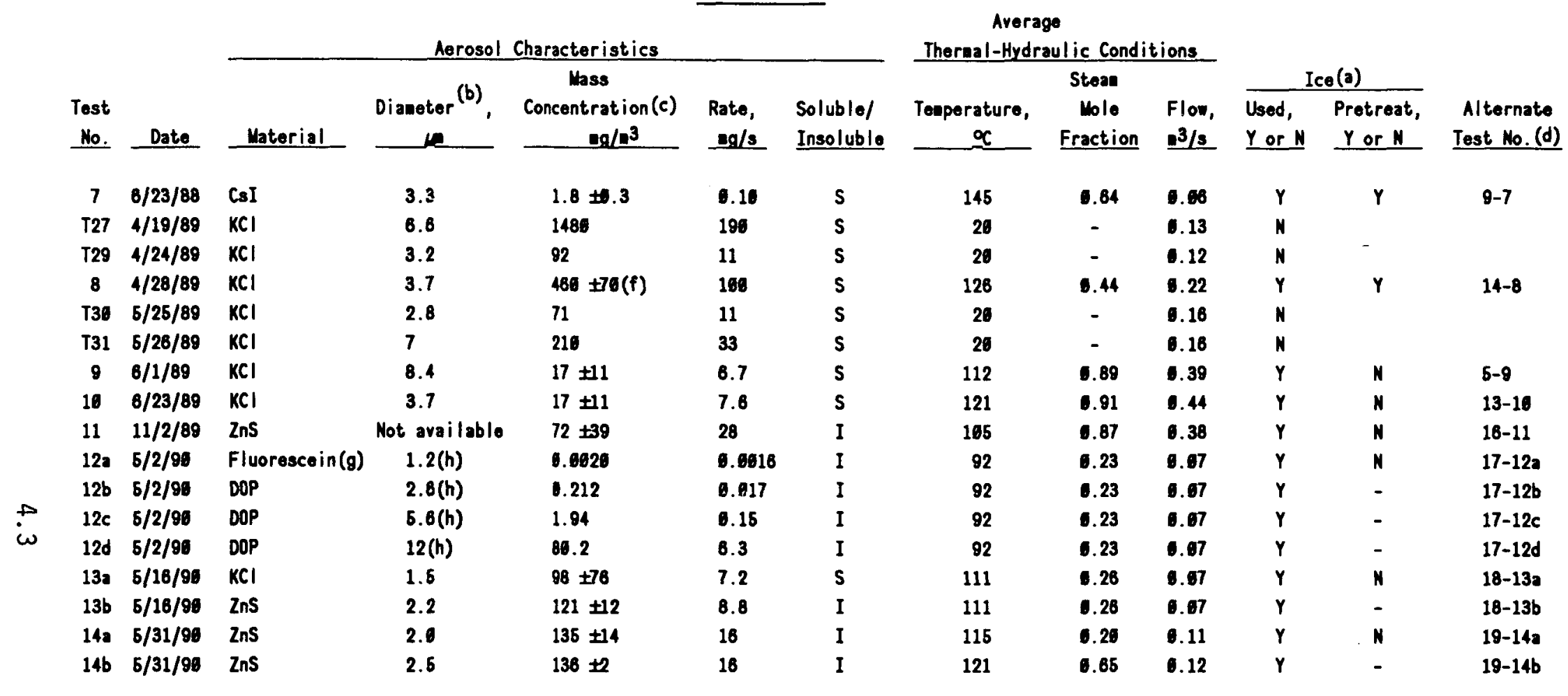

(a) See Table 3.3 for additional details.

(b) Using results of chesical analyses when available, otherwise using results of gravinetric analysis. Data are significant to about two digits, additional digits are listed to avoid the use of scientific notation. Results of Tests 12a, 12b, 12c, and 12d were based on two sanples only; range of data $= \pm 0.66065, \pm 0.011, \pm 0.613$, and $\pm 4.9 \mathrm{~m}^{3}$, respectively.

(d) Identification schene used in Appendixes C through 0 .

(e) Aerosol filter sanples were analyzed using a fluoroscopic analysis and DF was calculated without converting the data to actual aerosol nass concentration. This was possible for the PC (probe calibration) test series because the particles wore nonodisperse and did not change size or percentage tracer between the inlet and outlot of the test soction. The tracer was uranino (sodiun fluorescoin).

(f) Generator failed for part of tost; $100 \mathrm{ng} / \mathrm{m}^{3}$ is for periods when generator was working.

(g) Fluorescein, $\mathrm{C}_{28} \mathrm{H}_{12} \mathrm{O}_{5}$, fluorescent conpound also used as a tracer in DOP.

(h) ANDs for Tosts 12a, 12b, 12c, and 12d are listed as those produced by the VOAG; neasured sizes were 0.9, 0.9, 3.1, and $12 \mu \mathrm{m}$, respectively. 
with the three high flow rate, high steam mole fraction tests (Tests 9, 10 and 11) or because of the desire to maintain as much of the inventory as possible throughout those investigations, which were conducted as a continuous and connected series (Tests $V-1, V-2$, and $V-3$; and Tests 12a, 12b, 12c, 12d, 13a, $13 b, 14 a$, and 14b).

The series of tests conducted in December 1987, and designated with the letters PC were performed to obtain information concerning the extent of particle loss in the sampling probes upstream of the collection substrate (see Section 3.5 Aerosol Characterization). These tests were conducted without ice and using monodisperse oleic acid particles suspended in air. However, information concerning test system and test section particle retention was also obtained as part of these calibration efforts and will be discussed in Section 4.3 along with that obtained during Test 2 and several trial tests (designated with the letter $\mathrm{T}$ ), which were also conducted without either ice or steam.

The series of tests conducted in June 1988, and designated with the letter $V$, were performed to better define the complex buoyancy-driven flow fields that were observed almost from the onset of testing. Review of Table 4.1 will reveal that ice was used for this series of tests and that cold and hot air were mixed under three sets of conditions including two different flow rates and temperatures. Steam was not used because the tests involved hot wire anemometer velocity measurements frequently followed by smoke injection and observations to gain insights concerning the direction of flow. Results of these tests will be discussed in the following section along with supplemental information obtained during certain of the other tests listed in Table 4.1. As indicated earlier, the observance of the flow fields also prompted the installation (after Test 4) of additional particle sampling stations (including those that would permit sampling of all four flow channels or quadrants at elevations near the bottom and top of the ice-basket region) and thermocouple assemblies or rakes in the horizontal diffuser. Single test section thermocouples were replaced with rakes after Test 7 to provide comprehensive flow-channel temperature measurements at several elevations.

The final tests, conducted in May 1990, were selected from a list of candidates developed after a review of existing data identified the test parameters and associated experimentation that appeared to be the most valuable sources of supplemental information. To maximize the amount of data generated during this final effort, three separate ice inventories were used to conduct a series of successive tests, each with different inlet conditions. Review of Table 4.1 will reveal that investigations with the first inventory were conducted using steady thermal-hydraulic conditions but with different monodisperse particle sizes (Tests 12a, 12b,12c, and 12d). Tests 13a and 13b were performed using the same ice inventory and similar thermal-hydraulic conditions but the material used to generate polydisperse aerosols was changed from soluble to insoluble between the two experiments. Tests $14 a$ and 14b, on the other hand, were performed using the same ice inventory but with soluble polydisperse particles throughout the investigation. In these latter tests thermal-hydraulic conditions were changed between the two experiments. 


\subsection{THERMAL-HYDRAULIC RESULTS}

Initially, temperature measurements were only made in the flow channels of the ice-basket section. As a result of observations made from early tests, thermocouple rakes were installed in the diffuser section. As indicated earlier, it appeared likely that the introduction of hot gases into the cold air was causing formation of complex buoyancy-induced flow fields.

The following discussion of thermal-hydraulic behavior will be divided into two sections: early test program observations and the impetus to replace instrumentation; and discussion of the observations and conclusions of the thermal-hydraulic behavior. Appendix B contains copies of the general data reduction procedures.

The extent of the thermal-hydraulic information that could be obtained was determined by the instrumentation available for a given test. Table 4.2 indicates by " $x$ " the instrumentation available for each test. The most detailed thermal-hydraulic results are typically for the tests where thermocouple rakes were used in the ice-basket section and the diffuser.

\subsubsection{Tests 1 through 7}

Thermal-hydraulic results for Tests 1 through 7 are discussed as a group. The grouping of the tests was based on the ice-basket section flow-channel temperature measurement approach. Tests 1 through 7 used single-element thermocouples to monitor temperatures in the ice-basket section. Tests 8 through 14 used thermocouple rakes in place of the single-element thermocouples.

TABLE 4.2. Instrumentation Available for Each Test

Ice-Basket Flow-Channel

Test No. $\underline{\text { Temperature Measurement }}$

$\frac{\text { Diffuser Rakes }}{\text { Expansion Station 6A/Square Duct }}$

$\begin{aligned} 1 & \text { x } \\ 2 & \text { x } \\ 3 & \text { x } \\ 4 & \text { x } \\ 5 & \text { x } \\ 6 & \text { x } \\ 7 & \\ 8 & \\ 9 & \\ 10 & \\ 11 & \\ 12 & \\ 13 & \\ 14 & \end{aligned}$

$\begin{array}{ll}\mathbf{x} & \\ \mathbf{x} & \\ \mathbf{x} & \\ \mathbf{x} & \\ \mathbf{x} & \\ \mathbf{x} & \\ & \\ & \mathbf{x} \\ & \mathbf{x} \\ & \mathbf{x} \\ & \mathbf{x} \\ & \mathbf{x} \\ & \end{array}$




\subsubsection{Thermal-Hydraulic Observations - Tests 1 through 4}

\begin{tabular}{|c|c|c|c|c|}
\hline Test & $\begin{array}{c}\text { Stęam, } \\
\mathrm{m}^{3} / \mathrm{s}\end{array}$ & $\begin{array}{l}\text { Air } \\
\mathrm{m}^{3} / \mathrm{s} \\
\end{array}$ & $\begin{array}{c}\text { Totzal, } \\
\mathrm{m}^{3} / \mathrm{s} \\
\end{array}$ & $\begin{array}{l}\mathrm{T} 630, \\
{ }^{\circ} \mathrm{C} \\
\end{array}$ \\
\hline $\begin{array}{l}1 \\
2 \\
3 \\
4\end{array}$ & $\begin{array}{l}0.08 \\
0 \\
0 \\
0.09\end{array}$ & $\begin{array}{l}0.13 \\
0.03 \\
0.03 \\
0.13\end{array}$ & $\begin{array}{l}0.21 \\
0.03 \\
0.03 \\
0.22\end{array}$ & $\begin{array}{r}123 \\
91 \\
90 \\
125\end{array}$ \\
\hline
\end{tabular}

Ice-basket section temperature data were limited for the first four tests. The first and third tests were compromised by impaired function of the computer-based data acquisition system. Test 1 data was interrupted several times by power fluctuations. The problem was corrected by utilizing a conditioned power circuit for the DAS. Test 3 ice-basket section temperature measurements are not available because of the failure of a DAS thermocouple board. In spite of the problems, there was sufficient data available from the first tests to indicate that the thermal profiles within the ice-basket flow channels were different than expected. The one exception being Test 2, which was a no-ice case.

Data from Tests 1 and 4 indicated that the process stream cooled substantially between the downcomer and the inlet turning vanes. For example, the average downcomer temperature for Test 4 was $125^{\circ} \mathrm{C}$ and the average temperature at Level 5 was approximately $60^{\circ} \mathrm{C}$. The $65^{\circ} \mathrm{C}$ temperature decrease occurred over a relatively short distance between the inlet of the diffuser and the inlet turning vane section. In addition, thermal stratification was evident in the ice-basket section for Tests 1 and 4 , see Figures 4.1 and 4.2. The stratification suggested the existence of large-scale fluid structures, such as recirculation zones, within the ice-basket section.

Test 2 was performed without ice in the ice baskets and without steam in the process stream, i.e., a dry test. The large cold reservoir of Tests 1 and 4 was not available for Test 2. As expected for a dry test, the thermal profiles at Levels 5 and 1 for Test 2 were not significantly stratified, Figure 4.3. There was, however, a $30^{\circ} \mathrm{C}$ drop in temperature between the downcomer and inlet turning vane section. The process stream for Test 2 was a low thermal energy stream and the temperature decrease between the downcomer and the inlet turning vane section was probably caused by energy transfer to the diffuser walls. The slight downward trend exhibited at both Levels 5 and 1 tracked with the trend of the downcomer temperature.

Between the pre-melt and test phases of the third and fourth tests, limited flow visualization (via smoke injection) observations were made. Definite areas of downflow were observed. Previous computations indicated that downflow would occur near the ice surface. In addition, it was expected that the downflow zones would resolve as small mixing cells on the scale of the flow-channel diameter, $30.5 \mathrm{~cm}$. The smoke injection observations indicated that the downflow pattern exceeded the expected nominal $30.5-\mathrm{cm}$ length scale. 
Test 1

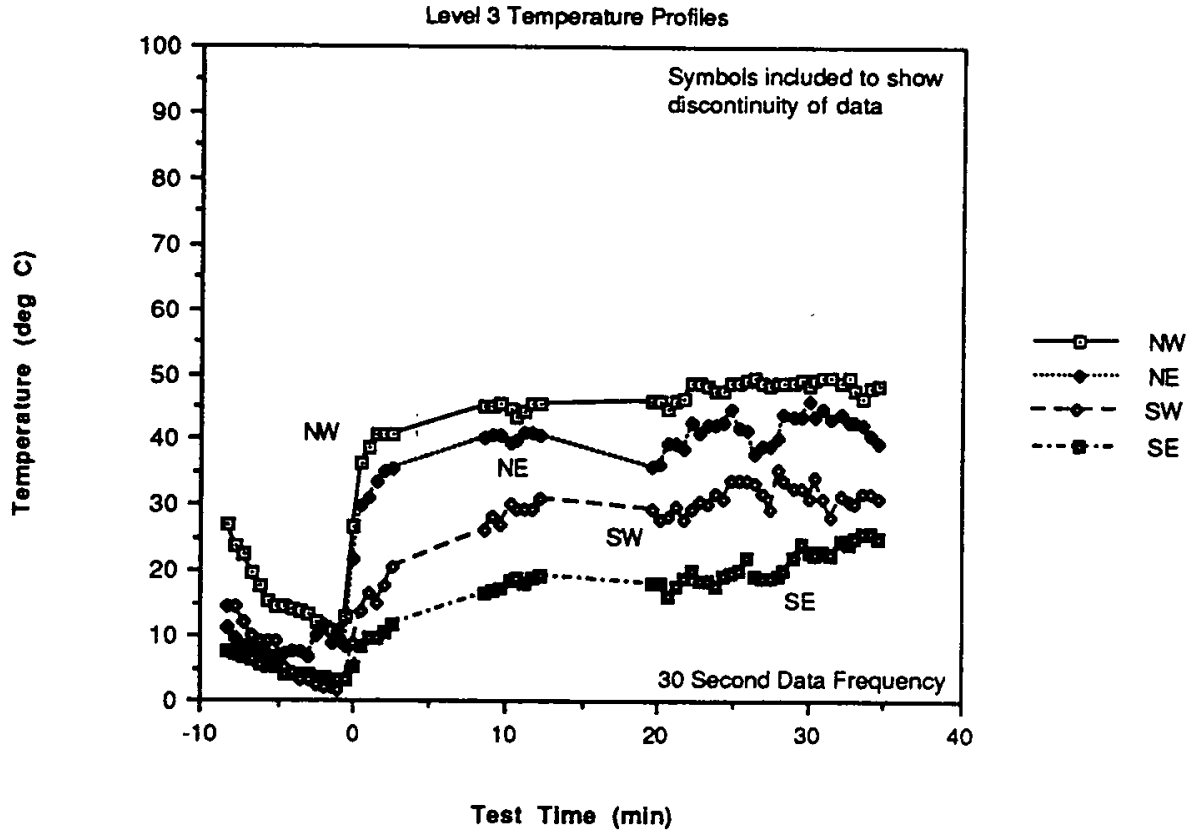

Test 1

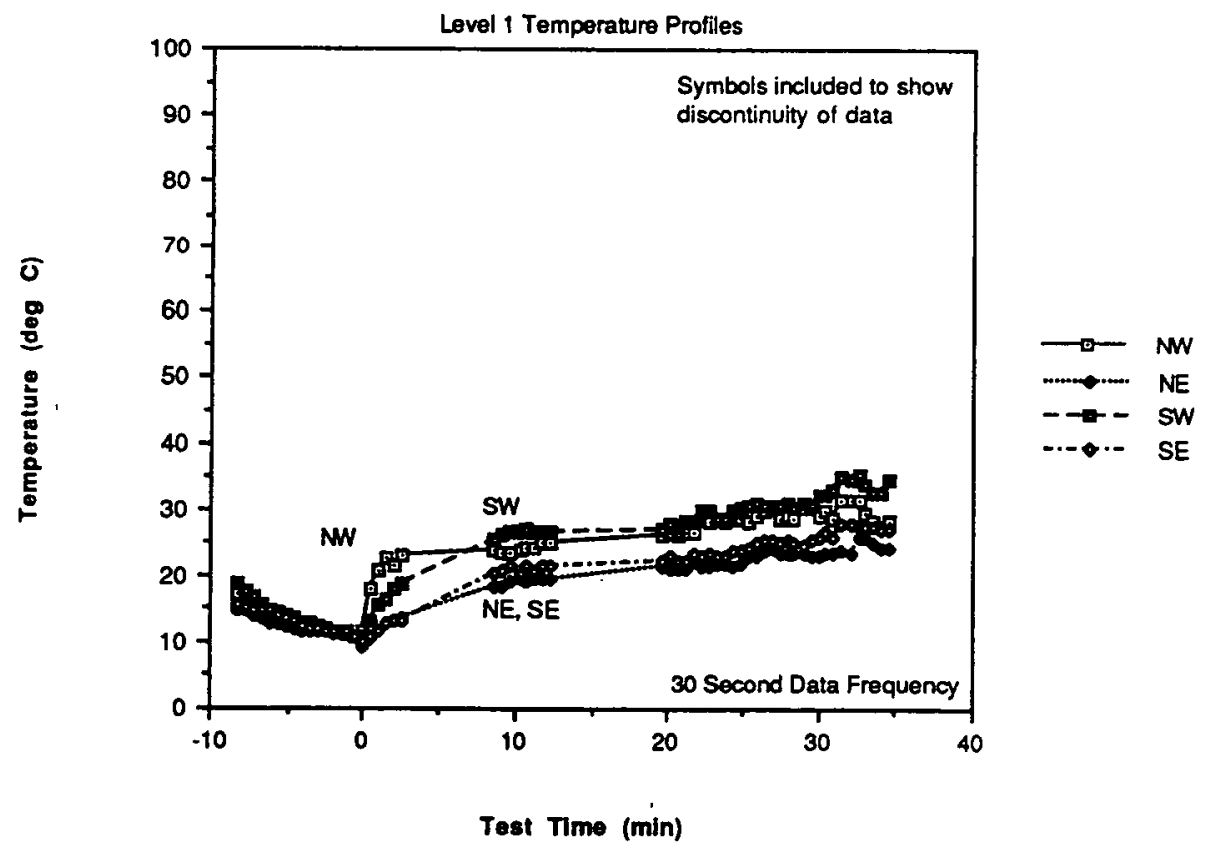

FIGURE 4.1. Ice-Basket Section Thermal Profiles, Test, 1 
Test 4

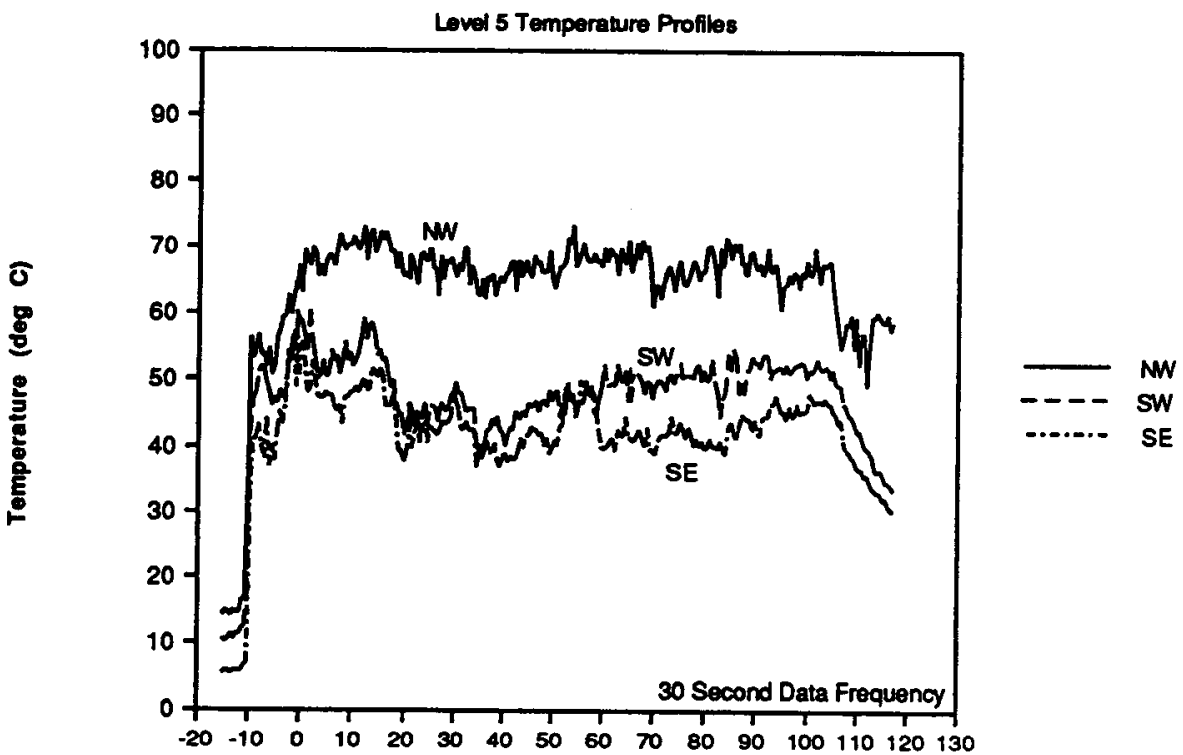

Test Time (min)

Test 4

Level 1 Temperature Profiles

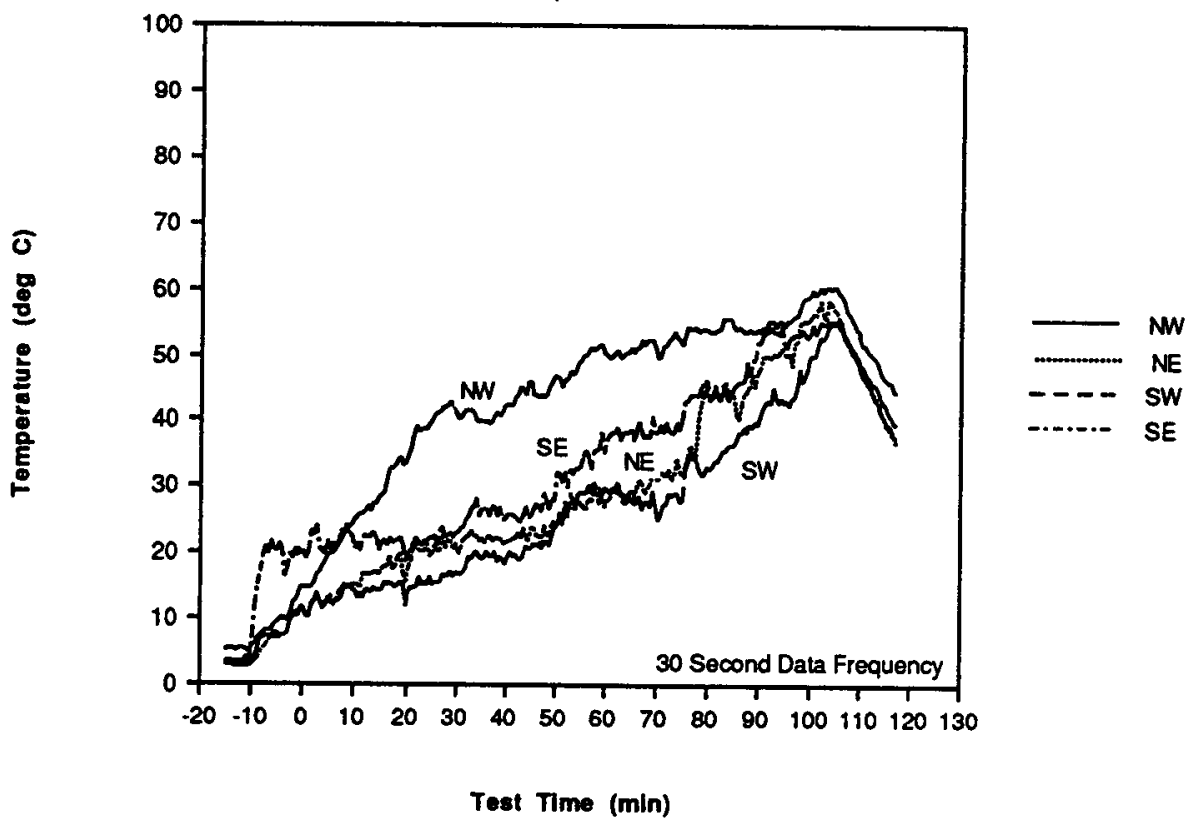

FIGURE 4.2. Ice-Basket Section Thermal Profiles, Test 4 4.8 
Test 2

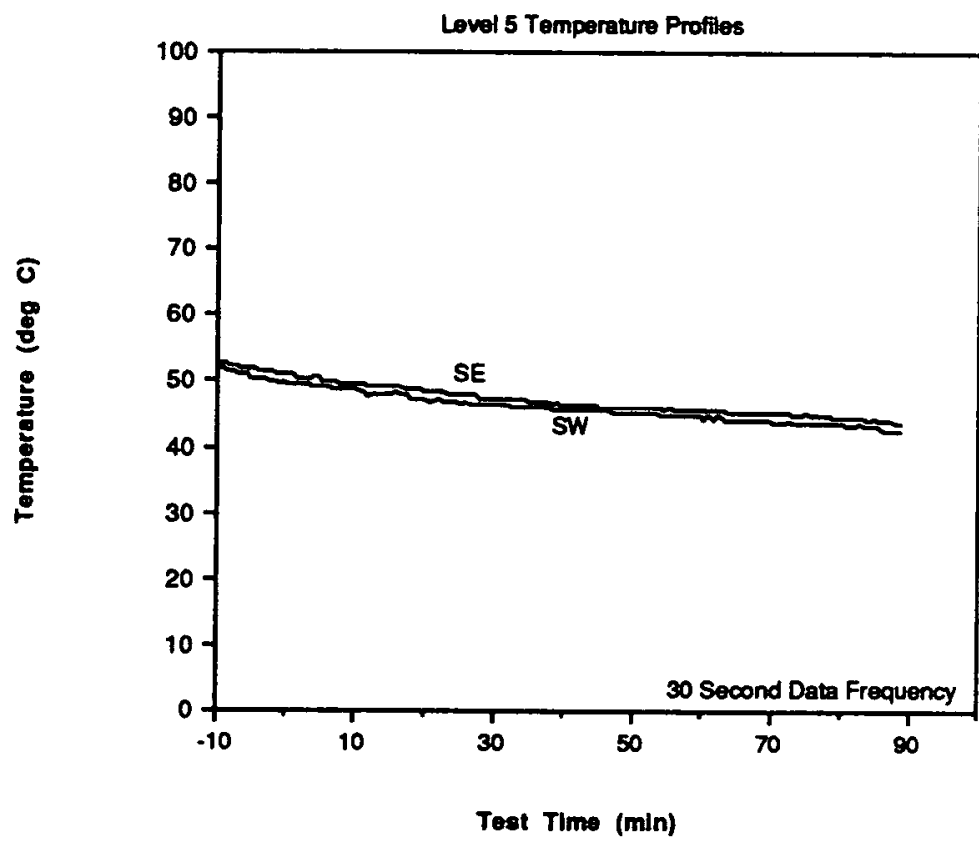

-..-. SE

$---S W$

Test 2

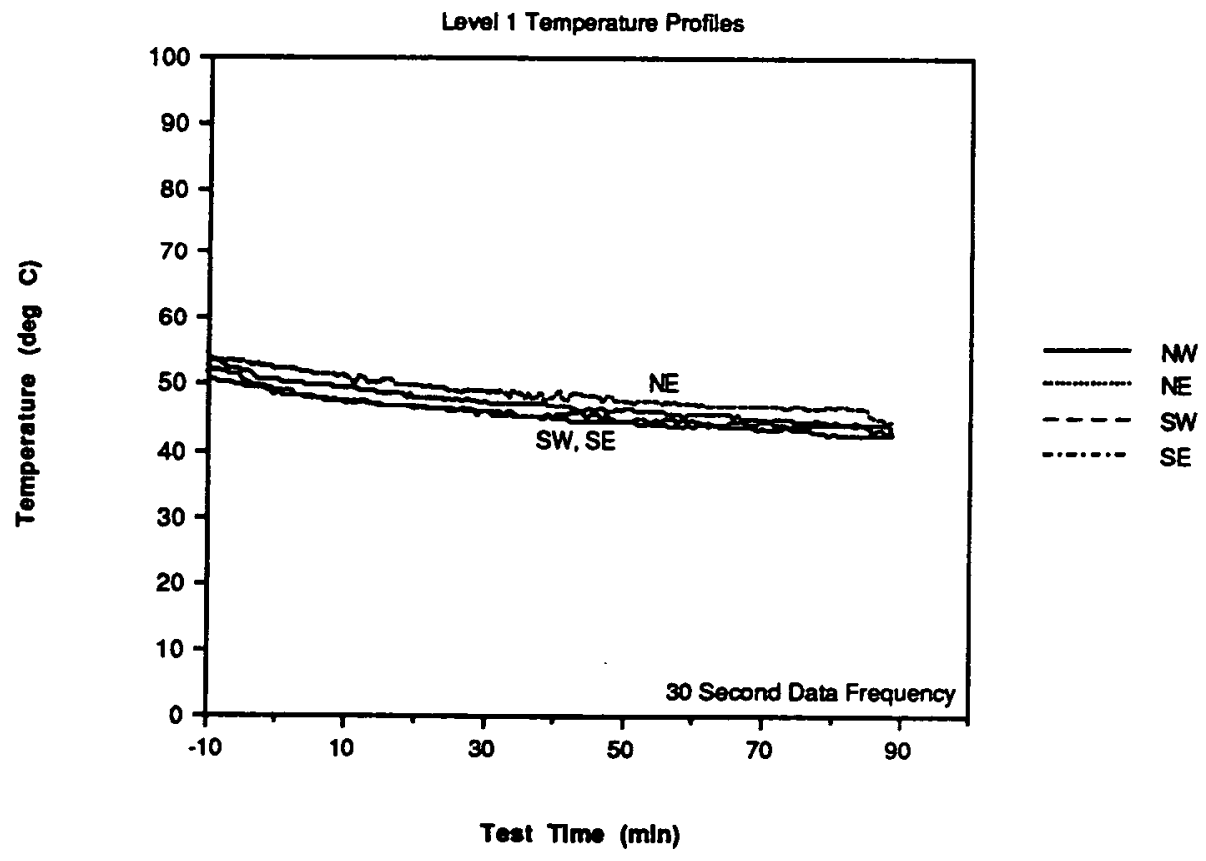

FIGURE 4.3. Ice-Basket Section Thermal Profiles, Test 2

$$
4.9
$$


Observation of probable flow non-uniformities led to modification of the test system (e.g., additional sampling penetrations and temperature measurements within the diffuser).

\subsubsection{Thermal-Hydraulic Observations - Tests 5 through 7}

$\begin{array}{ccccc}\text { Test } & \begin{array}{c}\text { Steam, } \\ \mathrm{m}^{3} / \mathrm{s}\end{array} & \begin{array}{l}\text { Air } \\ \mathrm{m}^{3} / \mathrm{s}\end{array} & \begin{array}{c}\text { Total, } \\ \mathrm{m}^{3} / \mathrm{s}\end{array} & \begin{array}{l}\text { T630, } \\ { }^{0} \mathrm{C}\end{array} \\ 5 & 0 & 0.15 & 0.15 & 184 \\ 6 & 0.11 & 0.05 & 0.16 & 123(\mathrm{a}) \\ 7 & 0.04 & 0.02 & 0.06 & 145(\mathrm{~b})\end{array}$

(a) Average of centerline thermocouple rake readings.

(b) Off-center line thermocouple reading.

The stable stratification observed in the ice-basket section led to the installation of thermocouple rakes (indication only elements) in the diffuser section. This was done to determine the diffuser thermal profile, specifically to assess how far back into the diffuser the stratification existed. Prior to the performance of the fifth test, thermocouple rakes were installed in the expansion section of the diffuser, locations $b$ and $d$ in Figure 4.4. Combined, the data from the ice-basket and diffuser sections for the fifth test provided additional insight into the previously observed thermal-hydraulic behavior of the test section.

Consider the ice-basket section thermal profiles at Levels 5 and 1 for Test 5, Figure 4.5. The profiles indicate that a stable north-south thermal stratification existed throughout the test phase. The north flow quadrants were consistently warmer than the south flow quadrants throughout the test phase of Test 5. Noteworthy are the relative magnitudes of the temperature fluctuations in the north quadrants at Level 5 . The relatively large fluctuations in the temperatures in the north quadrants indicated the presence of an interface, or mixing, region; whereas the negligible magnitude of fluctuation in the south quadrants indicated that essentially no mixing was occurring in the south quadrants. At Level 1, the stable north-south stratification was evident, but at a reduced magnitude. In addition, very little mixing was indicated at Level 1. As described below, the observation of a stable north-south stratification pattern was consistent with the diffuser thermal profiles.

The diffuser thermal profile of Test 5 confirmed suspicions as to the extensive nature of the thermal stratification. At the outlet of the diffuser (just upstream of the inlet turning vanes) the diffuser profile exhibited marked and stable stratification, Figure 4.6. The warmest and coldest temperatures occurred at the top and bottom of the diffuser, respectively. In fact, $50 \%$ of the cross-sectional flow area of the diffuser outlet was $20^{\circ} \mathrm{C}$ during the entire period of the test. The upper half of the diffuser exhibited isotherms of increasing magnitude proceeding up from the duct centerline. As 


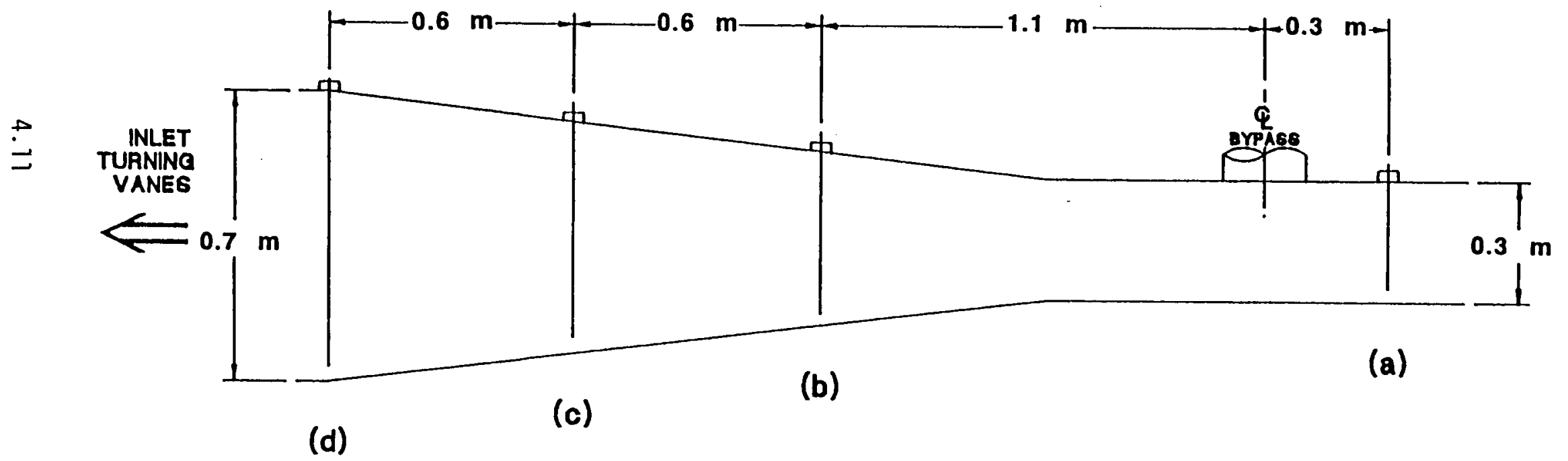

FIGURE 4.4. Diffuser Rake Locations 
Test 5

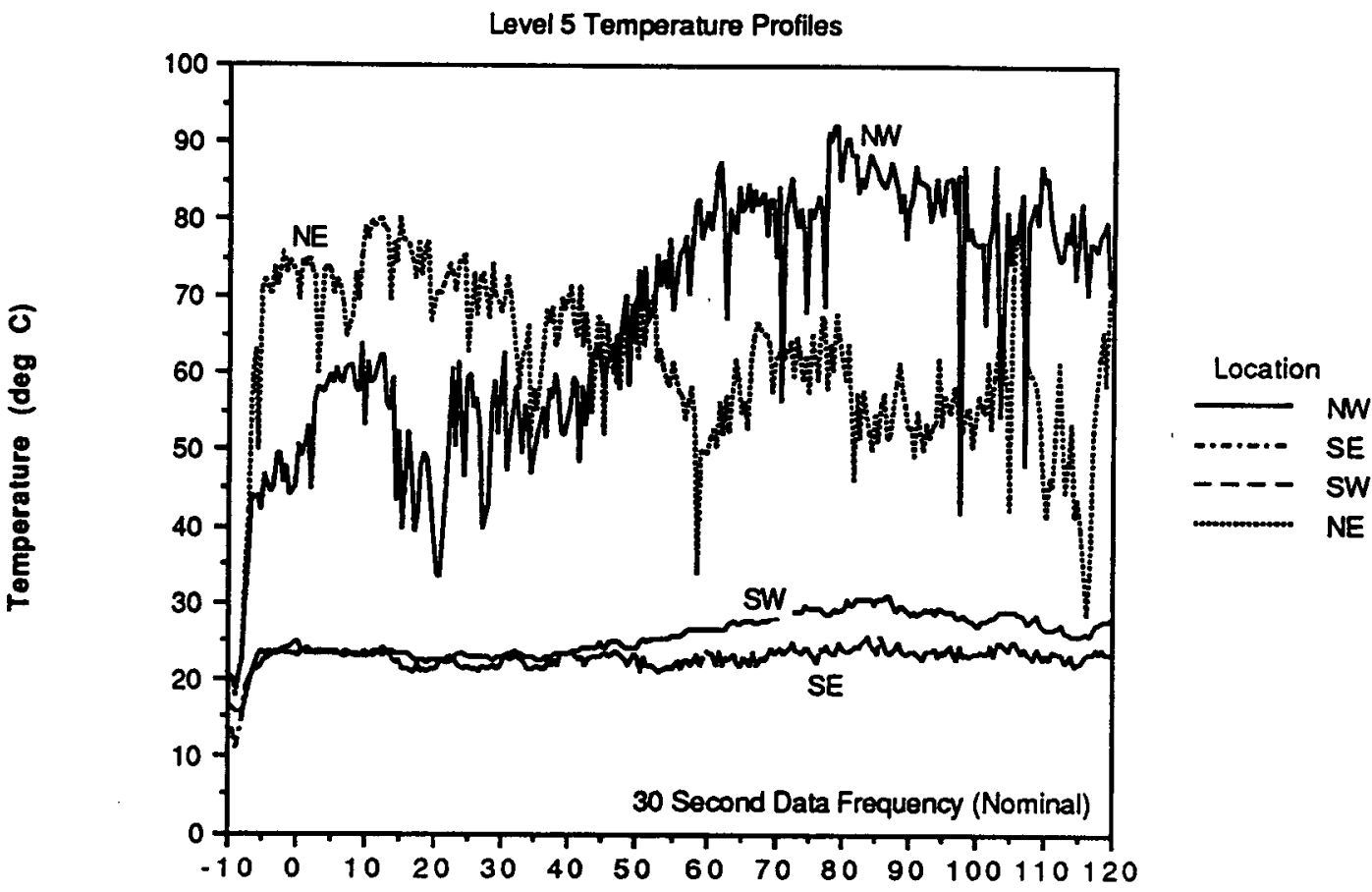

Test Time (min)

Test 5

Level 1 Temperature Profiles

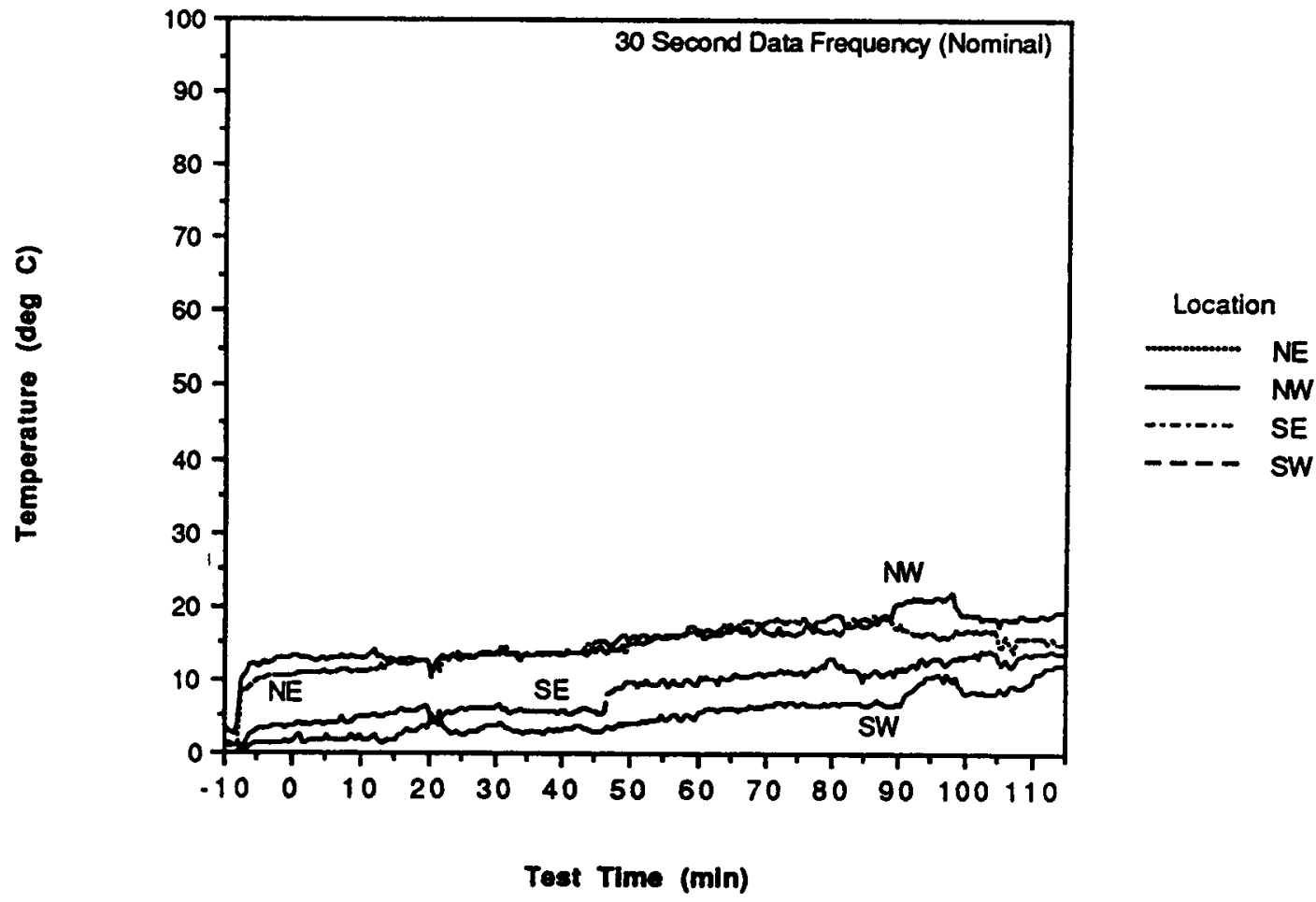

FIGURE 4.5. Ice-Basket Section Thermal Profiles, Test 5

$$
4.12
$$


Test 5

Dithuser Intet Temperature Profiles

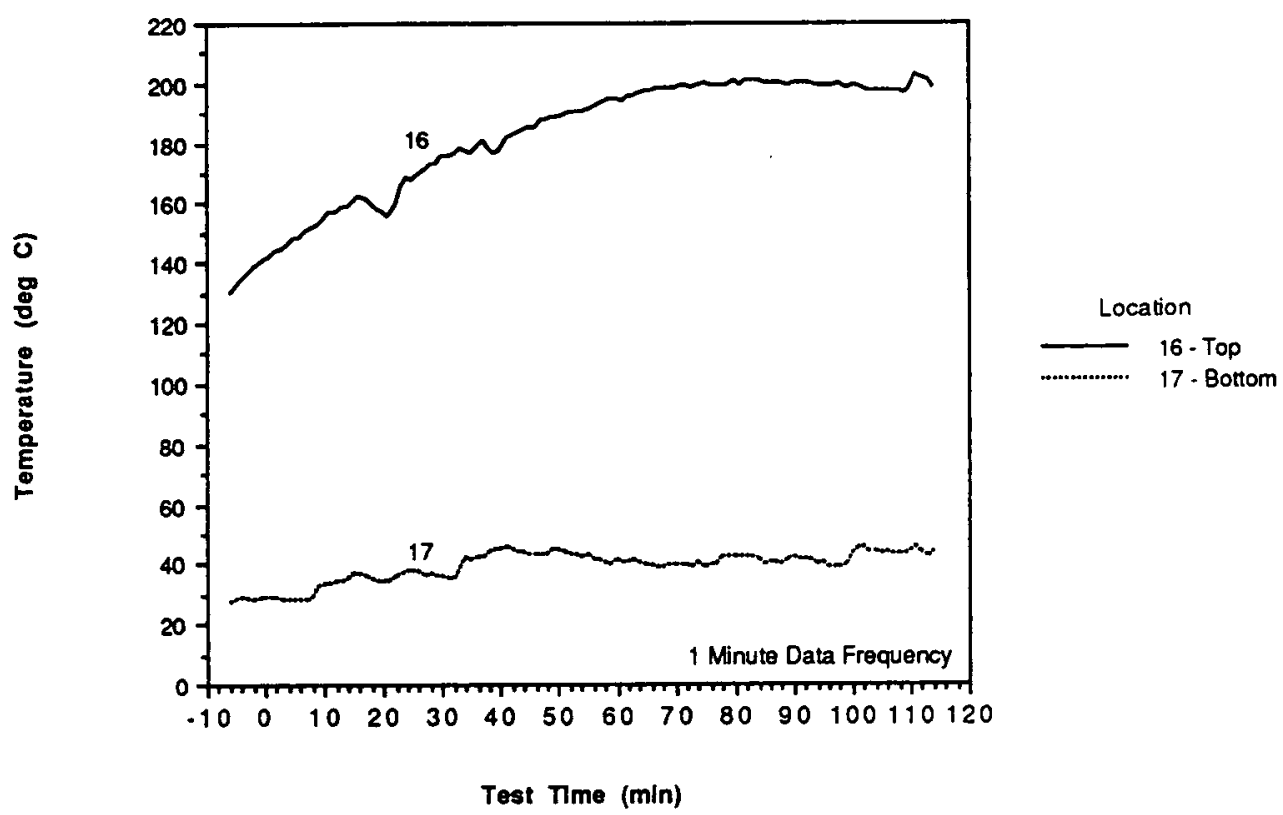

Test 5

Diffuser Outtet Temperaure Profiles

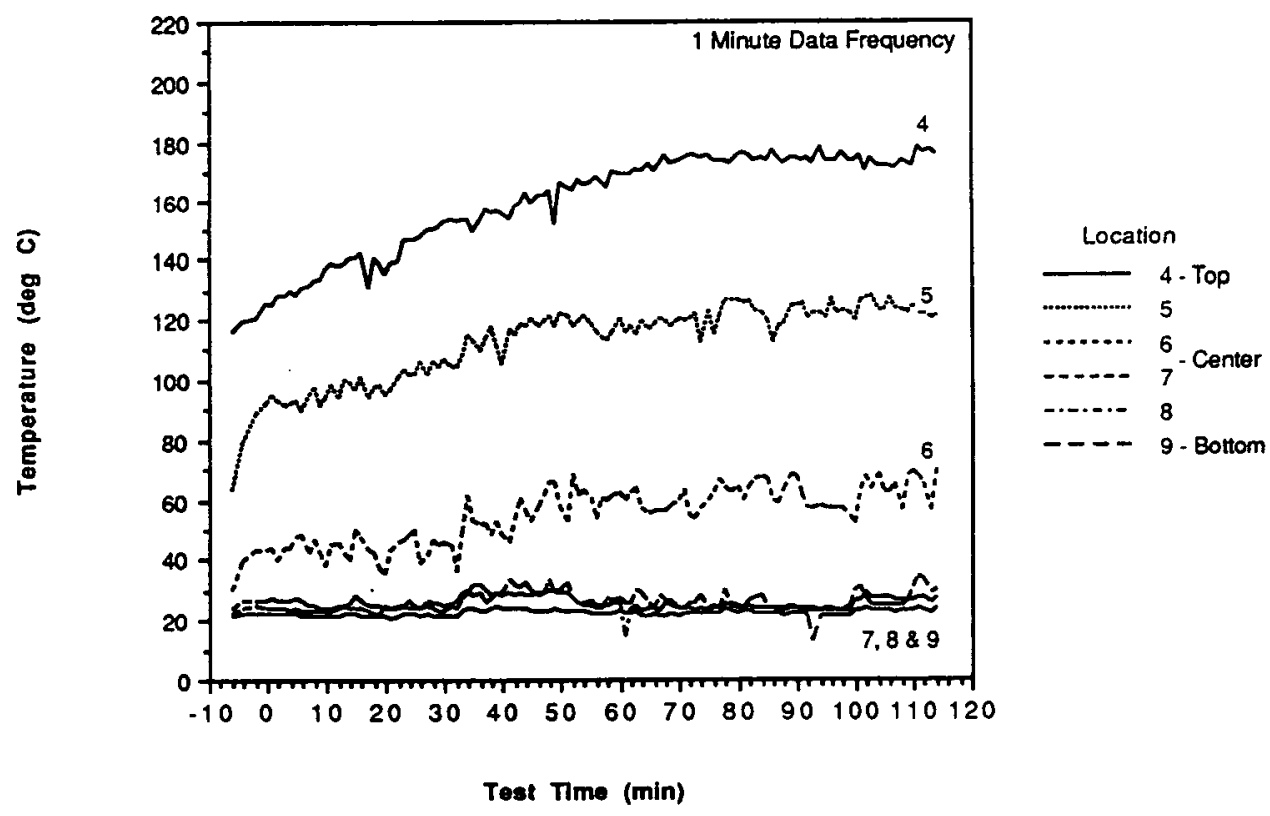

FIGURE 4.6. Diffuser Thermal Profiles, Test 5 
was the postulate in the ice-basket section thermal profiles, the magnitude of the temperature measurement fluctuations implied the degree of mixing occurring within the area of the temperature measurement. The stratification within the diffuser apparently influenced the thermal stratification within the ice-basket section. The upper, typically warmer, and lower regions of the diffuser aligned with the north and south halves of the ice-basket section, respectively. The alignment of the diffuser with the ice-basket section was apparently related to the north half of the ice-basket section being substantially warmer than the south half of the ice-basket section.

The thermal stratification, evident in the ice-basket section and the diffuser outlet was observed to extend back to at least the inlet of the diffuser, Figure 4.6. Only two inlet temperatures (top and bottom) were available on the rake initially installed at the diffuser inlet.

The combined observations of the diffuser and ice-basket section thermal profiles, while answering some questions, still did not define how far back the thermal stratification extended. Therefore, additional rakes were fabricated and installed in the diffuser and in the horizontal $30.5-\mathrm{cm}$ square duct between the downcomer and the diffuser, Station 6A. The additional rakes were in place for all of the tests performed subsequent to Test 5 .

Tests 6 and 7 were the last two tests to utilize the single-element thermocouples in the flow channels. The incomplete ice-basket section thermal profiles were the result (in part) of the installation problems caused by the shifting of the ice baskets. Test 6 temperature data exhibited many of the previously highlighted characteristics. The available data, Figures 4.7 and 4.8, indicated that at least at Level 5, the ice-basket section was thermally stratified north-south. As observed previously, the north half of the test section was warmer than the south half. Unlike previous tests, as can be seen in Figure 4.8, the stratification observed at Level 5, Figure 4.7, had weakened significantly at Level 3. Unfortunately, there was insufficient flow quadrant data available at Level 1 to generate a complete thermal profile at that level.

Test 6 was the first test during which the extent of the stratification in the diffuser could be defined. The upstream square duct (Station 6A) was not stratified during Test 6 , Figure 4.9. Thus, the stratification was limited (for Test 6) to the expansion region of the diffuser. The diffuser outlet was stratified, as shown in Figure 4.9. The lower half of the diffuser remained at approximately $45^{\circ} \mathrm{C}$, except near the end of the test. As seen before, isotherms of increasing magnitude existed in the diffuser. The reduction of the stratification observed in the latter portion of the test was attributed to the exhaustion of the ice inventory. That is to say, under the flow conditions of Jests 1 through 6, except Test 2, the thermal stratification magnitude of the diffuser was apparently directly related to the ice inventory of the ice-basket section. 
Test 6

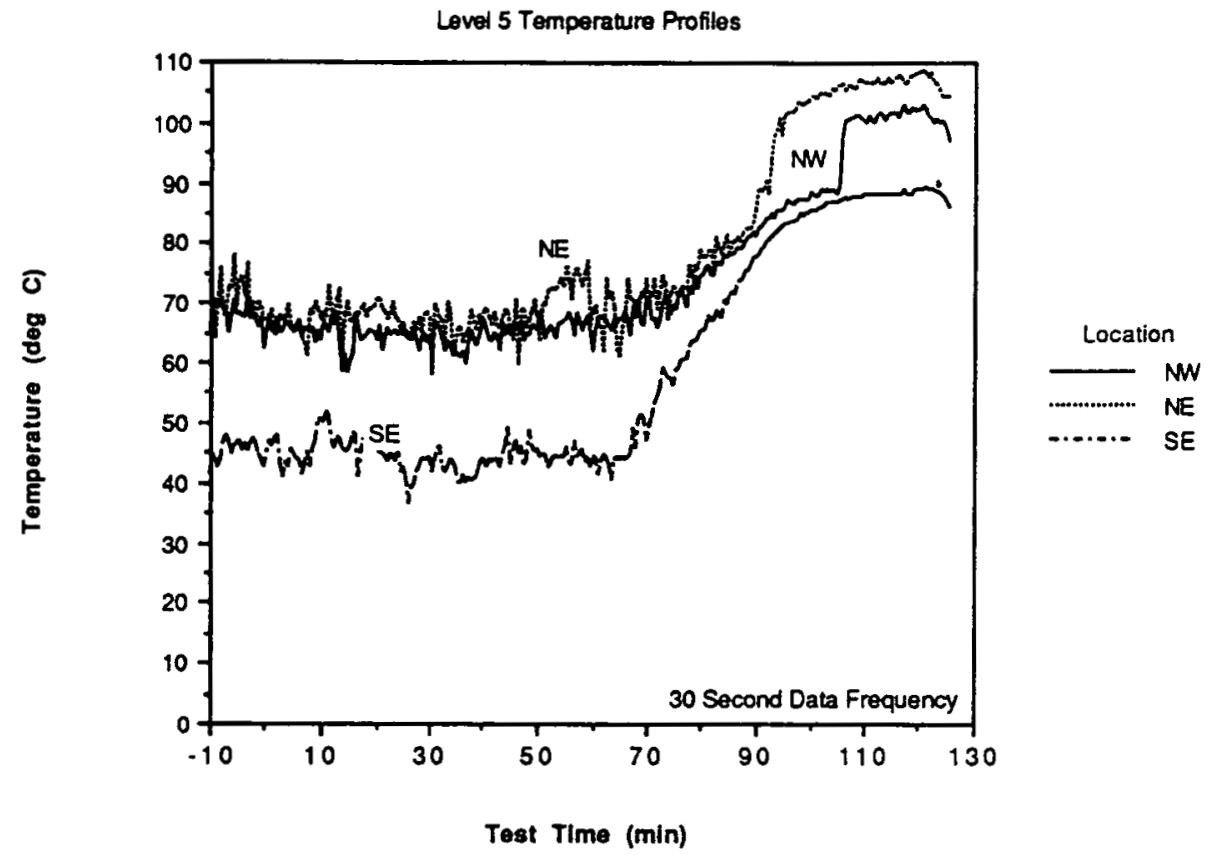

Test 6

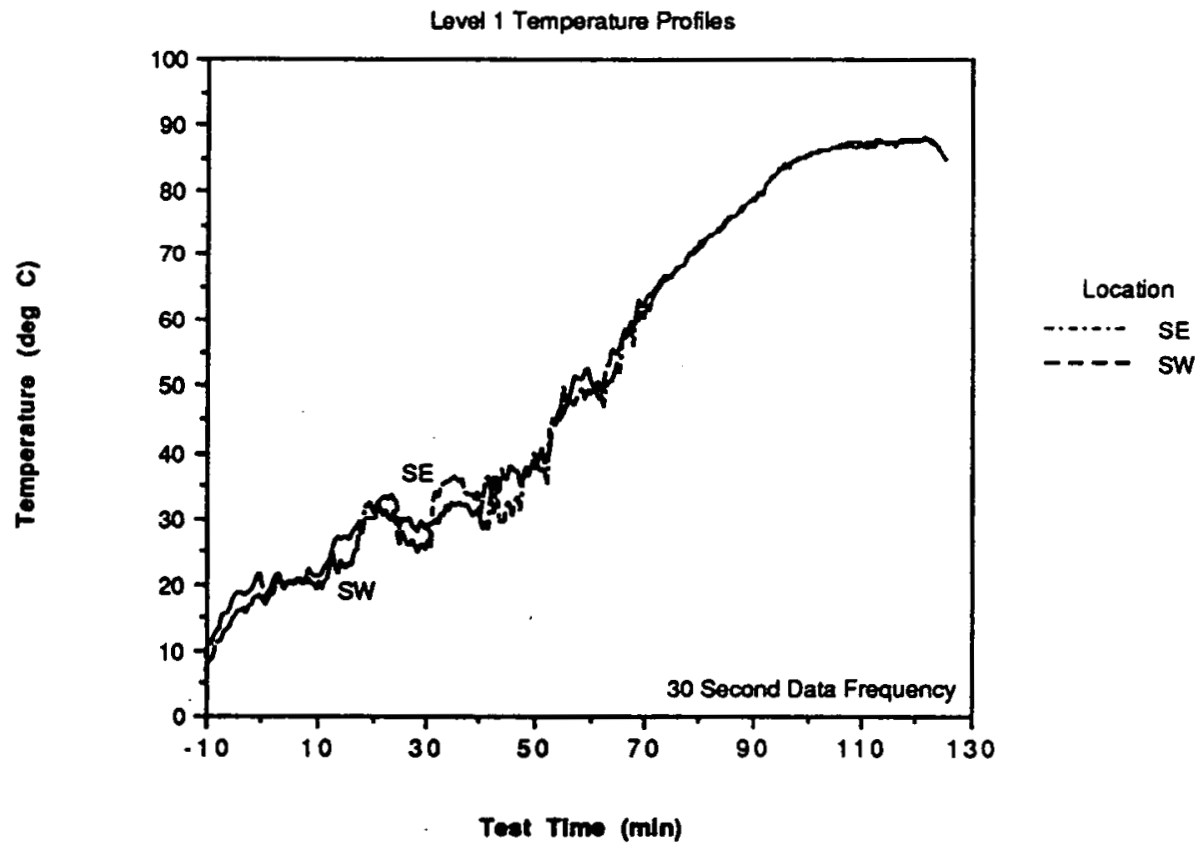

FIGURE 4.7. Ice-Basket Section Thermal Profiles, Test 6, Levels 1 and 5 4.15 
Test 6

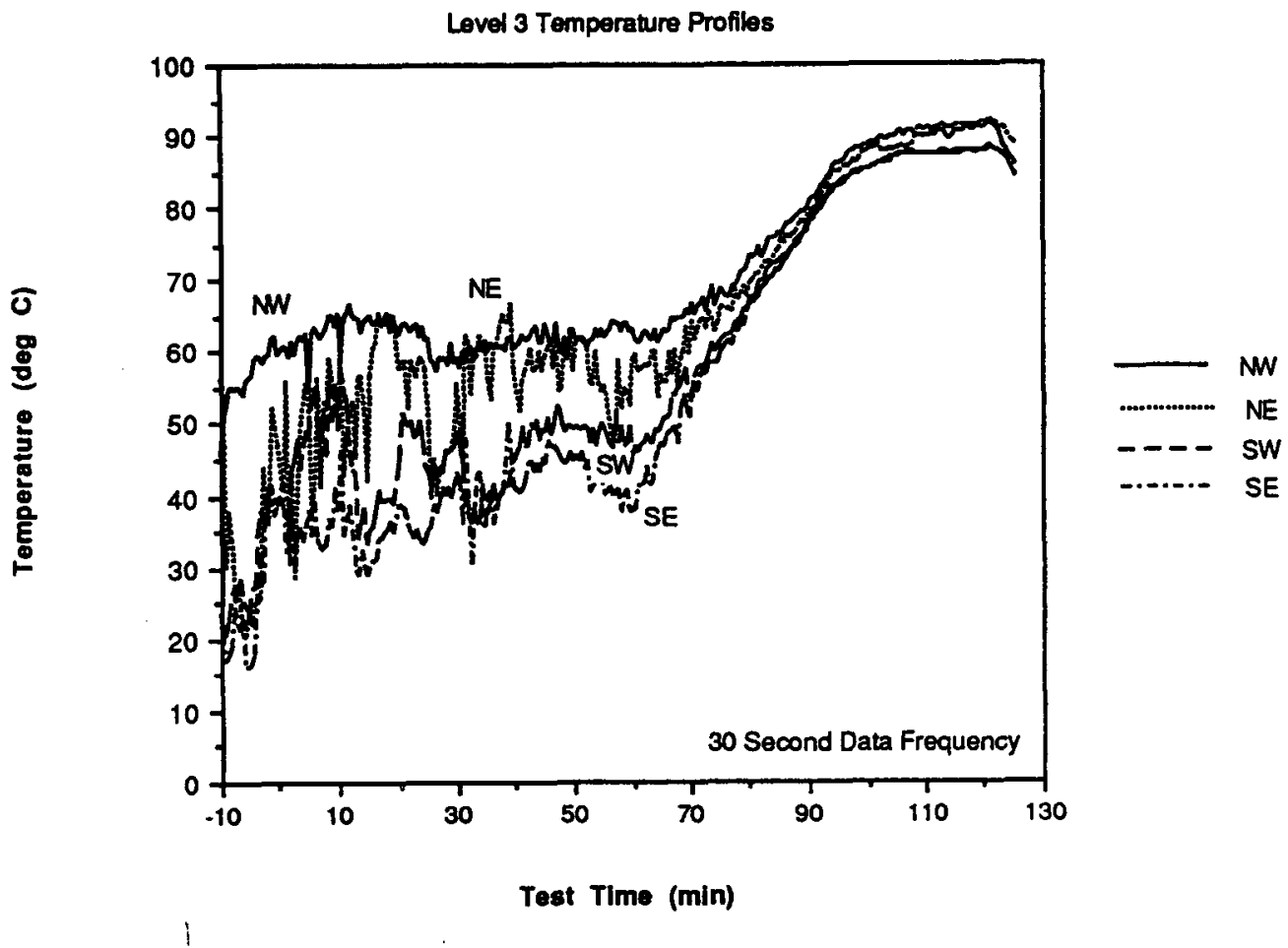

FIGURE 4.8. Ice-Basket Section Thermal Profiles, Test 6, Level 3

The thermal profiles of both the diffuser and ice-basket section of Test 7 were similar to those of Test 6 . As shown in Figure 4.10, Level 5 of the ice-basket section exhibited a definite, albeit relatively small magnitude, north-south thermal stratification. Again, the north half of the test section was warmer than the south. As observed in Test 6 , the definite stratification was essentially eliminated at Levels 3 and 1 . The thermal profiles at Levels 3 and 1 exhibited characteristics of mixing with the concomitant loss of stratification definition. Unlike Test 6 , the square duct for Test 7 exhibited some thermal stratification, Figure 4.11. The thermal stratification at the diffuser outlet for Test 7 was also stratified. In this case (Figure 4.11), the cold region (temperature $<50^{\circ} \mathrm{C}$ ) included most of the diffuser outlet cross-sectional area. The only hot portion of the diffuser outlet duct was the uppermost region. The ice-basket section stratification at Level 5 was consistent with the diffuser outlet stratification (i.e., the north half of the ice-basket section aligned with the upper, warmer half of the diffuser).

\subsubsection{General Observations}

With the exception of Test 2, the thermal profiles for the conditions examined in the first seven tests indicated that the diffuser stratified and that the thermal profile at Level 5 was consistent with the diffuser 
Test 6

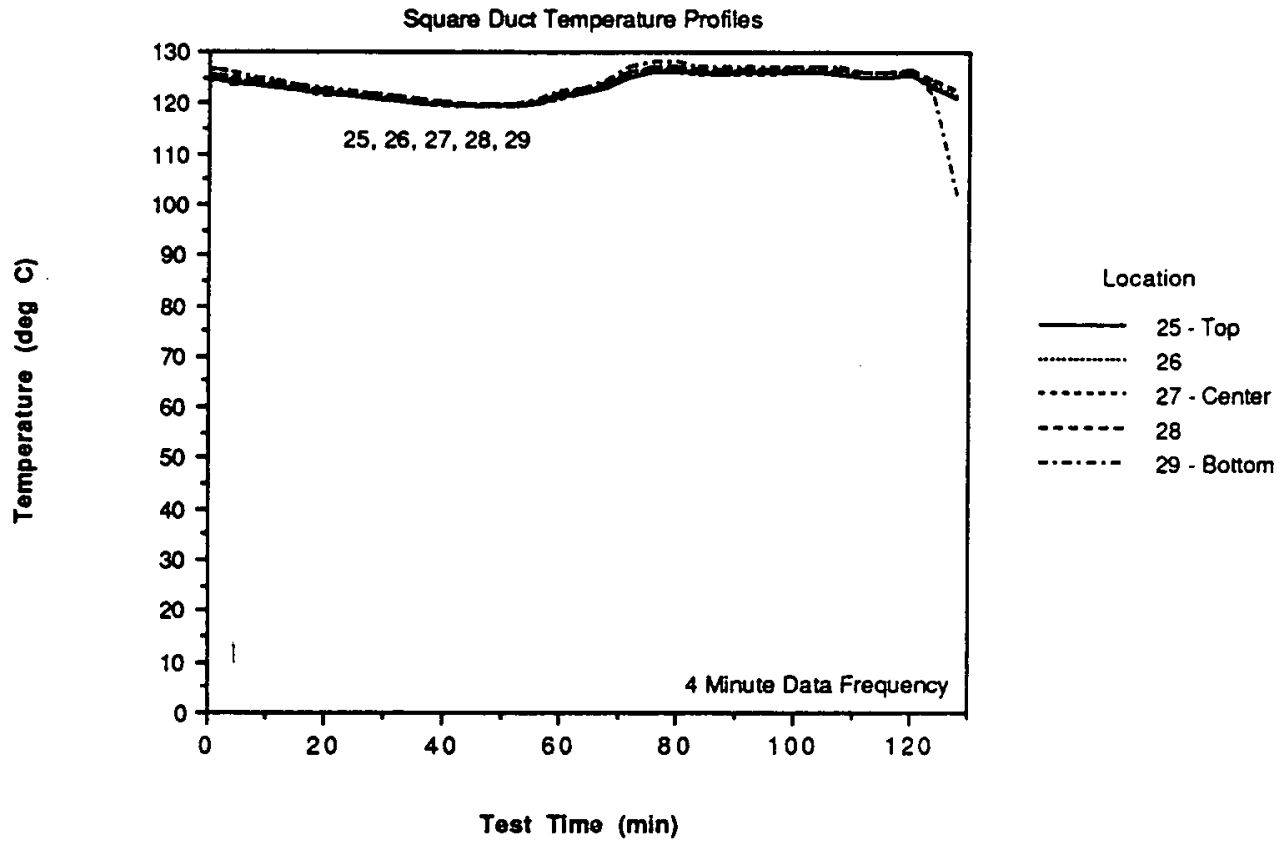

Test 6

Diffuser Outet Temperature Profiles

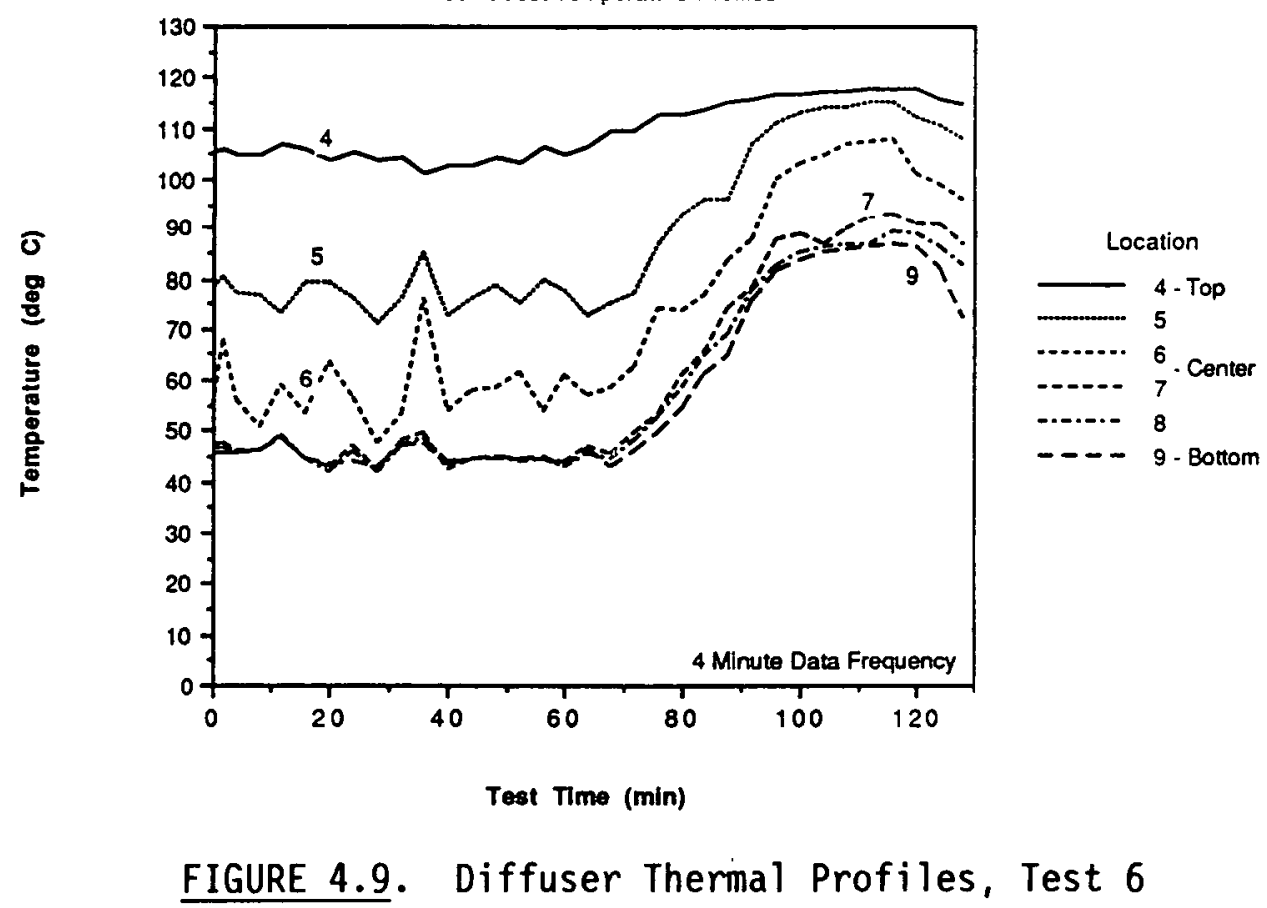

4.17 

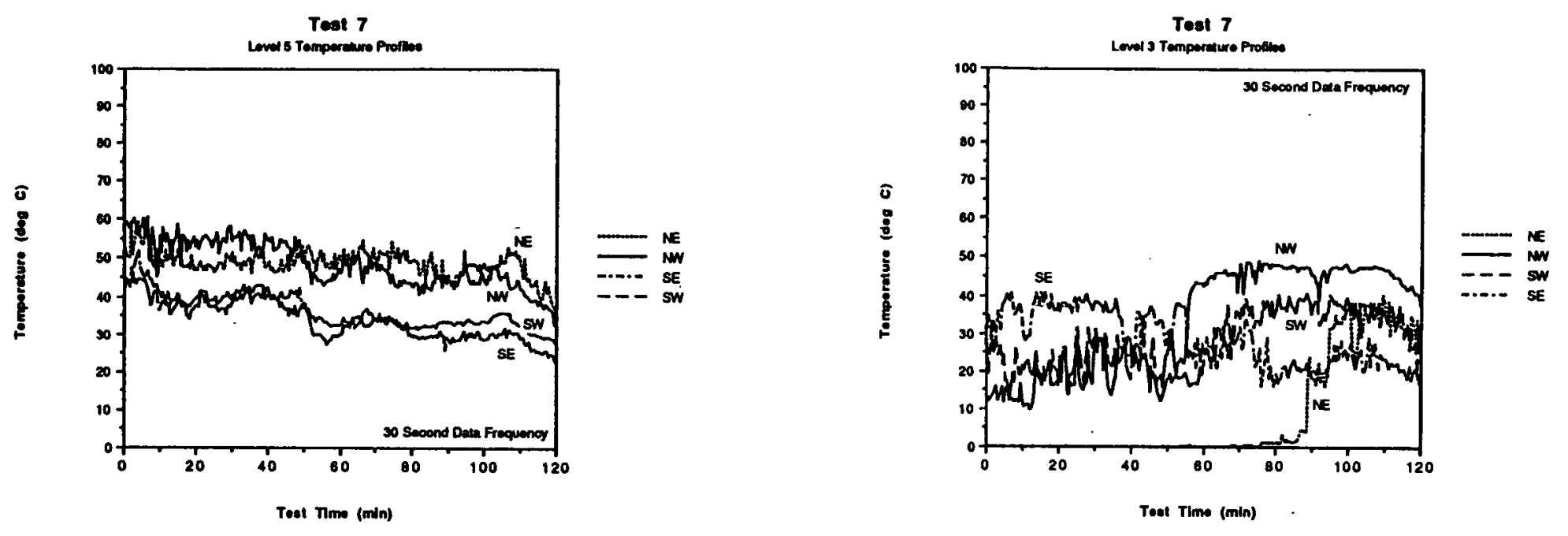

$\stackrel{+}{\infty}$

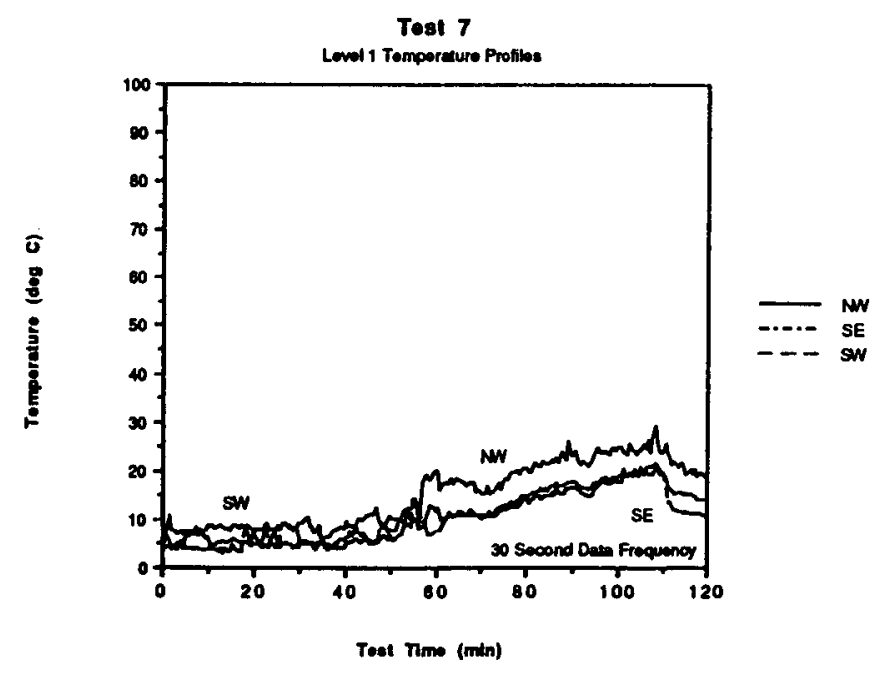

FIGURE 4.10. Ice-Basket Section Thermal Profiles, Test 7 
Test 7

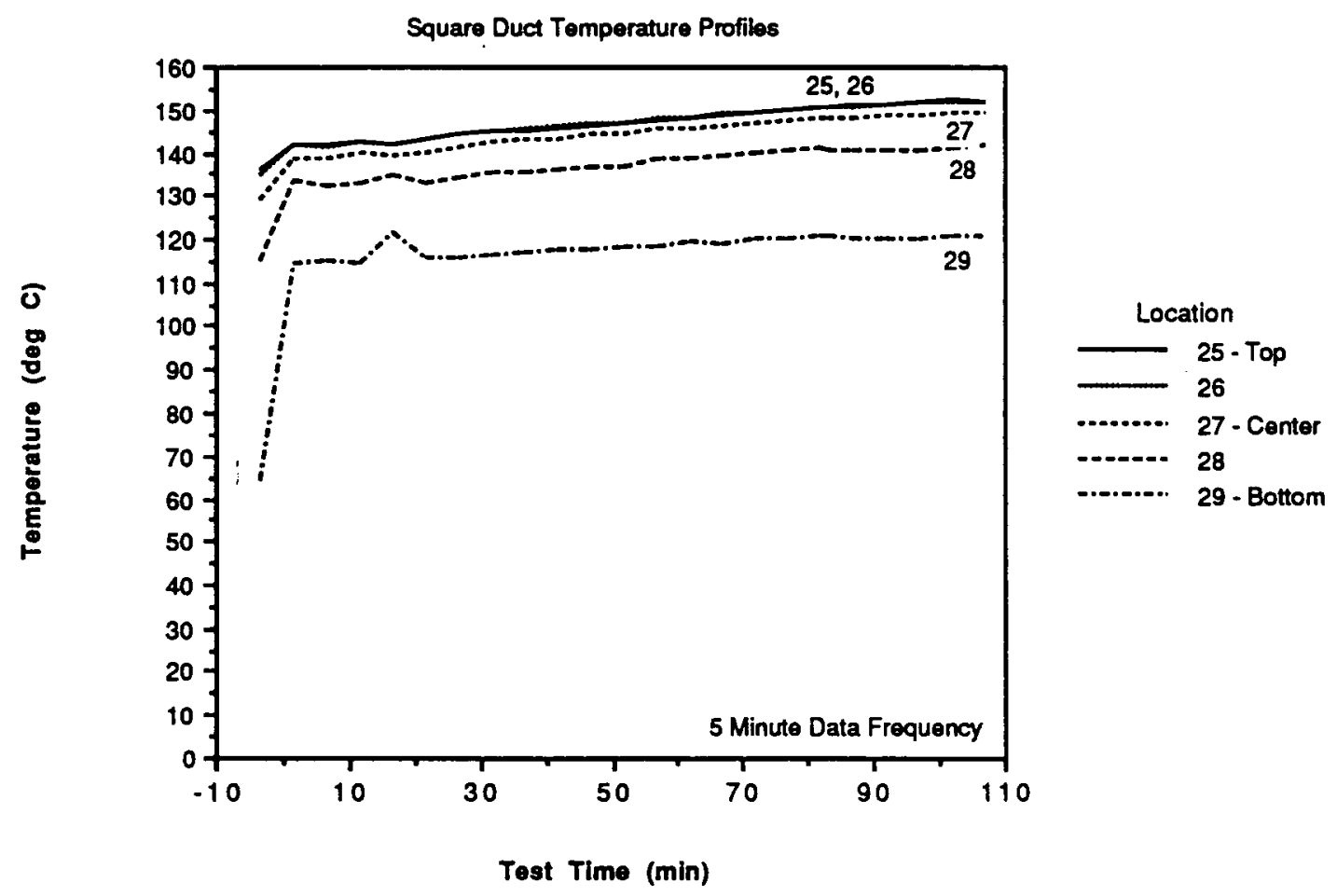

Test 7

Diffuser Outlet Temperature Profiles

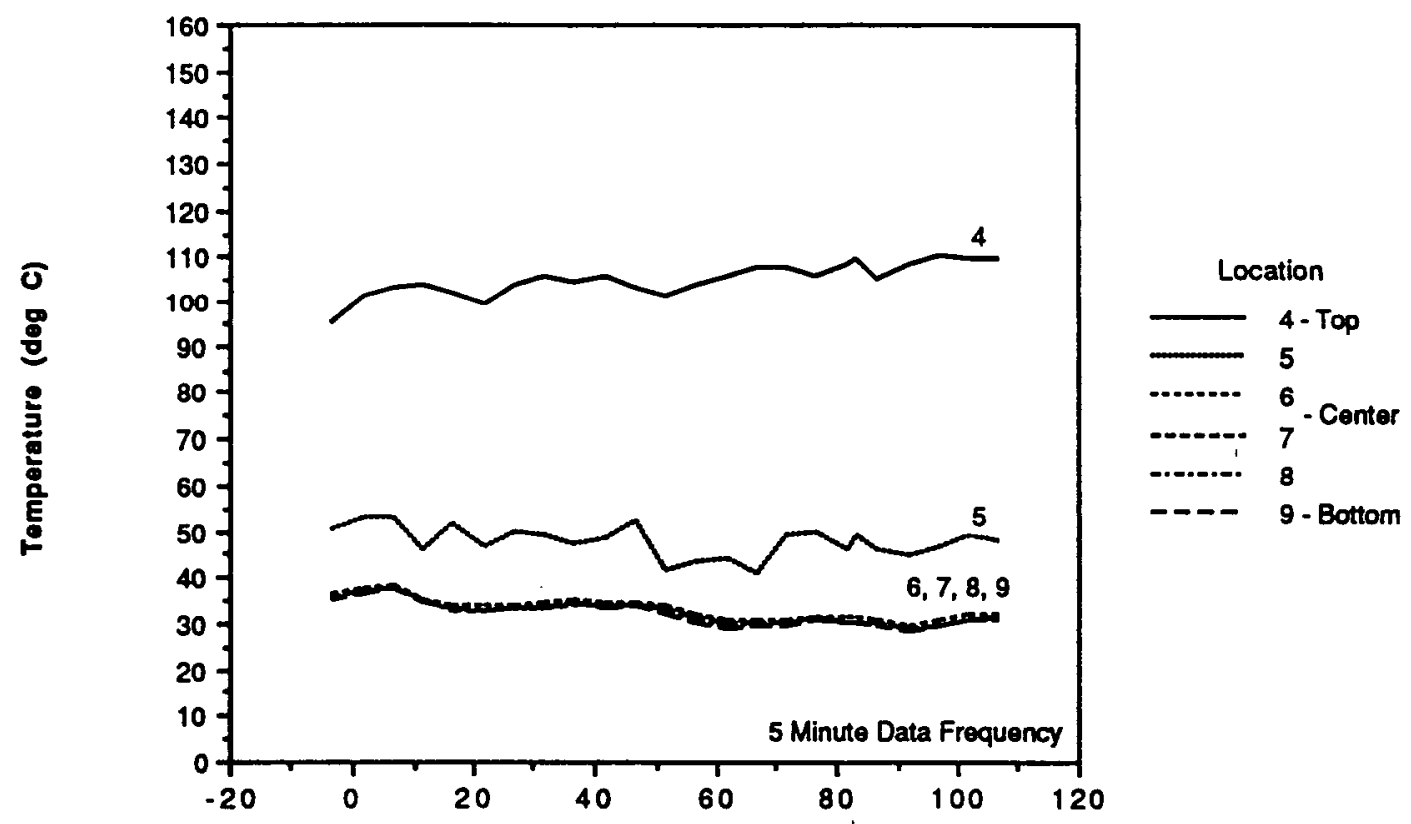

Tost Timo (min)

FIGURE 4.11. Diffuser Thermal Profiles, Test 7 
stratification. The upper section of the diffuser was significantly warmer than the lower section. The upper section of the duct was aligned with the north half of the ice-basket test section. Thus, the north half of the test section was aligned with a relatively hot process stream. The thermal stratification of the ice-basket section, typically evident at Level 5, did not always persist up through the ice-basket section. The stability of the ice-basket stratification was apparently related to the noncondensible fraction of the process stream. Decreasing the noncondensible fraction (Tests 6 and 7 relative to Test 1 ) tended to destabilize the ice-basket thermal stratification.

\subsubsection{Velocity Profile Measurements}

A special series of velocity measurements involving ice-filled baskets was performed in June 1988 between Tests 6 and 7 . Performance of the velocity profile measurements was motivated by the repeated observation of thermal stratification during the aerosol retention tests. The primary objective of the velocity measurements was to gain insight into the complex flow structures implied by the observed temperature stratification in the diffuser and the ice-basket sections. Nominal conditions of the velocity measurements are listed in Table 4.1 as $V-1, V-2$, and $V-3$. Velocity magnitude measurements were made using a ruggedized hot wire anemometer. When possible, direction of the measured velocity was investigated by flow visualization. Flow visualization was accomplished by injecting titanium dioxide powder, a procedure commonly used in heating and ventilation flow tracing. Velocity measurements and flow visualization could not be performed in conjunction with a production test because conditions of a production test (aerosol injection, and condensing atmosphere) were, incompatible with the velocity measurement techniques employęd. Nominal measurement conditions were air flows of $0.14 \mathrm{~m}^{3} / \mathrm{s}$ and $0.30 \mathrm{~m}^{3} / \mathrm{s}$. The measurement conditions did not involve the injection of steam because, as mentioned before, a condensing atmosphere was not desirable. Two thermal conditions, unheated and heated, were examined for the nominal $0.14 \mathrm{~m}^{3} / \mathrm{s}$ flow rate. One thermal condition, unheated, was examined for the nominal flow rate of $0.30 \mathrm{~m}^{3} / \mathrm{s}$. The term "unheated" refers to the cases when the input of thermal energy was caused by the compressive heating associated with the operation of the air blower. The term "heated" refers to conditions when the compressive heating was supplemented by use of the air heater. All unheated measurements were completed prior to the heated tests. The primary findings of the velocity measurements are described below.

\subsubsection{Diffuser Velocity Measurements}

Diffuser velocity profiles were measured for each of the three nominal flow conditions. Velocity profiles were measured at the outlet of the diffuser (just upstream of the entrance to the inlet turning vanes) for Tests $v-1$ and $v-3$ (unheated, nominal flow rates of 0.14 and $0.3 \mathrm{~m}^{3} / \mathrm{s}$ ). The velocity profile for condition $V-2$ (heated, nominal flow rate of $0.14 \mathrm{~m}^{3} / \mathrm{s}$ ) was measured at the approximate mid-point of the diffusing section. The three velocity profiles are presented in Figure 4.12. Each profile is presented relative to an arbitrary nominal $2 \mathrm{~m} / \mathrm{s}$ reference velocity. 


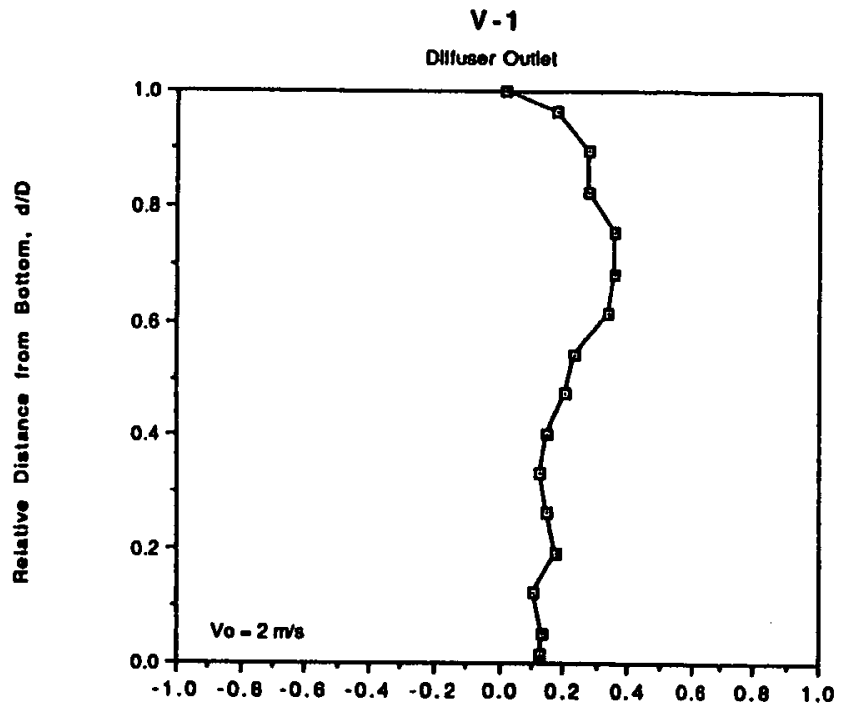

Rolallve Volocily, VNo

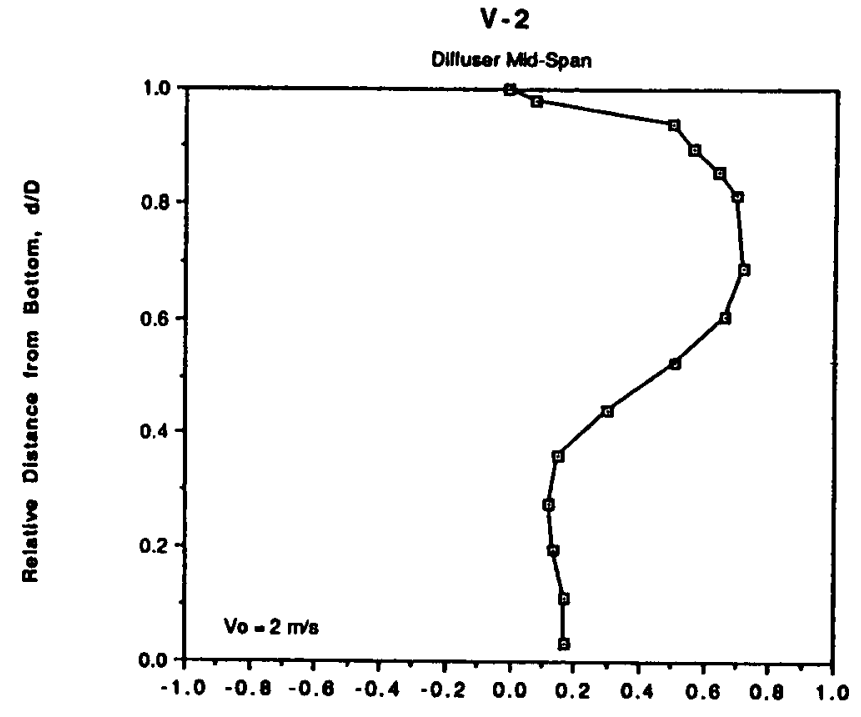

Rolatlve Velocliy, V/Vo

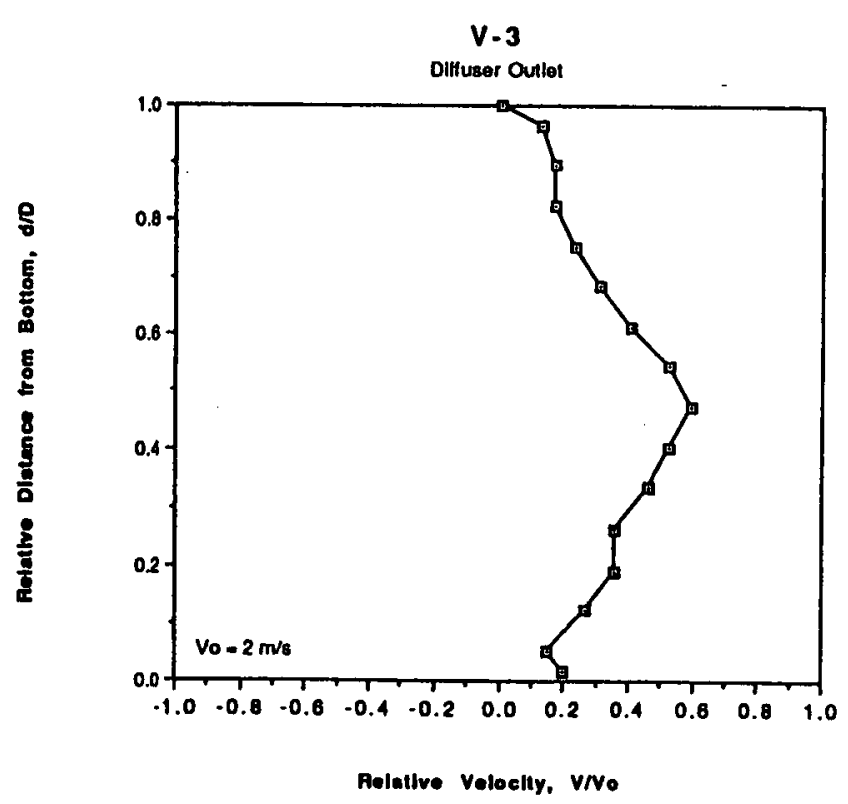

FIGURE 4.12. Velocity Profiles 
As described in Section 3.1.2, the diffuser was a square cross-section duct that expanded in the direction of flow. There were no obstructions, baffles or other flow-impeding structures in the duct. Therefore, the velocity profiles were expected to exhibit the maximum velocity at or near the centerline of the duct and taper symmetrically about the duct centerline towards the duct wall. Only the measurements made for $v-3$ (unheated, nominal $0.3 \mathrm{~m}^{3} / \mathrm{s}$ flow rate). Figure 4.12 , yielded a profile similar to expectations. The velocity measurements for both the unheated and heated cases of $0.14 \mathrm{~m} / \mathrm{s}$ flow, Figure 4.12, $V-1$ and $V-2$, yielded profiles whose maximum velocities were significantly offset from the duct centerline. In addition, the taper of the profiles toward the duct wall was not symmetric about the duct centerline. Both $V-1$ and $V-2$ (unheated and heated thermal conditions of nominal $0.14 \mathrm{~m}^{3} / \mathrm{s}$ flow rate) yielded diffuser velocity profiles showing significantly reduced velocities in the bottom half of the duct. Flow visualization studies could not be conducted in the diffuser region because of the absence of visual access. Additional clues to the character of the diffuser flow at relatively low flow rates can be gained from consideration of the results of the icebasket section velocity measurements.

\subsubsection{Ice-Basket Section Flow Measurements}

Velocity magnitude measurements were made at Levels 5 and 1 of the icebasket section with a ruggedized hot-wire anemometer. Measurements were made with the ice baskets initially full of ice. The resulting available flow cross-sectional area is shown in Figure 4.13 , where the hatched areas correspond to regions filled with ice. The resulting cross section is easily described in terms of flow quadrants, whose centers are shown by an " $X$ ". Velocity measurement transverses were made along the north and south transects shown in Figure 4.13. A complete traverse yielded a profile for both north quadrants or both south quadrants. Based on the available flow area crosssection geometry, the velocity profiles were expected to exhibit the following characteristics. First, the maximum velocity should have occurred at the center of each flow region. Second, the velocity profile should have tapered symmetrically about the quadrant center toward the gap and the section walls. Third, the minimum velocity should have occurred near the wall of the test section. In general, the ice-basket section profiles exhibited the expected characteristics, Figures $4.14,4.15$, and 4.16 . One exception was the profiles at Level 5 for condition $V-2$ (heated $0.14 \mathrm{~m}^{3} / \mathrm{s}$ ). Figure 4.15 . The expected double peak character was not evident in either the north or south half profile. Also evident from both the heated and unheated $0.14 \mathrm{~m}^{3} / \mathrm{s}$ profiles (Figures 4.14 and 4.15 ) was the observable preference (higher velocity that implied higher flow rate) for flow in the north half of the test section. The profiles for $V-3$ (unheated $0.3 \mathrm{~m}^{3} / \mathrm{s}$ ), Figure 4.16 , did not exhibit a preference for northerly flow. 


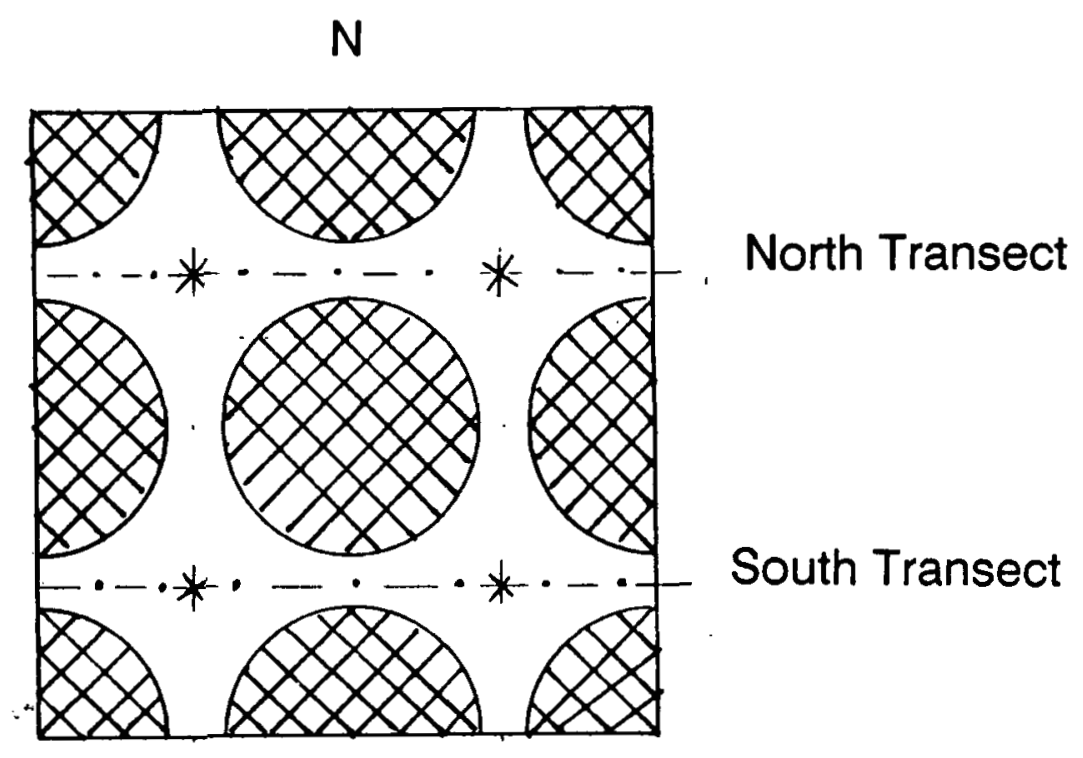

\section{FIGURE 4.13. Available Flow Cross-Sectional Area}

All of the profiles discussed up to this point were developed from velocity magnitude data. To complete the velocity studies, limited flow visualization studies were performed in the ice-basket section. Velocity direction could then be assigned based on the results of the flow visualization. The results of the flow visualization studies are summarized below.

Strong downward flow was observed in the southwest quadrant at Level 5 for conditions of $V-1$ (unheated, $0.14 \mathrm{~m}^{3} / \mathrm{s}$ ). Flow yisualization observations at Levels 1 and 5 for condition $V-2$ (heated, $0.14 \mathrm{~m}^{3} / \mathrm{s}$ ) were somewhat less conclusive than the unheated observations. At Level 5 the flow was observed to be essentially upward, with frequent occurrences of wafting. In other words, the flow pattern at Level 5 for condition V-2 was observed to fluctuate. Observation of flow pattern at Level 1 was more difficult than at Level 5. However, the observations made in the north half of the ice-basket section at Level 1 for $V-2$ conditions indicated that the flow was upward. The primary observation of the limited flow visualization tests was that at moderate flow rates $\left(0.14 \mathrm{~m}^{3} / \mathrm{s}\right)$ downward flow was observed in the lower southwest quadrant whereas upward flow was deduced in all of the quadrants of the upper region of ice-basket test section. In general, flows in the lower region of the test section were observed to change direction frequently. The flow switched between up, down, and transverse flow. Increasing the unheated volume flow rate to $0.3 \mathrm{~m}^{3} / \mathrm{s}$ el iminated the observable downflow at Level 5 . As before, there was no downflow observed at Level 1. At Levels 5 and 1 the previously observed sub-channel flow profiles were more pronounced for the higher flow rate case. 


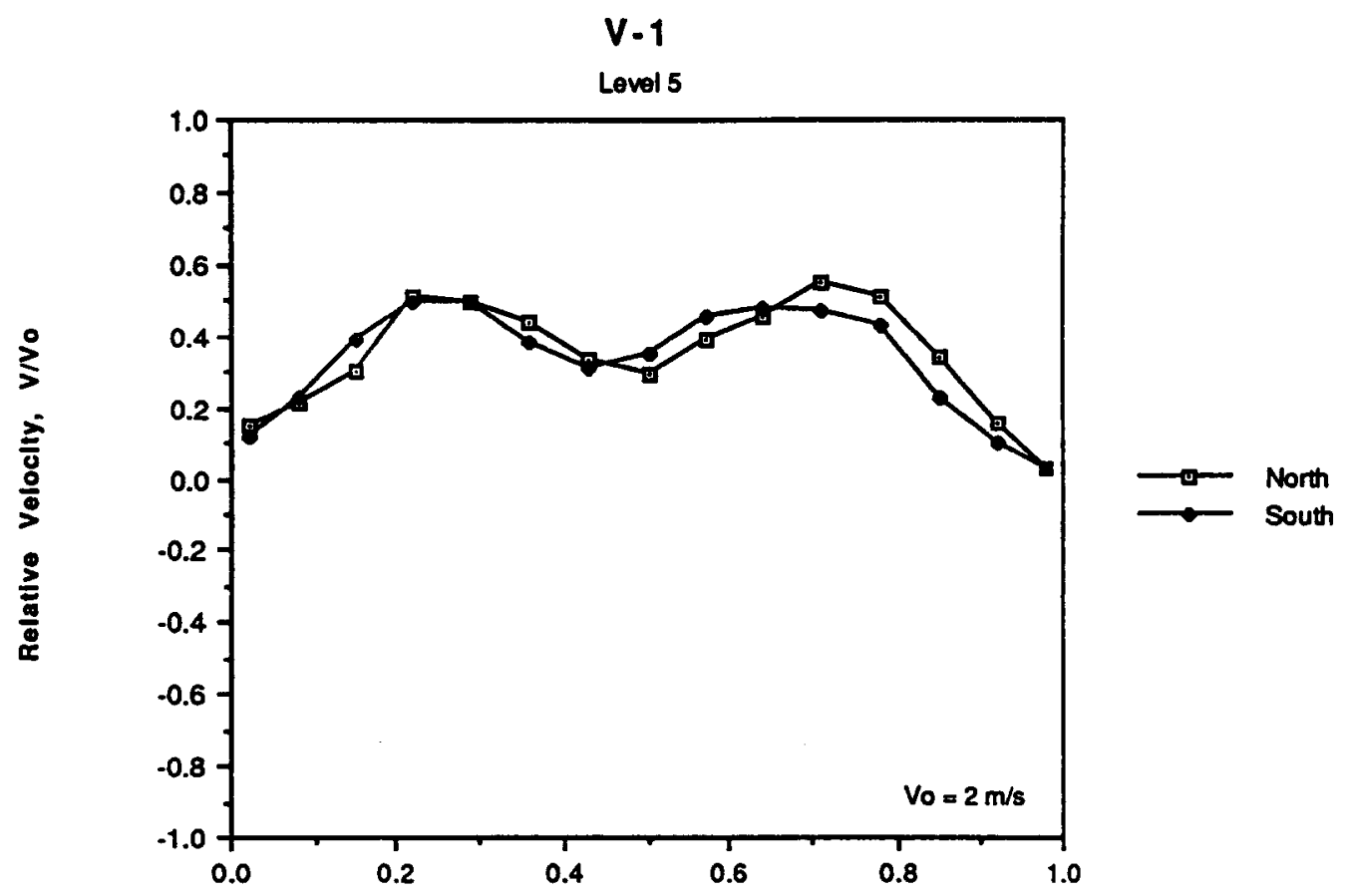

Relative distance from east to west

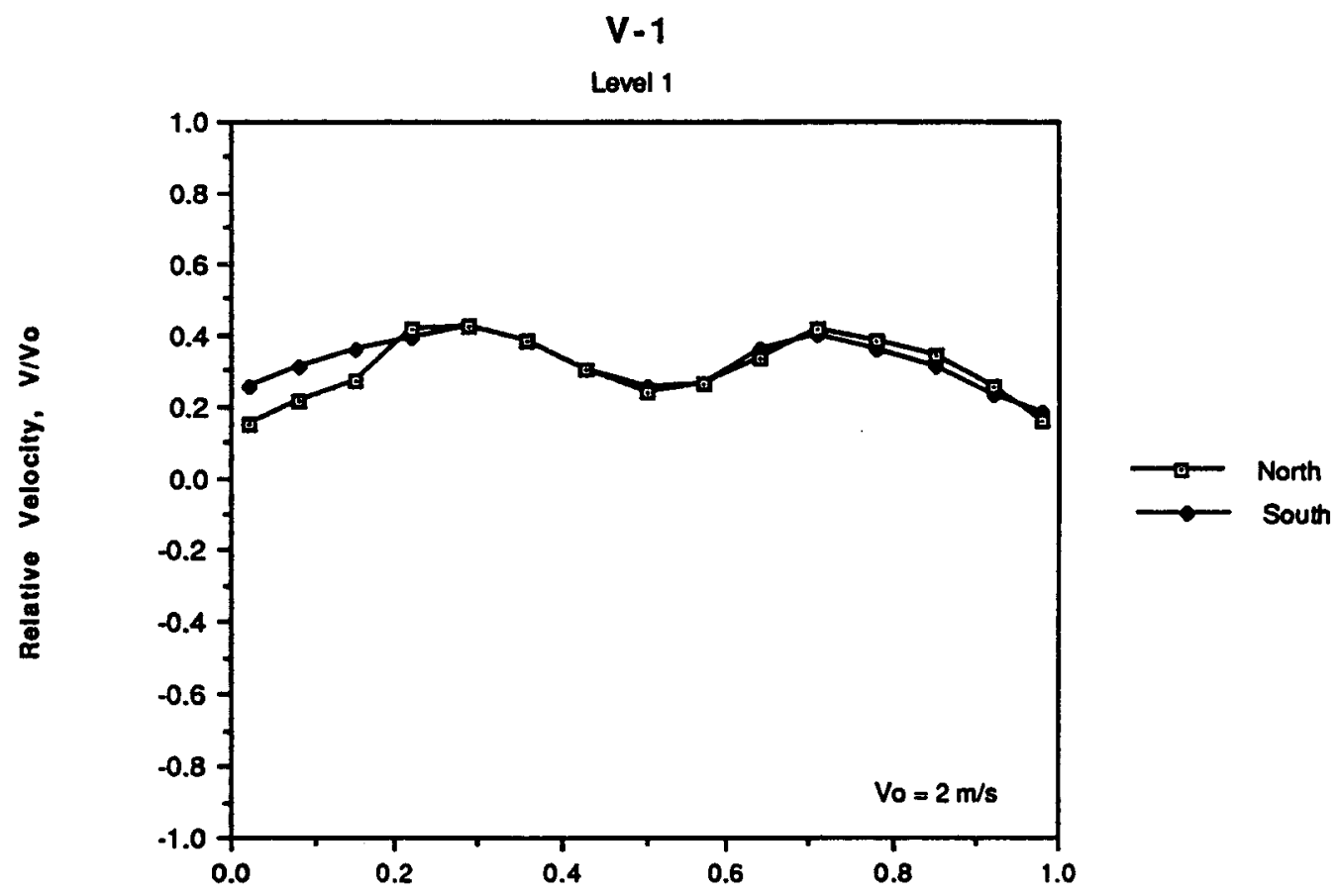

Relative distance from east to west

FIGURE 4.14. Velocity Profiles at Levels 5 and 1 for V-1 


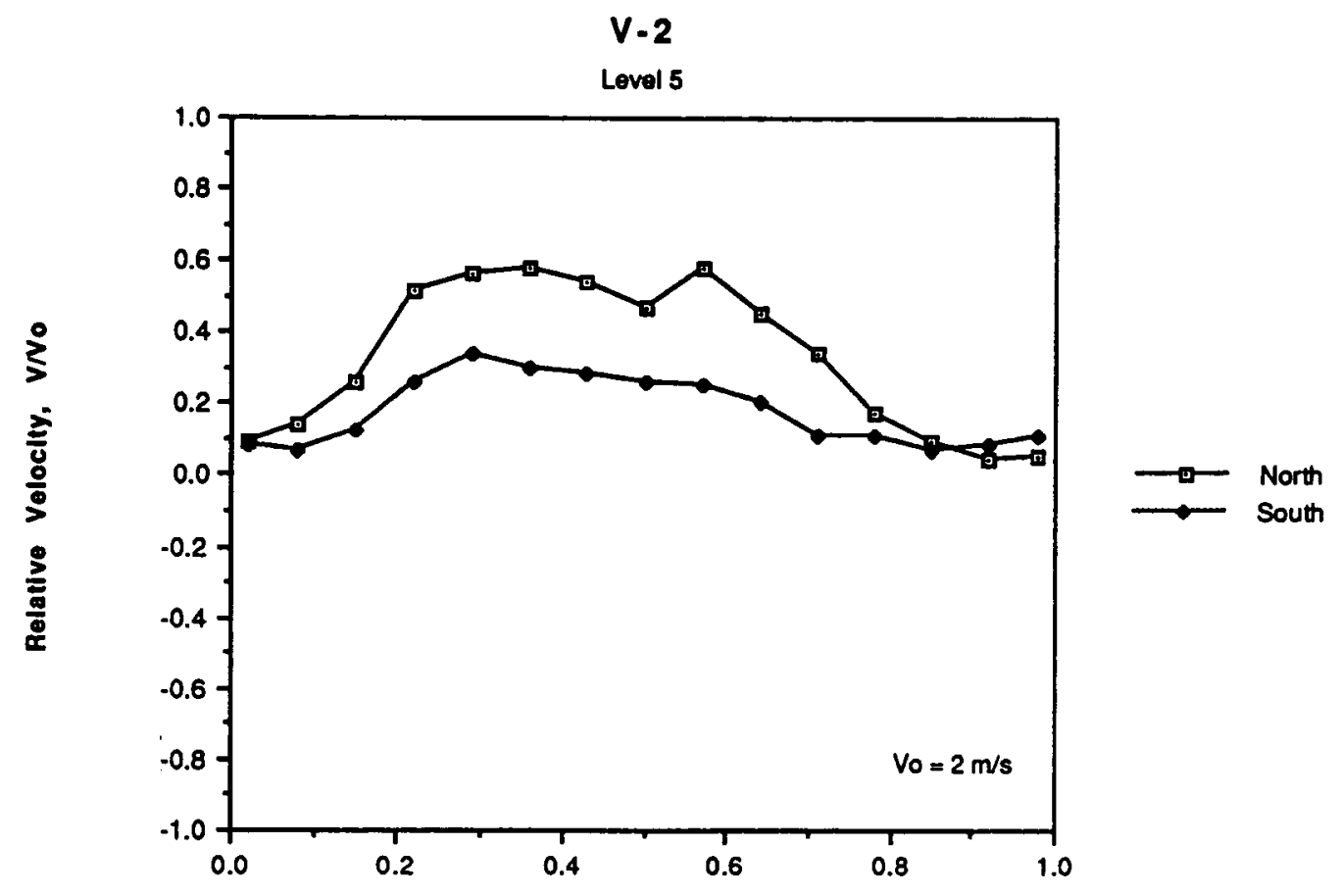

Relative distance from east to west

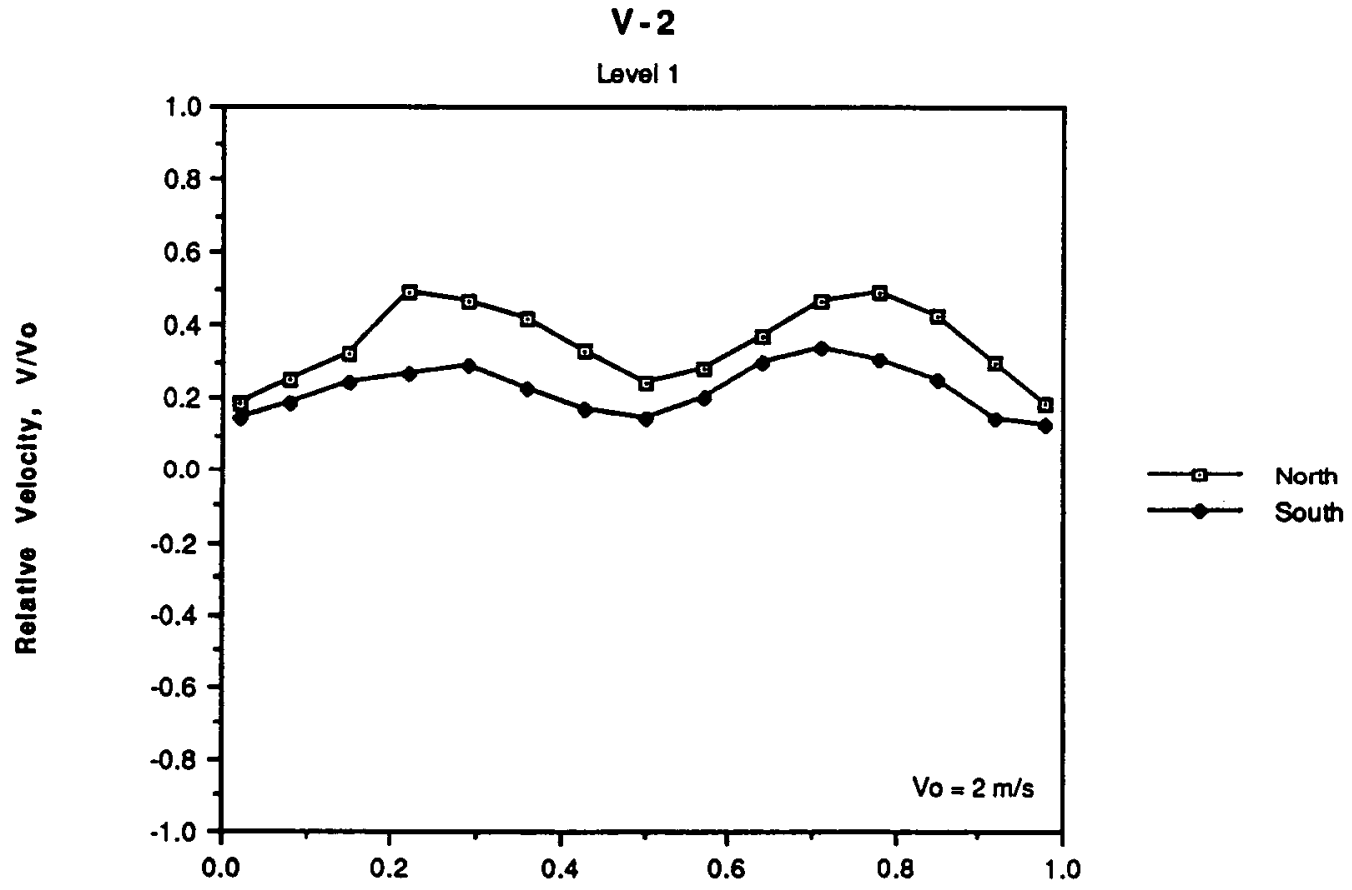

Relative distance from east to west

FIGURE 4.15. Velocity Profiles at Levels 5 and 1 for $V-2$ 


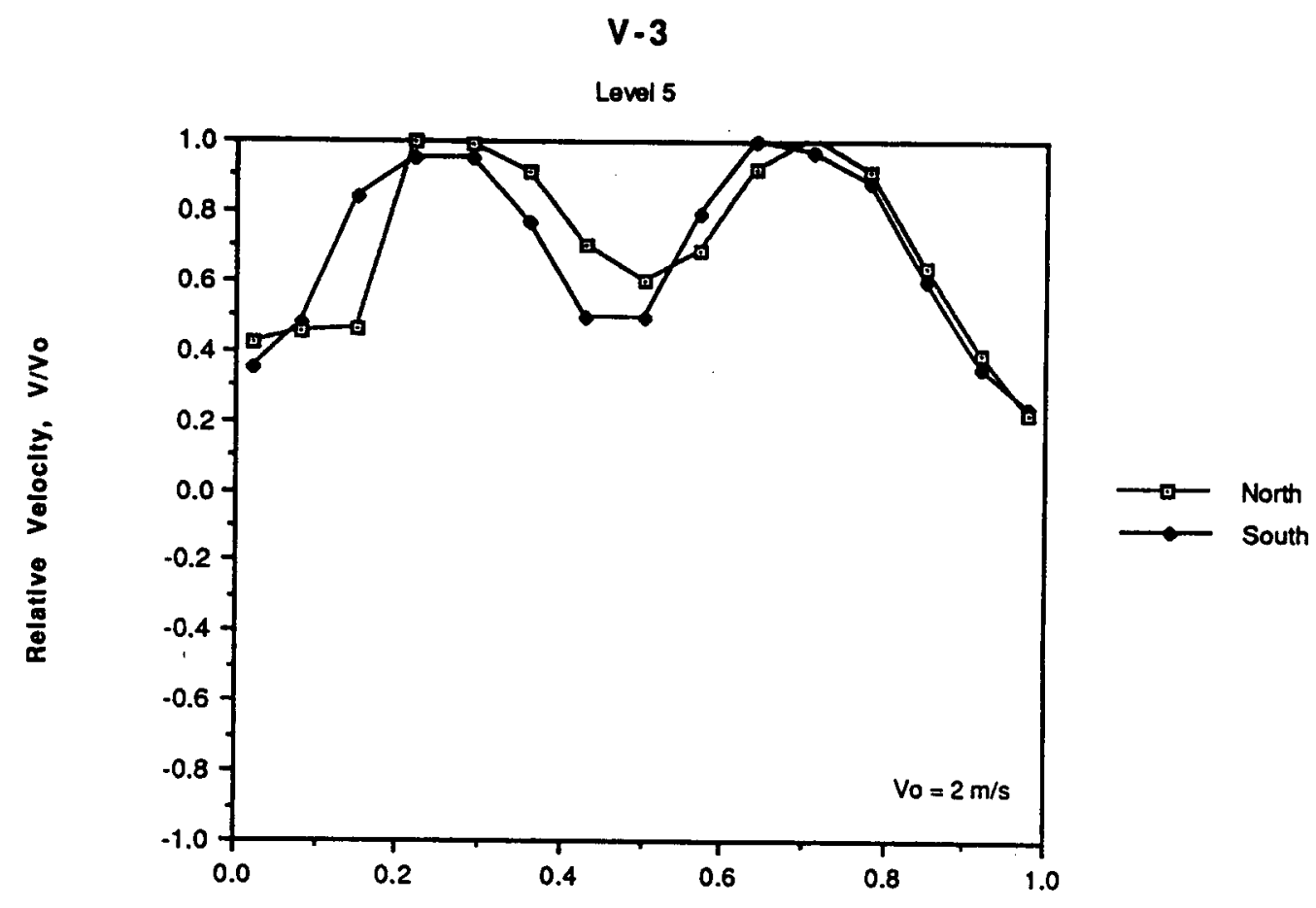

Relative distance from east to west

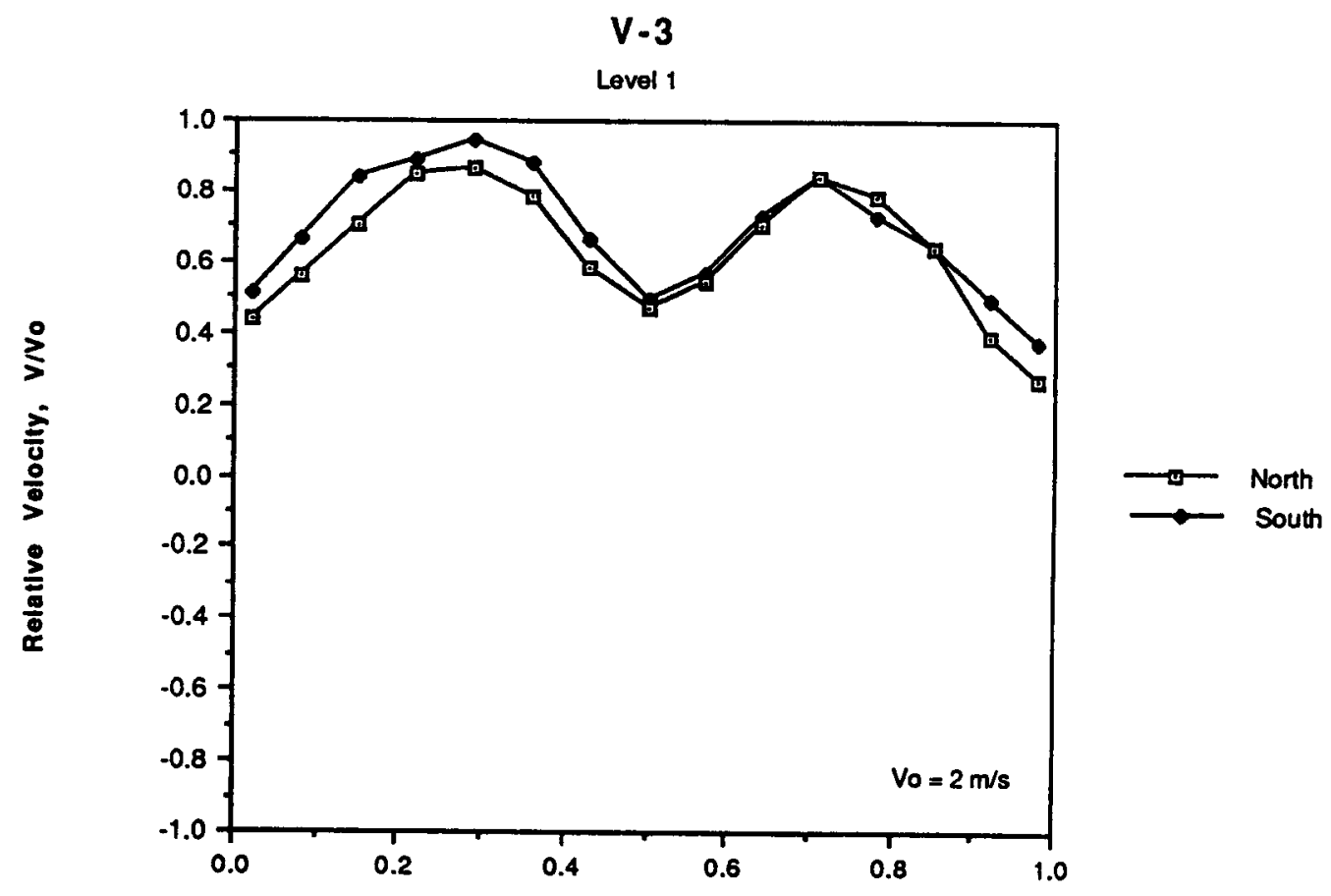

Relative distance from enst to west

FIGURE 4.16. Velocity Profiles at Levels 5 and 1 for $V-3$ 


\subsubsection{Estimated Volume Flow Rates}

Estimates of the volume flow rates were derived from the measured velocity profiles and reviewed for consistency with the flow visualization observations. Initially, all flows were assumed to be unidirectional through the diffuser and the ice-basket section. Visualization in the diffuser was not possible, hence any anomaly in the diffuser flow, such as direction, would have to be established by deduction. The flow rate analyses of $V-1$ will be considered in some detail. The analyses of $V-2$ and $V-3$ will then follow.

As described above, the condition $V-1$ yielded the observation of strong downflow in the southwest quadrant at Level 5 of the ice-basket test section. The volumetric flow rates derived from the velocity profiles for $V-1$ at Levels 1 and 5 of the ice-basket test section are presented in Table 4.3. Note that the total volume flow rate at Level 5 was greater than that at Level 1 . In addition, the total volume flow rate at Level 1 compared more favorably with the expected nominal flow rate, $0.14 \mathrm{~m}^{3} / \mathrm{s}$. The flows at both Levels 1 and 5 were apparently evenly distributed between the flow quadrants. The estimated out let volume flow rate of the diffuser, Table 4.3, exceeded both the approximate inlet volume flow rate and the estimated volume flow rate at Level 5. Finally, the observed strong downflow in the SW quadrant must be reconciled with the estimated volume flow rates at Level 5 and in the diffuser outlet.

First, on the basis of the observed strong downflow, the direction of flow in the southwest quadrant was assigned a downward direction. The sum of the remaining three upward flow quadrants, (NE, NW, and SE) was comparable to both the approximate inlet and Level 1 volume flow rates. Second, based on the shape of the velocity profile, the observed downward direction of flow in the southwest quadrant at Level 5 , and the excessive estimated total diffuser

\section{TABLE 4.3. Estimated Volumetric Flow Rates for V-1}

Location

Diffuser outlet

Level 5 by quadrant:

Northeast

Northwest

Southeast

Southwest

Total

Level 1 by quadrant:

Northeast

Northwest

Southeast

Southwest

Total \begin{tabular}{c}
$\begin{array}{c}\text { Estimated } \\
\mathrm{m}^{3} / \mathrm{s}\end{array}$ \\
\hline
\end{tabular}

0.22

0.051

0.054

0.051

0.048

0.20

0.044

0.043

0.046

0.042

0.18 
volume flow rate, the flow in the lower region of the diffuser was deduced to have been directed back towards the downcomer, i.e. reverse of the inlet flow. The revised diffuser pattern yielded an upper region flow rate nearly equal to the revised Level 5 upward flow rate. The estimated volume flow rate through the bottom section of the diffuser exceeded, but was similar to the estimated strong downward volume flow rate of the SW quadrant at Level 5. Figure 4.17 is the revised velocity profile for V-1 Level 5 and the diffuser that incorporate the directional changes.

In general, the preceding discussion highlights guidelines for interpretation of the results of the estimated volumetric flow rates. First, discrepancies between the estimated volume flow rates of Levels 1 and 5 indicated that an assumption of the estimate, such as flow direction was suspect. Second, excessive diffuser volume flow rate also indicated that an assumption of the estimate, such as flow direction, was suspect. Third, the flow distribution pattern, by itself, was not a reliable indicator of flow direction anomalies.

Consider now condition $V-2$, heated air at approximately $0.14 \mathrm{~m}^{3} / \mathrm{s}$. The estimated volume flow rates at Levels 1 and 5 of the ice-basket test section and the midway down the diffuser are presented in Table 4.4. Obvious discrepancies included the maldistribution of flow at both Level 1 and 5 and that the estimated volume flow rate at Level 1 exceeded the estimate at Level 5. The estimated diffuser volume flow rate for V-2 was comparable to the original diffuser flow rate estimate for $\mathrm{V}-1$ and exceeded the approximate inlet flow rate. The discrepancy between the Level 1 and Level 5 estimated flow rates can be attributed, at least in part, to the increase in available flow area at Level 5 caused by the loss of ice inventory noted in the test records. All of the volume flow rate estimates were computed using the same available flow area; an area corresponding to the ice baskets being full at each location. The loss of ice inventory at Level 5 increased the available flow area; it was not, however, possible to estimate this increase. The volume flow rate estimate for Level 5 employed the same flow area as the estimate for Level 1 and hence yielded a lower value than the probable actual flow rate. The flow observations for V-2 conditions were not as definitive at Leve 5 as they were for $V-1$ conditions. However, the diffuser velocity profiles for each case were quite similar. This observation coupled with the excessive flow rate led to the assertion that like the diffuser flow for $V-1$, the flow in the lower region of the diffuser for $V-2$ was directed back towards the downcomer. Evaluating the diffuser flow rate to account for the reverse direction flow yielded results that were similar to those reported for $v-1$. The revised diffuser pattern yielded an upper region flow rate nearly equal to the revised Level 1 upward flow rate. Though not observed and not as obvious from a volumetric flow basis because of the inability to account for the increased flow area, it is probable that for at least part of the time, some portion of the Level 5 flow for $V-2$ was downward. Figure 4.18 presents the revised version of the diffuser velocity profile for $v-2$. 


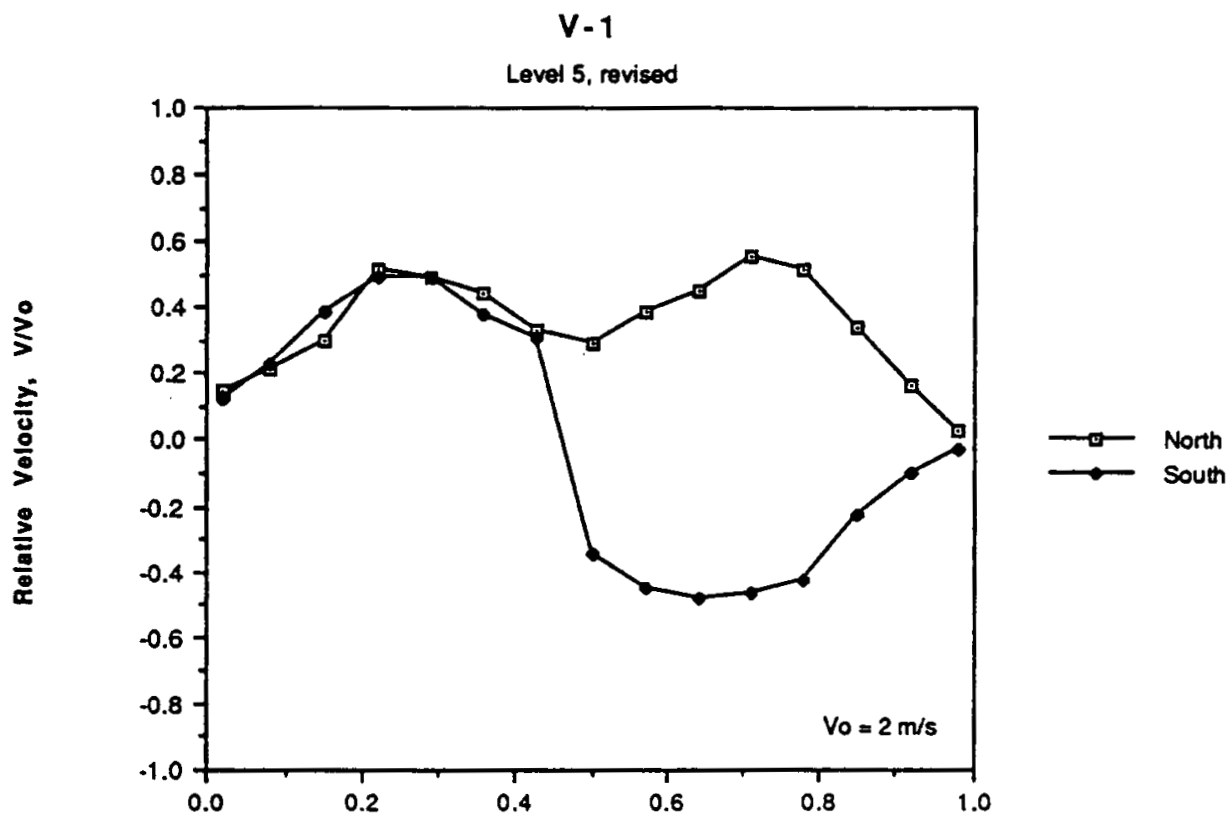

Relative distance from east to west

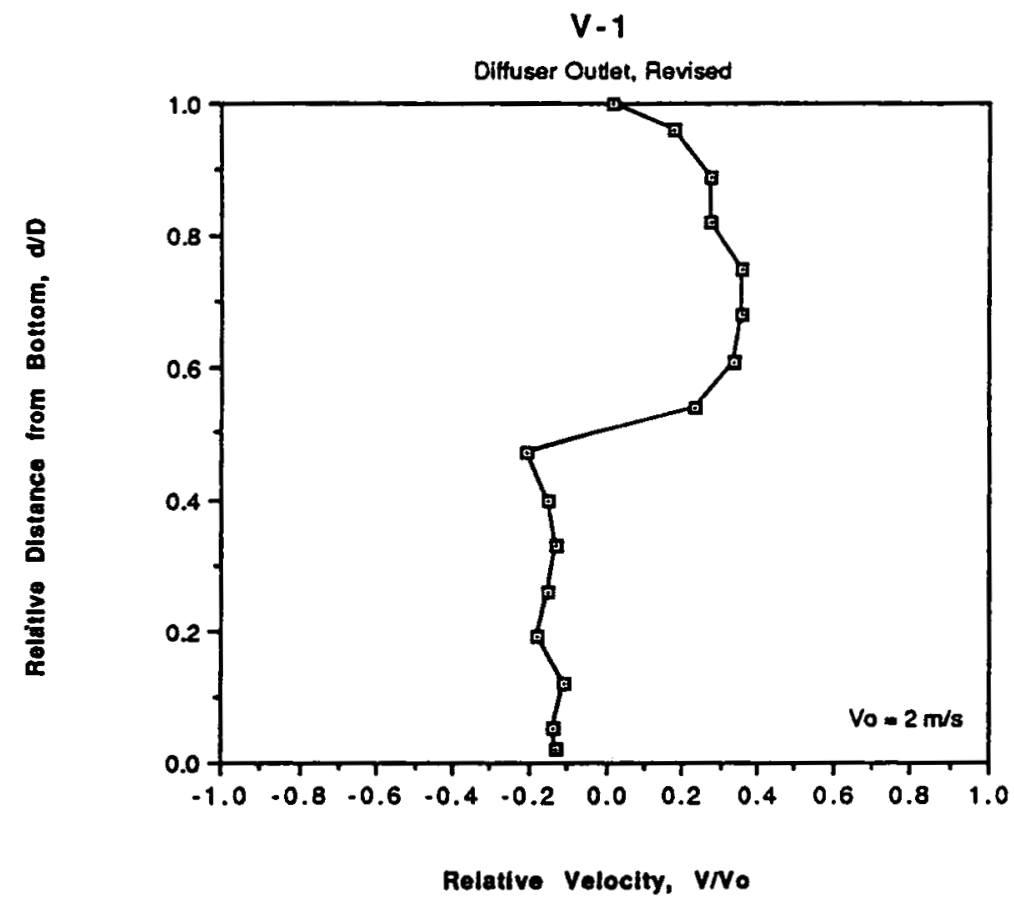

FIGURE 4.17. Revised Velocity Profile for V-1 Level 5 and the Diffuser 
TABLE 4.4. Estimated Volumetric Flow Rates for V-2

\begin{tabular}{l} 
Location \\
\hline Diffuser midspan \\
Leve1 5 by quadrant \\
Northeast \\
Northwest \\
Southeast \\
Southwest \\
Total \\
Leve1 1 by quadrant \\
Northeast \\
Northwest \\
Southeast \\
Southwest \\
Total
\end{tabular}

$\underset{\mathrm{m}^{3} / \mathrm{s}}{\text { Estimated Rate, }}$

$$
0.27
$$

0.057

0.033

0.032

0.016

0.14

0.051

0.051

0.031

0.035

0.16

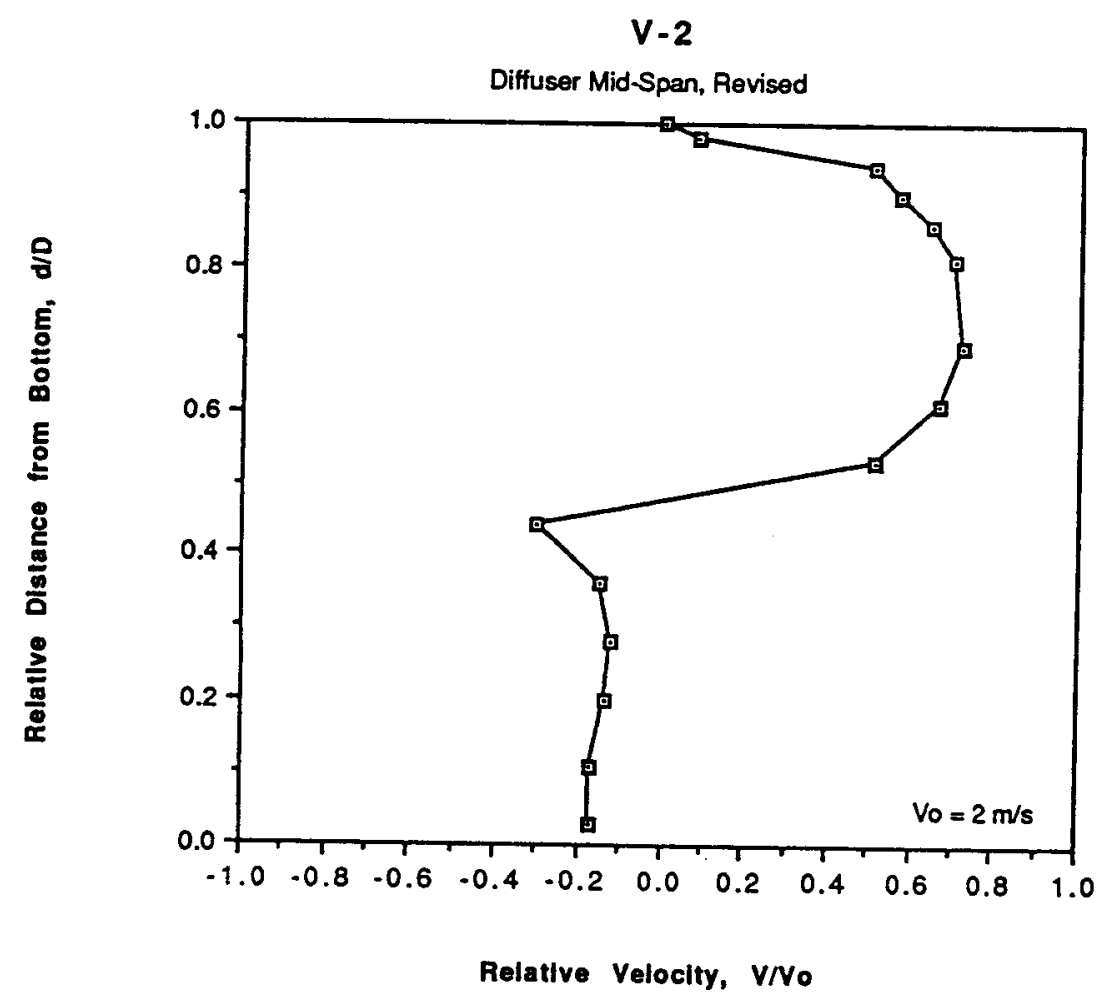

FIGURE 4.18. Revised Version of the Diffuser Velocity Profile for V-2 
The last set of volume flow estimates, Table 4.5 , is associated with $v-3,0.3 \mathrm{~m} / \mathrm{s}$ unheated, measurements. As with the velocity profiles the estimated volume flow rate results were congruent with expectations. The estimated volume flow rates at Leve1 1, Leve 15 , and the diffuser outlet agreed quite well with each other. The only notable characteristic was the slight change in the even flow distribution from Level 5 to Level 1 . The estimated volume flow rate results were consistent with the finding that for $V-3$, the diffuser and ice-basket section flows are unidirectional. None of the V-3 figures required revision.

\subsubsection{Velocity Measurement Summary}

In summary, the following observations were made as part of the series of velocity measurement tests and subsequent analyses. At moderate total volume flow rate $\left(0.14 \mathrm{~m}^{3} / \mathrm{s}\right)$ reverse flow occurred in the diffuser. Flow magnitude measurements and the history of a relatively cold region in the bottom half of the diffuser duct led to the deduction that the cold region was actually flowing back towards the downcomer. Downflow was observed in the ice-basket section at moderate noncondensible volume flow rates (approximately $0.14 \mathrm{~m} / \mathrm{s}$ ). The ice-basket section downflow and cold reverse flow in the diffuser were eliminated at higher noncondensible volume flow rates (approximately $0.3 \mathrm{~m}^{3} / \mathrm{s}$ ).

\subsubsection{Tests 8 through 14}

In the last seven tests (Tests 8 through 14) thermocouple rakes were installed in the ice-basket section to provide better definition of the thermal profiles. In addition, Tests 9, 10, and 11 were relatively high

TABLE 4.5. Estimated Volumetric Flow Rates for $V-3$

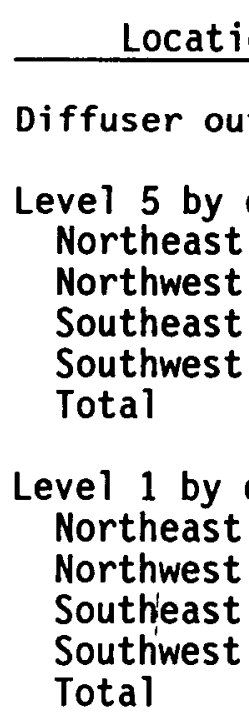

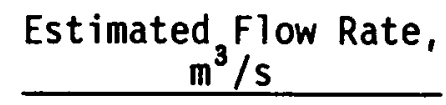

0.34

0.10

0.10

0.10

0.10

0.40

0.09

0.09

0.10

0.09

0.37 
flow rate tests. Tests 8 through 14 provided verification of observations made during the first seven tests, as well as additional insight into relatively high steam content tests.

\begin{tabular}{rcccc} 
Test & $\begin{array}{c}\text { Stęam, } \\
\mathrm{m}^{3} / \mathrm{s}\end{array}$ & $\begin{array}{c}\text { Air } \\
\mathrm{m}^{3} / \mathrm{s}\end{array}$ & $\begin{array}{c}\text { Toţal, } \\
\mathrm{m}^{3} / \mathrm{s}\end{array}$ & $\begin{array}{c}\text { T630, } \\
{ }^{\circ} \mathrm{C}\end{array}$ \\
\cline { 6 - 6 } 8 & 0.10 & 0.12 & 0.22 & 126 \\
9 & 0.35 & 0.04 & 0.39 & 112 \\
10 & 0.40 & 0.04 & 0.44 & 121 \\
11 & 0.34 & 0.04 & 0.38 & 105 \\
12 & 0.017 & 0.057 & 0.07 & 92 \\
13 & 0.02 & 0.05 & 0.07 & 111 \\
14 & 0.02 & 0.09 & 0.11 & 115 \\
& 0.08 & 0.04 & 0.12 & 121
\end{tabular}

The conditions of Test 8 were planned to duplicate the target conditions of both Tests 1 and 4 . The thermal profiles of the ice-basket section of Test 8 corresponded well with the data available from Tests 1 and 4 . The profile of Level 5 for Test 8, Figure 4.19, is stratified north to south. At Level 1 , the north-south stratification was weaker (relative to the stratification at Level 5 but still evident. As expected, the diffuser profile of Test 8 (Figure 4.20 ) shows that the diffuser outlet was stratified and, except for the bottom, the square duct was essentially isothermal. The complete ice-basket section thermal profiles of Test 8 verified the previously observed flow stratification and the link between the diffuser and ice-basket section flow field.

Completion of relatively high total flow rate and high steam fraction cases, Tests 9, 10, and 11 provided additional insight into the behavior of the diffuser at relatively high volume flow rates and the ice-basket section at relatively low noncondensible flow rates. Unfortunately, during Test 10 , the computer-based DAS failed to store the bulk of the test data. Thus, the following discussion is based on Tests 9 and 11 . The limited data of Test 10 does tend to support the observations based on review of Tests 9 and 11 .

The diffuser profiles of both Tests 9 and 11 (Figures 4.21 and 4.22) indicate that the diffuser outlet was not stratified under relatively high total volume flow rate conditions. The diffuser outlet stratification observed at the beginning of Test 11 was attributed to a boiler transient that temporarily and intermittently reduced the total diffuser volumetric flow rate. The rapid formation and breakup of the stratification is noteworthy. Once the boiler operation was stabilized during Test 11, the diffuser outlet profile showed no stratification.

The ice-basket section thermal profiles of Tests 9 and 11 exhibited similar trends. Review of the ice-basket section thermal profiles for Tests 9 and 11 (Figures 4.23 and 4.24 ) must consider that data for Test 11 were collected at a higher frequency than Test 9 . The profiles of Test 11 appear 
Test 8

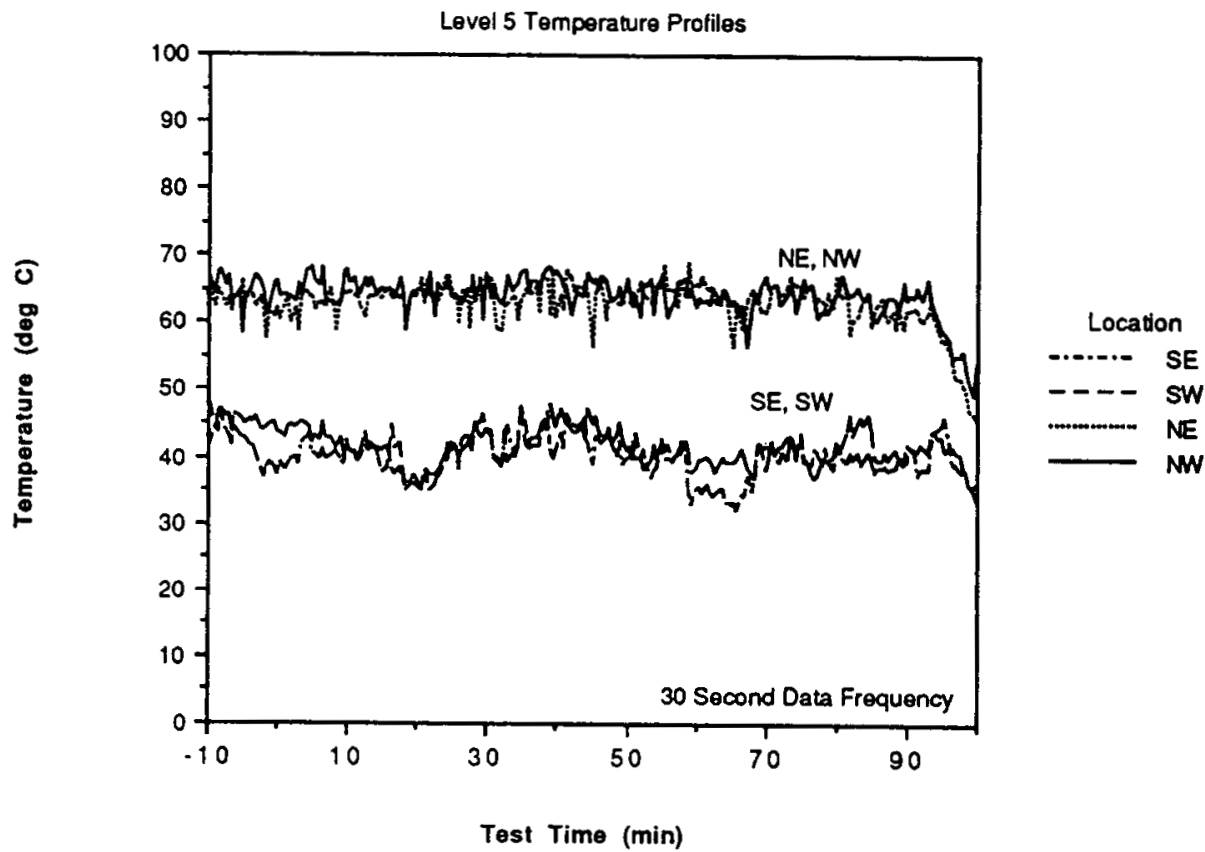

Test $B$

Level 1 Temperature Profiles

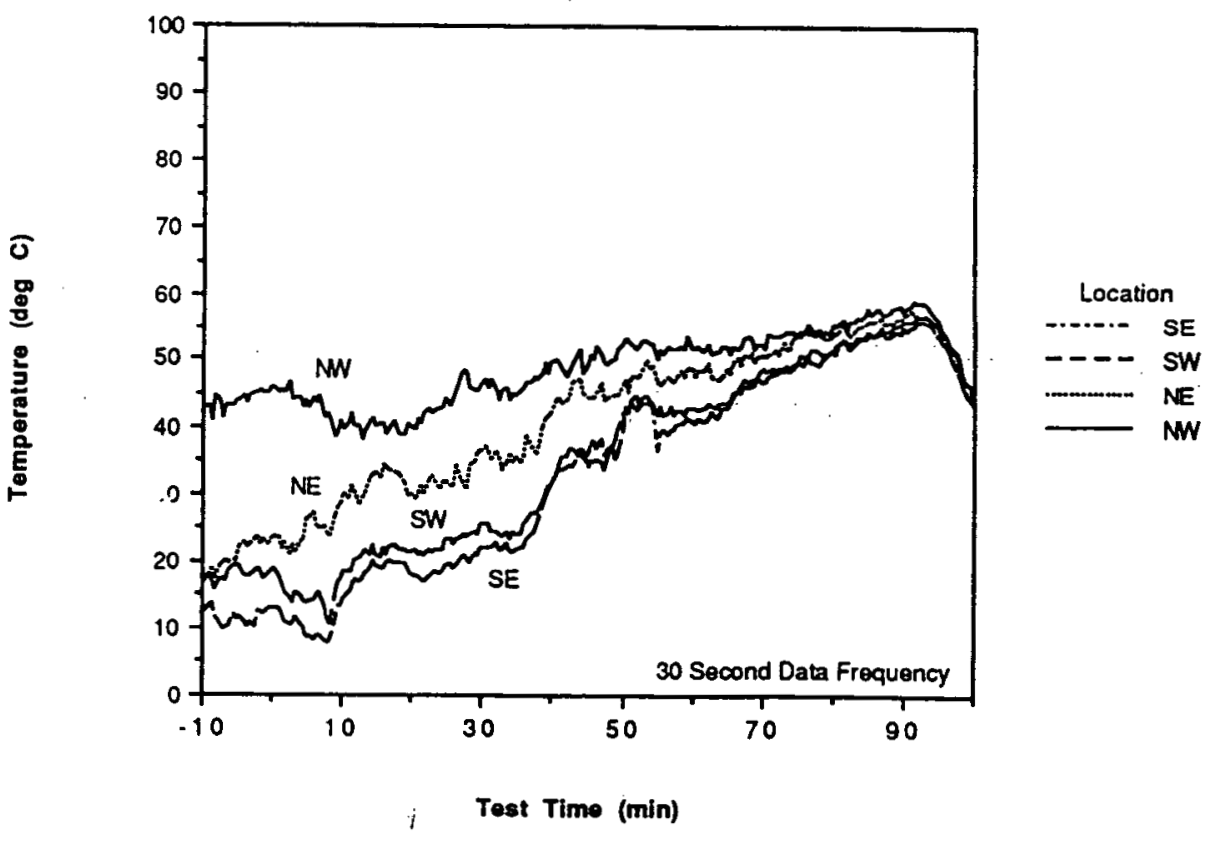

FIGURE 4.19. Ice-Basket Section Thermal Profiles, Test 8 
Test 8

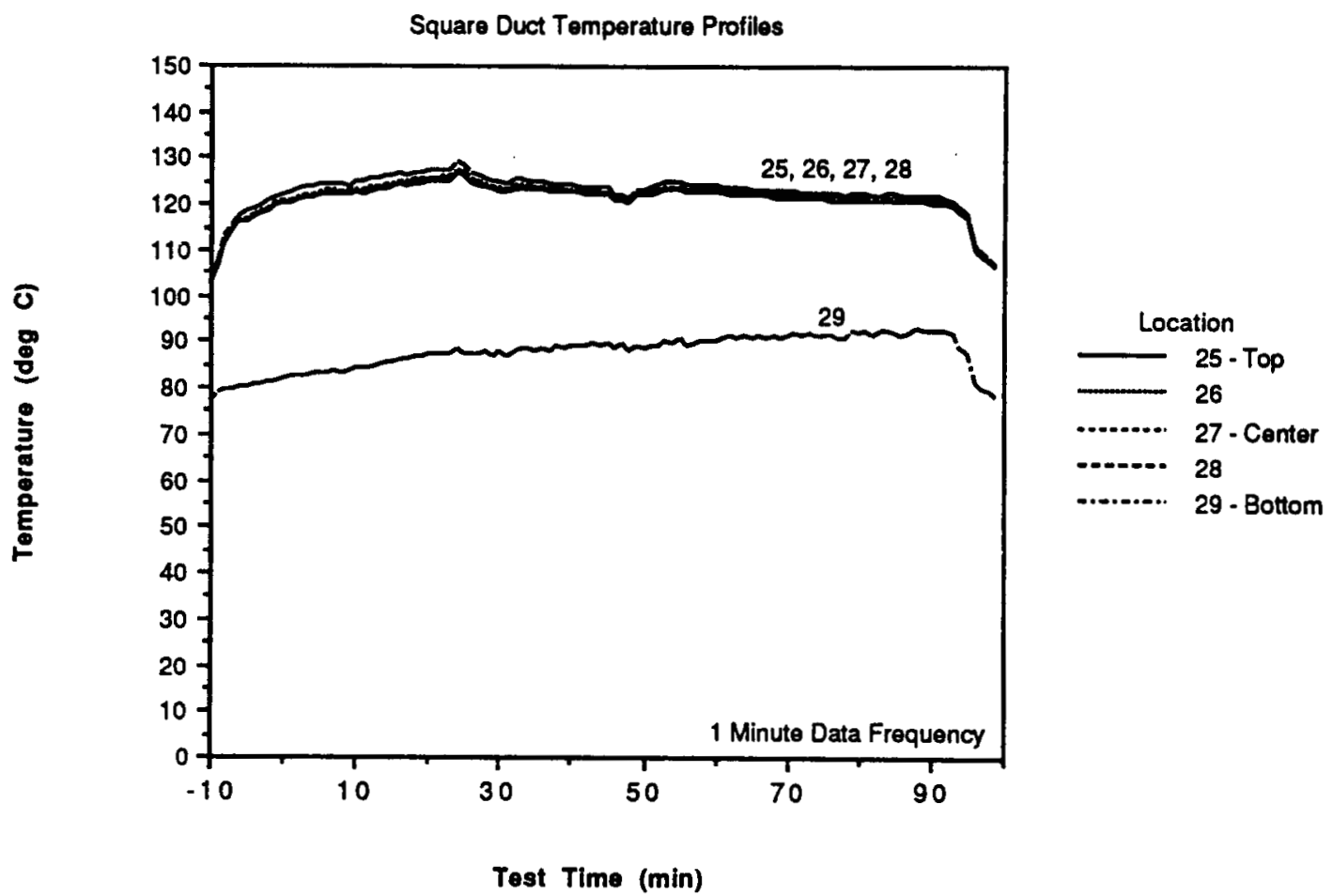

Test 8

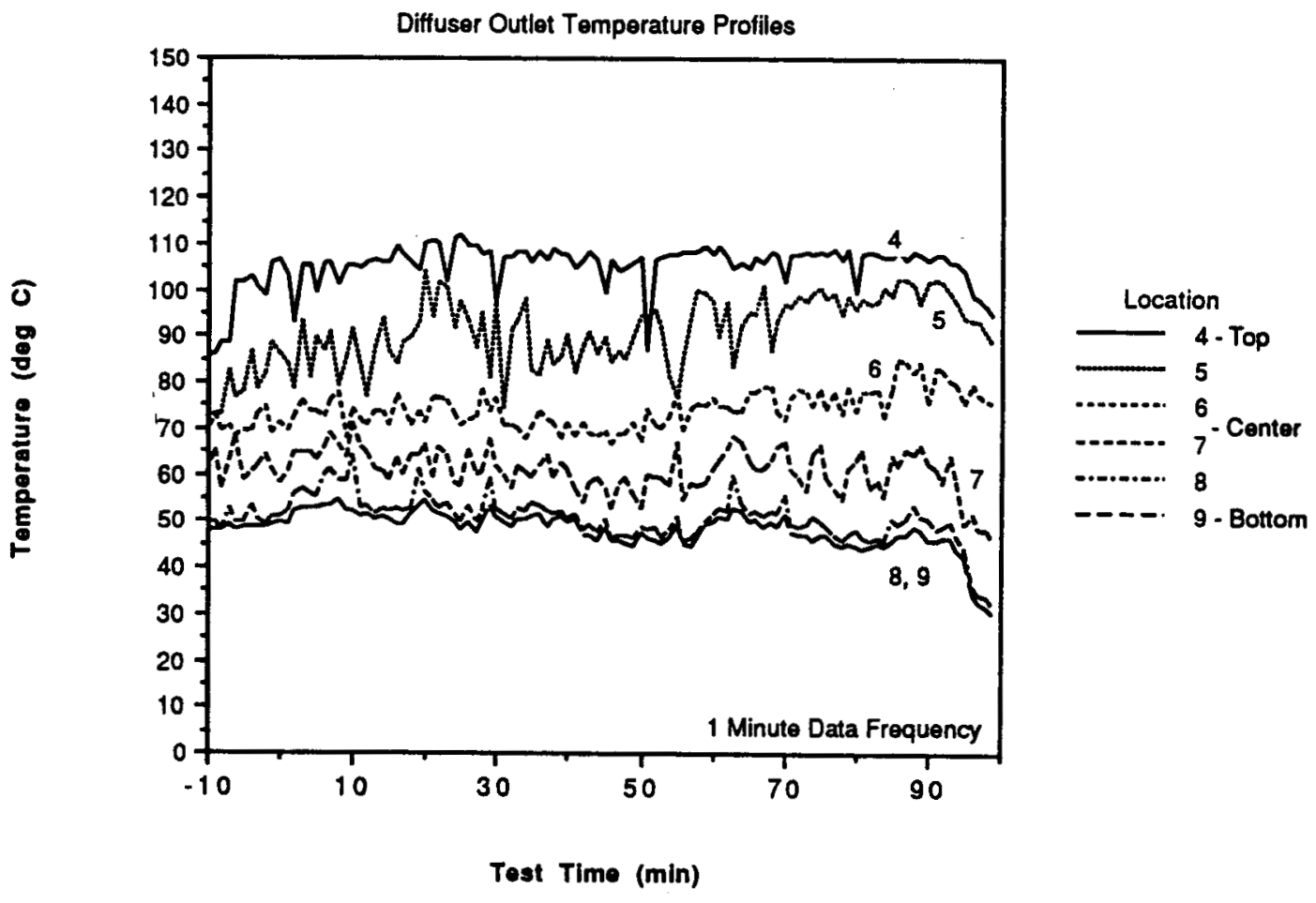

FIGURE 4.20. Diffuser Thermal Profiles, Test 8 
Test 9

Square Duct Temperature Profiles

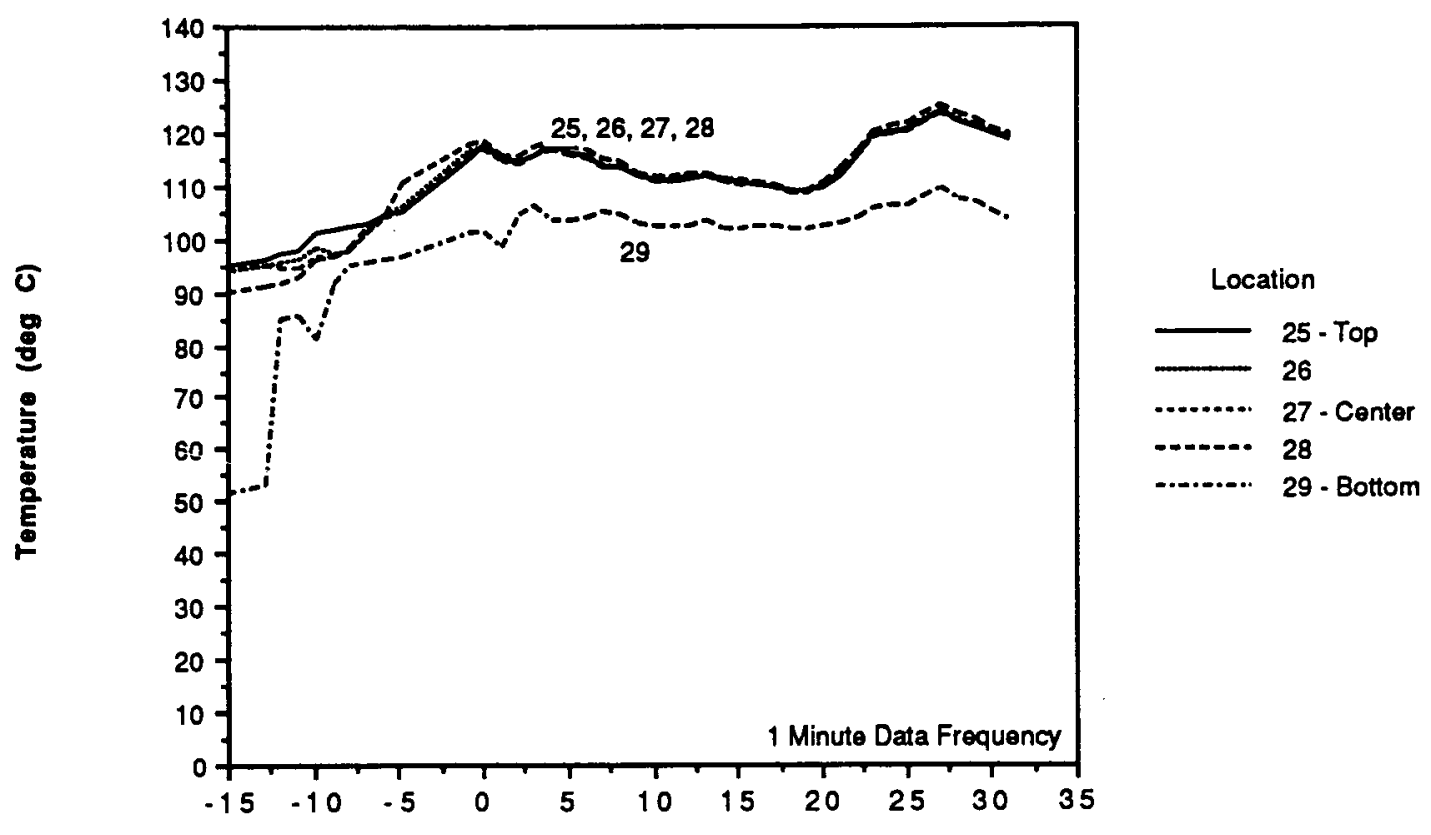

Test Time $(\mathrm{min})$

Test 9

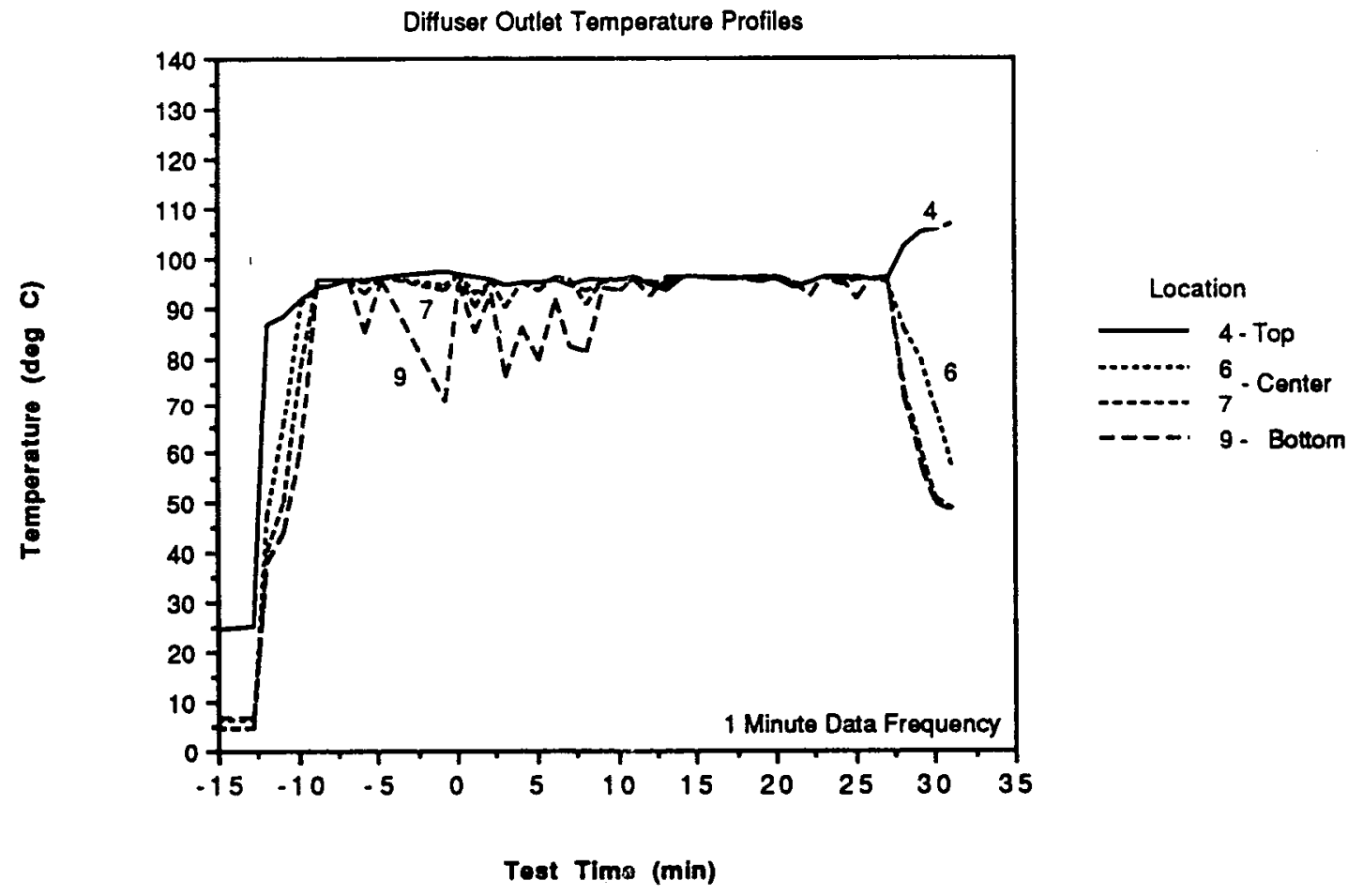

FIGURE 4.21. Diffuser Thermal Profiles, Test 9 
Test 11

Square Duct Temperature Profiles

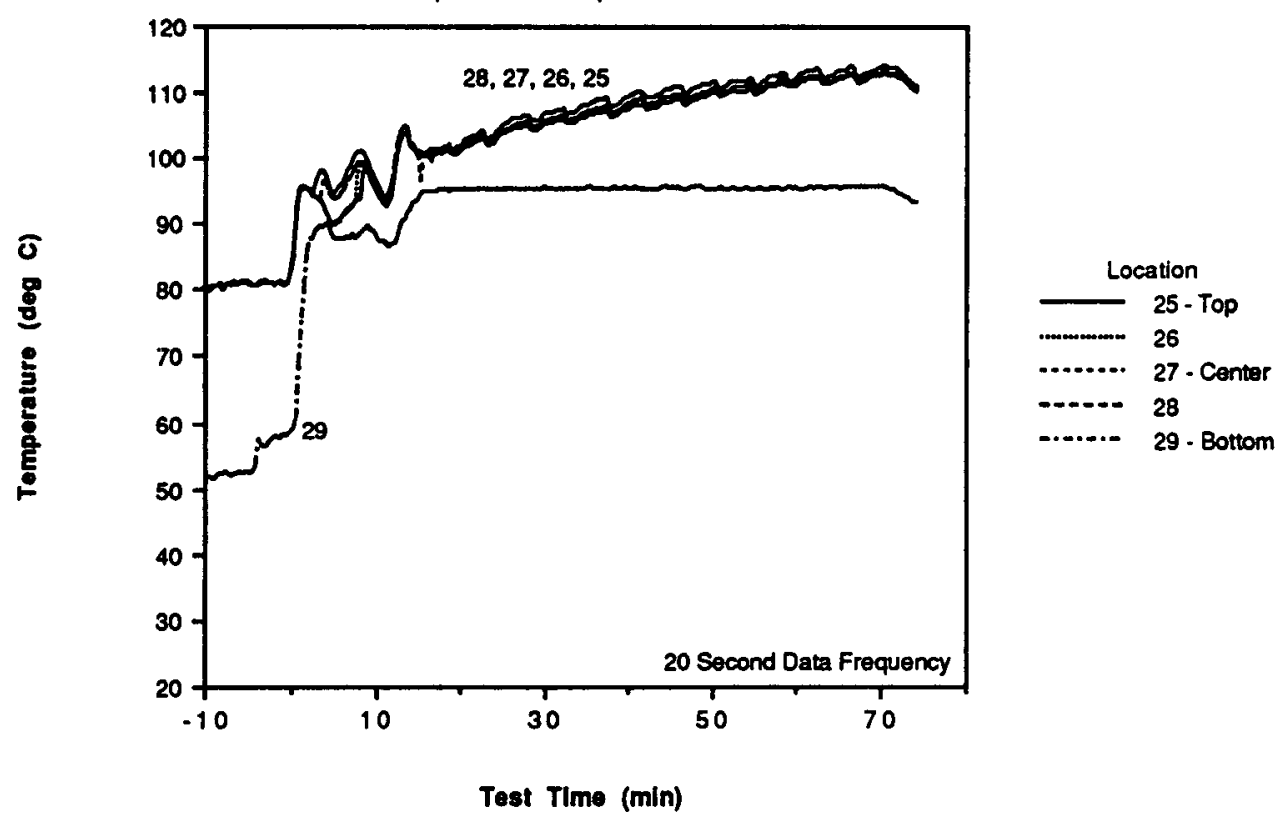

Test 11

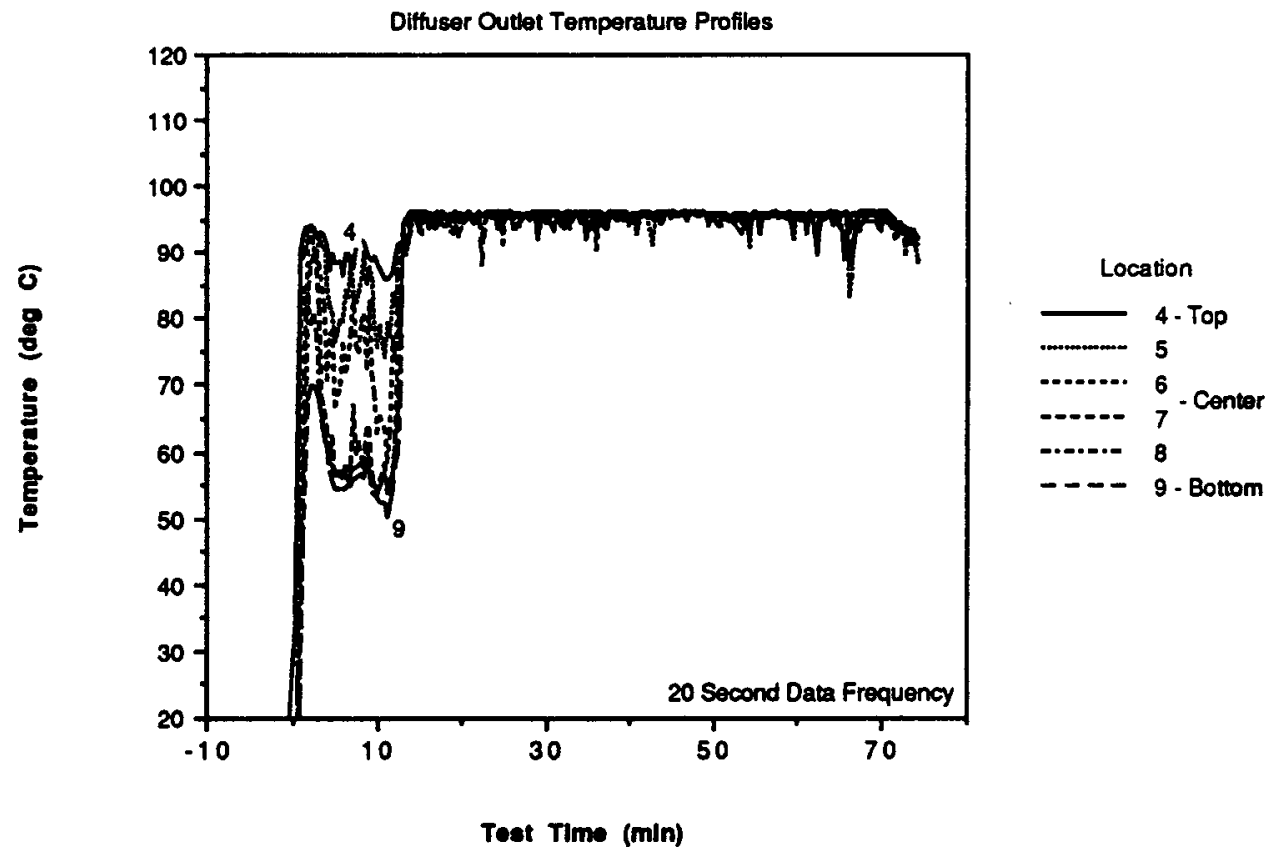

FIGURE 4.22. Diffuser Thermal Profiles, Test 11 
Test 9

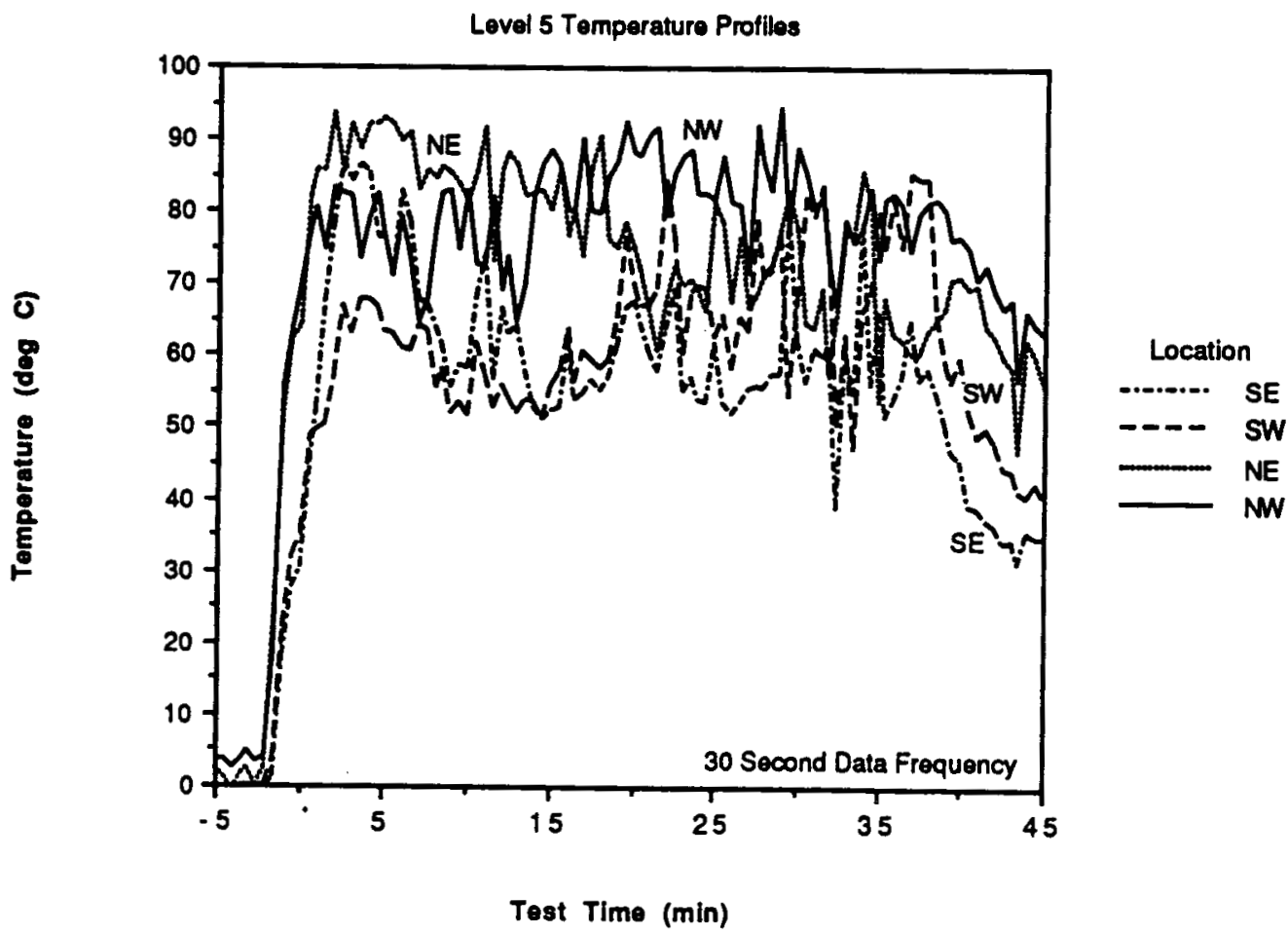

Test 9

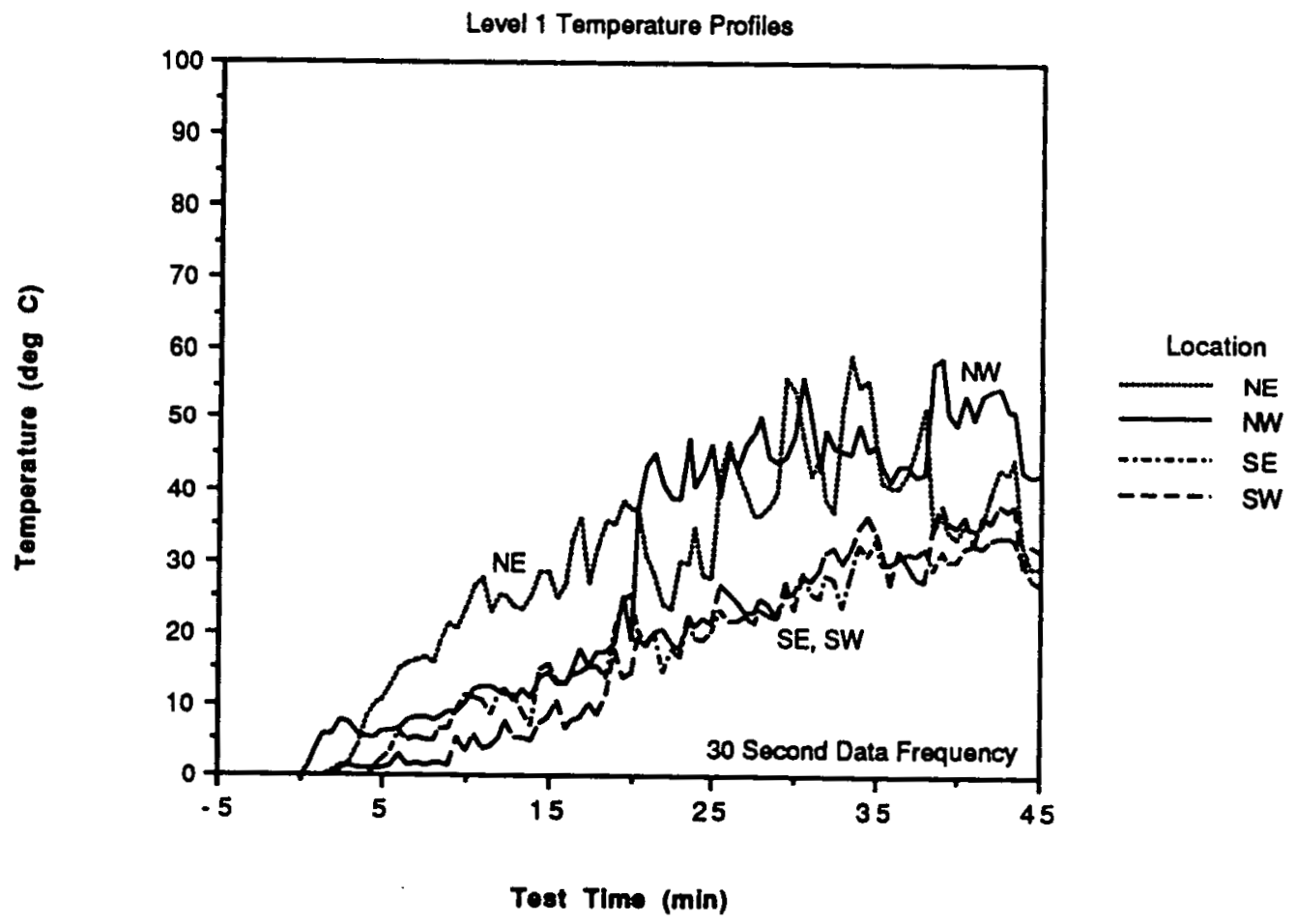

FIGURE 4.23. Ice-Basket Section Thermal Profiles, Test 9 
Test 11

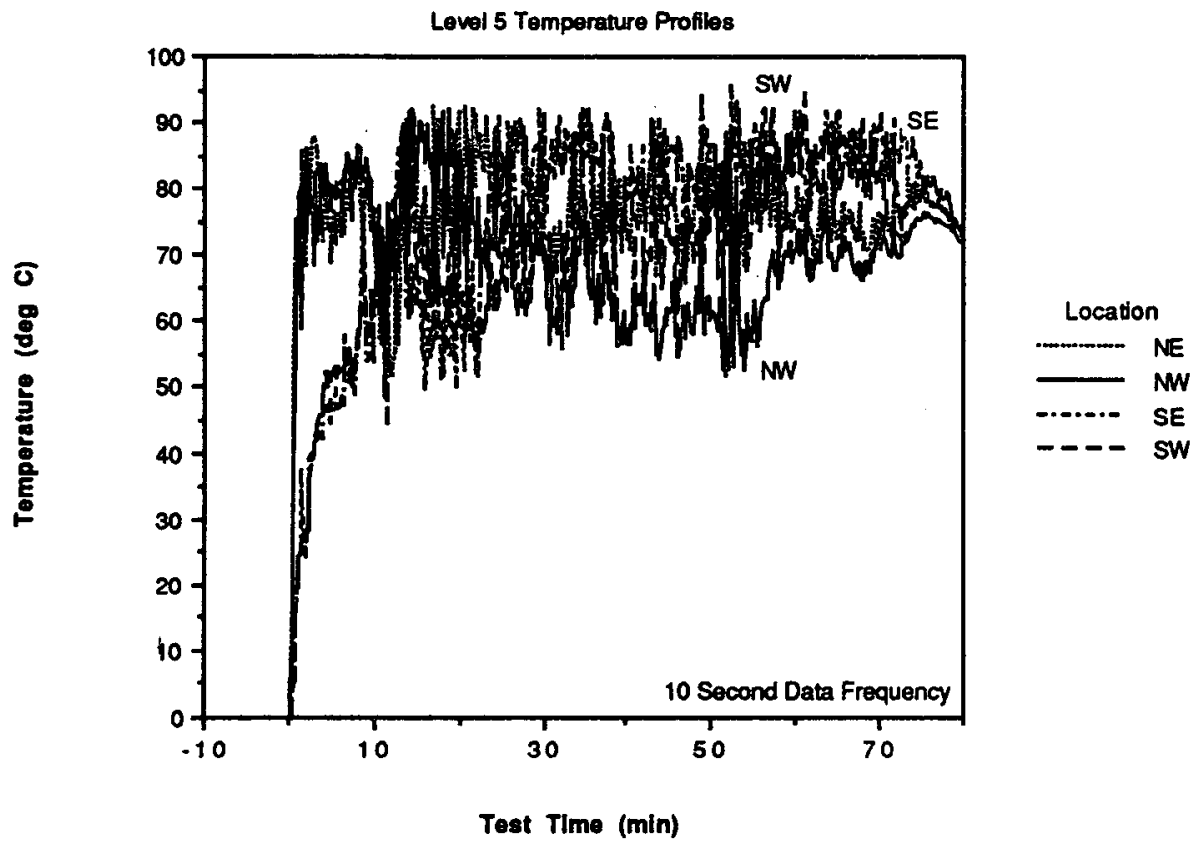

Test 11

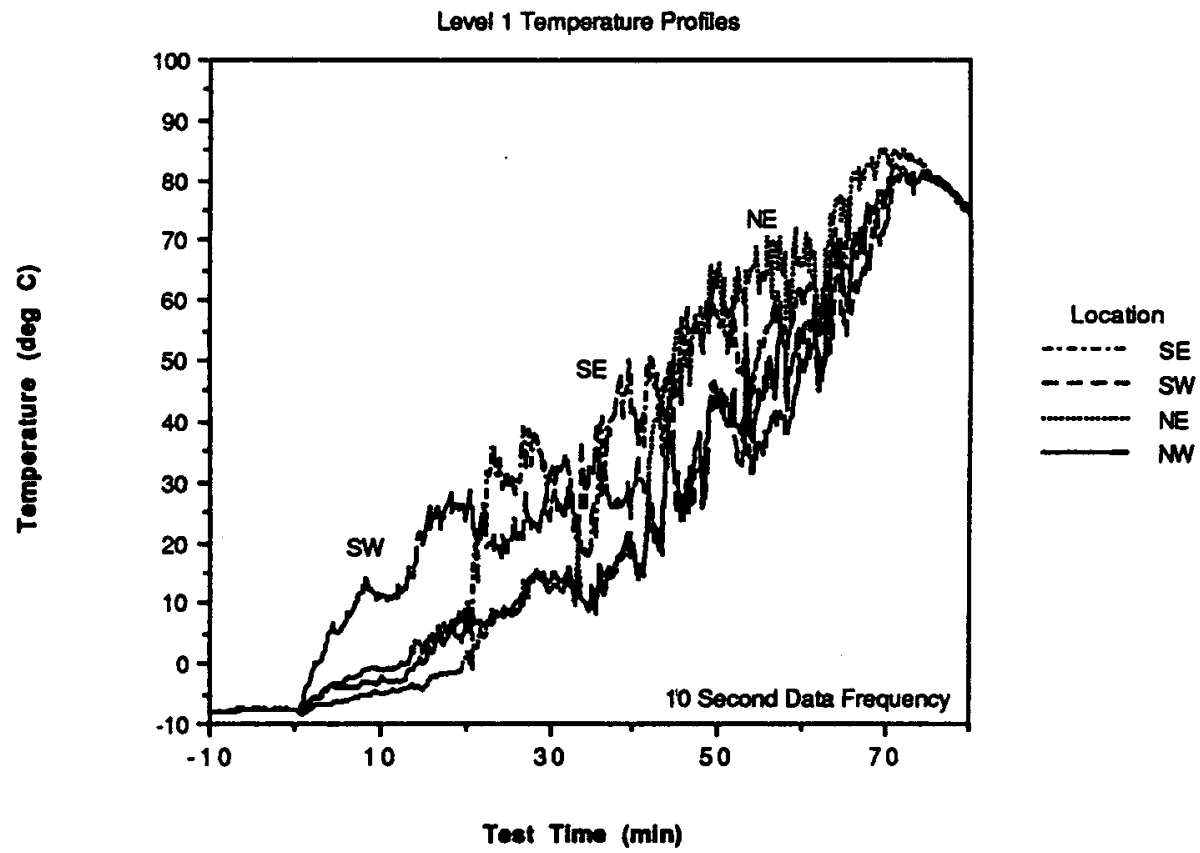

FIGURE 4.24. Ice-Basket Section Thermal Profiles, Test 11 
to fluctuate more rapidly. Unlike the previous tests, the thermal profiles at Levels 5 and 1 did not exhibit definitive stratification. Instead of stratification, the profiles implied substantial mixing. Unlike previous tests, the thermal characteristics of the test section could not be reliably predicted.

The primary thermal-hydraulic conclusions of Tests 9 and 11 are: the diffuser thermal stratification was eliminated by a relatively high total volumetric flow rate; and the ice-basket section thermal profiles for relatively low noncondensible flow rate were not characterized by stable stratification.

\subsubsection{Tests 12,13, and 14}

The inlet conditions for the final three tests were moderate total volume flow rate having relatively low condensible fraction. Thermal-hydraulic conditions for Tests 12 and 13 were quite similar, thus comparisons can be made. Test 14 was a higher volume flow rate test with two steam mole fractions and thus contrasted with Tests 12 and 13.

In all three tests, the square duct was essentially isothermal except at the bottom of the duct (Figures 4.25, 4.26, and 4.27). As seen in Tests 9 and 11 , the bottom of the duct in each test was approximately 10 to $15^{\circ} \mathrm{C}$ colder than the upper section of the duct. The temperature profiles at the square duct were similar for all three tests. The profile for Test 14 shows more spread in the upper region than seen for either Test 13 or 12 . Consistent with what has been observed before, the stratification increased and the nominal temperature of the stream decreased as the flow proceeded through the diffuser.

In the three subject tests, and unlike a number of previous tests when stratification in the diffuser had been observed, the diffuser outlet did not exhibit intermediate isotherms between the highest (generally the top) and the lowest (bottom) temperatures. Instead, four of the possible six profiles (one thermocouple was not operational) were grouped approximately $50^{\circ}$ to $60^{\circ} \mathrm{C}$ below the warmest region (top of the duct). Based on the results of $V-1$ and the thermal profiles at Level 5 (Figures $4.28,4.29$, and 4.30), a region of cold air (a large portion of the duct during the subject tests) is asserted to have flowed back towards the downcomer. The diffuser outlet profiles observed in Tests 12, 13, and 14 were similar to the profile observed for Test 7.

Test section thermal profiles for Tests 12, 13, and 14 exhibited characteristics of both types (high and low noncondensible flows) of previously observed ice-basket section behavior. It had been noted that, in general and as long as ice was present in the columns, the ice-basket section profiles were related to the noncondensible fraction in the gas stream. In general, the less noncondensible gas in the stream, the more prone the profiles were to exhibit the "crossover" of quadrant temperatures and eventual switching of quadrant thermal order. Again, in general and as long as there was ice 
Test 12

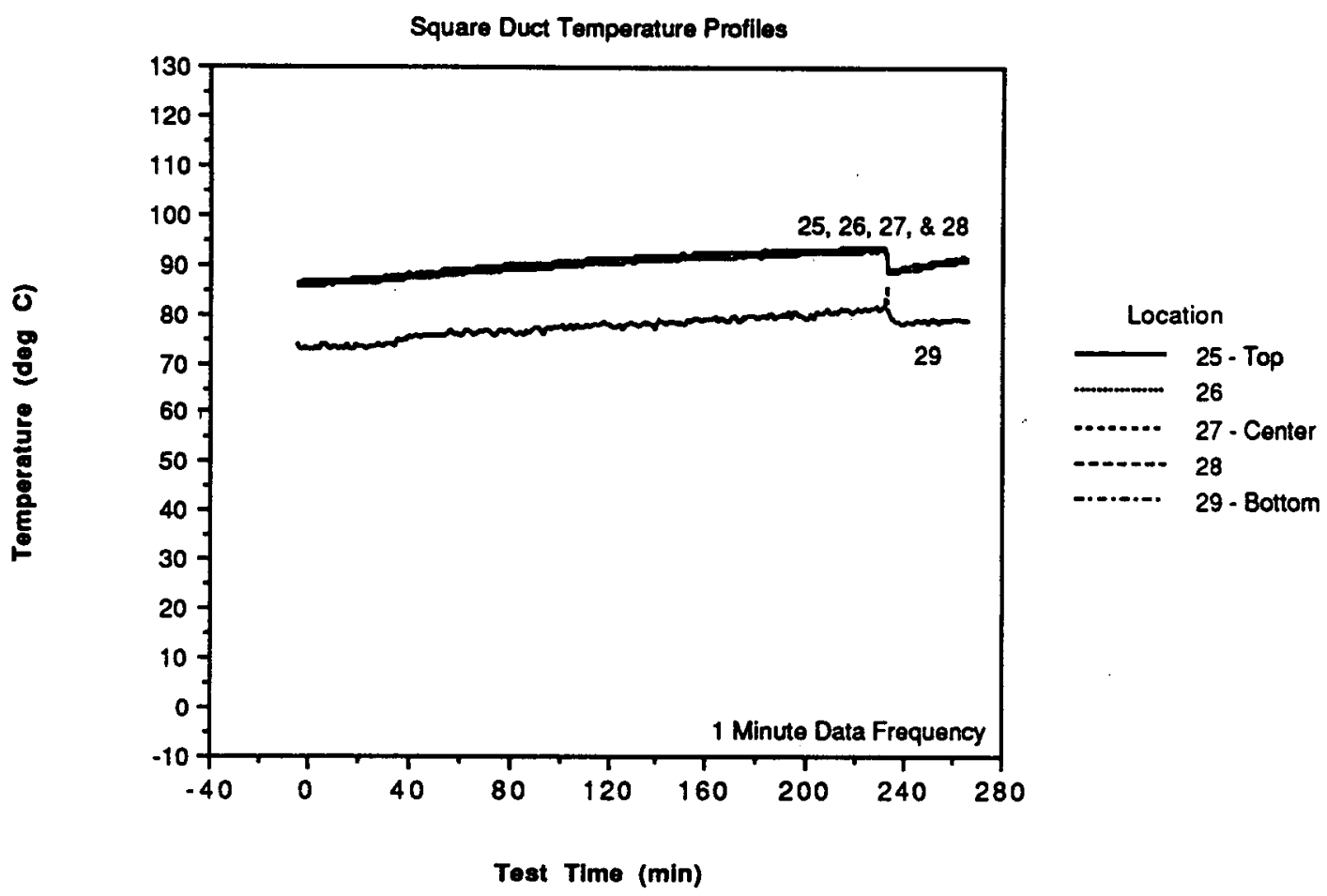

Test 12

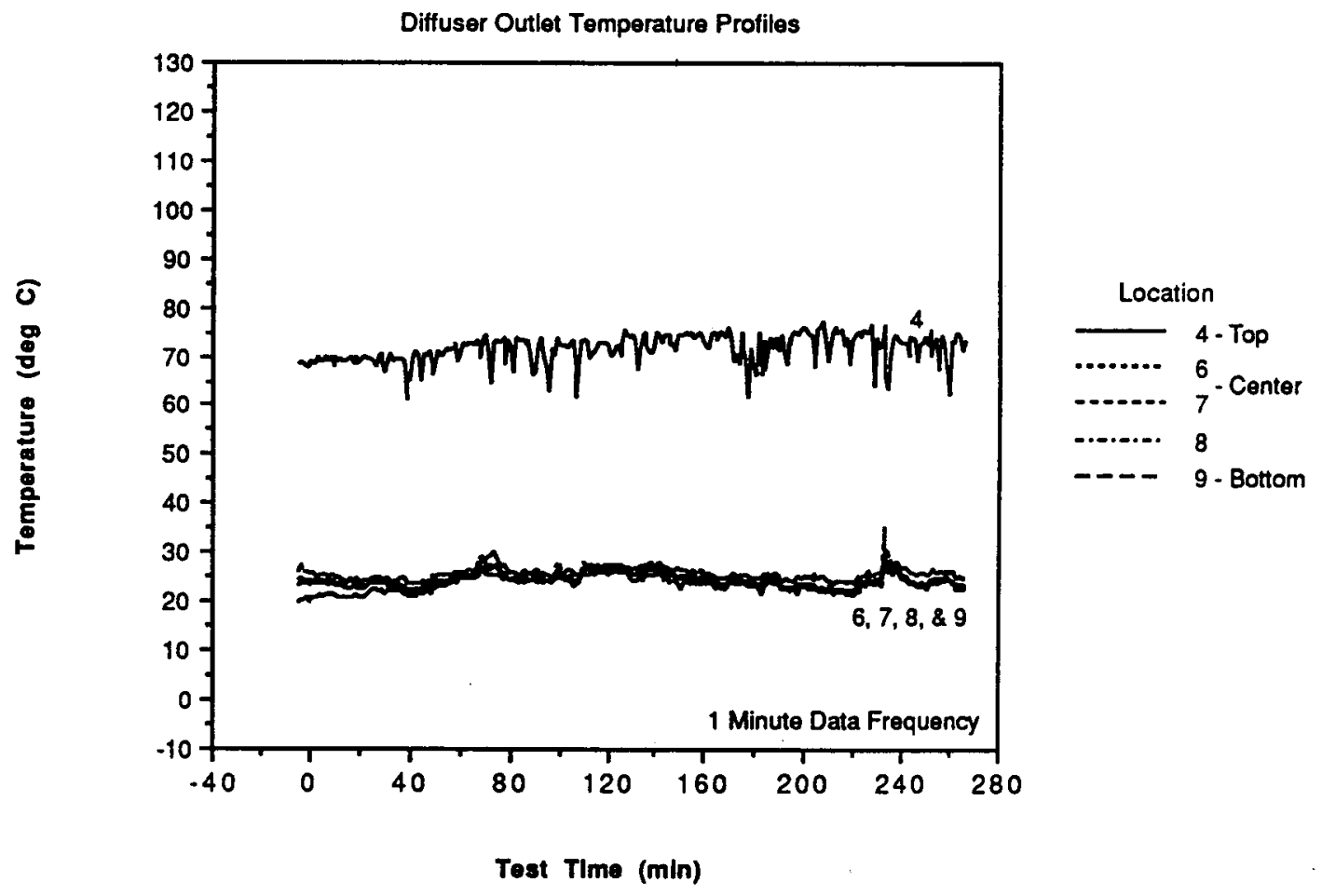

FIGURE 4.25. Diffuser Thermal Profiles, Test 12 
Test 13

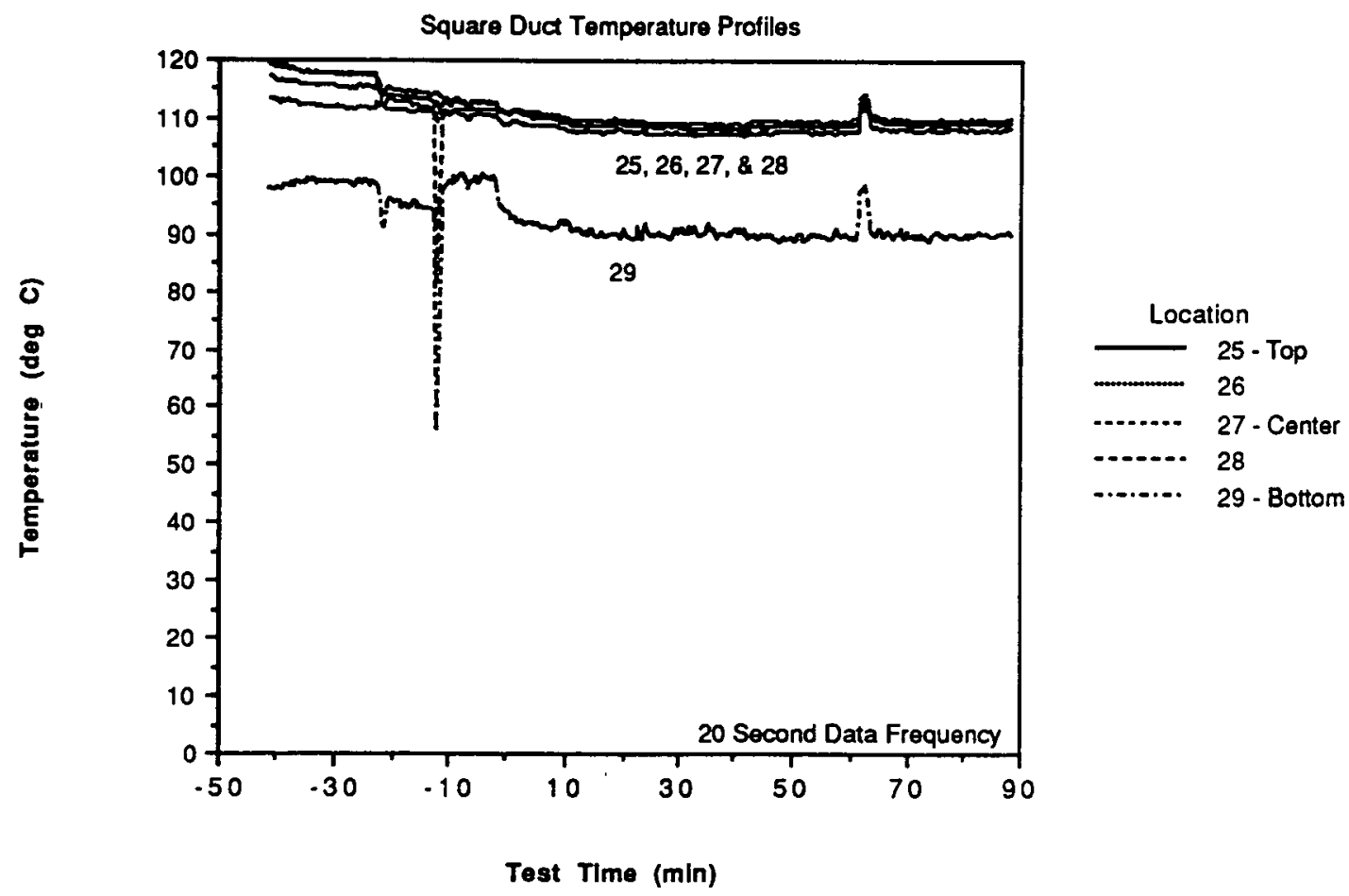

Test 13

Diffuser Outlet Temperature Protiles

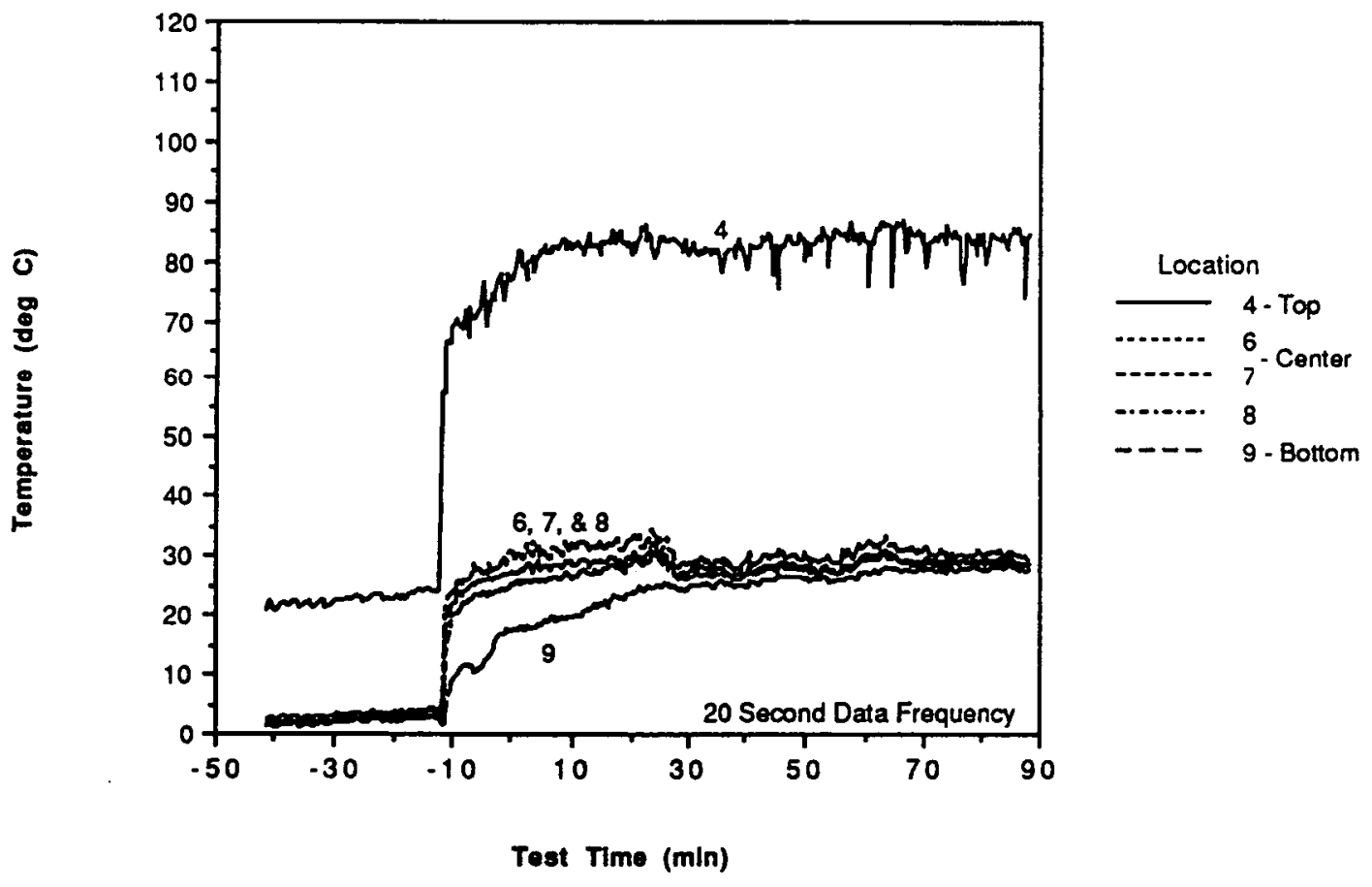

FIGURE 4.26. Diffuser Thermal Profiles, Test 13 
Test 14

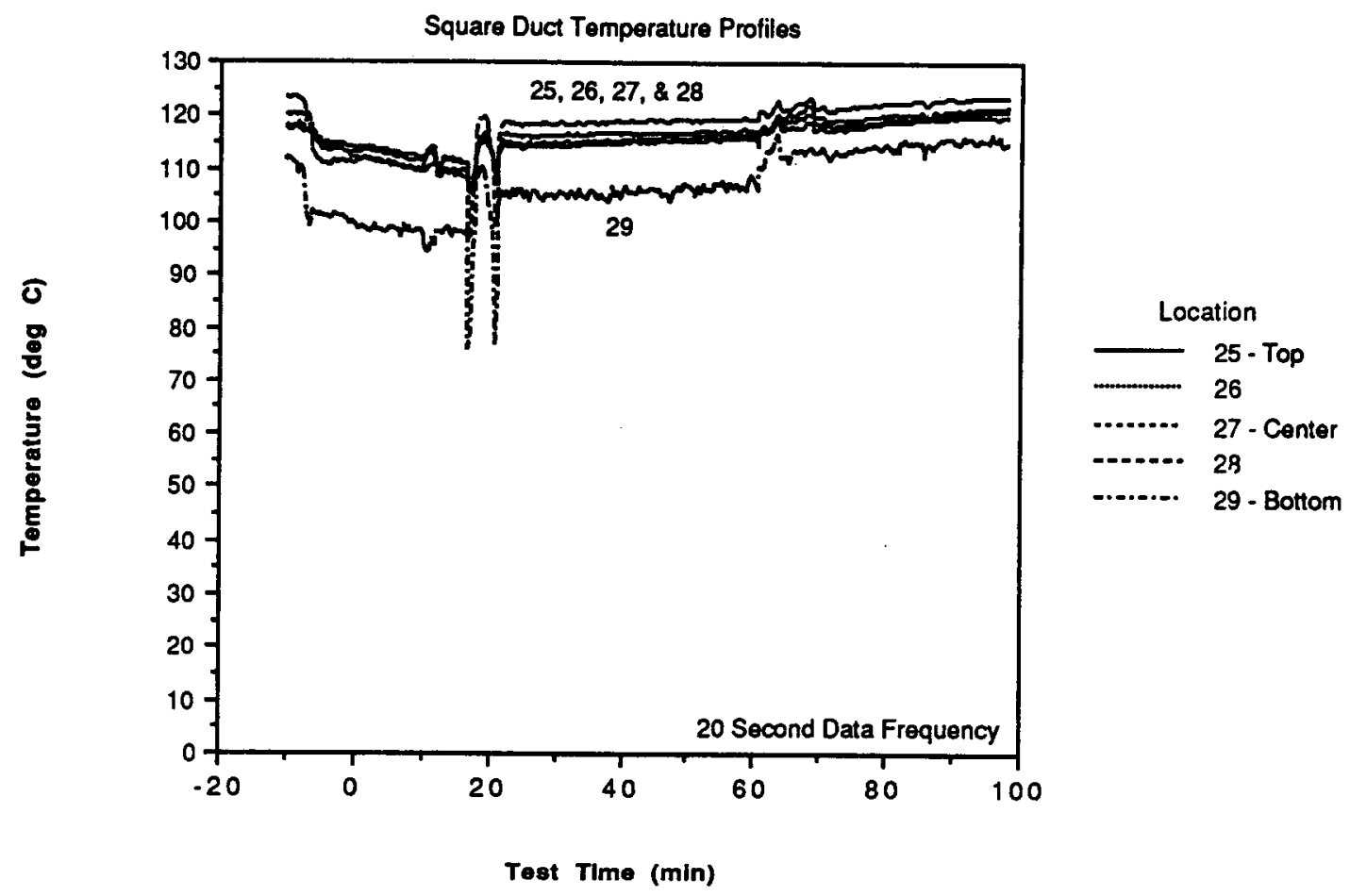

Test 14

Diffuser Outlet Temperature Profiles

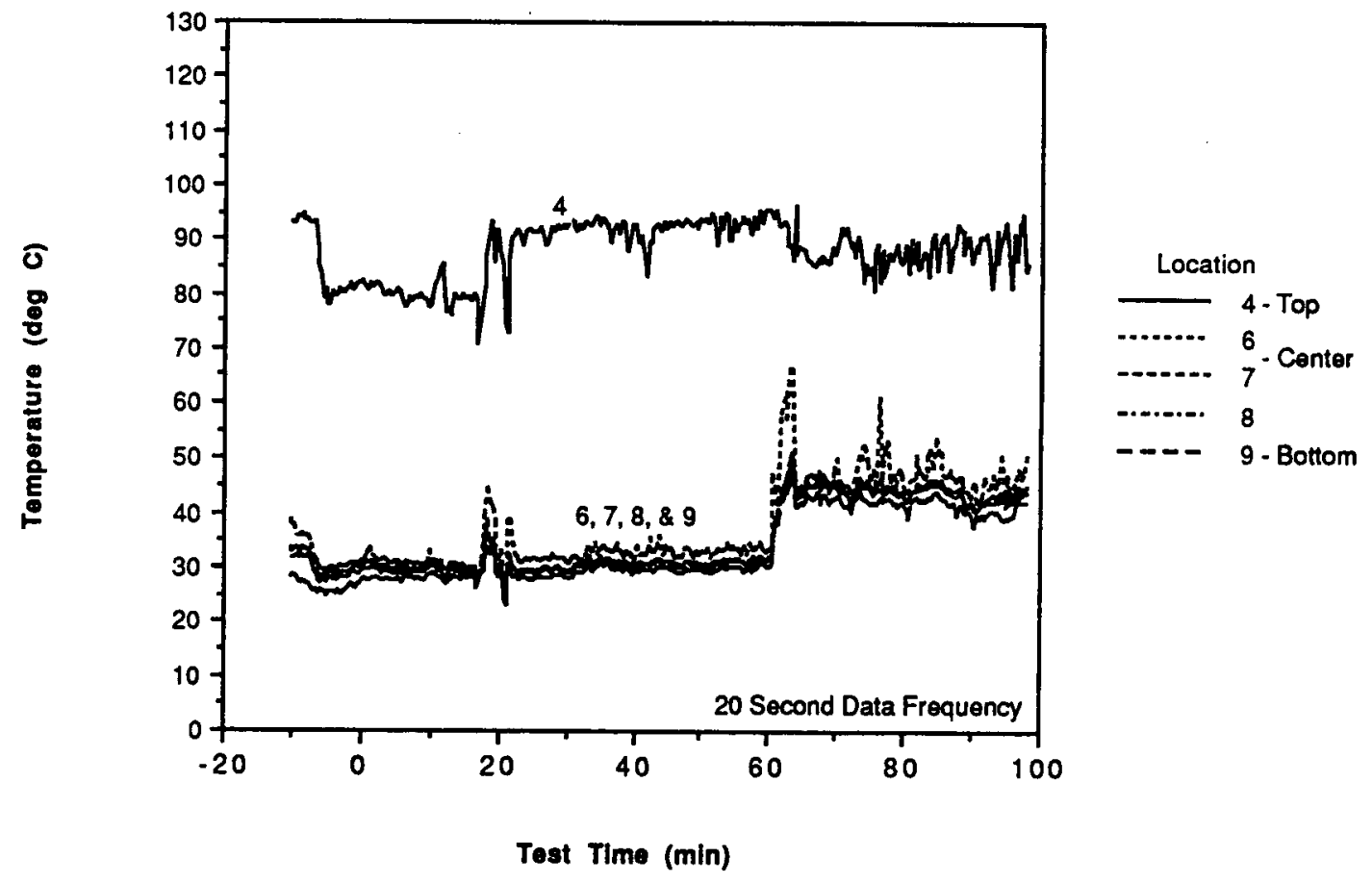

FIGURE 4.27. Diffuser Thermal Profiles, Test 14 
Test 12

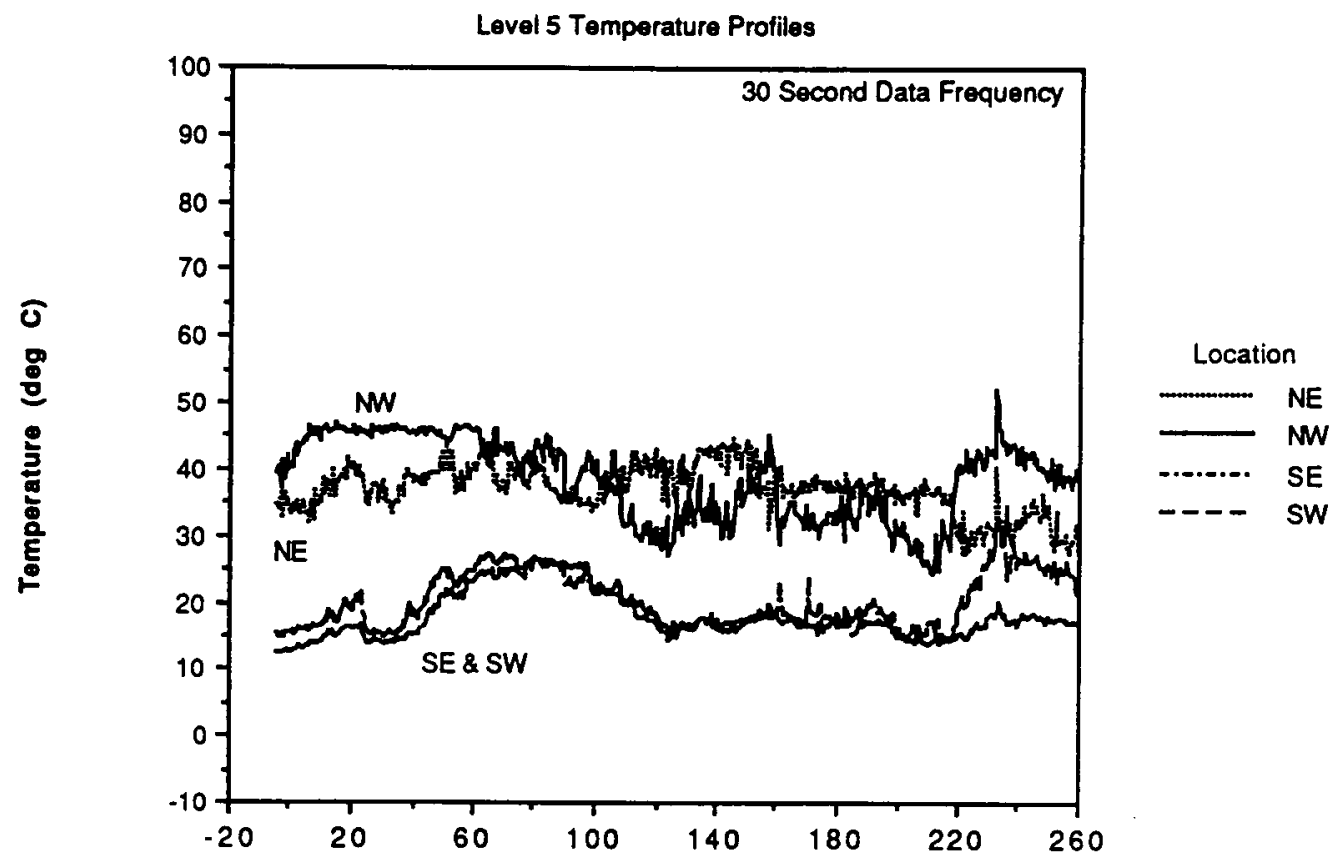

Test TIme (min)

Test 12

Level 1 Temperature Profiles

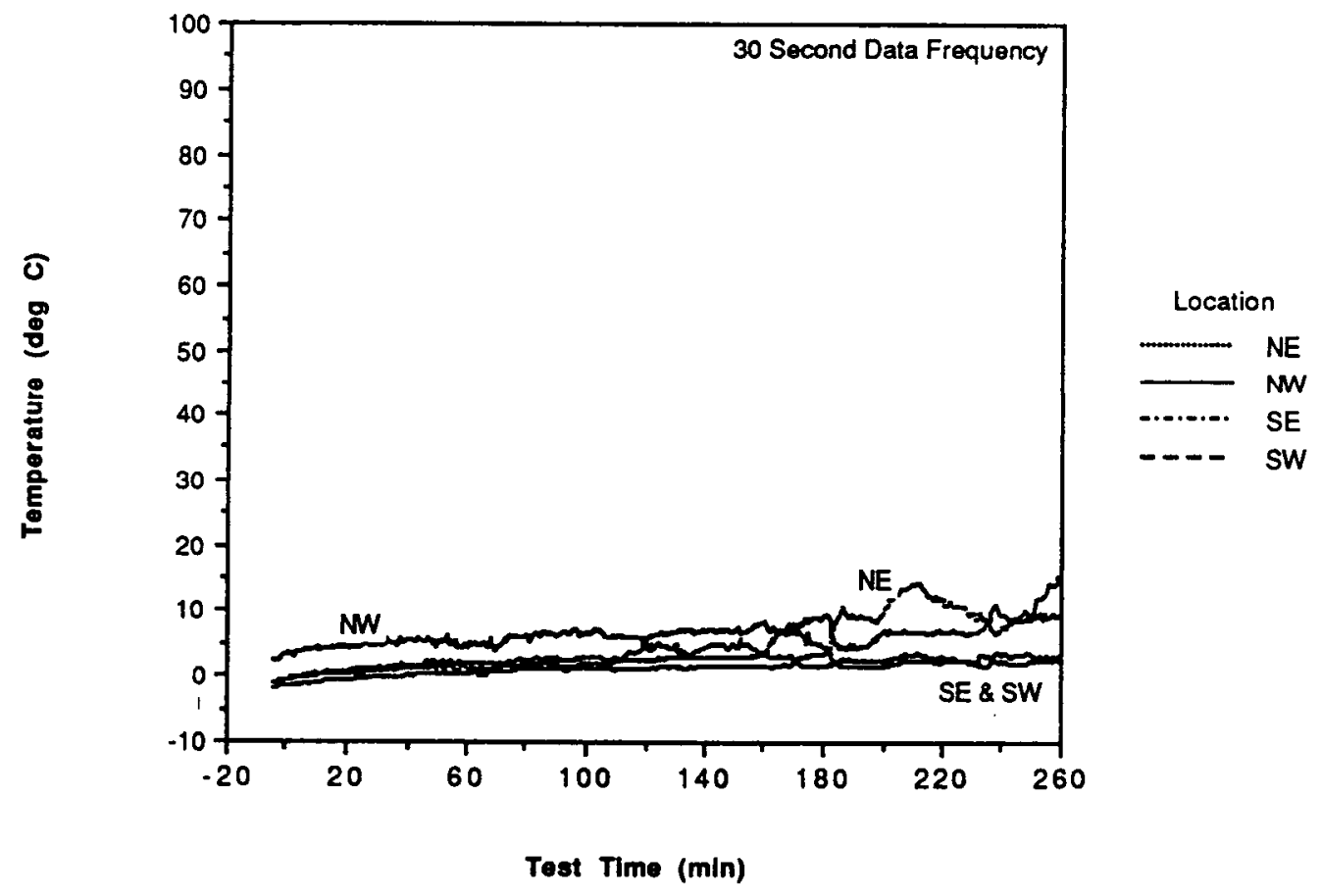

FIGURE 4.28. Ice-Basket Section Thermal Profiles, Test 12 
Test 13

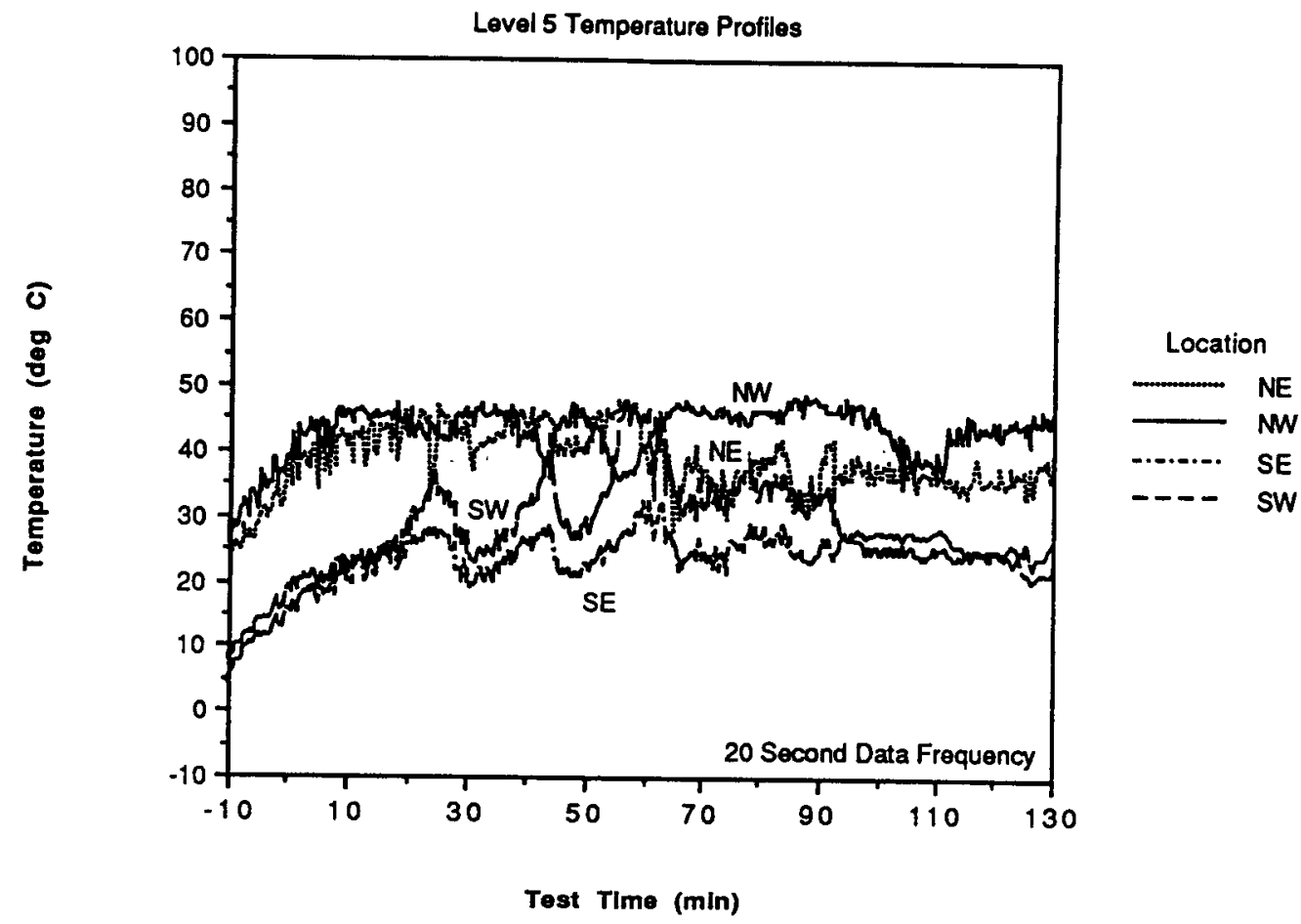

Test 13

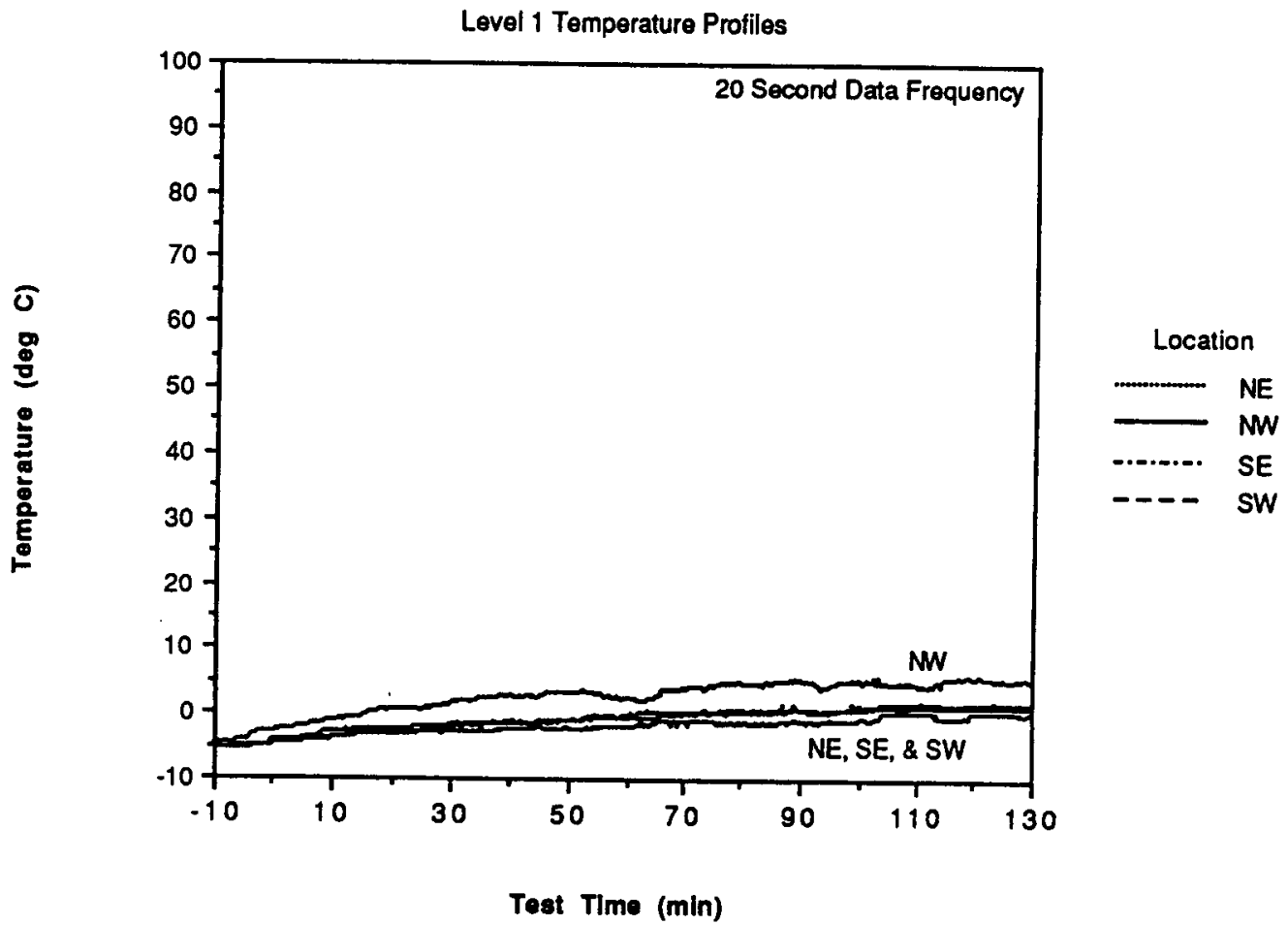

FIGURE 4.29. Ice-Basket Section Thermal Profiles, Test 13 
Test 14

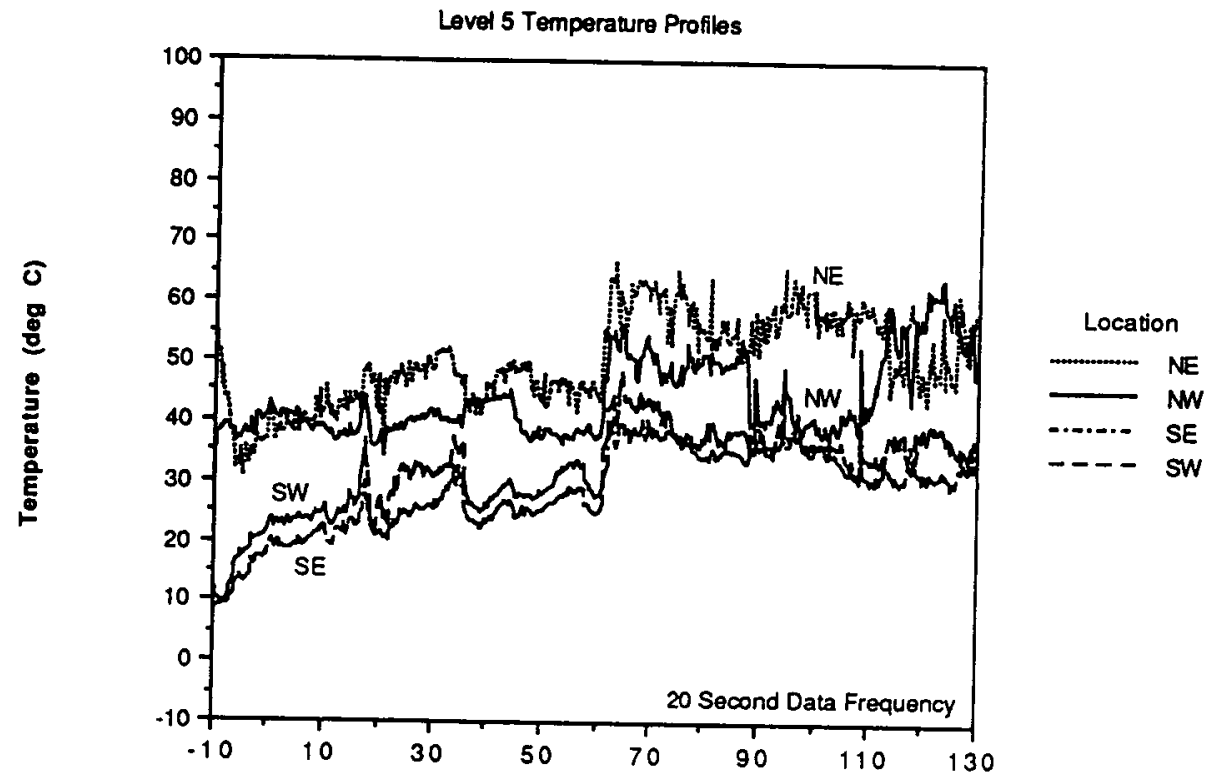

Test Time (min)

Test 14

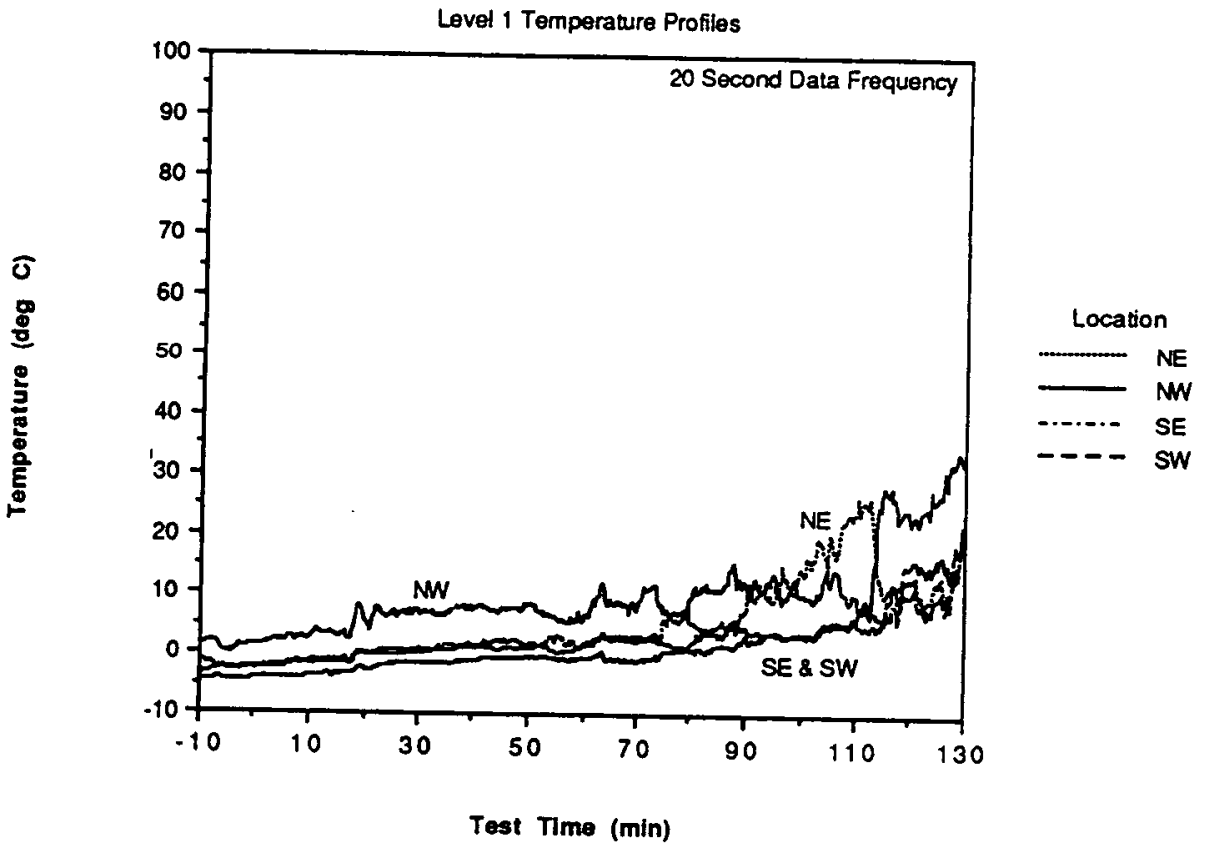

FIGURE 4.30. Ice-Basket Section Thermal Profiles, Test 14 
present, increasing the noncondensible fraction of the stream tended to stabilize the thermal stratification in the test section. Typically, the stable thermal pattern was north-south with the north being warmer than the south.

\subsubsection{Thermal-Hydraulic Observation Summary}

The thermal-hydraulic characteristics of the tests occurred in three general groups: 1) diffuser and ice-basket section thermally stratified; 2) diffuser and Level 5 of the ice-basket section thermally stratified, thermal profiles of other levels of the ice-basket section less well defined; and 3 ) diffuser not thermally stratified, ice-basket sections thermal profiles less well defined. Table 4.6 groups and summarizes the thermal-hydraulic observations of the tests.

TABLE 4.6. Thermal-Hydraulic Observations

\begin{tabular}{|c|c|c|}
\hline Test & Diffuser & Ice-Basket Section \\
\hline 1 & stratified & stratified \\
\hline 4 & $"$ & $"$ \\
\hline 5 & $"$ & $"$ \\
\hline 8 & $"$ & $"$ \\
\hline 6 & stratified & $\begin{array}{l}\text { Level } 5 \text { stratified, other levels } \\
\text { show stratification and less } \\
\text { well defined thermal profiles }\end{array}$ \\
\hline 7 & $"$ & " \\
\hline 12 & $"$ & $"$ \\
\hline 13 & $"$ & $"$ \\
\hline 14 & $"$ & $"$ \\
\hline 9 & not stratified & thermally less well defined \\
\hline 10 & $"$ & $"$ \\
\hline 11 & $"$ & $"$ \\
\hline
\end{tabular}

(a) Test 2 is not included because the test was conducted with the ice baskets empty. Test 3 was not included because sufficient data was not available because of the failure of a DAS component.

(b) Test 10 conclusion based on limited data and results of Tests 9 and 11 . 


\subsection{PARTICLE RETENTION}

Aerosol sampling was performed to provide information for determining the retention of particles within the test section and to measure the concentration of particles within the ice-basket region. Decontamination factor (DF) was determined as the ratio of particle mass flow rate at the inlet to that at the outlet. Particle retention ( $R$ ), the percentage of particulate mass retained in the test section, was also calculated. Particle retention results were determined for the 35 aerosol tests and were based on aerosol and thermal-hydraulic data. Information that contributed to particle retention results included steam mole fractions present at each measurement station, comparisons of mass and chemical analyses of aerosol samples, particle size distributions at the inlet and outlet, particle mass concentrations, and particle mass flow rates. The results of aerosol material mass balances were also used to provide independent estimates of DF for three tests.

\subsubsection{Steam Mole Fraction}

It was necessary to measure steam mole fraction (SMF) at each aerosol sampling station to provide information for the determination of aerosol mass concentrations and the subsequent determination of particle retention in the test section. Specifically, the SMF measured near the nozzle of the aerosol probe was necessary information for determining the total actual gas volume drawn through the collector during each filter and impactor sample. The flow rate of cool, noncondensible gas (air) through the critical orifice flow-rate controllers (Section 3.5) was corrected using temperature, SMF, and sample duration data. The result of this correction was the determination of the actual flow rate and total volume of each sample.

Results of SMF measurements during tests performed with ice present in the test section are listed in Appendix C. A worksheet prepared using Microsoft Excel ${ }^{(2)}$ was used to calculate both SMF and fog concentrations from data obtained at each aerosol sampling station. Procedures and equations used are listed at the end of each worksheet. The worksheets for each test were four or eight pages long depending on the number of condensate trap samples obtained. When more condensate was collected than would have been expected from saturated conditions, the residual amount, expressed in $\mathrm{mg} / \mathrm{m}^{3}$, was assigned to the column of the worksheet titled "fog." SMF and fog concentrations are listed on page 2 or pages 3 and 4 of the worksheets.

SMF at the inlet to the test section (Station 6A) ranged from about 0.0 to 0.94 (Appendix C, and Tables 4.11 and 4.12 in Section 4.3.6). Thus, SMF often had a significant affect on the calculation of actual aerosol volumes sampled at the inlet. Most steam condensation occurred near the inlet of the ice-basket region, thus very low steam mole fractions were usually measured in the cooler gases present in the upper ice-basket region and the test section outlet. As a result, only when ice loads had depleted and temperatures at the outlet had increased did the SMF data and aerosol sample volume correction

(a) Microsoft Corporation, Bellevue, Washington. 
become significant at the outlet (Station 0 ). Uncertainties associated with the condensate trap measurement technique for very low SMF were not important, however, because corrections to the aerosol sample volumes in these cases were not large.

In general, the worksheets in Appendix $C$ show that SMF was uniform at the inlet (Station 6A) throughout most tests, and that it increased at the sampling stations located within the ice-basket region and at the outlet as the tests progressed, i.e., as the heat present in the inlet gas penetrated through the test section. Measured values of SMF were greater at lower elevations within the ice-basket region and seemed to correspond to the pattern of ice depletion (bottom to top). Figure 4.31 shows the results of SMF measurements at the inlet and outlet of the test section for Tests $13 \mathrm{~b}, 8$, and 11, in order of increasing thermal energy of the inlet gases (see Table 4.1). Review will reveal that the SMF of the out let gas did not increase during Test 13b (the test that had the least amount of thermal energy supplied in the inlet gas flow). On the other hand, the SMF of the outlet gas did increase to about 0.10 during Test 8 and to about 0.20 during Test 11 (after $60 \mathrm{~min})$. During the latter two tests, greater rates of thermal energy were supplied to the test section by the inlet gas, and ice loads were significantly depleted.

In addition to providing information about inlet and outlet conditions, SMF measurements were made in the ice-basket region from gas samples obtained using the two quad stations (during Tests $8,9,10,11,13 \mathrm{a}, 13 \mathrm{~b}, 14 \mathrm{a}$, and 14b). During these tests, SMF was measured from the centerline of the four open channels between the ice baskets both at lower (Quad Station 5A) and upper (Quad Station 1A) elevations within the ice-basket region. Varying degrees of stratification between the channels were generally observed at the lower elevation, with flow channels 2 and 4 (NW and NE) typically having greater SMFs. At the upper elevation, however, SMF was essentially the same in all four flow channels. These results suggest that flow recirculation cells were largely confined to the inlet and the lower elevations of the icebasket region.

\subsubsection{Sample Analyses: Mass and Chemistry}

Several data sets were analyzed using both gravimetric and chemical procedures, thus providing the opportunity to compare the two methods. Most data sets were analyzed only for sample mass; chemical or fluoroscopic procedures were usually reserved for samples containing insufficient particulate mass for gravimetric analysis or samples for which parts of the substrate backing was lost on the filter holders. Tests having all or some aerosol samples analyzed by both gravimetric and chemical procedures included $7,8,13 a, 13 b, 14 a$, and 14b. While measurements of mass included all particulate matter on the samples, chemical analyses were ion specific and results were then converted to the total mass of the compound used as the aerosol source material. Chemical analyses of samples containing ZnS, CsI ; and $\mathrm{KCl}$ were usually performed for a single type of ion $\left(\mathrm{Zn}^{2+}, \mathrm{Cs}^{+}, \text {and } \mathrm{Cl}\right)^{2}$, respectively). However, a second ion was also analyzed on a selected number 

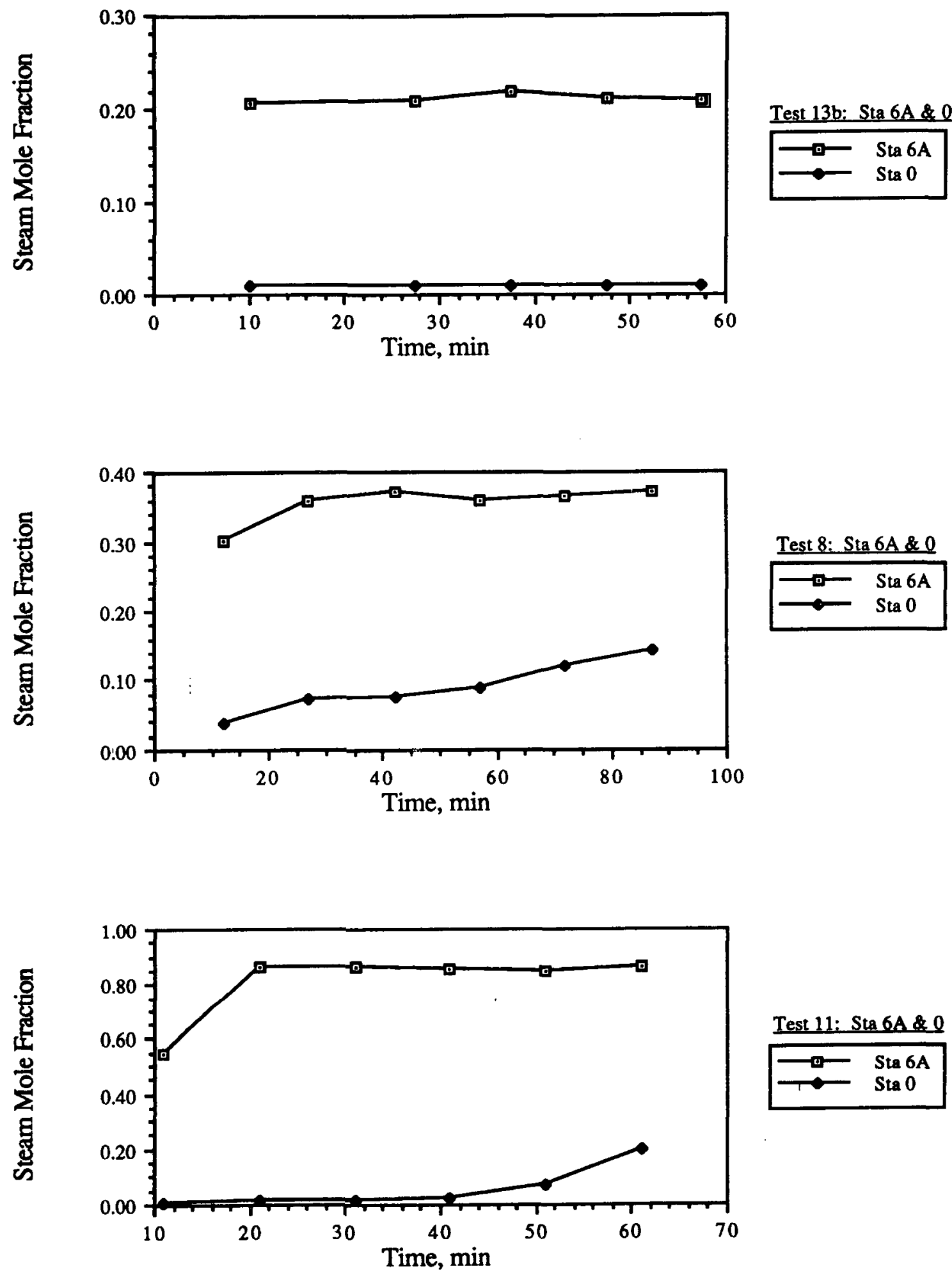

FIGURE 4.31. Steam Mole Fraction Versus Time for the Test Section Inlet (Station 6A) and the Outlet (Station 0) During Tests 13b, 8, and 11. Tests are listed in order of increasing rate of thermal energy supplied to the test section inlet. Measurements were made using condensate traps. 
of $\mathrm{KCl}$ and $\mathrm{CsI}$ samples ( $\mathrm{K}^{+}$and $\mathrm{I}^{-}$, respectively). Dark brown or black deposits were present on samples during Tests 9 and 10 and may have contaminated the mass data, but because the source of the material was likely oil from the boiler, it should not have interfered with the chemical analyses.

In general, the comparison of the elements present on samples analyzed for two ions was good. The comparison of chemical to gravimetric sample analyses was also good. Tables 4.7 and 4.8 show these comparisons for filter and cascade impactor data from all tests for which such comparisons could be

TABLE 4.7. Comparisons of Chemical Analyses of Aerosol Samples Analyzed for Two Ions

\begin{tabular}{|c|c|c|c|c|c|c|c|c|}
\hline \multirow[b]{3}{*}{ Test } & \multirow[b]{2}{*}{ Ions } & \multirow{3}{*}{$\begin{array}{c}\text { Ideal Results } \\
\text { Mass Ratio } \\
\end{array}$} & \multicolumn{3}{|c|}{ Filter Samples } & \multicolumn{3}{|c|}{ Cascade Inpactor Sanples } \\
\hline & & & \multirow{2}{*}{$\begin{array}{l}\text { No. of } \\
\text { Filters }\end{array}$} & \multirow{2}{*}{$\begin{array}{l}\text { Mass } \\
\text { Ratio }\end{array}$} & \multirow{2}{*}{$\begin{array}{c} \pm 1 \text { STD } \\
\text { Deviation }\end{array}$} & \multirow{2}{*}{$\begin{array}{l}\text { No. of } \\
\text { Stages }\end{array}$} & \multirow{2}{*}{$\begin{array}{l}\text { Mass } \\
\text { Ratio }\end{array}$} & \multirow{2}{*}{$\begin{array}{l} \pm 1 \text { STD } \\
\text { Deviatio }\end{array}$} \\
\hline & 1st 2nd & & & & & & & \\
\hline 7 & $\mathrm{Cs}^{+}$ & $C_{3} / C_{s I}=0.51$ & 4 & 0.51 & 6.64 & 5 & 6.65 & 0.13 \\
\hline 8 & $\mathrm{Cl}^{-} \mathrm{K}^{+}$ & $\mathrm{Cl} / \mathrm{KCl}=0.48$ & 8 & 0.46 & 6.02 & 8 & 0.49 & 0.64 \\
\hline 13a & $\mathrm{Cl}^{-} \mathrm{K}^{+}$ & $\mathrm{Cl} / \mathrm{KCl}=0.48$ & 5 & 0.42 & 6.62 & 6 & 0.48 & 0.14 \\
\hline
\end{tabular}

TABLE 4.8. Comparisons of Chemical Analyses and Gravimetric Analyses of Aerosol Samples

\begin{tabular}{|c|c|c|c|c|c|c|c|}
\hline & Ideal & & ilter San & ples & Cascad & - Inpacte & Saaples \\
\hline $\begin{array}{c}\text { Ion } \\
\text { Analyzed }\end{array}$ & $\begin{array}{l}\text { Percentage } \\
\text { of Coupound }\end{array}$ & $\begin{array}{l}\text { No. of } \\
\text { Filters }\end{array}$ & $\begin{array}{l}\text { Mass (a) } \\
\text { Ratio } \\
\end{array}$ & $\begin{array}{l}\text { 土1 STD } \\
\text { Deviation }\end{array}$ & $\begin{array}{l}\text { No. of } \\
\text { Stages }\end{array}$ & $\begin{array}{l}\text { Mass (a) } \\
\text { Ratio }\end{array}$ & $\begin{array}{l} \pm 1 \text { STD } \\
\text { Doviation }\end{array}$ \\
\hline
\end{tabular}

Potassiun Chloride

$\begin{array}{lllllllll}8 & \mathrm{Cl}^{-} & 0.48 & 7 & 1.65 & 0.08 & 8 & 0.87 & 0.11 \\ 13 \mathrm{z} & \mathrm{Cl}^{-} & 0.48 & 11 & 1.68 & 0.11 & 4 & 0.96 & 0.12\end{array}$

Zinc Sulfide

$\begin{array}{ccccccccc}13 \mathrm{~b} & \mathrm{Zn}^{2+} & 0.67 & 29 & 0.92 & 0.12 & 11 & 6.73 & 6.69 \\ 140 & \mathrm{Zn}^{2+} & 0.67 & 14 & 0.97 & 0.18 & 11 & 0.82 & 6.18 \\ 14 \mathrm{~b} & \mathrm{Zn}^{2+} & 0.67 & 19 & 1.69 & 0.25 & 11 & 6.82 & 0.11\end{array}$

(a) The mass ratio is the ratio of the mass calculated based on the results of the chenical analysis to that aeasured graviatrically. 
made. The measured mass ratio of ions was within less than one standard deviation of the ideal mass ratio for four of six categories of comparison (Table 4.7). It is likely that the $\mathrm{I}^{-}$values for the cascade impactor samples from Test 7 were low because of loss of I gas during sample handling. It was not clear whether the $\mathrm{Cl}^{-}$results were less than actual, or whether the $\mathrm{K}^{+}$ results were greater than actual for the filter samples from Test $13 a$.

Comparisons of the sample masses based on results of the chemical analyses with the gravimetric results were made for those samples having masses greater than $0.25 \mathrm{mg}$ (Table 4.8). This was done to limit the gravimetric uncertainty to less than $20 \%$. The two methods provided sample masses that averaged within $\pm 9 \%$ for the filter samples (Table 4.8). The results for the impactor samples indicated that the sample masses determined chemically were less than those determined gravimetrically. The chemical-to-mass ratios for the impactor samples ranged from 0.73 to 0.90 . Control impactors, heated and sampling clean air, did not show substrate mass changes sufficient to cause this difference, and no reason for the difference was determined. It is important to note that the discrepancy between the chemical and gravimetric results did not greatly affect test data. This was because the results of cascade impactor samples were dependent on the relative masses present on the eight stages in each impactor and the actual difference between the subsequently determined particle size distributions based on either chemistry or mass was small (Section 4.3.3).

\subsubsection{Particle Size Distribution and Morphology}

Results of measured aerosol particle size distributions are shown graphically in Appendix $D$ for Test 2 and each aerosol test performed with ice present in the baskets. The results are plotted on log-probability scales and represent the aerodynamic mass distributions of suspended particles. On the selected scales, a straight-line $f$ it is an indication that the particle size distribution is log-normal. The aerodynamic mass median diameter (AMMD) and the geometric standard deviation (GSD) of the aerosols measured at various locations within the test section are listed on each figure in the appendix (on the figures, MMAD is equivalent to AMMD). AMMD was determined using data from all impactor stages and the mass collected on the top of Stage 0 . Because of the non-ideal nature of the cascade impactors, log-normal particle size distributions were generally determined neglecting the two largest particle sizes in each data set or the data from stages cumulatively collecting less than about 5 or $10 \%$ of the total sampled particulate mass on both extremes of the size distributions. This only influenced the determination of GSD.

Other information presented on the figures in Appendix D include the time when samples were obtained (particle size was measured twice during most tests), the type of analysis method used (gravimetric or chemical), and the location from which samples were obtained. While symbols used to plot data were generally selected to represent the location of the sample, results for Test 11 (Alternate Test No. 16-11) were plotted by analys is method to show a comparison of gravimetric ( $m$, representing mass analysis) and chemical ( $z$, representing zinc analysis) analyses of the same samples. The location from 
which samples were obtained was listed in the figure title. For the other tests, the symbol "I" was used to plot data from samples obtained at the inlet (Station 6A), and the symbol " 0 " was used to plot data from samples obtained at the outlet (Station 0 ). The symbols " $B$ " and " $T$ " were used for samples obtained near the bottom and top of the ice-basket region (Stations $5 A$ and $1 A 1$ or 1B), respectively. Finally, the symbol "E" was used for the few samples obtained between the inlet turning vanes and the bottom of the ice baskets (Station 6B).

A summary of aerosol particle size distribution results is shown in Table 4.9. AMMDs measured at the inlet to the test section ranged from 0.9 to $12 \mu \mathrm{m}$, excluding Test 3. Particle size during Test 3 exceeded both the target value of $12 \mu \mathrm{m}$ and the measurement limit of the cascade impactors and was probably much greater than $15 \mu \mathrm{m}$. Mechanisms that influenced particle retention in the test section al'so influenced the change in AMMD between the inlet and outlet. Steam condensation caused particle growth to occur as well as removal by diffusiophoresis. As steam condensed and the gas flow cooled, the bulk gas flow rate decreased and the residence time within the test section increased, leading to increased deposition of the larger particles by gravitational settling. Size dependent removal of particles by gravitational settling was also influenced by the actual flow rate of noncondensible gas (air) through the test section. Particle solubility also influenced growth and, therefore, removal. In addition, the presence of flow recirculation cells within the test section probably contributed to particle growth and deposition by both redirecting and mixing particles and gases.

Correlations between the change in AMMD between the inlet and outlet of the test section and aerosol characteristics and thermal-hydraulic conditions were only clear for one parameter--inlet AMMD. The median size of particles at the outlet was compared to that at the inlet for each test by calculating a volume ratio equal to the cube of the ratio of the two AMMDs. Volume ratios of more than unity indicate an increase in AMMD between the inlet and the outlet of the test section. For tests performed with ice in the test section, the range of volume ratios was 0.43 to 54 (again excluding Test 3 ). Inlet AMMDs greater than $5 \mu \mathrm{m}$ were associated with all but one of the cases for which the volume ratios were less than unity. The maximum volume ratio for tests with inlet AMMDs greater than $5 \mu \mathrm{m}$ was 1.33. The decrease in particle size between the inlet and outlet was attributed to increased size-selective settling losses of the larger particles within the test section. This result was also supported by the results of Test 3 , regardless of the uncertainty in inlet AMMD. Consideration of SMF, noncondensible gas flow rate (related to average particle residence time in the test section), and particle solubility did not reveal additional relationships between inlet and outlet AMMD. Although individually thought to influence particle growth and removal, complex combinations of these parameters caused unpredictable changes in particle size. Test 7 was the only case having an inlet AMMD less than $5 \mu \mathrm{m}$ and a volume ratio less than unity. The reason for this is not known. 
TABLE 4.9. Aerosol Particle Size Distribution Results of Cascade Impactor Measurements

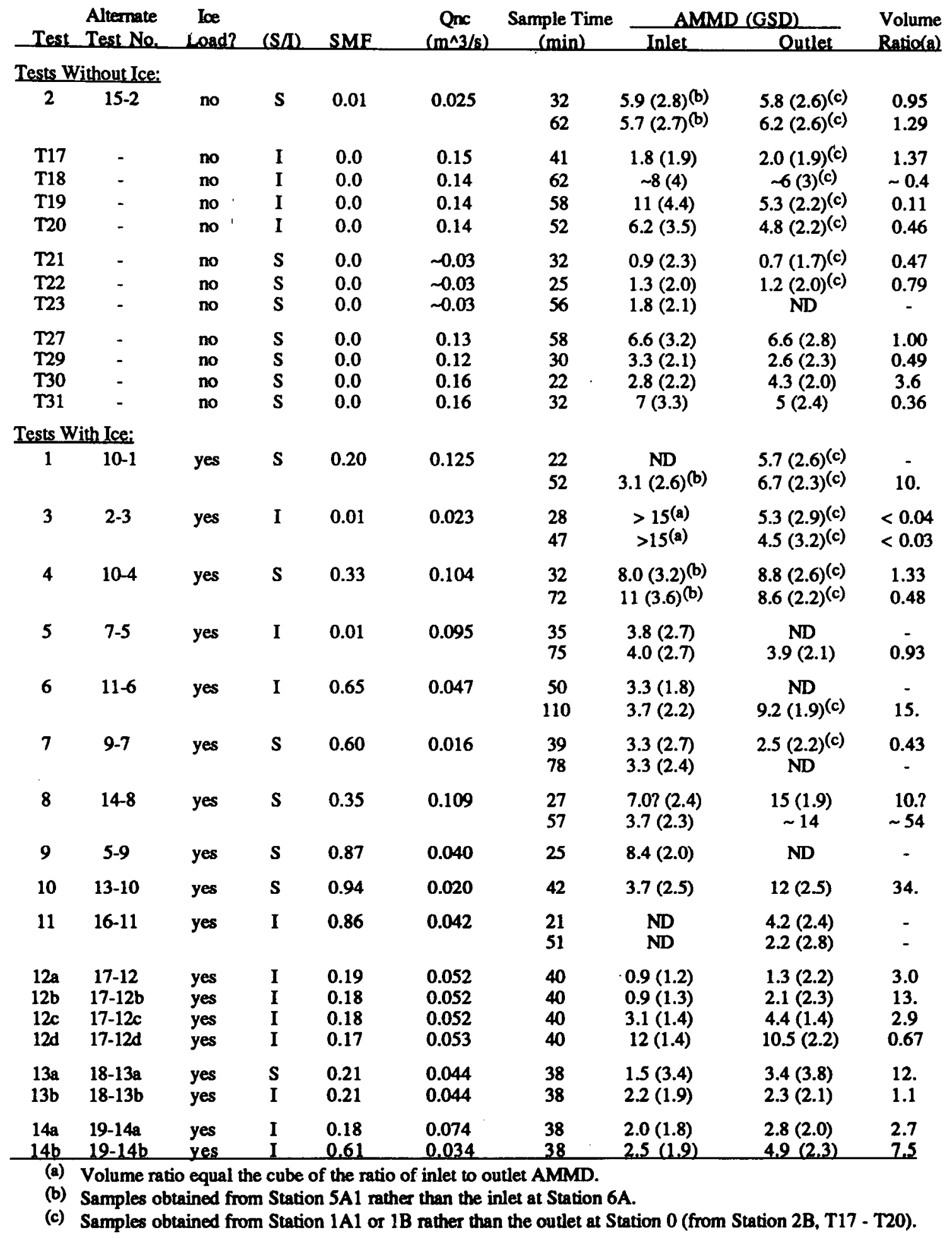


Volume ratios for tests performed without ice present in the test section were generally less than unity. This was attributed to the absence of the particle growth mechanism provided by water vapor from condensing steam and melting ice. As with tests containing ice, the volume ratios were usually least for aerosols having the largest inlet AMMDs.

In addition to particle size distribution, other measurements revealed information about the morphology of the particles produced by the three types of aerosol generators. Particles ranged from rough to perfect spheres, and most agglomerates of primaries were near-spherical. Samples obtained within the test section were usually not possible to characterize because of flooding caused by condensation of steam and melting ice. However, it is anticipated that the influence of humidity, during tests with steam and ice, would cause an increase in the sphericity of particles. Samples obtained close to the aerosol generators did provide useful particle morphology information. The spherical shape of the droplets produced by the vibrating orifice aerosol generator during Tests $12 \mathrm{a}$ through $12 \mathrm{~d}$ and seyeral calibration tests was verified by collecting particles on fluorad ${ }^{k}$ coated glass slides and inspecting them using an optical microscope. Scanning electron micrographs of CsI particles generated using the ultrasonic nozzle aerosol generator revealed less perfect spheres and spheres with single large dimples. Samples were collected by filtration using membrane filters and by deposition (settling) to glass cover slips. The range of particle sizes was between $<1$ and about $3 \mu \mathrm{m}$. While most particles were singlets, about $20 \%$ of the particles consisted of agglomerates of two or three primaries. Even the agglomerates were roughly spherical, however, as the primaries tended to adhere closely to one another rather than forming typical barbell or chain shapes. Figure 4.32 shows $C_{\{}$, particles collected near the generator on both glass slide and Millipore ${ }^{(6)}$ membrane filter substrate.

Scanning electron micrographs of $\mathrm{ZnS}$ particles produced by the energy mill revealed a greater degree of agglomeration of primary particles than did either of the other two methods of aerosol generation. This was not unexpected as the energy mill was used to mechanically disperse dry powders. Particles and agglomerates were, however, roughly spherical. Potassium chioride particles produced using the same generator were not examined, but were not expected to be greatly dissimilar. Samples of ZnS particles were obtained on glass cover slips near the generator and on deposition coupons inserted into the ice-basket region at Station $3 \mathrm{~A}$ (shown in Figure 4.33) and on Nucleopore ${ }^{(c)}$ membrane filters at Station $6 \mathrm{~A}$ at the inlet of the test section and Station $1 \mathrm{Al}$ at the upper portion of the ice-basket region (shown in Figure 4.34). Samples from the test section were obtained during Tests 5 and 6 . Particles

(a) Registered trademark of $3 M$ Commercial Chemical Division, St. Paul, Minnesota.

(b) Millipore, Bedford, Massachusetts.

(c) Nucleopore, Pleasanton, California. 

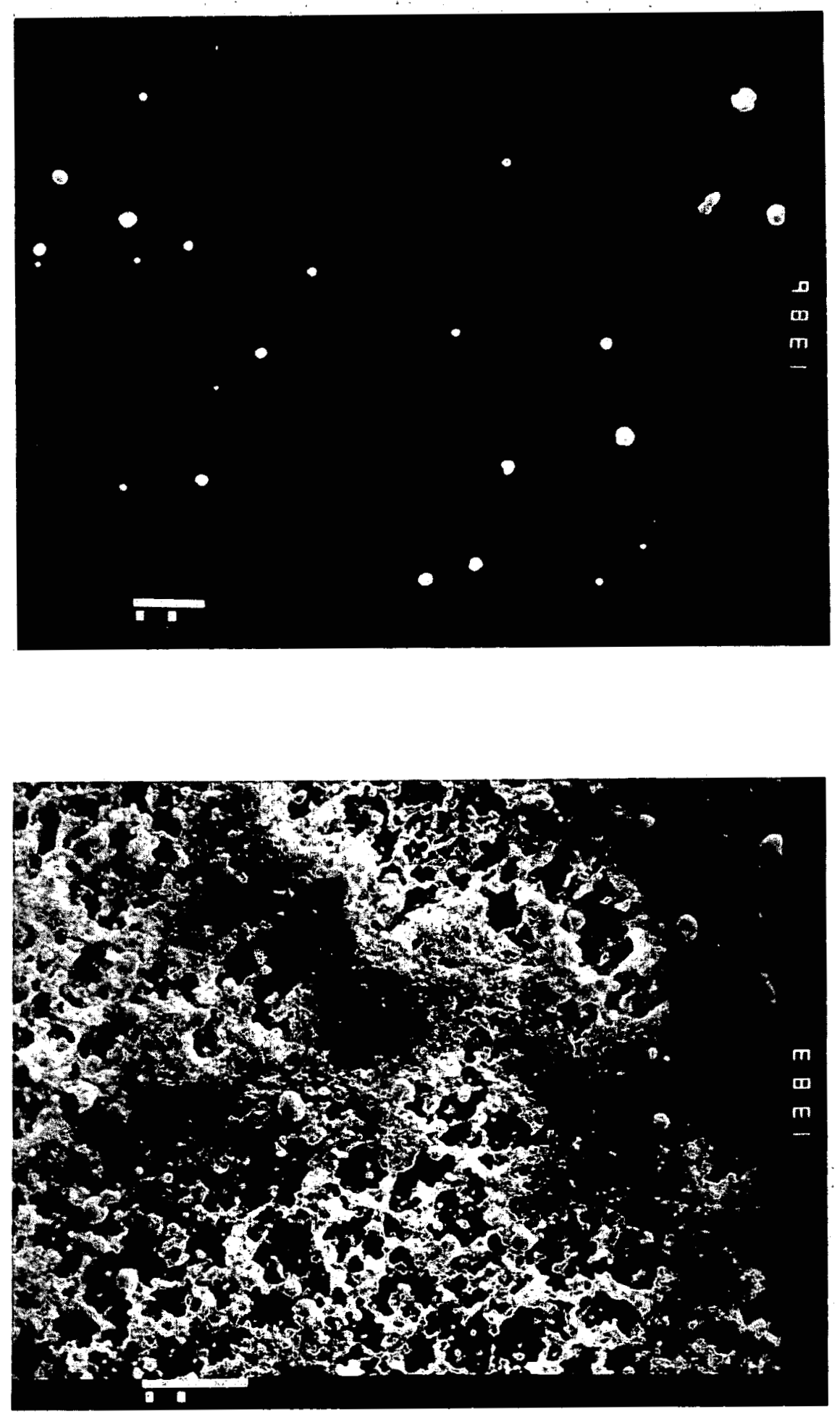

FIGURE 4.32. Scanning Electron Micrographs of CsI Particles Collected Near the Ultrasonic Nozzle Aerosol Generator on Glass Slide (Top) and Millipore Membrane Substrate (Bottom). The length of a bar with two dots is $10 \mu \mathrm{m}$. 

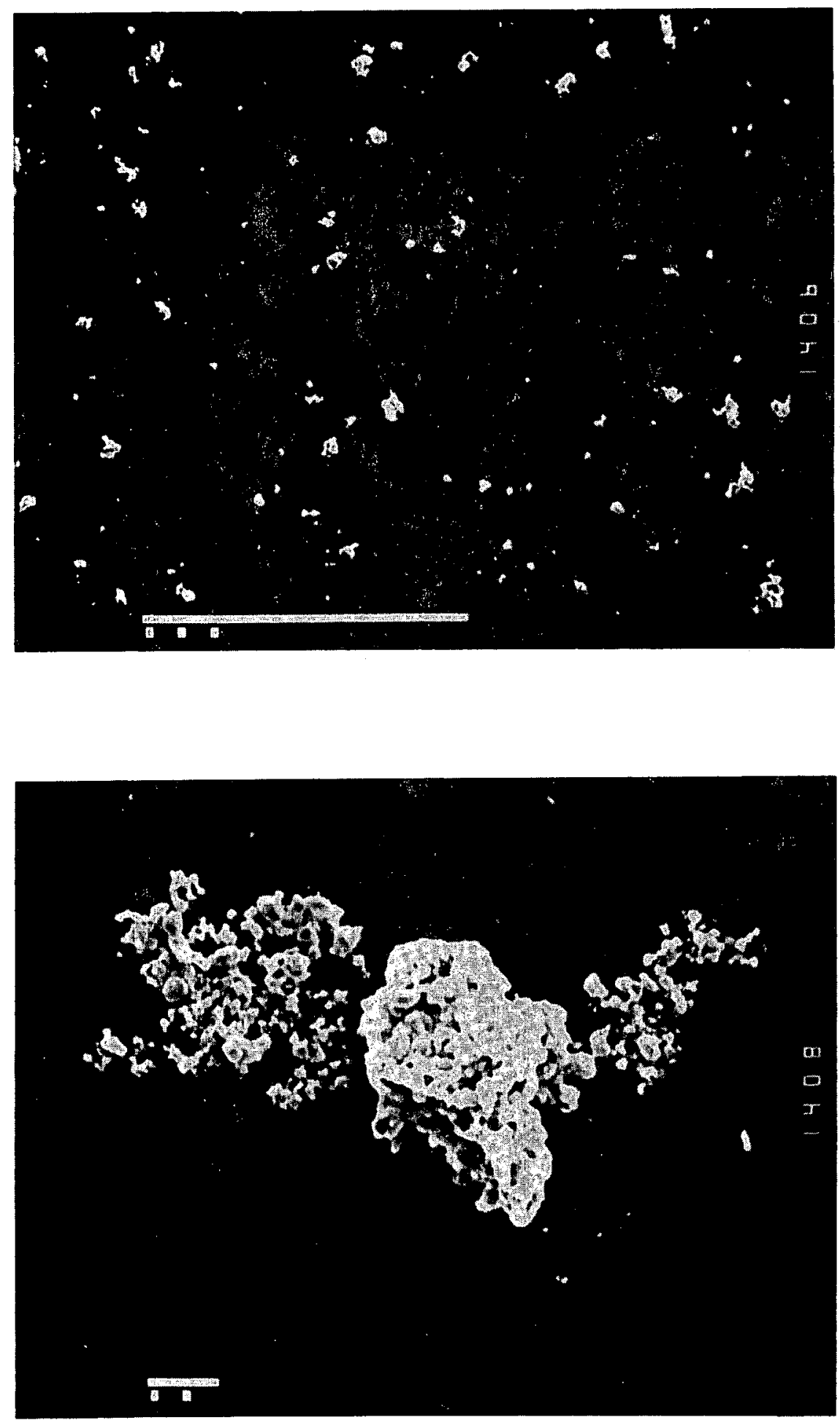

FIGURE 4.33. Scanning Electron Micrographs of ZnS Particles Generated by the Energy Mill and Collected on Deposition Inserts in the Ice-Basket Region During Test 5. The large agglomerate in the lower micrograph likely formed on the deposition insert during sampling. The length of a bar with two dots is $10 \mu \mathrm{m}$, that with 3 dots is $100 \mu \mathrm{m}$. 

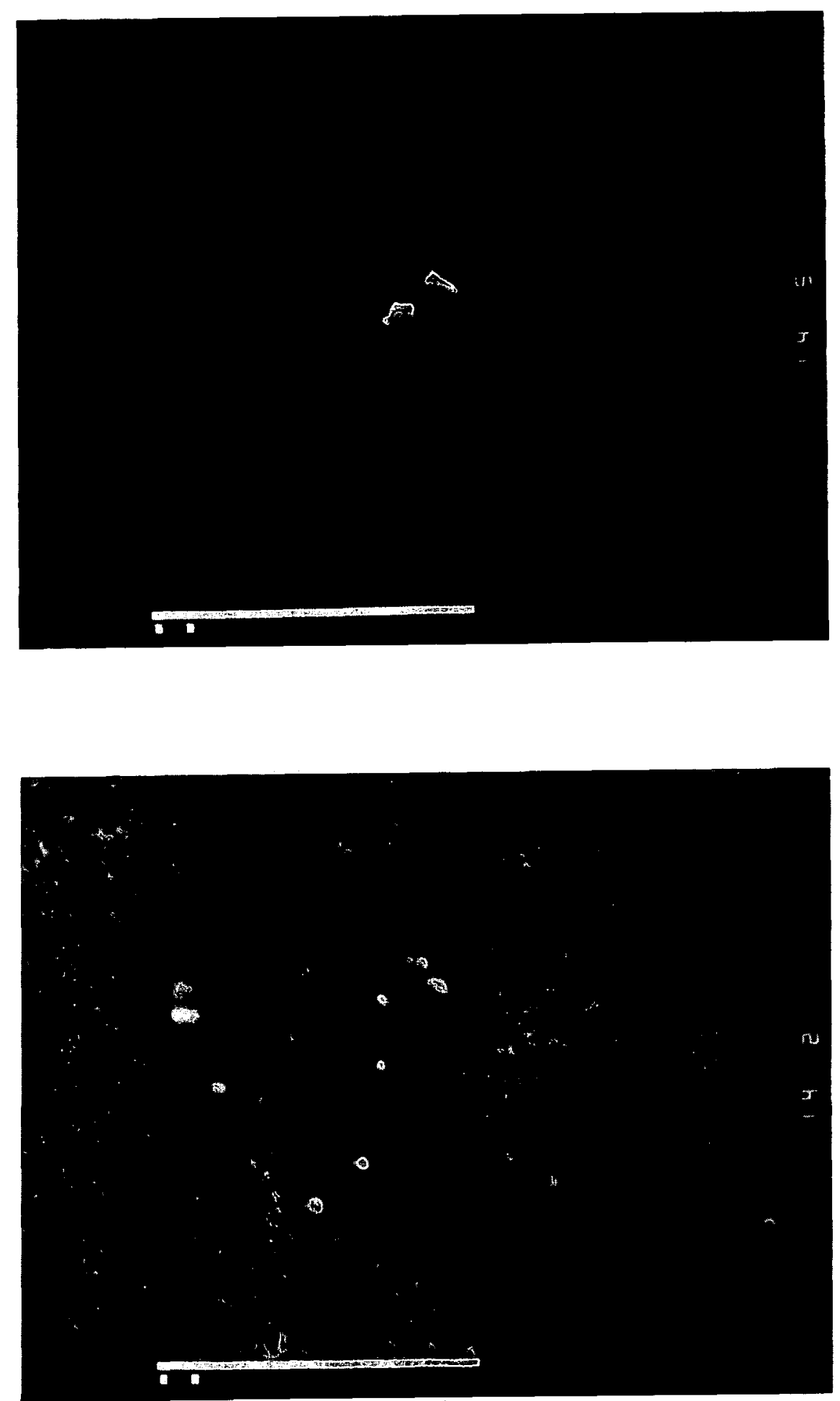

FIGURE 4.34. Scanning Electron Micrographs of ZnS Particles Generated by the Energy Mill and Collected on Nucleopore Filters at the Inlet (Lower Micrograph) and Upper Ice-Basket Region (Upper Micrograph) During Test 6 . The length of a bar with two dots is $10 \mu \mathrm{m}$. 
collected near the generator ranged between about 0.5 and $2.5 \mu \mathrm{m}$ and were perhaps evenly distributed between singlets and agglomerates having less than about five primaries. Samples collected on deposition inserts in the icebasket region generally showed particles and larger agglomerates ranging in size from less than 1 to about $9 \mu \mathrm{m}$. It was likely, however, that contact with

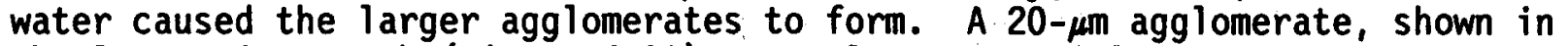
the lower micrograph (Figure 4.33), was almost certainly formed on the collection substrate. The size of the primary particles near the agglomerate ranged between 0.5 and $3 \mu \mathrm{m}$. Particles typically less than or equal to $1 \mu \mathrm{m}$ were collected on membrane filters at the inlet and the top of the ice-basket region (Figure 4.34 ).

\subsubsection{Particle Mass Concentration}

Aerosol particle mass concentrations are listed for Test 2 and aerosol tests with ice present in the test section on the third page of each aerosol worksheet in Appendix E. Aerosol mass concentrations were based on the mass of suspended particulate matter per actual volume of gas and did not include the mass of the gas (air and steam) or water droplets present in the samples. The concentrations are the result of data obtained at aerosol measurement stations during tests, calculations performed using the worksheet, and gravimetric, chemical, or fluorometric analysis of filter samples. The sum of mass collected in some cascade impactors was also used to obtain aerosol mass concentrations. However, because of interstage particle losses, the latter data generally under-represented actual aerosol conditions. Data in Appendix $E$ include information about aerosol mass concentration at the inlet and outlet and within the four flow channels in the ice-basket region and concerning the vertical profile of particle concentration in the outlet of the test section.

The vertical profile measurements were made to determine whether the use of the single sampler located at the cross-section centerline at Station 0 was sufficient to represent the aerosol distribution within the test section (Section 3.5.3). Measurements indicated that the aerosol mass concentration was greater in the lower than in the upper regions of the exhaust duct. However, in nearly every case, the sampler located at the centerline represented nearly the mean. For all nine sets of measurements made using the vertical profile aerosol sampler the ratio of the aerosol concentration measured at the centerline position was $0.95 \pm 0.16$ times that of the average of all five concentrations measured across the profile. Use of the probe located at the centerline of the exhaust duct (Station 0 ) was thus shown to provide data closely representative of the average aerosol characteristics present in the gas exiting the test section.

While aerosol mass concentrations at the inlet and outlet were determined as a step in calculating particle retention in the test section, concentrations present in the ice-basket region provided information on the spatial distribution of particles as influenced by thermal-hydraulic conditions. The results of aerosol mass concentration distributions are shown in Appendix $F$ for tests with ice present in the test section. The figures in Appendix $F$ 
were prepared using data listed in Appendix $E$. The first test performed using a quad station was 5 (Alternate Test No. 7-5). Data were obtained for all subsequent tests except 12. Quad Stations $5 A$ and $1 A$ provided data from the centerline of each open flow channel between ice baskets.

A summary of the distribution of aerosol mass concentration in the lower and upper elevations of the ice-basket region are shown in Table 4.10. The flow channels between ice baskets are identified by orientation as SW, NW, $S E$, and $N E$, and correspond to flow channels 1,2, 3, and 4, respectively. Data exclude three samples taken during Test 8 that were affected by the failure of the aerosol generator. The distribution of aerosol mass concentration in the ice-basket region was determined during one trial test in the absence of both ice and steam and at ambient temperature. The test, T31, provided a baseline of the distribution of aerosol in the lower ice-basket region (only Quad Station 5A was used) for an AMMD of $7 \mu \mathrm{m}$ and a gas flow rate of $0.16 \mathrm{~m}^{3} / \mathrm{s}$. As shown the table, the distribution of particles was uniform,

TABLE 4.10. Distribution of Aerosol Mass Concentration in the Ice-Basket Region

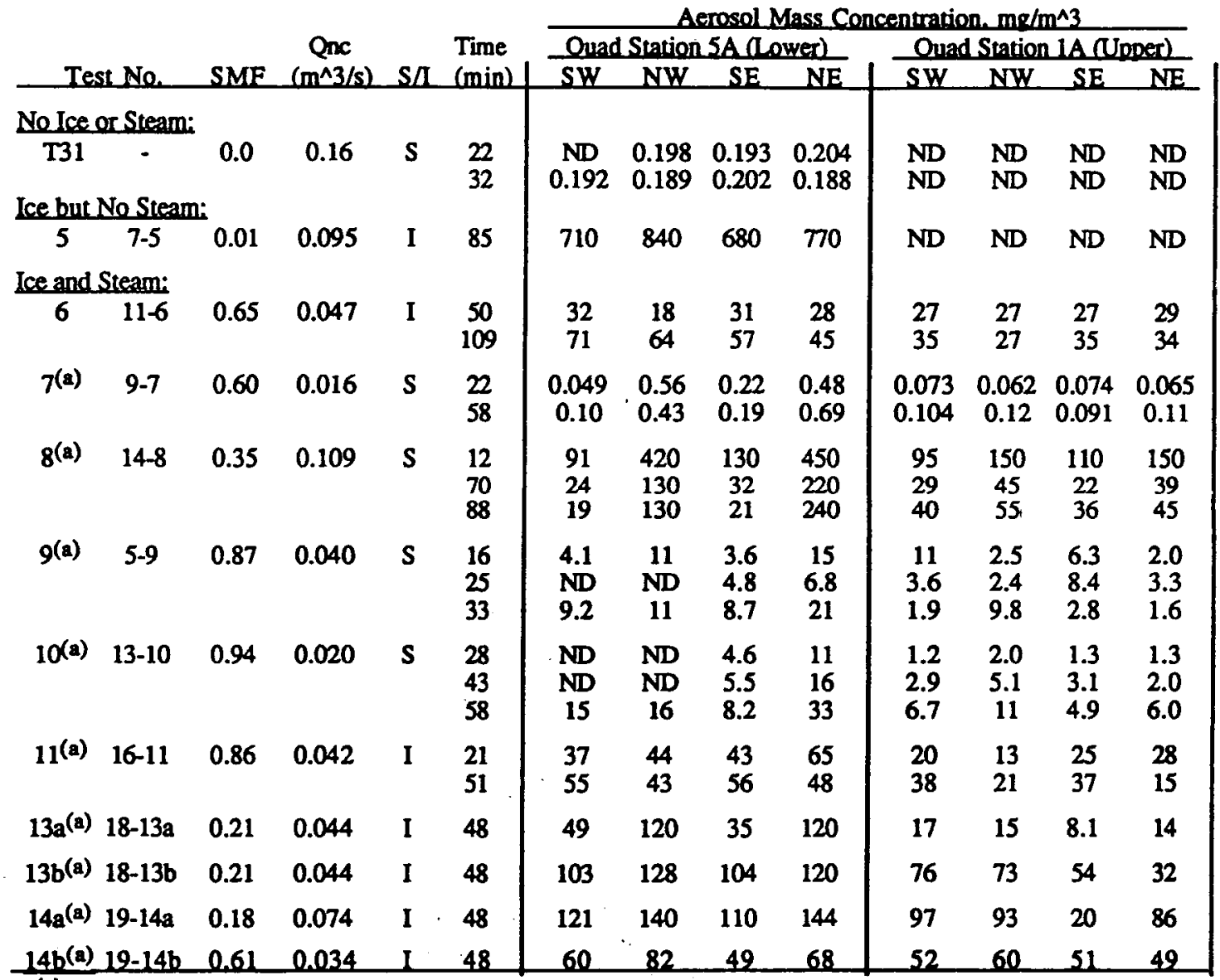

(a) Results based on chemical rather than gravimetric amalysis of filter samples. Gravimetric analyses were also available for Tests 8, 13a, 13b, 14a, and 14b. Results of gravimetric analyses were similar (Appendix E). 
with the difference between the minimum and maximum concentrations being only 5 and $7 \%$ for samples obtained at 22 and 32 min during the test. This result confirmed that in the absence of ice and steam (or hot air) the aerosol was essentially well-mixed in the inlet diffuser and distributed uniformly into the ice-basket region by the inlet turning vanes.

Test 5 provided the next simplest case because it was performed with ice and, although the inlet temperature was $191^{\circ} \mathrm{C}$, without steam. The distribution of aerosol concentration between the open flow channels in the lower ice-basket region was less uniform than during $T 31$, the baseline test. The difference between the minimum and maximum concentrations was 24\% for the single case measured. In addition, slightly greater aerosol concentrations (16\%) were present in the NW and NE flow channels compared to the SW and SE channels. It is believed that cold air possibly descending from the ice-basket region caused the warmer inlet flow $\left(191^{\circ} \mathrm{C}\right)$ to be deflected upward in the inlet diffuser, thus preferentially entering the open flow channels NW and NE.

Results of the distribution of aerosol mass concentration during tests having both ice and steam revealed even greater differences between the four open flow channels in the ice-basket region (Table 4.10). Aerosol mass concentrations were generally greater in the two channels receiving flow from the upper region of the inlet diffuser. This difference was pronounced near the bottom of the ice-basket region (Quad Station 5A), and greatly reduced near the top (Quad Station 1A). Greater concentrations were measured in the NW and NE than in the SW and SE flow channels at Quad Station 5A in 16 of 19 test cases. The ratio of aerosol concentrations in the north to those in the south flow channels ranged between 0.73 and 9.3 at Quad Station 5A, and averaged $2.7 \div 2.1$. In contrast, the range of concentrations between north and south flow channels ranged from 0.26 to 2.4 at Quad Station $1 A$, and averaged $1.1=0.5$. This provides an indication that flow recirculation cells may have been limited to the inlet diffuser and the lower regions of the ice-basket region. No clear relationship between single test parameters and the degree of channeling of aerosol mass concentration was evident although SMF and the flow rate of the noncondensible fraction of the inlet gas flow were probably the most important parameters.

\subsubsection{Particle Mass Flow Rate}

Particle mass flow rates were determined at the inlet and outlet of the test section (Stations $6 \mathrm{~A}$ and 0 ) to provide information for determining particle retention (Section 4.3.6). These results were determined from data generally obtained during three or more periods of each test. Particle mass flow rates were calculated as the product of aerosol mass concentration and the actual gas flow rate present in the test section at the time and location of each aerosol sample. Particle mass flow rate is defined as the mass of aerosol particles passing the sampling location per unit time and does not include the mass of the gas (air and steam) or water droplets. Particle mass flow rates are listed in Appendix E for Test 2 and each test with ice present in the test section. As described previously (Section 3.5.7), the aerosol mass concentration data obtained at intermediate stations within the ice-basket 
region could not be used to determine intermediate DFs (for example, the DF between Stations $6 A$ and $5 A$ ). This was because, although the average gas composition and aerosol concentration might be known (especially at the quad stations where samples were obtained from each open flow quadrant between the ice baskets) the direction and magnitude of the gas flow in each channel and in the interchannel and interbasket regions were not known.

Figures in Appendix $G$ show particle mass flow rate versus time at the inlet and outlet of the test section for each test. Particle mass flow rates in the figures represent values determined in Appendix E. Sampling was not performed during the early periods of each test to allow the test section to be purged about five times by the inlet gases. The duration of this delay varied and was based on the thermal-hydraulic characteristics of each test. In the figures, straight lines connect data obtained from the same station and do not represent instantaneous particle mass flow rate information. Solid lines connecting the data points represent results based on gravimetric analysis of the aerosol samples, and dashed lines represent those based on chemical analyses. Tests $12 \mathrm{a}$ and $12 \mathrm{~b}$, and Tests $12 \mathrm{c}$ and $12 \mathrm{~d}$ were plotted on the same figures, with data from one test connected using solid lines, and the other using dashed lines. All data from Test 12a through $12 \mathrm{~d}$ were analyzed using a fluoroscopic method. Where particle mass flow rates were available based on gravimetric and chemical methods of analysis, both sets of results are plotted on the same scales. Results based on both types of analyses were similar, as shown in the figures for Tests $8,10,11,13 a, 13 b, 14 a$, and $14 b$.

Aerosol particle mass flow rate results show that aerosol generation was roughly steady during most tests. An exception was the particle mass flow rate passing the inlet during Test 8 (Appendix 6 ). The inability to maintain a steady inlet aerosol particle flow rate during the test was the result of intermittent failure of the energy mill aerosol generator.

\subsubsection{Particle Retention: Decontamination Factor}

Particle capture in the test section was determined as decontamination factor (DF) and particle retention percentage (R), as described in Section 3.5.7. Summaries of all DF and $R$ results are shown in Tables 4.11 and 4.12 , and the test data are shown graphically in Figures 4.35 through 4.46 . Agreement between gravimetric and chemical analyses was usualiy good, as shown in the results of Tests $8,13 a, 13 b, 14 a$, and 14b, all tests for which comparison between the two analytical methods was possible (Tables 4.11 and 4.12, and Figures 4.38,4.42, 4.44, and 4.46). Data presented in the tables are separated into four categories by the presence or absence of steam and by inlet noncondensible gas flow rate, two test variables thought to have affected particle capture in the test section. Steam influenced particle capture primarily by condensing on ice and other cool surfaces and removing particles by Stefan flow but also by contributing water vapor for particle growth and subsequent sedimentation. Both steam content and noncondensible gas flow rate also influenced particle capture by affecting the residence time of particles in the ice-basket region. Gas flow rates were arbitrarily separated into two categories, low and medium. Low noncondensible gas flow rates were those between about 0.03 and $0.07 \mathrm{~m}^{3} / \mathrm{s}$, medium rates were between 0.10 and $0.17 \mathrm{~m}^{3} / \mathrm{s}$. 
TABLE 4.11. Results of DF Measurements: Simple Case (No Steam)

\begin{tabular}{|c|c|c|c|c|c|c|c|c|c|}
\hline Test & Ice & $\begin{array}{c}\text { Inlet } \\
\text { Temp. } \\
\left({ }^{\circ} \mathrm{C}\right)\end{array}$ & $\begin{array}{l}\text { Inlet } \\
\text { SMF }\end{array}$ & $\begin{array}{c}\text { Inlet Flow } \\
\text { Rate } \\
(\mathrm{m} 3 / \mathrm{s}) \\
\end{array}$ & $\begin{array}{c}\text { Particle } \\
\text { Solubility } \\
\text { (S/I) }\end{array}$ & $\begin{array}{c}\text { Inlet }^{(a)} \\
\text { AMMD } \\
\text { (um) }\end{array}$ & $\begin{array}{l}\text { No. of (b) } \\
\text { Samples } \\
\text { \& Analysis }\end{array}$ & $\begin{array}{c}\text { Test }(c, d) \\
\text { Section } \\
\text { DF }\end{array}$ & $\begin{array}{c}\text { Particle }^{(d)} \\
\text { Retention } \\
\text { R (\%) }\end{array}$ \\
\hline \multicolumn{10}{|c|}{ Low gas flow rate } \\
\hline $\mathrm{T} 21^{(\mathrm{e})}$ & No & $\sim 20$ & 0.0 & $\sim 0.03$ & $S$ & 0.9 & $1, \mathrm{~m}$ & 1.3 to 1.7 & 24 to 40 \\
\hline $\mathrm{T} 22^{(\mathrm{e})}$ & No & $\sim 20$ & 0.0 & $\sim 0.03$ & $S$ & 1.3 & $1, \mathrm{~m}$ & $\underline{1.11}$ & 10 \\
\hline $\mathrm{T} 23^{(\mathrm{e})}$ & No & $\sim 20$ & 0.0 & $\sim 0.03$ & $S$ & 1.8 & $1, \mathrm{~m}$ & 1,0 & $=0$ \\
\hline 2 & No & 86 & 0.0 & 0.031 & $\mathbf{S}$ & 6 & $2, \mathrm{~m}$ & $3.0,2.1 \quad \underline{2.2}$ & $67,53 \quad 55$ \\
\hline 3 & Yes & 85 & 0.0 & 0.029 & I & $>15$ & $3, \mathrm{~m}$ & $11,7.5 \quad 2.4$ & $91,87 \underline{89}$ \\
\hline
\end{tabular}

Medium gas flow rate

\begin{tabular}{|c|c|c|c|c|c|c|c|c|c|}
\hline $\mathrm{PCl}$ & No & -20 & 0.0 & 0.15 & I & 5 & $2, \mathrm{f}$ & $1.03,1.14 \quad 1.08$ & $2.5,12 \underline{8}$ \\
\hline PC3 & No & -20 & 0.0 & 0.15 & I & 11 & $3, \mathrm{f}$ & $1.6,1.3 \underline{1.4}$ & $37,22 \quad 29$ \\
\hline PC6 & No & -20 & 0.0 & 0.15 & I & 11 & $3, \mathrm{f}$ & $1.4,1.5 \overline{1.4}$ & $31,34 \overline{29}$ \\
\hline PC4 & No & -20 & 0.0 & 0.15 & I & 15 & $2, \mathrm{f}$ & $1.7,1.8 \quad \underline{1.7}$ & $40,43 \quad 41$ \\
\hline PC5 & No & $\sim 20$ & 0.0 & 0.15 & I & 15 & $4, f$ & $1.5,1.71 .7$ & $33,42 \leq 1$ \\
\hline $\mathrm{T} 17^{(\mathrm{f})}$ & No & $\sim 20$ & 0.0 & 0.15 & I & 1.8 & $1, \mathrm{~m}$ & 1,0 & $=0$ \\
\hline $\mathrm{T} 18^{(f)}$ & No & $\sim 20$ & 0.0 & 0.14 & I & $\sim 8$ & $1, \mathrm{~m}$ & 1,13 & $\underline{12}$ \\
\hline T19(f) & No & $\sim 20$ & 0.0 & 0.14 & I & 11 & $1, \mathrm{~m}$ & 1.32 & 24 \\
\hline $\mathrm{T} 20^{(f)}$ & No & $\sim 20$ & 0.0 & 0.14 & I & 6 & $1, \mathrm{~m}$ & 1.19 & $\underline{16}$ \\
\hline $\mathrm{T} 27$ & No & $\sim 20$ & 0.0 & 0.13 & $\mathbf{S}$ & 7 & $3, \mathrm{~m}$ & $1.3,1.4 \quad 1.4$ & $24,31 \quad 29$ \\
\hline $\mathrm{T} 29$ & No & $\sim 20$ & 0.0 & 0.13 & $\mathbf{S}$ & 3 & $3, \mathrm{~m}$ & $1.09,1.2 \underline{1.11}$ & $8,14 \underline{10}$ \\
\hline $\mathrm{T} 30$ & No & $\sim 20$ & 0.0 & 0.16 & $\mathbf{S}$ & 3 & $2, \mathrm{~m}$ & $1.4,1.09 \quad 1.2$ & $28,8 \underline{18}$ \\
\hline $\mathrm{T} 31$ & No & -20 & 0.0 & 0.16 & $S$ & 7 & $2, \mathrm{~m}$ & $1.17,1.14 \underline{1.16}$ & $14,13 \quad 14$ \\
\hline 5 & Yes & 191 & 0.0 & 0.10 & I & 4 & $3, \mathrm{~m}$ & $2.4,2.4 \underline{2.4}$ & $58,58 \quad 58$ \\
\hline (a) & \multicolumn{9}{|c|}{$\begin{array}{l}\text { AMMD = aerodynamic mass median diameter. PC tests were performed using monodisperse particles, all } \\
\text { other aerosols were polydisperse (Section } 4.3 .3 \text { ). }\end{array}$} \\
\hline (b) & \multicolumn{9}{|c|}{ Analysis method: gravimetric $(m)$, chemical $(c)$, or fluoroscopic $(f)$} \\
\hline (c) & \multicolumn{9}{|c|}{ Determined between Station 6A and 0 except for Tests 2 and 3 (between $6 \mathrm{~A}$ and $1 \mathrm{Al}$ ). } \\
\hline (d) & \multicolumn{9}{|c|}{$\begin{array}{l}\text { DF and } R \text { results are listed as initial, final, average. Intermediate test results are not listed but are shown } \\
\text { in Figures } 4.35 \text { through } 4.46 \text { and may be calculated from the spreadsheets. Average test results determined } \\
\text { by averaging all aerosol particle mass flow rate data. }\end{array}$} \\
\hline (e) & \multicolumn{9}{|c|}{ Results based on outlet samples obtained at Station 1B. } \\
\hline & \multicolumn{9}{|c|}{ Results based on outlet samples obtained at Station 2B. } \\
\hline
\end{tabular}


TABLE 4.12. Results of DF Measurements: Complex Case (Both Ice and Steam Present)

\begin{tabular}{ccccccccc} 
& & Inlet & \multicolumn{2}{c}{ NC Flow(a) $^{(a)}$ Particle } & Inlet(b) & No. of (c) & Test(d,e) & Particle(e) \\
Test & Temp. & Inlet & Rate & Solubility & AMMD & Samples & Section & $\begin{array}{c}\text { Retention } \\
\text { R }\end{array}$ \\
\hline
\end{tabular}

Low noncondensible gas flow rate

\begin{tabular}{|c|c|c|c|c|c|c|c|c|c|}
\hline 6 & Yes & 122 & 0.65 & 0.063 & I & 4 & $2, \mathrm{~m}$ & $7,4 \underline{4.5}$ & 86,7378 \\
\hline $7^{(f)}$ & Yes & 146 & 0.60 & 0.023 & $\mathbf{S}$ & 3 & $4, c$ & $\begin{array}{c}350,33 \quad \underline{58} \\
46,33 \quad 36\end{array}$ & 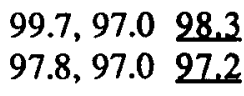 \\
\hline 9 & Yes & 102 & 0.87 & 0.051 & $S$ & 8 & $3, \mathrm{c}$ & $19,57 \underline{29}$ & $95,98.296 .6$ \\
\hline 10 & Yes & 114 & 0.94 & $\sim 0.03$ & $S$ & 4 & $3, \mathrm{c}$ & $82,6(\mathrm{~g})$ & $98.8,83(\mathrm{~g})$ \\
\hline 11 & Yes & 105 & 0.86 & 0.054 & I & $\mathrm{ND}^{(\mathrm{h})}$ & $3, \mathrm{c}$ & $24,8 \quad 16$ & $95.9,88 \quad 93.7$ \\
\hline $12 a$ & Yes & 86 & 0.19 & 0.065 & I & $0.9(i)$ & $2, \mathrm{f}$ & 11,910 & 91,8990 \\
\hline $12 b$ & Yes & 90 & 0.18 & 0.065 & I & $0.9^{(i)}$ & $2, \mathrm{f}$ & $9,4 \underline{6}$ & $89,76 \quad 84$ \\
\hline $12 c$ & Yes & 91 & 0.18 & 0.065 & I & $3.1^{(i)}$ & $2, \mathrm{f}$ & 6,55 & $82,80 \underline{80}$ \\
\hline $12 d$ & Yes & 91 & 0.17 & 0.065 & I & $12^{(\mathrm{i})}$ & $2, \mathrm{f}$ & $13,18 \quad 15$ & $92,9 4 \longdiv { 2 3 . 6 }$ \\
\hline $13 a$ & Yes & 107 & 0.21 & 0.058 & $S$ & $\begin{array}{l}1.4 \\
1.5\end{array}$ & $\begin{array}{l}1, m \\
2, c\end{array}$ & $\begin{array}{c}-,-24 \\
-, 16 \underline{23}\end{array}$ & $\begin{array}{r}-,-95.8 \\
-, 9495.7\end{array}$ \\
\hline $13 b$ & Yes & 107 & 0.21 & 0.058 & I & $\begin{array}{l}2.0 \\
2.2\end{array}$ & $\begin{array}{l}3, \mathrm{~m} \\
3, \mathrm{c}\end{array}$ & $\begin{array}{ll}3,3 & 3.4 \\
3,3 & 3.1\end{array}$ & $\begin{array}{l}70,66 \quad 71 \\
65,63 \underline{68}\end{array}$ \\
\hline $14 b$ & Yes & 120 & 0.61 & 0.034 & I & $\begin{array}{l}2.2 \\
2.5\end{array}$ & $\begin{array}{l}3, \mathrm{~m} \\
3, \mathrm{c}\end{array}$ & $\begin{array}{c}10,1011 \\
9,92\end{array}$ & $\begin{array}{c}90,9091.0 \\
89,88 \quad 89\end{array}$ \\
\hline
\end{tabular}

Medium noncondensible gas flow rate

$\begin{array}{cccccccccc}1 & \text { Yes } & 121 & 0.20 & 0.17 & \mathrm{~S} & 3 & 3, \mathrm{~m} & 7,8 \underline{8} & 85,88 \underline{87} \\ 4 & \text { Yes } & 122 & 0.33 & 0.14 & \mathrm{~S} & -9 & 3, \mathrm{~m} & 17,12 \underline{14} & 94,9293 \\ 8 & \text { Yes } & 122 & 0.35 & 0.15 & \mathrm{~S} & 5 & 3, \mathrm{~m} & 7,10 \underline{9.0} & 86,90 \underline{89} \\ & & & & & & 4 & 3, \mathrm{c} & 6,10 \underline{8.5} & 84,90 \underline{88} \\ 14 \mathrm{a} & \text { Yes } & 114 & 0.18 & 0.098 & \mathrm{I} & 2.0 & 3, \mathrm{~m} & 3,3 \underline{2.8} & 70,64 \underline{64} \\ & & & & & 2.0 & 2, \mathrm{c} & 2.5,-\underline{2.4} & 60,-\underline{58}\end{array}$
(a) NC = approximate noncondensible portion of inlet gas flow rate.
(b) $\mathrm{AMMD}=$ aerodynamic mass median diameter. Test 12a through $12 \mathrm{~d}$ were performed using monodisperse particles, all other aerosols were polydisperse (Section 4.3.3).
(c) Analysis method: gravimetric (m), chemical (c), or fluoroscopic (f).
(d) Determined between Station 6A and 0 except for Tests 1 and 4 (between 6A and 1A1).
(e) $\mathrm{DF}$ and $\mathrm{R}$ results are listed as initial, final, average. Intermediate test results are not listed but are shown in Figures 4.35 through 4.46 and may be calculated from the spreadsheets. Average test results determined by averaging all aerosol particle mass flow rate data.
(f) The first row of results include the entire test; the second row only the last half of the test. Conditions were not stable during the first $\sim 50 \mathrm{~min}$.
(g) The variation in results between the beginning and end of Test 10 was sufficiently great as to preclude the determination of a test-average result.
(h) No data available. Approximate $A M M D=4 \mu \mathrm{m}$.
(i) AMMDs measured at Station 6A are listed, produced sizes were 1.2, 2.6, 5.6, and $12 \mu \mathrm{m}$. 

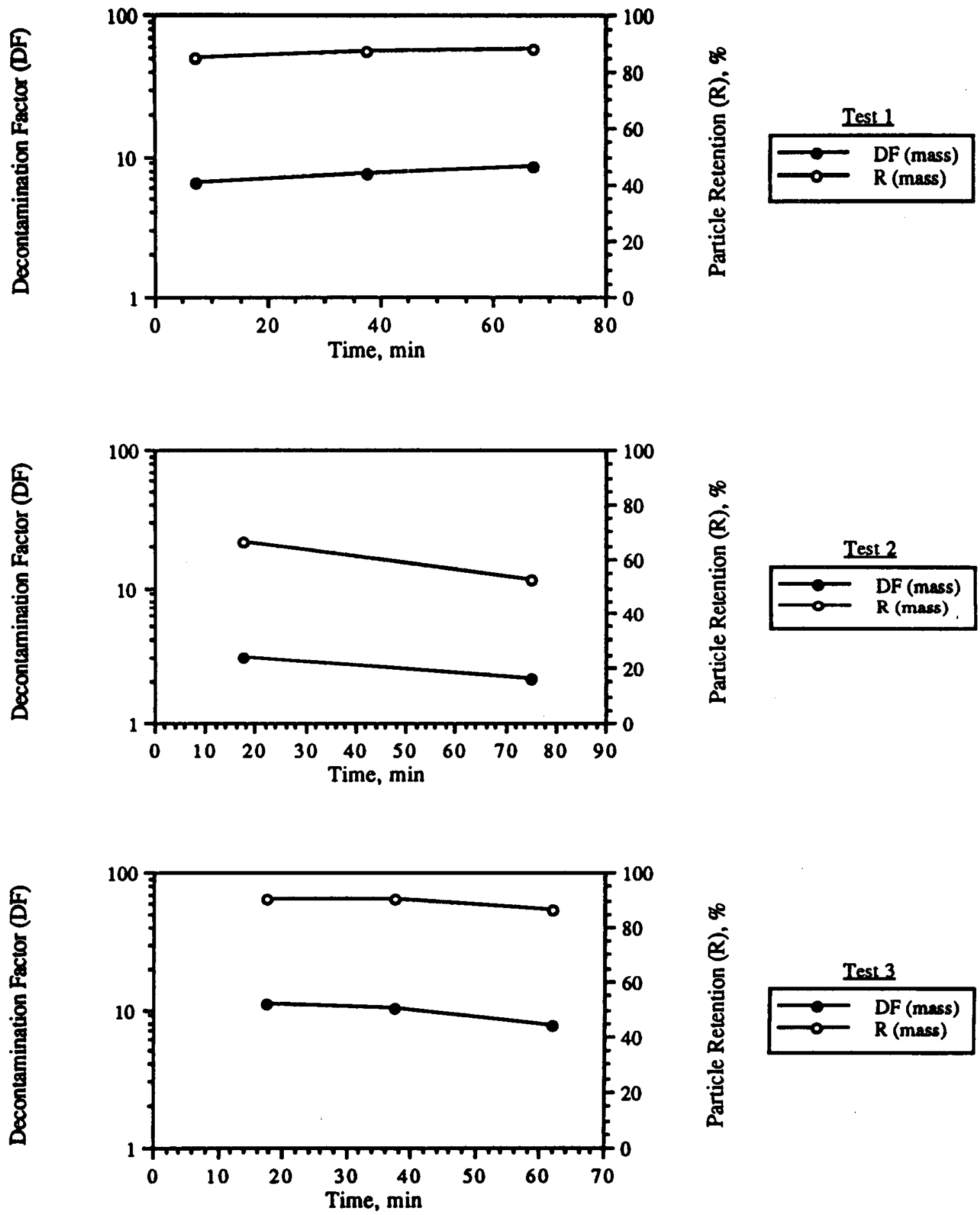

FIGURE 4.35. Decontamination Factor and Particle Retention Results for Tests 1,2 , and 3. Results were based on gravimetric (mass) sample analysis. 

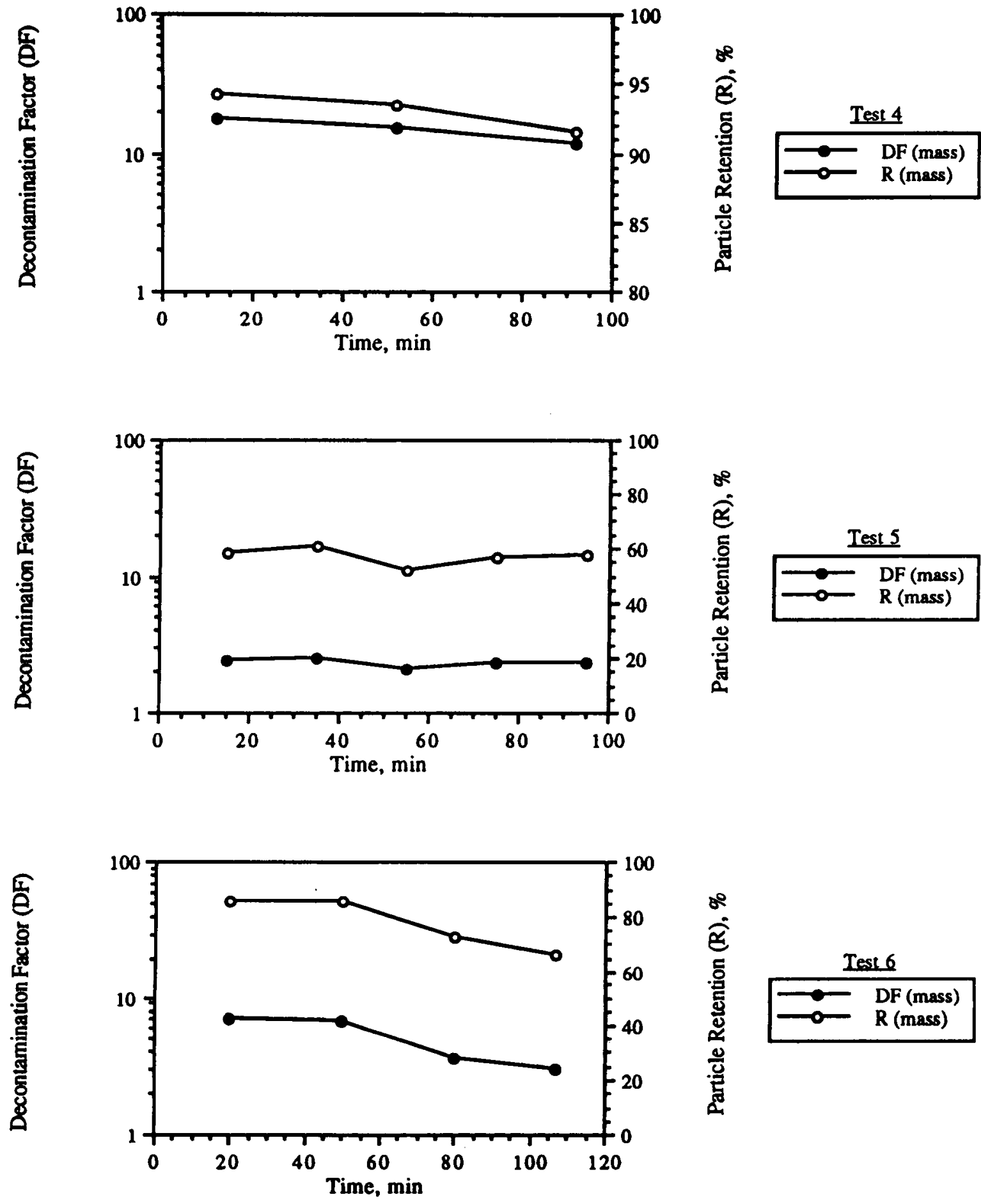

FIGURE 4.36. Decontamination Factor and Particle Retention Results for Tests 4, 5, and 6. Results were based on gravimetric (mass) sample analysis. Results for Test 5 (35 and $75 \mathrm{~min}$ ) and Test 6 (50 and $107 \mathrm{~min}$ ) were calculated based on estimated inlet particle mass flow rates. 

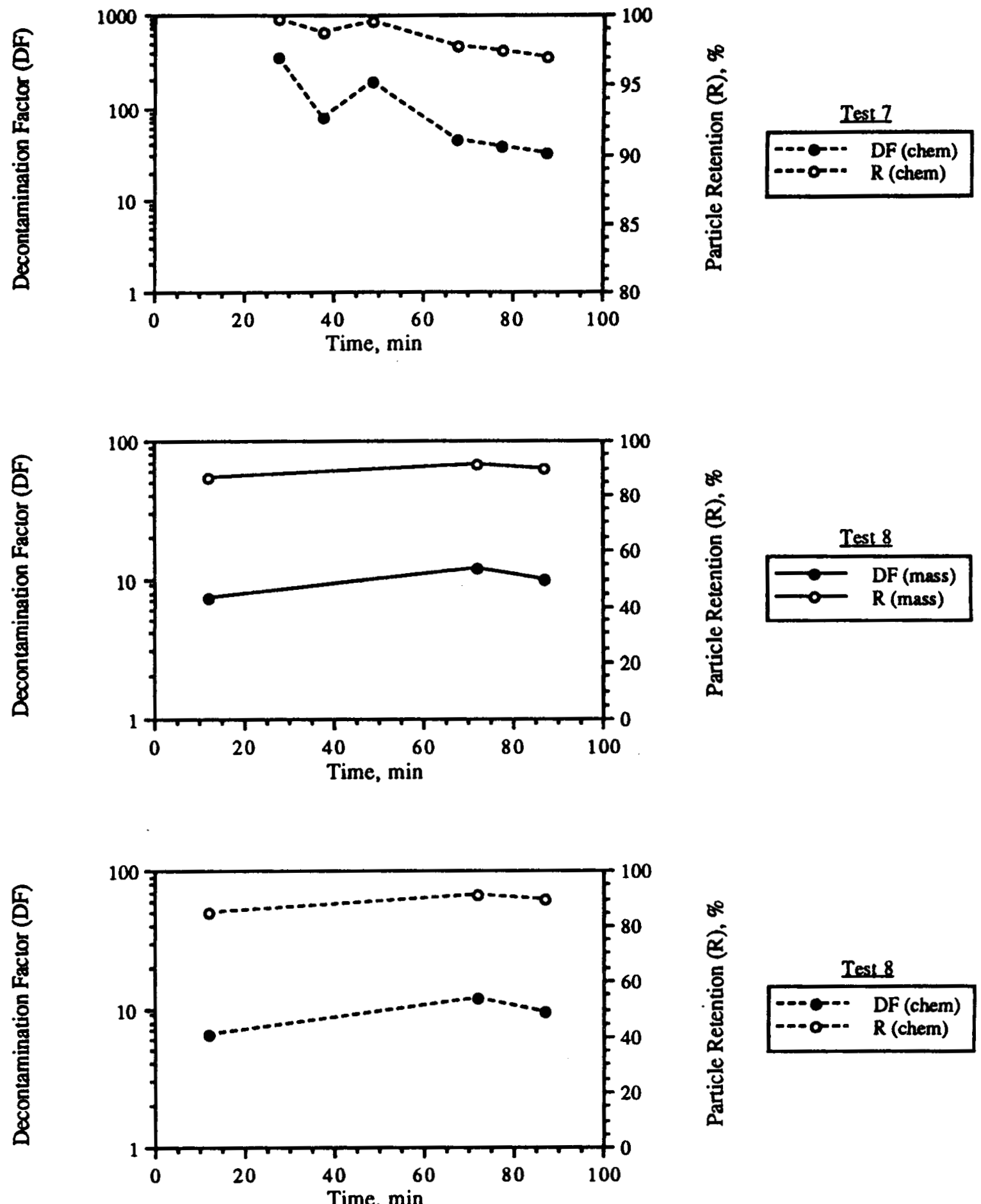

FIGURE 4.37. Decontamination Factor and Particle Retention Results for Tests 7 and 8 . Test 8 results were available based on both gravimetric (mass) and chemical (chem) sample analyses. Results for Test 7 (38 and $78 \mathrm{~min}$ ) were calculated based on estimated inlet particle mass flow rates. 

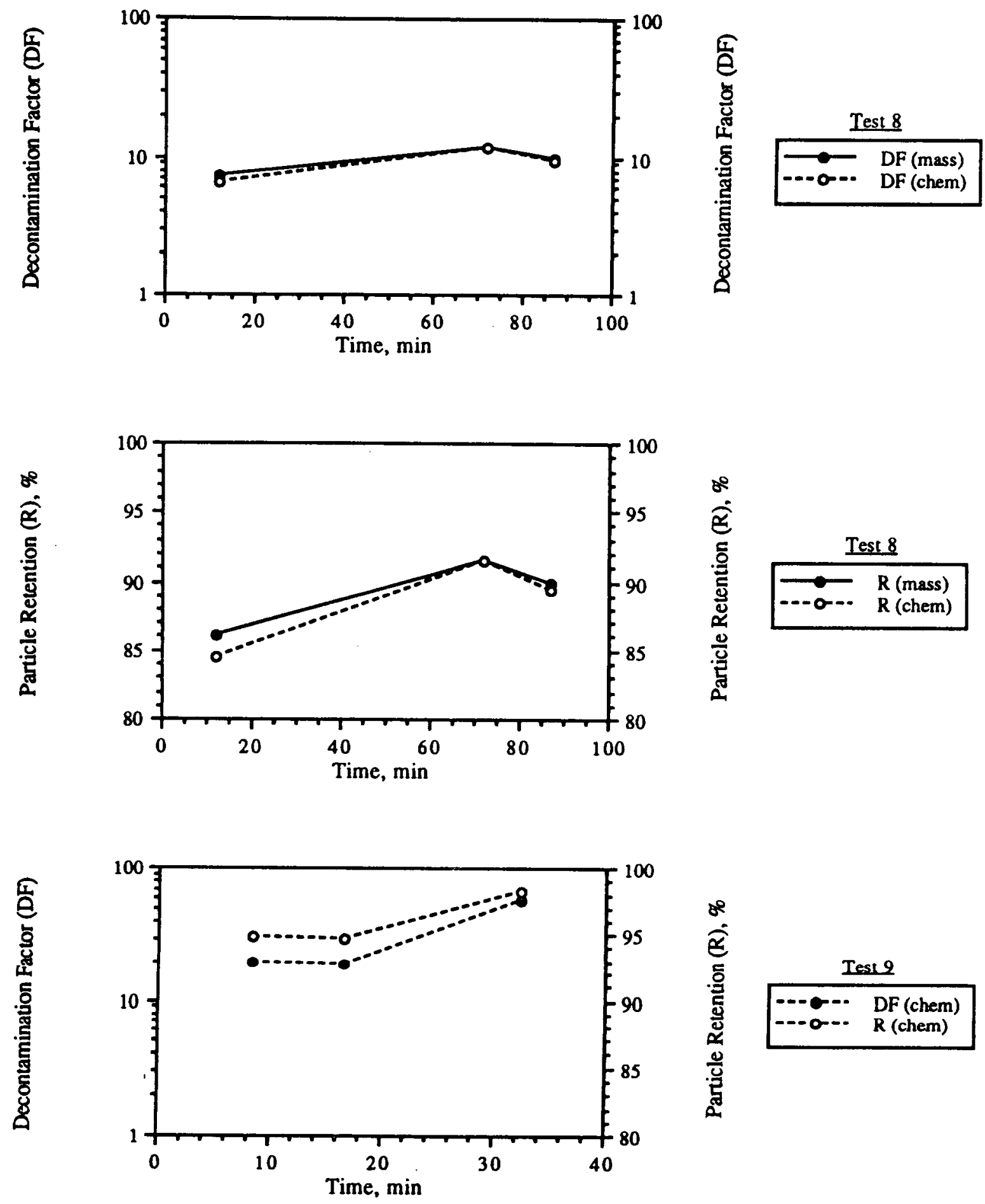

FIGURE 4.38. Decontamination Factor and Particle Retention Results for Test 8 (contd) and Test 9 . Test 8 results were available based on both gravimetric (mass) and chemical (chem) sample analyses and are compared for both DF and $R$. 

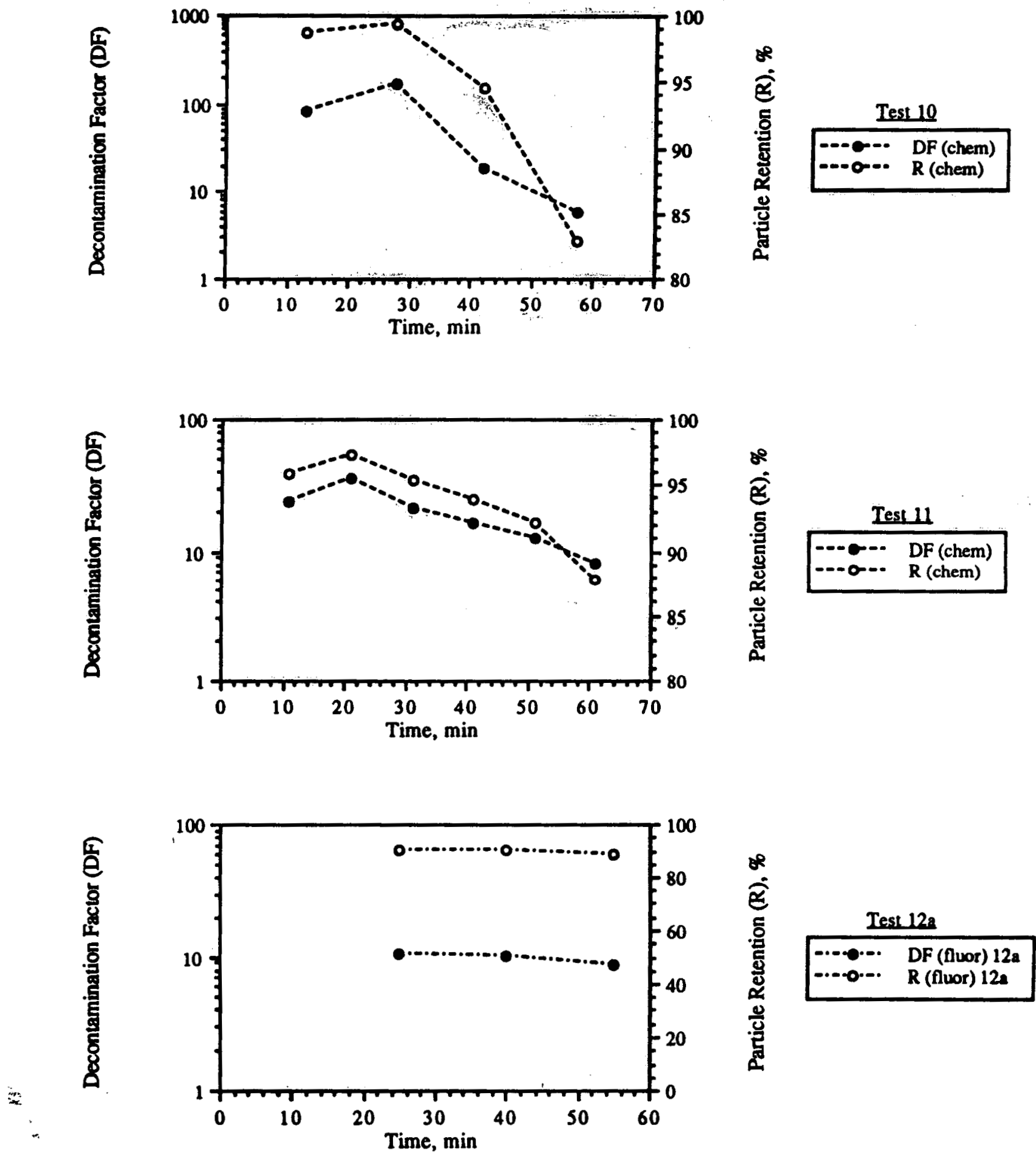

FIGURE 4.39. Decontamination Factor and Particle Retention Results for Tests 10,11 , and 12a. Test $12 \mathrm{a}$ results were based on fluoroscopic (fluor) sample analysis. Results for Test 10 (42 min), Test 11 $(21,32$, and $51 \mathrm{~min})$, and Test $12 \mathrm{a}(40 \mathrm{~min})$ were calculated based on estimated inlet particle mass flow rates. 

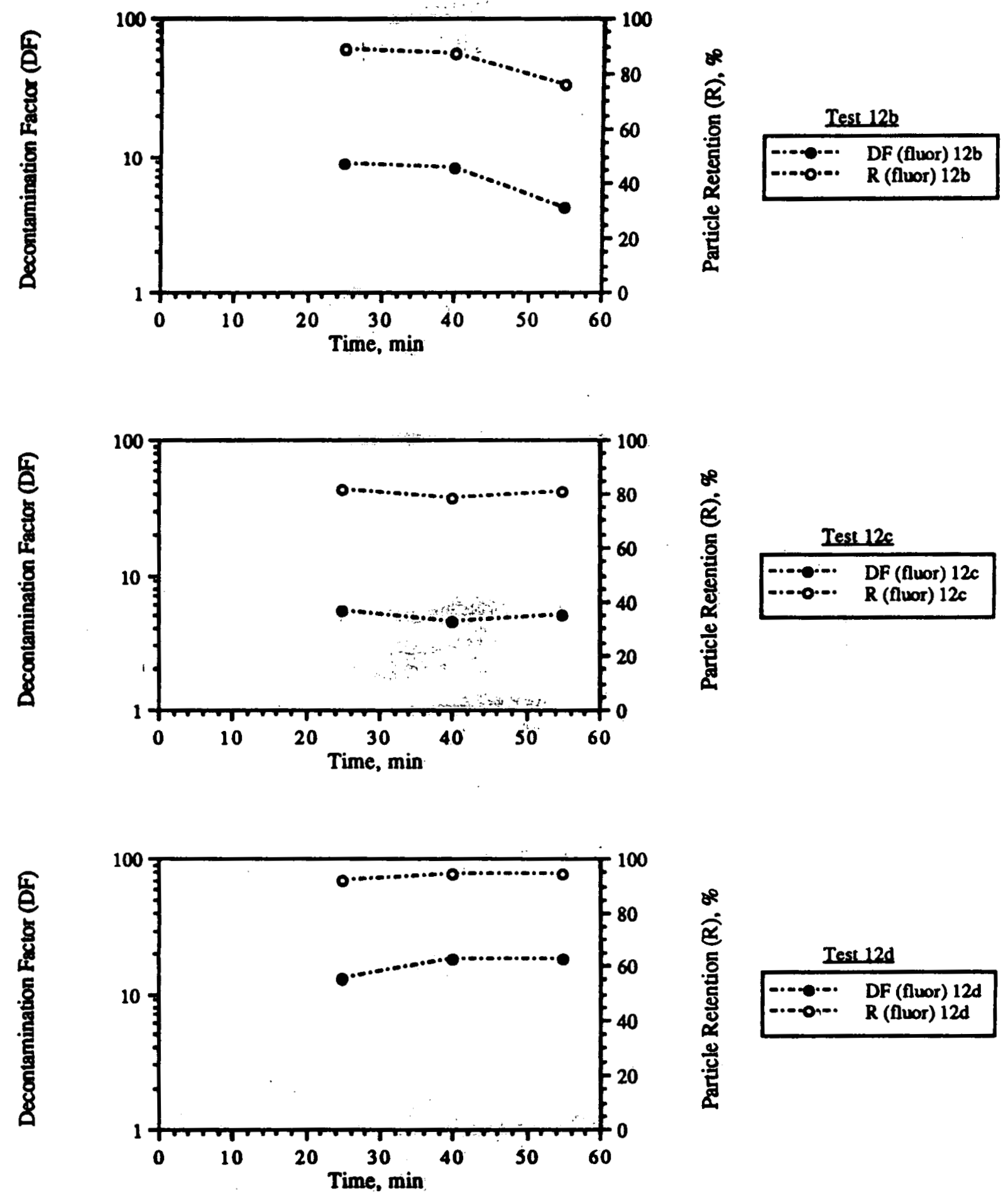

FIGURE 4.40. Decontamination Factor and Particle Retention Results for Tests 12b, 12c, and 12d. Results were based on fluoroscopic (fluor) sample analysis. Results for each test at 40 min were calculated based on estimated inlet particle mass flow rates. 

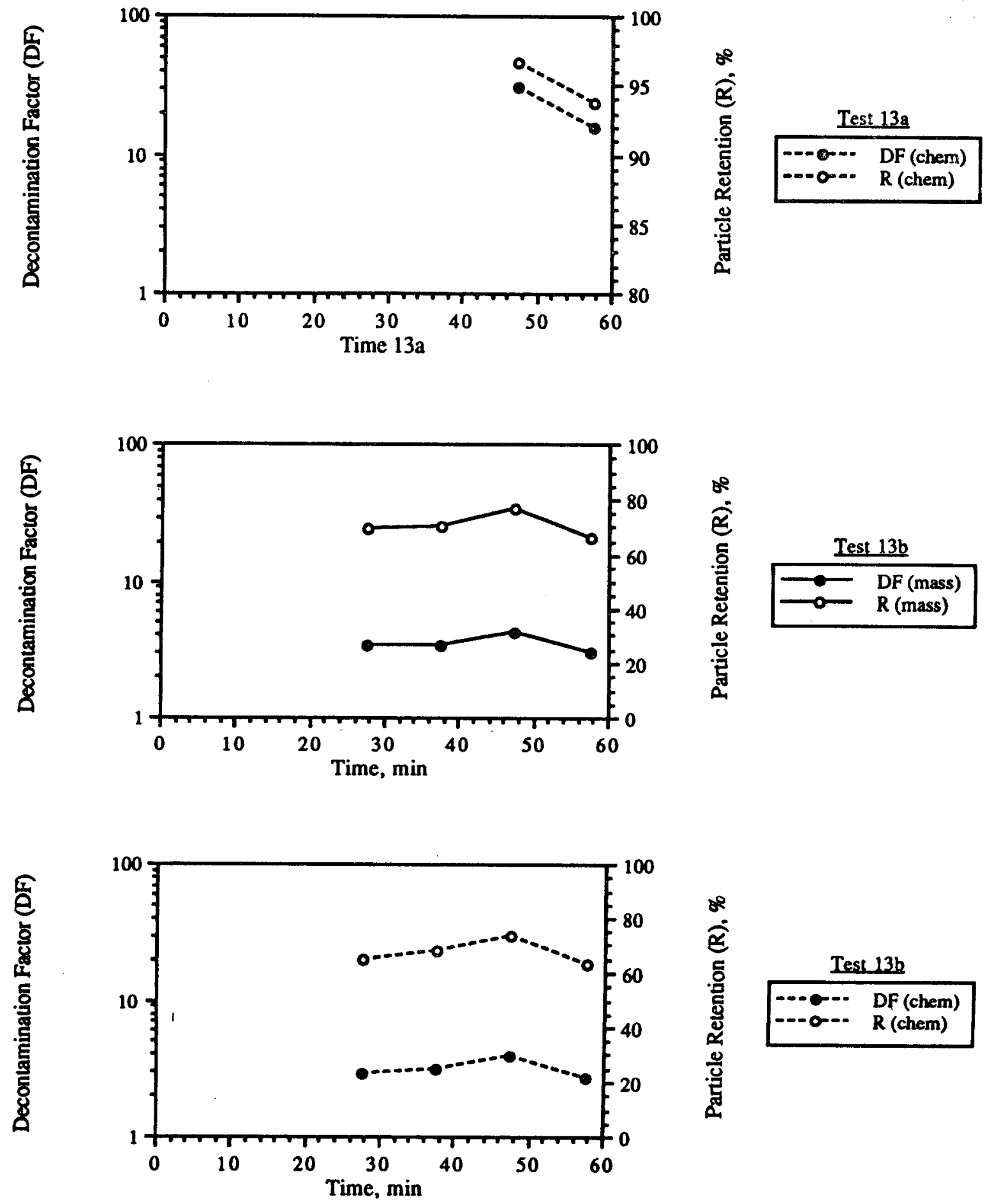

FIGURE 4.41. Decontamination Factor and Particle Retention Results for Tests 13a and 13b. Test 13b results were available based on both gravimetric (mass) and chemical (chem) sample analyses. Results for Test 13b ( $38 \mathrm{~min}$ ) were calculated based on estimated inlet particle mass flow rates. 

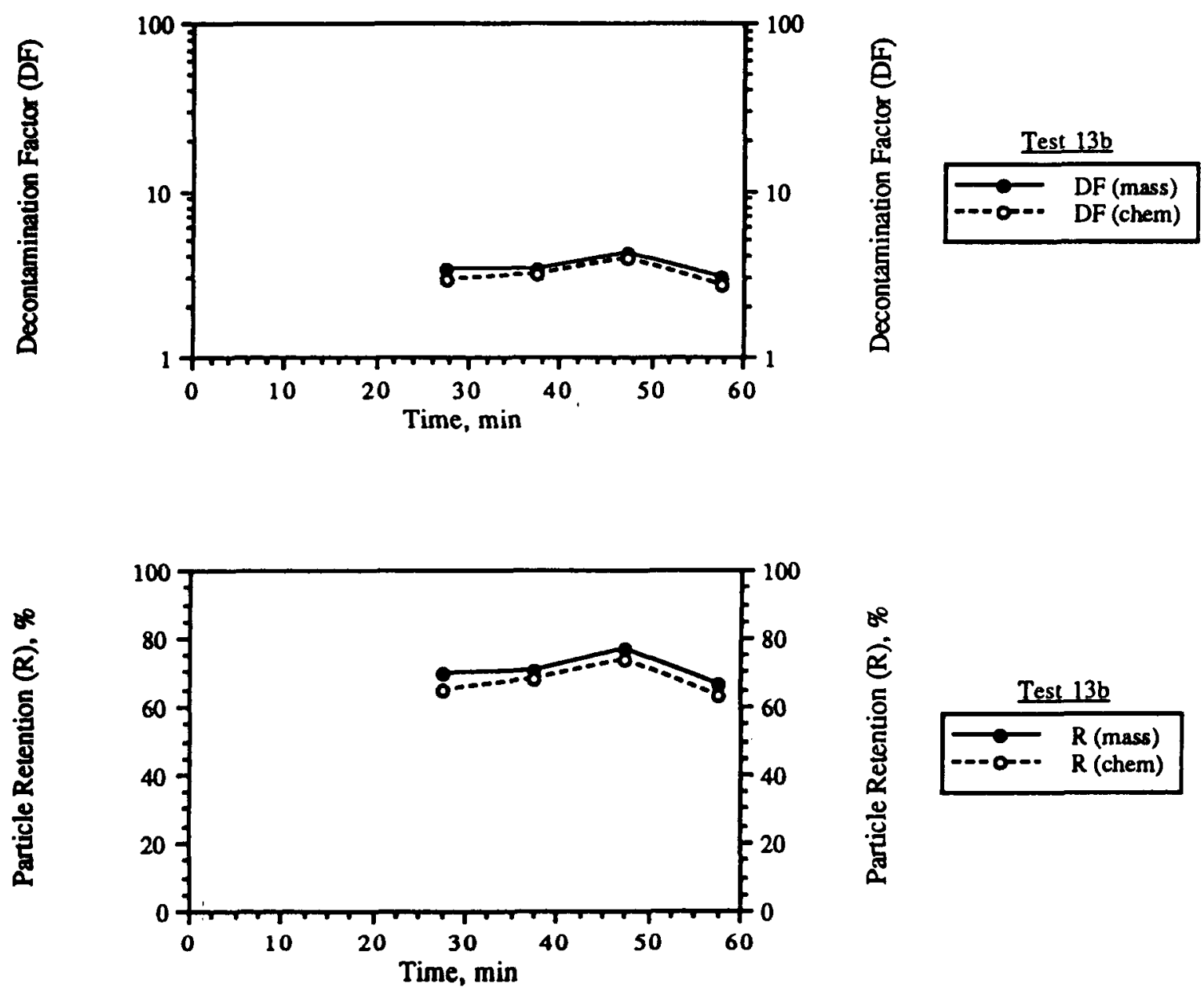

FIGURE 4.42. Decontamination Factor and Particle Retention Results for Test 13b (contd). Test 13b results were available based on both gravimetric (mass) and chemical (chem) sample analyses and are compared for both DF and R. Results for Test 13b (38 min) were calculated based on estimated inlet particle mass flow rates. 

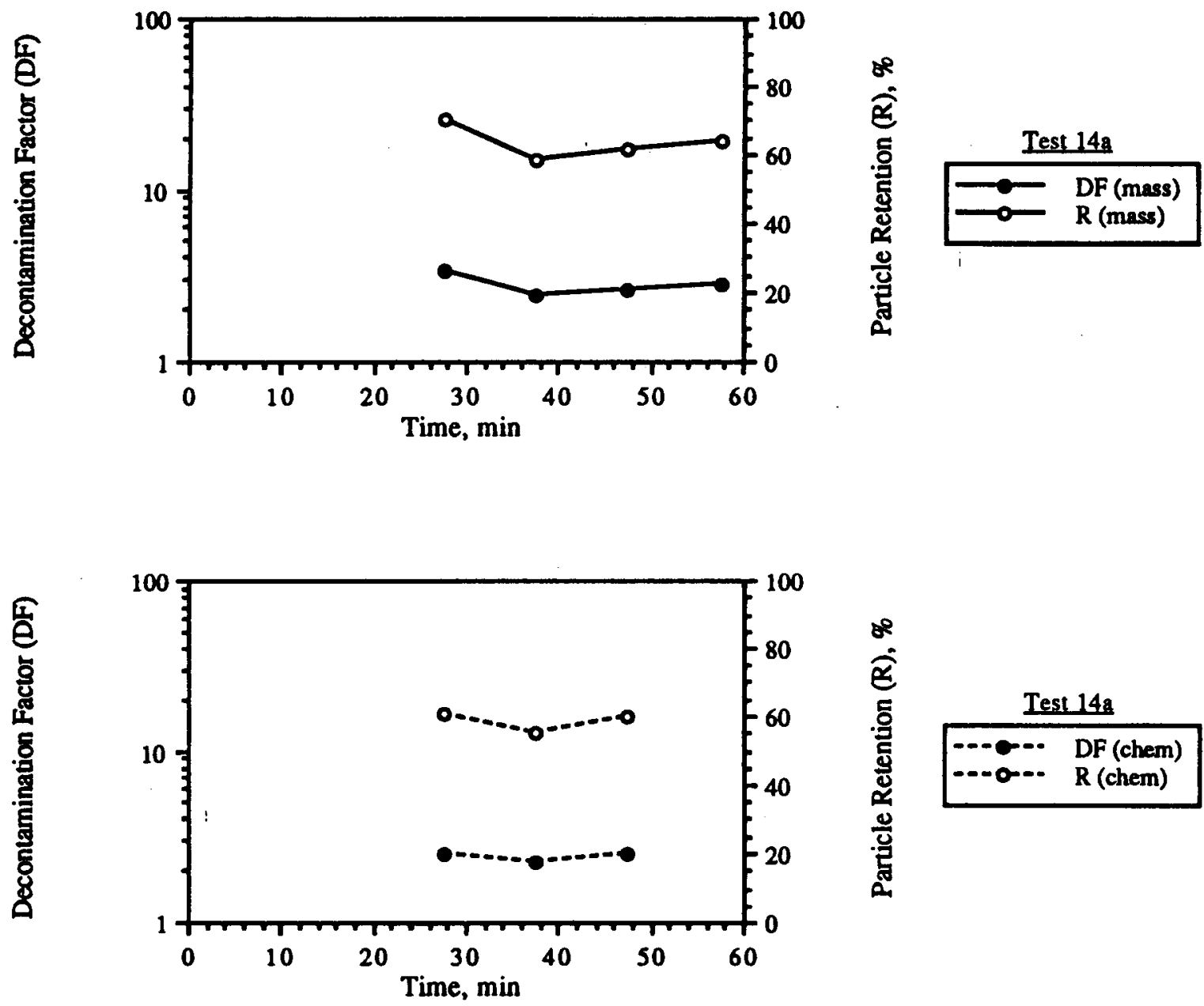

FIGURE 4.43. Decontamination Factor and Particle Retention Results for Test 14a. Test 14a results were available based on both gravimetric (mass) and chemical (chem) sample analyses. Results for Test 14a (38 min) were calculated based on estimated inlet particle mass flow rates. 

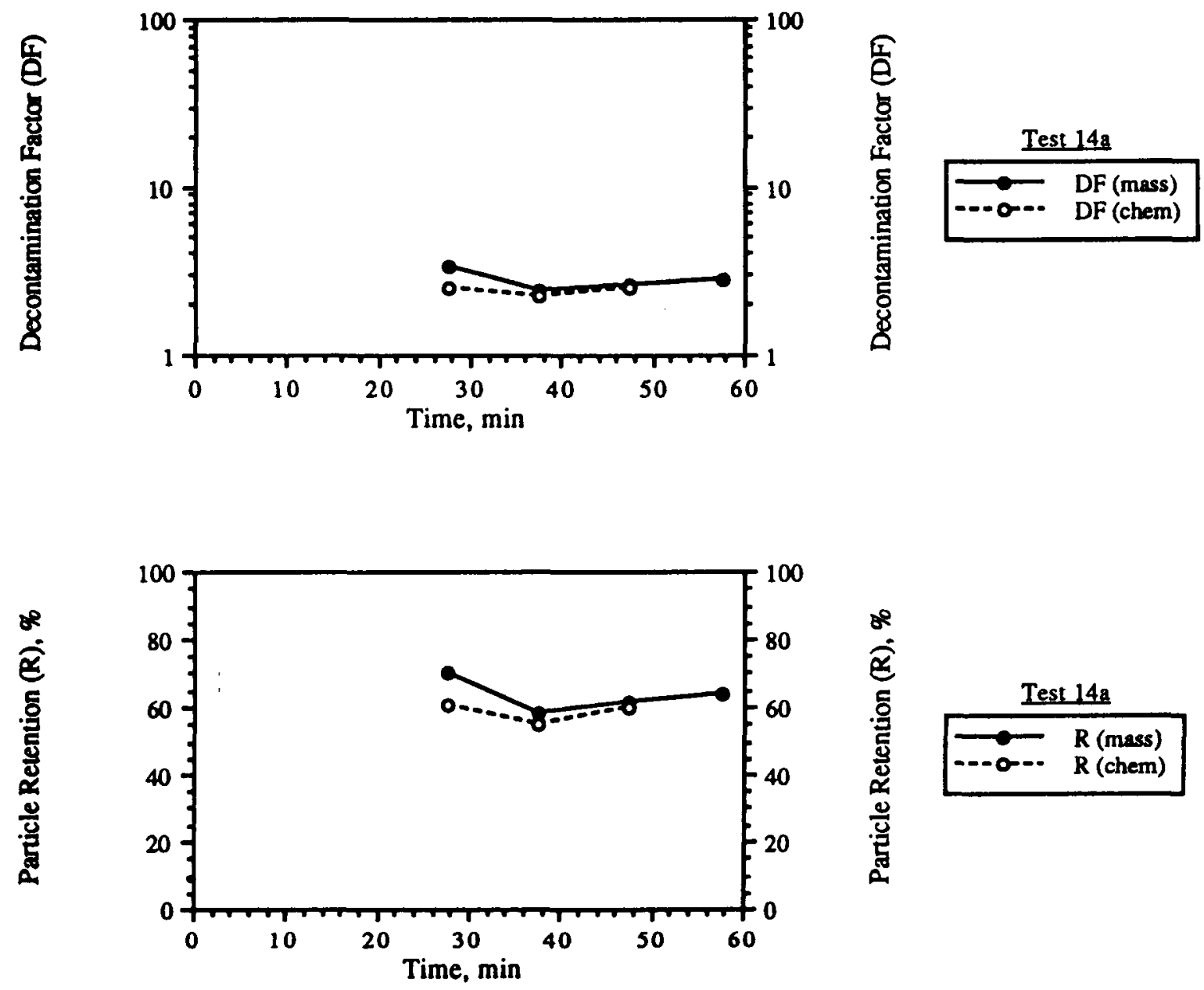

FIGURE 4.44. Decontamination Factor and Particle Retention Results for Test $14 a$ (contd). Test 14a results were available based on both gravimetric (mass) and chemical (chem) sample analyses and are compared for both DF and R. Results for Test 14a (38 min) were calculated based on estimated inlet particle mass flow rates. 

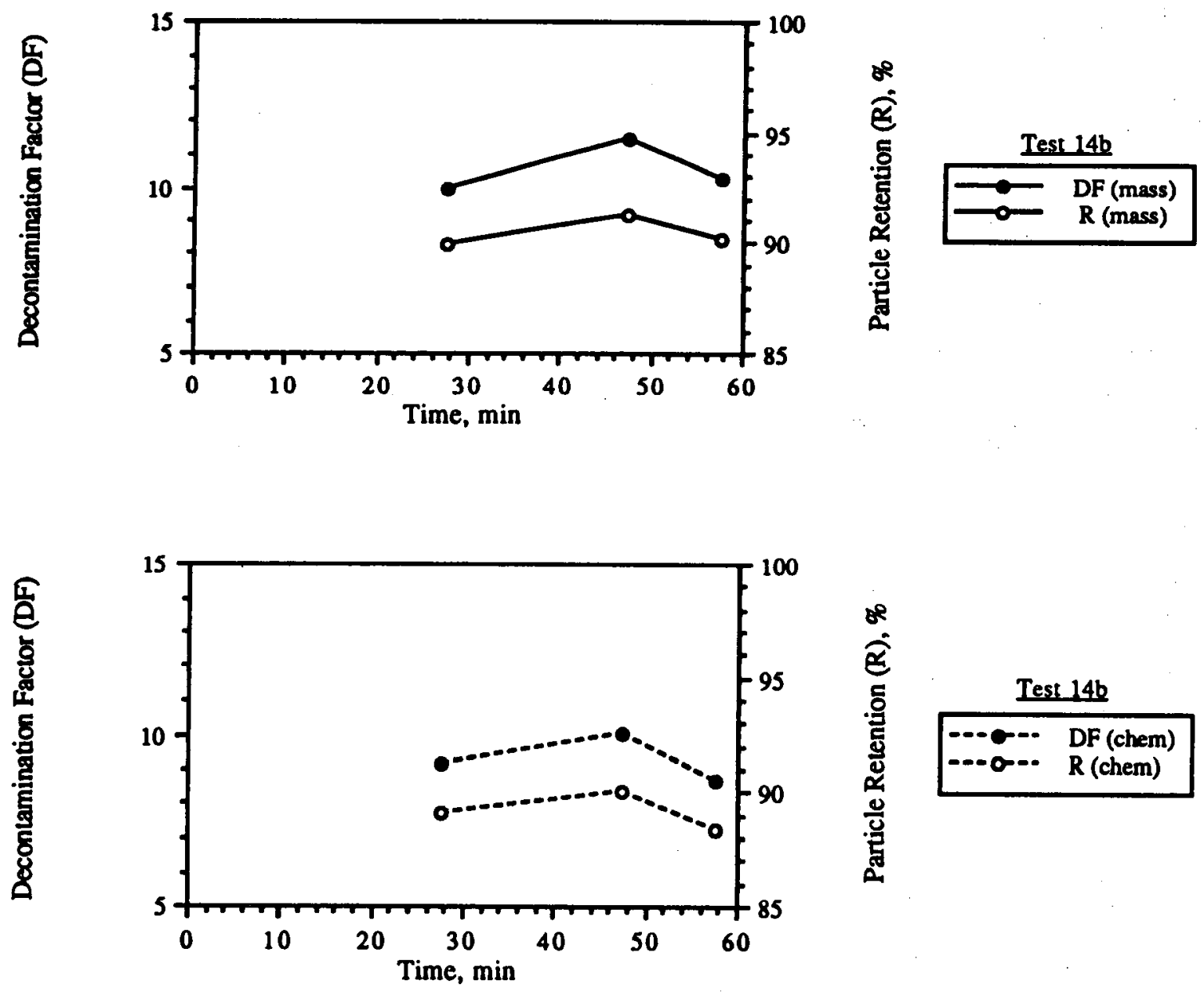

FIGURE 4.45. Decontamination Factor and Particle Retention Results for Test 14b. Test 14b results were available based on both gravimetric (mass) and chemical (chem) sample analyses. 

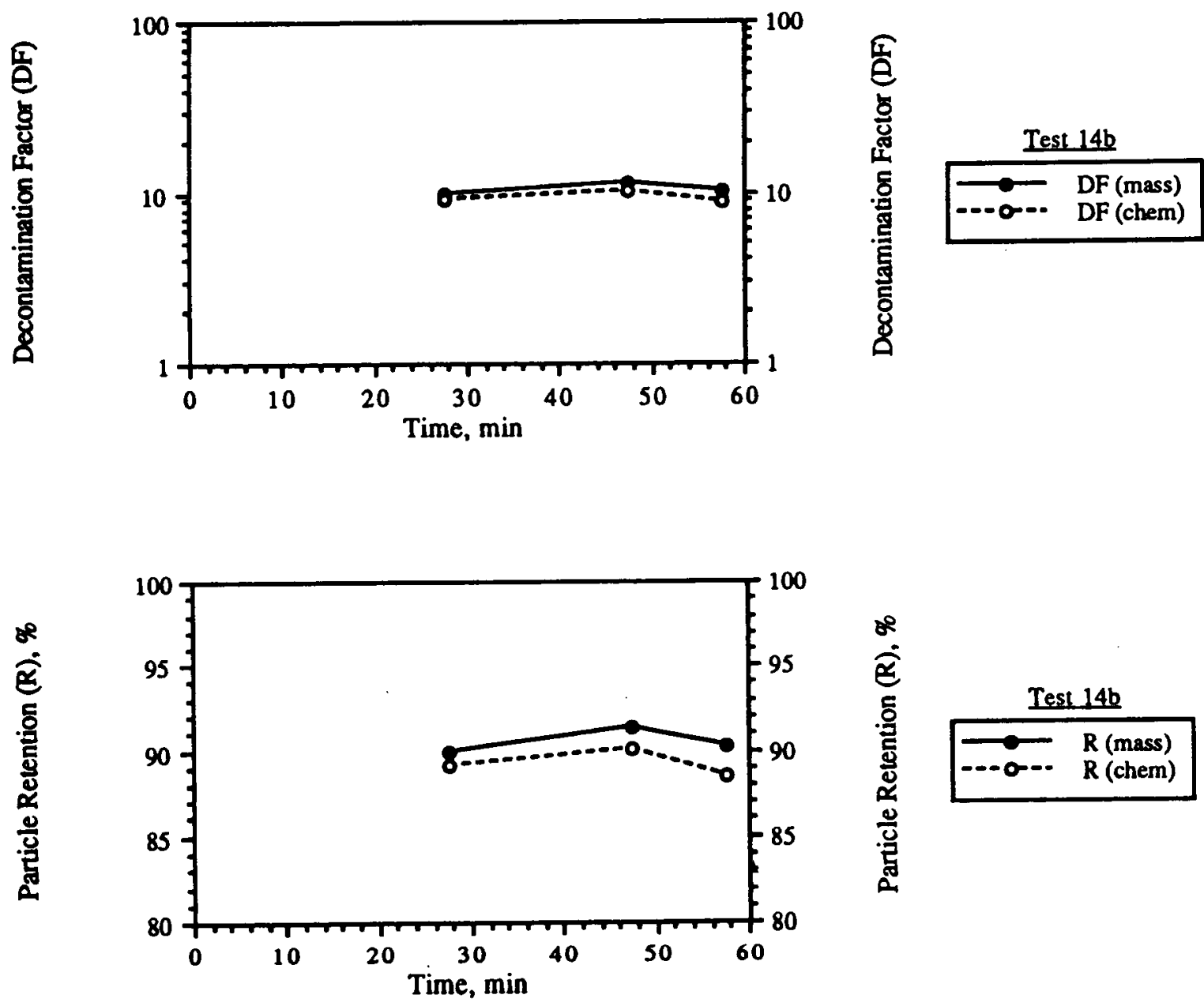

FIGURE 4.46. Decontamination Factor and Particle Retention Results for Test $14 \mathrm{~b}$ (contd). Test $14 \mathrm{~b}$ results were available based on both gravimetric (mass) and chemical (chem) sample analyses and are compared for both $\mathrm{DF}$ and $\mathrm{R}$. 
In addition to SMF and noncondensible gas flow rate, other test parameters potentially affecting particle retention in the test section included particle solubility, inlet particle size, and inlet gas temperature. Soluble particles resulted in greater particle retention than did insoluble particles. The largest particle sizes tested were shown to provide moderately increased particle retention. Over the range of variables tested, particle density, aerosol concentration, and temperature were not believed to significantly affect particle retention.

Tests performed without ice or steam resulted in DF values less than 2.2 ( $R \leq 55 \%$ ) at low gas flow rates, and values ranging between 1.0 and 1.7 $(R=0$ to $41 \%$ ) at medium flow rates (Table 4.11$)$. Greater particle retention at low gas flow rates was attributed to increased residence time and increased settling losses, especially in the inlet region. The particle retention measured during Test T21 was greater than that of similar tests for reasons that were not determined. Because particle size was the only parameter varied during the 13 tests performed at medium gas flow rates (and without ice), it was possible to determine its influence on particle retention in the test section. These results indicated that DF and $R$ increased as particle size increased from 2 to $15 \mu \mathrm{mi}$ however, unlike many experimental investigations, the degree of increase in particle retention in the test section was not great. Over the range of particle sizes considered, DF increased between roughly 1 and 1.7 ( $R$ between less than 10 and $41 \%$ ).

Data from the PC tests (performed without ice or steam and using monodisperse particles) showed the influence of particle settling in the inlet region for a gas flow rate of $0.15 \mathrm{~m}^{3} / \mathrm{s}$. For particle sizes of 4,11 , and $15 \mu \mathrm{m}$, measured DFs between Stations $6 \mathrm{~A}$ and 0 were $1.08 \neq 0.08,1.42 \neq 0.12$, and $1.71 \neq 0.17$, respectively (Table 4.11 ). In comparison, the related DFs between Stations 6B and 1B (roughly equivalent to the ice-basket region of the test section) were $1.02 \neq 0.00,1.11 \neq 0.01$, and $1.15 \neq 0.06$, respectively. The number of DF measurements performed for each particle size were 2, 6, and 6 , for the 5-, 11-, and 15- $\mu \mathrm{m}$ particle sizes, respectively. The data indicated that nearly all of the difference between the two sets of DF measurements was caused by particle loss between Stations $6 \mathrm{~A}$ and $6 \mathrm{~B}$ rather than between Stations $1 B$ and 0 . These results suggest that particle settling losses in the inlet region were the most significant contributing factor to particle capture in the test section for these tests performed without ice or steam.

Two of the simple case tests (no steam) were performed with filled ice baskets and heated inlet air (Table 4.11). Particle retention during Test 3 was influenced by the $>15-\mu \mathrm{m}$ inlet AMMD and was therefore not suitable for comparison with other tests. However, results of Test 5 , performed at medium gas flow rate, showed increased particle retention in the test section. DF was 2.4 for Test 5 compared to 1.1 to 1.4 for comparable tests performed with no ice and with cool inlet air flow, $R$ was $58 \%$ compared to about 8 to $29 \%$.

Results of tests performed with both ice and steam present (Table 4.12) were potentially influenced by several test parameters. In order of presumed importance over the ranges tested, these inlet parameters were SMF, noncondensible gas flow rate, particle solubility, and particle size. All tests 
performed using ice and steam provided greater particle retention than did any tests performed without steam, with the exception of Test 3 (which had a $D F$ of 9 caused by an AMMD $>15 \mu \mathrm{m}$ ). Test-average DFs ranged between 3 and 36 ( $R$ between 68 and $97.2 \%$ ) for low inlet noncondensible gas flow rates. For medium gas flow rates, DFs ranged between 2.4 and 14 ( $R$ between 58 and $93 \%$ ).

Comparison between tests performed at low and medium noncondensible gas flow rates was only possible for five insoluble-particle tests performed having SMFs between 0.18 and 0.21 (Tests 12a, 12b,12c, 13b, and 1), and two soluble-particle tests performed having SMFs of 0.20 and 0.21 (Tests $13 \mathrm{~b}$ and 14a). For insoluble particles, the four low gas flow rate tests averaged DFs about twice that of the single medium gas flow case. For the two solubleparticle tests, the DF during the low gas flow rate test was about 3 times greater than that during the medium gas flow rate test. Combined, comparison of low SMF tests indicated that measured DFs were 2 to 3 times greater during tests performed at low noncondensible gas flow rates.

Test-average results were difficult to determine for Tests 7 and 10 . This was because the data indicated changing particle retention effectiveness in the test section during the tests. For Test 7, DF ranged between 82 and 350 ( $R$ between 98.8 and $99.7 \%$ ) before stabilizing at values of 36 (DF) and $97.2 \%$ (R) during the second half of the test. During Test 10, DF decreased from 82 to 6 throughout the test ( $R$ from 98.8 to $83 \%$ ), and did not appear to stabilize. In comparison to these tests where particle retention changed between 10 and 14 times during the tests, test section particle retention changed less than about 3 times during any of the other tests. Because Tests 7 and 10 were performed with steam and had very low noncondensible gas flow rates, relatively great particle retention was anticipated throughout the tests. The reason that particle retention had decreased by the end of the tests was not determined. Speculation that the ice inventory may have been almost completely depleted were not supported by available liquid sump data. The sump data indicated that perhaps $25 \%$ of the ice inventory remained at the end of Test 10 .

It was possible to determine the influence of steam content on particle retention for the low noncondensible flow rate tests with ice and steam (Table 4.12). This was because SMF was varied between 0.17 and 0.87 during these tests (excluding Test 10). Test results were grouped into three SMF ranges. Six tests $(12 a, 12 b, 12 c, 12 d, 13 a$, and 13b) performed at SMF $=0.19 \neq 0.02$ resulted in $D F=11 \neq 8(R=86 \pm 10 \%)$. Three tests $(6,7$, and $14 \mathrm{~b})$ performed at $S M F=0.62 \pm 0.03$ resulted in an average DF of 16 ( $R=88 \%)$. Two tests ( 9 and 11) performed at $S M F=0.86 \neq 0.01$ resulted in an average DF of $22 \pm 9(R=$ $95.2 \neq 2.1 \%$ ). In the analysis, uncertainty limits are equal to the standard deviation of the means. No standard deviation was determined for the 0.62 SMF case because of widely scattered results. DF approximately doubled as SMF increased between 0.19 and 0.86 . Using a method described by Winegardner, Postma, and Jankowski (1983), the measured DF was found in all cases to be greater than that predicted for steam condensation acting alone. The difference between the measured DF and that predicted solely based on steam condensation increased with decreasing SMF, and was probably caused by settling of particles in the test section. 
Particle solubility may have influenced particle retention in the test section in the presence of ice and steam. Simple consideration of six soluble-particle and nine comparable insoluble-particle tests (neglecting only Test 10 of all tests listed in Table 4.12) indicates that soluble particles were retained in the test section at greater effectiveness than were insoluble particles. Soluble-particle tests were performed at SMF between 0.20 and 0.87 (average SMF $=0.43 \neq 0.26$ ), and resulted in test-average DFs of $20 \pm 11$ $(R=93.1 \neq 4.2)$. Insoluble-particle tests were performed at SMF between 0.17 and 0.86 (average SMF $=0.36 \pm 0.27$ ), and resulted in test-average DFs of 8.0 $\pm 5(R=82 \neq 11 \%)$. In the analys is, uncertainty limits were the standard deviation of the means. In addition to consideration of both groups of tests, four specific test-by-test comparisons were possible. The comparisons were made of tests having similar noncondensible gas flow rates, SMF, and particle size. Test 9 (soluble) was compared with Test 11 (insoluble): test-average particle retention results were $D F=29(R=96.6 \%)$ and $D F=16(R=93.7 \%)$ for Tests 9 and 11, respectively. Test 7 (soluble) was compared with Test 14b (insoluble): test-average particle retention results were $D F=36(R=$ $97.2 \%)$ and $D F=10(R=90.0 \%)$ for Tests 7 (second half of the test) and $14 \mathrm{~b}$, respectively. Test 1 (soluble) was compared with Test 14 a (insoluble): test-average particle retention results were $D F=8(R=87 \%)$ and $D F=2.6(R$ $=61 \%$ ) for Tests 1 and $14 a$, respectively. In the final specific test case, Test 13a (soluble) was compared with Tests 12a, 12b, 12c, and 13b (insoluble): test-average particle retention results were $D F=24$ ( $R=95.8 \%$ ) for Test $13 a$, and $D F=10,6,5$, and $3.3(R=90,84,80$, and $70 \%)$ for Tests $12 a, 12 b$, $12 c$, and $13 b$, respectively. In all specific cases, particle retention in the test section was greatest during the soluble-particle tests.

The influence of inlet particle size was considered for comparable tests of both low gas flow rate (Tests 12 a through $12 d$ ) and medium gas flow rate (Tests 1,4, and 8 ). In both cases, the single tests having the largest inlet particle sizes resulted in DFs no greater than twice those of the tests performed with smaller inlet AMMDs.

\subsubsection{Aerosol Material Mass Balance}

Estimates of the ability to recover test material were made for three tests following the procedure described in Section 3.5.6. This was done by monitoring all known effluent streams both during the tests and during post-test clean-up operations. Material recovered from the test system compared to the total mass introduced via the aerosol generator was 93, 87, and $73 \%$ for Tests 4,9 , and 10, respectively. Probable under-represented effluent streams included the mass deposited between the generator and the mixing duct, M2; the mass in the mixing duct, M3; the mass remaining in the test section after testing and complete ice melt, M4; and the mass deposited in the test section and removed during the test via the drainage sump, $M 7$ (see Figure 3.17).

The majority of uncertainty in the estimation of test section particle retention based on the mass balance analyses also included the effluent streams listed above. Although all effluent streams were effectively sampled and analyzed during Test 4, difficulties were encountered measuring M3 and M7 
during Test 9, and M2 and M4 during Test 10 . By assigning the missing mass (the difference between $M 1$ and the sum of M2 through M10) to the parameters thought to be in question and considering the uncertainty associated with the other parameters, Equations (3) and (4) were solved for each test for average, minimum, and maximum expected DF values. The results of the percentage recovery and the estimated particle retention results for the three tests, based on the mass balance analysis, are shown in Table 4.13. Because the assignment of missing mass influenced the results, the particle retention estimates for Tests 9 and 10 include a wide range of values. Equations (3) and (4) yielded similar results for Tests 4 and 9 , but different results for Test 10. This may have been caused by misassignment of the missing mass for Test 10 .

The DF and $R$ values determined using the results of aerosol samples (the primary analysis method) are also shown (Table 4.13) to provide comparison with the estimates based on the aerosol material mass balance analysis. Results of the mass balance agreed well with the aerosol results for Test 4 where $D F=11(R=91 \%)$ and $D F=14(R=93 \%)$ for the two methods, respectively. The mass balance resulted in lower particle retention during Test 9; $D F=6(R=83 \%)$ and $D F=29(R=96.6 \%)$ for the mass balance and aerosol methods, respectively. Comparison of the two methods for Test 10 is difficult because of uncertainties associated with the mass balance analys is and because the instantaneous DF measured by aerosol samples ranged from 82 to 6. Results of the mass balance for Test 10 ranged from $D F=7$ to $23(R=$ 85 to $96 \%)$ using Equation (3) and $D F=14$ to 45 ( $R=93$ to $98 \%)$ using Equation (4).

TABLE 4.13. Aerosol Material Recovery and Estimated Particle Retention Based on an Aerosol Material Mass Balance

\begin{tabular}{|c|c|c|c|c|c|c|c|c|}
\hline \multirow[b]{2}{*}{ Test } & \multirow{2}{*}{$\begin{array}{c}\text { Recovered } \\
\text { Mass } \\
\text { Percentage, } \\
\times \\
\end{array}$} & \multirow[b]{2}{*}{ Paraneter } & \multicolumn{2}{|c|}{ Equation (3) } & \multicolumn{2}{|c|}{ Equation (4) ${ }^{(a)}$} & \multicolumn{2}{|c|}{ Aorosol Sanplos } \\
\hline & & & Range & Average & Range & Average & Start/End & Average \\
\hline 4 & 93 & $\begin{array}{l}\text { DF } \\
R(x)\end{array}$ & $\begin{array}{l}16 \text { to } 12 \\
96 \text { to } 92\end{array}$ & $\begin{array}{l}11 \\
91\end{array}$ & $\begin{array}{l}10 \text { to } 12 \\
90 \text { to } 92\end{array}$ & $\begin{array}{l}11 \\
81\end{array}$ & $\begin{array}{l}17 \text { to } 12 \\
94 \text { to } 92\end{array}$ & $\begin{array}{l}14 \\
83\end{array}$ \\
\hline 9 & 87 & $\begin{array}{l}\text { DF } \\
R(x)\end{array}$ & $\begin{array}{l}3 \text { to } 13 \\
67 \text { to } 92\end{array}$ & 63 & $\begin{array}{l}N^{(b)} \\
{ }_{N D}^{(b)}\end{array}$ & $\begin{array}{r}6 \\
83\end{array}$ & $\begin{array}{l}19 \text { to } 57 \\
95 \text { to } 98\end{array}$ & $\begin{array}{l}29 \\
96.6\end{array}$ \\
\hline 10 & 73 & $\begin{array}{l}\text { DF } \\
R(x)\end{array}$ & $\begin{array}{r}7 \text { to } 23 \\
85 \text { to } 88\end{array}$ & $\begin{array}{l}12 \\
92\end{array}$ & $\begin{array}{l}14 \text { to } 45 \\
93 \text { to } 98\end{array}$ & $\begin{array}{l}24 \\
96\end{array}$ & $\begin{array}{l}82 \text { to } 6 \\
99 \text { to } 83\end{array}$ & $\begin{array}{l}\text { (c) } \\
\text { (c) }\end{array}$ \\
\hline
\end{tabular}

(a) Soe Section 3.6.8.

(b) $\mathrm{ND}=$ not deternined.

(c) The variation in results between the beginning and end of Test 10 was sufficiently great to preclude deteraination of a test-average result. 


\subsection{CONCLUSIONS}

Test results provided information about thermal-hydraulic conditions and aerosol particle characteristics and retention in a test section constructed to represent full-scale height and reduced-scale cross section of the ice compartment of an ice condenser containment system. A total of 38 tests were performed, including 35 tests with aerosols. Of these, 19 tests provided both thermal-hydraulic and aerosol data. Thermal-hydraulic data included characterization of inlet gas flow, temperature profiles, and thermal behavior related to flow stratification within the test section. Aerosol data included information about the retention of particles within the test section for tests with and without ice and steam, and for a variety of inlet gas flow and aerosol characteristics. Particle retention was determined as DF, the ratio of particle mass flow in to that out of the test section, and $R$, the mass percentage of particles retained in the test section. "Test-average" DF and $R$ were determined for each test using the average results of particle mass flow rate measurements at the inlet and outlet. Other aerosol information included particle size at the inlet and outlet and the distribution of aerosol mass concentration within the ice-basket region.

\subsection{THERMAL-HYDRAULIC CONCLUSIONS}

The following general conclusions were made based on the diffuser and ice-basket section temperature measurements, and apply as long as there is ice in the baskets. The thermal behavior of the diffuser was determined by the total volume flow rate. The diffuser was not significantly stratified for total volume flow rates of at least $0.4 \mathrm{~m}^{3} / \mathrm{s}$. Thermal stratification of the diffuser occurred for total volume flow rates $0.2 \mathrm{~m}^{3} / \mathrm{s}$ or lower. The ice-basket section thermal behavior was primarily influenced by the noncondensible volume flow rate. A break point between stratified and less well defined flow characteristics was evident at approximately $0.1 \mathrm{~m}^{3} / \mathrm{s}$. Ice-basket section noncondensible flows greater than $0.1 \mathrm{~m} / \mathrm{s}$ resulted in stable thermal stratification whereas flows less than $0.1 \mathrm{~m}^{3} / \mathrm{s}$ resulted in less well defined thermal behavior with frequent temperature crossovers between flow channels.

\subsection{AEROSOL CONCLUSIONS}

Particle retention in the test section varied greatly under differing combinations of test parameters. Test-average DF ranged between 1.0 and 36 ( $R$ between $\sim 0$ and $97.2 \%$ ). In order of importance, test parameters that caused particle retention in the test section in the absence of ice were particle size and gas flow rate. More parameters influenced particle retention in the presence of ice, and in estimated order of importance, were steam mole fraction (SMF), noncondensible gas flow rate (residence time), particle solubility, and particle size. With the exception of SMF, the order of these parameters is not certain because individual parameters were difficult to isolate given the limited number of tests and the large number and ranges of parameters. other parameters not ranked, but believed to have had negligible influence on 
particle retention over the ranges tested, were the geometric standard deviation of the particle size distribution, particle density, aerosol concentration, and inlet gas temperature.

Tests performed without steam or ice (simple case) provided the least particle retention. Neglecting tests having particle sizes greater than $12 \mu \mathrm{m}, \mathrm{DFs}$ were limited to 2.2 ( $\mathrm{R} \leq 55 \%)$. Both gas flow rate and particle size influenced these results; the greatest particle retentions were measured during tests with particle sizes greater than 5 to $10 \mu \mathrm{m}$ and tests having low $\left(0.03\right.$ to $\left.0.07 \mathrm{~m}^{3} / \mathrm{s}\right)$ gas flow rates. Greater particle retention at low gas flow rates was attributed to increased residence time and increased settling losses, especially in the inlet region. For the simple case, the influence of particle size was most clearly demonstrated during a series of monodisperse aerosol tests that were performed at a single flow rate. These tests also showed the influence of particle settling in the inlet region. For particle sizes of 5,11 , and $15 \mu \mathrm{m}$, measured DFs between Stations $6 \mathrm{~A}$ and 0 were $1.08 \pm 0.08$, $1.42 \neq 0.12$, and $1.71 \neq 0.17$, respectively. In comparison, the related DFs between Stations 6B and $1 \mathrm{~B}$ (roughly equivalent to the ice-basket region of the test section) were $1.02 \neq 0.00,1.11 \neq 0.01$ and $1.15 \neq 0.06$, respectively. These results suggest that upstream particle settling losses in the inlet diffuser region were the most significant contributing factor to particle capture in the test section during tests performed without ice or steam.

Tests performed with ice and steam (complex case) resulted in greater particle retention than did tests performed without ice and steam (again neglecting Test 3, which had an inlet AMMD $>15 \mu \mathrm{m})$. Test-average DF ranged between 2.4 and 36 ( $R$ between 58 and $97.2 \%$ ). The influences on particle retention were ranked over the tested ranges of several parameters:

1. The influence of SMF on particle retention in the test section was possible to determine for 11 low noncondensible flow rate tests performed with ice and steam. Six tests having an SMF of $0.19 \neq 0.02$ resulted in $D F=11 \pm 8(R=86 \pm 10 \%)$. Three tests having SMF = $0.62 \pm 0.03$ resulted in $D F=16(R=88 \%)$. Two tests having SMF = $0.86 \neq 0.01$ resulted in $D F=22 \neq 9(R=95.2 \neq 2.1 \%)$. Note that $D F$ and $R$ are not related when results are grouped and averaged in sets of two or more tests. This is a result of the nonlinear relationship between $D F$ and $R$. Uncertainty limits equal the standard deviation of the means. DF approximately doubled as SMF increased between 0.19 and 0.86 .

Using a method described by Winegardner, Postma, and Jankowski (1983), assuming well-mixed flows and particle removal solely as a result of steam condensation, calculated values for retention for the above steam mole fractions $(0.19,0.62$, and 0.86$)$ are $D F=1.2(R=17 \%), D F=2.4$ $(R=58 \%)$, and $D F=6.3(R=84 \%)$, respectively. Review of the above will reveal that measured values for $D F$ are up to almost 10 times larger than calculated values for the lowest steam mole fraction, 0.19 . The large ratio is primarily attributed to supplemental capture by settling in the diffuser and/or the ice-basket section during the experiments. The smallest ratio (best comparison) of measured to calculated DF, 22/6.3 or 3.5 , is associated with the largest steam mole fraction, 0.86 . In 
this case, it is believed that high inlet flow rates prevented any significant retention in the diffuser by sedimentation. Further, most of the particles were then removed in or near the condensation zone. Relatively few particles remained to be acted on in the remaining length of the ice-basket section.

2. Noncondensible gas flow rate was anticipated to influence particle retention in the test section by influencing residence time and the period available for particle growth. Complex-case tests were performed using two ranges of noncondensible gas flow rates, low $\left(0.02\right.$ to $\left.0.06 \mathrm{~m}^{3} / \mathrm{s}\right)$ and medium $\left(0.1\right.$ to $\left.0.17 \mathrm{~m}^{3} / \mathrm{s}\right)$. Comparison of low SMF tests indicated that measured DFs were 2 to 3 times greater during tests performed at low noncondensible gas flow rates.

3. Particle solubility appeared to have influenced particle retention in the test section during tests performed with ice and steam. Six soluble-particle and nine insoluble-particle tests were compared. Soluble-particle tests were performed at SMF between 0.20 and 0.87 (average SMF $=0.43 \pm 0.26$ ), and resulted in test-average DFs of 20 $\pm 11(R=93.1 \pm 4.2 \%)$. Insoluble-particle tests were performed at SMF between 0.17 and 0.86 (average $=0.36 \neq 0.27$ ), and resulted in test-average DFs of $8 \pm 5(R=82=11 \%)$. In addition, specific comparisons were made of four sets of tests based on approximately similar noncondensible gas flow rates, SMF, and particle size. In all cases, soluble particles were retained in the test section at levels between 1.8 and 7.3 times those of comparable insoluble particles.

4. The influence of inlet particle size was considered for comparable tests for both low and medium gas flow rates. In both cases, the single test having the largest inlet particle size resulted in a DF no greater than twice that of tests performed with smaller inlet particle sizes. The influence of inlet AMMD appeared to be limited to particle sizes greater than about $10 \mu \mathrm{m}$.

Particle retention results based on a mass balance analysis were compared to those of the aerosol measurements (the standard method) and provided mixed results. Results of the mass balance agreed well with the aerosol results for Test 4 where $D F=11(R=91 \%)$ and $D F=14(R=93 \%)$ for the mass balance and aerosol methods, respectively. However, the mass balance method resulted in lower particle retention than did the aerosol method for Test 9; DF $=6$ $(R=83 \%)$ and $D F=29(R=96.6 \%)$, respectively. Comparison of the two methods for Test 10 was difficult because of uncertainties associated with the mass balance analysis and because the instantaneous DF determined using the aerosol method varied greatly over the duration of the test. Difficulties encountered in recovering all generated aerosol mass provided a level of uncertainty in the mass balance method results and favored the aerosol method. 
In addition to particle retention measurements made at the inlet and outlet of the test section, measurements of SMF and particle mass concentration that were performed in the lower and upper regions of the ice-basket region also provided useful information. Data obtained from the four open flow channels provided indications that flow recirculation cells were largely confined to the inlet and the lower elevations of the ice-basket region.

\subsection{CODE VALIDATION}

Severe accident computer code simulations involve the analyses of complex conditions including complicated flow patterns and airborne particle behavior within containment. Comparison of calculations with experimental data is needed to gain confidence that the codes being used can adequately estimate physical, chemical, and ultimately, radiological conditions. As indicated in the introduction, test results are being published at this time for use in the development of analytical models and the generation of model-data comparisons. The results may be especially important for comparisons involving calculations from codes that have been developed to provide best-estimates of flow patterns, heat transfer, and/or particle behavior in environments involving the mixing of hot and cold gases and/or transient steam condensation in the presence of noncondensibles. It should be noted that preliminary, unpublished thermal-hydraulic data have already been used in comparisons involving CONTAIN and COBRA-NC computer code calculations (Russell and Williams 1989, Eschbach 1991). 


\subsection{REFERENCES}

Berglund, R. N., and B. Y. H. Liu. 1973. "Generation of Monodisperse Aerosol Standards." Environ. Sci. Technol. 7:147-153.

Eschbach, E. J. 1991. "Overview of Ice Condenser Research at Pacific Northwest Laboratory." PNL-SA-19296, Pacific Northwest Laboratory, Richland, Washington. Presented at the International Ice Condenser Symposium, Charlotte, North Carolina, April 1991.

Hinds, W.C. 1982. Aerosol Technology. 1st edition, pp. 240-244. John Wiley \& Sons, Inc., New York.

Liparulo, N. J., C. G. Tinkler, and J. A. George. 1976. "The Ice Condenser System for Containment Pressure Suppression." Nuclear Safety $17(6): 710-721$.

Liu, B. Y. H., and D. Y. H. Pui. 1974. "Electrical Neutralization of Aerosols." Aerosol Sci. 5:465-472.

OwCzarski, P. C., R. I. Schreck, and W. K. Winegardner. 1985. ICEDF:A Code for Aerosol Particle Capture in Ice Compartments. NUREG/CR-4130, PNL-5379, prepared by Pacific Northwest Laboratory for the U.S Nuclear Regulatory Commission, Washington, D.C.

Perry, R. H., and C. H. Chilton, eds. 1973. Chemical Engineer's Handbook. 5th ed., pp. 5-12. McGraw-Hill Book Co., New York.

Russell, N. A., and D. C. Williams. 1989. Comparison of CONTAIN Code Simulations to Experimental Ice Condenser Test Data. SAND89-3096C, Sandia National Laboratories, Albuquerque, New Mexico. Presented at the Canadian Nuclear Society's 2nd International Conference on Containment Operation and Design, Toronto, Canada, October 1990.

Shapiro, A. H. 1953. The Dynamics and Thermodynamics of Compressible Fluid Flow, Vol. 1, p. 85. Ronald Press Company, New York.

Winegardner, W. K., A. K. Postma, and M. W. Jankowski. 1983. Studies of Fission Product Scrubbing Within Ice Compartments. NUREG/CR-3248, PNL-4691, prepared by Pacific Northwest Laboratory for the U.S Nuclear Regulatory Commission, Washington, D.C. 
APPENDIX A

EXPERIMENTAL STRATEGY 
As indicated in the introduction, the original focus of the investigation was to obtain data for the validation of the ICEDF computer code. The code was developed to estimate the extent of particle retention in the ice compartment of a pressurized water reactor (PWR) ice-condenser containment system during severe nuclear reactor accidents. As a result of the validation focus, at least initially, experimental design was based on a comprehensive statistical strategy to obtain data that could be used in making comparisons with code calculations. Specifically, efforts centered on obtaining data that could be used to define particle retention, from a set of experiments derived from the statistical analysis of independent variables that make up the analytical models that, in turn, comprise the code. Because of the relationship to severe accidents, ranges of values for the variables to be considered in the development of the test design or plan were partially obtained from computer-generated estimates of conditions arising from postulated reactor accident scenarios. A brief description of the analytical models used in the development of the ICEDF computer code is presented below followed by selected information concerning the ranges of values that were developed for independent variables and the statistically-based experimental design.

\section{A.1 ICEDF COMPUTER CODE}

Development of the ICEDF computer code was based on the assumptions that the particle depletion process is first order with respect to airborne concentration and that the gas phase is perfectly mixed. The former perfect sink assumption was used because it was anticipated that low fluid velocities and the presence of water would minimize particle resuspension. For a perfectly mixed gas, the airborne particle concentration is set equal to the outlet or lowest concentration. The model for particle retention in terms of the decontamination factor, or its reciprocal, penetration, in a single wellmixed volume is then derived from a material balance written for the gas phase in the volume. Such a model could overpredict penetration because the driving force, concentration, is minimized. A model for minimum penetration can also be developed by considering a flow pattern in which there is negligible mixing in the direction of flow. By dividing the flow path into $n$ segments connected in series, overall penetration can be expressed as the product of the segment penetrations. Penetration in each segment may be computed using the model developed for well-mixed flow by noting that the particle removal rate constant for each of the $n$ regions can be obtained by dividing the overall rate constant by the number of segments. Overall penetration associated with unidirectional flow can then be computed if the gas flow rate is taken as constant for all of the segments and $n$ is allowed to become arbitrarily large. The penetration model for either the well-mixed or the unidirectional case can be reduced to one that contains only terms for the gas flow rate and the removal rate 
constants for the various particle retention mechanisms. In development of the ICEDF code, expressions for the latter rate constants were developed for sedimentation, impaction and interception, diffusion, diffusiophoresis, and thermophoresis. Sensitivity and accident analyses suggested that sedimentation and diffusiophoresis could be especially important particle removal processes. Parameters, and therefore potentially important experimental variables associated with the former process include particle size and mass. Inlet steam mole fraction and ice inventory are two of the factors related to the steam condensation rate and, therefore, particle removal by diffusiophoresis, or more appropriately, by Stephan flow. The ICEDF code also includes analytical models to calculate the extent of particle growth in the presence of condensible vapors. Consequently, particle solubility also becomes a potentially important parameter or variable. Additional details concerning the code and underlying assumptions are contained in Owczarski, Schreck, and Winegardner (1985) and Winegardner, Postma, and Jankowski (1983).

\section{A.2 RANGES FOR INDEPENDENT VARIABLES}

Insights concerning the conditions under which the ICEDF code might be applied and thus possible ranges of values associated with key independent variables were developed by reviewing information supplied by Battelle's Columbus Laboratories $(\mathrm{BCL})$. This information resulted from work to estimate the amount of radioactive material that could be released from light water reactor (LWR) power plants under specific, hypothetical accident conditions. The data that was reviewed was developed for the Sequoyah Power Station, a Westinghouse PWR with an ice-condenser containment. Five accident sequences were investigated for this plant to represent cases of high risk, severe consequences, and most importantly, a wide range of physical conditions. Table A.1 lists ranges of values initially selected for several of the variables (values enclosed in braces). Also shown in Table A.1 are percentages related to the times estimated accident conditions were at or near these ranges (ranges estimated for accident conditions, enclosed in parentheses or brackets, were not constructed to match those selected for variables; therefore, those ranges for accident conditions closest to the variable ranges are usually reported). Review of Table A.1 will reveal that the highest percentages are associated with temperature and aerosol mass concentration. The least wellmatched ranges are associated with flow rate. In fact, the highest percentages for estimated flow rates are associated with ranges (in brackets) with values at or orders-of-magnitude below the low end of the range selected for this variable. The low estimated flow rates reflect the fact that for the accident sequences investigated, electrical power is not available for the fans that cause air to be continuously recirculated through the ice bed. Values for flow rates finally selected for the experiments correspond to reactor flow rates ranging from 15 to $80 \mathrm{~m}^{3} / \mathrm{s}$ and deliberately include values associated with fan flow. Additional information concerning the ranges of values selected for the independent variables and accident thermal-hydraulic and aerosol conditions developed as the result of the review of the $B C L$ work can be found in Kannberg, Piepel, Owczarski, and Liebetrau (1986): Kannberg, Ross, Eschbach, and Ligotke (1987); and Chemical Engineering Branch (1986). 
TABLE A.1. Percentage of Time Accident Conditions are Encompassed by Design Testing Ranges(a)

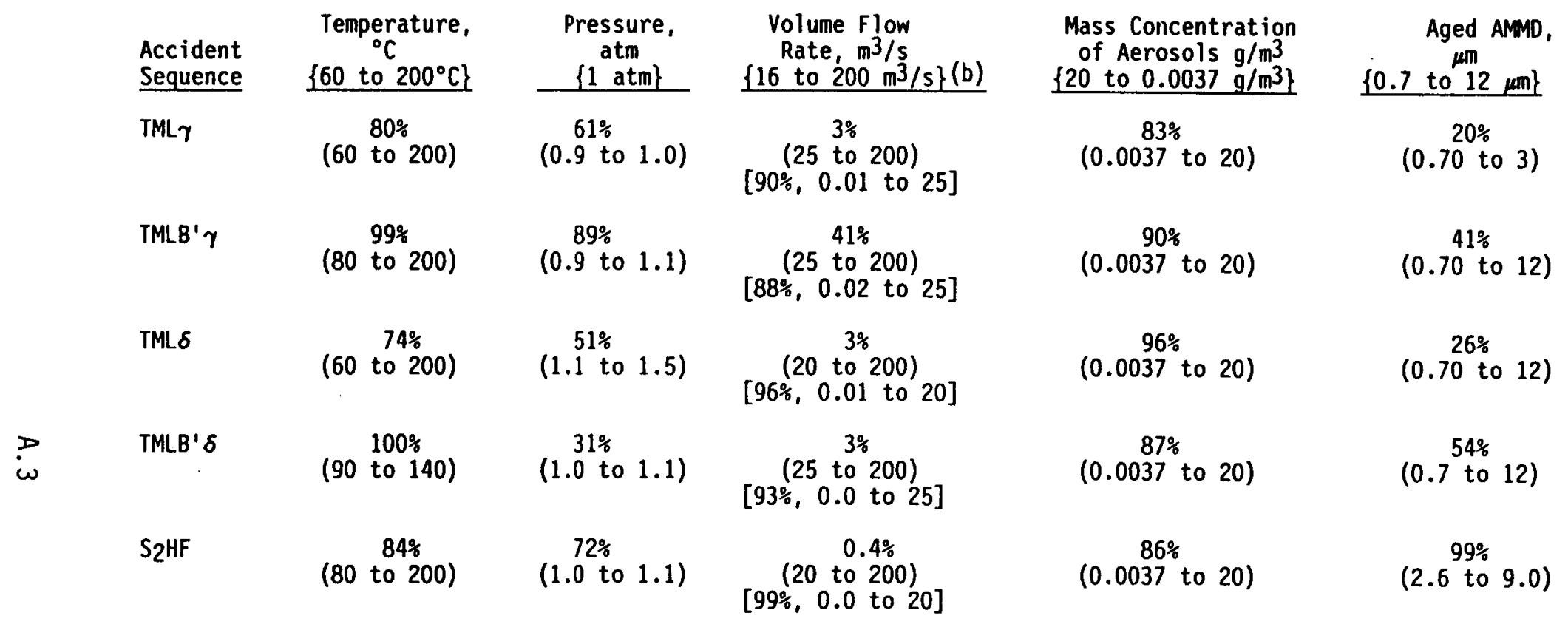

(a) Ranges of values initially selected for development of test design are enclosed by braces \{\}; ranges of values estimated for accident conditions are enclosed by parentheses ( ) or brackets [ ].

(b) Plant scale flow rate, for test section inlet multiply by 0.002 . 


\section{A.3 EXPERIMENTAL DESIGN}

The statistically-based experimental design or plan was ultimately reduced to one based on eight variables: gas flow rate, temperature, and steam mole fraction and aerosol particle diameter, density, solubility, and count and mass concentration. Further, based on cost considerations, it was determined that the design could consist of a set of only 15 test cases or individual experiments. The following breakdown was then selected for these 15 experiments: 9 experimental region boundary points; 2 experimental region interior points: 3 replicates $(2$ of boundary points and 1 of an interior point); and 1 point outside the experimental region (a test to be conducted without an ice inventory). The nine-to-two split between the boundary and the interior points was somewhat arbitrary. However, the considerable interest in validating the ICEDF code in the boundary areas of the experimental region led to locating the preponderance of the 11 at-large points at this location, i.e., where the most information about variable behavior could be obtained.

The computer code DETMAX (Mitchell 1974) was used to provide a balanced representation of the factor space, i.e., attempt to uniformly distribute the nine points over the experimental region boundary. With this method, candidate plans are selected to maximize the determinant of the design matrix for the screening model

$$
Y=\beta_{0}+\sum_{i}^{n} \beta_{i} x_{i}
$$

where $\beta$ values are constants and $x_{j}$ denotes the independent variables. Sets of points for which the determinant of the design matrix is maximum are sets for which the variance of the response variable $Y$ is minimum. Consequently, among designs of a given size, those that maximize the determinant of the design matrix yield the most information about $Y$.

The nine-point design based on the boundary of the region of interest and selected with the aid of the DETMAX code then served as the core of the experimental plan. The two interior points, to gain insights concerning the curvature of the response surface, were specified by assignment of midrange parameter values. The balance of the four cases is made up of the three replicates and the one no-ice experiment. As indicated above, two replicates were selected from the nine boundary points and the third is an interior point. Use of the ICEDF code in conjunction with an initially developed test plan derived from hundreds of candidate cases and that also considered the presence or absence of ice as a variable indicated that a number of the tests could have a response so small that it could be obscured by the measurement variation expected during a test. As a result, early in the program it was decided to remove the ice inventory from the list of variables and to use ice in all the tests except one. This reduced the number of variables to eight but introduced a bias in the test design. However, it was reasoned that the one test without ice could be used to investigate this bias and that it was more important to obtain data for conditions useful for model validation than to expend significant resources obtaining data of marginal use. 
The final 15-experiment design is shown in Table A.2. Case numbers 10 and 11 are the interior points. Case numbers 12 and 13 are replicates of the boundary points 4 and 5 , while case number 14 is the replicate for the interior point case no. 10. Review of Table A.2 will reveal that, except for the ice inventory, conditions selected for the no-ice experiment (case no. 15) are the same as those for case no. 2. The values shown in Table A.2 were ultimately used as target conditions for only 11 of the experiments; test numbers (case numbers) $1(10-14), 2(15), 3(2), 4(10-14), 5(7), 6(11), 7$ (9), 8 (1014), $9(5-13), 10(5-13)$, and $11(16)$. As indicated in the text of this report, there were indications of complex, buoyancy-driven flow fields including stratified flow in the diffuser region and separated zones of up and down flow in the ice-basket region, almost from the onset of testing. Code validation efforts, therefore, were hindered by the fact the analytical models that had been used to represent material balances (particle depletion) were developed assuming well-mixed volumes. As a result of curtailed validation efforts, the final series of eight tests was chosen to identify groups of experiments that could be conducted with the same ice inventory and at the same time provide the most data for filling in information gaps associated with selected variables.

\section{A.4 REFERENCES}

Chemical Engineering Branch. 1986. Compilation of Contract Research for the Chemical Engineering Branch, Division of Engineering Technology, Annual Report for FY 1985. NUREG-1215, U.S. Nuclear Regulatory Commission, Washington, D.C.

Kannberg, L. D., G. F. Piepel, P. C. Owczarski, and A. M. Liebetrau. 1986. "Ice Condenser Experimental PIan." In Thirteenth Water Reactor Safety Research Information Meeting: Proceedings. NUREG/CP-0072, U.S. Nuclear Regulatory Commission, Washington D.C.

Kannberg, L. D., B. A. Ross, E. J. Eschbach, and M. W. Ligotke. 1987. "Ice Condenser Testing Facility and Plans." In Fourteenth Water Reactor Safety Research Information Meeting: Proceedings. NUREG/CP-0082, U.S. Nuclear Regulatory Commission, Washington D.C.

Mitche11, T. J. 1974. "Algorithm for the Construction of D-Optimal Experimental Designs." Technometrics 16(2):203-210.

Owczarski, P. C., R. I. Schreck, and W. K. Winegardner. 1985. ICEDF:A Code for Aerosol Particle Capture in Ice Compartments. NUREG/CR-4130, PNL-5379, prepared by Pacific Northwest Laboratory for the U.S Nuclear Regulatory Commission, Washington, D.C.

Winegardner, W. K., A. K. Postma, and M. W. Jankowski. 1983. Studies of Fission Product Scrubbing With in Ice Compartments. NUREG/CR-3248, PNL-4691, prepared by Pacific Northwest Laboratory for the U.S. Nuclear Regulatory Commission, Washington D.C. 
TABLE A.2. Test Matrix

Particulate Characteristics

\begin{tabular}{|c|c|c|c|}
\hline $\begin{array}{l}\text { Case } \\
\text { No. }\end{array}$ & $\begin{array}{c}\text { AMMD, (a) } \\
\frac{m}{m}\end{array}$ & $\begin{array}{c}\text { Density, } \\
\text { g/cc } \\
\end{array}$ & $\begin{array}{c}\text { Mass } \\
\text { Concentration, } \\
\mathrm{g} / \mathrm{m}^{3}\end{array}$ \\
\hline 1 & 12.00 & 4.5 & 7.0000 \\
\hline 2 & 12.00 & 2.0 & 0.7360 \\
\hline 3 & 0.70 & 2.0 & 0.0037 \\
\hline 4 & 12.00 & 2.0 & 19.5400 \\
\hline 5 & 4.22 & 2.0 & 7.0000 \\
\hline 6 & 12.00 & 2.0 & 1.770 \\
\hline 7 & 4.98 & 4.5 & 7.000 \\
\hline 8 & 12.00 & 2.0 & 0.7360 \\
\hline 9 & 1.25 & 4.5 & 0.0037 \\
\hline 10 & 6.00 & 2.0 & 4.0000 \\
\hline 11 & 2.00 & 4.5 & 0.0250 \\
\hline $\begin{array}{c}\text { Replicate } \\
12(4)\end{array}$ & 12.00 & 2.0 & 19.5400 \\
\hline $13(5)$ & 4.22 & 2.0 & 7.0000 \\
\hline $14(10)$ & 6.00 & 2.0 & 4.000 \\
\hline $\begin{array}{l}\text { No ice } \\
15(2)\end{array}$ & 12.00 & 2.0 & 0.7360 \\
\hline $\begin{array}{l}\text { (a) AMMD } \\
\text { (b) } S= \\
\text { (c) } F=\end{array}$ & $\begin{array}{l}=\text { aerody } \\
\text { soluble, } \\
\text { full ice }\end{array}$ & $\begin{array}{l}\text { mic mass } \\
=\text { insolub } \\
\text { skets, } E\end{array}$ & $\begin{array}{l}\text { dian diameter. } \\
\text { empty ice baske }\end{array}$ \\
\hline
\end{tabular}

\section{Test Section}

\begin{tabular}{c}
$\begin{array}{c}\text { Volume Flow } \\
\text { Rate, } \\
\mathrm{m}^{3} / \mathrm{s}\end{array}$ \\
\hline 0.380 \\
0.030 \\
0.380 \\
0.033 \\
0.380 \\
0.030 \\
0.380 \\
0.380 \\
0.030 \\
0.220 \\
0.220 \\
0.033 \\
0.380 \\
0.220 \\
0.030
\end{tabular}

Steam

$$
\begin{aligned}
& \text { Steam } \\
& \text { Mole }
\end{aligned}
$$

Fraction

0.1960

0.0400

0.0400

0.9000

0.9000

0.0400

0.0400

0.9000

0.9000

0.4200

0.6000

Ice (c)

Fraction

F

$F$

$F$

$F$

$F$

200

200

200

125

125

105

105

125

60

$\begin{array}{ll}0.9000 & F \\ 0.9000 & F \\ 0.4200 & F\end{array}$

0.0400

E

I 
APPENDIX B

THERMAL-HYDRAULIC GENERAL DATA REDUCTION PROCEDURES 
APPENDIX B

THERMAL-HYDRAULIC GENERAL DATA REDUCTION PROCEDURES

The following specific tradenames are used in the various data reduction procedures. The use of these tradenames is for research accountability only and does not mean to imply PNL's endorsement of this item.

Columbia $300 \mathrm{D}$

EDLIN

Epson

Fluke

IBM

IBM AT

IBM PC

IBM BASICA

IBM DOS 2.1 and 3.3

IBM PC

Keithley

LabTech Notebook

LOTUS

MS DOS 2.1

Smarterm 100

$3 \mathrm{M}$

WordPerfect Library
Columbia Data Products, Columbia, Maryland IBM, Boca Raton, Florida

Epson Corporation, Nagano, Japan

John Fluke Manufacturing Company, Inc., Everett, Washington

IBM, Boca Raton, Florida

IBM, Boca Raton, Florida

IBM, Boca Raton, Florida

IBM, Boca Raton, Florida

IBM, Boca Raton, Florida

IBM, Boca Raton, Florida

Keithley Data Acquisition and Control Inc., Cleveland, Ohio

Laboratory Technologies Corporation, Wilmington, Massachusetts

Lotus Development Corporation, Cambridge, Massachusetts

Microsoft Corporation, Redmond, Washington

Persoft, Inc., Madison, Wisconsin

3M, St. Paul, Minnesota

WordPerfect Corporation, Orem, Utah 
BUILDING / ROOM 336 BUILDING CONTROL ROOM

\section{A. INTRODUCTION}

Data acquisition at the High Bay Test Facility (HBTF) is accomplished by two systems. The primary data acquisition system is computer based and consists of an IBM PC with a hard card and IBM DOS 2.1, Keithley data acquisition hardware system, and an Epson printer. The computer data acquisition software is LabTech Notebook version 4.11. Currently, the computer data acquisition system supports 96 thermocouples and 16 meters (flow and pressure). Fluke data loggers are utilized when it is necessary to add instrumentation to specific locations. The model $22240 \mathrm{~B}$ Fluke data loggers are both equipped with remote programming capabilities (Option 17) and can therefore serve as input to magnetic recording devices (tape recorders) for data storage. Hereafter, DAS refers only to the computer based data acquisition system and data logger(s) refers to the model $2240 \mathrm{~B}$ Fluke data logger $(s)$.

The DAS computer is energized by the conditioned power circuit of the HBTF Control Room. If the DAS computer is energized by an unconditioned power supply it is subject to operational failures due to the power fluctuations which occur during facility operation.

Each test run at the HBTF has a unique designation and a specific DAS configuration. Care must be taken when running the DAS because the data files are over written - not appended.

\section{B. COMPUTER BASED DATA ACQUISITION SYSTEM}

1. Basic menu operations of the Notebook software are detailed in the "Menu Systems" section of Chapter 4 of the LabTech Notebook Manual located in the Control Room. First time users should acquaint themselves with the basic menu options and selection procedures prior to using Notebook and especially before revising data acquisition setups.

2. Supply power to all components of the DAS system by turning on the power strip located next to the computer. The PC will boot itself up from the hard card providing that both of the disk drive doors are OPEN. Appearance of the $C>$ prompt indicates completion of the boot up procedures.

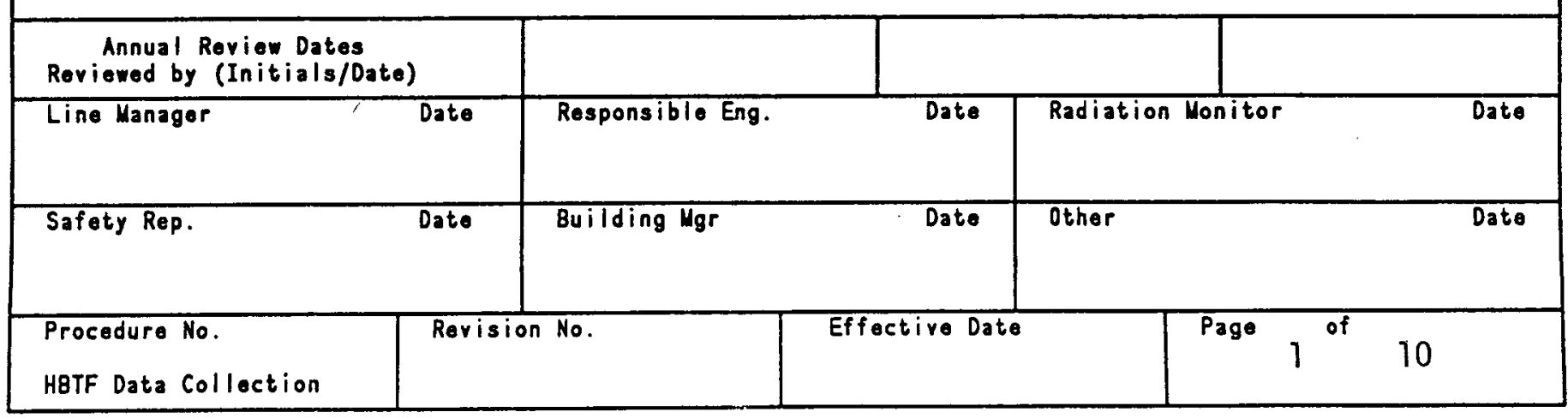


3. Data acquisition software is located in the subdirectory nb. After initial boot up the subdirectory is accessed by the command cd/nb. After entering the appropriate subdirectory, the data acquisition software is accessed by the command $\mathrm{nb}$. The main menu of Notebook will appear across the top of the monitor screen upon execution of the access command. A brief description of each option appears underneath the main menu line when the option is highlighted by moving the screen cursor over the option name.

Menu options are selected by pressing the key with the first letter of the option or by moving the screen cursor over the option and pressing the enter key. While in the Notebook menu mode the escape, Esc, key allows one to move from the lower level menus to the next higher level menu.

NOTE B.3-1: Once data collection has been initiated (two step procedure) pressing the escape Esc key will abort data collection and will return the system to the main Notebook menu.

4. Not all of the available instruments may be required for a test. Therefore, it will be necessary to configure Notebook data acquisition setups to meet the unique needs of each test. Given that a project specific configuration has been developed it is expected that only the SETUP main menu option will need to be invoked prior to a test. Specifically, the options DISPLAY and FILES of the SETUP main menu option will require revision. Each test will be unique and will require a unique DISPLAY and FILES configuration and will thereby result in a test specific Notebook setup file. The guidelines for DISPLAY and FILES are described in the Labtech Notebook Manual located in the Control Room.

NOTE B.4-1: The number of channels which can be stored in a Notebook data file is default limited to 35 . A typical HBTF run consists of 70 100 channels. It is therefore necessary to override the defualt or configure multiple data storage files. In addition, the sampling frequency of the channels written to a data file must be the same. Thus it is necessary to use multiple data files if the total number of single frequency channels is greater than 35 and/or if multiple sampling frequencies are utilized.

NOTE B.4-2: Notebook over writes data files each time "GO" from the main menu is selected. Therefore the data file names must be unique. This is of the UTMOST IMPORTANCE since no online hardcopy backup exists for the DAS.

5. Notebook Configuration, Data Storage Files, and Trial Run

The instrumentation necessary for a given test in the HBTF is to be specified by the cognizant staff as part of test preparation.

\begin{tabular}{|l|c|c|c|}
\hline $\begin{array}{l}\text { Procedure No. } \\
\text { HBTF Data Collection }\end{array}$ & Revision No. & Page of & 2 \\
\hline
\end{tabular}


TITLE HIGH BAY TEST FACILITY DATA COLLECTION SYSTEMS

Typically, it is necessary to fully specify each instrument channel in the first project configuration. All subsequent configurations can then be generated by minor editing of the first configuration.

Each test configuration is to be saved under a unique filename. It is suggested that the filename serve as an acronym of the project, test matrix point, chronological order, and test phase.

For Example: I10-1A = I ICEDF Validation Tests, 10 Test Matrix Condition, 1 Chronological order of test performance, and A Preconditioning phase of the test.

Within each Notebook setup file the data files must be specified (FILES option of the main menu option SETUP). It is suggested that the test acronym be utilized in the data file name specification. Flexibility in specifying the data file name is available with the filename extension.

NOTE B.5-1: Premature Data Acquisition Termination or Computer Crash It is necessary to rename the files to prevent loss of data by over writing as a result of inadvertent Esc (data acquisition abort command) or a computer crash. In the event of premature data acquisition termination remain in Notebook, revise the data file filename extensions, and restart acquisition by issuing the GO command. If the: computer locks up and/or crashes: re-boot the system, issue CHKDSK/F DOS command, reenter Notebook, revise the data filename extensions, and restart acquisition by issuing the "GO" command. The DAS operator should note the time of resumption of data acquisition and give that information to the data reduction engineer for use in the interpretation of the data.

Prior to test commencement, a check on the DAS setup and instrumentation via a brief run of the DAS is suggested. The objective of this check is to verify that the desired data is being gathered and that the instruments are operational. Retrieve the appropriate setup file, rename the data files if desired, start data acquisition by issuing the GO command. After a few cycles abort data acquisition by pressing the escape, Esc, key. Access the data files created during operation and verify that the desired channels are being sampled and written to file. Make corrections to the setup files and troubleshoot instrumentation as needed.

\section{Production Test Run}

Energize the DAS for test data acquisition. Retrieve the appropriate acquisition setup. Data interpretation is expedited by referencing the computer internal clock with an external clock.

Establishing the correspondence between the computer internal clock and an external clock is necessary in order to reference the data collected with significant test events such as aerosol injection.

\begin{tabular}{|l|l|r|r}
\hline $\begin{array}{l}\text { Procedure No. } \\
\text { HatF Data Collection }\end{array}$ & Revision No. & Page of ive Date & 3 \\
\hline
\end{tabular}


To establish the time reference note the external clock time when the GO command is issued. This establishes the external clock time of data collection start. Since the DAS operator remains in the Control Room during testing the external clock reference should be made to a timepiece carried by the engineer responsible for data reduction or his delegate. The data reduction engineer or his delegate must be present during the test. It is the responsibility of the data reduction engineer or his delegate to note down the time of significant test events such as injection of aerosols. The DAS operator should also make notes on the occurrence of test related events.

Initiate data acquisition a few minutes before start of the production test.

Upon completion of the test terminate DAS operation by pressing the escape key, Esc.

7. Data File Backup

Refer to IBM DOS 2.1 Manual in the Control Room for descriptions of the commands mentioned below.

The data files created during the production test run MUST be COPIED IMMEDIATELY after termination of data collection. The easiest way to copy a few files is to use the DOS COPY command. Data files must be copied onto formatted floppy disks.

NOTE B.7-1: It is suggested that floppy disks be formatted as part of test preparation. In past experience the data files have been copied to one disk. The data file sizes will vary from test to test. Therefore it is prudent to have a reasonable number of formatted disk available for copying.

Given the consequences of lost data, two copies of all test data should be made on floppy disks. The source data files are, in general, not erased from the internal fixed disk. It may become necessary to erase data and/or setup files from the internal hard disk in order to have sufficient space for the data to be collected during future tests.

Files backed up from a fixed disk to floppies via the BACKUP command are only useful when reinstalled on the fixed disk using the RESTORE command. The DAS system as a whole is backed up periodically (determined by the frequency of tests) using the BACKUP command. The data reduction engineer is responsible for the system backups.

\begin{tabular}{|l|l|l|l|}
\hline $\begin{array}{l}\text { Procedure No. } \\
\text { HBTF Data Collection }\end{array}$ & Revision No. & Effective Date & $4^{\text {of }} 10$ \\
\hline
\end{tabular}


C. FLUKE DATA LOGGERS and COLUMBIA DATA CARTRIDGE RECORDERS

1. Basic operating instructions for the two Fluke 2240B data loggers available for use in the HBTF Building are presented in Section 2 of the 2240B Instruction Manuals located in the Control Room. Front panel controls and indicators are described in the first few pages of Section 2. Of particular interest for the user in support of current HBTF tests are subsections 2-36, "Output Control" and 240, "Scan Control". "Output Control" covers enabling the printer and any external devices such as the Columbia 300 D cartridge tape recorder. The frequency of data collection is described in "Scan Control".

2. Programming of the Fluke is also covered in Section 2 "Operating Instructions": primarily in subsections 2-46 through 2-81. The Fluke can be readily programmed once the channel designations of the instruments to be monitored have been determined. Review the descriptions of the following options in the Fluke 2240B Instruction Manual to assign channel numbers: Option-06, "Low Level Scanner"; Option-07, "Solder Pin Connector"; Option-08, "Isothermal Block Connector".

3. It is prudent to verify the programming of the data loggers prior to a production test run. To list the data logger program the ALL DATA switch of the PRINTER ENABLE group and the RESET switch of the SCAN CONTROL group must be engaged prior to engaging the PROGRAM LIST switch. Review the program list and make the necessary changes to the data logger program. Re-list the program and verify that all corrections have been made. Repeat the listing, review, and revise sequence as needed.

4. Add paper to the data logger tray and replace the printer ribbon as necessary. Data logger supplies are kept in the five drawer vertical file in the HBTF Control Room.

5. If a data cartridge recorder is to be utilized in conjunction with the data logger(s) the operating instructions for the Columbia Data Cartridge Recorder (hereafter referred to by Columbia) should be reviewed. Manufacturer Operating Instructions are available in the HBTF Control Room. Columbia front panel switches and control options are described in the operating Instructions. The basics of Columbia operation related to this application are covered in steps 8 thru 11 .

NOTE C.5-1: Installation of Fluke Option-17 in both of the data loggers expands the data storage media options. Previous experience with the Columbia $300 \mathrm{D}$ data cartridge recorder indicates that use of the printer as a backup source of data collection is prudent.

\begin{tabular}{|l|l|l|l|}
\hline $\begin{array}{l}\text { Procedure No. } \\
\text { HBTF Data Collection }\end{array}$ & Revision No. & Eage of ective Date & 5 \\
\hline
\end{tabular}




\section{TITLE HIGH BAY TEST FACILITY DATA COLLECTION SYSTEMS}

6. Verify that the proper switch settings and connections have been made between the Fluke and the Columbia. (It is not necessary to perform this step prior to each test. Step 6 should be performed at the start of the test program, or if the logger has just been returned from calibration or from use with another test program).

7. The Fluke option 17 switches should be set as follows:

$\begin{array}{ccr}\text { Switch } & \frac{\text { Position }}{1,2,3} & \begin{array}{r}\text { Setting } \\ \text { S1 }\end{array} \\ \text { Off } \\ \text { S2 } & 1,4 & \text { off } \\ & 2,3 & \text { On } \\ \text { S3 } & 1,2,3 & \text { off } \\ & 4 & \text { On } \\ \text { S4 } & 1,3,4 & \text { off } \\ & 2 & \text { On }\end{array}$

Switch location is defined in the Option 17 section of the Fluke 2240B Instruction Manual.

8. To correspond to the data logger settings the switches on the underside of the Columbia must be set as follows:

\begin{tabular}{|c|c|c|}
\hline Switch & Position & Setting \\
\hline $\begin{array}{l}\text { Terminal } \\
\text { \& Modem/CPU } \\
\text { switches }\end{array}$ & $\begin{array}{c}1,2,3,4 \\
5 \\
6,7,8\end{array}$ & $\begin{array}{l}\text { Off } \\
\text { On } \\
\text { Off }\end{array}$ \\
\hline A & $\begin{array}{c}\frac{1}{2} \\
3,4,5,6,7,8\end{array}$ & $\begin{array}{l}\text { Off } \\
\text { On } \\
\text { Off }\end{array}$ \\
\hline B & $\begin{array}{c}1,2,3,4 \\
5 \\
6,7,8\end{array}$ & $\begin{array}{l}\text { Off } \\
\text { On } \\
\text { Off }\end{array}$ \\
\hline
\end{tabular}

9. Turn on the Columbia and install a blank 3M DC300 X/LP (or equivalent) data cartridge in the Columbia. The tape position indicators on the front panel of the Columbia should indicate that the head is at the Load Point on Track 1 (Track light 1 is illuminated and Status light $L$ is illuminated). If the tape is not at the Load Point of Track 1 engage the FWD (forward) and REV (reverse) switches simultaneously and the Columbia will locate the Load Point on Track.1.

\begin{tabular}{|l|l|l|l|}
\hline $\begin{array}{l}\text { Procedure No. } \\
\text { HeTF Data Collection }\end{array}$ & Revision No. & Eage 6 of $^{\text {Pfective Date }}$ \\
\hline
\end{tabular}


TITLE HIGH BAY TEST FACILITY DATA COLLECTION SYSTEMS

10. To store data from the data logger on tape via the Columbia the option 17 cable must be installed between the option 17 board and the terminal port of the Columbia. Both the data logger and recorder must be on and ready for use. Both Printer Enable and External Enable switches on the data logger front panel must be engaged. The WRITE front panel switch of the Columbia must be engaged (indicated by the light above the switch being illuminated). The TRANSPARENCY switch on the Columbia must be in the on position. Data will be transmitted to the data logger internal printer and the external recorder at the interval prescribed by the data logger program.

Evidence of the proper operation of the data recorder is the movement of the tape - which occurs automatically when the buffer of the recorder is full or when the STOP switch on the front panel is engaged. Engaging the STOP switch causes the Columbia to dump the contents of the buffer whether it is full or not. To resume recording data the WRITE and STOP switches must be disengaged (indicated by the lights above WRITE and STOP being off). The WRITE switch must be disengaged first followed by the STOP switch. Once STOP has been disengaged, the WRITE switch can be re-engaged and the recorder should be ready to receive data from the data logger.

11. The special measurement cognizant staff member or his delegate is responsible for the data logger acquisition start and the establishment of a time reference between the DAS and the data logger $(s)$.

12. Terminate data collection by the data logger and recorder at the end of the test. Engage the STOP switch on the recorder and then disengage the Internal and External Enable switches and engage the Reset switch of the data logger. Disengage the WRITE and then the STOP switches of the recorder. Rewind the data tape to the Load Point by engaging the FORWARD and REVERSE switches simultaneously. When the tape has rewound remove and label the tape from the recorder and turn off the recorder. Remove and label the corresponding hardcopy from the data logger. De-energize the data logger $(s)$.

\section{DOWNLOADING TEST DATA IN PREPARATION FOR DATA REDUCTION}

1. Downloading the data from the DAS and the Columbia $300 \mathrm{D}$ requires working knowledge of communications software (Smarterm 100), spreadsheet software (LOTUS 123), programming (BASICA) language, and a line editor (DOS EDLIN). Downloading operations are performed in the cognizant staff office and not at the HBTF. The manuals for the specified software are located in the office of E.J. Eschbach, 2400 Stevens room 2412.

Page 7 of 10


TITLE HIGH BAY TEST FACILITY DATA COLLECTION SYSTEMS

2. The data collected by the DAS must be reformatted for use with the spreadsheet software, LOTUS 123. The DAS data will be incorporated into LOTUS spreadsheets using the /FILE IMPORT NUMBERS command string. This command string copies a LOTUS recognized print file (designated by a .PRN extension) of standard ASCII characters to the current spreadsheet.

The ASCII files to be imported are limited in size to 240 characters wide and 8192 characters long. The NUMBERS option allows copying numbers and labels enclosed in quotes. LOTUS 123 creates a number cell for each number and label cell for each character string enclosed in quotes. The sequence of steps to reformat the DAS files into usable LOTUS 123 files is described below.

a. A simple BASICA program to read and then write the DAS generated files into files which satisfy the size constraints of LOTUS 123 import command. By trial and error it has been determined that, in general, at most 16 channels (width) of data can be imported as a file. To date the length limit has not been a problem. An example of a program which reads and writes 23 channels of DAS output to files of 16 and 7 channels is included in Attachment 1 . Examples of "before" and "after" format are also included in Attachment 1.

NOTE D.2.a-1: In the example BASICA program of Attachment 1 the DAS time stamp is read as a character string and all output files are written with the PRN extension. The example program in Attachment 1 will not meet the needs of all the DAS applications. The program has to be tailored to the DAS data file structure.

b. Once the original DAS files have been split into widths compatible with LOTUS 123 the BASICA single quotes, ', which enclose the channel labels and the time stamp must be replaced by LOTUS recognized double quotes, ". This is accomplished using the DOS EDLIN global replace command on the partioned .PRN files. Refer to the DOS manual for guidance on EDLIN and syntax of the EDLIN replace command.

c. The partioned DAS data can now be imported into a LOTUS 123 spreadsheet using the /FILE IMPORT NUMBERS command string. It is suggested that the partioned files be imported in sequence so that the original DAS channel sequence is reproduced in the LOTUS spreadsheet. In general, the DAS files have been defined such that the channels which are expected to require computations, typically process measurements, are separate from those measurements which do not require computation, such as test section temperature data.

d. Once the spreadsheet equivalents of the DAS files have been created, various LOTUS 123 commands are utilized to construct the desired data reduction spreadsheets. 
TITLE HIGH BAY TEST FACILITY DATA COLLECTION SYSTEMS

3. Downloading the data collected by the Columbia 300 D to LOTUS 123 requires that the tape be downloaded to a $P C$ and then reformatted to be compatible with LOTUS 123 . Downloading the tape to a PC requires that a Columbia recorder, the appropriate serial port cable, a PC, and communications software (e.g. Smarterm 100) be available for use. Once downloaded to a PC the data files are reformatted so that the data from a single data logger scan will appear as a row in the LOTUS 123 spreadsheets. The steps required to download data from the Columbia tapes to the LOTUS are described below.

a. The switches on the underside of the Columbia remain as set in section C.8 of this procedure. To download, a serial cable is connected to the MODEM/CPU port of the Columbia and the appropriate $P C$ serial port. The Columbia Transparency switch is in the off position. Energize the Columbia and insert the data tape to be downloaded. Verify that the tape is at the Load Point on Track 1 , refer to section C.9 of this procedure. Engage the front panel ONLINE switch.

b. Boot up the PC. Refer to Section 4 "Using Smarterm 100" and Section 5 "ASCII File Transfer" of the Smarterm Manual for introduction to the operation of Smarterm 100 in ASCII file transfer operations. Activate the communications software by issuing the command string ST100. A Smarterm configuration for the Columbia has been setup and verified. The desired configuration is saved under the name "COLUMBIA". Select the "COLUMBIA" configuration for use by entering the corresponding configuration number. Alt C selects the capture mode and the capture options of "COLUMBIA" will be displayed. Follow the menu guidance to change the name of the file to be created on either a floppy or the hardcard directory (the drive must be specified). When ready to download the tape simply depress the keyboard return key. The tape may begin to be read and the data will be echoed on the PC screen. If the tape does not start, engage the READ switch on the front panel of the Columbia. As currently defined in the Smarterm software, the data will be echoed on the screen. If no data is seen, stop the tape and return to the capture mode menu by the Alt C command. Check the physical connections and capture menu options. Rewind the tape to the Load Point on Track 1 (refer to step C.9) and try the capture again.

c. When the tape is emptied of desired data, terminate downloading by issuing the Alt $X$ command. The Alt $X$ command closes the computer file and returns computer operation to the operating system. If it is preferred to return to Smarterm 100 mode issue the Alt C command.

Procedure No.

HBTF Data Collection
Effective Date

Revision No.

9

10 
d. The data file(s) transferred by downloading the Columbia to the PC must be reformatted by a BASICA program similar to the one utilized with the DAS data. The program is written to accommodate repeated occurrence of two character strings followed by a specific number of single data. The program is not capable of dealing with blank lines or missing data. Therefore, prior to utilizing a BASICA program to write the continuous data into columnar format the data must be reviewed for blanks and delimiters must be added to the downloaded data. Both operations are accomplished using EDLIN.

Invoke EDLIN for the desired file. Delete all blank lines and incomplete data scans. Using the global replace command add comma delimiters between the four pieces of alpha-numeric data on each line. The editing operations are depicted in Attachment 2. Exit the editor in such a way that the revisions to the file are saved.

The edited files can now be used as input to the BASICA program which will read all the alphanumeric data but will only write the instrument readings to a .PRN file for use with LOTUS. As was the case with the DAS data the BASICA single quotes, ', enclosing the character strings must be replaced with LOTUS recognized double quotes,". The line editor (EDLIN) must be used again to perform the replacement of the single quotes with double quotes. A flowchart of the entire process and a listing of a sample program are included in Attachment 2.

NOTE D.3.d-1: The program listing in Attachment 2 is only an example. The loop counters and output file sizes will vary and depend on the number of active channels on the data logger.

\begin{tabular}{|l|c|c|c|}
\hline $\begin{array}{l}\text { Procedure Ho. } \\
\text { HeTF Data Collection }\end{array}$ & Rerision No. Effective Date & Page \\
\hline
\end{tabular}




\section{BASICA Program Listing}

The program listed below is an example of the BASICA programs used to convert the Labtech Notebook generated data files to a format compatible with LOTUS Import command width Iimitations.

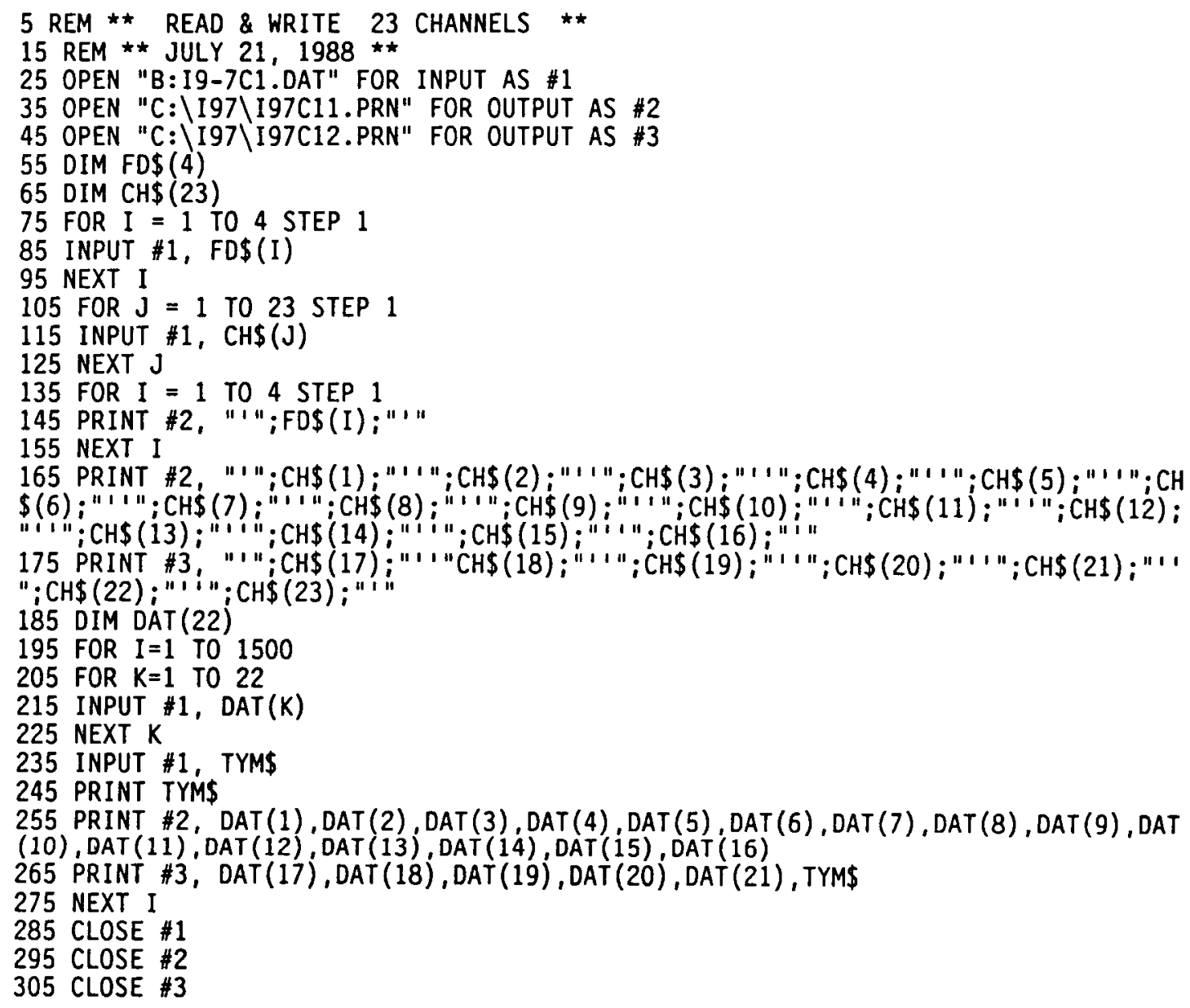


Listed below is an example of the data structure produced by Labtech Notebook during a typical test run. The 23 channel width can not be directly iaported into a LOTS workshoet. The data nust be rewritten in files not exceeding 16 channels in width.

\section{"LABTECH NOTEBOOK"}

ICEDF9.7C1"

The tine is 12:57:53.92.

"The date is 6-22-1988."

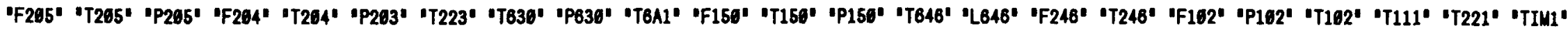

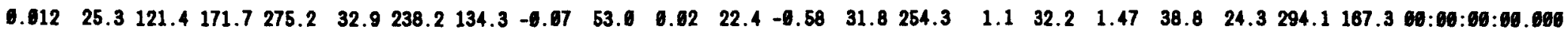

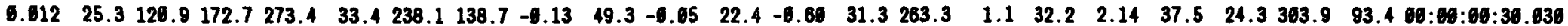

$\begin{array}{llllllllllllllllllllllll}0.014 & 25.3 & 121.1 & 172.9 & 274.3 & 33.2 & 238.2 & 140.1 & -6.13 & 52.0 & -0.61 & 22.4 & -6.68 & 31.8 & 271.3 & 1.1 & 31.7 & 2.65 & 36.1 & 25.3 & 368.7 & 43.1 & 00: 66: 01: 66.060\end{array}$

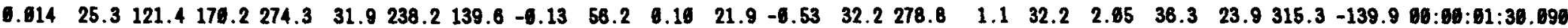

The 'READ \& WRITE 23 CHANNES' BASICA progran listed on the previous page partions the single 23 channel file into files of 16 and 7 channel widths. The two 'narrow" files can now be directly inported into a LOTUS worksheet. Examples of the LoTus compatible files are listed below.

"LABTECH NOTEBOOK'

"ICEDF9.7C1'

i The time is 12:57:53.92."

The date is 8-22-1988.'

"F265" "T265" "P265" "F264" "T264" "P263" "T223" "T63g" "P63g" "T6A1" "F156" "T15g" "P158" "T646" "L646" "F246"

\begin{tabular}{|c|c|c|c|c|c|c|c|c|c|c|c|}
\hline .012 & 25.3 & 121.4 & 171.7 & 275.2 & 32.9 & 238.2 & 134.3 & -.07 & 63 & .62 & 22.4 \\
\hline-.58 & 31.8 & 254.3 & 1.1 & & & & & & & & \\
\hline .012 & 25.3 & 120.9 & 172.7 & 273.4 & 33.4 & 238.1 & 138.7 & -.13 & 49.3 & -.65 & 22.4 \\
\hline-.6 & 31.3 & 263.3 & 1.1 & & & & & & & & \\
\hline .014 & 25.3 & 121.1 & 172.9 & 274.3 & 33.2 & 238.2 & 140.1 & -.13 & 52 & -.01 & 22.4 \\
\hline-.56 & 31.8 & 271.3 & 1.1 & & & & & & & & \\
\hline 014 & 25.3 & 121.4 & 170.2 & 274.3 & 31.9 & 238.2 & 139.6 & -.13 & 56.2 & 9.999999E-62 & \\
\hline 21.9 & -.53 & 32.2 & 278.8 & & & & & & & & \\
\hline
\end{tabular}

\section{'T246" "F162" "P162" 'T162" "T111" "T221" "TIM1"}

\begin{tabular}{|c|c|c|c|c|c|c|}
\hline 32.2 & 1.47 & 38.8 & 24.3 & 294.1 & 167.3 & $60: 69: 06: 00.600$ \\
\hline 32.2 & 2.14 & 37.5 & 24.3 & 383.9 & 93.4 & $69: 00: 06: 39.630$ \\
\hline 31.7 & 2.05 & 36.1 & 25.3 & 388.7 & 43.1 & $68: 68: 61: 00.869$ \\
\hline 32.2 & 2.05 & 36.3 & 23.9 & 315.3 & -139.9 & $60: 09: 01: 30.096$ \\
\hline
\end{tabular}


HBTF Data Collection

Attachment 2

Page 1 of 3

Flowchart of Steps to Transfer Taped Data to LOTUS

Download tape to PC

Edit the down loaded data

- Delete incomplete scans

- Delete blank lines

- Delimit the data strings with commas

Reformat using BASICA program

- Listing page 3

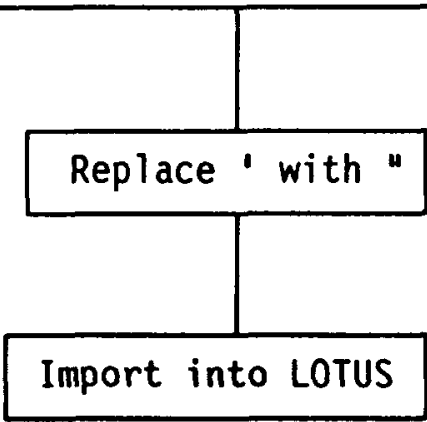


Y609:19:04:30

X061097
$\mathrm{A} 0+13.4 \mathrm{~F}$
A $1+13.9 \mathrm{~F}$
A $2+14.4 \mathrm{~F}$
A $3+13.7 \mathrm{~F}$
A $4+15.8 \mathrm{~F}$
A $5+13.1 \mathrm{~F}$
A $6+13.0 \mathrm{~F}$
A $7+12.8 \mathrm{~F}$
A $8+12.9 F$
A $9+13.4 F$
A $13+12.3 \mathrm{~F}$
A $14+12.1 \mathrm{~F}$
A $15+11.7 \mathrm{~F}$
A $16+12.1 \mathrm{~F}$
A $17+11.6 \mathrm{~F}$
A $18+12.4 F$
A $19+14.0 \mathrm{~F}$
A $25+14.4 F$
A $26+14.5 \mathrm{~F}$
A $27+15.0 \mathrm{~F}$
A $28+15.0 \mathrm{~F}$
A $29+14.1 F$

$Y 609: 19: 34: 30$ $\times 061097$

A $0+12.2 \mathrm{~F}$
$\mathrm{~A} 1+12.4 \mathrm{~F}$
$\mathrm{~A} 2+12.9 \mathrm{~F}$
$\mathrm{~A} 3+12.6 \mathrm{~F}$
$\mathrm{~A} 4+14.9 \mathrm{~F}$
$\mathrm{~A} 5+11.5 \mathrm{~F}$
$\mathrm{~A} 6+11.3 \mathrm{~F}$
$\mathrm{~A} 7+11.1 \mathrm{~F}$
$\mathrm{~A} 8+11.2 \mathrm{~F}$
$\mathrm{~A} 9+12.0 \mathrm{~F}$
$\mathrm{~A} 13+10.5 \mathrm{~F}$
$\mathrm{~A} 14+10.3 \mathrm{~F}$
$\mathrm{~A} 15+9.9 \mathrm{~F}$
$\mathrm{~A} 16+10.3 \mathrm{~F}$
$\mathrm{~A} 17+9.8 \mathrm{~F}$
$\mathrm{~A} 18+10.6 \mathrm{~F}$
$\mathrm{~A} 19+12.6 \mathrm{~F}$
$\mathrm{~A} 25+12.8 \mathrm{~F}$
$\mathrm{~A} 26+12.7 \mathrm{~F}$
$\mathrm{~A} 27+13.3 \mathrm{~F}$
$\mathrm{~A} 28+13.7 \mathrm{~F}$
$\mathrm{~A} 29+12.4 \mathrm{~F}$

$\mathrm{Y} 609,19,04,30$ X061097

$\mathrm{A}, \quad 0,+13.4, \mathrm{~F}$

A, $1,+13.9, F$

A , 2, +14.4, $\mathrm{F}$

A $3,+13.7, \mathrm{~F}$

A $\quad 4,+15.8, F$

A, $5,+13.1, F$

$A, \quad 6,+13.0, F$

A $\quad 7,+12.8, F$

$A, \quad 8,+12.9, F$

A $9,+13.4, F$

A, 13, +12.3, F

A , 14, +12.1, F

A, $15,+11.7, F$

A, $16,+12.1, F$

A, 17, +11.6, F

A, $18,+12.4$, $F$

A, 19, +14.0, F

A, $25,+14.4, F$

A, $26,+14.5, F$

A, 27, +15.0, F

$A, 28,+15.0, F$

A, 29, +14.1, F $Y 609,19,34,30$ $\times 061097$

A, $0,+12.2, F$

A, $1,+12.4, F$

A, 2, +12.9, F

A, 3, +12.6, F

A, $4,+14.9, F$

A $\quad 5,+11.5, F$

A, $6,+11.3, F$

A, $7,+11.1, F$

A, $8,+11.2, F$

A, $9,+12.0, F$

A, $13,+10.5, F$

A $14,+10.3, F$

A, $15,+9.9, \mathrm{~F}$

A, $16,+10.3, F$

A, $17,+9.8, \mathrm{~F}$

A, $18,+10.6, F$

A, $19,+12.6, F$

$A, 25,+12.8, F$

A , 26, +12.7, F

$A, 27,+13.3, F$

A , 28, +13.7, F

A, $29,+12.4, F$
HBTF Data Collection Attachment 2

Page 2 of 3

The left column is a data as it appears after being downloaded from the tape. The character strings with a leading $Y$ and $X$ are the Fixed Data entries of the data logger. The leading $A$ is associated with instrument data. The integers following the A denotes the instrument channel number. The sign of the reading follows the channel number. The magnitude of the reading follows the sign. The last character represents the unit of the instrument reading. The middle column is the edited version of the left column. This is the format needed as input to the reformat program. All of the necessary deletions and delimitation can be done using the DOS line editor EDLIN. The deletions are obvious. To delimit the strings use the replace command as follows, do not type the double quotes!

Replace ":" with" Replace "A" with "Á," Replace "+" with ", +" Replace "+ "with "+" Replace "+ " with "+" Replace " $F$ " with ",F"

The third and fourth replace commands delete the double and single spaces between the sign and the magnitude. 
HBTF Data Collection

Attachment 2

Page 3 of 3

\section{BASICA Program Listing}

The program listed below is an example of the BASICA programs used to convert the edited tape data to a format compatible with LOTUS Import command width limitations.

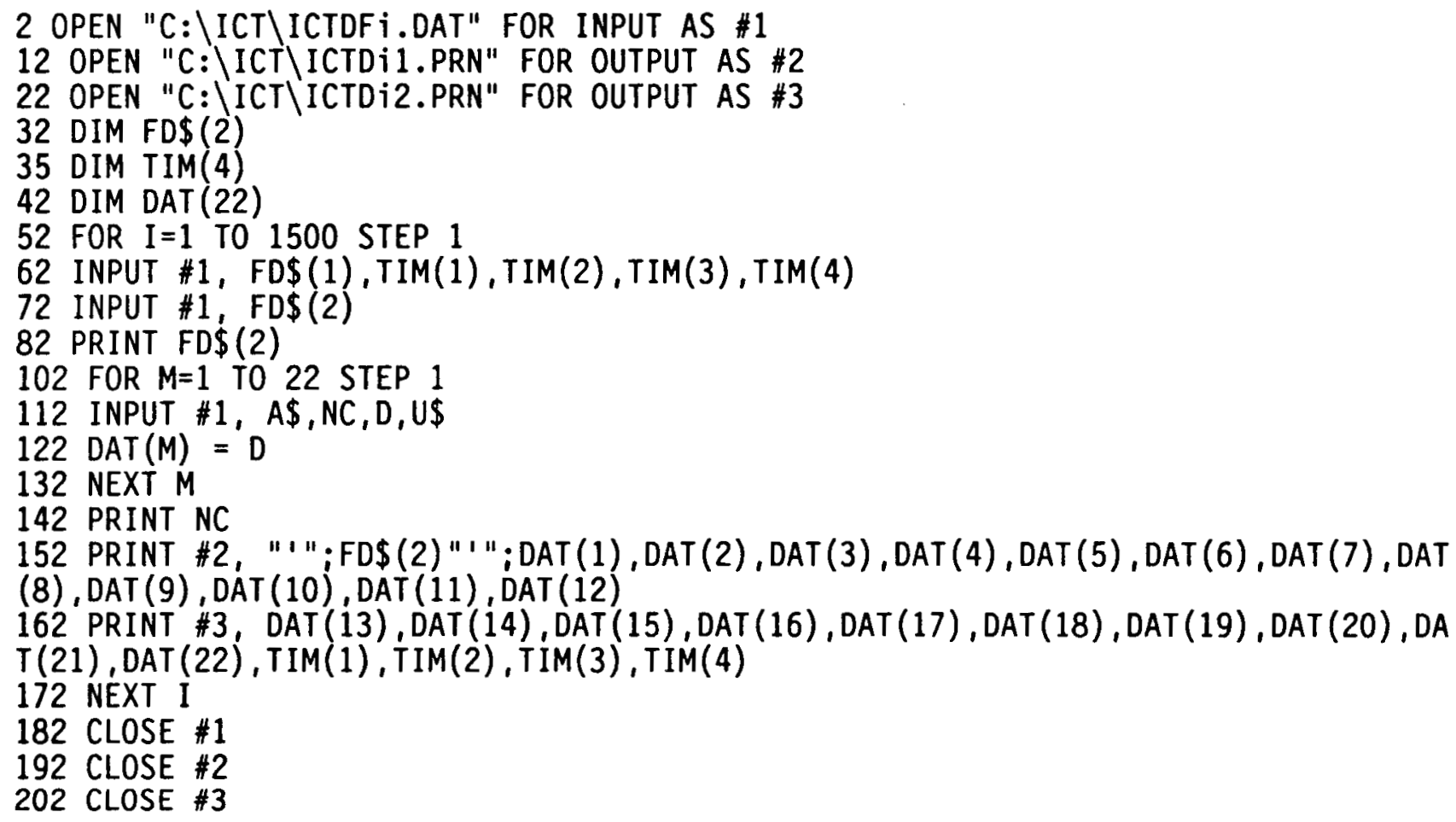



BUILDING / ROOM 336 BUILDING \& 2400 STEVENS ROOM 2412

\section{A. INTRODUCTION}

Data collection by the computer based and data logger systems currently used at the 336 Building (High Bay Test Facility) and general guidance on data downloading and generation of LOTUS 123 compatible files is covered in the HBTF Data Collection procedure. The objective of this procedure is to present the data processing activities utilized to generate the data reports of the ice condenser tests (ICT) performed in the High Bay Test Facility.

Data processing for the ICT runs can be grouped into two general categories: recreation of the data files in LOTUS 123 files and generation of the desired spreadsheets from the LOTUS data file.

Familiarity with IBM BASICA and LOTUS 123 (version 2 compatible) is required for implementation of this procedure.

Filenames mentioned in this procedure are representative of the filenames utilized in the test reports. Some difference in filenames and content may occur.

\section{B. DOWNLOADING TEST DATA IN PREPARATION FOR DATA REDUCTION}

The general procedures utilized to download data from the PC based data acquisition system (DAS) and the data logger-cartridge tape recorder are covered in Section D of the HBTF Data Collection procedure. Downloading and LOTUS 123 compatibility preparation of the data logger-cartridge tape recorder data is covered in the HBTF Data Collection procedure. Significant extension of the HBTF Data Collection Procedure is required by the necessity to repetitively divide the DAS (computer based data acquisition system) files prior to importation into LOTUS.

In general, data collected by the DAS is written to three primary data files; temperature, meters, and reference temperature files. Each primary file includes a time stamp. The temperature file consists of ninety plus thermocouple channels, the meter file consists of ten to fifteen meter channels, and seven channels in the reference temperature file. In general,

\begin{tabular}{|c|c|c|c|c|c|c|}
\hline \multicolumn{7}{|c|}{$\begin{array}{l}\text { Annual Review Dates } \\
\text { Reviewed by (Initisls/Date) }\end{array}$} \\
\hline Line Manager & Date & Responsible & Date & Radiat & Monitor & Date \\
\hline Safety Rep. & Date & Building Mgr & Date & Other & & Dato \\
\hline $\begin{array}{l}\text { Procedure No. } \\
\text { ICT Data Processing }\end{array}$ & Revi & No. & Effective Da & & $\begin{array}{l}\text { Page } \\
\\
\end{array}$ & \\
\hline
\end{tabular}


it is only necessary to divide the ninety plus temperature file. The size of the meter and reference temperature files do not exceed the LOTUS 123 Import command limitations (see HBTF Data Collection procedure or a LOTUS manual for detailed information regarding the LOTUS 123 Import command). The primary meter and reference temperature files are copied directly to a single floppy diskette for transfer to an IBM AT computer for further processing. Hereafter, the discussion in this section covers the division of the primary temperature file.

Division of the ninety plus channel primary temperature file is conducted in phases, using two BASICA programs which read and write the data into multiple files. The first phase subdivides the single primary file (which is too large to be copied to a single low density diskette) into five secondary files each of which can be copied onto a $360 \mathrm{kB}$ floppy diskette. Out of convenience and because it works, each of the secondary files consists of no more that 20 channels of data. To preserve data traceability, the data channels are read and subsequently written in the same order of occurrence as in the primary data file. NO COMPUTATIONS are performed during the subdivision of the primary data file into the five secondary files. The following word equation is a representation of the relationship between the primary and secondary temperature files for the " $i$ th" run.

$$
\begin{aligned}
& \text { ICTIA.DAT \{Primary temperature file for test i\}= } \\
& \text { ICTiAl.PRN } \quad \text { Secondary file, file channels 1-20\} + } \\
& \text { ICTiA2.PRN } \quad \text { Secondary file, file channels 21-40\} + } \\
& \text { ICTiA3.PRN } \quad \text { Secondary file, file channels 41-60\}+ } \\
& \text { ICTiA4.PRN } \quad \text { Secondary file, file channels 61-80\} + } \\
& \text { ICTIA5.PRN \{Secondary file, file channels 81-90+\}. }
\end{aligned}
$$

NOTE: B.1 The order of occurrence in the data files generated by the DAS software is indicated by the file channel number. The particular instrument being monitored is defined by the data channel number. Data channel numbers are unique to the instruments. The file channel numbers are not unique to the instruments, are not necessarily equal to the unique data channel numbers, and can be different for each test run.

Listing of the BASICA programs which are utilized to partition the primary temperature files consisting of 97 and 94 channels are presented in Attachment 1. Division of the ICT primary temperature file into the five secondary files takes approximately two hours on the Data Acquisition System (DAS) host IBM PC.

The secondary temperature files are then copied to individual low density diskettes. The remainder of the data processing is performed on an IBM AT computer in the office of EJ Eschbach.

\begin{tabular}{l|l}
\hline Proceduro No. & Revision No. \\
ICT Data Processing &
\end{tabular}


The secondary temperature files are copied onto the internal disk drive of an IBM AT computer in preparation for the second phase of the division of the temperature files. Generation of tertiary files from the secondary files is accomplished by repeating the partitioning performed in the generation of the secondary files from the primary files. The secondary files are partitioned into tertiary files having no more than 10 channels each.

The following word equations are representations of the relationship between the secondary and tertiary temperature data files for the " $i$ th" run.

ICTIA1.PRN $\quad$ Secondary file, file channels 1-20\} $=$

ICTIAP1.PRN $\quad$ Tertiary file, file channels 1-10\} +

ICTiAP2.PRN \{Tertiary file, file channels 11-20\}.

ICTiA2.PRN $\quad\{$ Secondary file, file channels $21-40\}=$

ICTiAP3.PRN \{Tertiary file, file channels $21-30\}+$ ICTiAP4.PRN Tertiary file, file channels 31-40\}.

ICTiA3.PRN $\quad\{$ Secondary file, file channels $41-60\}=$

ICTiAP5.PRN
ICTiAP6.PRN $\quad\left\{\begin{array}{l}\text { Tertiary file, file channels } 41-50\}+ \\ \text { Tertiary file, file channels } 51-60\}\end{array}\right.$

ICTiA4.PRN $\quad$ Secondary file, file channels 61-80 $=$

ICTiAP7.PRN $\quad$ Tertiary file, file channels $61-70\}+$ ICTiAP8.PRN \{Tertiary file, file channels 71-80\}.

ICTIA5.PRN $\quad$ Secondary file, file channels $81-90+\}=$

ICTiAP9.PRN \{Tertiary file, file channels 81-90\} + ICTIAPO.PRN \{Tertiary file, file channels $91-90+$.

Listing of the BASICA programs that are utilized to partition the secondary files consisting of no more than 20 channels are presented in Attachment 2. Division of each secondary temperature file into two tertiary files takes approximately 30 minutes on an IBM AT. 
TITLE ICE CONDENSER TEST DATA PROCESSING

The final step in casting the data into LOTUS compatible format is to replace the BASICA accepted single quotation marks, which enclose character strings such as titles and labels, with LOTUS accepted double quotation marks. This replacement can be accomplished quickly using a global replace command of editing software such as EDLIN or WordPerfect Library PE.

\section{RECREATING DATA FILES IN LOTUS 123}

Once in LOTUS compatible format, the data files can be imported into LoTUS 123 spreadsheets. To enhance traceability and multiple utilization of data, the primary DAS files are recreated in LOTUS 123.

As mentioned previously, the primary meter and reference temperature files can be imported directly into LOTUS spreadsheets. Each file is imported directly into a separate spreadsheet and saved under the same filename as the primary file except that LOTUS attaches the WK1 extension. In general, the primary meter filename is of the form ICTiB.DAT and the corresponding LOTUS filename is ICTiB.WK1. Similarly, the primary reference temperature filename is ICTIC.DAT and the corresponding LOTUS filename is ICTiC.WK1.

The LOTUS compatible tertiary temperature files are imported into LOTUS 123 spreadsheets in the order of appearance in the primary data file. Recreation of the primary data file order (albeit in 3 spreadsheets) promotes

traceability of the data from the primary file to the spreadsheet files. In general, the tertiary temperature files are imported into three spreadsheets of nominally 30 channels of data. The breakdown most recently utilized follows:

$$
\begin{aligned}
\text { ICTiA1.WK1 = IMPORT of ICTIAP1.PRN + ICTIAP2.PRN + ICTIAP3.PRN } & =\text { file channels } 1-30 \\
\text { ICTiA2.WK1 = IMPORT of ICTiAP4.PRN + ICTIAP5.PRN + ICTIAP6.PRN } & \text { file channels } 31-60 \\
\text { ICTiA3.WK1 = IMPORT of ICTiAP7.PRN + ICTIAP8.PRN + ICTIAP9.PRN } & + \text { ICTiAP0.PRN } \\
= & \text { file channels } 61-90+.
\end{aligned}
$$

An additional level of traceability is added to the temperature files by the insertion of the appropriate file channel number, $1-90+$, under the label of the data column. For example, Attachment 3 is a listing of the labels and file channel numbers from an example spreadsheet for ICT \#i.

Completion of the procedure presented in subsection 0.3 of HBTF Data Collection procedure results in a LOTUS compatible file of the data logger-cartridge tape recorder diffuser temperature data. The diffuser temperature data is not utilized in any other data processing and is therefore imported directly into the appropriate report spreadsheet as discussed in the following section.

\begin{tabular}{|l|l|l|r|}
\hline Procodure No. & Revision Ko. & Effective Date & Page \\
ICT Data Processing & & & 4
\end{tabular}




\section{TEST REPORT SPREADSHEETS}

After completion of the preceding steps the DAS based data from a test run will be in LOTUS 123 files and can readily be marked, using the LOTUS Range/Name/Create command and recombined into the desired spreadsheets via the LOTUS File/Combine/Copy/Named-range command. The following spreadsheets are typically created from the LOTUS 123 files for each ICT run:

Lower case " $i$ " appearing in the filename is an index representing the run number of the ICT test program.

It should be noted that the number of digits presented in the spreadsheets is not intended to represent the accuracy of the data and any subsequent computations.

LISKN.WK1

L1FC.WK1

L2SKN.WK1

L2FC.WK1

L3SKN.WKI

L3FC.WK1

L4SKN.WK1

L4FC.WK1

L5SKN.WKI

L5FC.WKI
Level 1 skin temperatures

Level 1 flow channel temperatures

Level 2 skin temperatures

Level 2 flow channel temperatures

Level 3 skin temperatures

Level 3 flow channel temperatures

Level 4 skin temperatures

Level 4 flow channel temperatures

Level 5 skin temperatures

Level 5 flow channel temperatures

MISCT.WK1 generally contains the following data:

T221

T223

T631

T630

T646

T647

T648

T649

T150

$\mathrm{T} 152$

T151

T246

TIME
Temperature of air to the mixing chamber

Temperature of steam to the mixing chamber

Temperature at the 12 inch square duct

Temperature at the 12 inch square duct

Test section (large) sump temperature

Test section (large) sump temperature

Diffuser (small) sump temperature

Diffuser (small) sump temperature

Exit temperature, downstream of the exit turning vanes

Exit temperature, downstream of the exit turning vanes and approximately 3 inches upstream of $T 150$. Used in lieu of humidity sensor.

Exit temperature from humidity sensor RTD (humidity sensor not always in use).

Temperature at sump flowmeter

Time stamp data (TIM1, time channel \#1), elapsed seconds.
Procedure No.

ICT Data Processing
Effective Date

5

8 
TITLE ICE CONDENSER TEST DATA PROCESSING

MISCP.WK1 generally contains the following data:

L646

L648

P630

P150

F150

H151

F246

TIM2
Weight of test section (large) sump, lb Weight of diffuser (small) sump, 1b Test section inlet pressure, above inlet turning vanes, inches of water gage

Exit pressure, 6 inch exit pipe, inches of water gage

Pitot probe delta $P$, inches of water gage

Percent relative humidity of exit stream (humidity

sensor not always in use). When installed, the sensor was located approximately 3 inches upstream of $\mathrm{T} 150$.

Sump flowmeter, gpm

Time stamp data (time channel \#2), elapsed seconds.

INLETi.WK1 generally contains the following:

P203

T203

F203i

F203a

P102

$\mathrm{T} 102$

F102i

F102a

P101

F101

P205

T205

F205i

F205a

Air

SMF

TIM2
Pressure at steam flowmeter F203 in psig and psia Temperature at steam flowmeter $\mathrm{F} 203$ in ${ }^{\circ} \mathrm{F}$ Indicated steam flow rate, $\mathrm{lb} / \mathrm{hr}$ i

Actual steam flow rate, $\mathrm{l} b / \mathrm{hr}$ a, corrected for meter conditions.

Pressure at air flowmeter F102 in psig and psia

Temperature at air flowmeter $\mathrm{F} 102$ in ${ }^{\circ} \mathrm{F}$

Indicated air flow rate, $1 \mathrm{~b} / \mathrm{min} i$

Actual air flow rate, $1 b /$ min $a$, corrected for meter conditions

Pressure at blower vortex meter, F101, in psig

Actual air flow rate, scfm, computed by the vortex meter flow computer. Standard conditions defined as $60^{\circ} \mathrm{F}$ and $14.7 \mathrm{psia}$ by the flow computer manufacturer.

Pressure at air flowmeter F205 in psig and psia

Temperature at air flowmeter F205 in ${ }^{\circ} \mathrm{F}$

Indicated air flow rate, $1 \mathrm{~b} / \mathrm{min} i$

Actual air flow rate, $1 b /$ min $a$, corrected for meter conditions.

Air flow rate, $1 \mathrm{~b} / \mathrm{min}$ a

Steam mole fraction of inlet stream based on meters

Time stamp data, TIM2 time channel \#2, elapsed seconds

Not all of the instruments listed above are monitored for each test. The desired test conditions dictated the selection of the active instruments.

The computations involved in the development of the spreadsheet that describes the inlet conditions based on meter readings, INLETi.WK1 are described section E of this SOP.

\begin{tabular}{|l|c|c|c|}
\hline $\begin{array}{l}\text { Procedure Ko. } \\
\text { ICT Data Processing }\end{array}$ & Rerision No. & Page of fective Date & 6 \\
\hline
\end{tabular}


TITLE ICE CONDENSER TEST DATA PROCESSING

The diffuser data, downloaded and edited in accordance with HBTF Data Collection procedure subsection D.3 can be imported directly into a LOTUS 123 spreadsheet. Appropriate spreadsheet headers can be incorporated before or after importation of the diffuser LOTUS compatible files. The typical filename of the diffuser data for ICT \# $i$ is TSTDIFi.WK1.

\section{E. INLET SPREADSHEET COMPUTATIONS}

The inlet condition spreadsheet corrects the flow meter signals for local conditions and computes the inlet steam mole fraction based on the metered air and steam flows.

The expressions utilized to correct the flow meter readings are listed below.

$$
\begin{aligned}
& \text { High Range Steam Flowmeter } \\
& \left(0-2000 \mathrm{lb} / \mathrm{hr}, 35 \mathrm{psig}, 400^{\circ} \mathrm{F}\right) \\
& \text { Low Range Steam Flowmeter } \\
& \left(0-100 \mathrm{lb} / \mathrm{hr}, 35 \mathrm{psig}, 400^{\circ} \mathrm{F}\right) \\
& \text { Low Range Air Flowmeter } \\
& \left(0-2 \mathrm{lb} / \mathrm{min}, 45 \mathrm{psig}, 70^{\circ} \mathrm{F}\right) \\
& \text { High Range Air Flowmeter } \\
& \left(0-5 \mathrm{lb} / \mathrm{min}, 45 \mathrm{psig}, 70^{\circ} \mathrm{F}\right)
\end{aligned}
$$

\begin{tabular}{|c|c|c|}
\hline where: & $\begin{array}{l}V_{S} \\
V_{a} \\
T_{s} \\
T_{a} \\
P_{s} \\
P_{a} \\
a \\
i\end{array}$ & $\begin{array}{l}\text { Steam specific volume at the scale conditions } \\
\text { Steam specific volume at the local conditions } \\
\text { Scale temperature, absolute units } \\
\text { Local temperature, absolute units } \\
\text { Scale pressure, absolute units } \\
\text { Local pressure, absolute units } \\
\text { Subscript a, actual rate or conditions } \\
\text { Subscript } i \text {, indicated value. }\end{array}$ \\
\hline
\end{tabular}$$
F 203_{a}=F 203 i * \sqrt{\left(V_{s} / V_{a}\right)}
$$$$
F 204_{a}=F 204_{i} * \sqrt{\left(V_{s} / V_{a}\right)}
$$$$
F 205_{a}=F 205_{i} * \sqrt{\left(T_{s} / P_{s}\right)} \sqrt{\left(P_{a} / T_{a}\right)}
$$$$
F 102 a=F 102 i * \sqrt{\left(T_{s} / P_{s}\right)} \sqrt{\left(P_{a} / T_{a}\right)}
$$

Values of local temperature and pressure are obtained from the thermocouples and pressure transmitters located at each of the flowmeters. Correction of the indicated air flow rates requires only the local temperature and pressure. Correction of the steam flow rates, requires that the local steam specific volume be determined. The steam specific volume is computed using a double precision BASICA program which utilizes the local temperature and pressure readings as input. The steam specific volume program computes the specific volume of steam based on the ASME Region 2 steam specific volume calculations. Copies of the relevant ASME material and a listing of the double precision BASICA program SSV.BAS are included as Attachment 4.

\begin{tabular}{|l|l|l|c|}
\hline $\begin{array}{l}\text { Procedure No. } \\
\text { ICT Data Processing }\end{array}$ & Revision No. & Page of octive Dato & 7 \\
\hline
\end{tabular}


The vortex meter data is converted to scfm by the flow computer associated with the vortex meter. The signals of the thermocouple (T101) and pressure transmitter (P101) are routed directly to the flow computer for use in the computation of scfm. Standard conditions as defined by the flow computer manufacturer are $60^{\circ} \mathrm{F}$ and $14.7 \mathrm{psia}$. No additional corrections are required for the vortex meter scfm data.

The inlet steam mole fraction, SMF, based on the meter readings is computed by the following expression:

$$
\begin{aligned}
& \text { SMF }=\text { moles of steam/(moles of steam+moles of air) } \\
& S M F=\frac{M_{S} / 18.015}{M_{S} / 18.015+\frac{\left(M_{a} / 28.97\right) \star 60 \mathrm{~min} / \mathrm{hr}}{2}} \\
& \text { where } \left.M_{s} \text { is the actual weight flow rate of steam, } 1 b / h r\right)_{a} \\
& M_{a} \text { is the actual weight flow rate of air, ib/min) a } \\
& 18.015 \text { is the molecular weight of water vapor } \\
& 28.97 \text { is the nominal molecular weight of air. }
\end{aligned}
$$


ICT Data Processing

Attachment 1

Page 1 of 2

\section{Listing of BASIC Program to Partion} Primary file into Secondary Files

\section{Channel Primary File}

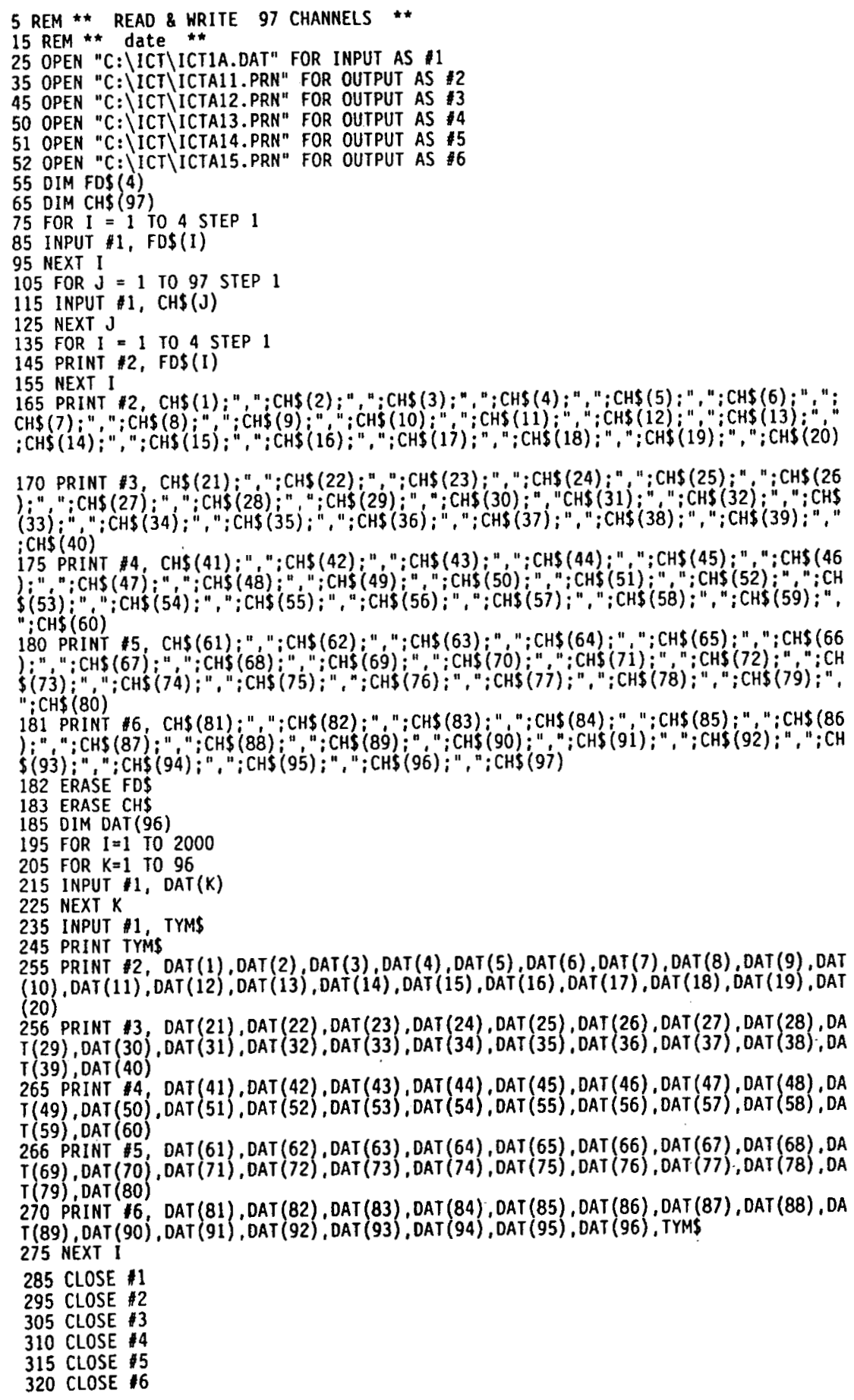




\section{Listing of BASIC Program to Partion \\ Primary file into Secondary files}

\section{Channel Primary File}

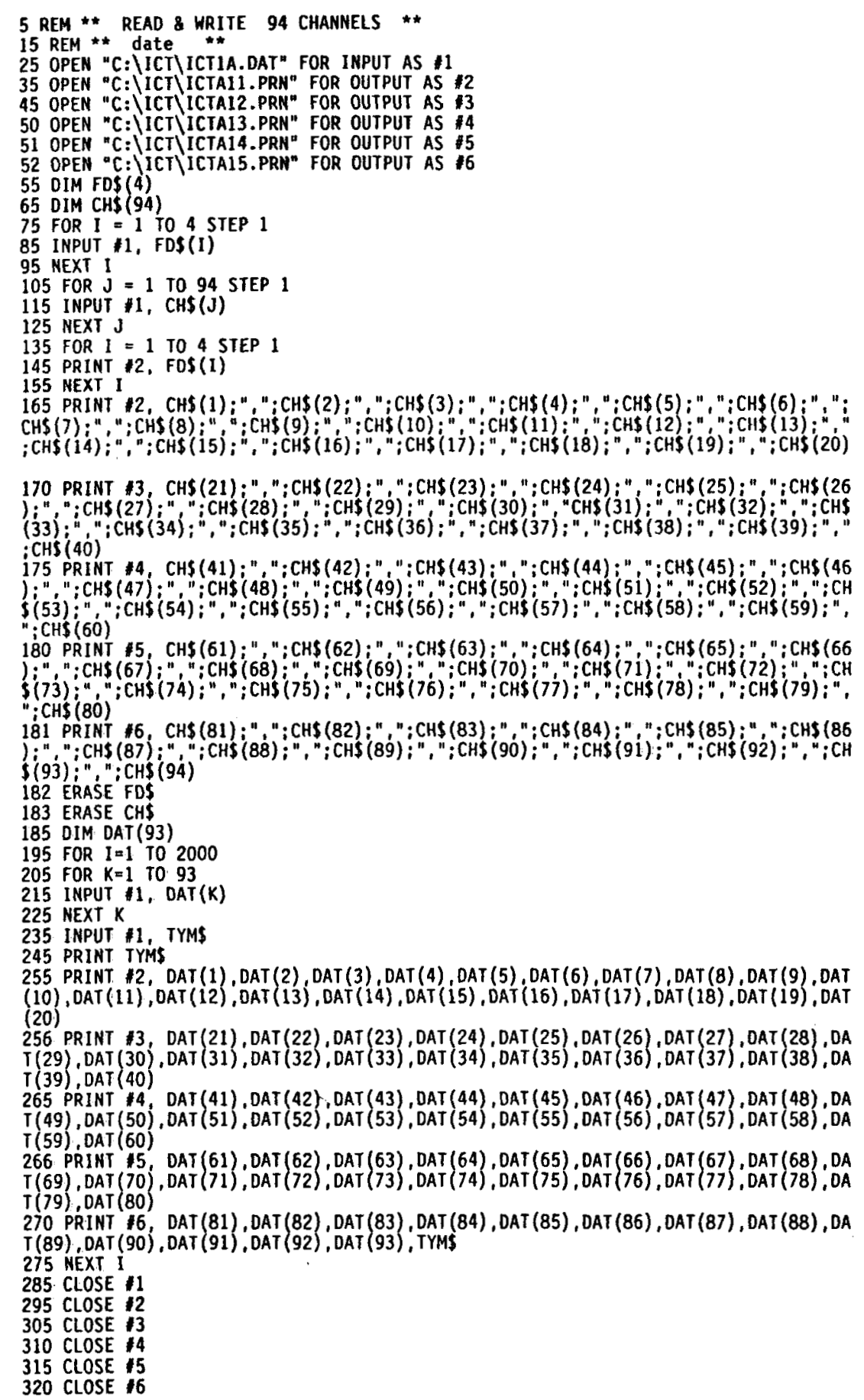


ICT Data Processing

Attachment 2

Page 1 of 2

\section{Listing of BASIC Program to Partion Secondary files into Tertiary files}

\section{Channel Secondary Files}

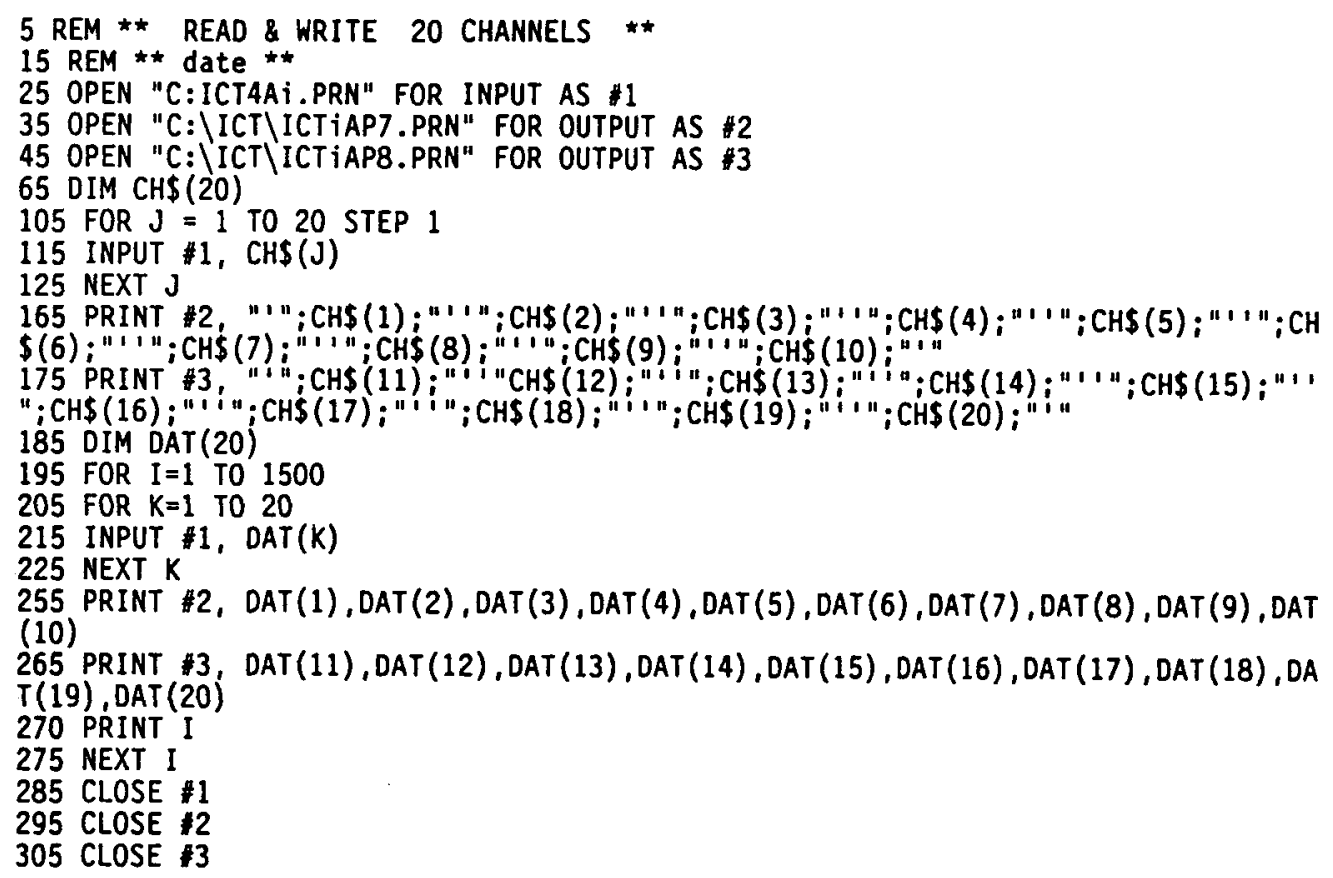


ICT Data Processing

Attachment 2

Page 2 of 2

Listing of BASIC Program to Partion

Secondary Files into Tertiary Files

\section{Channel Secondary File}

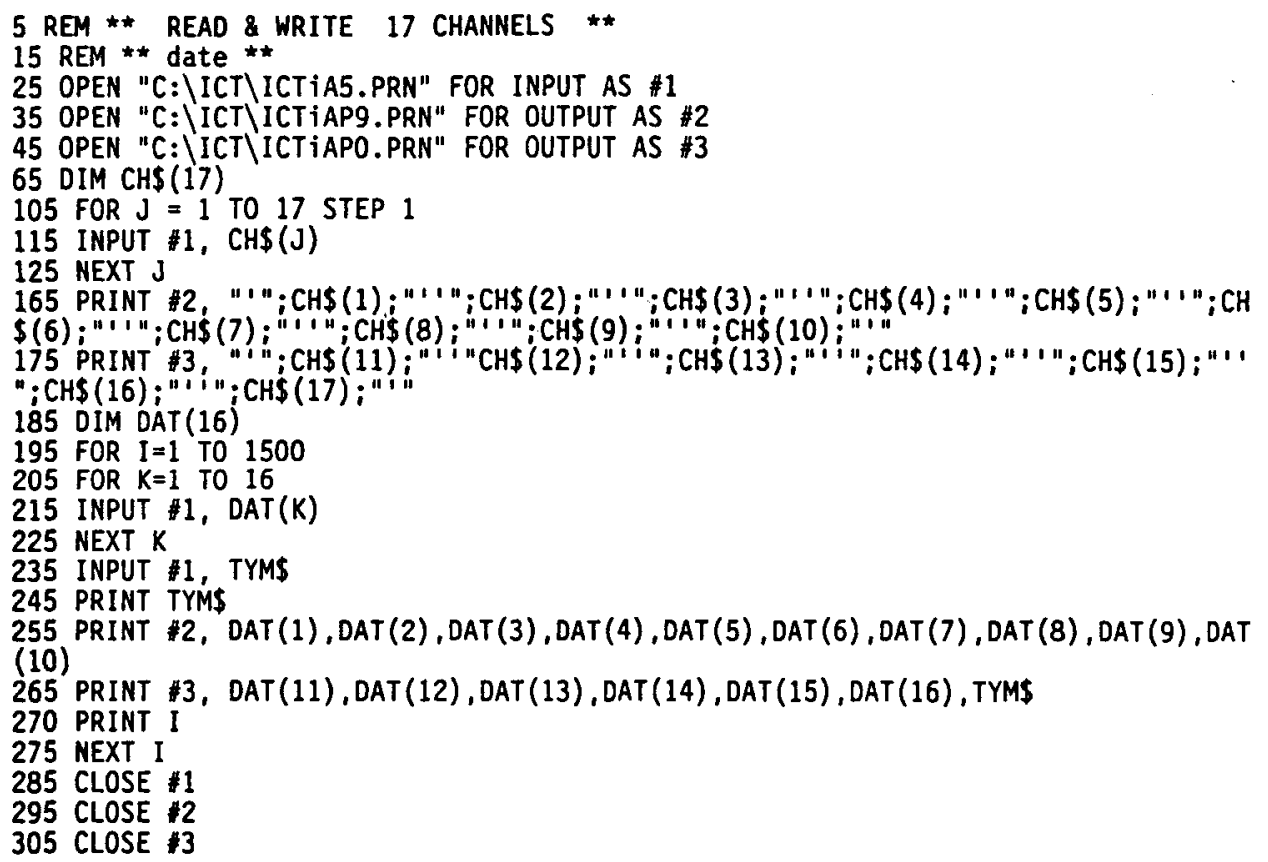

\section{Channel Secondary File}

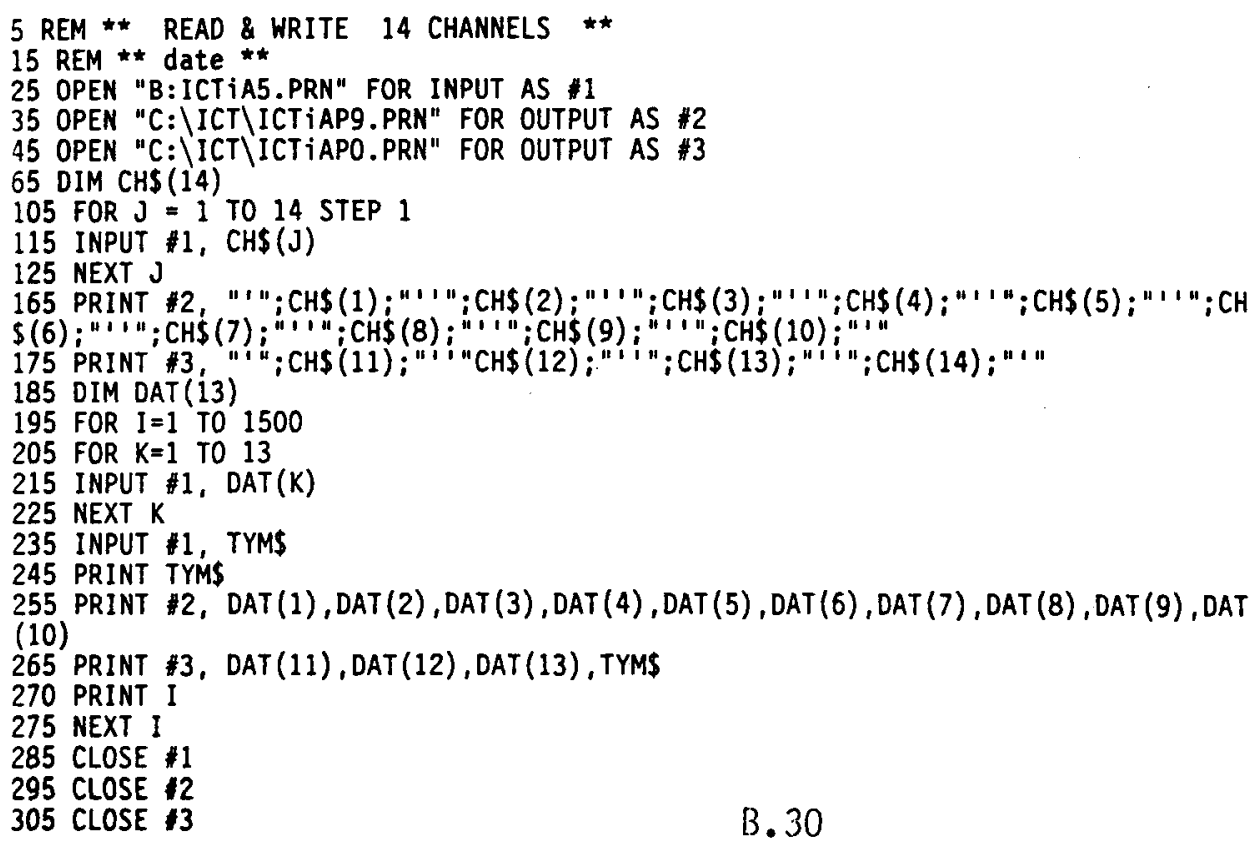


ICT Data Processing Attachment 3

Page 1 of 1

Labels and File Channel Numbers of a Generalized Data File in LOTUS 123

Typical of ICTiA1.WK1:

LABTECH NOTEBOOK

ICT\# $i$

The time is $h \mathrm{~h}: \mathrm{mm}: \mathrm{ss} . \mathrm{ss}$.

The date is mm-dd-year.

$\begin{array}{lllllllll}\text { T001 } & \text { T002 } & \text { T003 } & \text { T004 } & \text { T005 } & \text { T006 } & \text { T007 } & \text { T008 } & \text { T009 } \\ 1 & 2 & 3 & 4 & 5 & 6 & 7 & 8 & 9\end{array}$

$\begin{array}{lllllllll}\text { T010 } & \text { T011 } & \text { T012 } & \text { T013 } & \text { T014 } & \text { T015 } & \text { T016 } & \text { T017 } & \text { T018 } \\ 10 & 11 & 12 & 13 & 14 & 15 & 16 & 17 & 18\end{array}$

$\begin{array}{lllllllll}\text { T019 } & \text { T020 } & \text { T021 } & \text { T022 } & \text { T023 } & \text { T024 } & \text { T025 } & \text { T026 } & \text { T027 } \\ 19 & 20 & 21 & 22 & 23 & 24 & 25 & 26 & 27\end{array}$

T028 T029 T030

$\begin{array}{lll}28 & 29 & 30\end{array}$

Typical of ICTiA2. WK1:

\begin{tabular}{lllllllll}
\hline T031 & T032 & T033 & T034 & T035 & T036 & T037 & T038 & T039 \\
31 & 32 & 33 & 34 & 35 & 36 & 37 & 38 & 39 \\
T040 & T041 & T042 & T043 & T044 & T045 & T046 & T047 & T048 \\
40 & 41 & 42 & 43 & 44 & 45 & 46 & 47 & 48 \\
T049 & T050 & T051 & T052 & T053 & T054 & T055 & T056 & T057 \\
49 & 50 & 51 & 52 & 53 & 54 & 55 & 56 & 57
\end{tabular}

T058 T059 T060

$58 \quad 59 \quad 60$

Typical of ICTiA3.WK1:

\begin{tabular}{lllllllll}
\hline T061 & T062 & T063 & T064 & T065 & T066 & T067 & T068 & T069 \\
61 & 62 & 63 & 64 & 65 & 66 & 67 & 68 & 69 \\
T070 & T071 & T072 & T073 & T074 & T075 & T076 & T077 & T078 \\
70 & 71 & 72 & 73 & 74 & 75 & 76 & 77 & 78 \\
T079 & T080 & T081 & T082 & T083 & T084 & T085 & T086 & T087 \\
79 & 80 & 81 & 82 & 83 & 84 & 85 & 86 & 87 \\
T088 & T089 & T090 & T091 & T092 & T093 & T094 & T095 & T096 \\
88 & 89 & 90 & 91 & 92 & 93 & 94 & 95 & 96
\end{tabular}

TIME

97 

ICT Data Processing

Attachment 4

Comparison of Double Precision BASIC Program and Table Values for Steam Specific Volume

Region 2 Superheated Steam Specific Volume BASIC

\begin{tabular}{|c|c|c|c|c|c|c|}
\hline $\begin{array}{r}\text { Temp } \\
(K)\end{array}$ & $\begin{array}{l}\text { Press } \\
(\mathrm{Pa})\end{array}$ & $\begin{array}{c}\text { Calc'd } \\
\text { Super } \\
\text { Spec } \\
\text { vol } \\
\text { (ft3/lbm) }\end{array}$ & $\begin{array}{c}\text { Calc'd } \\
\text { Super } \\
\text { Spec } \\
\text { vol } \\
\text { (m3/kg) }\end{array}$ & $\begin{array}{l}\text { Table* } \\
\text { Super } \\
\text { Spec } \\
\text { vol } \\
(\mathrm{m} 3 / \mathrm{kg})\end{array}$ & $\begin{array}{c}\text { Calc'd } \\
\text { minus } \\
\text { Table } \\
(\mathrm{m} 3 / \mathrm{kg})\end{array}$ & $\begin{array}{c}\text { Diff } \\
(C-T) / T \\
\frac{\%}{6}\end{array}$ \\
\hline $\begin{array}{l}3.1499 \\
3.1499 \\
3.1499 \\
3.1499 \\
3.1499 \\
3.1499 \\
3.1499 \\
3.1499 \\
3.1499 \\
3.1499 \\
3.1499 \\
3.1499\end{array}$ & $\begin{array}{l}1000 \\
1000 \\
1000 \\
1000 \\
1000 \\
1000 \\
2000 \\
2000 \\
2000 \\
2000 \\
2000 \\
3000 \\
3000 \\
3000\end{array}$ & & & $\begin{array}{r}1.6958 \\
2.172 \\
2.639 \\
3.103 \\
3.565 \\
4.028 \\
1.0803 \\
1.3162 \\
1.5493 \\
1.7814 \\
2.013 \\
0.7163 \\
0.8753 \\
1.0315 \\
1.1867 \\
1.3414\end{array}$ & $\begin{array}{l}-0 . \\
0.0 \\
-0 . \\
-0 . \\
0.0 \\
-0 . \\
0.0 \\
-0 . \\
-0 . \\
-0 . \\
-0 . \\
0.0\end{array}$ & \\
\hline
\end{tabular}

\footnotetext{
*Extracted from Table A.1.3 - Thermodynamic Properties of Steam Superheated Vapor in Fundamentals of Classical Thermodynamics, SI Version Second Edition, Van Wylen and Sonntag, John Wiley \& Sons 1978.
} 
Listing of Double Precision BASIC Program Calculation of Steam Specific Volume Based on ASME Equations for Region 2

\section{Program Listing INPUT REQUIREMENT: Temperature in ${ }^{\circ} \mathrm{K}$ and Total Pressure in $\mathrm{Pa}$}

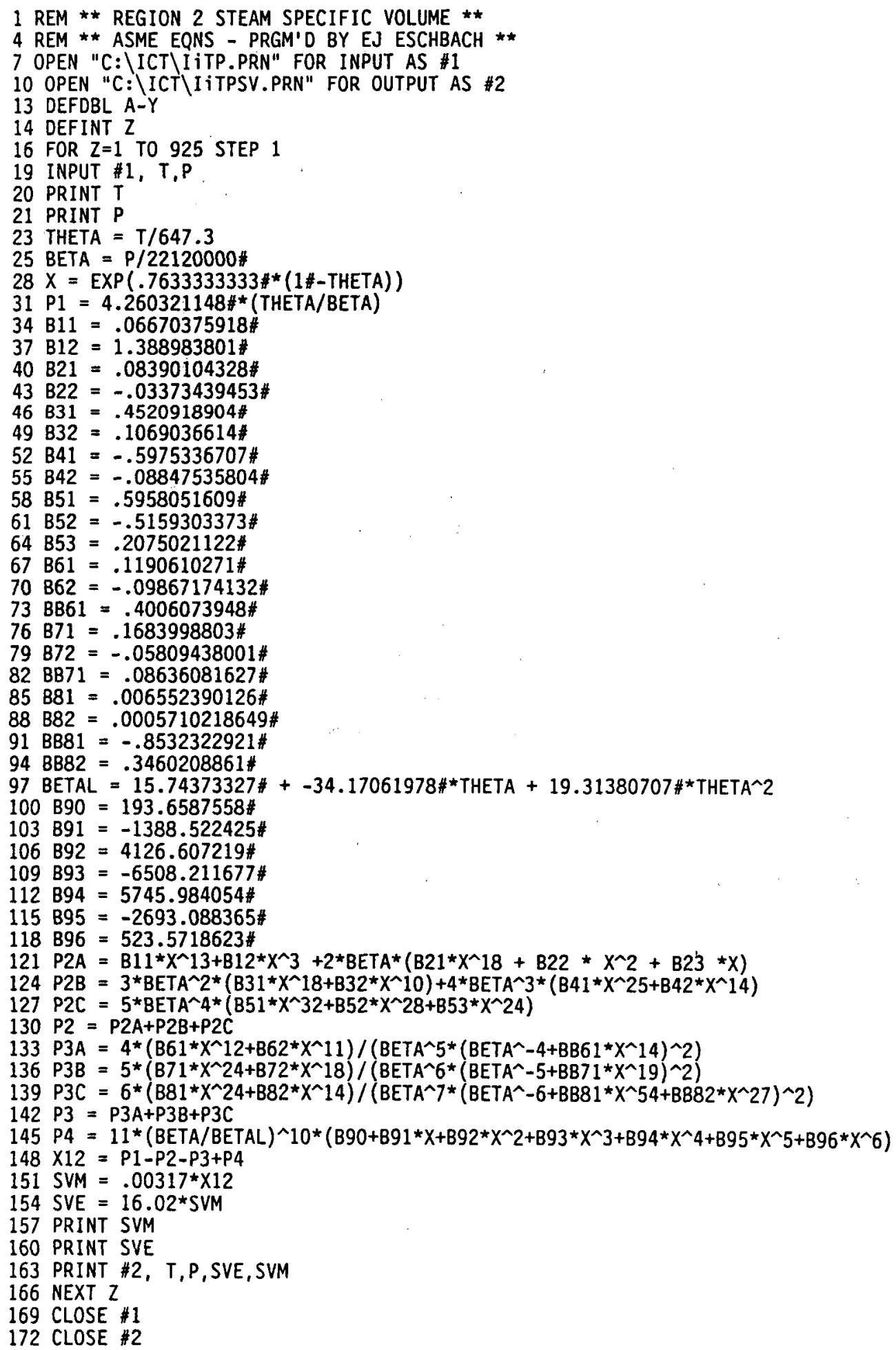


ICT Data Processing

Attachment 4

Applicable Portions of the 1967 ASME Steam Tables

Steam Table Page

Cover

3 through 6

9

12 through 25

B. 35 



\section{7 \\ ASME \\ STEAM \\ TAB LES}

SECOND EDITION

THERMODYNAMIC

AND TRANSPORT

PROPERTIES

OF STEAM

comprising

TABLES AND CHARTS FOR STEAM AND WATER

calculated using

THE 1967 IFC FORMULATION FOR INOUSTRIAL USE in conformity with

THE 1963 INTERNATIONAL SKELETON TABLES

as adopted by the

Sixth International Conference on the Properties of Steam

prepared by

C. A. Meyer

R. B. McClintock

G. J. Silvestri

R. C. Spencer, Jr.

for

The ASME Research Committee on Properties of Steam

THE AMERICAN SOCIETY OF MECHANICAL ENGINEERS

United Engineering Center - 345 East 47th Street - New York, N. Y. 10017 


\section{Thermodynamic Properties}

The thermodynamic properties are presented here in nine tables and thirteen charts. These were computed from the equations adopted in the "1967 IFC Formulation for Industrial Use," which is reproduced in toto in Appendixes 1 and 2. As indicated earlier, it was not possible to settle on a single equation of state for the behavior of steam over the entire pressure and temperature range covered by these tables. It was possible to fit the existing experimental data with requisite precision if the range was divided into suitable subregions. Six such subregions were found useful and an equation of state fitted for each. The details of how these equations may be handled on a variety of computers are to be found in a paper by McClintock and Silvestri."

In the discussion which follows, the equation numbers are those given in Appendixes 1,2 , and 5 , and the subregions are those delineated in Figures $I$ and 2 taken from the "1967 IFC Formulation for Industrial Use." These subregions have four interregional boundaries. Two are the constant temperature lines between Subregions 1 and 4 and 5 and $6(622 \mathrm{~F})$, and between Subregions 3 and 4 (705.47 F). Another is the saturation line well delineated in Tables 1 and 2 . The fourth is that between the superheated and critical Subregions 2 and 3 and is shown in Table 8.

Discontinuities in property values exist along the interregional boundaries between Subregions 1 and 4 and between Subregions 2 and 3. The magnitude of these discontinuities is discussed and described in detail in Appendix 3. In the tables, property values lying on these interregional boundaries were calculated using the equations of Subregions 1 and 2 rather than those of Subregions 3 and 4.

\section{SATURATION PROPERTIES}

Table 1 lists the saturation pressure and specific volume, entropy, and enthalpy values for saturated steam and for saturated water as well as the changes in these upon vaporization at round values of temperature from 705 to $32 \mathrm{~F}^{*}$ and at the critical and triple points. The saturation pressure was calculated at the given temperature using Equation 5 (App. 1). Along the boundaries of Subregions 1 and 2, the saturated steam and water property values were calculated directly as a function of the temperature and saturation pressure using Equations 9.1 and 9.2 (App. 1). Along the boundaries of Subregions 3 and 4, where the independent variables of the equations are specific volume and temperature, the specific volume was varied until the pressure obtained from Equations 9.3 and 9.4 (App. 1) converged to the saturation pressure within,

$$
\frac{p(E q 9.3 \text { or } 9.4)-p(E q 5)}{p(E q 5)}<5 \times 10^{-17}
$$

except, at the critical point $(705.47 \mathrm{~F})$ where the specific volume was fixed at $3.17 \mathrm{~cm}^{3} / \mathrm{g}$. The resulting specific volume and temperature were then used in Equations 9.3 and 9.4 to calculate the remaining property values.

In the first page of Table 2, the same functions plus the steam and water specific internal energies are given at round values of pressure from 30 to 0.2 inches of mercury. The remaining pages of Table 2 show all these functions from 3200 to 0.1 psia, and at the critical, boiling, and triple points.

\footnotetext{
'R. B. McClintoct and C.J. Silvestri," Formulations and tterative Procedures for the Calculation of Properties of Stean, "The American Society of Mechanical Engineers, Niew York. 1967: napep presented at the Joinc Power Conference, Detroit. Hlich., September 1967. - The temperature is given in decreasing order to facilitate visual interpolation.
} 
Thermodynamic Properties

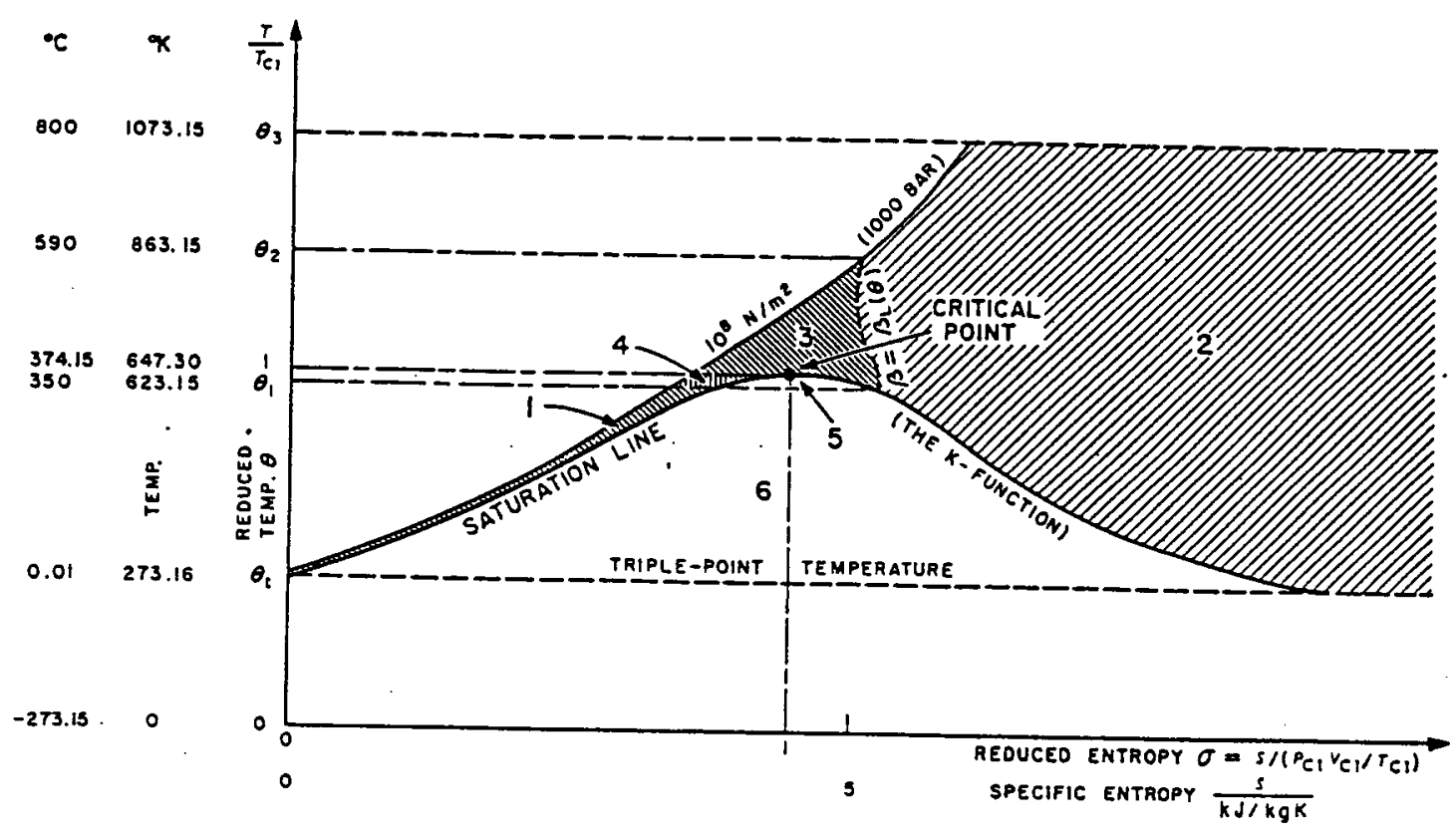

FIG. I ILLUSTRATION OF SUBREGIONS ON THE TEMPERATURE-ENTROPY DIAGRAM

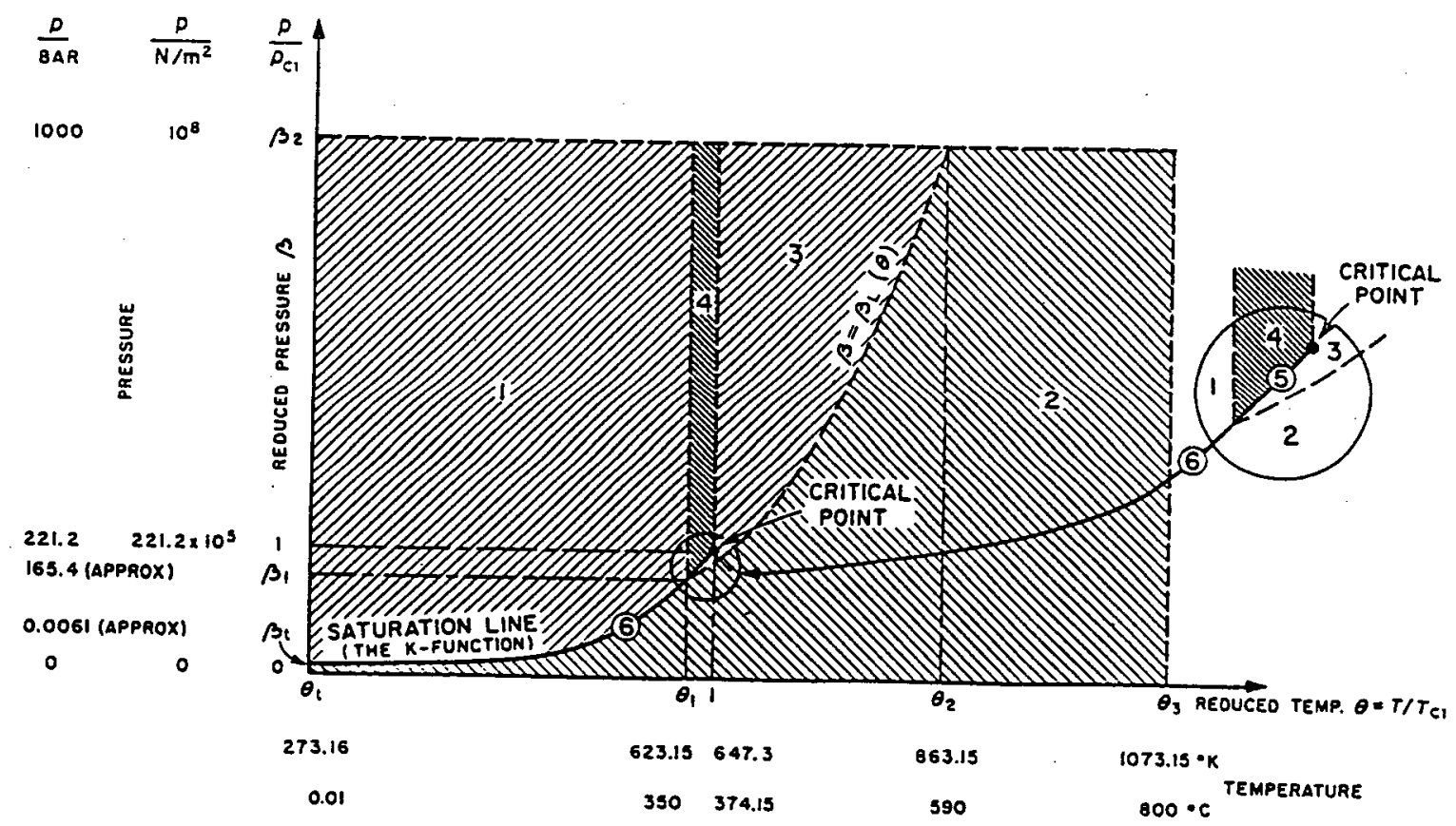

FIG. 2 ILLUSTRATION OF SUBREGIONS ON THE PRESSURE-TEMPERATURE DIAGRAM 
The saturation temperatures at the desired pressures were obtained by iteration using Equation 5 with convergence on pressure to $10^{-10}$ bars (except at the critical point $(374.15 \mathrm{C}$ ), the boiling point (100 C)and triple point $(0.01 \mathrm{C})$ where no iteration was required]. From this point the calculation procedures were identical to those of Table 1.

Discrepancies may exist between the tabulated values of $h_{f_{g}}, v_{f_{g}}, s_{f_{g}}$, and those obtained by substracting the corresponding liquid and vapor values since values for the liquid and vapor were rounded after the values of $h_{f,}, v_{f_{\mathrm{g}}}$, and $s_{f_{\mathrm{g}}}$, were computed.

\section{SUPERHEATED STEAM AND COMPRESSED WATER}

Table 3, which constitutes the major portion of these Tables, is devoted to the specific volume, enthalpy, and entropy of the superheated steam and the compressed water for temperatures from 1500 to $32 \mathrm{~F}$ in 10 degree intervals, and pressures of 0.12 to 15,500 psia. The tabulated properties were calculated using procedures similar to those described for Table 1, except that the given pressure was used in place of that obtained from Equation 5.

\section{CRITICAL REGION}

Table 4 provides the same properties at $2 \mathrm{~F}$ and 20 psia steps to permit more accurate interpolation in the critical region ( 800 to $650 \mathrm{~F} ; 2800$ to $3980 \mathrm{psia}$ ) where the properties vary rapidly. The procedures for calculating the values were the same as for Table 3.

\section{ISENTROPIC AND ISENTHALPIC TABLES}

The arrangement of Tables 5 and 6 is designed to facilitate the solution of isentropic and isenthalpic flow problems. In Table 5, the enthalpy is tabuiated as a function of the pressure for 6.0 to 0.25 inches and 0.12 to 15,500 psia, and of the entropy in steps of $0.01 \mathrm{Btu} / \mathrm{lbm}$ F. Calculations in Subregion 2 required the approximation of the temperature, which, together with the specified pressure, was used to calculate entropy using Equation 9.2. Iteration on the temperature was continued until convergence within $2 \times 10^{-5} \mathrm{~J} / \mathrm{g} \times \mathrm{C}$ was achieved at each tabulated entropy. The resulting values of temperature and the specified pressure were then used to determine the enthalpy by Equation 9.2. For Subregion 3, approximations of the temperature and specific volume were used with an intermediate convergence on the desired pressure to calculate entropy by Equation 9.3. Iteration and convergence similar to that for Subregion 2 was utilized with the final step being the determination of enthalpy by Equation 9.3, using the final values of temperature and specific volume. In Subregions 5 and 6 , procedures similar to those for Table 2 were utilized to determine the saturated steam and water values with iteration to the desired entropy.

Table 6 contains entropy values for the same pressure range as Table 5 and for enthalpy in steps of 10 $\mathrm{Btu} / \mathrm{lbm}$. The calculation procedure was similar to that for Table 5, with enthalpy and entropy interchanged.

\section{SUPERSATURATED STEAM}

Shown in Table 7 are values for specific volume, enthalpy, and entropy of supersaturated steam at pressures of 0.12 to 1500 psia and from the saturation temperature to a temperature corresponding to approximately $4^{1 / 2}$ percent moisture. The calculation procedure follows that for Subregions 2 and 3 of Table 3 .

\section{IFC BOUNDARIES}

Table 8 gives the boundary between Subregions 2 and 3 . Values of specific volume, enthalpy, and entropy have been calculated for each applicable pressure or tempernture of Tables 3 and 4. The interregional boundary function (Equation 3.2.2, App. 1) is used to find the pressure at a given temperature. When pressure was the 
independent variable, iteration was used with Equation 3.2 .2 and convergence to within $5 \times 10^{-5}$ bars of the desired pressure. The values of specific volume, enthalpy, and entropy were evaluated using Equation 9.2 of Subtegion 2. It should be noted that Equation 9.3 of Subregion 3 would provide slightly different values at these points, differing by the discontinuity on the interregional boundry.

\section{SPECIFIC HEAT}

Table 9 gives the specific heat at constant pressure (isobaric heat capacity) for the superbeated vapor and the compressed liquid. The values have been calculated largely from the formulas contained in the "Supplement to the 1967 IFC Formulation" (see Appendix 2). A plot of the values resulting from the above equations showed local variations near the interregional boundaries of about 5 percent. In these regions (shown by solid lines in Figure 3) use was made of a graphical spline fit for smoothing the tables. It should be noted that Figure 3 gives the reciprocal of the specific heat, thereby avoiding the excursions to infinity which is characteristic of normal plots in this region.

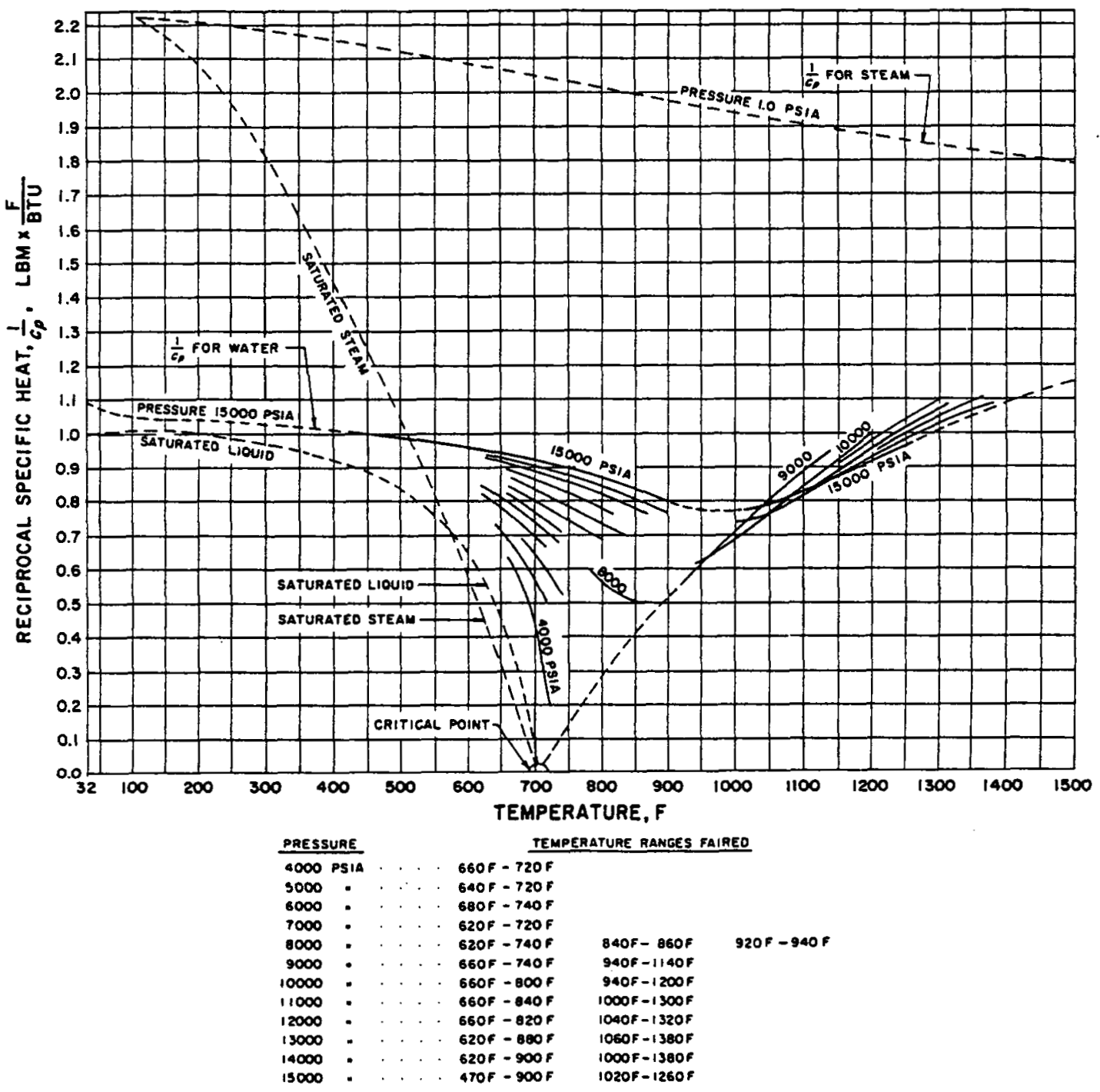

FIG. 3 SPECIFIC HEAT FORMULA SHOWING GRAPHICALLY-FAIRED REGIONS 


\section{Units, Notation, and Constants}

The notation and units employed in these tables are as follows:

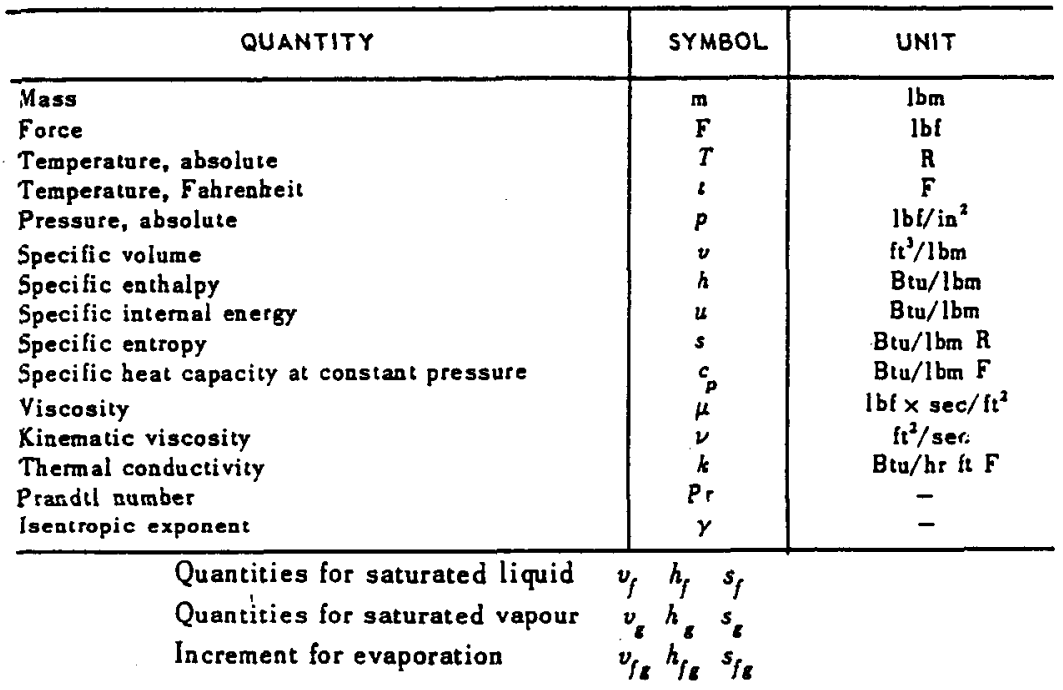

The relationships between the temperatureg scales are as follows:

$$
\begin{array}{ll}
\text { In British units } & T-t=459.67 \mathrm{~F} \\
\text { In metric units } & T_{K}-t_{c}=273.15 \mathrm{C} \text { and } \mathrm{lC}=1 \mathrm{~K}=1.8 \mathrm{~F}=1.8 \mathrm{R}
\end{array}
$$

The following factors were used in converting the dimensionless equations of Appendix $l$ to the above indicated units. See Tables $13-19$ for conversion for $\mathrm{lbf}, \mathrm{lbm}$, etc.

$$
\begin{aligned}
& p=\beta \frac{22120000 \times 0.0254 \times 0.0254}{9.80665 \times 0.45359237} \\
& T=\theta(647.3 \times 1.8) \\
& v=X \frac{0.00317 \times 0.45359237}{0.3048 \times 0.3048 \times 0.3048} \\
& h=\epsilon \frac{22120000 \times 0.00317}{2.326} \\
& s=\sigma \frac{22120000 \times 0.00317}{647.3 \times 4186.8}
\end{aligned}
$$

The liquid phase at the triple-point of water substance is the state for which the specific internal energy and the specific entropy are each made exactly zero. 
With the increasing use of digital computers, particularly in complicated calculations relating to plant design and cycle optimization, it has become necessary to have a formulation of the thermodynamic properties of water substance convenient for industrial use.

The various thermodynamic properties are not independent of each other. For example, when the pressure $p$ and temperature $T$ are chosen as the independent variables of the formulation, then expressions (here called derived functions) for the specific volume, entropy, enthalpy and all other thermodynamic properties may be derived directly by partial differentiation of the so-called canonical (or characteristic) function $g=g(p, T)$, where $g$ is the specific free enthalpy (Gibbs function). Similarly, when the-specific volume $v$ and temperature $T$ are chosen as the independent variables, then expressions for the pressure, specific entropy, enthalpy and all other thermodynamic properties may be derived directly by partial differentiation of the canonical function $f=f(v, T)$, where $f$ is the specific free energy (Helmholtz function). The formulation is presented in terms of these canonical functions, thereby maintaining thermodynamic consistency.

The canonical functions provide the definitive expression of the formulation. The derived functions are for practical use and are secondary to the canonical functions.

The formulation presented herein describes the thermodynamic properties of ordinary water substance throughout the whole of the region that extends in pressure from the ideal-gas limit (at zero pressure) to a pressure of $10^{\circ} \mathrm{N} / \mathrm{m}^{2}(1000 \mathrm{bar})$, and that extends in temperature from $273.16 \mathrm{~K}(0.01 \mathrm{C})$ to $1073.15 \mathrm{~K}(800 \mathrm{C})$.

This whole region is divided into six subregions, numbered 1 to 6 and shown on the temperature-entropy plane in Fig. 1 and on the pressuretemperature plane in Fig. 2.

Section 1 of this Statement lists the physical quantities, defines the quantity symbols and units used in the formulation, and defines certain constant quantities with the aid of which the expressions are presented in terms of reduced dimensionless variables.
Section 2 presents the reduced dimensionless quantities and also the required thermodynamic relations by means of which expressions for the derived functions can be obtained from the given canonical functions.

Section 3 specifies the sub-regions, which are identified by numbers, and gives information relating to equations which define the boundaries between subregions. These equations are identified by the letters $K$ and $L$, the $K$-function being the equation for the saturation line and the $L$-function being the equation for a boundary between two subregions in the single-phase region.

Section 4 gives the specification for the subformulation to be used in each subregion. Each such sub-formulation comprises the canonical function relevant to the subregion, logether with derived functions.

Section 5 presents the function giving the saturation line, which also serves as a boundary between subregions. This function is identified by the letter $K$.

Section 6 presents the canonical functions, which are identified by the letters $A, B, C$ and $D$. The canonical parts of the sub-formulations set out in Section 4 each comprise one or more of these principal canonical functions.

Section 7 gives the values of the constants of the formulation. Most of these values are given numerically; a few, which are derived from other constants, are given symbolically.

The material in sections 1 to 7 is sufficient and necessary to specify the formulation.

Section 8 gives the numerical values of the derived constants and a derived.form of the $L$-function convenient for computer use.

Section 9 presents those derived functions which are of practical importance.

Section 10 gives information on the magnitudes of small discontinuities in property values which occur at some of the boundaries between subregions and draws attention to the need for caution when making certain calculations. 


\section{Physical Quantities, Quantity Symbols, Units and Defined \\ Constant Quantities}

\subsection{Physical quantities (properties)}

The following physical quantities are given the symbols listed:

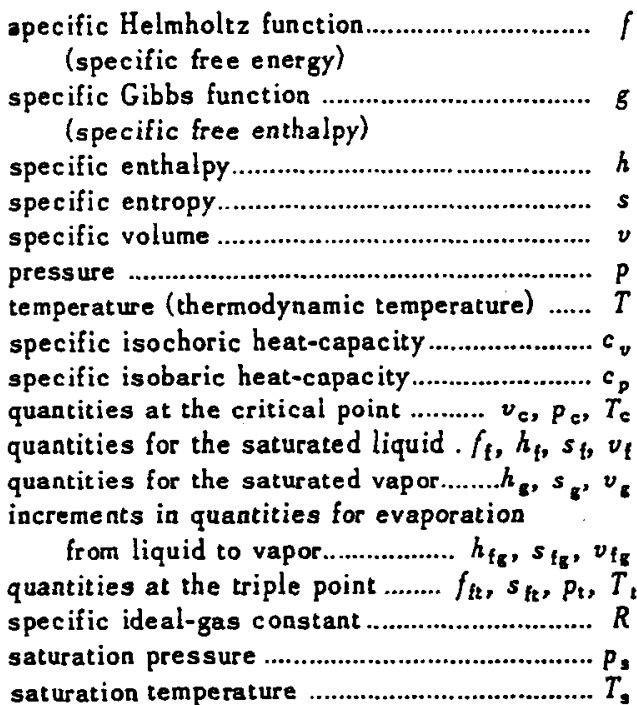

\subsection{Units}

The units of the Systeme International d'Unites (SI units) are used and have the definitions assigned to them by the Conférence Générale des Poids et Mesures, (CGPM).

These SI units are:

\begin{tabular}{|c|c|c|c|}
\hline Quantities & Units & $\begin{array}{c}\text { Unit } \\
\text { Symbol }\end{array}$ & Note \\
\hline$f, g, h$ & $\begin{array}{l}\text { joule per kilogramme } \\
\text { metre cubed per kilo- }\end{array}$ & $\begin{array}{l}\mathrm{J} / \mathrm{kg} \\
\mathrm{m}^{3} / \mathrm{kg}\end{array}$ & \\
\hline & $\begin{array}{l}\text { gramme } \\
\text { newton per metre } \\
\text { squared }\end{array}$ & $\left.\mathrm{N} / \mathrm{m}^{2}\right)$ & \\
\hline$p$ & $\begin{array}{l}\text { jquared } \\
\text { joule per metre cubed } \\
\text { pascal }\end{array}$ & $\begin{array}{l}\mathrm{J} / \mathrm{m}^{\mathrm{s}} \\
\mathrm{Pa}\end{array}$ & 1) \\
\hline$T$ & degree Kelvin & ${ }^{\circ} \mathrm{K}$ & 2) \\
\hline
\end{tabular}

$s, R, c_{v}, c_{p} \quad$ joule per kilogramme

$$
\text { degree Kelvin } \mathrm{J} / \mathrm{kg}^{\circ} \mathrm{K}
$$

Note 1: The names and unit symbols given here are synonyms for the same unit of pressure.

Note 2: The International Formulation Committee (IFC) of the International Conference on the Properties of Steam (ICPS) has adopted the statement that the replacement of these names and unit symbols by the following shall be tolerated:

$$
T \quad \text { kelvin }
$$

\section{$\mathrm{K}$} $s, R, c_{y}, c_{p}$ joule per kilogramme kelvin $\mathrm{J} / \mathrm{kg}_{\mathrm{g}} \mathrm{K}$

In this Statement of the Formulation use is made of these tolerated forms.

The equations giving the units adopted by the ICPS in terms of the SI units are:

$$
\begin{aligned}
& 1 \mathrm{~J} / \mathrm{g}=1000 \mathrm{~J} / \mathrm{kg} \\
& I \mathrm{~cm}^{3} / \mathrm{g}=0.001 \mathrm{~m}^{3} / \mathrm{kg} \\
& 1 \mathrm{bar}=100000 \mathrm{~N} / \mathrm{m}^{2}=100000 \mathrm{~J} / \mathrm{m}^{3} \\
& 1 \mathrm{~J} / \mathrm{g}{ }^{\circ} \mathrm{K}=1000 \mathrm{~J} / \mathrm{kg} \mathrm{K} .
\end{aligned}
$$

The International Organization for Standardization (ISO/R 31) has provided equations for other units in terms of SI units.

The definitions given by the CGPII and the ISO imply that

$$
T_{\mathrm{t}}=273.16 \mathrm{~K} \quad \text { (exactly) }
$$

and that the (thermodynamic) Celsius temperature is exactly $T-T_{0}$, where

$$
T_{0}=273.15 \mathrm{~K}
$$

(exactly)

The symbol $T$ in this Statement refers throughout to thermodynamic (absolute) temperature. Temperatures on the International Practical Scale of Temperature (1948) provide a closely approximate realization of the numerical values on the thermodynamic Celsius scale. The constants listed in Section 7 are appropriate for use when the International Practical Scale and the thermodynamic Celsius scale are treated as being identical. 


\subsection{Defined constant quontities}

In accordance with the decisions of the ICPS (Sth International Conference, London, 1956):

$$
s_{\mathrm{ft}}=0, f_{\mathrm{ft}}=0 \text {. }
$$

The IFC, at its First Meeting in Prague, 1965, defined certain symbols for certain constant quantities. Among these are:

$$
\begin{aligned}
& P_{1_{1}}=611.2 \mathrm{~N} / \mathrm{m}^{2}=611.2 \mathrm{~J} / \mathrm{m}^{3} \\
& T_{\mathrm{e}_{1}}=647.3 \mathrm{~K} \\
& P_{\mathrm{s}_{1}}=22120000 \mathrm{~N} / \mathrm{m}^{2}=22120000 \mathrm{~J} / \mathrm{m}^{\prime} \\
& v_{\mathrm{c}_{1}}=0.00317 \mathrm{~m}^{3} / \mathrm{kg} \\
& R_{1}=461.51 \mathrm{~J} / \mathrm{kg} \mathrm{K}
\end{aligned}
$$

[NOTE: Subscripts $t$ and $c$, appearing alone, would refer to the actual values at the actual triple and critical points respectively; these values are not known exactly. The further subscript 1 refers to the above constant quantities, which coincide with the values adopted by the 6 th International Conference, New York, 1963, as the nearest estimates, at that time, of the true values. It is stressed that the constants listed in Section 7 are those appropriate for use when the defined constant quantities are as given above, and that no alterations to these defined constant quantities can be made without reviewing the values of the constants listed.]

\section{Reduced Dimensionless Quantities and Thermodynamic Relations}

\subsection{Reduced dimensionless quantities}

a) In accord with IFC:

$$
\begin{aligned}
p / p_{c s} & =\beta \text {, the reduced pressure } \\
T / T_{c 1} & =\theta, \text { the reduced temperature } \\
v / v_{c 1} & =\chi \text {, the reduced volume } \\
h /\left(p_{c}, v_{c 1}\right) & =\epsilon, \text { the reduced enthalpy } \\
s /\left(p_{c 1} v_{c 1} / T_{c 1}\right) & =\sigma, \text { the reduced entropy }
\end{aligned}
$$

b) It has been found expedient to add

$$
\begin{array}{r}
g /\left(p_{c}, v_{c 1}\right)=c-\theta \sigma=\zeta \text {, the reduced free eathalpy } \\
\text { (Gibbs function) } \\
f /\left(p_{c 1}, v_{c 1}\right)=\zeta-\beta x=\psi \text {, the reduced free eaergy } \\
\text { (Helmholtz function) } \\
R_{1} T_{c 1} /\left(p_{c 1} v_{c 1}\right)=l_{32} \text { the reduced ideal-gas. } \\
\text { constant }
\end{array}
$$

Use is also made of

$P_{s} / p_{e_{1}}=\beta_{K}(\sigma)$, the reduced saturation pressure, where $p_{\mathrm{s}}=p_{\mathrm{s}}(T)$

$T_{\mathrm{s}} / T_{c 1}=\theta_{K}(\beta)$, the reduced saturation temperature, where $T_{s}=T_{s}(p)$

$T_{t} / T_{c 1}=\theta_{1}$, the reduced triple-point temperature

$p_{z} / p_{c 1}=\beta_{t}=\beta_{K}\left(\theta_{2}\right)$, the reduced triple-point pressure
Numerical values for $\theta_{\mathrm{t}}, \beta_{\mathrm{t}}, P_{\mathrm{c}}, v_{\mathrm{c} 1}, P_{\mathrm{c}}, v_{\mathrm{c} 1} / T_{\mathrm{cs}}$ and $l_{2}$ are given in Section 8 .

\subsection{Thermodynamic relations}

The known thermodynamic relations

$$
\begin{aligned}
& s=-\left(\partial_{g} / \partial T\right)_{p}=-(\partial f / \partial T)_{v} \\
& v=+\left(\partial_{g} / \partial p\right)_{T} \quad-(\partial f / \partial v)_{T} \\
& p=r s . \\
& h=g+T s=f+p v+T s .
\end{aligned}
$$

when written in terms of the reduced dimensionless quantities become:

$$
\begin{aligned}
& \sigma=-(\partial \zeta / \partial \theta)_{\beta}=-(\partial \psi / \partial \theta)_{\chi} \chi \\
& x=+(\partial \zeta / \partial \beta)_{\theta} \\
& \beta=\quad-(\partial \psi / \partial \chi)_{\theta} \\
& \epsilon=\zeta+\theta \sigma=\psi+\beta X+\theta \sigma
\end{aligned}
$$

The reduced specific heat-capacities are given by:

$$
\begin{aligned}
& \frac{c_{p} T_{c 1}}{P_{c 1} v_{c 1}}=-\theta\left(\frac{\partial^{2} \zeta}{\partial \theta^{2}}\right)_{\beta}=-\theta\left(\frac{\partial^{2} \psi}{\partial \theta^{2}}\right)_{X}+\theta\left(\frac{\partial^{2} \psi}{\partial \chi \partial \theta}\right)^{2} /\left(\frac{\partial^{2} \psi}{\partial \chi^{2}}\right)_{\theta} \\
& \frac{c_{v} T_{c 1}}{P_{c 1} v_{c 1}}=-\theta\left(\frac{\partial^{2} \psi}{\partial \theta^{2}}\right)_{X}=-\theta\left(\frac{\partial^{2} \zeta}{\partial \theta^{2}}\right)_{\beta}+\theta\left(\frac{\partial^{2} \zeta}{\partial \theta \partial \beta}\right)^{2} /\left(\frac{\partial^{2} \zeta}{\partial \beta^{2}}\right)_{\theta}
\end{aligned}
$$




\section{Specification of the Sub-Regions}

3.1 The subregions are specified in the following table and illustrated in Figs. 1 and 2.

\begin{tabular}{c|l|c}
\hline $\begin{array}{c}\text { Temperature } \\
\text { range }\end{array}$ & \multicolumn{1}{|c|}{ Pressure range } & $\begin{array}{c}\text { Sub- } \\
\text { region }\end{array}$ \\
\hline \multirow{2}{*}{$\theta_{\mathrm{t}} \leqq \theta \leqq \theta_{1}$} & $0 \leqq \beta<\beta_{K}(\theta)$ & 2 \\
& $\beta=\beta_{K}(\theta)$ & 6 \\
& $\beta_{K}(\theta)<\beta \leqq \beta_{2}$ & 1 \\
\hline & $0 \leqq \beta \leqq \beta_{L}(\theta)$ & 2 \\
$\theta_{1}<\theta<1$ & $\beta_{L}(\theta)<\beta<\beta_{K}(\theta)$ & 3 \\
& $\beta=\beta_{K}(\theta)$ & 5 \\
\hline $1 \leqq \theta<\theta_{2}$ & $\beta_{K}(\theta)<\beta \leqq \beta_{2}$ & 4 \\
\hline$\theta_{2} \leqq \theta \leqq \theta_{3}$ & $0 \leqq \beta \leqq \beta_{L}(\theta)$ & 2 \\
\hline
\end{tabular}

The functions $\beta_{K}(\theta)$ and $\beta_{L}(\theta)$ are equations for boundaries between subregions, the $K$-function being the equation for the saturation line and the $L$-function the equation for the boundary between subregions 2 and 3 . These functions, and the constants required to complete the specification of the subregions in the table, are specified in Sections 3.2 and 3.3 respectively.

3.2 Equations for boundaries between subregions

\subsubsection{The K-function}

Reduced saturation pressure

This function is given in Section 5 .

\subsubsection{The L-function}

Keduced pressure along the boundary besween subregions 2 and 3.

$\beta_{L}=\beta_{L}(\theta)=\frac{\left(\theta_{2}-\theta\right) \beta_{1}+\left(\theta-\theta_{1}\right) \beta_{2}-L\left(\theta_{2}-\theta\right)\left(\theta-\theta_{1}\right)}{\theta_{2}-\theta_{1}}$

whence

$$
\frac{d \beta_{L}}{d \theta}=\beta_{L}^{\prime}=\beta_{L}{ }^{\prime}(\theta)=\frac{\beta_{2}-\beta_{1}-L\left(\theta_{2}-2 \theta+\theta_{1}\right)}{\theta_{2}-\theta_{1}}
$$

Derived forms for $\beta_{L}$ and $\beta_{L}{ }^{\prime}$, convenient for computer use, are given in Section 8.2

3.3 Constents relating to boundaries between subregions

\subsubsection{Primary constants}

The constant $L$ and the constants relating to the $K$-function are given in Section 7.1 .

\subsubsection{Expressions for values of degived con-} stonts

Expressions for the values of the derived constants $\theta_{2}, \theta_{1}, \theta_{2}, \theta_{3}, \beta_{1}$ and $\beta_{2}$ are given in Section 7.2

\subsubsection{Numerical values of derived constants}

The numerical values of $\theta_{1}, \theta_{1}, \theta_{2}, \theta_{3}, \beta_{1}$ and $\beta_{2}$ are given in Section 8.1, and the numerical values of the constants relating to the derived forms for $\beta_{L}$ and $\beta_{L}$ 'are given in Section 8.2. 


\section{Sub-Formulations}

For each subregion there are set out be low

(1) the canonical function, and

(2) the derived functions, and the relations between the canonical and derived functions.

The functions of each sub-formulation are identified by the same number as that identifying the subregion.

- The functions $\zeta_{A}(\theta, \beta), \zeta_{B}(\theta, \beta), \psi_{C}(\theta, \chi)$ and $\psi_{D}(\theta, \chi)$ are given in Section 6 .

The purpose of introducing the terms $\alpha_{0}$ and $\alpha_{1} \theta$ is explained in Section 7.2.

\subsection{Subregion 1}

$\zeta=\zeta_{1}(\theta, \beta)=\zeta_{A}(\theta, \beta)+\alpha_{0}+\alpha_{1} \theta$

$X=\chi_{1}{ }^{\prime}(\theta, \beta)=\left(\partial \zeta_{1} / \partial \beta\right)_{\theta}$

$\sigma=\sigma_{2}(\theta, \beta)=-\left(\partial \zeta_{1} / \partial \theta\right)_{\beta}$

$\epsilon=\epsilon_{1}(\theta, \beta)=\zeta_{1}+\sigma_{2} \theta$

\subsection{Subregion 2}

$\zeta=\zeta_{2}(\theta, \beta)=\zeta_{B}(\theta, \beta)+\alpha_{0}+\alpha_{2} \theta$

$X=\gamma_{2}(\theta, \beta)=\left(\partial \zeta_{2} / \partial \beta\right)_{\theta}$

$\sigma=\sigma_{2}(\theta, \beta)=-\left(\partial \zeta_{2} / \partial \theta\right)_{\beta}$

$\epsilon=\epsilon_{2}(\theta, \beta)=\zeta_{2}+\sigma_{2} \theta$

\subsection{Subregion 3}

$$
\begin{aligned}
\psi & =\psi_{3}(\theta, X)=\psi_{C}(\theta, \chi)+\alpha_{0}+\alpha_{1} \theta \\
\beta & =\beta_{3}|\theta, \chi|=-\left(\partial \psi_{3} / \partial_{X}\right)_{\theta} \\
\sigma & =\sigma_{3}|\theta, \chi|=-\left(\partial \psi_{3} / \partial \theta\right)_{X} \\
\cdots \quad \epsilon & \left.=\epsilon_{3} \mid \theta, \chi\right\}=\psi_{3}+\sigma_{3} \theta+\beta_{3} X \\
\zeta & =\zeta_{3}|\theta, \chi|=\psi_{3}+\beta_{3} X
\end{aligned}
$$

Expressions having $\theta$ and $\beta$ as the independent variables are needed later.

The equation $\beta=\beta,\{\theta, \chi\}$, when solved for $\chi$, gives $X=\chi_{3}(\theta, \beta)$. If there be more than one such root, then $\chi_{3}$ is the greatest of these.

Then

$$
\begin{aligned}
& \sigma=\sigma_{3}\left\{\theta, \chi_{3}(\theta, \beta)\right\}=\sigma_{3}(\theta, \beta) \\
& \epsilon=\epsilon_{1}\left\{\theta, \chi_{3}(\theta, \beta)\right\}=\epsilon_{2}(\theta, \beta) \\
& \zeta=\zeta_{3}\left\{\theta, \chi_{1}(\theta, \beta)\right\}=\zeta_{2}(\theta, \beta)
\end{aligned}
$$

\subsection{Subregion 4}

$$
\begin{aligned}
& \psi=\psi_{4}(\theta, \chi)=\psi_{C}(\theta, \chi)+\alpha_{0}+\alpha_{1} \theta+\psi_{D}(\theta, \chi) \\
& \beta=\beta_{4}\{\theta, \chi\}=-\left(\partial \psi_{4} / \partial \chi\right)_{\theta} \\
& \sigma=\sigma_{4}\{\theta, \chi\}=-\left(\partial \psi_{4} / \partial \theta\right) \\
& \epsilon=\epsilon_{4}\{\theta, \chi\}=\psi_{4}+\sigma_{4} \theta+\beta_{4} \chi \\
& \zeta=\zeta_{4}\{\theta, \chi\}=\psi_{4}+\beta_{4} \chi
\end{aligned}
$$

Expressions having $\theta$ and $\beta$ as the independent variables are needed later.

The equation $\beta=\beta_{4}(\theta, \chi)$, when solved for $\chi$, gives $\chi=\chi_{4}(\theta, \beta)$. If there be more than one such root, then $\chi_{4}$ is the least of these.

\section{Then}

$\sigma=\sigma_{4}\left\{\theta, \chi_{4}(\theta, \beta)\right\}=\sigma_{4}(\theta, \beta)$

$\epsilon=\epsilon_{4}\left\{\theta, \chi_{4}(\theta, \beta)\right\}=\epsilon_{4}(\theta, \beta)$

$\zeta=\zeta_{4}\left\{\theta, \chi_{4}(\theta, \beta)\right\}=\zeta_{4}(\theta, \beta)$

\section{5,6 Subregions 5 and 6}

$$
\begin{aligned}
\beta & =\beta_{K}(\theta) \\
\text { Dryness fraction } & =\frac{\chi-\chi_{f}}{\chi_{q}-\chi_{i}}=\frac{\sigma-\sigma_{q}}{\sigma_{z}-\sigma_{i}}=\frac{\epsilon-\epsilon_{f}}{\epsilon_{g}-\epsilon_{i}} .
\end{aligned}
$$

where the subscripts $f_{\text {and }} g$ refer respectively to the liquid and gaseous phases and the quantities bearing these subscripts are given below.

\subsection{Subregion 5}

$$
\begin{array}{ll}
x_{f}=x_{4}\left(\theta, \beta_{K}(\theta)\right), & x_{E}=x_{3}\left(\theta, \beta_{K}(\theta)\right) \\
\sigma_{f}=\sigma_{4}\left(\theta, \beta_{K}(\theta)\right), & \sigma_{B}=\sigma_{1}\left(\theta, \beta_{K}(\theta)\right) \\
\epsilon_{f}=c_{4}\left(\theta, \beta_{K}(\theta)\right), & \epsilon_{E}=\epsilon_{3}\left(\theta, \beta_{K}(\theta)\right)
\end{array}
$$

\subsection{Subregion 6}

$$
\begin{array}{ll}
x_{I}=\chi_{1}\left(\theta, \beta_{K}(\theta)\right), & \chi_{E}=\chi_{2}\left(\theta, \beta_{K}(\theta)\right) \\
\sigma_{I}=\sigma_{1}\left(\theta, \beta_{K}(\theta)\right), & \sigma_{E}=\sigma_{2}\left(\theta, \beta_{K}(\theta)\right) \\
\epsilon_{I}=\epsilon_{1}\left(\theta, \beta_{K}(\theta)\right), & \epsilon_{t}=\epsilon_{2}\left(\theta, \beta_{K}(\theta)\right)
\end{array}
$$

The definitions given in Sections 4.1 to 4.4 of the derived functions $\chi_{i}, \sigma_{i}, c_{i}(i=1$ to 4$)$ are hereby extended to include $\beta=\beta_{K}(\theta)$.

The function $\beta_{K}(\theta)$ is given in Section 5 . 


\section{The K-Function (Saturation Line)}

\section{Reduced seturation pressure}

This function gives the saturation line, which is also a boundary between sub-regions.

The equation for the reduced saturation pressure, $\beta_{K}$, as a function of the reduced temperature, $\theta$, is

$$
\beta_{K}(\theta)=\exp \left[\frac{1}{\theta} \frac{\sum_{\nu=1}^{s} \cdot k_{\nu}(1-\theta)^{\nu}}{1+k_{s}(1-\theta)+k_{7}(1-\theta)^{2}}-\frac{(1-\theta)}{k_{1}(1-\theta)^{2}+k_{3}}\right]
$$

- The constants of the $K$-function are given in Section 7.1 .

\section{Canonical Functions}

\section{I The A-Function}

Reducad free enthalpy (Gibbs function)

$$
\begin{aligned}
\zeta_{A}(\theta, \beta) & =A_{0} \theta(1-\ln \theta)+\sum_{\nu=1}^{10} A_{\nu} \theta^{\nu-1}+A_{11}\left(\frac{17}{29} Z-\frac{17}{12} Y\right) Z^{12 / 17} \\
& +\left\{A_{12}+A_{13} \theta+A_{14} \theta^{2}+A_{13}\left(a_{6}-\theta\right)^{10}+A_{16}\left(a_{7}+\theta^{19}\right)^{-1} \mid \beta-\left(a_{1}+\theta^{11}\right)^{-1}\left(A_{12} \beta+A_{18} \beta^{2}+A_{11} \beta^{3}\right)\right. \\
& -A_{20} \theta^{10}\left(a_{9}+\theta^{2}\right)\left\{\left(a_{10}+\beta\right)^{-3}+a_{13} \beta\right\}+A_{21}\left(a_{12}-\theta\right) \beta^{3}+A_{32} \theta^{-20} \beta^{4}
\end{aligned}
$$

where

$$
\begin{aligned}
& Z=Y+\left(a_{3} Y^{2}-2 a_{4} \theta+2 a_{3} \beta\right)^{t} \\
& Y=1-a_{3} \theta^{2}-a_{2} \theta^{-c}
\end{aligned}
$$


Appendix 1

\subsection{The B-Function}

Reduced free enthalpy (Gibbs function)

$$
\begin{aligned}
& \zeta_{B}(\theta, \beta)=l_{1} \theta \ln \beta+B_{0} \theta(1-\ln \theta)+\sum_{\nu=1}^{S} B_{0 \nu} \theta^{\nu-1}-\left(B_{12} X^{13}+B_{12} X^{\prime}\right) \beta-\left(B_{21} X^{12}+B_{22} X^{2}+B_{23}, X\right) \beta^{2} \\
& -\left(B_{31} X^{14}+B_{32} X^{10}\right) \beta^{3}-\left(B_{41} X^{25}+B_{42} X^{14}\right) \beta^{4}-\left(B_{31} X^{32}+B_{32} X^{24}+B_{33} X^{24}\right) \beta^{5} \\
& -\frac{\left(B_{01} X^{12}+B_{82} X^{11}\right) \beta^{4}}{1+b_{81} X^{14} \beta^{4}}-\frac{\left(B_{11} X^{24}+B_{22} X^{14}\right) \beta^{5}}{1+b_{12} X^{19} \beta^{5}}-\frac{\left(B_{81} X^{34}+B_{32} X^{14}\right) \beta^{6}}{1+\left(b_{61} X^{54}+b_{12} X^{27}\right) \beta^{6}} \\
& +\beta\left(\frac{\beta}{\beta_{L}}\right)^{10} \sum_{\nu=0}^{0} B_{2 \nu} X^{\nu}
\end{aligned}
$$

where $X=\exp \{6(1-\theta)\}$ and $\beta_{L}=\beta_{L}(\theta)$, the expression for which is given in Section 3.2.2.

\begin{tabular}{|c|c|c|c|c|c|c|c|c|}
\hline \multirow[b]{2}{*}{$\mu$} & \multirow[b]{2}{*}{$n(\mu)$} & \multicolumn{3}{|c|}{$z(\mu, \nu)$} & \multirow{2}{*}{$\ell(\mu)$} & \multicolumn{2}{|c|}{$x(\mu, \lambda)$} & \multirow[b]{2}{*}{$\mu$} \\
\hline & & $\nu=1$ & $\nu=2$ & $\nu=3$ & & $\lambda=1$ & $\lambda=2$ & \\
\hline 1 & 2 & 13 & 3 & - & - & - & - & 1 \\
\hline 2 & 3 & 18 & 2 & 1 & - & - & - & 2 \\
\hline 3 & 2 & 18 & 10 & - & - & - & - & 3 \\
\hline 4 & 2 & 25 & 14 & - & - & - & - & 4 \\
\hline 5 & 3 & 32 & 28 & 24 & - & - & - & 5 \\
\hline 6 & 2 & 12 & 11 & - & 1 & 14 & - & 6 \\
\hline 7 & 2 & 24 & 18 & - & 1 & 19 & - & 7 \\
\hline 8 & 2 & 24 & 14 & - & 2 & 54 & 27 & 8 \\
\hline
\end{tabular}

The $B$-function may also be expressed more compactly as follows:

$$
\begin{aligned}
\zeta_{B}(\theta, \beta) & =I_{1} \theta \ln \beta+B_{0} \theta(1-\ln \theta)+\sum_{\nu=1}^{s} B_{0 \nu} \theta^{\nu-1} \\
& -\sum_{\mu=1}^{s}\left\{\beta^{\mu} \sum_{\nu=1}^{n(\mu)} B_{\mu \nu} X^{2(\mu, \nu)}\right\}-\sum_{\mu=0}^{\infty} \frac{\sum_{\nu=1}^{n(\mu)} B_{\mu \nu} X^{2(\mu, \nu)}}{\beta^{2-\mu}+\sum_{\lambda=1}^{l(\mu)} b_{\mu \lambda} X^{x(\mu, \lambda)}} \\
& +\beta\left(\frac{\beta}{\beta_{L}}\right)^{10} \sum_{\nu=0}^{0} B_{o \nu} X^{\nu}
\end{aligned}
$$

The numbers of terms $n(\mu)$ and $\ell(\mu)$, and the exponents $z(\mu, \nu)$ and $x(\mu, \lambda)$ are as follows: 
Reduced free energy (Helmholtz function)

$$
\begin{aligned}
& \psi_{C}(\theta, x)=C_{00}+C_{01} x+\sum_{\nu=2}^{11} C_{0 \nu} x^{1-\nu}+C_{012} \ln x+\left\{C_{13} x+\sum_{\nu=2}^{\theta} C_{1 \nu}^{*} x^{1-\nu}+C_{11} \ln x\right\}(\theta-1) \\
& +\left\{C_{21} x+\sum_{\nu=2}^{7} C_{2 \nu} x^{1-\nu}+C_{21} \ln x\right\}(\theta-1)^{2} \\
& +\left\{C_{31} \ddot{\chi}+\sum_{\nu=2}^{D} C_{3 \nu} \chi^{1-\nu}+C_{310} \ln \chi\right\}(\theta-1)^{3}+\left(C_{40}+C_{41} \chi^{-3}\right) \theta^{-23}(\theta-1)+C_{30} \theta \ln \theta \\
& +x^{6} \sum_{\nu=0}^{4} C_{6 \nu} \theta^{-2-\nu}+\sum_{\nu=0}^{\infty} C_{7 \nu}(\theta-1)^{\nu+1}
\end{aligned}
$$

\subsection{The D-function}

Reduced free energy (Helmholtz function)

$$
\psi_{D}(\theta, x)=\sum_{\mu=3}^{4} \sum_{\nu=0}^{4} D_{\mu \nu} y^{\mu} x^{-\nu}+y^{32} \sum_{\nu=0}^{2} D_{5 \nu} x^{\nu}
$$

where

$$
y=(1-\theta) /\left(1-\theta_{1}\right)
$$

\subsection{Constants relating to canonical functions}

The values of the constants introduced in Sections $6.1,6.2,6.3$ and 6.4 are given in Section 7.1 . 
Appendix 1

\section{Values of the Constants}

7.1 Numericol volues of the primory constonts

7.1.1 Sub-region 1

$$
\begin{aligned}
& A_{0}=6.824687741 \times 10^{3} \\
& A_{1}=-5.422063673 \times 10^{2} \\
& A_{z}=-2.096666205 \times 10^{4} \\
& A_{3}=3.941286787 \times 10^{4} \\
& A_{4}=-6.733277739 \times 10^{4} \\
& A_{3}=9.902381028 \times 10^{4} \\
& A_{0}=-1.093911774 \times 10^{5} \\
& A_{7}=8.590841667 \times 10^{4} \\
& A_{8}=-4.511168742 \times 10^{4} \\
& A_{0}=1.418138926 \times 10^{4} \\
& A_{10}=-2.017271113 \times 10^{3} \\
& A_{11}{ }^{\circ}=7.982692717 \times 10^{\circ} \\
& A_{12}=-2.616571843 \times 10^{-2} \\
& A_{13}=1.522411790 \times 10^{-3} \\
& A_{14}=2.284279054 \times 10^{-2} \\
& A_{13}=2.421647003 \times 10^{2} \\
& A_{18}=1.269716088 \times 10^{-10} \\
& A_{11}=2.074838328 \times 10^{-7} \\
& A_{1 \mathrm{a}}=2.174020350 \times 10^{-\mathrm{B}} \\
& A_{19}=1.105710498 \times 10^{-0} \\
& A_{20}=1.293441934 \times 10^{1} \\
& A_{21}=1.308119072 \times 10^{-5} \\
& A_{22}=6.047626338 \times 10^{-14} \\
& a_{1}=8.438375405 \times 10^{-1} \\
& a_{2}=5.362162162 \times 10^{-4} \\
& a_{3}=1.720000000 \times 10^{\circ} \\
& a_{1}=7.342278489 \times 10^{-2} \\
& a_{s}=4.975858870 \times 10^{-2} \\
& a_{6}=6.537154300 \times 10^{-1} \\
& a_{1}=1.150000000 \times 10^{-0} \\
& \text { a. }=1.510800000 \times 10^{-3} \\
& \text { a, }=1.418800000 \times 10^{-1} \\
& a_{10}=7.002753165 \times 10^{\circ} \\
& a_{11}=2.995284926 \times 10^{-4} \\
& a_{12}=2.040000000 \times 10^{-1}
\end{aligned}
$$

\subsubsection{Sub-region 2}

$$
\begin{aligned}
& B_{0}=1.683599274 \times 10^{1} \\
& B_{01}=2.856067796 \times 10^{\prime} \\
& B_{02}=-5.438923329 \times 10^{\prime} \\
& B_{0_{3}}=4.330662834 \times 10^{-1} \\
& B_{04}=-6.547711697 \times 10^{-1} \\
& B_{09}=8.565182058 \times 10^{-2} \\
& B_{11}=6.670375918 \times 10^{-2} \\
& B_{12}=1.388983801 \times 10^{\circ} \\
& B_{21}=8.390104328 \times 10^{-2} \\
& B_{22}=2.614670893 \times 10^{-2} \\
& B_{23}=-3.373439453 \times 10^{-2} \\
& B_{31}=4.520918904 \times 10^{-1} \\
& B_{32}=1.069036614 \times 10^{-1} \\
& B_{41}=-5.975336707 \times 10^{-1} \\
& B_{42}=-8.847535804 \times 10^{-2} \\
& B_{31}=5.958051609 \times 10^{-1} \\
& B_{52}=-5.159303373 \times 10^{-1} \\
& B_{53}=2.075021122 \times 10^{-1} \\
& B_{01}=1.190610271 \times 10^{-1} \\
& B_{02}=-9.867174132 \times 10^{-2} \\
& B_{11}=1.683998803 \times 10^{-1} \\
& B_{12}=-5.809438001 \times 10^{-2} \\
& B_{B_{1}}=6.552390126 \times 10^{-3} \\
& B_{12}=5.710218649 \times 10^{-4} \\
& B_{00}=1.936587558 \times 10^{2} \\
& B_{21}=-1.388522425 \times 10^{3} \\
& B_{92}=4.126607219 \times 10^{3} \\
& B_{03}=-6.508211677 \times 10^{3} \\
& B_{94}=5.745984054 \times 10^{3} \\
& B_{9 J}=-2.693088365 \times 10^{3} \\
& B_{90}=5.235718623 \times 10^{2} \\
& b=7.633333333 \times 10^{-1} \\
& b_{01}=4.006073948 \times 10^{-1} \\
& b_{71}=8.636081627 \times 10^{-2} \\
& b_{s 1}=-8.532322921 \times 10^{-1} \\
& b_{12}=3.460208861 \times 10^{-1}
\end{aligned}
$$


7.1.3 Sub-regions 3 and 4

$$
\begin{aligned}
& C_{00}=-6.839900000 \times 10^{\circ} \\
& C_{01}=-1.722604200 \times 10^{-2} \\
& C_{02}=-7.771750390 \times 10^{\circ} \\
& C_{03}=4.204607520 \times 10^{\circ} \\
& C_{01}=-2.768070380 \times 10^{\circ} \\
& C_{03}=2.104197070 \times 10^{\circ} \\
& C_{01}=-1.146495880 \times 10^{\circ} \\
& C_{01}=2.231380850 \times 10^{-1} \\
& C_{03}=1.162503630 \times 10^{-1} \\
& C_{00}=-8.209005440 \times 10^{-2} \\
& C_{010}=1.941292390 \times 10^{-2} \\
& C_{011}=-1.694705760 \times 10^{-3} \\
& C_{012}=-4.311577033 \times 10^{\circ} \\
& C_{11}=7.086360850 \times 10^{-1} \\
& C_{12}=1.236794550 \times 10^{1} \\
& C_{13}=-1.203890040 \times 10^{1} \\
& C_{11}=5.404374220 \times 10^{\circ} \\
& C_{15}=-9.938650430 \times 10^{-1} \\
& C_{10}=6.275231820 \times 10^{-2} \\
& C_{11}=-7.747430160 \times 10^{\circ} \\
& C_{21}=-4.298850920 \times 10^{\circ} \\
& C_{22}=4.314305380 \times 10^{1} \\
& C_{23}=-1.416193130 \times 10^{1} \\
& C_{24}=4.041724590 \times 10^{\circ} \\
& C_{23}=1.555463260 \times 10^{\circ} \\
& C_{20}=-1.665689350 \times 10^{\circ} \\
& C_{21}=3.248811580 \times 10^{-1} \\
& C_{21}=1.936553250 \times 10^{1} \\
&
\end{aligned}
$$

$$
\begin{aligned}
& C_{31}=7.948418420 \times 10^{-0} \\
& C_{32}=8.088597470 \times 10^{1} \\
& C_{33}=-8.361533800 \times 10^{1} \\
& C_{34}=3.586365170 \times 10^{1} \\
& C_{31}=7.518959540 \times 10^{0} \\
& C_{30}=-1.261606400 \times 10^{1} \\
& C_{37}=1.097174620 \times 10^{0} \\
& C_{30}=2.121454920 \times 10^{0} \\
& C_{30}=-5.465295660 \times 10^{-1} \\
& C_{310}=8.328754130 \times 10^{0} \\
& C_{40}=2.759717760 \times 10^{-0} \\
& C_{41}=-5.090739850 \times 10^{-4} \\
& C_{30}=2.106363320 \times 10^{2} \\
& C_{00}=5.528935335 \times 10^{-2} \\
& C_{01}=-2.336365955 \times 10^{-1} \\
& C_{0_{12}}=3.697071420 \times 10^{-1} \\
& C_{03}=-2.596415470 \times 10^{-1} \\
& C_{01}=6.828087013 \times 10^{-2} \\
& C_{70}=-2.571600553 \times 10^{2} \\
& C_{71}=-1.518783715 \times 10^{2} \\
& C_{72}=2.220723208 \times 10^{1} \\
& C_{73}=-1.802039570 \times 10^{2} \\
& C_{74}=2.357096220 \times 10^{3} \\
& C_{73}=-1.462335698 \times 10^{4} \\
& C_{70}=4.542916630 \times 10^{4} \\
& C_{77}=-7.053556432 \times 10^{4} \\
& C_{70}=4.381571428 \times 10^{4}
\end{aligned}
$$


Appendix 1

7.1.4 Sub-region 4

$$
\begin{aligned}
& D_{30}=-1.717616747 \times 10^{\circ} \\
& D_{31}=3.526389875 \times 10^{\circ} \\
& D_{32}=-2.690899373 \times 10^{\circ} \\
& D_{33}=9.070982605 \times 10^{-1} \\
& D_{34}=-1.138791156 \times 10^{-1} \\
& D_{40}=1.301023613 \times 10^{\circ} \\
& D_{41}=-2.642777743 \times 10^{\circ} \\
& D_{42}=1.996765362 \times 10^{\circ} \\
& D_{43}=-6.661557013 \times 10^{-1} \\
& D_{44}=8.270860589 \times 10^{-2} \\
& D_{50}=3.426663535 \times 10^{-4} \\
& D_{31}=-1.236521258 \times 10^{-3} \\
& D_{52}=1.155018309 \times 10^{-3}
\end{aligned}
$$

7.1.5 Saturation line

$$
\begin{aligned}
& k_{1}=-7.691234564 \times 10^{0} \\
& k_{2}=-2.608023696 \times 10^{1} \\
& k_{3}=-1.681706546 \times 10^{2} \\
& k_{4}=6.423285504 \times 10^{1} \\
& k_{3}=-1.189646225 \times 10^{2} \\
& k_{4}=4.167117320 \times 10^{\circ} \\
& k_{7}=2.097506760 \times 10^{1} \\
& k_{2}=10^{\circ} \\
& k_{9}=6
\end{aligned}
$$

-7.1.6 Boundary between subregions 2 and 3

$$
L=7.160997524 \times 10^{\circ}
$$

A derived form of the $L$-function and the values of the resulting derived constants are given in Section 8.2.

7.2 Expressions for volues of derived constonts

$$
\begin{array}{ll}
\theta_{1}=27316 / 64730 & \beta_{1}=10000 / 2212 \\
\theta_{1}=62315 / 64730 & \beta_{1}=\beta_{K}\left(\theta_{1}\right) \\
\theta_{2}=86315 / 64730 & \beta_{t}=\beta_{K}\left(\theta_{t}\right) \\
\theta_{2}=107315 / 64730 & l_{1}=R_{1} T_{c}, /\left(p_{c 1} v_{c 1}\right)
\end{array}
$$

The numerical values of the above 8 constants are given to 10 digits in Section 8.1.

The constants $\alpha_{0}$ and $\alpha_{1}$. may be taken each to be zero. If it be desired that the calculated values of the internal energy and entropy at the reference state (the liquid phase at the triple point) each approximate to zero with the highest precision, then these constants should be evaluated, to suit the computer in use, by means of the following expressions:

$$
\begin{aligned}
& a_{0}=\left[-\zeta_{A}+\beta\left(\partial \zeta_{A} / \partial \beta\right)_{\theta}+\theta\left(\partial \zeta_{A} / \partial \theta\right)_{\beta}\right]_{\theta=\theta_{2},}, \beta=\beta_{1} \\
& a_{1}=\left[-\left(\partial \zeta_{A} / \partial \theta\right)_{\beta}\right]_{\theta=\theta_{2}, \beta=\beta_{1}}
\end{aligned}
$$




\section{Derived Constants}

8.1 Numerical values of derived constents

$$
\begin{aligned}
& \alpha_{0}=0, \alpha_{1}=0 \\
& \beta_{2}=4.520795660 \times 10^{\circ} \\
& \theta_{1}=4.219990731 \times 10^{-1} \\
& \theta_{1}=9.626911787 \times 10^{-1} \\
& \theta_{2}=1.333462073 \times 10^{\circ} \\
& \theta_{1}=1.657886606 \times 10^{\circ} \\
& l_{1}=4.260321148 \times 10^{\circ} \\
& \beta_{1}=7.475191707 \times 10^{-1} \\
& \beta_{1}=2.763311032 \times 10^{-3}
\end{aligned}
$$

For convenience the adopted constant quantities are repeated here:

$$
\begin{array}{lll}
T_{c 1}=647.3 \quad \mathrm{~K} & \text { (exactly) } \\
P_{e 1}=22120000 \mathrm{~N} / \mathrm{m}^{2} & \text { (exactly) } \\
v_{c 1}=0.00317 \quad \mathrm{~m}^{3} / \mathrm{kg} & \text { (exactly) }
\end{array}
$$

whence the constant quantities given below are derived:

$$
\begin{aligned}
P_{c 1} v_{c 1} & =70120.4 \mathrm{~J} / \mathrm{kg}_{\mathrm{g}} \quad \text { (exactly) } \\
P_{e 1} v_{c 1} / T_{c 1} & =108.3275143 \mathrm{~J} / \mathrm{kg}_{\mathrm{g}} \mathrm{K}
\end{aligned}
$$

8.2 Derived form of the L.function and values of the constonts reloting thereto

When the $L$-function is rearranged to give

$$
\beta_{L}=\beta_{L}(\theta)=L_{0}+L_{2} \theta+L_{2} \theta^{2}
$$

and consequently

$$
\frac{d \beta_{L}}{d \theta}=\beta_{L}^{\prime}=\beta_{L}^{\prime}(\theta)=L_{1}+2 L_{2} \theta
$$

then the derived constants $L_{0}, L_{1}$ and $L_{2}$ have the numerical values

$$
\begin{aligned}
& L_{0}=1.574373327 \times 10^{1} \\
& L_{1}=-3.417061978 \times 10^{1} \\
& L_{2}=1.931380707 \times 10^{1}
\end{aligned}
$$

\section{Derived Functions}

\subsection{Sub-region 1}

Reduced volume, $v / v_{c 1}=\chi_{1}=\left(\partial \zeta_{A} / \partial \beta\right)_{\theta}$

$$
\begin{aligned}
\chi_{1}=A_{11} a_{3} & 2^{-5 / 17}+\left\{A_{12}+A_{13} \theta+A_{14} \theta^{2}+A_{13}\left(a_{1} \cdots \theta\right)^{10}+A_{18}\left(a_{2}+\theta^{19}\right)-1 \mid\right. \\
& -\left(a_{1}+\theta^{11}\right)-1\left(A_{12}+2 A_{18} \beta+3 A_{19} \beta^{7}\right) \\
& \left.-A_{20} \theta^{10}\left(a_{1}+\theta^{2}\right) \mid-3\left(a_{10}+\beta\right)^{-4}+a_{11}\right\}+3 A_{21}\left(a_{12}-\theta\right) \beta^{2} \\
& +4 A_{22} \theta^{-20} \beta^{3}
\end{aligned}
$$

where

$$
\begin{aligned}
& Z=Y+\left(a_{3} Y^{2}-2 a_{4} \theta+2 a_{3} \beta\right)^{i} \\
& Y=1-a_{1} \theta^{2}-a_{2} \theta^{-\theta}
\end{aligned}
$$


Appendix 1

Reduced entropy, $s /\left(p_{c 1} v_{c 1} / T_{c 1}\right)=\sigma_{1}=-\left(\partial \zeta_{A} / \partial \theta\right)_{B}-a_{1}$

$$
\begin{aligned}
\sigma_{1}=-a_{1}+ & A_{0} \ln \theta-\sum_{v=2}^{10}(\nu-1) A_{2} \theta^{v-2}+A_{12}\left[\left\{\frac{5}{12} Z-\left(a_{3}-1\right) Y\right\} Y^{\prime}+a_{4}\right] Z^{-5 / 17} \\
& +1-A_{13}-2 A_{14} \theta+10 A_{13}\left(a_{6}-\theta\right)^{9}+19 A_{16}\left(a_{1}+\theta^{19}\right)^{-2} \theta^{14} \mid \beta \\
& -11\left(a_{1}+\theta^{11}\right)^{-2} \theta^{10}\left(A_{12} \beta+A_{14} \beta^{2}+A_{19} \beta^{3}\right)+d_{20} \theta^{17}\left(18 a_{9}+20 \theta^{2}\right)\left(\left(a_{10}+\beta\right)^{-3}+a_{11} \beta !\right. \\
& +A_{21} \beta^{3}+20 A_{21} \theta^{-21} \beta^{4}
\end{aligned}
$$

where $y^{\prime}=-2 a_{1} \theta+6 a_{2} \theta^{-7}$

Reduced enthalpy, $h /\left(p_{\mathrm{cl}}{ }_{\mathrm{c}}^{\nu_{\mathrm{c}}}\right)=\epsilon_{1}=\zeta_{A}+\alpha_{0}+\alpha_{1} \theta+\theta \sigma_{1}$

$$
\begin{aligned}
& \epsilon_{1}=a_{0}+A_{0} \theta-\sum_{\nu=1}^{10}(\nu-2) A_{\nu} \theta^{\nu-1}+A_{11}\left[Z\left\{17\left(\frac{Z}{29}-\frac{y}{12}\right)+5 \theta \frac{Y^{\prime}}{12}\right\}+a_{4} \theta-\left(a_{3}-1\right) \theta Y^{\prime} Y^{\prime}\right] Z^{-3 / 17} \\
& +\left|A_{12}-A_{34} \theta^{2}+A_{13}\left(9 \theta+a_{6}\right)\left(a_{6}-\theta\right)^{9}+A_{16}\left(20 \theta^{19}+a_{7}\right)\left(a_{7}+\theta^{19}\right)^{-2}\right| \beta \\
& -\left(12 \theta^{11}+a_{1}\right)\left(a_{1}+\theta^{11}\right)^{-2}\left(A_{17} \beta+A_{18} \beta^{2}+A_{19} \beta^{3}\right)+A_{20} \theta^{11}\left(17 a_{9}+19 \theta^{2}\right)\left(\left(a_{10}+\beta\right)^{-3}+a_{11} \beta 1\right. \\
& +A_{21} a_{12} \beta^{3}+21 A_{22} \theta^{-20} \beta^{4}
\end{aligned}
$$

\subsection{Sub-region 2}

Reduced valume, $v / v_{c 1}=\chi_{2}=\left(\partial \zeta_{B} / \partial \beta\right)_{\theta}$

$$
\begin{aligned}
& \chi_{2}=l_{2} \theta / \beta-\sum_{\mu=1}^{3} \mu \beta^{\mu-1} \sum_{\nu=1}^{n(\mu)} B_{\mu \nu} X^{2(\mu, \nu)}-\sum_{\mu=0}^{0} \frac{(\mu-2) \beta^{1-\mu} \sum_{\nu=1}^{n(\mu)} B_{\mu \nu} X^{2(\mu, \nu)}}{\left\{\beta^{2-\mu}+\sum_{\lambda=1}^{2(\mu)} b_{\mu \lambda} X^{x(\mu, \lambda)}\right\}^{2}} \\
& +11\left(\frac{\beta}{\beta_{L}}\right)^{10} \sum_{\nu=0}^{0} B_{o \nu} X^{\nu}
\end{aligned}
$$

where

$X=\exp \{b(1-\theta)\}$

$\beta_{L}=\beta_{L}(\theta)$, the expression for which is given in Section 3.2.2, and the numbers of terms $n(\mu)$ and $\mathfrak{l}(\mu)$, and the exponents $z(\mu, \nu)$ and $x(\mu, \lambda)$, are listed in Section 6.2. 
Reduced entropy, $s i\left(p_{c 1} v_{c 1}, T_{c 1}\right)=\sigma_{2}=-\left(\partial_{\zeta}{ }_{B} / \partial \theta\right)_{3}-\alpha_{1}$

$$
\begin{aligned}
& \sigma_{2}=-\alpha_{1}-1_{1} \ln \beta+B_{0} \ln \theta-\sum_{\nu=1}^{3}(\nu-1) B_{0 \nu} \theta^{\nu-2}-b \sum_{\mu=1}^{3} \beta^{\mu} \sum_{\nu=1}^{n(\mu)} z(\mu, \nu) B_{\mu \nu} X^{z(\mu, \nu)} \\
& -b \sum_{\mu=0}^{\infty}\left[\frac{\sum_{\nu=1}^{n(\mu)} B_{\mu \nu} X^{z(\mu, \nu)}\left(z(\mu, \nu)-\frac{\sum_{\lambda=1}^{\ell(\mu)} x(\mu, \lambda) b_{\mu \lambda} X^{x(\mu, \lambda)}}{\beta^{2-\mu}+\sum_{\lambda=1}^{\ell(\mu)} b_{\mu \lambda} X^{x(\mu, \lambda)}}\right]}{\left.\beta^{2-\mu}+\sum_{\lambda=1}^{\ell(\mu)} b_{\mu \lambda} X^{x(\mu, \lambda)}\right]}\right] \\
& +\beta\left(\frac{\beta}{\beta_{L}}\right)^{10} \sum_{\nu=0}^{0}\left[\left\{\frac{10 \beta_{L}^{\prime}}{\beta_{L}}+\nu b\right\} B_{9 \nu} Y^{\nu}\right]
\end{aligned}
$$

Reduced enthalpy, $h /\left(p_{c 1} v_{c 1}\right)=\epsilon_{2}=\zeta_{B}+\alpha_{0}+\alpha_{1} \theta+\theta \sigma_{2}$

$$
\begin{aligned}
& \epsilon_{2}=\alpha_{0}+B_{0} \theta-\sum_{\nu=1}^{g} B_{0 \nu}(\nu-2) \theta^{\nu-1}-\sum_{\mu=1}^{3} \beta^{\mu} \sum_{\nu=1}^{n(\mu)} B_{\mu \nu}(1+z(\mu, \nu) b \theta) X^{z(\mu, \nu)} \\
& -\sum_{\mu=0}^{\infty n(\mu)} B_{\mu \nu X^{z(\mu, \nu)}}\left[\frac{b \theta \sum_{\lambda=1}^{\ell(\mu)} x(\mu, \lambda) b_{\mu \lambda} X^{x(\mu, \lambda)}}{\beta^{2-\mu}+\sum_{\lambda=1}^{\ell(\mu)} b_{\mu \lambda} X^{x(\mu, \lambda)}}\right] \\
& +\beta\left(\frac{\beta}{\beta_{L}}\right)^{\mathrm{s} 0} \sum_{\nu=0}^{\infty}\left[\left\{1+\theta\left(\frac{10 \beta_{L}^{\prime}}{\beta_{L}}+\nu b\right)\right\} B_{\theta \nu} X^{\nu}\right]
\end{aligned}
$$


APPENDIX C

STEAM MOLE FRACTION DATA REDUCTION WORKSHEETS 
Test:

\begin{tabular}{l|l} 
ICEDF & $10-1$ \\
\hline
\end{tabular}

\begin{tabular}{|c|c|c|}
\hline Date of & \multicolumn{2}{|c|}{ Q.A. Verffication: } \\
Analysis & Name & Date \\
\hline $9 / 4 / 90$ & MWL & $7 / 29 / 9$ \\
\hline
\end{tabular}

\begin{tabular}{|c|c|c|c|c|c|c|c|c|}
\hline $\begin{array}{l}\text { Sample } \\
\text { ID No. }\end{array}$ & $\begin{array}{c}\text { Test Clock } \\
\text { (min) }\end{array}$ & $\begin{array}{l}\text { Sample } \\
\text { Duration } \\
\Delta t \text { (min) }\end{array}$ & $\begin{array}{c}\text { To } \\
\left(^{\circ} \mathrm{C}\right) \\
\end{array}$ & $\begin{array}{c}\text { Critical } \\
\text { Orifice } \\
(\#) \\
\end{array}$ & $\begin{array}{c}C O \\
\Delta P \\
\left\langle{ }^{n} \mathrm{Hg}\right\rangle\end{array}$ & $\begin{array}{c}\text { Condensate } \\
\mathrm{H} 2 \mathrm{O} \text { Mass } \\
\text { (g) }\end{array}$ & $\begin{array}{l}\text { Crit. Orifice } \\
\text { Flow Rate } \\
@ 20^{\circ} \mathrm{C} \\
\text { (lpm) }\end{array}$ & $\begin{array}{l}\text { Crit. Orifice } \\
\text { Flow Corr. } \\
\text { Factor } \\
(-)\end{array}$ \\
\hline $\begin{array}{c}\text { C6A-1 } \\
\text { C6A-2 } \\
\text { C6A-3 } \\
\text { C6A-4\&5 } \\
\text { C6A-5 }\end{array}$ & $\begin{array}{c}7.00 \\
23.00 \\
38.00 \\
53.00 \\
67.00\end{array}$ & $\begin{array}{l}3.00 \\
4.00 \\
4.00 \\
8.00 \\
4.00\end{array}$ & $\begin{array}{l}115 \\
120 \\
125 \\
123 \\
122\end{array}$ & $\begin{array}{l}69 \\
69 \\
69 \\
69 \\
69\end{array}$ & & $\begin{array}{l}2.53 \\
3.74 \\
4.00 \\
8.88\end{array}$ & $\begin{array}{l}5.030 \\
5.030 \\
5.030 \\
5.030 \\
5.030\end{array}$ & $\begin{array}{l}1.00 \\
1.00 \\
1.00 \\
1.00 \\
1.00\end{array}$ \\
\hline $\begin{array}{c}\text { C5A1-1 } \\
\text { C5A1-117 } \\
\text { C5A1-2 } \\
\text { C5A1-l19 } \\
\text { C5A1-3 }\end{array}$ & $\begin{array}{c}7.00 \\
22.50 \\
38.00 \\
52.50 \\
68.00\end{array}$ & $\begin{array}{l}4.00 \\
3.00 \\
4.00 \\
3.00 \\
4.00\end{array}$ & $\begin{array}{l}50 \\
53 \\
42 \\
51 \\
44\end{array}$ & $\begin{array}{l}69 \\
58 \\
58 \\
58 \\
58\end{array}$ & & $\begin{array}{l}1.39 \\
1.22 \\
1.01\end{array}$ & $\begin{array}{l}5.030 \\
9.140 \\
9.140 \\
9.140 \\
9.140\end{array}$ & $\begin{array}{l}1.00 \\
1.00 \\
1.00 \\
1.00 \\
1.00\end{array}$ \\
\hline $\begin{array}{l}\text { C4B-1 } \\
\text { C4B-2 } \\
\text { C4B-3 } \\
\text { C4B-4 } \\
\text { C4B-5 }\end{array}$ & $\begin{array}{c}7.00 \\
22.00 \\
37.00 \\
52.00 \\
67.00\end{array}$ & $\begin{array}{l}4.00 \\
4.00 \\
4.00 \\
4.00 \\
4.00\end{array}$ & $\begin{array}{l}25 \\
31 \\
34 \\
35 \\
32\end{array}$ & $\begin{array}{l}58 \\
58 \\
58 \\
58 \\
58\end{array}$ & & $\begin{array}{l}0.00 \\
0.00 \\
0.01 \\
0.04 \\
0.17\end{array}$ & $\begin{array}{l}9.140 \\
9.140 \\
9.140 \\
9.140 \\
9.140\end{array}$ & $\begin{array}{l}1.00 \\
1.00 \\
1.00 \\
1.00 \\
1.00\end{array}$ \\
\hline $\begin{array}{l}\text { C2B-1 } \\
\text { C2B-2 } \\
\text { C2B-3 } \\
\text { C2B-4 } \\
\text { C2B-5 }\end{array}$ & $\begin{array}{c}7.00 \\
22.00 \\
37.00 \\
52.00 \\
67.00\end{array}$ & $\begin{array}{l}4.00 \\
4.00 \\
4.00 \\
4.00 \\
4.00\end{array}$ & $\begin{array}{l}26 \\
28 \\
37 \\
36 \\
35\end{array}$ & $\begin{array}{l}69 \\
69 \\
69 \\
69 \\
69\end{array}$ & & $\begin{array}{l}0.05 \\
0.12 \\
0.27 \\
0.27 \\
0.14\end{array}$ & $\begin{array}{l}5.030 \\
5.030 \\
5.030 \\
5.030 \\
5.030\end{array}$ & $\begin{array}{l}1.00 \\
1.00 \\
1.00 \\
1.00 \\
1.00\end{array}$ \\
\hline $\begin{array}{c}\text { C1A1-1 } \\
\text { C1A1-116 } \\
\text { C1A1-2 } \\
\text { C1A1-l18 } \\
\text { C1A1-3 }\end{array}$ & $\begin{array}{c}7.00 \\
21.50 \\
37.00 \\
51.50 \\
67.67\end{array}$ & $\begin{array}{l}4.00 \\
3.00 \\
4.00 \\
3.00 \\
4.00\end{array}$ & $\begin{array}{l}22 \\
25 \\
32 \\
30 \\
35\end{array}$ & $\begin{array}{l}58 \\
55 \\
58 \\
55 \\
58\end{array}$ & & $\begin{array}{l}0.00 \\
0.32 \\
0.33 \\
0.50 \\
0.63\end{array}$ & $\begin{array}{c}9.140 \\
15.230 \\
9.140 \\
15.230 \\
9.140\end{array}$ & $\begin{array}{l}1.00 \\
1.00 \\
1.00 \\
1.00 \\
1.00\end{array}$ \\
\hline C6A-6 X & 81.50 & 5.00 & 93 & 50 & & 13.81 & 27.230 & 1.00 \\
\hline
\end{tabular}

ICEDF Gas Composition Analysis (page 1)

C.1 
Prolect: Test:

ICEDF $10-1$

\begin{tabular}{|c|c|c|c|c|c|c|c|c|}
\hline $\begin{array}{l}\text { Sample } \\
\text { ID No. }\end{array}$ & $\begin{array}{c}\text { Dry Gas } \\
\text { Volume } \\
\left(1 @ 20^{\circ} \mathrm{C}\right)\end{array}$ & $\begin{array}{c}\text { Sat. Vapor } \\
\left(\mathrm{T}<100^{\circ} \mathrm{C}\right) \\
(\mathrm{Psat} / \mathrm{Po})\end{array}$ & $\begin{array}{c}\text { H2O Vapor } \\
\text { Spec. Vol. } \\
\left(\mathrm{T}<100^{\circ} \mathrm{C}\right) \\
(\mathrm{m} 3 / \mathrm{kg})\end{array}$ & $\begin{array}{c}\text { H2O Vapor } \\
\text { Spec. Vol. } \\
\left(\mathrm{T} \geq 100^{\circ} \mathrm{C}\right) \\
(\mathrm{m} 3 / \mathrm{kg})\end{array}$ & $\begin{array}{l}\text { Dry Gas } \\
\text { Volume } \\
\text { (I @ To) }\end{array}$ & $\begin{array}{c}\text { H2O Gas } \\
\text { Volume } \\
\text { (1@ To) }\end{array}$ & $\begin{array}{c}\text { SMF } \\
(-)\end{array}$ & $\begin{array}{c}\text { Fog } \\
\text { @ To } \\
\left(\mathrm{mg} / \mathrm{m}^{\wedge} 3\right)\end{array}$ \\
\hline $\begin{array}{c}\text { C6A-1 } \\
\text { C6A-2 } \\
\text { C6A-3 } \\
\text { C6A-4\&5 } \\
\text { C6A-5 }\end{array}$ & $\begin{array}{l}15.090 \\
20.120 \\
20.120 \\
40.240 \\
20.120\end{array}$ & $\begin{array}{l}T \geq 100^{\circ} \mathrm{C} \\
T \geq 100^{\circ} \mathrm{C} \\
T \geq 100^{\circ} \mathrm{C} \\
T \geq 100^{\circ} \mathrm{C} \\
T \geq 100^{\circ} \mathrm{C}\end{array}$ & $\begin{array}{l}\mathrm{T} \geq 100^{\circ} \mathrm{C} \\
\mathrm{T} \geq 100^{\circ} \mathrm{C} \\
\mathrm{T} \geq 100^{\circ} \mathrm{C} \\
\mathrm{T} \geq 100^{\circ} \mathrm{C} \\
\mathrm{T} \geq 100^{\circ} \mathrm{C}\end{array}$ & $\begin{array}{l}1.769 \\
1.792 \\
1.816 \\
1.807 \\
1.802\end{array}$ & $\begin{array}{l}19.98 \\
26.99 \\
27.33 \\
54.39 \\
27.12\end{array}$ & $\begin{array}{c}4.48 \\
6.70 \\
7.26 \\
16.04 \\
0.00\end{array}$ & $\begin{array}{l}0.183 \\
0.199 \\
0.210 \\
0.228\end{array}$ & $\begin{array}{l}\text { S. H. Vap. } \\
\text { S. H. Vap. } \\
\text { S. H. Vap. } \\
\text { S. H. Vap. }\end{array}$ \\
\hline $\begin{array}{c}\text { C5A1-1 } \\
\text { C5A1-I17 } \\
\text { C5A1-2 } \\
\text { C5A1-I19 } \\
\text { C5A1-3 }\end{array}$ & $\begin{array}{l}20.120 \\
27.420 \\
36.560 \\
27.420 \\
36.560\end{array}$ & $\begin{array}{l}0.1223 \\
0.1416 \\
0.0814 \\
0.1285 \\
0.0904\end{array}$ & $\begin{array}{l}12.242 \\
10.584 \\
18.047 \\
11.663 \\
16.378\end{array}$ & $\begin{array}{l}T<100^{\circ} \mathrm{C} \\
T<100^{\circ} \mathrm{C} \\
T<100^{\circ} \mathrm{C} \\
T<100^{\circ} \mathrm{C} \\
T<100^{\circ} \mathrm{C}\end{array}$ & $\begin{array}{l}22.18 \\
30.51 \\
39.31 \\
30.32 \\
39.55\end{array}$ & $\begin{array}{l}0.00 \\
0.00 \\
2.04 \\
1.83 \\
1.50\end{array}$ & $\begin{array}{l}0.049 \\
0.057 \\
0.036\end{array}$ & $\begin{array}{l}\text { Not Sat. } \\
\text { Not Sat. } \\
\text { Not Sat. }\end{array}$ \\
\hline $\begin{array}{l}\text { C4B-1 } \\
\text { C4B-2 } \\
\text { C4B-3 } \\
\text { C4B-4 } \\
\text { C4B-5 }\end{array}$ & $\begin{array}{l}36.560 \\
36.560 \\
36.560 \\
36.560 \\
36.560\end{array}$ & $\begin{array}{l}0.0308 \\
0.0443 \\
0.0527 \\
0.0557 \\
0.0470\end{array}$ & $\begin{array}{l}41.168 \\
30.772 \\
26.604 \\
25.344 \\
29.315\end{array}$ & $\begin{array}{l}T<100^{\circ} \mathrm{C} \\
T<100^{\circ} \mathrm{C} \\
T<100^{\circ} \mathrm{C} \\
T<100^{\circ} \mathrm{C} \\
T<100^{\circ} \mathrm{C}\end{array}$ & $\begin{array}{l}37.18 \\
37.93 \\
38.31 \\
38.43 \\
38.06\end{array}$ & $\begin{array}{l}0.00 \\
0.00 \\
0.01 \\
0.06 \\
0.23\end{array}$ & $\begin{array}{l}0.000 \\
0.000 \\
0.000 \\
0.002 \\
0.006\end{array}$ & $\begin{array}{l}\text { Not Sat. } \\
\text { Not Sat. } \\
\text { Not Sat. } \\
\text { Not Sat. } \\
\text { Not Sat. }\end{array}$ \\
\hline $\begin{array}{l}\text { C2B-1 } \\
\text { C2B-2 } \\
\text { C2B-3 } \\
\text { C2B-4 } \\
\text { C2B-5 }\end{array}$ & $\begin{array}{l}20.120 \\
20.120 \\
20.120 \\
20.120 \\
20.120\end{array}$ & $\begin{array}{l}0.0328 \\
0.0370 \\
0.0623 \\
0.0589 \\
0.0557\end{array}$ & $\begin{array}{l}39.219 \\
35.592 \\
23.001 \\
24.144 \\
25.344\end{array}$ & $\begin{array}{l}T<100^{\circ} \mathrm{C} \\
T<100^{\circ} \mathrm{C} \\
T<100^{\circ} \mathrm{C} \\
T<100^{\circ} \mathrm{C} \\
T<100^{\circ} \mathrm{C}\end{array}$ & $\begin{array}{l}20.53 \\
20.67 \\
21.29 \\
21.22 \\
21.15\end{array}$ & $\begin{array}{l}0.06 \\
0.15 \\
0.39 \\
0.39 \\
0.20\end{array}$ & $\begin{array}{l}0.003 \\
0.007 \\
0.018 \\
0.018 \\
0.009\end{array}$ & $\begin{array}{l}\text { Not Sat. } \\
\text { Not Sat. } \\
\text { Not Sat. } \\
\text { Not Sat. } \\
\text { Not Sat. }\end{array}$ \\
\hline $\begin{array}{c}\text { C1A1-1 } \\
\text { C1A1-I16 } \\
\text { C1A1-2 } \\
\text { C1A1-I18 } \\
\text { C1A1-3 }\end{array}$ & $\begin{array}{l}36.560 \\
45.690 \\
36.560 \\
45.690 \\
36.560\end{array}$ & $\begin{array}{l}0.0255 \\
0.0308 \\
0.0470 \\
0.0418 \\
0.0557\end{array}$ & $\begin{array}{l}50.704 \\
41.168 \\
29.315 \\
32.301 \\
25.344\end{array}$ & $\begin{array}{l}T<100^{\circ} \mathrm{C} \\
T<100^{\circ} \mathrm{C} \\
T<100^{\circ} \mathrm{C} \\
T<100^{\circ} \mathrm{C} \\
T<100^{\circ} \mathrm{C}\end{array}$ & $\begin{array}{l}36.81 \\
46.47 \\
38.06 \\
47.25 \\
38.43\end{array}$ & $\begin{array}{l}0.00 \\
0.40 \\
0.45 \\
0.67 \\
0.89\end{array}$ & $\begin{array}{l}0.000 \\
0.009 \\
0.012 \\
0.014 \\
0.023\end{array}$ & $\begin{array}{l}\text { Not Sat. } \\
\text { Not Sat. } \\
\text { Not Sat. } \\
\text { Not Sat. } \\
\text { Not Sat. }\end{array}$ \\
\hline C6A-6 $X$ & 136.150 & 0.7748 & 2.119 & $T<100^{\circ} \mathrm{C}$ & 170.07 & 22.68 & 0.118 & Not Sat. \\
\hline
\end{tabular}

ICEDF Gas Composition Analysis (page 2)

C.2 


\begin{tabular}{l|l|} 
Project: & Test: \\
\hline ICEDF & $10-1$ \\
\hline
\end{tabular}

\begin{tabular}{|c|c|c|c|c|c|c|c|c|}
\hline \multirow[b]{2}{*}{$\begin{array}{l}\text { Sample } \\
\text { ID No. }\end{array}$} & \multirow{2}{*}{$\begin{array}{c}\mathrm{T}<100^{\circ} \mathrm{C} \\
\text { Psat/Po } \\
\text { Formula } 1 \\
\end{array}$} & \multirow{2}{*}{$\begin{array}{l}\mathrm{T}<25^{\circ} \mathrm{C} \\
\text { Vs (m3/kg) } \\
\text { Formula A }\end{array}$} & \multirow{2}{*}{$\begin{array}{l}25^{\circ} \leq \mathrm{T} \leq 65^{\circ} \\
\text { Vs (m3/kg) } \\
\text { Formula B } \\
\end{array}$} & \multirow{2}{*}{$\begin{array}{c}\mathrm{T}>65^{\circ} \mathrm{C} \\
V_{s}(\mathrm{~m} 3 / \mathrm{kg}) \\
\text { Formula C }\end{array}$} & \multicolumn{4}{|c|}{ VOL(max) M(H2O, sat) Critical Orifice Calib. } \\
\hline & & & & & $\begin{array}{c}\mathrm{H} 2 \mathrm{O}, \mathrm{T}<10 \\
(1 @ \mathrm{To})\end{array}$ & $\begin{array}{c}\mathrm{T}<100^{\circ} \mathrm{C} \\
\text { (g) }\end{array}$ & $\mathrm{CO}(\#)$ & $Q(\mathrm{lpm})$ \\
\hline C6A-1 & $\mathrm{T} \geq 100^{\circ} \mathrm{C}$ & & & $T>100^{\circ} \mathrm{C}$ & $T>100^{\circ} \mathrm{C}$ & $T>100^{\circ} \mathrm{C}$ & 50 & 27.23 \\
\hline C6A-2 & $T \geq 100^{\circ} \mathrm{C}$ & $T \geq 100^{\circ} \mathrm{C}$ & $\mathrm{T} \geq 100^{\circ} \mathrm{C}$ & $T \geq 100^{\circ} \mathrm{C}$ & $\mathrm{T} \geq 100^{\circ} \mathrm{C}$ & $\mathrm{T} \geq 100^{\circ} \mathrm{C}$ & $\begin{array}{l}53 \\
55\end{array}$ & $\begin{array}{l}19.76 \\
15.23\end{array}$ \\
\hline C6A-3 & $T \geq 100^{\circ} \mathrm{C}$ & $\mathrm{T} \geq 100^{\circ} \mathrm{C}$ & $T \geq 100^{\circ} \mathrm{C}$ & $\mathrm{T} \geq 100^{\circ} \mathrm{C}$ & $\mathrm{T} \geq 100^{\circ} \mathrm{C}$ & $\mathrm{T} \geq 100^{\circ} \mathrm{C}$ & 58 & 9.14 \\
\hline C6A-4\&5 & $T \geq 100^{\circ} \mathrm{C}$ & $T \geq 100^{\circ} \mathrm{C}$ & $T \geq 100^{\circ} \mathrm{C}$ & $T \geq 100^{\circ} \mathrm{C}$ & $\mathrm{T} \geq 100^{\circ} \mathrm{C}$ & $T \geq 100^{\circ} \mathrm{C}$ & & \\
\hline C6A-5 & $\mathrm{T} \geq 100^{\circ} \mathrm{C}$ & $\mathrm{T} \geq 100^{\circ} \mathrm{C}$ & $\mathrm{T} \geq 100^{\circ} \mathrm{C}$ & $\mathrm{T} \geq 100^{\circ} \mathrm{C}$ & $\mathrm{T} \geq 100^{\circ} \mathrm{C}$ & $\mathrm{T} \geq 100^{\circ} \mathrm{C}$ & 65 & 6.97 \\
\hline C5A1-1 & 0.1223 & & 12.242 & & 3.091 & 2.064 & $\begin{array}{l}69 \\
74\end{array}$ & $\begin{array}{l}5.03 \\
2.47\end{array}$ \\
\hline C5A1-I17 & 0.1416 & & 10.584 & & 5.032 & 3.358 & 77 & 1.45 \\
\hline C5A1-2 & 0.0814 & & 18.047 & & 3.485 & 2.371 & 80 & 1.03 \\
\hline C5A1-I19 & 0.1285 & & 11.663 & & 4.469 & 2.983 & & \\
\hline C5A1-3 & 0.0904 & & 16.378 & & 3.930 & 2.655 & & \\
\hline C4B-1 & 0.0308 & & 41.168 & & 1.182 & 0.932 & & \\
\hline C4B-2 & 0.0443 & & 30.772 & & 1.758 & 1.290 & & \\
\hline C4B-3 & 0.0527 & & 26.604 & & 2.129 & 1.520 & & \\
\hline C4B-4 & 0.0557 & & 25.344 & & 2.268 & 1.606 & & \\
\hline C4B-5 & 0.0470 & & 29.315 & & 1.875 & 1.362 & & \\
\hline C2B-1 & 0.0328 & & 39.219 & & 0.696 & 0.541 & & \\
\hline С2B-2 & 0.0370 & & 35.592 & & 0.795 & 0.603 & & \\
\hline C2B-3 & 0.0623 & & 23.001 & & 1.413 & 0.987 & & \\
\hline C2B-4 & 0.0589 & & 24.144 & & 1.328 & 0.934 & & \\
\hline C2B-5 & 0.0557 & & 25.344 & & 1.248 & 0.884 & & \\
\hline C1A1-1 & 0.0255 & 50.704 & & & 0.962 & 0.745 & & \\
\hline C1A1-I16 & 0.0308 & & 41.168 & & 1.477 & 1.165 & & \\
\hline C1A1-2 & 0.0470 & & 29.315 & & 1.875 & 1.362 & & \\
\hline C1A1-I18 & 0.0418 & & 32.301 & & 2.059 & 1.527 & & \\
\hline C1A1-3 & 0.0557 & & 25.344 & & 2.268 & 1.606 & & \\
\hline C6A-6 $X$ & 0.7748 & & & 2.119 & 585.116 & 356.331 & & \\
\hline & & & & & & & & \\
\hline & & & & & & & & \\
\hline & & & & & & & & \\
\hline & & & & & & & & \\
\hline
\end{tabular}

ICEDF Gas Composition Analysis (page 3) 
ICEDF SMF WkSht 6/88 supersedes ICEDF SMF WkSht 9/87 ICEDF SMF SkSht $10 / 89$ supersedes ICEDF SMF WkSht 6/88

1) Open "ICEDF SMF WkSht 10/89". 2) Enter test name. 3) Save as "ICEDF testname month/year".

\section{How this spreadsheet works}

CO flow rate determined by Lookup function: Column H, Cells AB \& AC. Pressure correction added 5/23/89.

Dry gas volume $=$ CO flow rate ${ }^{\bullet}$ sample duration ${ }^{\bullet}$ pressure correction

Actual dry gas volume $=\mathrm{VOL}(\mathrm{dry}$, actual $)=$ sample duration ${ }^{*} \mathrm{CO}$ flow rate * $(273+\mathrm{TO}) / 293$.

$\mathrm{H} 2 \mathrm{O}$ specific volume $=1.227+0.004712$ (To) for To $\geq 100^{\circ} \mathrm{C}$.

H2O saturated steam partial pressure (Psat/Po $=$ Formula1) for $\mathrm{T}<100^{\circ} \mathrm{C}$.

Formula1 $=0.0107-3.451^{*} 10^{\wedge}-4^{*} \mathrm{~F} 10+5.359^{*} 10^{\wedge}-5^{\star} \mathrm{F} 10^{\wedge} 2-5.694^{*} 10^{\wedge}-7^{\star} \mathrm{F} 10^{\wedge} 3+1.057^{*} 10^{\wedge}-8^{*} \mathrm{~F} 10^{\wedge} 4$

Actual $\mathrm{H} 2 \mathrm{O}$ gas volume:

$T<100^{\circ} \mathrm{C}: \quad \operatorname{VOL}(\max )=\left[\left(P_{s a t} / \mathrm{Po}\right) *(\mathrm{VOL}(\right.$ dry, actual $\left.))\right] /[1-($ Psat/Po $)]$. See BNW 51060, pg 133. $\mathrm{VOL}(\max )=\mathrm{VOL}(\mathrm{H} 2 \mathrm{O}$, saturated, maximum possible at $\mathrm{T})$

Fog Check: compare $\mathrm{H} 2 \mathrm{O}$ mass collected to $\mathrm{H} 2 \mathrm{O}$ mass required for sample saturation $M(H 2 O$, sat $)=[[V O L(d r y$, actual $)+\operatorname{VOL}(H 2 O, \max )] / V s(H 2 O$ vapor, sat $)](1000 / 1000)$ Vs $(\mathrm{H} 2 \mathrm{O}$ vapor, sat $)=$ FormulaA if $\mathrm{T}<25^{\circ} \mathrm{C},=$ FormulaC if $\mathrm{T}>65^{\circ} \mathrm{C}$. Formula $A=199.61 * 10^{\wedge}(-2.7052 \theta-2(T))$. FormulaB $=138.44 \cdot 10^{\wedge}(-2.1068 \theta-2(T))$. FormulaC $=68.411 * 10^{\wedge}(-1.6225 \theta-2(T))$.

1) If condensate mass $<M(\mathrm{H} 2 \mathrm{O}$, sat):

$\operatorname{VOL}(\mathrm{H} 2 \mathrm{O}$, actual $)=(\mathrm{RH})$ * $(\mathrm{VOL}(\max ))$. Print "Not Sat."

2) If condensate mass $=M(\mathrm{H} 2 \mathrm{O}$, sat): $\mathrm{RH}=$ condensate mass $/ \mathrm{M}(\mathrm{H} 2 \mathrm{O}$, sat $)$.

3) If condenate mass $>M(\mathrm{H} 2 \mathrm{O}$, sat):

VOL(H2O, actual) $=$ VOL (max). Calculate and print fog mass conc.

Fog Conc $=$ condensate mass $-\mathrm{M}(\mathrm{H} 2 \mathrm{O}$, sat $) /$ sample vol. (sample vol $=\left(1000 \mathrm{~m}^{\wedge} 3 / /\right)^{\star} \Sigma$ [actual $\mathrm{H} 2 \mathrm{O} \&$ dry vols])

$\mathrm{T} \geq 100^{\circ} \mathrm{C}: \quad \operatorname{Vol}(\mathrm{H} 2 \mathrm{O})=(\text { condensate mass " sat steam spec vol })^{*}(1000 / 1000)$. Print "S. H. Vap."

SMF = Actual $\mathrm{H} 20$ gas volume / total gas volume (ie., the sum of actual dry and actual $\mathrm{H} 2 \mathrm{O}$ volumes, = sample vol', Not included: 1) possible temp variations, 2) possible supersaturation.

CO upstream pressure correction factor added to spreadsheet on 6/14/89 (in draft form in 5/89).

Modifications: ICEDF SMF WkSht 6/89 superseded ICEDF SMF WkSht 9/87

1) Original date of this version was $6 / 14 / 89$.

2) 1st modification was made $9 / 14 / 89$ :

Crit orifice flow corr. factor formula was changed to print "" if test time was "".

Sample analysis date cell was added to top of page 1.

ICEDF SMF WkSht 10/89 superseded ICEDF SMF WkSht 6/89

1) Changed printer page set-up, and minor editing. 2) Changed SMF col eq to print "n if no H2O mass is entered.

3) Changed Fog column equation to print "'" if no SMF is calculated, and ¿Sat? if SMF is calculated based on assumed saturation when no $\mathrm{H} 2 \mathrm{O}$ mass is entered.

4) Changed Sample ID column 12/1/89 to match new test plan (no C6B1 or C6B2). 
Project: Test:

\begin{tabular}{l|l}
\hline ICEDF & 10.4 \\
\hline
\end{tabular}

\begin{tabular}{|c|c|c|}
\hline Date of & \multicolumn{2}{|c|}{ Q.A. Verfification: } \\
Analysis & Name & Date \\
\hline 9/3/90 & MWL & $7 / 29 / 91$ \\
\hline
\end{tabular}

\begin{tabular}{|c|c|c|c|c|c|c|c|c|}
\hline $\begin{array}{l}\text { Sample } \\
\text { ID No. }\end{array}$ & $\begin{array}{l}\text { Test Clock } \\
\text { (min) }\end{array}$ & $\begin{array}{l}\text { Sample } \\
\text { Duration } \\
\Delta t \text { (min) }\end{array}$ & $\begin{array}{c}\text { To } \\
\left({ }^{\circ} \mathrm{C}\right)\end{array}$ & $\begin{array}{c}\text { Critical } \\
\text { Orifice } \\
(\#)\end{array}$ & $\begin{array}{c}\text { CO } \\
\Delta P \\
(" \mathrm{Hg})\end{array}$ & $\begin{array}{c}\text { Condensate } \\
\mathrm{H} 2 \mathrm{O} \text { Mass } \\
\text { (g) }\end{array}$ & $\begin{array}{c}\text { Crit. Orifice } \\
\text { Flow Rate } \\
\text { @ 20 } \\
\text { (lpm) } \\
\end{array}$ & $\begin{array}{c}\text { Crit. Orifice } \\
\text { Flow Corr. } \\
\text { Factor } \\
(-1)\end{array}$ \\
\hline $\begin{array}{l}\text { C6A-1 } \\
\text { C6A-2 } \\
\text { C6A-3 } \\
\text { C6A-4 } \\
\text { C6A-5 }\end{array}$ & $\begin{array}{l}12.50 \\
32.50 \\
52.50 \\
72.67 \\
92.50\end{array}$ & $\begin{array}{l}15.00 \\
15.00 \\
15.00 \\
15.00 \\
15.00\end{array}$ & $\begin{array}{l}113 \\
122 \\
125 \\
126 \\
124\end{array}$ & $\begin{array}{l}65 \\
65 \\
65 \\
65 \\
65\end{array}$ & & $\begin{array}{l}38.47 \\
38.46 \\
40.08 \\
39.03 \\
39.62\end{array}$ & $\begin{array}{l}6.970 \\
6.970 \\
6.970 \\
6.970 \\
6.970\end{array}$ & $\begin{array}{l}1.00 \\
1.00 \\
1.00 \\
1.00 \\
1.00\end{array}$ \\
\hline $\begin{array}{l}\text { C5A1-1 } \\
\text { C5A1-2 } \\
\text { C5A1-3 } \\
\text { C5A1-4 } \\
\text { C5A1-5 }\end{array}$ & $\begin{array}{l}13.50 \\
32.50 \\
52.50 \\
72.50 \\
93.00\end{array}$ & $\begin{array}{l}13.00 \\
15.00 \\
15.00 \\
15.00 \\
16.00\end{array}$ & $\begin{array}{l}49 \\
48 \\
51 \\
50 \\
51\end{array}$ & $\begin{array}{l}65 \\
65 \\
65 \\
65 \\
65\end{array}$ & & $\begin{array}{l}10.60 \\
10.51 \\
10.01 \\
10.10 \\
10.27\end{array}$ & $\begin{array}{l}6.970 \\
6.970 \\
6.970 \\
6.970 \\
6.970\end{array}$ & $\begin{array}{l}1.00 \\
1.00 \\
1.00 \\
1.00 \\
1.00\end{array}$ \\
\hline $\begin{array}{l}\text { C4B-1 } \\
\text { C4B-2 } \\
\text { C4B-3 } \\
\text { C4B-4 } \\
\text { C4B-5 }\end{array}$ & $\begin{array}{l}12.50 \\
32.50 \\
52.50 \\
72.50 \\
91.25\end{array}$ & $\begin{array}{l}15.00 \\
15.00 \\
15.00 \\
15.00 \\
12.50\end{array}$ & $\begin{array}{l}41 \\
35 \\
48 \\
50 \\
50\end{array}$ & $\begin{array}{l}65 \\
65 \\
65 \\
65 \\
65\end{array}$ & & $\begin{array}{c}8.16 \\
7.21 \\
9.38 \\
10.05 \\
8.54\end{array}$ & $\begin{array}{l}6.970 \\
6.970 \\
6.970 \\
6.970 \\
6.970\end{array}$ & $\begin{array}{l}1.00 \\
1.00 \\
1.00 \\
1.00 \\
1.00\end{array}$ \\
\hline $\begin{array}{l}\text { C2B-1 } \\
\text { C2B-2 } \\
\text { C2B-3 } \\
\text { C2B-4 } \\
\text { C2B-5 }\end{array}$ & $\begin{array}{l}12.50 \\
32.50 \\
52.50 \\
72.88 \\
92.50\end{array}$ & $\begin{array}{l}15.00 \\
15.00 \\
15.00 \\
15.77 \\
15.00\end{array}$ & $\begin{array}{l}28 \\
29 \\
30 \\
35 \\
48\end{array}$ & $\begin{array}{l}65 \\
65 \\
65 \\
65 \\
65\end{array}$ & & $\begin{array}{r}4.44 \\
4.92 \\
5.79 \\
7.97 \\
11.04\end{array}$ & $\begin{array}{l}6.970 \\
6.970 \\
6.970 \\
6.970 \\
6.970\end{array}$ & $\begin{array}{l}1.00 \\
1.00 \\
1.00 \\
1.00 \\
1.00\end{array}$ \\
\hline $\begin{array}{l}\text { C1A1-1 } \\
\text { C1A1-2 } \\
\text { C1A1-3 }\end{array}$ & $\begin{array}{l}12.50 \\
32.50 \\
82.50\end{array}$ & $\begin{array}{l}15.00 \\
15.00 \\
35.00\end{array}$ & $\begin{array}{l}16 \\
20 \\
38\end{array}$ & $\begin{array}{l}65 \\
65 \\
65\end{array}$ & & $\begin{array}{c}2.84 \\
8.52 \\
19.00\end{array}$ & $\begin{array}{l}6.970 \\
6.970 \\
6.970\end{array}$ & $\begin{array}{l}1.00 \\
1.00 \\
1.00\end{array}$ \\
\hline
\end{tabular}

ICEDF Gas Composition Analysis (page 1)

C.5 
Project: Test:

\begin{tabular}{l|l} 
ICEDF & $10-4$
\end{tabular}

\begin{tabular}{|c|c|c|c|c|c|c|c|c|}
\hline $\begin{array}{l}\text { Sample } \\
\text { ID No. }\end{array}$ & $\begin{array}{l}\text { Dry Gas } \\
\text { Volume } \\
\left(1 @ 20^{\circ} \mathrm{C}\right)\end{array}$ & $\begin{array}{c}\text { Sat. Vapor } \\
\left(\mathrm{T}<100^{\circ} \mathrm{C}\right) \\
(\text { Psat/Po })\end{array}$ & $\begin{array}{c}\text { H2O Vapor } \\
\text { Spec. Vol. } \\
\left(\mathrm{T}<100^{\circ} \mathrm{C}\right) \\
(\mathrm{m} 3 / \mathrm{kg})\end{array}$ & $\begin{array}{c}\text { H2O Vapor } \\
\text { Spec. Vol. } \\
\left(\mathrm{T} \geq 100^{\circ} \mathrm{C}\right) \\
(\mathrm{m} 3 / \mathrm{kg})\end{array}$ & $\begin{array}{l}\text { Dry Gas } \\
\text { Volume } \\
\text { (l@ To) }\end{array}$ & $\begin{array}{l}\text { H2O Gas } \\
\text { Volume } \\
\text { (1@To) }\end{array}$ & $\begin{array}{c}\text { SMF } \\
(-)\end{array}$ & $\begin{array}{c}\text { Fog } \\
@ \text { To } \\
\left(m g / m^{\wedge} 3\right)\end{array}$ \\
\hline $\begin{array}{l}\text { C6A-1 } \\
\text { C6A-2 } \\
\text { C6A-3 } \\
\text { C6A-4 } \\
\text { C6A-5 }\end{array}$ & $\begin{array}{l}104.550 \\
104.550 \\
104.550 \\
104.550 \\
104.550\end{array}$ & $\begin{array}{l}T \geq 100^{\circ} \mathrm{C} \\
T \geq 100^{\circ} \mathrm{C} \\
T \geq 100^{\circ} \mathrm{C} \\
T \geq 100^{\circ} \mathrm{C} \\
T \geq 100^{\circ} \mathrm{C}\end{array}$ & $\begin{array}{l}\mathrm{T} \geq 100^{\circ} \mathrm{C} \\
\mathrm{T} \geq 100^{\circ} \mathrm{C} \\
\mathrm{T} \geq 100^{\circ} \mathrm{C} \\
\mathrm{T} \geq 100^{\circ} \mathrm{C} \\
T \geq 100^{\circ} \mathrm{C}\end{array}$ & $\begin{array}{l}1.759 \\
1.802 \\
1.816 \\
1.821 \\
1.811\end{array}$ & $\begin{array}{l}137.73 \\
140.95 \\
142.02 \\
142.37 \\
141.66\end{array}$ & $\begin{array}{l}67.69 \\
69.30 \\
72.79 \\
71.07 \\
71.76\end{array}$ & $\begin{array}{l}0.330 \\
0.330 \\
0.339 \\
0.333 \\
0.336\end{array}$ & $\begin{array}{l}\text { S. H. Vap. } \\
\text { S. H. Vap. } \\
\text { S. H. Vap. } \\
\text { S. H. Vap. } \\
\text { S. H. Vap. }\end{array}$ \\
\hline $\begin{array}{l}\text { C5A1-1 } \\
\text { C5A1-2 } \\
\text { C5A1-3 } \\
\text { C5A1-4 } \\
\text { C5A1-5 }\end{array}$ & $\begin{array}{c}90.610 \\
104.550 \\
104.550 \\
104.550 \\
111.520\end{array}$ & $\begin{array}{l}0.1164 \\
0.1107 \\
0.1285 \\
0.1223 \\
0.1285\end{array}$ & $\begin{array}{l}12.851 \\
13.490 \\
11.663 \\
12.242 \\
11.663\end{array}$ & $\begin{array}{l}\mathrm{T}<100^{\circ} \mathrm{C} \\
\mathrm{T}<100^{\circ} \mathrm{C} \\
\mathrm{T}<100^{\circ} \mathrm{C} \\
T<100^{\circ} \mathrm{C} \\
T<100^{\circ} \mathrm{C}\end{array}$ & $\begin{array}{c}99.58 \\
114.54 \\
115.61 \\
115.25 \\
123.32\end{array}$ & $\begin{array}{l}13.12 \\
14.26 \\
14.99 \\
15.12 \\
15.39\end{array}$ & $\begin{array}{l}0.116 \\
0.111 \\
0.115 \\
0.116 \\
0.111\end{array}$ & $\begin{array}{c}16.24 \\
7.43 \\
\text { Not Sat. } \\
\text { Not Sat. } \\
\text { Not Sat. }\end{array}$ \\
\hline $\begin{array}{l}\text { C4B-1 } \\
\text { C4B-2 } \\
\text { C4B-3 } \\
\text { C4B-4 } \\
\text { C4B-5 }\end{array}$ & $\begin{array}{l}104.550 \\
104.550 \\
104.550 \\
104.550 \\
87.125\end{array}$ & $\begin{array}{l}0.0773 \\
0.0557 \\
0.1107 \\
0.1223 \\
0.1223\end{array}$ & $\begin{array}{l}18.944 \\
25.344 \\
13.490 \\
12.242 \\
12.242\end{array}$ & $\begin{array}{l}\mathrm{T}<100^{\circ} \mathrm{C} \\
T<100^{\circ} \mathrm{C} \\
T<100^{\circ} \mathrm{C} \\
T<100^{\circ} \mathrm{C} \\
T<100^{\circ} \mathrm{C}\end{array}$ & $\begin{array}{c}112.04 \\
109.90 \\
114.54 \\
115.25 \\
96.05\end{array}$ & $\begin{array}{c}9.38 \\
6.48 \\
14.01 \\
15.04 \\
12.78\end{array}$ & $\begin{array}{l}0.077 \\
0.056 \\
0.109 \\
0.115 \\
0.117\end{array}$ & $\begin{array}{c}14.45 \\
22.47 \\
\text { Not Sat. } \\
\text { Not Sat. } \\
\text { Not Sat. }\end{array}$ \\
\hline $\begin{array}{l}\text { C2B-1 } \\
\text { C2B-2 } \\
C 2 B-3 \\
C 2 B-4 \\
C 2 B-5\end{array}$ & $\begin{array}{l}104.550 \\
104.550 \\
104.550 \\
109.917 \\
104.550\end{array}$ & $\begin{array}{l}0.0370 \\
0.0394 \\
0.0418 \\
0.0557 \\
0.1107\end{array}$ & $\begin{array}{l}35.592 \\
33.907 \\
32.301 \\
25.344 \\
13.490\end{array}$ & $\begin{array}{l}\mathrm{T}<100^{\circ} \mathrm{C} \\
\mathrm{T}<100^{\circ} \mathrm{C} \\
T<100^{\circ} \mathrm{C} \\
T<100^{\circ} \mathrm{C} \\
T<100^{\circ} \mathrm{C}\end{array}$ & $\begin{array}{l}107.40 \\
107.76 \\
108.12 \\
115.54 \\
114.54\end{array}$ & $\begin{array}{c}4.13 \\
4.41 \\
4.71 \\
6.82 \\
14.26\end{array}$ & $\begin{array}{l}0.037 \\
0.039 \\
0.042 \\
0.056 \\
0.111\end{array}$ & $\begin{array}{l}11.74 \\
14.34 \\
20.35 \\
25.69 \\
11.55\end{array}$ \\
\hline $\begin{array}{l}\text { C1A1-1 } \\
\text { C1A1-2 } \\
\text { C1A1-3 }\end{array}$ & $\begin{array}{l}104.550 \\
104.550 \\
243.950\end{array}$ & $\begin{array}{l}0.0173 \\
0.0224 \\
0.0658\end{array}$ & $\begin{array}{l}73.680 \\
57.430 \\
21.912\end{array}$ & $\begin{array}{l}T<100^{\circ} \mathrm{C} \\
T<100^{\circ} \mathrm{C} \\
T<100^{\circ} \mathrm{C}\end{array}$ & $\begin{array}{l}103.12 \\
104.55 \\
258.94\end{array}$ & $\begin{array}{c}1.81 \\
2.39 \\
18.23\end{array}$ & $\begin{array}{l}0.017 \\
0.022 \\
0.066\end{array}$ & $\begin{array}{l}13.49 \\
62.26 \\
22.91\end{array}$ \\
\hline
\end{tabular}

ICEDF Gas Composition Analysis (page 2)

C. 6 
Project: Test:

ICEDF $10-4$

\begin{tabular}{|c|c|c|c|c|c|c|c|c|}
\hline \multirow[b]{2}{*}{$\begin{array}{l}\text { Sample } \\
\text { ID No. }\end{array}$} & \multirow{2}{*}{$\begin{array}{l}\mathrm{T}<100^{\circ} \mathrm{C} \\
\text { Psat/Po } \\
\text { Formula } 1\end{array}$} & \multirow{2}{*}{$\begin{array}{l}\mathrm{T}<25^{\circ} \mathrm{C} \\
\mathrm{Vs}(\mathrm{m} 3 / \mathrm{kg}) \\
\text { Formula A }\end{array}$} & \multirow{2}{*}{$\begin{array}{l}25^{\circ} \leq \mathrm{T} \leq 65^{\circ} \\
\text { Vs (m3/kg) } \\
\text { Formula B }\end{array}$} & \multirow{2}{*}{$\begin{array}{l}\mathrm{T}>65^{\circ} \mathrm{C} \\
\text { Vs (m3/kg) } \\
\text { Formula C }\end{array}$} & \multicolumn{4}{|c|}{ VOL(max) $\mathrm{M}(\mathrm{H} 2 \mathrm{O}$, sat) Critical Orifice Calib. } \\
\hline & & & & & $\begin{array}{c}\mathrm{H} 2 \mathrm{O}, \mathrm{T}<100 \\
(1 @ \mathrm{To})\end{array}$ & $\begin{array}{c}\mathrm{T}<100^{\circ} \mathrm{C} \\
(\mathrm{g})\end{array}$ & $\mathrm{Co}(\#)$ & $Q(\operatorname{lpm})$ \\
\hline & & & & & & & 50 & 27.23 \\
\hline C6A-1 & $T \geq 100^{\circ} \mathrm{C}$ & $T \geq 100^{\circ} \mathrm{C}$ & $T \geq 100^{\circ} \mathrm{C}$ & $T \geq 100^{\circ} \mathrm{C}$ & $T \geq 100^{\circ} \mathrm{C}$ & $T \geq 100^{\circ} \mathrm{C}$ & 53 & 19.76 \\
\hline C6A-2 & $\mathrm{T} \geq 100^{\circ} \mathrm{C}$ & $\mathrm{T} \geq 100^{\circ} \mathrm{C}$ & $T \geq 100^{\circ} \mathrm{C}$ & $\mathrm{T} \geq 100^{\circ} \mathrm{C}$ & $\mathrm{T} \geq 100^{\circ} \mathrm{C}$ & $\mathrm{T} \geq 100^{\circ} \mathrm{C}$ & 55 & 15.23 \\
\hline C6A-3 & $T \geq 100^{\circ} \mathrm{C}$ & $T \geq 100^{\circ} \mathrm{C}$ & $T \geq 100^{\circ} \mathrm{C}$ & $T \geq 100^{\circ} \mathrm{C}$ & $\mathrm{T} \geq 100^{\circ} \mathrm{C}$ & $T \geq 100^{\circ} \mathrm{C}$ & 58 & 9.14 \\
\hline C6A-4 & $\mathrm{T} \geq 100^{\circ} \mathrm{C}$ & $\mathrm{T} \geq 100^{\circ} \mathrm{C}$ & $\mathrm{T} \geq 100^{\circ} \mathrm{C}$ & $T \geq 100^{\circ} \mathrm{C}$ & $T \geq 100^{\circ} \mathrm{C}$ & $T \geq 100^{\circ} \mathrm{C}$ & & \\
\hline C6A-5 & $T \geq 100^{\circ} \mathrm{C}$ & $T \geq 100^{\circ} \mathrm{C}$ & $\mathrm{T} \geq 100^{\circ} \mathrm{C}$ & $T \geq 100^{\circ} \mathrm{C}$ & $T \geq 100^{\circ} \mathrm{C}$ & $\mathrm{T} \geq 100^{\circ} \mathrm{C}$ & 65 & $\begin{array}{l}6.97 \\
503\end{array}$ \\
\hline C5A1-1 & 0.1164 & & 12.851 & & 13.118 & 8.770 & 74 & 2.47 \\
\hline C5A1-2 & 0.1107 & & 13.490 & & 14.265 & 9.549 & 77 & 1.45 \\
\hline C5A1-3 & 0.1285 & & 11.663 & & 17.041 & 11.374 & 80 & 1.03 \\
\hline C5A1-4 & 0.1223 & & 12.242 & & 16.061 & 10.726 & & \\
\hline C5A1-5 & 0.1285 & & 11.663 & & 18.177 & 12.133 & & \\
\hline C4B-1 & 0.0773 & & 18.944 & & 9.381 & 6.410 & & \\
\hline C4B-2 & 0.0557 & & 25.344 & & 6.485 & 4.592 & & \\
\hline C4B-3 & 0.1107 & & 13.490 & & 14.265 & 9.549 & & \\
\hline C4B-4 & 0.1223 & & 12.242 & & 16.061 & 10.726 & & \\
\hline C4B-5 & 0.1223 & & 12.242 & & 13.384 & 8.939 & & \\
\hline C2B-1 & 0.0370 & & 35.592 & & 4.132 & 3.134 & & \\
\hline C2B-2 & 0.0394 & & 33.907 & & 4.414 & 3.308 & & \\
\hline C2B-3 & 0.0418 & & 32.301 & & 4.712 & 3.493 & & \\
\hline C2B-4 & 0.0557 & & 25.344 & & 6.818 & 4.828 & & \\
\hline C2B-5 & 0.1107 & & 13.490 & & 14.265 & 9.549 & & \\
\hline $\begin{array}{l}\text { C1A1-1 } \\
\text { C1A1-2 }\end{array}$ & $\begin{array}{l}0.0173 \\
0.0224\end{array}$ & $\begin{array}{l}73.680 \\
57.430\end{array}$ & & & $\begin{array}{l}1.811 \\
2.392\end{array}$ & $\begin{array}{l}1.424 \\
1.862\end{array}$ & & \\
\hline C1A1-3 & 0.0658 & & 21.912 & & 18.228 & 12.649 & & \\
\hline & & & & & & & & \\
\hline & & & & & & & & \\
\hline & & & & & & & & \\
\hline & & & & & & & & \\
\hline & & & & & & & & \\
\hline & & & & & & & & \\
\hline & & & & & & & & \\
\hline
\end{tabular}

ICEDF Gas Composition Analysis (page 3)

C. 7 
1) Open "ICEDF SMF WkSht 10/89". 2) Enter test name. 3) Save as "ICEDF testname month/year".

\section{How this spreadsheet works}

CO flow rate determined by Lookup function: Column H, Cells AB \& AC. Pressure correction added 5/23/89.

Dry gas volume $=\mathrm{CO}$ flow rate ${ }^{*}$ sample duration * pressure correction.

Actual dry gas volume $=$ VOL $(d r y$, actual $)=$ sample duration $* \mathrm{CO}$ flow rate * $(273+$ To $) / 293$.

$\mathrm{H} 2 \mathrm{O}$ specific volume $=1.227+0.004712(\mathrm{TO})$ for $\mathrm{To} \geq 100^{\circ} \mathrm{C}$.

$\mathrm{H} 2 \mathrm{O}$ saturated steam partial pressure (Psat $/ \mathrm{Po}=$ Formula1) for $\mathrm{T}<100^{\circ} \mathrm{C}$.

Formula1 $=0.0107-3.451^{*} 10^{\wedge}-4^{\star} \mathrm{F} 10+5.359^{*} 10^{\wedge}-5^{*} \mathrm{~F} 10^{\wedge} 2-5.694^{*} 10^{\wedge}-7^{*} \mathrm{~F} 10^{\wedge} 3+1.057^{*} 10^{\wedge}-8^{*} \mathrm{~F} 10^{\wedge} 4$

Actual $\mathrm{H} 2 \mathrm{O}$ gas volume:

$T<100^{\circ} \mathrm{C}: \quad \operatorname{VOL}(\max )=\left[(\text { Psat/ Po })^{\bullet}(\mathrm{VOL}\right.$ (dry, actual) $\left.)\right][1$ - (Psat/Po) $]$. See BNW 51060, pg 133. $\operatorname{VOL}(\max )=\operatorname{VOL}(\mathrm{H} 2 \mathrm{O}$, saturated, maximum possible at $\mathrm{T})$

Fog Check: compare $\mathrm{H} 2 \mathrm{O}$ mass collected to $\mathrm{H} 2 \mathrm{O}$ mass required for sample saturation $\mathrm{M}(\mathrm{H} 2 \mathrm{O}$, sat $)=[[\mathrm{VOL}$ (dry, actual) $+\mathrm{VOL}(\mathrm{H} 2 \mathrm{O}, \max )] \mathrm{Vs}(\mathrm{H} 2 \mathrm{O}$ vapor, sat $)](1000 / 1000)$

Vs $(\mathrm{H} 2 \mathrm{O}$ vapor, sat $)=$ FormulaA if $\mathrm{T}<25^{\circ} \mathrm{C},=$ FormulaC if $\mathrm{T}>65^{\circ} \mathrm{C}$. FormulaA $=199.61 * 10^{\wedge}(-2.7052 \theta-2(T))$. FormulaB $=138.44^{*} 10^{\wedge}(-2.1068 \theta-2(T))$. FormulaC $=68.411 \cdot 10^{\wedge}(-1.6225 \theta-2(T))$.

1) If condensate mass $<M(\mathrm{H} 2 \mathrm{O}$, sat):

VOL(H2O, actual $)=(\mathrm{RH}){ }^{*}(\mathrm{VOL}(\max ))$. Print "Not Sat."

2) If condensate mass $=M(\mathrm{H} 2 \mathrm{O}$, sat):

$\mathrm{RH}=$ condensate mass $/ \mathrm{M}(\mathrm{H} 2 \mathrm{O}$, sat $)$.

VOL(H2O, actual) $=$ VOL(max). Print "Sat." (saturated).

3) If condenate mass $>M(\mathrm{H} 2 \mathrm{O}$, sat):

VOL $(H 2 O$, actual $)=$ VOL(max $)$. Calculate and print fog mass conc.

Fog Conc $=$ condensate mass $-\mathrm{M}(\mathrm{H} 2 \mathrm{O}$, sat $) /$ sample vol.

(sample vol $=\left(1000 \mathrm{~m}^{\wedge} 3 / /\right)^{*} \Sigma$ [actual $\mathrm{H} 2 \mathrm{O} \&$ dry vols])

$T \geq 100^{\circ} \mathrm{C}: \quad \operatorname{Vol}(\mathrm{H} 2 \mathrm{O})=$ (condensate mass * sat steam spec vol)*(1000/1000). Print "S. H. Vap."

$\mathrm{SMF}=\mathrm{Actual} \mathrm{H} 20$ gas volume / total gas volume (ie., the sum of actual dry and actual $\mathrm{H} 2 \mathrm{O}$ volumes, = sample vol",

Not included: 1) possible temp variations, 2) possible supersaturation.

CO upstream pressure correction factor added to spreadsheet on 6/14/89 (in draft form in 5/89).

Modifications: ICEDF SMF WkSht 6/89 superseded ICEDF SMF WkSht 9/87

1) Original date of this version was $6 / 14 / 89$.

2) 1st modification was made 9/14/89:

Crit orifice flow corr. factor formula was changed to print "" if test time was "".

Sample analysis date cell was added to top of page 1.

ICEDF SMF WkSht 10/89 superseded ICEDF SMF WkSht 6/89

1) Changed printer page set-up, and minor editing. 2) Changed SMF col eq to print " " if no H2O mass is entered.

3) Changed Fog column equation to print "' if no SMF is calculated, and ¿Sat? if SMF is calculated

based on assumed saturation when no $\mathrm{H} 2 \mathrm{O}$ mass is entered.

4) Changed Sample ID column 12/1/89 to match new test plan (no C6B1 or C6B2). 


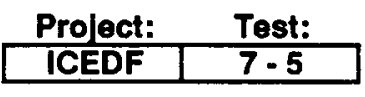

\begin{tabular}{|c|c|c|}
\hline Date of & \multicolumn{3}{|c|}{ Q.A. Verification: } \\
Analysis & Name & Date \\
\hline $9 / 2 / 90$ & MWL & $7 / 29 / 9 /$ \\
\hline
\end{tabular}

\begin{tabular}{|c|c|c|c|c|c|c|c|c|}
\hline $\begin{array}{l}\text { Sample } \\
\text { ID No: }\end{array}$ & $\begin{array}{l}\text { Test Clock } \\
\text { (min) }\end{array}$ & $\begin{array}{l}\text { Sample } \\
\text { Duration } \\
\Delta t \text { (min) } \\
\end{array}$ & $\begin{array}{l}\text { To } \\
\left({ }^{\circ} \mathrm{C}\right)\end{array}$ & $\begin{array}{c}\text { Critical } \\
\text { Orifice } \\
(\#)\end{array}$ & $\begin{array}{c}C O \\
\Delta P \\
(" \mathrm{Hg})\end{array}$ & $\begin{array}{c}\text { Condensate } \\
\mathrm{H} 2 \mathrm{O} \text { Mass } \\
\text { (g) }\end{array}$ & \begin{tabular}{|c} 
Crit. Orifice \\
Flow Rate \\
@ 20ㄷ \\
(lpm) \\
\end{tabular} & $\begin{array}{c}\text { Crit. Orifice } \\
\text { Flow Corr. } \\
\text { Factor } \\
(\cdot)\end{array}$ \\
\hline C6A & various & 20 each & $160-200$ & 65 & & 0.00 & 6.970 & \\
\hline $\begin{array}{l}\text { C6B-1 } \\
\text { C6B-2 } \\
\text { C6B-3 } \\
\text { C6B-4 } \\
\text { C6B-5 }\end{array}$ & $\begin{array}{l}15.00 \\
35.50 \\
56.00 \\
76.00 \\
93.00\end{array}$ & $\begin{array}{l}20.00 \\
19.00 \\
19.50 \\
19.50 \\
14.50\end{array}$ & $\begin{array}{l}25 \\
23 \\
23 \\
28 \\
30\end{array}$ & $\begin{array}{l}65 \\
65 \\
65 \\
65 \\
65\end{array}$ & & $\begin{array}{c}11.34 \\
9.87 \\
19.20 \\
13.61 \\
20.85\end{array}$ & $\begin{array}{l}6.970 \\
6.970 \\
6.970 \\
6.970 \\
6.970\end{array}$ & $\begin{array}{l}1.00 \\
1.00 \\
1.00 \\
1.00 \\
1.00\end{array}$ \\
\hline $\begin{array}{l}\text { C4B-1 } \\
\text { C4B-2 } \\
\text { C4B-3 } \\
\text { C4B-4 } \\
\text { C4B-5 }\end{array}$ & $\begin{array}{l}15.00 \\
35.00 \\
55.00 \\
75.00 \\
95.00\end{array}$ & $\begin{array}{l}20.00 \\
20.00 \\
20.00 \\
20.00 \\
20.00\end{array}$ & $\begin{array}{l}19 \\
20 \\
15 \\
15 \\
15\end{array}$ & $\begin{array}{l}65 \\
65 \\
65 \\
65 \\
65\end{array}$ & & $\begin{array}{l}0.34 \\
1.09 \\
1.18 \\
1.11 \\
0.97\end{array}$ & $\begin{array}{l}6.970 \\
6.970 \\
6.970 \\
6.970 \\
6.970\end{array}$ & $\begin{array}{l}1.00 \\
1.00 \\
1.00 \\
1.00 \\
1.00\end{array}$ \\
\hline $\begin{array}{l}\text { C2B-1 } \\
\text { C2B-2 } \\
\text { C2B-3 } \\
\text { C2B-4 } \\
\text { C2B-5 }\end{array}$ & $\begin{array}{l}15.00 \\
34.50 \\
54.50 \\
75.00 \\
95.00\end{array}$ & $\begin{array}{l}19.70 \\
19.00 \\
19.00 \\
19.50 \\
20.00\end{array}$ & $\begin{array}{c}5 \\
6 \\
7 \\
9 \\
10\end{array}$ & $\begin{array}{l}65 \\
65 \\
65 \\
65 \\
65\end{array}$ & & $\begin{array}{l}0.00 \\
0.07 \\
0.17 \\
0.29 \\
0.52\end{array}$ & $\begin{array}{l}6.970 \\
6.970 \\
6.970 \\
6.970 \\
6.970\end{array}$ & $\begin{array}{l}1.00 \\
1.00 \\
1.00 \\
1.00 \\
1.00\end{array}$ \\
\hline $\begin{array}{l}\text { C1B-1 } \\
\text { C1B-2 } \\
\text { C1B-3 }\end{array}$ & $\begin{array}{l}15.00 \\
55.00 \\
95.00\end{array}$ & $\begin{array}{l}20.00 \\
20.00 \\
20.00\end{array}$ & $\begin{array}{l}0 \\
5 \\
5\end{array}$ & $\begin{array}{l}65 \\
65 \\
65\end{array}$ & & $\begin{array}{l}0.00 \\
0.00 \\
0.03\end{array}$ & $\begin{array}{l}6.970 \\
6.970 \\
6.970\end{array}$ & $\begin{array}{l}1.00 \\
1.00 \\
1.00\end{array}$ \\
\hline
\end{tabular}

ICEDF Gas Composition Analysis (page 1)

C. 9 
\begin{tabular}{c|c|}
\hline Project: & Test: \\
\hline ICEDF & $7-5$ \\
\hline
\end{tabular}

\begin{tabular}{|c|c|c|c|c|c|c|c|c|}
\hline $\begin{array}{l}\text { Sample } \\
\text { ID No. }\end{array}$ & $\begin{array}{c}\text { Dry Gas } \\
\text { Volume } \\
\left(1 @ 20^{\circ} \mathrm{C}\right)\end{array}$ & $\begin{array}{c}\text { Sat. Vapor } \\
\left(\mathrm{T}<100^{\circ} \mathrm{C}\right) \\
\text { (Psat/Po) }\end{array}$ & $\begin{array}{c}\text { H2O Vapor } \\
\text { Spec. Vol. } \\
\left(\mathrm{T}<100^{\circ} \mathrm{C}\right) \\
(\mathrm{m} 3 / \mathrm{kg})\end{array}$ & $\begin{array}{l}\text { H2O Vapor } \\
\text { Spec. Vol. } \\
\left(T \geq 100^{\circ} \mathrm{C}\right) \\
(\mathrm{m} 3 / \mathrm{kg})\end{array}$ & $\begin{array}{l}\text { Dry Gas } \\
\text { Volume } \\
\text { (1@ To) }\end{array}$ & $\begin{array}{l}\text { H2O Gas } \\
\text { Volume } \\
(1 @ \text { To }) \\
\end{array}$ & $\begin{array}{c}\text { SMF } \\
(-)\end{array}$ & $\begin{array}{c}\text { Fog } \\
@ \text { To } \\
\left(\mathrm{mg} / \mathrm{m}^{\wedge} 3\right)\end{array}$ \\
\hline C6A & & $\mathrm{T} \geq 100^{\circ} \mathrm{C}$ & $\mathrm{T} \geq 100^{\circ} \mathrm{C}$ & \#VALUE! & & \#VALUE! & & \\
\hline $\begin{array}{l}\text { C6B-1 } \\
\text { C6B-2 } \\
\text { C6B-3 } \\
\text { C6B-4 } \\
\text { C6B-5 }\end{array}$ & $\begin{array}{l}139.400 \\
132.430 \\
135.915 \\
135.915 \\
101.065\end{array}$ & $\begin{array}{l}0.0308 \\
0.0271 \\
0.0271 \\
0.0370 \\
0.0418\end{array}$ & $\begin{array}{l}41.168 \\
47.642 \\
47.642 \\
35.592 \\
32.301\end{array}$ & $\begin{array}{l}\mathrm{T}<100^{\circ} \mathrm{C} \\
\mathrm{T}<100^{\circ} \mathrm{C} \\
\mathrm{T}<100^{\circ} \mathrm{C} \\
T<100^{\circ} \mathrm{C} \\
T<100^{\circ} \mathrm{C}\end{array}$ & $\begin{array}{l}141.78 \\
133.79 \\
137.31 \\
139.63 \\
104.51\end{array}$ & $\begin{array}{l}4.51 \\
3.73 \\
3.83 \\
5.37 \\
4.56\end{array}$ & $\begin{array}{l}0.031 \\
0.027 \\
0.027 \\
0.037 \\
0.042\end{array}$ & $\begin{array}{c}53.23 \\
50.78 \\
115.05 \\
65.77 \\
160.20\end{array}$ \\
\hline $\begin{array}{l}\text { C4B-1 } \\
\text { C4B-2 } \\
\text { C4B-3 } \\
\text { C4B-4 } \\
\text { C4B-5 }\end{array}$ & $\begin{array}{l}139.400 \\
139.400 \\
139.400 \\
139.400 \\
139.400\end{array}$ & $\begin{array}{l}0.0210 \\
0.0224 \\
0.0162 \\
0.0162 \\
0.0162\end{array}$ & $\begin{array}{l}61.122 \\
57.430 \\
78.416 \\
78.416 \\
78.416\end{array}$ & $\begin{array}{l}\mathrm{T}<100^{\circ} \mathrm{C} \\
\mathrm{T}<100^{\circ} \mathrm{C} \\
\mathrm{T}<100^{\circ} \mathrm{C} \\
\mathrm{T}<100^{\circ} \mathrm{C} \\
T<100^{\circ} \mathrm{C}\end{array}$ & $\begin{array}{l}138.92 \\
139.40 \\
137.02 \\
137.02 \\
137.02\end{array}$ & $\begin{array}{l}0.43 \\
1.40 \\
1.50 \\
1.41 \\
1.23\end{array}$ & $\begin{array}{l}0.003 \\
0.010 \\
0.011 \\
0.010 \\
0.009\end{array}$ & $\begin{array}{l}\text { Not Sat. } \\
\text { Not Sat. } \\
\text { Not Sat. } \\
\text { Not Sat. } \\
\text { Not Sat. }\end{array}$ \\
\hline $\begin{array}{l}\text { C2B-1 } \\
\text { C2B-2 } \\
\text { C2B-3 } \\
\text { C2B-4 } \\
\text { C2B-5 }\end{array}$ & $\begin{array}{l}137.309 \\
132.430 \\
132.430 \\
135.915 \\
139.400\end{array}$ & $\begin{array}{l}0.0102 \\
0.0104 \\
0.0107 \\
0.0116 \\
0.0121\end{array}$ & $\begin{array}{l}146.192 \\
137.363 \\
129.068 \\
113.950 \\
107.069\end{array}$ & $\begin{array}{l}T<100^{\circ} \mathrm{C} \\
T<100^{\circ} \mathrm{C} \\
T<100^{\circ} \mathrm{C} \\
T<100^{\circ} \mathrm{C} \\
T<100^{\circ} \mathrm{C}\end{array}$ & $\begin{array}{l}130.28 \\
126.10 \\
126.55 \\
130.81 \\
134.64\end{array}$ & $\begin{array}{l}0.00 \\
0.10 \\
0.23 \\
0.38 \\
0.67\end{array}$ & $\begin{array}{l}0.000 \\
0.001 \\
0.002 \\
0.003 \\
0.005\end{array}$ & $\begin{array}{l}\text { Not Sat. } \\
\text { Not Sat. } \\
\text { Not Sat. } \\
\text { Not Sat. } \\
\text { Not Sat. }\end{array}$ \\
\hline $\begin{array}{l}\text { C1B-1 } \\
\text { C1B-2 } \\
\text { C1B-3 }\end{array}$ & $\begin{array}{l}139.400 \\
139.400 \\
139.400\end{array}$ & $\begin{array}{l}0.0107 \\
0.0102 \\
0.0102\end{array}$ & $\begin{array}{l}199.609 \\
146.192 \\
146.192\end{array}$ & $\begin{array}{l}T<100^{\circ} \mathrm{C} \\
T<100^{\circ} \mathrm{C} \\
T<100^{\circ} \mathrm{C}\end{array}$ & $\begin{array}{l}129.88 \\
132.26 \\
132.26\end{array}$ & $\begin{array}{l}0.00 \\
0.00 \\
0.05\end{array}$ & $\begin{array}{l}0.000 \\
0.000 \\
0.000\end{array}$ & $\begin{array}{l}\text { Not Sat. } \\
\text { Not Sat. } \\
\text { Not Sat. }\end{array}$ \\
\hline
\end{tabular}

ICEDF Gas Composition Analysis (page 2) 
Project: Test:

ICEDF 7 -5

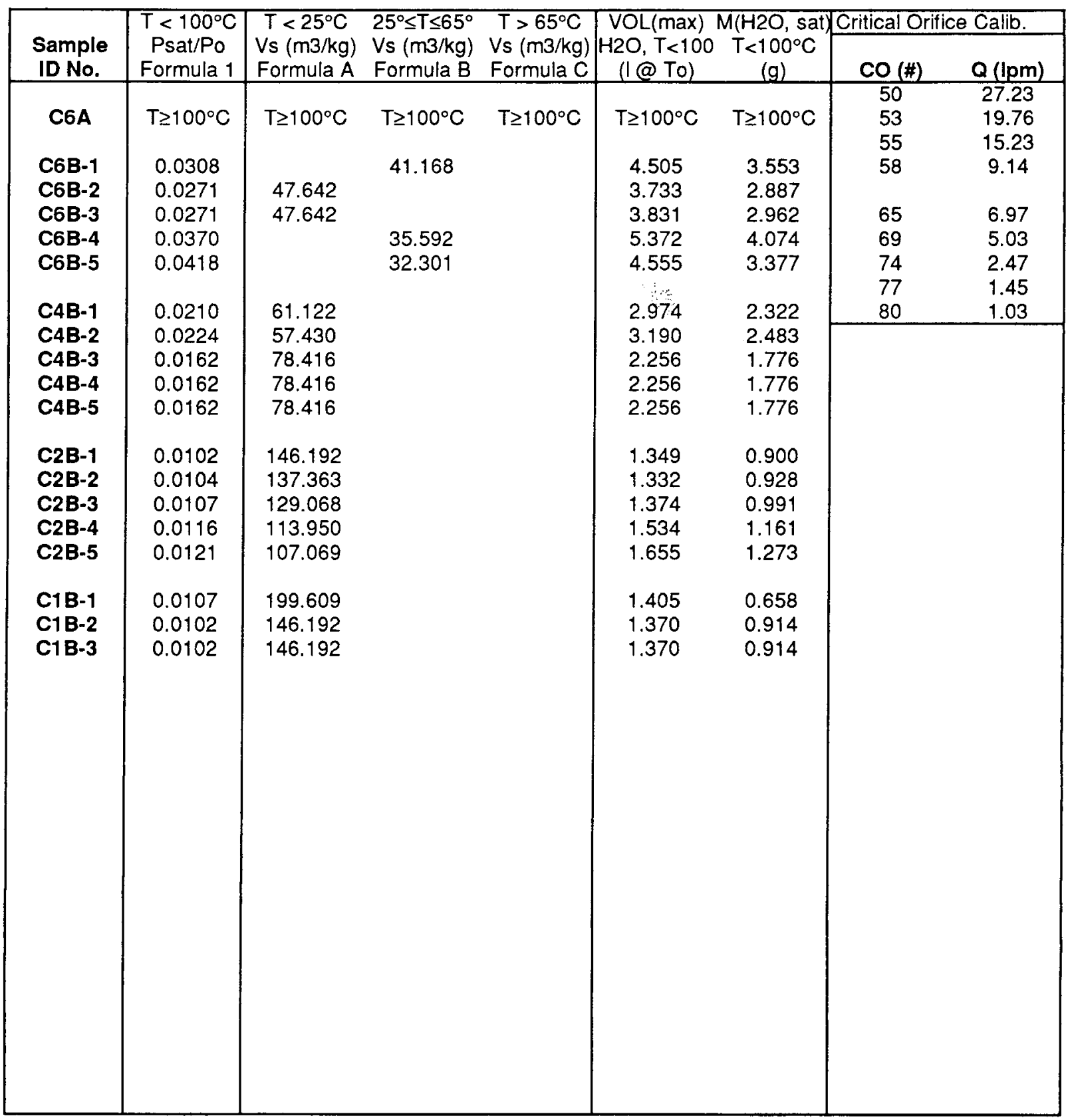

ICEDF Gas Composition Analysis (page 3)

C. 11 
ICEDF SMF WkSht 6/88 supersedes ICEDF SMF WkSht $9 / 87$

ICEDF SMF SkSht 10/89 supersedes ICEDF SMF WkSht 6/88

1) Open "ICEDF SMF WkSht 10/89". 2) Enter test name. 3) Save as "ICEDF testname month/year".

\section{How this spreadsheet works}

CO flow rate determined by Lookup function: Column $\mathrm{H}$, Cells $A B$ \& AC. Pressure correction added 5/23/89.

Dry gas volume $=\mathrm{CO}$ flow rate $"$ sample duration " pressure correction.

Actual dry gas volume $=\mathrm{VOL}(\mathrm{dry}$, actual $)=$ sample duration * CO flow rate * $(273+\mathrm{To}) / 293$.

$\mathrm{H} 2 \mathrm{O}$ specific volume $=1.227+0.004712$ (To) for To $\geq 100^{\circ} \mathrm{C}$.

H2O saturated steam partial pressure (Psat/Po $=$ Formula1) for $T<100^{\circ} \mathrm{C}$.

Formula1 $=0.0107-3.451^{*} 10^{\wedge}-4^{\star} \mathrm{F} 10+5.359^{*} 10^{\wedge}-5^{\star} \mathrm{F} 10^{\wedge} 2-5.694^{*} 10^{\wedge}-7^{\star} \mathrm{F} 10^{\wedge} 3+1.057^{*} 10^{\wedge}-8^{\star} \mathrm{F} 10^{\wedge} 4$

Actual $\mathrm{H} 2 \mathrm{O}$ gas volume:

$\mathrm{T}<100^{\circ} \mathrm{C}: \quad \operatorname{VOL}(\max )=[($ Psat $/ \mathrm{Po}) *(\mathrm{VOL}($ dry, actual $))] /[1$ - (Psat/Po $\left.)\right]$. See BNW 51060, pg 133. $\mathrm{VOL}(\max )=\operatorname{VOL}(\mathrm{H} 2 \mathrm{O}$, saturated, maximum possible at $\mathrm{T})$

Fog Check: compare $\mathrm{H} 2 \mathrm{O}$ mass collected to $\mathrm{H} 2 \mathrm{O}$ mass required for sample saturation $\mathrm{M}(\mathrm{H} 2 \mathrm{O}, \mathrm{sat})=[[\mathrm{VOL}(\mathrm{dry}$, actual $)+\mathrm{VOL}(\mathrm{H} 2 \mathrm{O}, \max )] / \mathrm{Vs}(\mathrm{H} 2 \mathrm{O}$ vapor, sat $)](1000 / 1000)$

$\mathrm{Vs}(\mathrm{H} 2 \mathrm{O}$ vapor, sat $)=$ FormulaA if $\mathrm{T}<25^{\circ} \mathrm{C},=$ FormulaC if $\mathrm{T}>65^{\circ} \mathrm{C}$. FormulaA $=199.61 \cdot 10^{\wedge}(-2.7052 \theta-2(T))$.

FormulaB $=138.44^{*} 10^{\wedge}(-2.1068 \theta-2(T))$.

FormulaC $=68.411 * 10^{\wedge}(-1.6225 e-2(T))$

1) If condensate mass $<M(\mathrm{H} 2 \mathrm{O}$, sat):

$\operatorname{VOL}(\mathrm{H} 2 \mathrm{O}$, actual $)=(\mathrm{RH}){ }^{*}(\mathrm{VOL}(\max ))$. Print "Not Sat."

2) If condensate mass $=\mathrm{M}(\mathrm{H} 2 \mathrm{O}$, sat):

$\mathrm{RH}=$ condensate mass $/ \mathrm{M}(\mathrm{H} 2 \mathrm{O}$, sat $)$.

VOL $(\mathrm{H} 2 \mathrm{O}$, actual) $=$ VOL (max). Print "Sat." (saturated).

3) If condenate mass $>M(\mathrm{H} 2 \mathrm{O}$, sat):

VOL $(\mathrm{H} 2 \mathrm{O}$, actual $)=$ VOL(max $)$. Calculate and print fog mass conc.

Fog Conc $=$ condensate mass $-\mathrm{M}(\mathrm{H} 2 \mathrm{O}$, sat $) /$ sample vol.

(sample vol $=\left(1000 \mathrm{~m}^{\wedge} 3 /\right)^{\star} \Sigma$ [actual $\mathrm{H} 2 \mathrm{O} \&$ dry vols])

$\mathrm{T} \geq 100^{\circ} \mathrm{C}: \quad \operatorname{Vol}(\mathrm{H} 2 \mathrm{O})=($ condensate mass * sat steam spec vol)* $(1000 / 1000)$. Print "S. H. Vap."

SMF = Actual $\mathrm{H} 20$ gas volume / total gas volume (ie., the sum of actual dry and actual $\mathrm{H} 2 \mathrm{O}$ volumes, = sample vol",

Not included: 1) possible temp variations, 2) possible supersaturation.

CO upstream pressure correction factor added to spreadsheet on 6/14/89 (in draft form in 5/89).

Modifications: ICEDF SMF WkSht 6/89 superseded ICEDF SMF WkSht 9/87

1) Original date of this version was $6 / 14 / 89$.

2) 1st modification was made $9 / 14 / 89$ :

Crit orifice flow corr. factor formula was changed to print "' if test time was "'".

Sample analysis date cell was added to top of page 1.

ICEDF SMF WkSht 10/89 superseded ICEDF SMF WkSht 6/89

1) Changed printer page set-up, and minor editing. 2) Changed SMF col eq to print "n if no H2O mass is entered.

3) Changed Fog column equation to print "'" if no SMF is calculated, and ¿Sat? if SMF is calculated

based on assumed saturation when no $\mathrm{H} 2 \mathrm{O}$ mass is entered.

4) Changed Sample ID column 12/1/89 to match new test plan (no C6B1 or C6B2). 
Prolect: Test:

ICEDF $11-6$

\begin{tabular}{|c|c|c|}
\hline Date of & \multicolumn{2}{|c|}{ Q.A. Verification: } \\
Analysis & Name & Date \\
\hline $8 / 31 / 90$ & MWL & $7 / 29 / 91$ \\
\hline
\end{tabular}

\begin{tabular}{|c|c|c|c|c|c|c|c|c|}
\hline $\begin{array}{l}\text { Sample } \\
\text { ID No. }\end{array}$ & $\begin{array}{c}\text { Test Clock } \\
\text { (min) }\end{array}$ & $\begin{array}{l}\text { Sample } \\
\text { Duration } \\
\Delta t \text { (min) }\end{array}$ & $\begin{array}{l}\text { To } \\
\left({ }^{\circ} \mathrm{C}\right)\end{array}$ & $\begin{array}{c}\text { Critical } \\
\text { Orifice } \\
(\#)\end{array}$ & $\begin{array}{c}C O \\
\Delta P \\
\left({ }^{n} \mathrm{Hg}\right)\end{array}$ & $\begin{array}{c}\text { Condensate } \\
\text { H2O Mass } \\
\text { (g) }\end{array}$ & $\begin{array}{c}\text { Crit. Orifice } \\
\text { Flow Rate } \\
@ 20^{\circ} \mathrm{C} \\
(\mathrm{lpm}) \\
\end{array}$ & $\begin{array}{l}\text { Crit. Orifice } \\
\text { Flow Corr. } \\
\text { Factor } \\
(-)\end{array}$ \\
\hline $\begin{array}{l}\text { C6A-1 } \\
\text { C6A-2 } \\
\text { C6A-3 } \\
\text { C6A-4 }\end{array}$ & $\begin{array}{c}15.50 \\
44.63 \\
75.00 \\
105.00\end{array}$ & $\begin{array}{l}6.00 \\
6.00 \\
6.00 \\
6.00\end{array}$ & $\begin{array}{l}122 \\
118 \\
123 \\
125\end{array}$ & $\begin{array}{l}65 \\
65 \\
65 \\
65\end{array}$ & $\begin{array}{l}\text { ND } \\
\text { ND } \\
\text { ND } \\
\text { ND }\end{array}$ & $\begin{array}{l}57.04 \\
49.94 \\
63.80 \\
60.02\end{array}$ & $\begin{array}{l}6.970 \\
6.970 \\
6.970 \\
6.970\end{array}$ & $\begin{array}{l}1.00 \\
1.00 \\
1.00 \\
1.00\end{array}$ \\
\hline $\begin{array}{l}\text { C6B-1 } \\
\text { C6B-2 } \\
\text { C6B-3 } \\
\text { C6B-4 }\end{array}$ & $\begin{array}{c}20.25 \\
50.00 \\
80.25 \\
110.00\end{array}$ & $\begin{array}{l}16.50 \\
20.00 \\
20.00 \\
20.00\end{array}$ & $\begin{array}{l}58 \\
55 \\
58 \\
88\end{array}$ & $\begin{array}{l}65 \\
65 \\
65 \\
65\end{array}$ & $\begin{array}{l}N D \\
N D \\
N D \\
N D\end{array}$ & $\begin{array}{l}56.26 \\
48.14 \\
32.00 \\
64.99\end{array}$ & $\begin{array}{l}6.970 \\
6.970 \\
6.970 \\
6.970\end{array}$ & $\begin{array}{l}1.00 \\
1.00 \\
1.00 \\
1.00\end{array}$ \\
\hline $\begin{array}{l}\text { C4B-1 } \\
\text { C4B-2 } \\
\text { C4B-3 } \\
\text { C4B-4 }\end{array}$ & $\begin{array}{r}20.00 \\
50.00 \\
80.00 \\
106.50\end{array}$ & $\begin{array}{c}16.00 \\
16.00 \\
16.00 \\
9.00\end{array}$ & $\begin{array}{l}52 \\
51 \\
66 \\
84\end{array}$ & $\begin{array}{l}65 \\
65 \\
65 \\
65\end{array}$ & $\begin{array}{l}\text { ND } \\
\text { ND } \\
\text { ND } \\
\text { ND }\end{array}$ & $\begin{array}{l}12.45 \\
14.05 \\
29.64 \\
56.28\end{array}$ & $\begin{array}{l}6.970 \\
6.970 \\
6.970 \\
6.970\end{array}$ & $\begin{array}{l}1.00 \\
1.00 \\
1.00 \\
1.00\end{array}$ \\
\hline $\begin{array}{l}\text { C2B-1 } \\
\text { C2B-2 } \\
\text { C2B-3 } \\
\text { C2B-4 }\end{array}$ & $\begin{array}{c}20.00 \\
39.00 \\
80.00 \\
110.00\end{array}$ & $\begin{array}{l}16.00 \\
18.00 \\
16.00 \\
16.00\end{array}$ & $\begin{array}{l}26 \\
44 \\
68 \\
85\end{array}$ & $\begin{array}{l}65 \\
65 \\
65 \\
65\end{array}$ & $\begin{array}{l}\text { ND } \\
\text { ND } \\
\text { ND } \\
\text { ND }\end{array}$ & $\begin{array}{c}6.27 \\
13.00 \\
33.16 \\
55.35\end{array}$ & $\begin{array}{l}6.970 \\
6.970 \\
6.970 \\
6.970\end{array}$ & $\begin{array}{l}1.00 \\
1.00 \\
1.00 \\
1.00\end{array}$ \\
\hline $\begin{array}{l}\text { C1B-1 } \\
\text { C1B-2 } \\
\text { C1B-3 } \\
\text { C1B-4 }\end{array}$ & $\begin{array}{c}20.00 \\
50.00 \\
80.00 \\
108.00\end{array}$ & $\begin{array}{l}16.00 \\
16.00 \\
16.00 \\
12.00\end{array}$ & 86 & $\begin{array}{l}65 \\
65 \\
65 \\
65\end{array}$ & $\begin{array}{l}\text { ND } \\
\text { ND } \\
\text { ND } \\
\text { ND }\end{array}$ & $\begin{array}{c}8.95 \\
12.18 \\
36.24 \\
83.86\end{array}$ & $\begin{array}{l}6.970 \\
6.970 \\
6.970 \\
6.970\end{array}$ & $\begin{array}{l}1.00 \\
1.00 \\
1.00 \\
1.00\end{array}$ \\
\hline
\end{tabular}

ICEDF Gas Composition Analysis (page 1)

C. 13 
Project: Test:

\begin{tabular}{|l|l}
\hline ICEDF & $11-6$
\end{tabular}

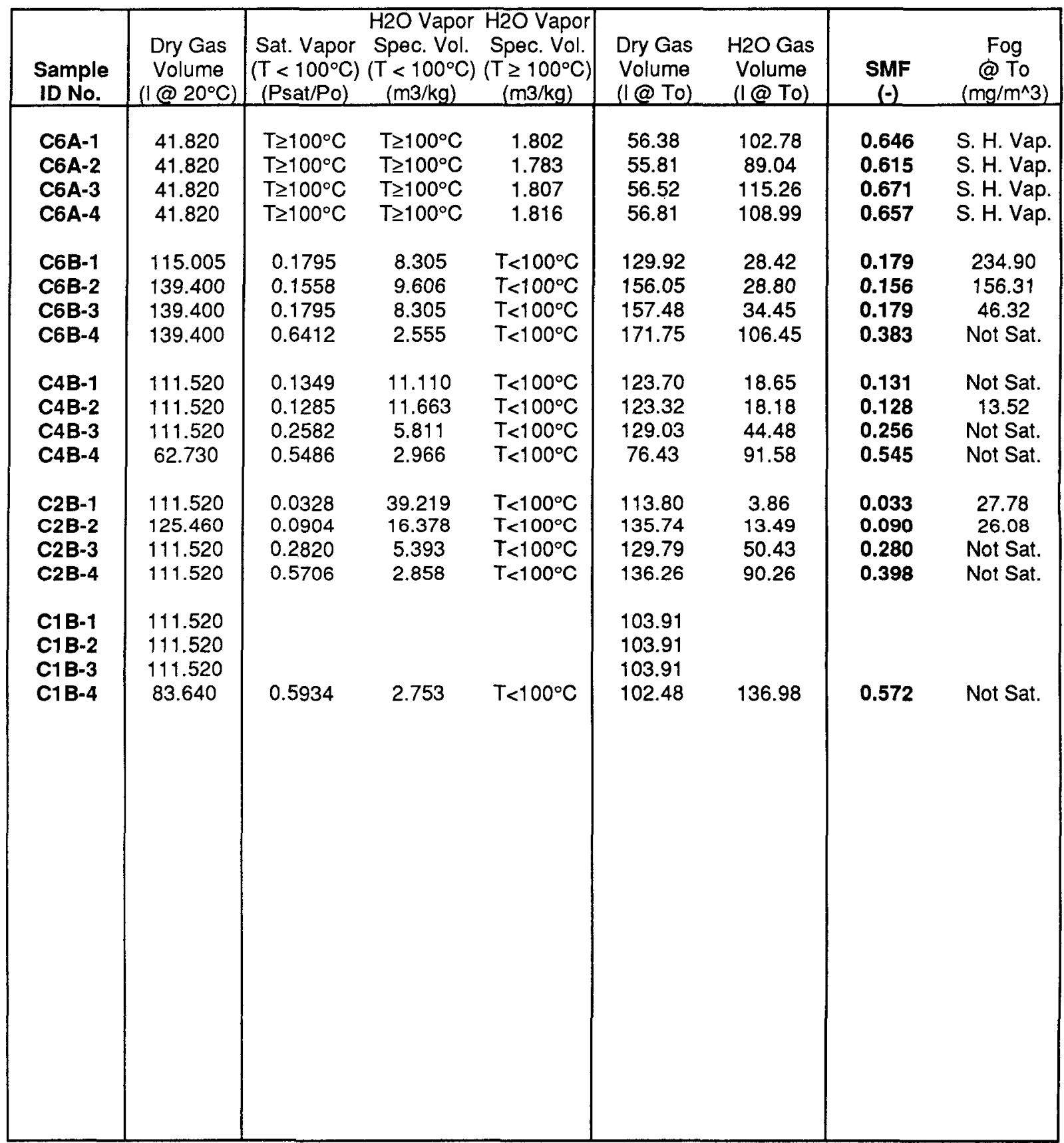

ICEDF Gas Composition Analysis (page 2)

C. 14 
Project: Test:

\begin{tabular}{l|l}
\hline ICEDF & $11-6$ \\
\hline
\end{tabular}

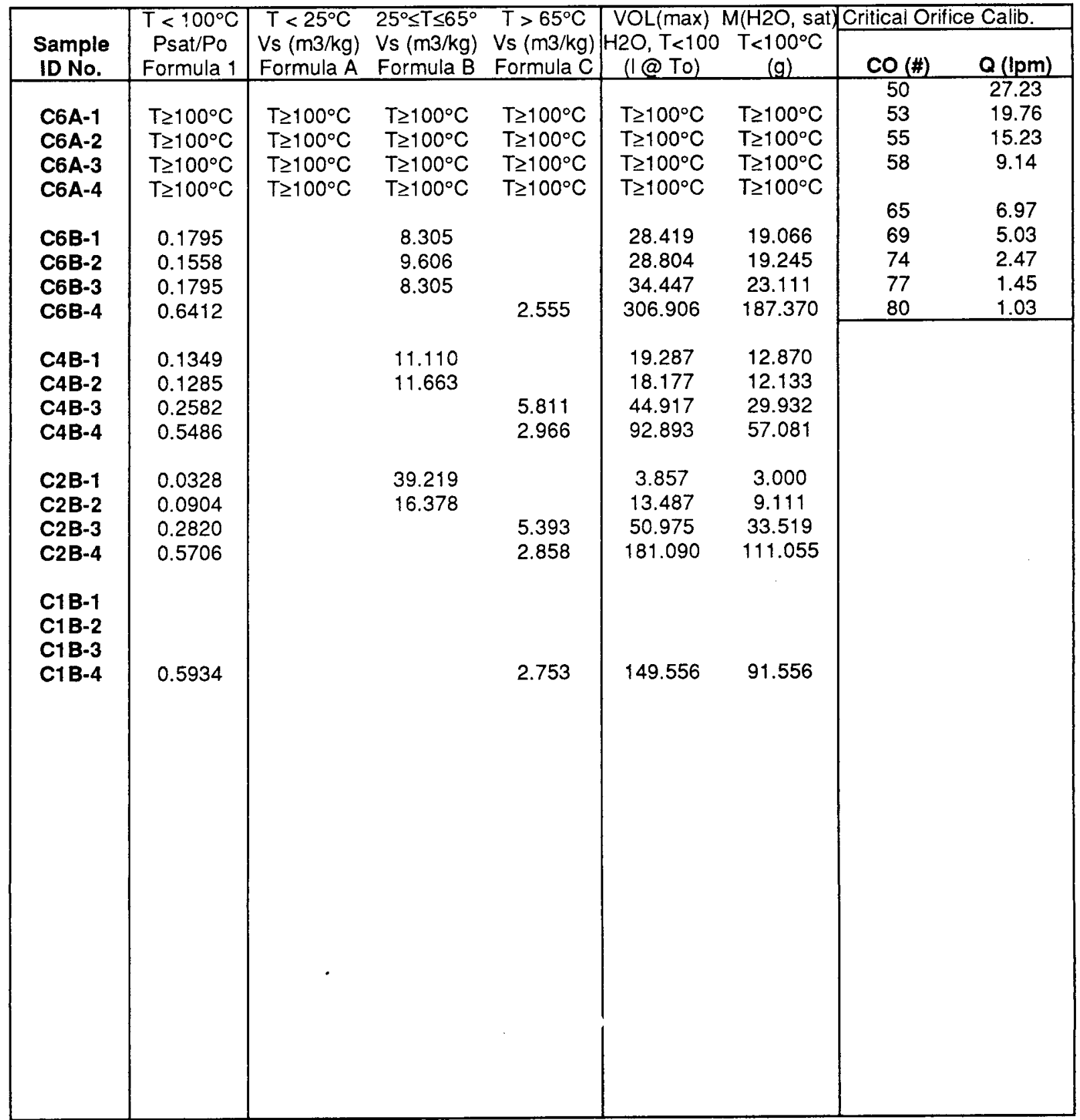

ICEDF Gas Composition Analysis (page 3)

C. 15 
ICEDF SMF WkSht $6 / 88$ supersedes ICEDF SMF WkSht $9 / 87$ ICEDF SMF SkSht 10/89 supersedes ICEDF SMF WkSht 6/88

1) Open "ICEDF SMF WkSht 10/89". 2) Enter test name. 3) Save as "ICEDF testname month/year".

\section{How this spreadsheet works}

CO flow rate determined by Lookup function: Column H, Cells AB \& AC. Pressure correction added 5/23/89.

Dry gas volume $=$ CO flow rate * sample duration * pressure correction.

Actual dry gas volume $=$ VOL $(d r y$, actual $)=$ sample duration * CO flow rate * $(273+$ To $) / 293$.

$\mathrm{H} 2 \mathrm{O}$ specific volume $=1.227+0.004712(\mathrm{To})$ for $\mathrm{To} \geq 100^{\circ} \mathrm{C}$.

H2O saturated steam partial pressure (Psat $/ \mathrm{Po}=$ Formula1) for $\mathrm{T}<100^{\circ} \mathrm{C}$.

Formula1 $=0.0107-3.451^{*} 10^{\wedge}-4^{*} \mathrm{~F} 10+5.359^{*} 10^{\wedge}-5^{*} \mathrm{~F} 10^{\wedge} 2-5.694^{*} 10^{\wedge}-7^{*} \mathrm{~F} 10^{\wedge} 3+1.057^{*} 10^{\wedge}-8^{*} \mathrm{~F} 10^{\wedge} 4$

Actual $\mathrm{H} 2 \mathrm{O}$ gas volume:

$T<100^{\circ} \mathrm{C}: \quad \operatorname{VOL}(\max )=\left[(\mathrm{Psat} / \mathrm{Po}){ }^{*}(\mathrm{VOL}(\mathrm{dry}\right.$, actual $\left.))\right][[1-($ Psat/Po $)]$. See BNW 51060, pg 133. $\mathrm{VOL}(\max )=\mathrm{VOL}(\mathrm{H} 2 \mathrm{O}$, saturated, maximum possible at $\mathrm{T})$

Fog Check: compare $\mathrm{H} 2 \mathrm{O}$ mass collected to $\mathrm{H} 2 \mathrm{O}$ mass required for sample saturation $\mathrm{M}(\mathrm{H} 2 \mathrm{O}$, sat) $=[\mathrm{VOL}$ (dry, actual) $+\mathrm{VOL}(\mathrm{H} 2 \mathrm{O}, \max )] / \mathrm{Vs}(\mathrm{H} 2 \mathrm{O}$ vapor, sat) $](1000 / 1000)$ $\mathrm{Vs}(\mathrm{H} 2 \mathrm{O}$ vapor, sat $)=$ FormulaA if $\mathrm{T}<25^{\circ} \mathrm{C},=$ FormulaC if $\mathrm{T}>65^{\circ} \mathrm{C}$.

$$
\begin{aligned}
& \text { FormulaA }=199.61 * 10^{\wedge}(-2.7052 \theta-2(T)) . \\
& \text { FormulaB }=138.44 * 10^{\wedge}(-2.1068 \theta-2(T)) . \\
& \text { FormulaC }=68.411 * 10^{\wedge}(-1.6225 \theta-2(T)) .
\end{aligned}
$$

1) If condensate mass $<M(\mathrm{H} 2 \mathrm{O}$, sat):

$\operatorname{VOL}(\mathrm{H} 2 \mathrm{O}$, actual $)=(\mathrm{RH}) *(\mathrm{VOL}(\max ))$. Print "Not Sat."

2) If condensate mass $=M(H 2 O$, sat $)$ :

$\mathrm{RH}=$ condensate mass $/ \mathrm{M}(\mathrm{H} 2 \mathrm{O}$, sat $)$.

VOL $(\mathrm{H} 2 \mathrm{O}$, actual $)=\mathrm{VOL}(\max )$. Print "Sat." (saturated).

3) If condenate mass $>M(\mathrm{H} 2 \mathrm{O}$, sat):

$\mathrm{VOL}(\mathrm{H} 2 \mathrm{O}$, actual $)=\mathrm{VOL}(\max )$. Calculate and print fog mass conc.

Fog Conc $=$ condensate mass $-\mathrm{M}(\mathrm{H} 2 \mathrm{O}$, sat $) /$ sample vol.

(sample vol $\left.=\left(1000 \mathrm{~m}^{\wedge} 3 / 1\right)\right)^{\star} \Sigma$ [actual $\mathrm{H} 2 \mathrm{O} \& \mathrm{dry}$ vols])

$\mathrm{T} \geq 100^{\circ} \mathrm{C}: \quad \operatorname{Vol}(\mathrm{H} 2 \mathrm{O})=\left(\right.$ condensate mass ${ }^{*}$ sat steam spec vol) ${ }^{*}(1000 / 1000)$. Print "S. H. Vap."

SMF = Actual $\mathrm{H} 20$ gas volume / total gas volume (ie., the sum of actual dry and actual $\mathrm{H} 2 \mathrm{O}$ volumes, = sample vol,

Not included: 1) possible temp variations, 2) possible supersaturation.

CO upstream pressure correction factor added to spreadsheet on 6/14/89 (in draft form in 5/89).

Modifications: ICEDF SMF WkSht 6/89 superseded ICEDF SMF WkSht 9/87

1) Original date of this version was $6 / 14 / 89$.

2) 1st modification was made 9/14/89:

Crit orifice flow corr. factor formula was changed to print "' if test time was "

Sample analysis date cell was added to top of page 1.

ICEDF SMF WkSht 10/89 superseded ICEDF SMF WkSht 6/89

1) Changed printer page set-up, and minor editing. 2) Changed SMF col eq to print "" if no $\mathrm{H} 2 \mathrm{O}$ mass is entered.

3) Changed Fog column equation to print "' if no SMF is calculated, and ¿Sat? if SMF is calculated based on assumed saturation when no $\mathrm{H} 2 \mathrm{O}$ mass is entered.

4) Changed Sample ID column 12/1/89 to match new test plan (no C6B1 or C6B2). 


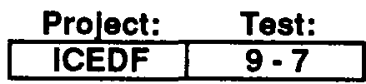

\begin{tabular}{|c|c|c|}
\hline Date of & Q.A. Verif & atio \\
\hline Analysis & Name & Date \\
\hline $8 / 27 / 90$ & MWL & $7 / 29 / 91$ \\
\hline
\end{tabular}

\begin{tabular}{|c|c|c|c|c|c|c|c|c|}
\hline $\begin{array}{l}\text { Sample } \\
\text { ID No. }\end{array}$ & $\begin{array}{c}\text { Test Clock } \\
\text { (min) }\end{array}$ & $\begin{array}{l}\text { Sample } \\
\text { Duration } \\
\Delta t \text { (min) }\end{array}$ & $\begin{array}{c}\text { To } \\
\left({ }^{\circ} \mathrm{C}\right)\end{array}$ & $\begin{array}{c}\text { Critical } \\
\text { Orifice } \\
(\#)\end{array}$ & $\begin{array}{c}C O \\
\Delta P \\
(n \mathrm{Hg})\end{array}$ & $\begin{array}{c}\text { Condensate } \\
\mathrm{H} 2 \mathrm{O} \text { Mass } \\
(\mathrm{g})\end{array}$ & $\begin{array}{c}\text { Crit. Orifice } \\
\text { Flow Rate } \\
@ 20^{\circ} \mathrm{C} \\
\text { (lpm) }\end{array}$ & $\begin{array}{l}\text { Crit. Orifice } \\
\text { Flow Corr. } \\
\text { Factor } \\
(-1)\end{array}$ \\
\hline C6A-1 & 12.50 & 5.00 & 140 & 74 & & 12.10 & 2.470 & 1.00 \\
\hline C6A-2 & 27.50 & 5.00 & 142 & 74 & & 14.29 & 2.470 & 1.00 \\
\hline C6A-3 & 48.50 & 5.00 & 144 & 74 & & 14.01 & 2.470 & 1.00 \\
\hline C6A-4 & 57.50 & 5.00 & 145 & 74 & & 13.28 & 2.470 & 1.00 \\
\hline C6A-5 & 67.50 & 5.00 & 147 & 74 & & 13.43 & 2.470 & 1.00 \\
\hline C6A-6 & 87.50 & 5.00 & 150 & 65 & & 36.07 & 6.970 & 1.00 \\
\hline C6A-7 & 97.50 & 5.00 & 150 & 65 & & 35.73 & 6.970 & 1.00 \\
\hline$C 0-1$ & 12.50 & 5.00 & 7 & 58 & & 0.00 & 9.140 & 1.00 \\
\hline $\mathrm{CO}-2$ & 27.50 & 5.00 & 7 & 58 & & 0.00 & 9.140 & 1.00 \\
\hline $\mathrm{CO}-3$ & 48.46 & 6.75 & 6 & 58 & & 0.21 & 9.140 & 1.00 \\
\hline $\mathrm{CO}-4$ & 60.02 & 5.00 & 10 & 58 & & 0.39 & 9.140 & 1.00 \\
\hline $\mathrm{CO}-5$ & 67.50 & 5.00 & 19 & 58 & & 1.05 & 9.140 & 1.00 \\
\hline $\mathrm{CO}-6$ & 87.50 & 5.00 & 30 & 58 & & 1.66 & 9.140 & 1.00 \\
\hline $\mathrm{Co-7}$ & 97.50 & 5.00 & 32 & 58 & & 2.32 & 9.140 & 1.00 \\
\hline C6B-1 & 12.50 & 5.00 & 41 & 58 & & 8.60 & 9.140 & 1.00 \\
\hline C6B-2 & 27.50 & 5.00 & 39 & 58 & & 6.51 & 9.140 & 1.00 \\
\hline C6B-3 & 47.58 & 5.00 & 37 & 58 & & 7.30 & 9.140 & 1.00 \\
\hline C6B-4 & 60.00 & 10.00 & 41 & 58 & & 17.45 & 9.140 & 1.00 \\
\hline C6B-5 & 72.50 & 10.00 & 19 & 58 & & 21.53 & 9.140 & 1.00 \\
\hline C6B-6 & 90.00 & 10.00 & 30 & 58 & & 10.87 & 9.140 & 1.00 \\
\hline C6B-7 & 100.50 & 10.00 & 33 & 58 & & 18.18 & 9.140 & 1.00 \\
\hline C4B-1 & 28.50 & 5.00 & 29 & 58 & & 0.00 & 9.140 & 1.00 \\
\hline C4B-2 & 48.50 & 5.00 & 27 & 58 & & 0.15 & 9.140 & 1.00 \\
\hline C4B-3 & 71.00 & 10.00 & 39 & 58 & & 3.27 & 9.140 & 1.00 \\
\hline C4B-4 & 91.00 & 10.00 & 37 & 58 & & 3.85 & 9.140 & 1.00 \\
\hline C2B-1 & 27.75 & 5.50 & 21 & 58 & & 0.28 & 9.140 & 1.00 \\
\hline C2B-2 & 47.50 & 5.00 & 12 & 58 & & 0.26 & 9.140 & 1.00 \\
\hline C2B-3 & 70.00 & 10.00 & 19 & 58 & & 1.11 & 9.140 & 1.00 \\
\hline C2B-4 & 90.00 & 10.00 & 28 & 58 & & 2.14 & 9.140 & 1.00 \\
\hline C1B-1 & 12.53 & 5.02 & 5 & 58 & & 0.48 & 9.140 & 1.00 \\
\hline C1B-2 & 27.55 & 5.03 & 5 & 58 & & 0.12 & 9.140 & 1.00 \\
\hline C1B-3 & 47.56 & 5.05 & 7 & 58 & & 0.15 & 9.140 & 1.00 \\
\hline C1B-4 & 57.57 & 5.00 & 10 & 58 & & 0.21 & 9.140 & 1.00 \\
\hline C1B-5 & 67.58 & 4.98 & 20 & 58 & & 0.63 & 9.140 & 1.00 \\
\hline C1B-6 & 89.53 & 3.07 & 32 & 58 & & 0.49 & 9.140 & 1.00 \\
\hline C1B-7 & 100.00 & 5.00 & 34 & 58 & & 1.29 & 9.140 & 1.00 \\
\hline
\end{tabular}




\begin{tabular}{|c|c|c|c|c|c|c|c|c|}
\hline $\begin{array}{l}\text { Project: } \\
\text { ICEDF }\end{array}$ & $\begin{array}{l}\text { Test: } \\
9-7 \\
\end{array}$ & & & & & & & \\
\hline $\begin{array}{l}\text { Sample } \\
\text { ID No. }\end{array}$ & $\begin{array}{c}\text { Dry Gas } \\
\text { Volume } \\
\left(1 @ 20^{\circ} \mathrm{C}\right)\end{array}$ & $\begin{array}{c}\text { Sat. Vapor } \\
\left(\mathrm{T}<100^{\circ} \mathrm{C}\right) \\
(\text { Psat/Po) }\end{array}$ & $\begin{array}{c}\text { H2O Vapor } \\
\text { Spec. Vol. } \\
\left(\mathrm{T}<100^{\circ} \mathrm{C}\right) \\
(\mathrm{m} 3 / \mathrm{kg}) \\
\end{array}$ & $\begin{array}{c}\text { H2O Vapor } \\
\text { Spec. Vol. } \\
\left(\mathrm{T} \geq 100^{\circ} \mathrm{C}\right) \\
(\mathrm{m} 3 / \mathrm{kg})\end{array}$ & $\begin{array}{l}\text { Dry Gas } \\
\text { Volume } \\
\text { (1@ To) }\end{array}$ & $\begin{array}{l}\text { H2O Gas } \\
\text { Volume } \\
(1 @ \text { To })\end{array}$ & $\begin{array}{c}\text { SMF } \\
(-) \\
\end{array}$ & $\begin{array}{c}\text { Fog } \\
@ \text { To } \\
\left(\mathrm{mg} / \mathrm{m}^{\wedge} 3\right)\end{array}$ \\
\hline $\begin{array}{l}\text { C6A-1 } \\
\text { C6A-2 } \\
\text { C6A-3 } \\
\text { C6A-4 } \\
\text { C6A-5 } \\
\text { C6A-6 } \\
\text { C6A-7 }\end{array}$ & $\begin{array}{l}12.350 \\
12.350 \\
12.350 \\
12.350 \\
12.350 \\
34.850 \\
34.850\end{array}$ & $\begin{array}{l}\mathrm{T} \geq 100^{\circ} \mathrm{C} \\
\mathrm{T} \geq 100^{\circ} \mathrm{C} \\
\mathrm{T} \geq 100^{\circ} \mathrm{C} \\
\mathrm{T} \geq 100^{\circ} \mathrm{C} \\
\mathrm{T} \geq 100^{\circ} \mathrm{C} \\
\mathrm{T} \geq 100^{\circ} \mathrm{C} \\
\mathrm{T} \geq 100^{\circ} \mathrm{C}\end{array}$ & $\begin{array}{l}\mathrm{T} \geq 100^{\circ} \mathrm{C} \\
\mathrm{T} \geq 100^{\circ} \mathrm{C} \\
\mathrm{T} \geq 100^{\circ} \mathrm{C} \\
\mathrm{T} \geq 100^{\circ} \mathrm{C} \\
\mathrm{T} \geq 100^{\circ} \mathrm{C} \\
\mathrm{T} \geq 100^{\circ} \mathrm{C} \\
T \geq 100^{\circ} \mathrm{C}\end{array}$ & $\begin{array}{l}1.887 \\
1.896 \\
1.906 \\
1.910 \\
1.920 \\
1.934 \\
1.934\end{array}$ & $\begin{array}{l}17.41 \\
17.49 \\
17.58 \\
17.62 \\
17.70 \\
50.31 \\
50.31\end{array}$ & $\begin{array}{l}22.82 \\
27.10 \\
26.70 \\
25.37 \\
25.78 \\
69.75 \\
69.09\end{array}$ & $\begin{array}{l}0.567 \\
0.608 \\
0.603 \\
0.590 \\
0.593 \\
0.581 \\
0.579\end{array}$ & $\begin{array}{l}\text { S. H. Vap. } \\
\text { S. H. Vap. } \\
\text { S. H. Vap. } \\
\text { S. H. Vap. } \\
\text { S. H. Vap. } \\
\text { S. H. Vap. } \\
\text { S. H. Vap. }\end{array}$ \\
\hline $\begin{array}{l}\mathrm{C} 0-1 \\
\mathrm{C} 0-2 \\
\mathrm{CO}-3 \\
\mathrm{CO}-4 \\
\mathrm{CO}-5 \\
\mathrm{CO}-6 \\
\mathrm{CO}-7\end{array}$ & $\begin{array}{l}45.700 \\
45.700 \\
61.695 \\
45.700 \\
45.700 \\
45.700 \\
45.700\end{array}$ & $\begin{array}{l}0.0107 \\
0.0107 \\
0.0104 \\
0.0121 \\
0.0210 \\
0.0418 \\
0.0470\end{array}$ & $\begin{array}{c}129.068 \\
129.068 \\
137.363 \\
107.069 \\
61.122 \\
32.301 \\
29.315\end{array}$ & $\begin{array}{l}T<100^{\circ} \mathrm{C} \\
T<100^{\circ} \mathrm{C} \\
T<100^{\circ} \mathrm{C} \\
T<100^{\circ} \mathrm{C} \\
T<100^{\circ} \mathrm{C} \\
T<100^{\circ} \mathrm{C} \\
T<100^{\circ} \mathrm{C}\end{array}$ & $\begin{array}{l}43.67 \\
43.67 \\
58.75 \\
44.14 \\
45.54 \\
47.26 \\
47.57\end{array}$ & $\begin{array}{l}0.00 \\
0.00 \\
0.30 \\
0.50 \\
0.98 \\
2.06 \\
2.34\end{array}$ & $\begin{array}{l}0.000 \\
0.000 \\
0.005 \\
0.011 \\
0.021 \\
0.042 \\
0.047\end{array}$ & $\begin{array}{c}\text { Not Sat. } \\
\text { Not Sat. } \\
\text { Not Sat. } \\
\text { Not Sat. } \\
6.28 \\
2.76 \\
12.43\end{array}$ \\
\hline $\begin{array}{l}\text { C6B-1 } \\
\text { C6B-2 } \\
\text { C6B-3 } \\
\text { C6B-4 } \\
\text { C6B-5 } \\
\text { C6B-6 } \\
\text { C6B-7 }\end{array}$ & $\begin{array}{l}45.700 \\
45.700 \\
45.700 \\
91.400 \\
91.400 \\
91.400 \\
91.400\end{array}$ & $\begin{array}{l}0.0773 \\
0.0694 \\
0.0623 \\
0.0773 \\
0.0210 \\
0.0418 \\
0.0497\end{array}$ & $\begin{array}{l}18.944 \\
20.874 \\
23.001 \\
18.944 \\
61.122 \\
32.301 \\
27.927\end{array}$ & $\begin{array}{l}T<100^{\circ} \mathrm{C} \\
T<100^{\circ} \mathrm{C} \\
T<100^{\circ} \mathrm{C} \\
T<100^{\circ} \mathrm{C} \\
T<100^{\circ} \mathrm{C} \\
T<100^{\circ} \mathrm{C} \\
T<100^{\circ} \mathrm{C}\end{array}$ & $\begin{array}{l}48.98 \\
48.66 \\
48.35 \\
97.95 \\
91.09 \\
94.52 \\
95.46\end{array}$ & $\begin{array}{l}4.10 \\
3.63 \\
3.21 \\
8.20 \\
1.95 \\
4.12 \\
5.00\end{array}$ & $\begin{array}{l}0.077 \\
0.069 \\
0.062 \\
0.077 \\
0.021 \\
0.042 \\
0.050\end{array}$ & $\begin{array}{c}109.24 \\
76.58 \\
98.10 \\
111.60 \\
215.05 \\
79.24 \\
145.17\end{array}$ \\
\hline $\begin{array}{l}\text { C4B-1 } \\
\text { C4B-2 } \\
\text { C4B-3 } \\
\text { C4B-4 }\end{array}$ & $\begin{array}{l}45.700 \\
45.700 \\
91.400 \\
91.400\end{array}$ & $\begin{array}{l}0.0394 \\
0.0349 \\
0.0694 \\
0.0623\end{array}$ & $\begin{array}{l}33.907 \\
37.362 \\
20.874 \\
23.001\end{array}$ & $\begin{array}{l}T<100^{\circ} \mathrm{C} \\
T<100^{\circ} \mathrm{C} \\
T<100^{\circ} \mathrm{C} \\
T<100^{\circ} \mathrm{C}\end{array}$ & $\begin{array}{l}47.10 \\
46.79 \\
97.33 \\
96.70\end{array}$ & $\begin{array}{l}0.00 \\
0.19 \\
4.74 \\
5.51\end{array}$ & $\begin{array}{l}0.000 \\
0.004 \\
0.046 \\
0.054\end{array}$ & $\begin{array}{l}\text { Not Sat. } \\
\text { Not Sat. } \\
\text { Not Sat. } \\
\text { Not Sat. }\end{array}$ \\
\hline $\begin{array}{l}\text { C2B-1 } \\
\text { C2B-2 } \\
\text { C2B-3 } \\
\text { C2B-4 }\end{array}$ & $\begin{array}{l}50.270 \\
45.700 \\
91.400 \\
91.400\end{array}$ & $\begin{array}{l}0.0239 \\
0.0135 \\
0.0210 \\
0.0370\end{array}$ & $\begin{array}{l}53.962 \\
94.528 \\
61.122 \\
35.592\end{array}$ & $\begin{array}{l}\mathrm{T}<100^{\circ} \mathrm{C} \\
\mathrm{T}<100^{\circ} \mathrm{C} \\
\mathrm{T}<100^{\circ} \mathrm{C} \\
T<100^{\circ} \mathrm{C}\end{array}$ & $\begin{array}{l}50.44 \\
44.45 \\
91.09 \\
93.90\end{array}$ & $\begin{array}{l}0.36 \\
0.34 \\
1.42 \\
2.83\end{array}$ & $\begin{array}{l}0.007 \\
0.008 \\
0.015 \\
0.029\end{array}$ & $\begin{array}{l}\text { Not Sat. } \\
\text { Not Sat. } \\
\text { Not Sat. } \\
\text { Not Sat. }\end{array}$ \\
\hline $\begin{array}{l}\text { C1B-1 } \\
\text { C1B-2 } \\
\text { C1B-3 } \\
\text { C1B-4 } \\
\text { C1B-5 } \\
\text { C1B-6 } \\
\text { C1B-7 }\end{array}$ & $\begin{array}{l}45.883 \\
45.974 \\
46.157 \\
45.700 \\
45.517 \\
28.060 \\
45.700\end{array}$ & $\begin{array}{l}0.0102 \\
0.0102 \\
0.0107 \\
0.0121 \\
0.0224 \\
0.0470 \\
0.0527\end{array}$ & $\begin{array}{c}146.192 \\
146.192 \\
129.068 \\
107.069 \\
57.430 \\
29.315 \\
26.604\end{array}$ & $\begin{array}{l}T<100^{\circ} \mathrm{C} \\
T<100^{\circ} \mathrm{C} \\
T<100^{\circ} \mathrm{C} \\
T<100^{\circ} \mathrm{C} \\
T<100^{\circ} \mathrm{C} \\
T<100^{\circ} \mathrm{C} \\
T<100^{\circ} \mathrm{C}\end{array}$ & $\begin{array}{l}43.53 \\
43.62 \\
44.11 \\
44.14 \\
45.52 \\
29.21 \\
47.88\end{array}$ & $\begin{array}{l}0.45 \\
0.18 \\
0.21 \\
0.27 \\
0.81 \\
0.67 \\
1.80\end{array}$ & $\begin{array}{l}0.010 \\
0.004 \\
0.005 \\
0.006 \\
0.017 \\
0.022 \\
0.036\end{array}$ & $\begin{array}{c}4.16 \\
\text { Not Sat. } \\
\text { Not Sat. } \\
\text { Not Sat. } \\
\text { Not Sat. } \\
\text { Not Sat. } \\
\text { Not Sat. }\end{array}$ \\
\hline
\end{tabular}


Project: Test:

\begin{tabular}{l|l}
\hline ICEDF & $\mathbf{9 - 7}$ \\
\hline
\end{tabular}

\begin{tabular}{|c|c|c|c|c|c|c|c|c|}
\hline \multirow[b]{2}{*}{$\begin{array}{l}\text { Sample } \\
\text { ID No. }\end{array}$} & \multirow{2}{*}{$\begin{array}{l}\mathrm{T}<100^{\circ} \mathrm{C} \\
\text { Psat/Po } \\
\text { Formula } 1\end{array}$} & \multirow{2}{*}{$\begin{array}{l}\mathrm{T}<25^{\circ} \mathrm{C} \\
\text { Vs (m3/kg) } \\
\text { Formula A }\end{array}$} & \multirow{2}{*}{$\begin{array}{l}25^{\circ} \leq \mathrm{T} \leq 65^{\circ} \\
\text { Vs }(\mathrm{m} 3 / \mathrm{kg}) \\
\text { Formula B }\end{array}$} & \multirow{2}{*}{$\begin{array}{l}\mathrm{T}>65^{\circ} \mathrm{C} \\
\mathrm{Vs}(\mathrm{m} 3 / \mathrm{kg}) \\
\text { Formula C }\end{array}$} & \multicolumn{4}{|c|}{ VOL(max) M(H2O, sat) Critical Orifice Calib. } \\
\hline & & & & & $\begin{array}{c}H 2 O, T<100 \\
(1 @ \text { To })\end{array}$ & $\begin{array}{c}T<100^{\circ} \mathrm{C} \\
\text { (g) }\end{array}$ & $\mathrm{CO}(\#)$ & $Q(\operatorname{lpm})$ \\
\hline & & & & & & & 50 & 27.23 \\
\hline C6A-1 & $T \geq 100^{\circ} \mathrm{C}$ & $T \geq 100^{\circ} \mathrm{C}$ & $T \geq 100^{\circ} \mathrm{C}$ & $T \geq 100^{\circ} \mathrm{C}$ & $\mathrm{T} \geq 100^{\circ} \mathrm{C}$ & $\mathrm{T} \geq 100^{\circ} \mathrm{C}$ & 53 & 19.76 \\
\hline C6A-2 & $T \geq 100^{\circ} \mathrm{C}$ & $T \geq 100^{\circ} \mathrm{C}$ & $T \geq 100^{\circ} \mathrm{C}$ & $T \geq 100^{\circ} \mathrm{C}$ & $\mathrm{T} \geq 100^{\circ} \mathrm{C}$ & $\mathrm{T} \geq 100^{\circ} \mathrm{C}$ & 55 & 15.23 \\
\hline C6A-3 & $T \geq 100^{\circ} \mathrm{C}$ & $\mathrm{T} \geq 100^{\circ} \mathrm{C}$ & $T \geq 100^{\circ} \mathrm{C}$ & $T \geq 100^{\circ} \mathrm{C}$ & $\mathrm{T} \geq 100^{\circ} \mathrm{C}$ & $T \geq 100^{\circ} \mathrm{C}$ & 58 & 9.14 \\
\hline C6A-4 & $\mathrm{T} \geq 100^{\circ} \mathrm{C}$ & $\mathrm{T} \geq 100^{\circ} \mathrm{C}$ & $\mathrm{T} \geq 100^{\circ} \mathrm{C}$ & $\mathrm{T} \geq 100^{\circ} \mathrm{C}$ & $\mathrm{T} \geq 100^{\circ} \mathrm{C}$ & $\mathrm{T} \geq 100^{\circ} \mathrm{C}$ & & \\
\hline C6A-5 & $\mathrm{T} \geq 100^{\circ} \mathrm{C}$ & $\mathrm{T} \geq 100^{\circ} \mathrm{C}$ & $\mathrm{T} \geq 100^{\circ} \mathrm{C}$ & $\mathrm{T} \geq 100^{\circ} \mathrm{C}$ & $\mathrm{T} \geq 100^{\circ} \mathrm{C}$ & $T \geq 100^{\circ} \mathrm{C}$ & 65 & 6.97 \\
\hline C6A-6 & $\mathrm{T} \geq 100^{\circ} \mathrm{C}$ & $\mathrm{T} \geq 100^{\circ} \mathrm{C}$ & $\mathrm{T} \geq 100^{\circ} \mathrm{C}$ & $\mathrm{T} \geq 100^{\circ} \mathrm{C}$ & $\mathrm{T} \geq 100^{\circ} \mathrm{C}$ & $\mathrm{T} \geq 100^{\circ} \mathrm{C}$ & 69 & 5.03 \\
\hline \multirow[t]{2}{*}{ C6A-7 } & \multirow[t]{2}{*}{$\mathrm{T} \geq 100^{\circ} \mathrm{C}$} & \multirow[t]{2}{*}{$\mathrm{T} \geq 100^{\circ} \mathrm{C}$} & \multirow[t]{2}{*}{$\mathrm{T} \geq 100^{\circ} \mathrm{C}$} & \multirow[t]{2}{*}{$\mathrm{T} \geq 100^{\circ} \mathrm{C}$} & \multirow[t]{2}{*}{$\mathrm{T} \geq 100^{\circ} \mathrm{C}$} & \multirow[t]{2}{*}{$\mathrm{T} \geq 100^{\circ} \mathrm{C}$} & 74 & 2.47 \\
\hline & & & & & & & 77 & 1.45 \\
\hline \multirow{2}{*}{$\begin{array}{l}\mathrm{CO}-1 \\
\mathrm{CO}-2\end{array}$} & \multirow{2}{*}{0.0107} & 129.068 & & & 0.474 & & 80 & 1.03 \\
\hline & & \multicolumn{2}{|l|}{129.068} & & \multirow{2}{*}{0.474} & & & \\
\hline $\mathrm{CO}-3$ & 0.0104 & 137.363 & & & & $\begin{array}{l}0.342 \\
0.432\end{array}$ & & \\
\hline $\mathrm{CO}-4$ & 0.0121 & \multicolumn{2}{|l|}{107.069} & & 0.543 & 0.417 & & \\
\hline $\mathrm{CO}-5$ & 0.0210 & \multirow[t]{2}{*}{61.122} & & & 0.975 & 0.761 & & \\
\hline $\mathrm{CO}-6$ & 0.0418 & & 32.301 & & 2.060 & 1.527 & & \\
\hline $\mathrm{CO}-7$ & 0.0470 & & 29.315 & & 2.344 & 1.703 & & \\
\hline C6B-1 & 0.0773 & & 18.944 & & 4.101 & 2.802 & & \\
\hline C6B-2 & 0.0694 & & 20.874 & & 3.631 & 2.505 & & \\
\hline C6B-3 & 0.0623 & & 23.001 & & 3.210 & 2.242 & & \\
\hline C6B-4 & 0.0773 & & 18.944 & & 8.201 & 5.603 & & \\
\hline C6B-5 & 0.0210 & 61.122 & & & 1.950 & 1.522 & & \\
\hline C6B-6 & 0.0418 & & 32.301 & & 4.120 & 3.054 & & \\
\hline C6B-7 & 0.0497 & & 27.927 & & 4.997 & 3.597 & & \\
\hline C4B-1 & 0.0394 & & 33.907 & & 1.929 & 1.446 & & \\
\hline C4B-2 & 0.0349 & & 37.362 & & 1.690 & 1.298 & & \\
\hline C4B-3 & 0.0694 & & 20.874 & & 7.261 & 5.010 & & \\
\hline C4B-4 & 0.0623 & & 23.001 & & 6.421 & 4.483 & & \\
\hline C2B-1 & 0.0239 & 53.962 & & & 1.233 & 0.958 & & \\
\hline C2B-2 & 0.0135 & 94.528 & & & 0.609 & 0.477 & & \\
\hline C2B-3 & 0.0210 & 61.122 & & & 1.950 & 1.522 & & \\
\hline C2B-4 & 0.0370 & & 35.592 & & 3.613 & 2.740 & & \\
\hline C1B-1 & 0.0102 & 146.192 & & & 0.451 & 0.301 & & \\
\hline C1B-2 & 0.0102 & 146.192 & & & 0.452 & 0.301 & & \\
\hline C1B-3 & 0.0107 & 129.068 & & & 0.479 & 0.345 & & \\
\hline C1B-4 & 0.0121 & 107.069 & & & 0.543 & 0.417 & & \\
\hline C1B-5 & 0.0224 & 57.430 & & & 1.042 & 0.811 & & \\
\hline C1B-6 & 0.0470 & & 29.315 & & 1.439 & 1.045 & & \\
\hline C1B-7 & 0.0527 & & 26.604 & & 2.662 & 1.900 & & \\
\hline
\end{tabular}


ICEDF SMF WkSht $6 / 88$ supersedes ICEDF SMF WkSht $9 / 87$

ICEDF SMF SkSht 10/89 supersedes ICEDF SMF WkSht 6/88

1) Open "ICEDF SMF WkSht 10/89". 2) Enter test name. 3) Save as "ICEDF testname month/year".

\section{How this spreadsheet works}

CO flow rate determined by Lookup function: Column $H$, Cells AB \& AC. Pressure correction added 5/23/89.

Dry gas volume $=\mathrm{CO}$ flow rate * sample duration * pressure correction

Actual dry gas volume $=\mathrm{VOL}(\mathrm{dry}$, actual $)=$ sample duration ${ }^{\bullet} \mathrm{CO}$ flow rate $*(273+$ To $) / 293$.

$\mathrm{H} 2 \mathrm{O}$ specific volume $=1.227+0.004712(\mathrm{To})$ for $\mathrm{To} \geq 100^{\circ} \mathrm{C}$.

H2O saturated steam partial pressure (Psat/Po $=$ Formula1) for $\mathrm{T}<100^{\circ} \mathrm{C}$.

Formula1 $=0.0107-3.451^{\star} 10^{\wedge}-4^{\star} \mathrm{F} 10+5.359^{\star} 10^{\wedge}-5^{\star} \mathrm{F} 10^{\wedge} 2-5.694^{\star} 10^{\wedge}-7^{\star} \mathrm{F} 10^{\wedge} 3+1.057^{\star} 10^{\wedge}-8^{\star} \mathrm{F} 10^{\wedge} 4$

Actual $\mathrm{H} 2 \mathrm{O}$ gas volume:

$\mathrm{T}<100^{\circ} \mathrm{C} ; \quad \operatorname{VOL}(\max )=[(\mathrm{Psat} / \mathrm{Po}) *(\mathrm{VOL}(\mathrm{dry}$, actual $))] /[1-($ Psat/Po $)]$. See BNW 51060, pg 133.

$\mathrm{VOL}(\max )=\mathrm{VOL}(\mathrm{H} 2 \mathrm{O}$, saturated, maximum possible at $\mathrm{T})$

Fog Check: compare $\mathrm{H} 2 \mathrm{O}$ mass collected to $\mathrm{H} 2 \mathrm{O}$ mass required for sample saturation $\mathrm{M}(\mathrm{H} 2 \mathrm{O}$, sat) $=[[\mathrm{VOL}$ (dry, actual) $+\mathrm{VOL}(\mathrm{H} 2 \mathrm{O}, \max )] / \mathrm{Ns}(\mathrm{H} 2 \mathrm{O}$ vapor, sat $)](1000 / 1000)$

$\mathrm{Vs}(\mathrm{H} 2 \mathrm{O}$ vapor, sat $)=$ FormulaA if $\mathrm{T}<25^{\circ} \mathrm{C},=$ FormulaC if $\mathrm{T}>65^{\circ} \mathrm{C}$.

FormulaA $=199.61 * 10^{\wedge}(-2.7052 \theta-2(T))$.

FormulaB $=138.44 * 10^{\wedge}(-2.1068 \theta-2(T))$.

FormulaC $=68.411 \cdot 10^{\wedge}(-1.6225 \theta-2(T))$.

1) If condensate mass $<\mathrm{M}(\mathrm{H} 2 \mathrm{O}$, sat):

$\operatorname{VOL}\left(\mathrm{H}_{2} \mathrm{O}\right.$, actual $)=(\mathrm{RH}) \bullet(\mathrm{VOL}(\max ))$. Print "Not Sat."

2) If condensate mass $=\mathrm{M}(\mathrm{H} 2 \mathrm{O}$, sat):

$\mathrm{RH}=$ condensate mass $/ \mathrm{M}(\mathrm{H} 2 \mathrm{O}$, sat $)$.

VOL $(\mathrm{H} 2 \mathrm{O}$, actual $)=$ VOL(max). Print "Sat." (saturated).

3) If condenate mass > $M(\mathrm{H} 2 \mathrm{O}$, sat):

$\mathrm{VOL}(\mathrm{H} 2 \mathrm{O}$, actual $)=\mathrm{VOL}(\max )$. Calculate and print fog mass conc.

Fog Conc $=$ condensate mass $-\mathrm{M}(\mathrm{H} 2 \mathrm{O}$, sat $) /$ sample vol. (sample vol $=\left(1000 \mathrm{~m}^{\wedge} 3 / \mathrm{l}\right){ }^{*} \Sigma$ [actual $\mathrm{H} 2 \mathrm{O} \&$ dry vols $]$ )

$\mathrm{T} \geq 100^{\circ} \mathrm{C}: \quad \operatorname{Vol}(\mathrm{H} 2 \mathrm{O})=(\text { condensate mass " sat steam spec vol })^{*}(1000 / 1000)$. Print "S. H. Vap."

SMF = Actual $\mathrm{H} 20$ gas volume / total gas volume (ie., the sum of actual dry and actual $\mathrm{H} 2 \mathrm{O}$ volumes, = sample vol',

Not included: 1) possible temp variations, 2) possible supersaturation.

CO upstream pressure correction factor added to spreadsheet on 6/14/89 (in draft form in 5/89).

Modifications: ICEDF SMF WkSht 6/89 superseded ICEDF SMF WkSht $9 / 87$

1) Original date of this version was $6 / 14 / 89$.

2) 1st modification was made $9 / 14 / 89$ :

Crit orifice flow corr. factor formula was changed to print "" if test time was "'.

Sample analysis date cell was added to top of page 1.

ICEDF SMF WkSht $10 / 89$ superseded ICEDF SMF WkSht 6/89

1) Changed printer page set-up, and minor editing. 2) Changed SMF col eq to print "n if no H2O mass is entered.

3) Changed Fog column equation to print "mo if no SMF is calculated, and ¿Sat? if SMF is calculated based on assumed saturation when no $\mathrm{H} 2 \mathrm{O}$ mass is entered.

4) Changed Sample ID column 12/1/89 to match new test plan (no C6B1 or C6B2). 


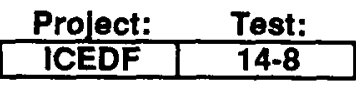

\begin{tabular}{|c|c|c|}
\hline Date of & \multicolumn{2}{|c|}{ Q.A. Veriflcatlon: } \\
Analysis & Name & Date \\
\hline $8 / 27 / 90$ & MWL & $7 / 29 / 91$ \\
\hline
\end{tabular}

\begin{tabular}{|c|c|c|c|c|c|c|c|c|}
\hline $\begin{array}{l}\text { Sample } \\
\text { ID No. }\end{array}$ & $\begin{array}{c}\text { Test Clock } \\
\text { (min) }\end{array}$ & $\begin{array}{l}\text { Sample } \\
\text { Duration } \\
\Delta t \text { (min) }\end{array}$ & $\begin{array}{c}\text { To } \\
\left({ }^{\circ} \mathrm{C}\right) \\
\end{array}$ & $\begin{array}{c}\text { Critical } \\
\text { Orifice } \\
(\#)\end{array}$ & $\begin{array}{c}C O \\
\Delta P \\
(n \mathrm{Hg}) \\
\end{array}$ & $\begin{array}{c}\text { Condensate } \\
\mathrm{H} 2 \mathrm{O} \text { Mass } \\
(\mathrm{g})\end{array}$ & $\begin{array}{l}\text { Crit. Orifice } \\
\text { Flow Rate } \\
@ 20^{\circ} \mathrm{C} \\
\text { (lpm) }\end{array}$ & $\begin{array}{l}\text { Crit. Orifice } \\
\text { Flow Corr. } \\
\text { Factor } \\
(-)\end{array}$ \\
\hline C6A-1 & 12.00 & 10.00 & 124 & 65 & ND & 22.68 & 6.970 & 1.00 \\
\hline C6A-2 & 27.00 & 10.00 & 125 & 65 & ND & 29.28 & 6.970 & 1.00 \\
\hline C6A-3 & 42.00 & 10.00 & 122 & 65 & ND & 30.81 & 6.970 & 1.00 \\
\hline C6A-4 & 57.00 & 10.00 & 122 & 65 & ND & 29.06 & 6.970 & 1.00 \\
\hline C6A-5 & 72.00 & 10.00 & 120 & 65 & ND & 29.91 & 6.970 & 1.00 \\
\hline C6A-6 & 87.00 & 10.00 & 120 & 65 & ND & 30.57 & 6.970 & 1.00 \\
\hline C6B1-1 & 12.00 & 10.00 & 60 & 65 & 1.0 & 12.73 & 6.970 & 0.97 \\
\hline C6B1-2 & 27.10 & 10.20 & 52 & 65 & 1.0 & 13.77 & 6.970 & 0.97 \\
\hline C6B1-3 & 42.00 & 10.00 & 54 & 65 & 1.0 & 11.83 & 6.970 & 0.97 \\
\hline C6B1-4 & 57.00 & 10.00 & 52 & 65 & 1.0 & 12.41 & 6.970 & 0.97 \\
\hline C6B1-5 & 72.00 & 10.00 & 54 & 65 & 1.0 & 13.43 & 6.970 & 0.97 \\
\hline C6B1-6 & 87.00 & 10.00 & 55 & 65 & 1.0 & 12.77 & 6.970 & 0.97 \\
\hline C6B2-1 & 12.00 & 10.00 & 62 & 65 & 1.0 & 19.27 & 6.970 & 0.97 \\
\hline C6B2-2 & 27.10 & 10.20 & 62 & 65 & 1.0 & 21.22 & 6.970 & 0.97 \\
\hline C6B2-3 & 42.00 & 10.00 & 62 & 65 & 1.0 & 18.43 & 6.970 & 0.97 \\
\hline C6B2-4 & 57.00 & 10.00 & 62 & 65 & 1.0 & 17.67 & 6.970 & 0.97 \\
\hline C6B2-5 & 72.00 & 10.00 & 60 & 65 & 1.0 & 17.79 & 6.970 & 0.97 \\
\hline C6B2-6 & 87.00 & 10.00 & 60 & 65 & 1.0 & 17.00 & 6.970 & 0.97 \\
\hline C5A1-1 & 12.00 & 4.00 & 35 & 58 & 1.2 & 0.71 & 9.140 & 0.96 \\
\hline C5A1-2 & 27.00 & 4.00 & 39 & 58 & 0.8 & 1.40 & 9.140 & 0.97 \\
\hline C5A1-3 & 42.00 & 4.00 & 40 & 58 & 0.8 & 2.65 & 9.140 & 0.97 \\
\hline C5A1-4 & 57.00 & 4.00 & 38 & 58 & 0.8 & 1.89 & 9.140 & 0.97 \\
\hline C5A1-5 & 72.00 & 4.00 & 38 & 58 & 1.0 & 2.14 & 9.140 & 0.97 \\
\hline C5A1-6 & 87.00 & 4.00 & 37 & 58 & 1.0 & 2.00 & 9.140 & 0.97 \\
\hline C5A2-1 & 12.00 & 4.00 & 55 & 58 & 1.2 & 6.01 & 9.140 & 0.96 \\
\hline C5A2-2 & 27.00 & 4.00 & 55 & 58 & 0.8 & 6.25 & 9.140 & 0.97 \\
\hline C5A2-3 & 42.00 & 4.00 & 55 & 58 & 0.8 & 6.90 & 9.140 & 0.97 \\
\hline C5A2-4 & 57.00 & 4.00 & 55 & 58 & 0.8 & 7.12 & 9.140 & 0.97 \\
\hline C5A2-5 & 72.00 & 4.00 & 60 & 58 & 1.0 & 7.90 & 9.140 & 0.97 \\
\hline C5A2-6 & 87.00 & 4.00 & 59 & 58 & 1.0 & 6.67 & 9.140 & 0.97 \\
\hline C5A3-1 & 12.00 & 4.00 & 35 & 58 & 1.6 & 1.33 & 9.140 & 0.95 \\
\hline C5A3-2 & 27.00 & 4.00 & 37 & 58 & ND & 1.85 & 9.140 & 1.00 \\
\hline C5A3-3 & 46.00 & 4.00 & 40 & 58 & ND & $?$ & 9.140 & 1.00 \\
\hline C5A3-4 & 69.00 & 4.10 & 30 & 58 & ND & 1.67 & 9.140 & 1.00 \\
\hline C5A3-5 & 89.00 & 4.00 & 30 & 58 & ND & 1.78 & 9.140 & 1.00 \\
\hline C5A4-1 & 12.00 & 4.00 & 50 & 58 & ND & 6.43 & 9.140 & 1.00 \\
\hline C5A4-2 & 27.00 & 4.00 & 51 & 58 & ND & 7.72 & 9.140 & 1.00 \\
\hline C5A4-3 & 46.00 & 4.00 & 52 & 58 & ND & 8.05 & 9.140 & 1.00 \\
\hline C5A4-4 & 69.00 & 4.10 & 55 & 58 & ND & 8.61 & 9.140 & 1.00 \\
\hline $\begin{array}{l}\text { C5A4-5 } \\
\text { C5A4-6 }\end{array}$ & 89.00 & 4.00 & 50 & 58 & ND & 9.18 & 9.140 & 1.00 \\
\hline
\end{tabular}




\begin{tabular}{|c|c|c|c|c|c|c|c|c|}
\hline \multirow{3}{*}{$\begin{array}{c}\text { Project: } \\
\text { ICEDF }\end{array}$} & \multirow{3}{*}{$\frac{\text { Test: }}{14-8}$} & & & & & & \multicolumn{2}{|c|}{ Q.A. Verification: } \\
\hline & & & & & & & Name & Date \\
\hline & & & & & & & & \\
\hline $\begin{array}{l}\text { Sample } \\
\text { ID No. }\end{array}$ & $\begin{array}{l}\text { Test Clock } \\
\text { (min) }\end{array}$ & $\begin{array}{l}\text { Sample } \\
\text { Duration } \\
\Delta t \text { (min) }\end{array}$ & $\begin{array}{c}\text { To } \\
\left({ }^{\circ} \mathrm{C}\right)\end{array}$ & $\begin{array}{c}\text { Critical } \\
\text { Orifice } \\
(\#)\end{array}$ & $\begin{array}{c}c O \\
\Delta P \\
(" \mathrm{Hg})\end{array}$ & $\begin{array}{c}\text { Condensate } \\
\mathrm{H} 2 \mathrm{O} \text { Mass } \\
\text { (g) }\end{array}$ & $\begin{array}{c}\text { Crit. Orifice } \\
\text { Flow Rate } \\
@ 20^{\circ} \mathrm{C} \\
\text { (lpm) } \\
\end{array}$ & $\begin{array}{c}\text { Crit. Orifice } \\
\text { Flow Corr. } \\
\text { Factor } \\
(-1)\end{array}$ \\
\hline C4B-1 & 12.12 & 10.25 & 39 & 65 & ND & 4.04 & 6.970 & 1.00 \\
\hline C4B-2 & 56.00 & 12.00 & 42 & 65 & ND & 6.79 & 6.970 & 1.00 \\
\hline C4B-3 & 73.00 & 10.00 & 48 & 65 & ND & 7.08 & 6.970 & 1.00 \\
\hline $\begin{array}{l}\text { C4B-4 } \\
\text { C4B-5 }\end{array}$ & 87.00 & 10.00 & 48 & 65 & ND & 7.58 & 6.970 & 1.00 \\
\hline C4B-6 & & & & & & & & \\
\hline C2B-1 & 12.00 & 10.00 & 16 & 65 & ND & 2.15 & 6.970 & 1.00 \\
\hline C2B-2 & 56.00 & 12.00 & 38 & 65 & ND & 2.92 & 6.970 & 1.00 \\
\hline C2B-3 & 73.00 & 10.00 & 44 & 65 & ND & 6.30 & 6.970 & 1.00 \\
\hline C2B-4 & 87.00 & 10.00 & 48 & 65 & $\mathrm{ND}$ & 6.67 & 6.970 & 1.00 \\
\hline $\begin{array}{l}\text { C2B-5 } \\
\text { C2B-6 }\end{array}$ & & & & & & & & \\
\hline C1A1-1 & 12.00 & 400 & 10 & 58 & 1.8 & 0.11 & 9140 & 0.94 \\
\hline C1A1-2 & 27.00 & 4.00 & 13 & 58 & 1.6 & 0.58 & 9.140 & $\begin{array}{l}0.94 \\
0.95\end{array}$ \\
\hline C1A1-3 & 42.00 & 4.00 & 30 & 58 & 1.6 & 1.64 & 9.140 & 0.95 \\
\hline C1A1-4 & 57.00 & 4.00 & 35 & 58 & 1.6 & 1.92 & 9.140 & 0.95 \\
\hline C1A1-5 & 72.00 & 4.00 & 40 & 58 & 1.6 & 2.83 & 9.140 & 0.95 \\
\hline C1A1-6 & 87.00 & 4.00 & 50 & 58 & 1.8 & 3.45 & 9.140 & 0.94 \\
\hline C1A2-1 & 12.00 & 4.00 & 30 & 58 & 1.6 & 1.29 & 9.140 & 0.95 \\
\hline C1A2-2 & 27.00 & 4.00 & 35 & 58 & 1.4 & 2.93 & 9.140 & 0.95 \\
\hline C1A2-3 & 42.00 & 4.00 & 35 & 58 & 1.6 & 3.34 & 9.140 & 0.95 \\
\hline C1A2-4 & 57.00 & 4.00 & 40 & 58 & 1.4 & 3.77 & 9.140 & 0.95 \\
\hline C1A2-5 & 72.00 & 4.00 & 45 & 58 & 1.5 & 4.17 & 9.140 & 0.95 \\
\hline C1A2-6 & 87.00 & 4.00 & 50 & 58 & 1.5 & 4.99 & 9.140 & 0.95 \\
\hline C1A3-1 & 12.00 & 4.00 & 6 & 58 & 2.0 & 0.23 & 9.140 & 0.93 \\
\hline C1A3-2 & 27.00 & 4.00 & 9 & 58 & 1.8 & 0.67 & 9.140 & 0.94 \\
\hline C1A3-3 & 42.00 & 4.00 & 14 & 58 & 1.8 & 0.65 & 9.140 & 0.94 \\
\hline C1A3-4 & 57.00 & 4.00 & 23 & 58 & 1.8 & 2.52 & 9.140 & 0.94 \\
\hline C1A3-5 & 72.00 & 4.00 & 31 & 58 & 1.5 & 3.73 & 9.140 & 0.95 \\
\hline C1A3-6 & 87.00 & 4.00 & 42 & 58 & 1.5 & 4.33 & 9.140 & 0.95 \\
\hline C1A4-1 & 12.00 & 4.00 & 27 & 58 & 2.0 & 0.40 & 9.140 & 0.93 \\
\hline C1A4-2 & 27.00 & 4.00 & 28 & 58 & 2.0 & 1.13 & 9.140 & 0.93 \\
\hline C1A4-3 & 42.00 & 4.00 & 44 & 58 & 1.9 & 0.44 & 9.140 & 0.94 \\
\hline C1A4-4 & 57.00 & 4.00 & 46 & 58 & 2.0 & 2.14 & 9.140 & 0.93 \\
\hline C1A4-5 & 72.00 & 4.00 & 52 & 58 & 2.5 & 2.78 & 9.140 & 0.92 \\
\hline C1A4-6 & 87.00 & 4.00 & 55 & 58 & 2.5 & 3.47 & 9.140 & 0.92 \\
\hline $\mathrm{CO}-1$ & 12.00 & 10.00 & 28 & 65 & 0.9 & 2.85 & 6.970 & 0.97 \\
\hline $\mathrm{CO}-2$ & 27.00 & 10.00 & 40 & 65 & 0.9 & 6.15 & 6.970 & 0.97 \\
\hline $\mathrm{CO}-3$ & 42.00 & 10.00 & 41 & 65 & 0.9 & 7.57 & 6.970 & 0.97 \\
\hline $\mathrm{CO}-4$ & 57.00 & 10.00 & 44 & 65 & 0.9 & 8.11 & 6.970 & 0.97 \\
\hline $\mathrm{C} 0.5$ & 72.00 & 10.00 & 50 & 65 & 0.9 & 11.07 & 6.970 & 0.97 \\
\hline $\mathrm{C} 0-6$ & 87.00 & 10.00 & 53 & 65 & 0.8 & 12.96 & 6.970 & 0.97 \\
\hline
\end{tabular}

ICEDF Gas Composition Analysis (page 2) 


\begin{tabular}{|c|c|c|c|c|c|c|c|c|}
\hline $\begin{array}{l}\text { Project: } \\
\text { ICEDF }\end{array}$ & $\begin{array}{l}\text { Test: } \\
14-8 \\
\end{array}$ & & & & & & & \\
\hline $\begin{array}{l}\text { Sample } \\
\text { ID No. }\end{array}$ & $\begin{array}{c}\text { Dry Gas } \\
\text { Volume } \\
\left(1 @ 20^{\circ} \mathrm{C}\right)\end{array}$ & $\begin{array}{c}\text { Sat. Vapor } \\
\left(T<100^{\circ} \mathrm{C}\right) \\
(\text { Psat/Po) }\end{array}$ & $\begin{array}{c}\mathrm{H} 2 \mathrm{O} \text { Vapor } \\
\text { Spec. Vol. } \\
\left(\mathrm{T}<100^{\circ} \mathrm{C}\right) \\
(\mathrm{m} 3 / \mathrm{kg})\end{array}$ & $\begin{array}{c}\text { H2O Vapor } \\
\text { Spec. Vol. } \\
\left(T \geq 100^{\circ} \mathrm{C}\right) \\
(\mathrm{m} 3 / \mathrm{kg})\end{array}$ & $\begin{array}{l}\text { Dry Gas } \\
\text { Volume } \\
\text { (1@ To) }\end{array}$ & $\begin{array}{l}\text { H2O Gas } \\
\text { Volume } \\
\text { (1@ To) }\end{array}$ & $\begin{array}{c}\text { SMF } \\
(-)\end{array}$ & $\begin{array}{c}\text { Fog } \\
@ \text { To } \\
\left(\mathrm{mg} / \mathrm{m}^{\wedge} 3\right)\end{array}$ \\
\hline C6A-1 & 69700 & $T>100^{\circ} \mathrm{C}$ & $T>100^{\circ} \mathrm{C}$ & 1011 & 0444 & 1108 & 0303 & $\mathrm{C} \mathrm{H}$ Van \\
\hline C6A-2 & 69.700 & $\mathrm{~T} \geq 100^{\circ} \mathrm{C}$ & $T \geq 100^{\circ} \mathrm{C}$ & $\begin{array}{l}1.811 \\
1.816\end{array}$ & $\begin{array}{l}94.44 \\
94.68\end{array}$ & $\begin{array}{l}41.00 \\
53.17\end{array}$ & $\begin{array}{l}0.303 \\
0.360\end{array}$ & S. H. Vap. \\
\hline C6A-3 & 69.700 & $T \geq 100^{\circ} \mathrm{C}$ & $\mathrm{T} \geq 100^{\circ} \mathrm{C}$ & 1.802 & 93.96 & 55.52 & 0.371 & S. H. Vap. \\
\hline C6A-4 & 69.700 & $\mathrm{~T} \geq 100^{\circ} \mathrm{C}$ & $\mathrm{T} \geq 100^{\circ} \mathrm{C}$ & 1.802 & 93.96 & 52.36 & 0.358 & S. H. Vap. \\
\hline C6A-5 & 69.700 & $T \geq 100^{\circ} \mathrm{C}$ & $T \geq 100^{\circ} \mathrm{C}$ & 1.792 & 93.49 & 53.61 & 0.364 & S. H. Vap. \\
\hline C6A-6 & 69.700 & $\mathrm{~T} \geq 100^{\circ} \mathrm{C}$ & $T \geq 100^{\circ} \mathrm{C}$ & 1.792 & 93.49 & 54.79 & 0.370 & S. H. Vap. \\
\hline C6B1-1 & 67.377 & 0.1969 & 7.537 & $\mathrm{~T}<100^{\circ} \mathrm{C}$ & 76.57 & 18.78 & 0.197 & 0.82 \\
\hline C6B1-2 & 68.724 & 0.1349 & 11.110 & $T<100^{\circ} \mathrm{C}$ & 76.23 & 11.89 & 0.135 & 66.27 \\
\hline C6B1-3 & 67.377 & 0.1486 & 10.083 & $\mathrm{~T}<100^{\circ} \mathrm{C}$ & 75.20 & 13.12 & 0.149 & 34.78 \\
\hline C6B1-4 & 67.377 & 0.1349 & 11.110 & $\mathrm{~T}<100^{\circ} \mathrm{C}$ & 74.74 & 11.65 & 0.135 & 53.65 \\
\hline C6B1-5 & 67.377 & 0.1486 & 10.083 & $\mathrm{~T}<100^{\circ} \mathrm{C}$ & 75.20 & 13.12 & 0.149 & 52.89 \\
\hline C6B1-6 & 67.377 & 0.1558 & 9.606 & $\mathrm{~T}<100^{\circ} \mathrm{C}$ & 75.43 & 13.92 & 0.156 & $38: 82$ \\
\hline C6B2-1 & 67.377 & 0.2158 & 6.840 & $T<100^{\circ} \mathrm{C}$ & 77.03 & 21.20 & 0.216 & 49.97 \\
\hline C6B2-2 & 68.724 & 0.2158 & 6.840 & $\mathrm{~T}<100^{\circ} \mathrm{C}$ & 78.58 & 21.62 & 0.216 & 65.58 \\
\hline C6B2-3 & 67.377 & 0.2158 & 6.840 & $T<100^{\circ} \mathrm{C}$ & 77.03 & 21.20 & 0.216 & 41.42 \\
\hline C6B2-4 & 67.377 & 0.2158 & 6.840 & $T<100^{\circ} \mathrm{C}$ & 77.03 & 21.20 & 0.216 & 33.68 \\
\hline C6B2-5 & 67.377 & 0.1969 & 7.537 & $T<100^{\circ} \mathrm{C}$ & 76.57 & 18.78 & 0.197 & 53.89 \\
\hline C6B2-6 & 67.377 & 0.1969 & 7.537 & $T<100^{\circ} \mathrm{C}$ & 76.57 & 18.78 & 0.197 & 45.60 \\
\hline C5A1-1 & 35.098 & 0.0557 & 25.344 & $T<100^{\circ} \mathrm{C}$ & 36.89 & 1.00 & 0.026 & Not Sat. \\
\hline C5A1-2 & 35.585 & 0.0694 & 20.874 & $T<100^{\circ} \mathrm{C}$ & 37.89 & 2.03 & 0.051 & Not Sat. \\
\hline C5A1-3 & 35.585 & 0.0733 & 19.886 & $T<100^{\circ} \mathrm{C}$ & 38.01 & 3.00 & 0.073 & 14.32 \\
\hline C5A1.4 & 35.585 & 0.0658 & 21.912 & $T<100^{\circ} \mathrm{C}$ & 37.77 & 2.66 & 0.066 & 1.11 \\
\hline C5A1-5 & 35.341 & 0.0658 & 21.912 & $T<100^{\circ} \mathrm{C}$ & 37.51 & 2.64 & 0.066 & 7.66 \\
\hline C5A1-6 & 35.341 & 0.0623 & 23.001 & $\mathrm{~T}<100^{\circ} \mathrm{C}$ & 37.39 & 2.48 & 0.062 & 6.68 \\
\hline C5A2-1 & 35.098 & 0.1558 & 9.606 & $\mathrm{~T}<100^{\circ} \mathrm{C}$ & 39.29 & 7.25 & 0.156 & 25.02 \\
\hline C5A2-2 & 35.585 & 0.1558 & 9.606 & $T<100^{\circ} \mathrm{C}$ & 39.84 & 7.35 & 0.156 & 28.34 \\
\hline C5A2-3 & 35.585 & 0.1558 & 9.606 & $T<100^{\circ} \mathrm{C}$ & 39.84 & 7.35 & 0.156 & 42.11 \\
\hline C5A2-4 & 35.585 & 0.1558 & 9.606 & $T<100^{\circ} \mathrm{C}$ & 39.84 & 7.35 & 0.156 & 46.78 \\
\hline C5A2-5 & 35.341 & 0.1969 & 7.537 & $T<100^{\circ} \mathrm{C}$ & 40.17 & 9.85 & 0.197 & 25.27 \\
\hline C5A2-6 & 35.341 & 0.1880 & 7.911 & $\mathrm{~T}<100^{\circ} \mathrm{C}$ & 40.05 & 9.27 & 0.188 & 8.84 \\
\hline C5A3-1 & 34.610 & 0.0557 & 25.344 & $T<100^{\circ} \mathrm{C}$ & 36.38 & 1.88 & 0.049 & Not Sat. \\
\hline C5A3-2 & 36.560 & 0.0623 & 23.001 & $\mathrm{~T}<100^{\circ} \mathrm{C}$ & 38.68 & 2.57 & 0.062 & 1.37 \\
\hline $\begin{array}{l}\text { C5A3-3 } \\
\text { C5A3-4 }\end{array}$ & $\begin{array}{l}36.560 \\
37.474\end{array}$ & $\begin{array}{l}0.0733 \\
0.0418\end{array}$ & $\begin{array}{l}19.886 \\
32.301\end{array}$ & $\begin{array}{l}T<100^{\circ} \mathrm{C} \\
T<100^{\circ} \mathrm{C}\end{array}$ & $\begin{array}{l}39.06 \\
38.75\end{array}$ & $\begin{array}{l}3.09 \\
1.69\end{array}$ & $\begin{array}{l}0.073 \\
0.042\end{array}$ & $\begin{array}{l}\text { ¿Sat? } \\
10.34\end{array}$ \\
\hline $\begin{array}{l}\text { C5A3-5 } \\
\text { C5A3-6 }\end{array}$ & 36.560 & 0.0418 & 32.301 & $T<100^{\circ} \mathrm{C}$ & 37.81 & 1.65 & 0.042 & 14.16 \\
\hline C5A4-1 & 36.560 & 0.1223 & 12.242 & $\mathrm{~T}<100^{\circ} \mathrm{C}$ & 40.30 & 5.62 & 0.122 & 58.34 \\
\hline C5A4-2 & 36.560 & 0.1285 & 11.663 & $\mathrm{~T}<100^{\circ} \mathrm{C}$ & 40.43 & 5.96 & 0.128 & 80.68 \\
\hline C5A4-3 & 36.560 & 0.1349 & 11.110 & $T<100^{\circ} \mathrm{C}$ & 40.55 & 6.32 & 0.135 & 81.72 \\
\hline C5A4-4 & 37.474 & 0.1558 & 9.606 & $\mathrm{~T}<100^{\circ} \mathrm{C}$ & 41.95 & 7.74 & 0.156 & 69.16 \\
\hline $\begin{array}{l}\text { C5A4-5 } \\
\text { C5A4-6 }\end{array}$ & 36.560 & 0.1223 & 12.242 & $\mathrm{~T}<100^{\circ} \mathrm{C}$ & 40.30 & 5.62 & 0.122 & 118.23 \\
\hline
\end{tabular}

ICEDF Gas Composition Analysis (page 3) 


\begin{tabular}{|c|c|c|c|c|c|c|c|c|}
\hline $\begin{array}{c}\text { Project: } \\
\text { ICEDF }\end{array}$ & & $\begin{array}{c}\text { Test: } \\
14-8\end{array}$ & & & & & & \\
\hline $\begin{array}{l}\text { Sample } \\
\text { ID No. }\end{array}$ & $\begin{array}{c}\text { Dry Gas } \\
\text { Volume } \\
\left(1 @ 20^{\circ} \mathrm{C}\right)\end{array}$ & $\begin{array}{c}\text { Sat. Vapor } \\
\left(\mathrm{T}<100^{\circ} \mathrm{C}\right) \\
\text { (Psat/Po) }\end{array}$ & $\begin{array}{c}\text { H2O Vapor } \\
\text { Spec. Vol. } \\
\left(\mathrm{T}<100^{\circ} \mathrm{C}\right) \\
(\mathrm{m} 3 / \mathrm{kg})\end{array}$ & $\begin{array}{c}\text { H2O Vapor } \\
\text { Spec. Vol. } \\
\left(\mathrm{T} \geq 100^{\circ} \mathrm{C}\right) \\
(\mathrm{m} 3 / \mathrm{kg}) \\
\end{array}$ & $\begin{array}{l}\text { Dry Gas } \\
\text { Volume } \\
\text { (1@ To) }\end{array}$ & $\begin{array}{l}\text { H2O Gas } \\
\text { Volume } \\
(1 @ \text { To })\end{array}$ & $\begin{array}{c}\text { SMF } \\
(-)\end{array}$ & $\begin{array}{c}\text { Fog } \\
@ \text { To } \\
\left(\mathrm{mg} / \mathrm{m}^{\wedge} 3\right)\end{array}$ \\
\hline $\begin{array}{r}\text { C4B-1 } \\
\text { C4B-2 } \\
\text { C4B-3 } \\
\text { C4B-4 } \\
\text { C4B-5 } \\
\text { C4B-6 } \\
\text { C2B-1 } \\
\text { C2B-2 } \\
\text { C2B-3 } \\
\text { C2B-4 } \\
\text { C2B-5 } \\
\text { C2B-6 } \\
\text { C1A1-1 } \\
\text { C1A1-2 } \\
\text { C1A1-3 } \\
\text { C1A1-4 } \\
\text { C1A1-5 } \\
\text { C1A1-6 } \\
\text { C1A2-1 } \\
\text { C1A2-2 } \\
\text { C1A2-3 } \\
\text { C1A2-4 } \\
\text { C1A2-5 } \\
\text { C1A2-6 } \\
\text { C1A3-1 } \\
\text { C1A3-2 } \\
\text { C1A3-3 } \\
\text { C1A3-4 } \\
\text { C0-4-5 } \\
\text { C1A3-5 } \\
\text { C1A3-6 } \\
\text { C1A4-1 } \\
\text { C1A4-2 } \\
\text { C1A4-3 } \\
\text { C1A4-4 } \\
\text { C1A4-5 } \\
\text { C1A4-6 } \\
\text { C0-1 }\end{array}$ & $\begin{array}{l}34.366 \\
34.610 \\
34.610 \\
34.610 \\
34.610 \\
34.366 \\
34.610 \\
34.854 \\
34.610 \\
34.854 \\
34.732 \\
34.732 \\
34.123 \\
34.366 \\
34.366 \\
34.366 \\
34.732 \\
34.732 \\
34.123 \\
34.123 \\
34.245 \\
34.123 \\
33.513 \\
33.513 \\
67.609 \\
67.609 \\
67.609 \\
67.609 \\
67.609 \\
67.841\end{array}$ & $\begin{array}{l}0.0121 \\
0.0143 \\
0.0418 \\
0.0557 \\
0.0733 \\
0.1223 \\
0.0418 \\
0.0557 \\
0.0557 \\
0.0733 \\
0.0951 \\
0.1223 \\
0.0104 \\
0.0116 \\
0.0152 \\
0.0271 \\
0.0443 \\
0.0814 \\
0.0349 \\
0.0370 \\
0.0904 \\
0.1001 \\
0.1349 \\
0.1558 \\
0.0370 \\
0.0733 \\
0.0773 \\
0.0904 \\
0.1223 \\
0.1416\end{array}$ & $\begin{array}{c}107.069 \\
88.819 \\
32.301 \\
25.344 \\
19.886 \\
12.242 \\
32.301 \\
25.344 \\
25.344 \\
19.886 \\
15.603 \\
12.242 \\
137.363 \\
113.950 \\
83.455 \\
47.642 \\
30.772 \\
18.047 \\
37.362 \\
35.592 \\
16.378 \\
14.864 \\
11.110 \\
9.606 \\
35.592 \\
19.886 \\
18.944 \\
16.378 \\
12.242 \\
10.584\end{array}$ & $\begin{array}{l}T<100^{\circ} \mathrm{C} \\
T<100^{\circ} \mathrm{C} \\
T<100^{\circ} \mathrm{C} \\
T<100^{\circ} \mathrm{C} \\
T<100^{\circ} \mathrm{C} \\
T<100^{\circ} \mathrm{C} \\
T<100^{\circ} \mathrm{C} \\
T<100^{\circ} \mathrm{C} \\
T<100^{\circ} \mathrm{C} \\
T<100^{\circ} \mathrm{C} \\
T<100^{\circ} \mathrm{C} \\
T<100^{\circ} \mathrm{C} \\
T<100^{\circ} \mathrm{C} \\
T<100^{\circ} \mathrm{C} \\
T<100^{\circ} \mathrm{C} \\
T<100^{\circ} \mathrm{C} \\
T<100^{\circ} \mathrm{C} \\
T<100^{\circ} \mathrm{C} \\
T<100^{\circ} \mathrm{C} \\
T<100^{\circ} \mathrm{C} \\
T<100^{\circ} \mathrm{C} \\
T<100^{\circ} \mathrm{C} \\
T<100^{\circ} \mathrm{C} \\
T<100^{\circ} \mathrm{C} \\
T<100^{\circ} \mathrm{C} \\
T<100^{\circ} \mathrm{C} \\
T<100^{\circ} \mathrm{C} \\
T<100^{\circ} \mathrm{C} \\
T<100^{\circ} \mathrm{C} \\
T<100^{\circ} \mathrm{C}\end{array}$ & $\begin{array}{l} \\
33.19 \\
33.78 \\
35.79 \\
36.38 \\
36.97 \\
37.89 \\
35.79 \\
36.64 \\
36.38 \\
37.23 \\
37.70 \\
38.29 \\
32.49 \\
33.08 \\
33.66 \\
34.72 \\
36.04 \\
37.34 \\
34.94 \\
35.05 \\
37.05 \\
37.15 \\
37.17 \\
37.52 \\
69.45 \\
72.22 \\
72.45 \\
73.15 \\
74.53 \\
75.48\end{array}$ & $\begin{array}{l}0.14 \\
0.49 \\
1.56 \\
2.15 \\
2.92 \\
5.17 \\
1.56 \\
2.16 \\
2.15 \\
2.94 \\
3.96 \\
5.34 \\
0.33 \\
0.39 \\
0.52 \\
0.97 \\
1.67 \\
3.31 \\
0.52 \\
1.35 \\
0.65 \\
3.18 \\
4.17 \\
5.19 \\
2.67 \\
5.71 \\
6.07 \\
7.27 \\
10.39 \\
12.45\end{array}$ & $\begin{array}{l} \\
0.004 \\
0.014 \\
0.042 \\
0.056 \\
0.073 \\
0.120 \\
0.042 \\
0.056 \\
0.056 \\
0.073 \\
0.095 \\
0.122 \\
0.010 \\
0.012 \\
0.015 \\
0.027 \\
0.044 \\
0.081 \\
0.015 \\
0.037 \\
0.017 \\
0.079 \\
0.101 \\
0.122 \\
0.037 \\
0.073 \\
0.077 \\
0.090 \\
0.122 \\
0.142\end{array}$ & $\begin{array}{c} \\
17.16 \\
\text { Not Sat. } \\
14.94 \\
3.54 \\
\\
\\
\text { Not Sat. } \\
5.66 \\
12.95 \\
10.38 \\
20.65 \\
\text { Not Sat. } \\
3.58 \\
36.06 \\
47.23 \\
43.55 \\
36.01 \\
32.70 \\
\text { Not Sat. } \\
11.25 \\
7.03 \\
49.62 \\
66.43 \\
51.11 \\
\text { Not Sat. } \\
2.95 \\
\text { Not Sat. } \\
\text { Not Sat. } \\
\text { Not Sat. } \\
\text { Not Sat. } \\
11.42 \\
28.63 \\
43.62 \\
39.80 \\
48.68 \\
52.91\end{array}$ \\
\hline
\end{tabular}

ICEDF Gas Composition Analysis (page 4) 


Project:
\begin{tabular}{|l|l|}
\hline ICEDF & Test: \\
\hline
\end{tabular}

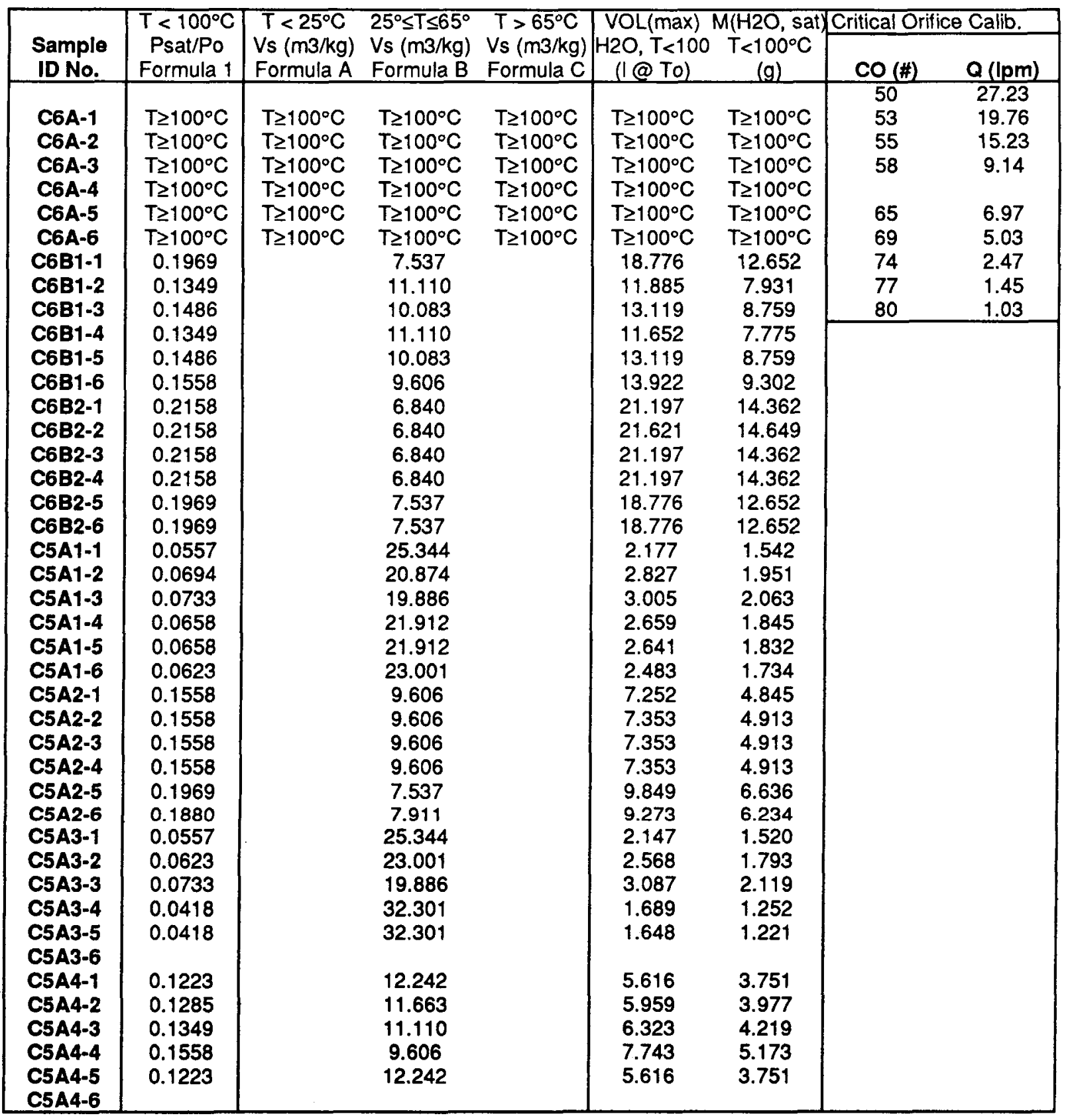

ICEDF Gas Composition Analysis (page 5) 
\begin{tabular}{l|l} 
Project: & Test: \\
\hline ICEDF & $14-8$
\end{tabular}

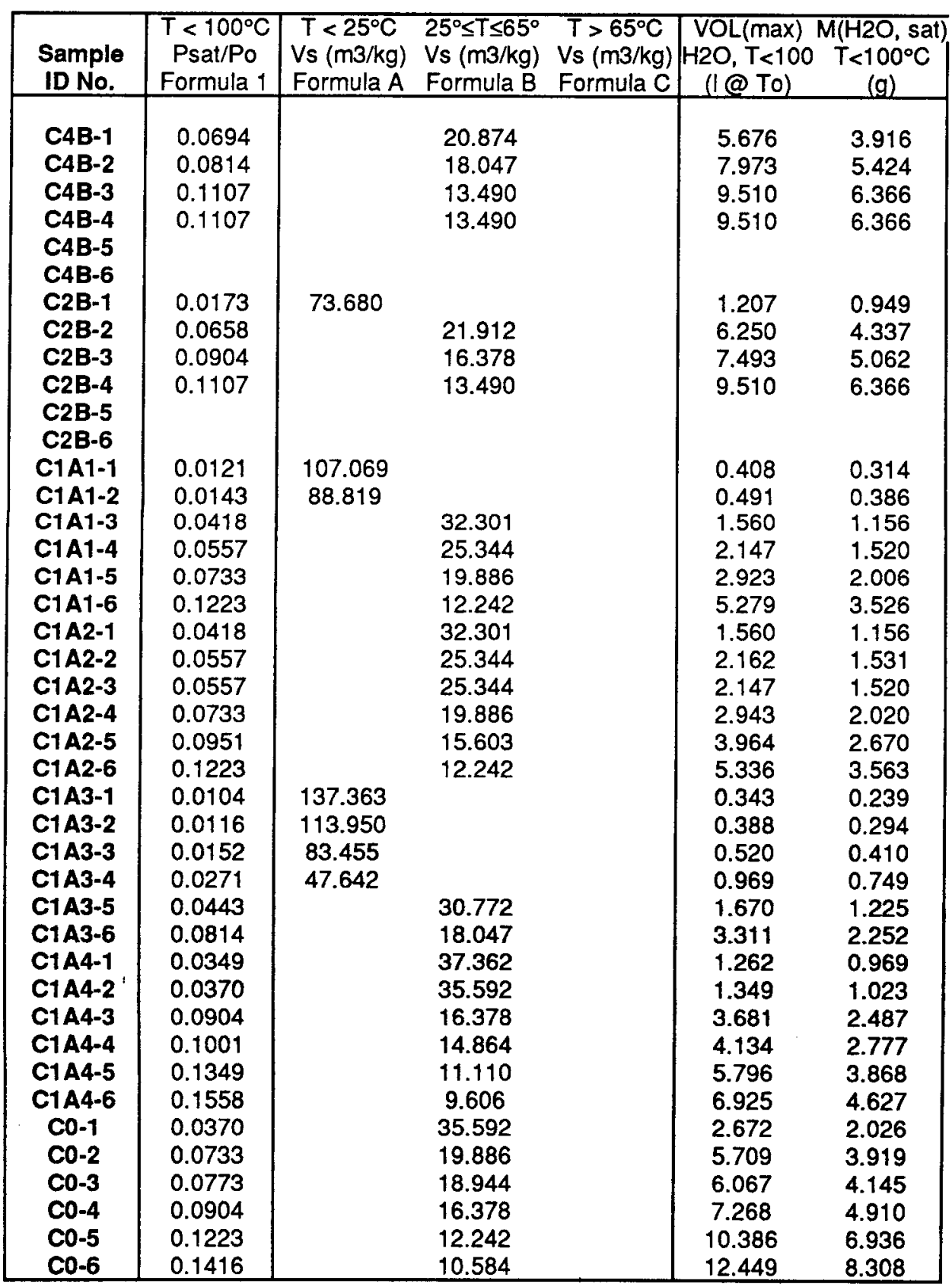

ICEDF Gas Composition Analysis (page 6)

C. 26 
ICEDF SMF WkSht 6/88 supersedes ICEDF SMF WkSht 9/87

\section{How to use "ICEDF SMF WkSht 6/88"}

1) Open "ICEDF SMF WKSht 6/88".

2) Enter test name at cell C2.

3) Save As "ICEDF testname month/year".

4) Enter data: Test Clock(enter)Sample Duration(enter)...

\section{How this spreadsheet works}

CO flow rate determined by Lookup function: Column $H$, Cells AB \& AC. Pressure correction added 5/23/89.

Dry gas volume $=\mathrm{CO}$ flow rate ${ }^{\bullet}$ sample duration ${ }^{\bullet}$ pressure correction

Actual dry gas volume $=$ VOL $($ dry, actual $)=$ sample duration * CO flow rate * $(273+$ To $) / 293$.

$\mathrm{H} 2 \mathrm{O}$ specific volume $=1.227+0.004712(\mathrm{To})$ for $\mathrm{To} \geq 100^{\circ} \mathrm{C}$.

H2O saturated steam partial pressure (Psat/Po = Formula1) for $\mathrm{T}<100^{\circ} \mathrm{C}$.

Formula1 $=0.0107-3.451^{\star} 10^{\wedge}-4^{\star} \mathrm{F} 10+5.359^{\star} 10^{\wedge}-5^{\star} \mathrm{F} 10^{\wedge} 2-5.694^{\star} 10^{\wedge}-7^{\star} \mathrm{F} 10^{\wedge} 3+1.057^{\star} 10^{\wedge}-8^{\star} \mathrm{F} 10^{\wedge} 4$

Actual $\mathrm{H} 2 \mathrm{O}$ gas volume:

$\mathrm{T}<100^{\circ} \mathrm{C}: \quad \operatorname{VOL}(\max )=[(\mathrm{Psat} / \mathrm{Po}) *(\mathrm{VOL}($ dry, actual $))] /[1-($ Psat/Po $)]$. See BNW 51060, pg 133. $\operatorname{VOL}(\max )=\operatorname{VOL}(\mathrm{H} 2 \mathrm{O}$, saturated, maximum possible at $\mathrm{T})$

Fog Check: compare $\mathrm{H} 2 \mathrm{O}$ mass collected to $\mathrm{H} 2 \mathrm{O}$ mass required for sample saturation $\mathrm{M}(\mathrm{H} 2 \mathrm{O}$, sat $)=[[\mathrm{VOL}($ dry, actual $)+\mathrm{VOL}(\mathrm{H} 2 \mathrm{O}, \max )] / \mathrm{Vs}(\mathrm{H} 2 \mathrm{O}$ vapor, sat $)](1000 / 1000)$

$\mathrm{Vs}(\mathrm{H} 2 \mathrm{O}$ vapor, sat $)=$ FormulaA if $\mathrm{T}<25^{\circ} \mathrm{C},=$ FormulaC if $\mathrm{T}>65^{\circ} \mathrm{C}$.

FormulaA $=199.61 * 10^{\wedge}(-2.7052 e-2(T))$.

FormulaB $=138.44^{\bullet} 10^{\wedge}(-2.1068 \mathrm{e}-2(\mathrm{~T}))$.

FormulaC $=68.411 \cdot 10^{\wedge}(-1.6225 \mathrm{e}-2(\mathrm{~T}))$.

1) If condensate mass < $\mathrm{M}(\mathrm{H} 2 \mathrm{O}$, sat):

$\operatorname{VOL}(\mathrm{H} 2 \mathrm{O}$, actual $)=(\mathrm{RH}) *(\mathrm{VOL}(\max ))$. Print "Not Sat."

2) If condensate mass $=M(H 2 O$, sat $)$ :

$\mathrm{RH}=$ condensate mass $/ \mathrm{M}(\mathrm{H} 2 \mathrm{O}$, sat $)$

3) If condenate mass $>\mathrm{M}(\mathrm{H} 2 \mathrm{O}$, sat):

$\operatorname{VOL}(\mathrm{H} 2 \mathrm{O}$, actual $)=\operatorname{VOL}(\max )$. Calculate and print fog mass conc.

Fog Conc $=$ condensate mass $-\mathrm{M}(\mathrm{H} 2 \mathrm{O}$, sat $) /$ sample vol.

(sample vol $=\left(1000 \mathrm{~m}^{\wedge} 3 / \mathrm{l}\right)^{\star} \sum$ [actual $\mathrm{H} 2 \mathrm{O}$ \& dry vols])

$T \geq 100^{\circ} \mathrm{C}: \quad \operatorname{Vol}(\mathrm{H} 2 \mathrm{O})=(\text { condensate mass " sat steam spec vol })^{*}(1000 / 1000)$. Print "S. H. Vap."

SMF = Actual $\mathrm{H} 20$ gas volume / total gas volume (ie., the sum of actual dry and actual $\mathrm{H} 2 \mathrm{O}$ volumes, = sample vol',

Not included: 1) possible temp variations, 2) possible supersaturation.

CO upstream pressure correction factor added to spreadsheet on $6 / 14 / 89$ (in draft form in 5/89). 
Modifications:

ICEDF SMF WKSht 6/89 superseded ICEDF SMF WkSht 9/87

1) Original date of this version was $6 / 14 / 89$.

2) 1st modification was made $9 / 14 / 89$ :

Crit orifice flow corr. factor formula was changed to print "n if test time was "n.

Sample analysis date cell was added to top of page 1.

ICEDF SMF WkSht 10/89 superseded ICEDF SMF WkSht 6/89

1) Changed printer page set-up, and minor editing.

2) Changed SMF column equation to print "' (blank) if no $\mathrm{H} 2 \mathrm{O}$ mass is entered.

3) Changed Fog column equation to print "' if no SMF is calculated, and $i$ Sat? if SMF is calculated based on assumed saturation when no $\mathrm{H} 2 \mathrm{O}$ mass is entered.

4) Changed Sample ID column 12/1/89 to match new test plan (no C6B1 or C6B2). 


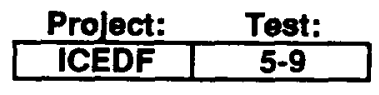

\begin{tabular}{|c|c|c|}
\hline $\begin{array}{c}\text { Date of } \\
\text { Analysis }\end{array}$ & \multicolumn{2}{|c|}{ N.A. Verlfication: } \\
Name & Date \\
\hline $8 / 27 / 90$ & MwL & $8 / 27 / 90$ \\
\hline
\end{tabular}

\begin{tabular}{|c|c|c|c|c|c|c|c|c|}
\hline $\begin{array}{l}\text { Sample } \\
\text { ID No. }\end{array}$ & $\begin{array}{c}\text { Test Clock } \\
\text { (min) }\end{array}$ & $\begin{array}{l}\text { Sample } \\
\text { Duration } \\
\Delta t \text { (min) } \\
\end{array}$ & $\begin{array}{c}\text { To } \\
\left.1^{\circ} \mathrm{C}\right)\end{array}$ & $\begin{array}{c}\text { Critical } \\
\text { Orifice } \\
(\#) \\
\end{array}$ & $\begin{array}{c}C O \\
\Delta P \\
(" H g)\end{array}$ & $\begin{array}{c}\text { Condensate } \\
\mathrm{H} 2 \mathrm{O} \text { Mass } \\
\text { (g) }\end{array}$ & $\begin{array}{c}\text { Crit. Orifice } \\
\text { Flow Rate } \\
@ 20^{\circ} \mathrm{C} \\
\text { (lpm) } \\
\end{array}$ & $\begin{array}{c}\text { Crit. Orifice } \\
\text { Flow Corr. } \\
\text { Factor } \\
(-)\end{array}$ \\
\hline C6A-1 & 8.50 & 5.00 & 106 & 80 & 0.5 & 24.91 & 1.033 & 0.98 \\
\hline C6A-2 & 16.50 & 5.00 & 101 & 80 & 0.6 & 26.04 & 1.033 & 0.98 \\
\hline C6A-3 & 24.50 & 5.00 & 100 & 80 & 0.3 & 27.22 & 1.033 & 0.99 \\
\hline C6A-4 & 32.50 & 5.00 & 104 & 80 & 0.6 & 25.69 & 1.033 & 0.98 \\
\hline $\mathrm{CO}^{-1}$ & 8.50 & 5.00 & 2 & 69 & 0.7 & 0.00 & 5.030 & 0.98 \\
\hline $\mathrm{CO-2}$ & 17.00 & 5.00 & 8 & 69 & 0.8 & 1.15 & 5.030 & 0.97 \\
\hline $\mathrm{CO}-3$ & 24.50 & 5.00 & 15 & 69 & 0.8 & 1.70 & 5.030 & 0.97 \\
\hline $\mathrm{Co-4}$ & 32.50 & 5.00 & 29 & 69 & 0.8 & 1.85 & 5.030 & 0.97 \\
\hline C6B1-1 & 8.50 & 5.00 & 65 & 80 & ND & 1.19 & 1.033 & 1.00 \\
\hline C6B2-1 & 16.50 & 5.00 & 69 & 80 & ND & 5.65 & 1.033 & 1.00 \\
\hline C6B1-2 & 24.50 & 5.00 & 80 & 80 & ND & 14.36 & 1.033 & 1.00 \\
\hline C6B2-2 & 32.50 & 5.00 & 85 & 80 & ND & 15.43 & 1.033 & 1.00 \\
\hline C6B1-3 & 8.50 & 5.00 & 79 & 80 & ND & 9.35 & 1.033 & 1.00 \\
\hline C6B2-3 & 16.50 & 5.00 & 80 & 80 & ND & 13.39 & 1.033 & 1.00 \\
\hline C6B1-4 & 24.50 & 5.00 & 73 & 80 & ND & 20.84 & 1.033 & 1.00 \\
\hline C6B2-4 & 32.50 & 5.00 & 93 & 80 & ND & 17.19 & 1.033 & 1.00 \\
\hline C5A1-2 & 16.50 & 3.00 & 45 & 65 & ND & 0.69 & 6.910 & 1.00 \\
\hline C5A2-2 & 16.50 & 3.00 & 70 & 65 & ND & 6.95 & 6.910 & 1.00 \\
\hline C5A3-2 & 16.50 & 3.00 & 32 & 65 & ND & 0.06 & 6.910 & 1.00 \\
\hline C5A4-2 & 16.50 & 3.00 & 62 & 65 & ND & 9.57 & 6.910 & 1.00 \\
\hline C5A1-3 & 24.60 & 3.00 & 60 & 65 & ND & 2.24 & 6.910 & 1.00 \\
\hline C5A2-3 & 24.60 & 3.00 & 52 & 65 & ND & 5.34 & 6.910 & 1.00 \\
\hline C5A3-3 & 24.60 & 3.00 & 50 & 65 & ND & 1.39 & 6.910 & 1.00 \\
\hline C5A4-3 & 24.60 & 3.00 & 52 & 65 & ND & 6.95 & 6.910 & 1.00 \\
\hline C5A1-4 & 32.50 & 3.00 & 65 & 65 & ND & 3.84 & 6.910 & 1.00 \\
\hline C5A2-4 & 32.50 & 3.00 & 65 & 65 & ND & 5.89 & 6.910 & 1.00 \\
\hline C5A3-4 & 32.50 & 3.00 & 48 & 65 & ND & 3.87 & 6.910 & 1.00 \\
\hline C5A4-4 & 32.50 & 3.00 & 55 & 65 & ND & 12.22 & 6.910 & 1.00 \\
\hline C1A1-2 & 16.50 & 3.00 & 5 & 58 & 12.0 & 0.86 & 9.140 & 0.60 \\
\hline C1A2-2 & 16.50 & 3.00 & 1 & 58 & 12.0 & 0.37 & 9.140 & 0.60 \\
\hline C1A3-2 & 16.50 & 3.00 & 5 & 58 & 10.0 & 0.64 & 9.140 & 0.67 \\
\hline C1A4-2 & 16.50 & 3.00 & 34 & 58 & 10.0 & 0.42 & 9.140 & 0.67 \\
\hline C1A1-3 & 25.00 & 3.33 & 15 & 58 & 12.0 & 1.13 & 9.140 & 0.60 \\
\hline C1A2-3 & 25.00 & 3.33 & 30 & 58 & 12.0 & 1.74 & 9.140 & 0.60 \\
\hline C1A3-3 & 25.00 & 3.33 & 15 & 58 & 10.0 & 1.00 & 9.140 & 0.67 \\
\hline C1A4-3 & 25.00 & 3.33 & 38 & 58 & 10.0 & 1.38 & 9.140 & 0.67 \\
\hline C1A1-4 & 32.60 & 3.00 & 25 & 58 & 12.0 & 0.53 & 9.140 & 0.60 \\
\hline C1A2-4 & 32.60 & 3.00 & 40 & 58 & 12.0 & 1.77 & 9.140 & 0.60 \\
\hline C1A3-4 & 32.60 & 3.00 & 15 & 58 & 10.0 & 2.03 & 9.140 & 0.67 \\
\hline C1A4-4 & 32.60 & 3.00 & 55 & 58 & 10.0 & 0.00 & 9.140 & 0.67 \\
\hline
\end{tabular}




\begin{tabular}{|c|c|c|c|c|c|c|c|c|}
\hline $\begin{array}{l}\text { Project: } \\
\text { ICEDF }\end{array}$ & $\begin{array}{c}\text { Test: } \\
5-9 \\
\end{array}$ & & & & & & & \\
\hline $\begin{array}{l}\text { Sample } \\
\text { ID No. }\end{array}$ & $\begin{array}{c}\text { Dry Gas } \\
\text { Volume } \\
\left(1 @ 20^{\circ} \mathrm{C}\right)\end{array}$ & $\begin{array}{c}\text { Sat. Vapor } \\
\left(\mathrm{T}<100^{\circ} \mathrm{C}\right) \\
(\text { Psat/Po) }\end{array}$ & $\begin{array}{c}\text { H2O Vapor } \\
\text { Spec. Vol. } \\
\left(\mathrm{T}<100^{\circ} \mathrm{C}\right) \\
(\mathrm{m} 3 / \mathrm{kg})\end{array}$ & $\begin{array}{c}\text { H2O Vapor } \\
\text { Spec. Vol. } \\
\left(\mathrm{T} \geq 100^{\circ} \mathrm{C}\right) \\
(\mathrm{m} 3 / \mathrm{kg})\end{array}$ & $\begin{array}{l}\text { Dry Gas } \\
\text { Volume } \\
\text { (1 @ To) }\end{array}$ & $\begin{array}{l}\text { H2O Gas } \\
\text { Volume } \\
(1 @ \text { To }) \\
\end{array}$ & $\begin{array}{c}\text { SMF } \\
(-)\end{array}$ & $\begin{array}{c}\text { Fog } \\
\text { @ To } \\
\left(\mathrm{mg} / \mathrm{m}^{\wedge} 3\right)\end{array}$ \\
\hline & & & & & & & & \\
\hline $\begin{array}{l}\text { C6A-1 } \\
\text { C6A-2 }\end{array}$ & $\begin{array}{l}5.079 \\
5.062\end{array}$ & $\begin{array}{l}T \geq 100^{\circ} \mathrm{C} \\
T \geq 100^{\circ} \mathrm{C}\end{array}$ & $\begin{array}{l}\mathrm{I} \geq 100^{\circ} \mathrm{C} \\
\mathrm{T} \geq 100^{\circ} \mathrm{C}\end{array}$ & $\begin{array}{l}1.726 \\
1.703\end{array}$ & $\begin{array}{l}6.57 \\
6.46\end{array}$ & $\begin{array}{l}43.01 \\
44.34\end{array}$ & $\begin{array}{l}0.867 \\
0.873\end{array}$ & $\begin{array}{l}\text { S. H. Vap. } \\
\text { S. H. Vap. }\end{array}$ \\
\hline C6A-3 & 5.113 & $\mathrm{~T} \geq 100^{\circ} \mathrm{C}$ & $\mathrm{T} \geq 100^{\circ} \mathrm{C}$ & 1.698 & 6.51 & 46.23 & 0.877 & S. H. Vap. \\
\hline C6A-4 & 5.062 & $\mathrm{~T} \geq 100^{\circ} \mathrm{C}$ & $\mathrm{T} \geq 100^{\circ} \mathrm{C}$ & 1.717 & 6.51 & 44.11 & 0.871 & S. H. Vap. \\
\hline Co-1 & 24.563 & 0.0102 & 176.229 & $\mathrm{~T}<100^{\circ} \mathrm{C}$ & 23.05 & 0.00 & 0.000 & Not Sat. \\
\hline $\mathrm{CO}-2$ & 24.479 & 0.0111 & 121.274 & $\mathrm{~T}<100^{\circ} \mathrm{C}$ & 23.48 & 0.26 & 0.011 & 40.19 \\
\hline $\mathrm{C} 0-3$ & 24.479 & 0.0162 & 78.416 & $\mathrm{~T}<100^{\circ} \mathrm{C}$ & 24.06 & 0.40 & 0.016 & 56.76 \\
\hline Co-4 & 24.479 & 0.0394 & 33.907 & $\mathrm{~T}^{\prime}<100^{\circ} \mathrm{C}$ & 25.23 & 1.03 & 0.039 & 40.94 \\
\hline C6B1-1 & 5.165 & 0.2470 & 5.913 & $T<100^{\circ} \mathrm{C}$ & 5.96 & 1.74 & 0.226 & Not Sat. \\
\hline C6B2-1 & 5.165 & 0.2946 & 5.195 & $\mathrm{~T}<100^{\circ} \mathrm{C}$ & 6.03 & 2.52 & 0.295 & 468.63 \\
\hline C6B1-2 & 5.165 & 0.4675 & 3.444 & $\mathrm{~T}<100^{\circ} \mathrm{C}$ & 6.22 & 5.46 & 0.467 & 938.57 \\
\hline C6B2-2 & 5.165 & 0.5706 & 2.858 & $\mathrm{~T}<100^{\circ} \mathrm{C}$ & 6.31 & 8.39 & 0.571 & 699.86 \\
\hline C6B1-3 & 5.165 & 0.4489 & 3.576 & $\mathrm{~T}<100^{\circ} \mathrm{C}$ & 6.21 & 5.05 & 0.449 & 550.81 \\
\hline C6B2-3 & 5.165 & 0.4675 & 3.444 & $T<100^{\circ} \mathrm{C}$ & 6.22 & 5.46 & 0.467 & 855.56 \\
\hline C6B1-4 & 5.165 & 0.3498 & 4.474 & $\mathrm{~T}<100^{\circ} \mathrm{C}$ & 6.10 & 3.28 & 0.350 & 1998.25 \\
\hline C6B2-4 & 5.165 & 0.7748 & 2.119 & $\mathrm{~T}<100^{\circ} \mathrm{C}$ & 6.45 & 22.20 & 0.775 & 128.18 \\
\hline C5A1-2 & 20.730 & 0.0951 & 15.603 & $\mathrm{~T}<100^{\circ} \mathrm{C}$ & 22.50 & 1.02 & 0.044 & Not Sat. \\
\hline C5A2-2 & 20.730 & 0.3076 & 5.005 & $\mathrm{~T}<100^{\circ} \mathrm{C}$ & 24.27 & 10.70 & 0.306 & Not Sat. \\
\hline C5A3-2 & 20.730 & 0.0470 & 29.315 & $\mathrm{~T}<100^{\circ} \mathrm{C}$ & 21.58 & 0.08 & 0.004 & Not Sat. \\
\hline C5A4-2 & 20.730 & 0.2158 & 6.840 & $\mathrm{~T}<100^{\circ} \mathrm{C}$ & 23.70 & 6.52 & 0.216 & 170.44 \\
\hline C5A1-3 & 20.730 & 0.1969 & 7.537 & $\mathrm{~T}<100^{\circ} \mathrm{C}$ & 23.56 & 3.32 & 0.124 & Not Sat. \\
\hline C5A2-3 & 20.730 & 0.1349 & 11.110 & $\mathrm{~T}<100^{\circ} \mathrm{C}$ & 22.99 & 3.59 & 0.135 & 110.90 \\
\hline C5A3-3 & 20.730 & 0.1223 & 12.242 & $\mathrm{~T}<100^{\circ} \mathrm{C}$ & 22.85 & 2.08 & 0.083 & Not Sat. \\
\hline C5A4-3 & 20.730 & 0.1349 & 11.110 & $T<100^{\circ} \mathrm{C}$ & 22.99 & 3.59 & 0.135 & 171.48 \\
\hline C5A1-4 & 20.730 & 0.2470 & 5.913 & $T<100^{\circ} \mathrm{C}$ & 23.91 & 5.61 & 0.190 & Not Sat. \\
\hline C5A2-4 & 20.730 & 0.2470 & 5.913 & $\mathrm{~T}<100^{\circ} \mathrm{C}$ & 23.91 & 7.84 & 0.247 & 16.36 \\
\hline C5A3-4 & 20.730 & 0.1107 & 13.490 & $T<100^{\circ} \mathrm{C}$ & 22.71 & 2.83 & 0.111 & 77.40 \\
\hline C5A4-4 & 20.730 & 0.1558 & 9.606 & $\mathrm{~T}<100^{\circ} \mathrm{C}$ & 23.21 & 4.28 & 0.156 & 340.42 \\
\hline C1A1-2 & 16.452 & 0.0102 & 146.192 & $\mathrm{~T}<100^{\circ} \mathrm{C}$ & 15.61 & 0.16 & 0.010 & 47.69 \\
\hline C1A2-2 & 16.452 & 0.0104 & 187.556 & $\mathrm{~T}<100^{\circ} \mathrm{C}$ & 15.39 & 0.16 & 0.010 & 18.47 \\
\hline C1 A3-2 & 18.280 & 0.0102 & 146.192 & $\mathrm{~T}<100^{\circ} \mathrm{C}$ & 17.34 & 0.18 & 0.010 & 29.68 \\
\hline C1A4-2 & 18.280 & 0.0527 & 26.604 & $\mathrm{~T}<100^{\circ} \mathrm{C}$ & 19.15 & 0.59 & 0.030 & Not Sat. \\
\hline C1A1-3 & 18.262 & 0.0162 & 78.416 & $\mathrm{~T}<100^{\circ} \mathrm{C}$ & 17.95 & 0.30 & 0.016 & 49.18 \\
\hline C1A2-3 & 18.262 & 0.0418 & 32.301 & $\mathrm{~T}<100^{\circ} \mathrm{C}$ & 18.88 & 0.82 & 0.042 & 57.33 \\
\hline C1A3-3 & 20.291 & 0.0162 & 78.416 & $\mathrm{~T}<100^{\circ} \mathrm{C}$ & 19.94 & 0.33 & 0.016 & 36.57 \\
\hline C1 A4-3 & 20.291 & 0.0658 & 21.912 & $\mathrm{~T}<100^{\circ} \mathrm{C}$ & 21.54 & 1.52 & 0.066 & 14.22 \\
\hline C1A1-4 & 16.452 & 0.0308 & 41.168 & $\mathrm{~T}<100^{\circ} \mathrm{C}$ & 16.73 & 0.53 & 0.031 & 6.41 \\
\hline C1 A2-4 & 16.452 & 0.0733 & 19.886 & $\mathrm{~T}<100^{\circ} \mathrm{C}$ & 17.58 & 1.39 & 0.073 & 43.05 \\
\hline C1A3-4 & 18.280 & 0.0162 & 78.416 & $\mathrm{~T}<100^{\circ} \mathrm{C}$ & 17.97 & 0.30 & 0.016 & 98.40 \\
\hline C1A4-4 & 18.280 & 0.1558 & 9.606 & $\mathrm{~T}<100^{\circ} \mathrm{C}$ & 20.46 & 0.00 & 0.000 & Not Sat. \\
\hline
\end{tabular}




Project:
\begin{tabular}{|l|c|}
\hline ICEDF & Test: \\
\hline
\end{tabular}

\begin{tabular}{|c|c|c|c|c|c|c|c|c|}
\hline \multirow[b]{2}{*}{$\begin{array}{l}\text { Sample } \\
\text { ID No. }\end{array}$} & \multirow{2}{*}{$\begin{array}{c}\mathrm{T}<100^{\circ} \mathrm{C} \\
\text { Psat/Po } \\
\text { Formula } 1\end{array}$} & \multirow{2}{*}{$\begin{array}{l}\mathrm{T}<25^{\circ} \mathrm{C} \\
\text { Vs }(\mathrm{m} 3 / \mathrm{kg}) \\
\text { Formula } \mathrm{A}\end{array}$} & \multirow{2}{*}{$\begin{array}{l}25^{\circ} \leq \mathrm{T} \leq 65^{\circ} \\
\text { Vs }(\mathrm{m} 3 / \mathrm{kg}) \\
\text { Formula B }\end{array}$} & \multirow{2}{*}{$\begin{array}{c}\mathrm{T}>65^{\circ} \mathrm{C} \\
V \mathrm{~s}(\mathrm{~m} 3 / \mathrm{kg}) \\
\text { Formula C }\end{array}$} & \multirow{2}{*}{\multicolumn{2}{|c|}{\begin{tabular}{|cc} 
VOL(max) & $M(H 2 O$, sat \\
$H 2 O, T<100$ & $T<100^{\circ} \mathrm{C}$ \\
$(1 @$ To $)$ & (g) \\
\end{tabular}}} & \multicolumn{2}{|c|}{ Critical Orifice Calib. } \\
\hline & & & & & & & $\mathrm{CO}(\#)$ & $\mathbf{Q}(\mathrm{lpm})$ \\
\hline & & & & & & & 50 & 27.23 \\
\hline C6A-1 & $\mathrm{T} \geq 100^{\circ} \mathrm{C}$ & $\mathrm{T} \geq 100^{\circ} \mathrm{C}$ & $T \geq 100^{\circ} \mathrm{C}$ & $T \geq 100^{\circ} \mathrm{C}$ & $T \geq 100^{\circ} \mathrm{C}$ & $T \geq 100^{\circ} \mathrm{C}$ & 53 & 19.76 \\
\hline C6A-2 & $\mathrm{T} \geq 100^{\circ} \mathrm{C}$ & $\mathrm{T} \geq 100^{\circ} \mathrm{C}$ & $\mathrm{T} \geq 100^{\circ} \mathrm{C}$ & $\mathrm{T} \geq 100^{\circ} \mathrm{C}$ & $\mathrm{T} \geq 100^{\circ} \mathrm{C}$ & $\mathrm{T} \geq 100^{\circ} \mathrm{C}$ & 55 & 15.23 \\
\hline C6A-3 & $\mathrm{T} \geq 100^{\circ} \mathrm{C}$ & $\mathrm{T} \geq 100^{\circ} \mathrm{C}$ & $\mathrm{T} \geq 100^{\circ} \mathrm{C}$ & $\mathrm{T} \geq 100^{\circ} \mathrm{C}$ & $\mathrm{T} \geq 100^{\circ} \mathrm{C}$ & $\mathrm{T} \geq 100^{\circ} \mathrm{C}$ & 58 & 9.14 \\
\hline C6A-4 & $\mathrm{T} \geq 100^{\circ} \mathrm{C}$ & $T \geq 100^{\circ} \mathrm{C}$ & $\mathrm{T} \geq 100^{\circ} \mathrm{C}$ & $\mathrm{T} \geq 100^{\circ} \mathrm{C}$ & $T \geq 100^{\circ} \mathrm{C}$ & $T \geq 100^{\circ} \mathrm{C}$ & & \\
\hline $\mathrm{Co-1}$ & 0.0102 & 176.229 & & & 0.238 & 0.132 & 65 & 6.91 \\
\hline $\mathrm{CO}-2$ & 0.0111 & 121.274 & & & 0.264 & 0.196 & 69 & 5.03 \\
\hline Co-3 & 0.0162 & 78.416 & & & 0.396 & 0.312 & 74 & 2.47 \\
\hline Co-4 & 0.0394 & & 33.907 & & 1.034 & 0.775 & 77 & 1.45 \\
\hline C6B1-1 & 0.2470 & & 5.913 & & 1.954 & 1.338 & 80 & 1.03 \\
\hline C6B2-1 & 0.2946 & & & 5.195 & 2.517 & 1.645 & & \\
\hline C6B1-2 & 0.4675 & & & 3.444 & 5.463 & 3.392 & & \\
\hline C6B2-2 & 0.5706 & & & 2.858 & 8.387 & 5.143 & & \\
\hline C6B1-3 & 0.4489 & & & 3.576 & 5.053 & 3.149 & & \\
\hline C6B2-3 & 0.4675 & & & 3.444 & 5.463 & 3.392 & & \\
\hline C6B1-4 & 0.3498 & & & 4.474 & 3.281 & 2.097 & & \\
\hline C6B2-4 & 0.7748 & & & 2.119 & 22.197 & 13.518 & & \\
\hline C5A1-2 & 0.0951 & & 15.603 & & 2.366 & 1.594 & & \\
\hline C5A2-2 & 0.3076 & & & 5.005 & 10.782 & 7.003 & & \\
\hline C5A3-2 & 0.0470 & & 29.315 & & 1.063 & 0.772 & & \\
\hline C5A4-2 & 0.2158 & & 6.840 & & 6.522 & 4.419 & & \\
\hline C5AT-3 & 0.1969 & & 7.537 & & 5.777 & 3.893 & & \\
\hline C5A2-3 & 0.1349 & & 11.110 & & 3.585 & 2.392 & & \\
\hline C5A3-3 & 0.1223 & & 12.242 & & 3.185 & 2.127 & & \\
\hline C5A4-3 & 0.1349 & & 11.110 & & 3.585 & 2.392 & & \\
\hline C5A1-4 & 0.2470 & & 5.913 & & 7.844 & 5.370 & & \\
\hline C5A2-4 & 0.2470 & & 5.913 & & 7.844 & 5.370 & & \\
\hline C5A3-4 & 0.1107 & & 13.490 & & 2.828 & 1.893 & & \\
\hline C5A4-4 & 0.1558 & & 9.606 & & 4.283 & 2.862 & & \\
\hline C1A1-2 & 0.0102 & 146.192 & & & 0.162 & 0.108 & & \\
\hline C1A2-2 & 0.0104 & 187.556 & & & 0.162 & 0.083 & & \\
\hline C1A3-2 & 0.0102 & 146.192 & & & 0.180 & 0.120 & & \\
\hline C1A4-2 & 0.0527 & & 26.604 & & 1.065 & 0.760 & & \\
\hline C1A1-3 & 0.0162 & 78.416 & & & 0.295 & 0.233 & & \\
\hline C1A2-3 & 0.0418 & & 32.301 & & 0.823 & 0.610 & & \\
\hline C1A3-3 & 0.0162 & 78.416 & & & 0.328 & 0.259 & & \\
\hline C1A4-3 & 0.0658 & & 21.912 & & 1.516 & 1.052 & & \\
\hline C1A1-4 & 0.0308 & & 41.168 & & 0.532 & 0.419 & & \\
\hline C1A2-4 & 0.0733 & & 19.886 & & 1.389 & 0.954 & & \\
\hline C1A3-4 & 0.0162 & 78.416 & & & 0.296 & 0.233 & & \\
\hline C1A4-4 & 0.1558 & & 9.606 & & 3.777 & 2.524 & & \\
\hline
\end{tabular}

ICEDF Gas Composition Analysis (page 3)

$$
\text { C. } 31
$$


ICEDF SMF WkSht 6/88 supersedes ICEDF SMF WkSht 9/87 ICEDF SMF SkSht 10/89 supersedes ICEDF SMF WkSht 6/88

1) Open "ICEDF SMF WkSht 10/89". 2) Enter test name. 3) Save as "ICEDF testname month/year".

\section{How this spreadsheet works}

CO flow rate determined by Lookup function: Column $\mathrm{H}$, Cells $A B \&$ AC. Pressure correction added 5/23/89.

Dry gas volume $=\mathrm{CO}$ flow rate ${ }^{*}$ sample duration ${ }^{\bullet}$ pressure correction.

Actual dry gas volume $=$ VOL(dry, actual $)=$ sample duration * CO flow rate * $(273+$ To)/293.

H2O specific volume $=1.227+0.004712($ To $)$ for To $\geq 100^{\circ} \mathrm{C}$.

$\mathrm{H} 2 \mathrm{O}$ saturated steam partial pressure (Psat/Po $=$ Formula1) for $\mathrm{T}<100^{\circ} \mathrm{C}$.

Formula $1=0.0107-3.451^{\star} 10^{\wedge}-4^{\star} \mathrm{F} 10+5.359^{\star} 10^{\wedge}-5^{\star} \mathrm{F} 10^{\wedge} 2-5.694^{\star} 10^{\wedge}-7^{\star} \mathrm{F} 10^{\wedge} 3+1.057^{\star} 10^{\wedge}-8^{\star} \mathrm{F} 10^{\wedge} 4$

Actual $\mathrm{H} 2 \mathrm{O}$ gas volume:

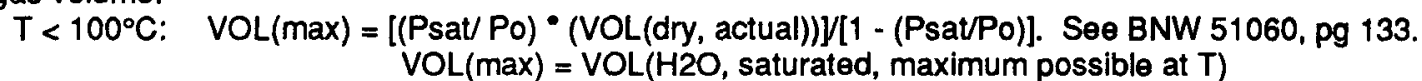

Fog Check: compare $\mathrm{H} 2 \mathrm{O}$ mass collected to $\mathrm{H} 2 \mathrm{O}$ mass required for sample saturation $M(H 2 O$, sat $)=[[$ VOL $($ dry, actual $)+$ VOL $(H 2 O, \max )] \mathrm{Ns}(\mathrm{H} 2 \mathrm{O}$ vapor, sat $)](1000 / 1000)$

$\mathrm{Vs}(\mathrm{H} 2 \mathrm{O}$ vapor, sat $)=$ FormulaA if $\mathrm{T}<25^{\circ} \mathrm{C},=$ FormulaC if $\mathrm{T}>65^{\circ} \mathrm{C}$.

FormulaA $=199.61 * 10^{\wedge}(-2.7052 \theta-2(T))$.

FormulaB $=138.44 * 10^{\wedge}(-2.1068 \theta-2(\mathrm{~T}))$.

FormulaC $=68.411 * 10^{\wedge}(-1.6225 e-2(T))$.

1) If condensate mass $<\mathrm{M}(\mathrm{H} 2 \mathrm{O}$, sat $)$ :

$\operatorname{VOL}(\mathrm{H} 2 \mathrm{O}$, actual $)=(\mathrm{RH}){ }^{*}(\mathrm{VOL}(\max ))$. Print "Not Sat."

$\mathrm{RH}=$ condensate mass / $\mathrm{M}(\mathrm{H} 2 \mathrm{O}$, sat $)$.

2) If condensate mass $=\mathrm{M}(\mathrm{H} 2 \mathrm{O}$, sat $)$ :

VOL(H2O, actual) = VOL(max). Print "Sat." (saturated).

3) If condenate mass $>\mathrm{M}(\mathrm{H} 2 \mathrm{O}$, sat $)$ :

$\operatorname{VOL}(\mathrm{H} 2 \mathrm{O}$, actual $)=\mathrm{VOL}(\max )$. Calculate and print fog mass conc.

Fog Conc $=$ condensate mass $-\mathrm{M}(\mathrm{H} 2 \mathrm{O}$, sat $)$ / sample vol. (sample vol $=\left(1000 \mathrm{~m}^{\wedge} 3 /\right)^{\star} \Sigma$ [actual $\mathrm{H} 2 \mathrm{O} \&$ dry vols])

$T \geq 100^{\circ} \mathrm{C}: \quad \operatorname{Vol}(\mathrm{H} 2 \mathrm{O})=\left(\right.$ condensate mass " sat steam spec vol) ${ }^{*}(1000 / 1000)$. Print "S. H. Vap."

SMF = Actual H2O gas volume / total gas volume (ie., the sum of actual dry and actual $\mathrm{H} 2 \mathrm{O}$ volumes, = sample vol'

Not included: 1) possible temp variations, 2) possible supersaturation.

CO upstream pressure correction factor added to spreadsheet on 6/14/89 (in draft form in 5/89).

Modifications: ICEDF SMF WkSht 6/89 superseded ICEDF SMF WkSht $9 / 87$

1) Original date of this version was $6 / 14 / 89$.

2) 1st modification was made $9 / 14 / 89$ :

Crit orifice flow corr. factor formula was changed to print "n if test time was "*n.

Sample analysis date cell was added to top of page 1.

ICEDF SMF WkSht 10/89 superseded ICEDF SMF WkSht 6/89

1) Changed printer page set-up, and minor editing. 2) Changed SMF col eq to print "w if no H2O mass is entered.

3) Changed Fog column equation to print "' if no SMF is calculated, and $¿$ Sat? if SMF is calculated based on assumed saturation when no $\mathrm{H} 2 \mathrm{O}$ mass is entered.

4) Changed Sample ID column 12/1/89 to match new test plan (no C6B1 or C6B2). 


\begin{tabular}{|c|c|c|c|c|c|c|c|c|}
\hline $\begin{array}{l}\text { Prolect: } \\
\text { ICEDF }\end{array}$ & $\begin{array}{l}\text { Test: } \\
13-10\end{array}$ & & & & & \begin{tabular}{|c|}
$\begin{array}{c}\text { Date of } \\
\text { Analysis }\end{array}$ \\
$3 / 23 / 90$ \\
\end{tabular} & $\begin{array}{c}\text { Q.A. Verfic } \\
\text { Name }\end{array}$ & $\begin{array}{c}\text { ation: } \\
\text { Date } \\
7 / 2991\end{array}$ \\
\hline $\begin{array}{l}\text { Sample } \\
\text { ID No. }\end{array}$ & $\begin{array}{c}\text { Test Clock } \\
\text { (min) }\end{array}$ & $\begin{array}{c}\text { Sample } \\
\text { Duration } \\
\Delta t \text { (min) }\end{array}$ & $\begin{array}{l}\text { To } \\
\left({ }^{\circ} \mathrm{C}\right)\end{array}$ & $\begin{array}{c}\text { Critical } \\
\text { Orifice } \\
(\#)\end{array}$ & $\begin{array}{c}C O \\
\Delta P \\
(n \mathrm{Hg})\end{array}$ & $\begin{array}{c}\text { Condensate } \\
\text { H2O Mass } \\
\text { (g) }\end{array}$ & $\begin{array}{l}\text { Crit. Orifice } \\
\text { Flow Rate } \\
@ 20^{\circ} \mathrm{C} \\
(\text { lpm) }\end{array}$ & $\begin{array}{l}\text { Crit. Orifice } \\
\text { Flow Corr. } \\
\text { Factor } \\
(-)\end{array}$ \\
\hline $\begin{array}{l}\text { C6A-1 } \\
\text { C6A-2 } \\
\text { C6A-3 } \\
\text { C6A-4 } \\
\text { C6A-5 } \\
\text { C6A-6 }\end{array}$ & $\begin{array}{l}12.50 \\
27.50 \\
42.50 \\
57.50\end{array}$ & $\begin{array}{l}7.00 \\
7.00 \\
7.00 \\
7.00\end{array}$ & $\begin{array}{l}104 \\
113 \\
118 \\
121\end{array}$ & $\begin{array}{l}80 \\
80 \\
80 \\
80\end{array}$ & $\begin{array}{l}1.1 \\
1.2 \\
1.2 \\
1.0\end{array}$ & $\begin{array}{l}75.71 \\
76.50 \\
79.92 \\
82.84\end{array}$ & $\begin{array}{l}1.033 \\
1.033 \\
1.033 \\
1.033\end{array}$ & $\begin{array}{l}0.96 \\
0.96 \\
0.96 \\
0.97\end{array}$ \\
\hline $\begin{array}{l}\text { C5A1-1 } \\
\text { C5A1-2 } \\
\text { C5A1-3 } \\
\text { C5A1-4 } \\
\text { C5A1-5 } \\
\text { C5A1-6 }\end{array}$ & $\begin{array}{l}27.50 \\
42.50 \\
57.50\end{array}$ & $\begin{array}{l}5.00 \\
5.00 \\
5.00\end{array}$ & $\begin{array}{c}\sim 45 \\
\sim 65 \\
73\end{array}$ & $\begin{array}{l}65 \\
65 \\
65\end{array}$ & $\begin{array}{l}3.7 \\
1.6 \\
2.4\end{array}$ & $\begin{array}{c}22.31 \\
1.43 \\
8.89\end{array}$ & $\begin{array}{l}6.910 \\
6.910 \\
6.910\end{array}$ & $\begin{array}{l}0.88 \\
0.95 \\
0.92\end{array}$ \\
\hline $\begin{array}{l}\text { C5A2-1 } \\
\text { C5A2-2 } \\
\text { C5A2-3 } \\
\text { C5A2-4 } \\
\text { C5A2-5 } \\
\text { C5A2-6 }\end{array}$ & $\begin{array}{l}27.50 \\
42.50 \\
57.50\end{array}$ & $\begin{array}{l}5.00 \\
5.00 \\
5.00\end{array}$ & $\begin{array}{c}\sim 50 \\
\sim 75 \\
88\end{array}$ & $\begin{array}{l}65 \\
65 \\
65\end{array}$ & $\begin{array}{l}3.2 \\
2.1 \\
2.6\end{array}$ & $\begin{array}{l}31.65 \\
10.23 \\
37.48\end{array}$ & $\begin{array}{l}6.910 \\
6.910 \\
6.910\end{array}$ & $\begin{array}{l}0.89 \\
0.93 \\
0.91\end{array}$ \\
\hline $\begin{array}{l}\text { C5A3-1 } \\
\text { C5A3-2 } \\
\text { C5A3-3 } \\
\text { C5A3-4 } \\
\text { C5A3-5 } \\
\text { C5A3-6 }\end{array}$ & $\begin{array}{l}27.50 \\
42.50 \\
57.50\end{array}$ & $\begin{array}{l}5.00 \\
5.00 \\
5.00\end{array}$ & $\begin{array}{l}45 \\
65 \\
63\end{array}$ & $\begin{array}{l}65 \\
65 \\
65\end{array}$ & $\begin{array}{l}4.0 \\
4.0 \\
7.0\end{array}$ & $\begin{array}{c}7.24 \\
7.25 \\
10.90\end{array}$ & $\begin{array}{l}6.910 \\
6.910 \\
6.910\end{array}$ & $\begin{array}{l}0.87 \\
0.87 \\
0.77\end{array}$ \\
\hline $\begin{array}{l}\text { C5A4-2 } \\
\text { C5A4-3 } \\
\text { C5A4-4 } \\
\text { C5A4-5 } \\
\text { C5A4-6 }\end{array}$ & $\begin{array}{l}27.50 \\
42.50 \\
57.50\end{array}$ & $\begin{array}{l}5.00 \\
5.00 \\
5.00\end{array}$ & $\begin{array}{l}50 \\
73 \\
79\end{array}$ & $\begin{array}{l}65 \\
65 \\
65\end{array}$ & $\begin{array}{l}3.0 \\
2.0 \\
3.0\end{array}$ & $\begin{array}{c}8.65 \\
34.25 \\
57.17\end{array}$ & $\begin{array}{l}6.910 \\
6.910 \\
6.910\end{array}$ & $\begin{array}{l}0.90 \\
0.93 \\
0.90\end{array}$ \\
\hline $\begin{array}{l}C 4 B-1 \\
C 4 B-2 \\
C 4 B-3 \\
C 4 B-4 \\
C 4 B-5 \\
C 4 B-6\end{array}$ & $\begin{array}{l}12.50 \\
25.85 \\
42.65 \\
57.50\end{array}$ & $\begin{array}{l}7.00 \\
7.00 \\
7.00 \\
7.00\end{array}$ & $\begin{array}{l}39 \\
35 \\
51 \\
70\end{array}$ & $\begin{array}{l}69 \\
69 \\
69 \\
69\end{array}$ & $\begin{array}{l}0.5 \\
0.5 \\
0.5 \\
0.5\end{array}$ & $\begin{array}{c}2.11 \\
5.23 \\
7.47 \\
23.02\end{array}$ & $\begin{array}{l}5.030 \\
5.030 \\
5.030 \\
5.030\end{array}$ & $\begin{array}{l}0.98 \\
0.98 \\
0.98 \\
0.98\end{array}$ \\
\hline
\end{tabular}




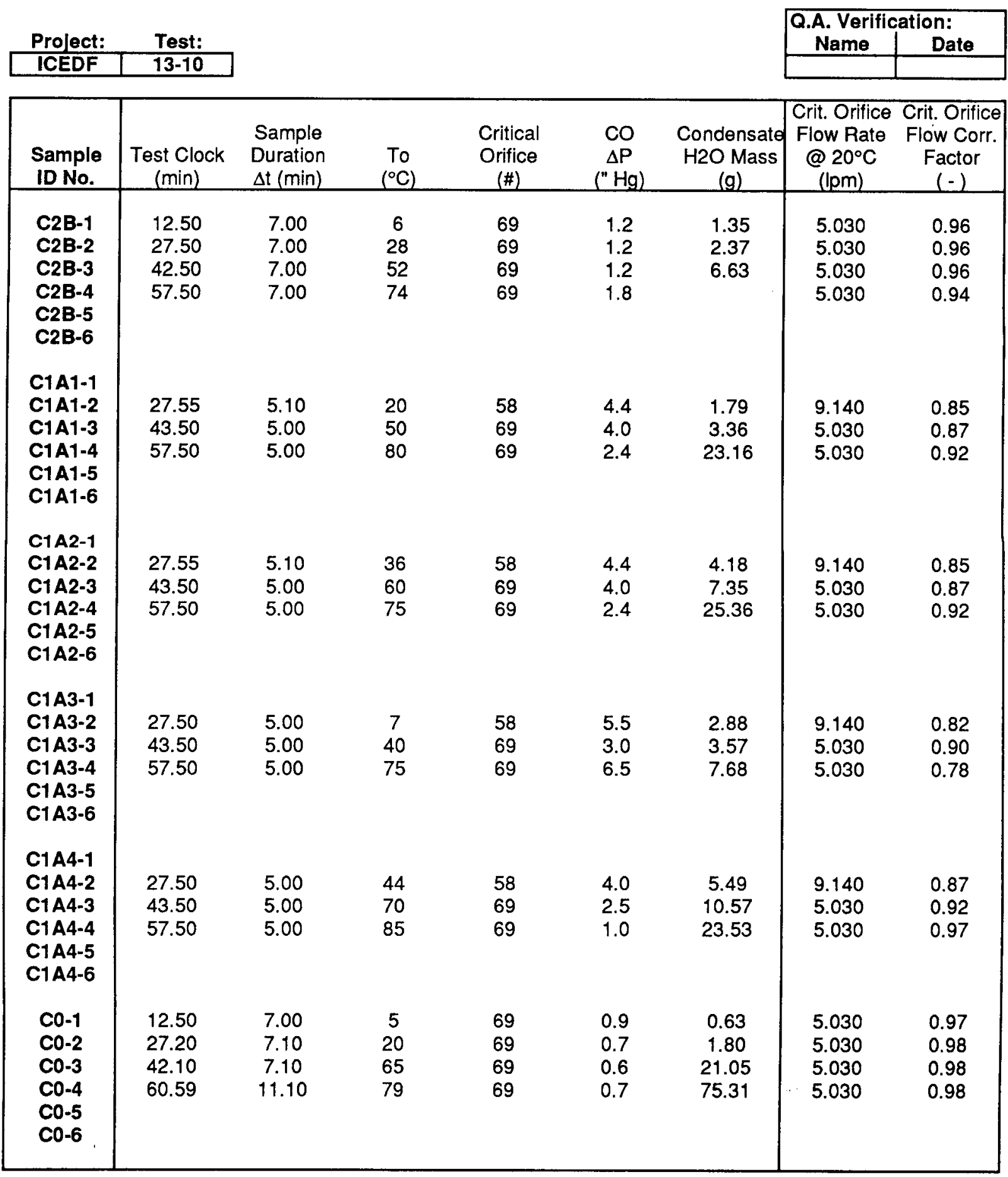

ICEDF Gas Composition Analysis (page 2)

$$
\text { C. } 34
$$




Project:
\begin{tabular}{|l|l|}
\hline ICEDF & Test: \\
\hline
\end{tabular}

\begin{tabular}{|c|c|c|c|c|c|c|c|c|}
\hline $\begin{array}{l}\text { Sample } \\
\text { ID No. }\end{array}$ & $\begin{array}{c}\text { Dry Gas } \\
\text { Volume } \\
\left(1 @ 20^{\circ} \mathrm{C}\right)\end{array}$ & $\begin{array}{c}\text { Sat. Vapor } \\
\left(\mathrm{T}<100^{\circ} \mathrm{C}\right) \\
(\text { Psat/Po) }\end{array}$ & $\begin{array}{c}\text { H2O Vapor } \\
\text { Spec. Vol. } \\
\left(\mathrm{T}<100^{\circ} \mathrm{C}\right) \\
(\mathrm{m} 3 / \mathrm{kg})\end{array}$ & $\begin{array}{c}\text { H2O Vapor } \\
\text { Spec. Vol. } \\
\left(\mathrm{T} \geq 100^{\circ} \mathrm{C}\right) \\
(\mathrm{m} 3 / \mathrm{kg})\end{array}$ & $\begin{array}{l}\text { Dry Gas } \\
\text { Volume } \\
\text { (1@To) }\end{array}$ & $\begin{array}{c}\text { H2O Gas } \\
\text { Volume } \\
(1 @ \text { To })\end{array}$ & $\begin{array}{c}\text { SMF } \\
(-)\end{array}$ & $\begin{array}{c}\text { Fog } \\
\text { @ To } \\
\left(\mathrm{mg} / \mathrm{m}^{\wedge} 3\right)\end{array}$ \\
\hline $\begin{array}{l}\text { C6A-1 } \\
\text { C6A-2 } \\
\text { C6A-3 } \\
\text { C6A-4 } \\
\text { C6A-5 } \\
\text { C6A-6 }\end{array}$ & $\begin{array}{l}6.966 \\
6.942 \\
6.942 \\
6.990\end{array}$ & $\begin{array}{l}T \geq 100^{\circ} \mathrm{C} \\
T \geq 100^{\circ} \mathrm{C} \\
T \geq 100^{\circ} \mathrm{C} \\
T \geq 100^{\circ} \mathrm{C}\end{array}$ & $\begin{array}{l}T \geq 100^{\circ} \mathrm{C} \\
T \geq 100^{\circ} \mathrm{C} \\
T \geq 100^{\circ} \mathrm{C} \\
T \geq 100^{\circ} \mathrm{C}\end{array}$ & $\begin{array}{l}1.717 \\
1.759 \\
1.783 \\
1.797\end{array}$ & $\begin{array}{l}8.96 \\
9.15 \\
9.26 \\
9.40\end{array}$ & $\begin{array}{l}130.00 \\
134.60 \\
142.50 \\
148.88\end{array}$ & $\begin{array}{l}0.936 \\
0.936 \\
0.939 \\
0.941\end{array}$ & $\begin{array}{l}\text { S. H. Vap. } \\
\text { S. H. Vap. } \\
\text { S. H. Vap. } \\
\text { S. H. Vap. }\end{array}$ \\
\hline $\begin{array}{l}\text { C5A1-1 } \\
\text { C5A1-2 } \\
\text { C5A1-3 } \\
\text { C5A1-4 } \\
\text { C5A1-5 } \\
\text { C5A1-6 }\end{array}$ & $\begin{array}{l}30.289 \\
32.707 \\
31.786\end{array}$ & $\begin{array}{c}T \geq 100^{\circ} \mathrm{C} \\
T \geq 100^{\circ} \mathrm{C} \\
0.3542\end{array}$ & $\begin{array}{c}T \geq 100^{\circ} \mathrm{C} \\
T \geq 100^{\circ} \mathrm{C} \\
4.424\end{array}$ & $\begin{array}{l}\text { \#VALUE! } \\
\text { \#VALUE! } \\
T<100^{\circ} \mathrm{C}\end{array}$ & 37.57 & $\begin{array}{c}\text { \#VALUE! } \\
\text { \#VALUE! } \\
13.93\end{array}$ & 0.271 & Not Sat. \\
\hline $\begin{array}{l}\text { C5A2-1 } \\
\text { C5A2-2 } \\
\text { C5A2-3 } \\
\text { C5A2-4 } \\
\text { C5A2-5 } \\
\text { C5A2-6 }\end{array}$ & $\begin{array}{l}30.865 \\
32.132 \\
31.556\end{array}$ & $\begin{array}{c}T \geq 100^{\circ} \mathrm{C} \\
T \geq 100^{\circ} \mathrm{C} \\
0.6289\end{array}$ & $\begin{array}{c}T \geq 100^{\circ} \mathrm{C} \\
T \geq 100^{\circ} \mathrm{C} \\
2.603\end{array}$ & $\begin{array}{l}\text { \#VALUE! } \\
\text { \#VALUE! } \\
T<100^{\circ} \mathrm{C}\end{array}$ & 38.83 & $\begin{array}{c}\text { \#VALUE! } \\
\text { \#VALUE! } \\
61.35\end{array}$ & 0.612 & Not Sat. \\
\hline $\begin{array}{l}\text { C5A3-1 } \\
\text { C5A3-2 } \\
\text { C5A3-3 } \\
\text { C5A3-4 } \\
\text { C5A3-5 } \\
\text { C5A3-6 }\end{array}$ & $\begin{array}{l}29.943 \\
29.943 \\
26.488\end{array}$ & $\begin{array}{l}0.0951 \\
0.2470 \\
0.2258\end{array}$ & $\begin{array}{c}15.603 \\
5.913 \\
6.516\end{array}$ & $\begin{array}{l}T<100^{\circ} \mathrm{C} \\
T<100^{\circ} \mathrm{C} \\
T<100^{\circ} \mathrm{C}\end{array}$ & $\begin{array}{l}32.50 \\
34.54 \\
30.38\end{array}$ & $\begin{array}{c}3.42 \\
10.59 \\
8.86\end{array}$ & $\begin{array}{l}0.095 \\
0.235 \\
0.226\end{array}$ & $\begin{array}{c}137.49 \\
\text { Not Sat. } \\
124.35\end{array}$ \\
\hline $\begin{array}{l}\text { C5A4-2 } \\
\text { C5A4-3 } \\
\text { C5A4-4 } \\
\text { C5A4-5 } \\
\text { C5A4-6 }\end{array}$ & $\begin{array}{l}31.095 \\
32.247 \\
31.095\end{array}$ & $\begin{array}{l}0.1223 \\
0.3498 \\
0.4489\end{array}$ & $\begin{array}{c}12.242 \\
4.474 \\
3.576\end{array}$ & $\begin{array}{l}\mathrm{T}<100^{\circ} \mathrm{C} \\
\mathrm{T}<100^{\circ} \mathrm{C} \\
\mathrm{T}<100^{\circ} \mathrm{C}\end{array}$ & $\begin{array}{l}34.28 \\
38.08 \\
37.36\end{array}$ & $\begin{array}{c}4.78 \\
20.48 \\
30.42\end{array}$ & $\begin{array}{l}0.122 \\
0.350 \\
0.449\end{array}$ & $\begin{array}{l}139.79 \\
361.34 \\
563.79\end{array}$ \\
\hline $\begin{array}{l}\text { C4B-1 } \\
\text { C4B-2 } \\
\text { C4B-3 } \\
\text { C4B-4 } \\
\text { C4B-5 } \\
\text { C4B-6 }\end{array}$ & $\begin{array}{l}34.623 \\
34.623 \\
34.623 \\
34.623\end{array}$ & $\begin{array}{l}0.0694 \\
0.0557 \\
0.1285 \\
0.3076\end{array}$ & $\begin{array}{c}20.874 \\
25.344 \\
11.663 \\
5.005\end{array}$ & $\begin{array}{l}T<100^{\circ} \mathrm{C} \\
T<100^{\circ} \mathrm{C} \\
T<100^{\circ} \mathrm{C} \\
T<100^{\circ} \mathrm{C}\end{array}$ & $\begin{array}{l}36.87 \\
36.40 \\
38.29 \\
40.53\end{array}$ & $\begin{array}{c}2.75 \\
2.15 \\
5.64 \\
18.01\end{array}$ & $\begin{array}{l}0.069 \\
0.056 \\
0.128 \\
0.308\end{array}$ & $\begin{array}{c}5.35 \\
96.24 \\
84.30 \\
193.43\end{array}$ \\
\hline
\end{tabular}

ICEDF Gas Composition Analysis (page 3) 


\begin{tabular}{|c|c|c|c|c|c|c|c|c|}
\hline $\begin{array}{l}\text { Project: } \\
\text { ICEDF }\end{array}$ & & $\frac{\text { Test: }}{13-10}$ & & & & & & \\
\hline $\begin{array}{l}\text { Sample } \\
\text { ID No. }\end{array}$ & $\begin{array}{c}\text { Dry Gas } \\
\text { Volume } \\
\left(1 @ 20^{\circ} \mathrm{C}\right)\end{array}$ & $\begin{array}{c}\text { Sat. Vapor } \\
\left(\mathrm{T}<100^{\circ} \mathrm{C}\right) \\
\text { (Psat/Po) }\end{array}$ & $\begin{array}{c}\text { H2O Vapor } \\
\text { Spec. Vol. } \\
\left(T<100^{\circ} \mathrm{C}\right) \\
(\mathrm{m} 3 / \mathrm{kg})\end{array}$ & $\begin{array}{c}\text { H2O Vapor } \\
\text { Spec. Vol. } \\
\left(\mathrm{T} \geq 100^{\circ} \mathrm{C}\right) \\
(\mathrm{m} 3 / \mathrm{kg})\end{array}$ & $\begin{array}{l}\text { Dry Gas } \\
\text { Volume } \\
\text { (1@ To) }\end{array}$ & $\begin{array}{c}\text { H2O Gas } \\
\text { Volume } \\
\text { (1@ To) }\end{array}$ & $\begin{array}{c}\text { SMF } \\
(-)\end{array}$ & $\begin{array}{c}\text { Fog } \\
@ \text { To } \\
\left(\mathrm{mg} / \mathrm{m}^{\wedge} 3\right)\end{array}$ \\
\hline $\begin{array}{l}\text { C2B-1 } \\
\text { C2B-2 } \\
\text { C2B-3 } \\
\text { C2B-4 } \\
\text { C2B-5 } \\
\text { C2B-6 }\end{array}$ & $\begin{array}{l}33.802 \\
33.802 \\
33.802 \\
33.097\end{array}$ & $\begin{array}{l}0.0104 \\
0.0370 \\
0.1349 \\
0.3648\end{array}$ & $\begin{array}{c}137.363 \\
35.592 \\
11.110 \\
4.310\end{array}$ & $\begin{array}{l}T<100^{\circ} \mathrm{C} \\
T<100^{\circ} \mathrm{C} \\
T<100^{\circ} \mathrm{C} \\
T<100^{\circ} \mathrm{C}\end{array}$ & $\begin{array}{l}32.19 \\
34.72 \\
37.49 \\
39.20\end{array}$ & $\begin{array}{l}0.34 \\
1.34 \\
5.85 \\
0.00\end{array}$ & $\begin{array}{l}0.010 \\
0.037 \\
0.135\end{array}$ & $\begin{array}{l}34.22 \\
37.63 \\
62.97\end{array}$ \\
\hline $\begin{array}{l}\text { C1A1-1 } \\
\text { C1A1-2 } \\
\text { C1A1-3 } \\
\text { C1A1-4 } \\
\text { C1A1-5 } \\
\text { C1A1-6 }\end{array}$ & $\begin{array}{l}39.777 \\
21.797 \\
23.138\end{array}$ & $\begin{array}{l}0.0224 \\
0.1223 \\
0.4675\end{array}$ & $\begin{array}{c}57.430 \\
12.242 \\
3.444\end{array}$ & $\begin{array}{l}T<100^{\circ} \mathrm{C} \\
T<100^{\circ} \mathrm{C} \\
T<100^{\circ} \mathrm{C}\end{array}$ & $\begin{array}{l}39.78 \\
24.03 \\
27.88\end{array}$ & $\begin{array}{c}0.91 \\
3.35 \\
24.47\end{array}$ & $\begin{array}{l}0.022 \\
0.122 \\
0.467\end{array}$ & $\begin{array}{c}26.58 \\
41.05 \\
152.11\end{array}$ \\
\hline $\begin{array}{l}\text { C1A2-1 } \\
\text { C1A2-2 } \\
\text { C1A2-3 } \\
\text { C1A2-4 } \\
\text { C1A2-5 } \\
\text { C1A2-6 }\end{array}$ & $\begin{array}{l}39.777 \\
21.797 \\
23.138\end{array}$ & $\begin{array}{l}0.0589 \\
0.1969 \\
0.3805\end{array}$ & $\begin{array}{c}24.144 \\
7.537 \\
4.152\end{array}$ & $\begin{array}{l}T<100^{\circ} \mathrm{C} \\
T<100^{\circ} \mathrm{C} \\
T<100^{\circ} \mathrm{C}\end{array}$ & $\begin{array}{l}41.95 \\
24.77 \\
27.48\end{array}$ & $\begin{array}{c}2.63 \\
6.07 \\
16.88\end{array}$ & $\begin{array}{l}0.059 \\
0.197 \\
0.380\end{array}$ & $\begin{array}{c}52.36 \\
105.59 \\
330.84\end{array}$ \\
\hline $\begin{array}{l}\text { C1A3-1 } \\
\text { C1A3-2 } \\
\text { C1A3-3 } \\
\text { C1A3-4 } \\
\text { C1A3-5 } \\
\text { C1A3-6 }\end{array}$ & $\begin{array}{l}37.322 \\
22.635 \\
19.701\end{array}$ & $\begin{array}{l}0.0107 \\
0.0733 \\
0.3805\end{array}$ & $\begin{array}{c}129.068 \\
19.886 \\
4.152\end{array}$ & $\begin{array}{l}T<100^{\circ} \mathrm{C} \\
T<100^{\circ} \mathrm{C} \\
T<100^{\circ} \mathrm{C}\end{array}$ & $\begin{array}{l}35.67 \\
24.18 \\
23.40\end{array}$ & $\begin{array}{c}0.39 \\
1.91 \\
12.13\end{array}$ & $\begin{array}{l}0.011 \\
0.073 \\
0.341\end{array}$ & $\begin{array}{c}72.13 \\
86.54 \\
\text { Not Sat. }\end{array}$ \\
\hline $\begin{array}{l}\text { C1A4-1 } \\
\text { C1A4-2 } \\
\text { C1A4-3 } \\
\text { C1A4-4 } \\
\text { C1A4-5 } \\
\text { C1A4-6 }\end{array}$ & $\begin{array}{l}39.607 \\
23.054 \\
24.312\end{array}$ & $\begin{array}{l}0.0904 \\
0.3076 \\
0.5706\end{array}$ & $\begin{array}{l}16.378 \\
5.005 \\
2.858\end{array}$ & $\begin{array}{l}T<100^{\circ} \mathrm{C} \\
T<100^{\circ} \mathrm{C} \\
T<100^{\circ} \mathrm{C}\end{array}$ & $\begin{array}{l}42.85 \\
26.99 \\
29.71\end{array}$ & $\begin{array}{c}4.26 \\
11.99 \\
38.37\end{array}$ & $\begin{array}{l}0.090 \\
0.308 \\
0.564\end{array}$ & $\begin{array}{c}55.48 \\
71.36 \\
\text { Not Sat. }\end{array}$ \\
\hline $\begin{array}{l}\mathrm{CO}-1 \\
\mathrm{CO}-2 \\
\mathrm{CO}-3 \\
\mathrm{CO}-4 \\
\mathrm{CO}-5 \\
\mathrm{CO}-6\end{array}$ & $\begin{array}{l}34.154 \\
34.880 \\
34.999 \\
54.530\end{array}$ & $\begin{array}{l}0.0102 \\
0.0224 \\
0.2470 \\
0.4489\end{array}$ & $\begin{array}{c}146.192 \\
57.430 \\
5.913 \\
3.576\end{array}$ & $\begin{array}{l}T<100^{\circ} \mathrm{C} \\
T<100^{\circ} \mathrm{C} \\
T<100^{\circ} \mathrm{C} \\
T<100^{\circ} \mathrm{C}\end{array}$ & $\begin{array}{l}32.41 \\
34.88 \\
40.37 \\
65.51\end{array}$ & $\begin{array}{c}0.34 \\
0.80 \\
13.24 \\
53.35\end{array}$ & $\begin{array}{l}0.010 \\
0.022 \\
0.247 \\
0.449\end{array}$ & $\begin{array}{c}12.40 \\
33.04 \\
223.49 \\
353.91\end{array}$ \\
\hline
\end{tabular}

ICEDF Gas Composition Analysis (page 4) 
Prolect: Test:

\begin{tabular}{|l|l|}
\hline ICEDF & $13-10$ \\
\hline
\end{tabular}

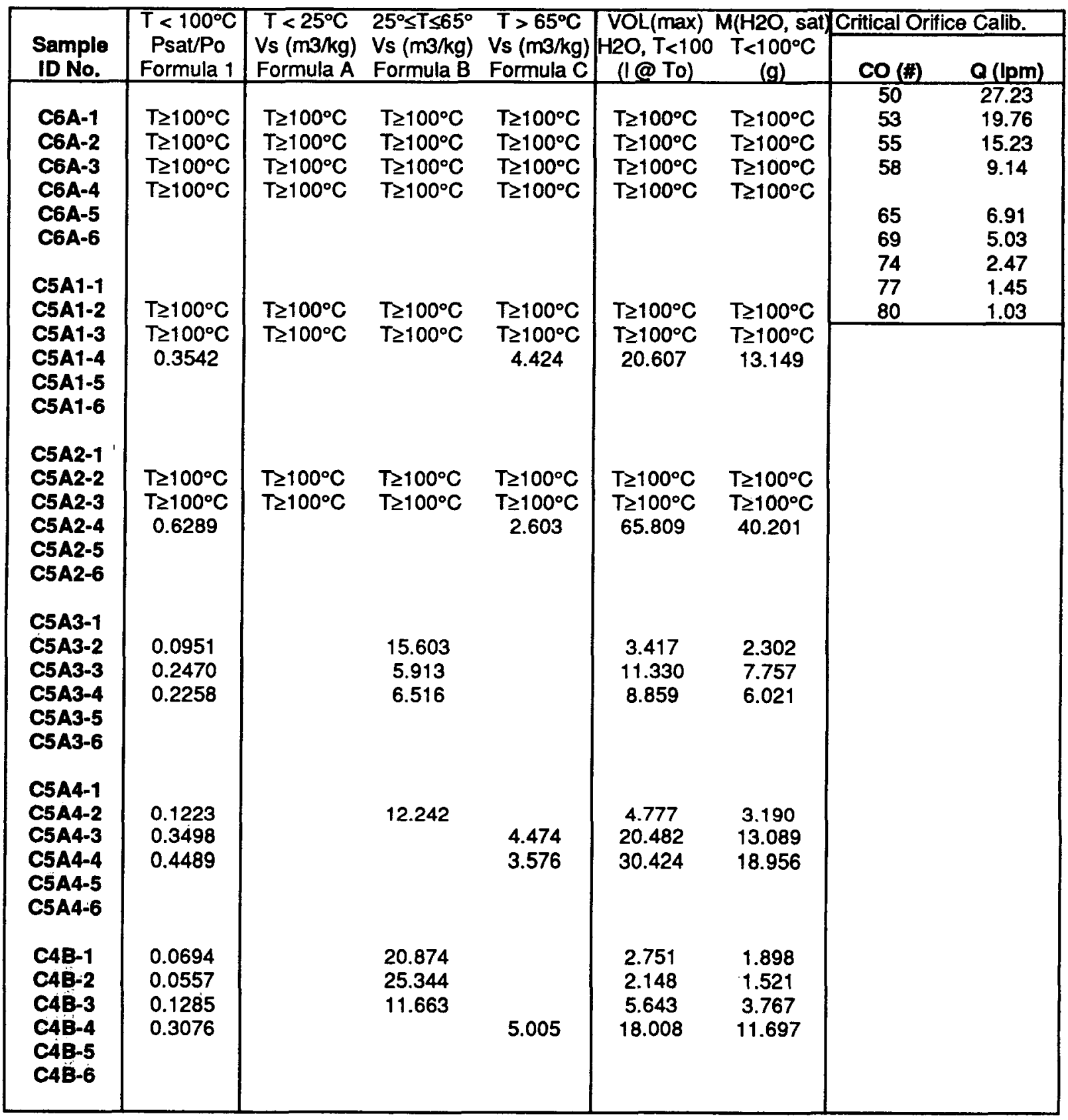

ICEDF Gas Composition Analysis (page 5) 
Prolect: Test:

ICEDF $13-10$

\begin{tabular}{|c|c|c|c|c|c|c|}
\hline $\begin{array}{l}\text { Sample } \\
\text { ID No. }\end{array}$ & $\begin{array}{c}\mathrm{T}<100^{\circ} \mathrm{C} \\
\text { Psat/Po } \\
\text { Formula } 1\end{array}$ & $\begin{array}{c}\mathrm{T}<25^{\circ} \mathrm{C} \\
\text { Vs }(\mathrm{m} 3 / \mathrm{kg}) \\
\text { Formula A }\end{array}$ & $\begin{array}{l}25^{\circ} \leq T \leq 65^{\circ} \\
\text { Vs }(\mathrm{m} 3 / \mathrm{kg}) \\
\text { Formula B }\end{array}$ & $\begin{array}{c}\mathrm{T}>65^{\circ} \mathrm{C} \\
\text { Vs }(\mathrm{m} 3 / \mathrm{kg}) \\
\text { Formula C }\end{array}$ & $\begin{array}{c}\text { VOL(max) } \\
\text { H2O, T<100 } \\
\text { (1@ To) }\end{array}$ & $\begin{array}{c}\mathrm{M}(\mathrm{H} 2 \mathrm{O}, \text { sat }) \\
\mathrm{T}<100^{\circ} \mathrm{C} \\
(\mathrm{g})\end{array}$ \\
\hline $\begin{array}{l}\text { C2B-1 } \\
\text { C2B-2 } \\
\text { C2B-3 } \\
\text { C2B-4 } \\
\text { C2B-5 } \\
\text { C2B-6 }\end{array}$ & $\begin{array}{l}0.0104 \\
0.0370 \\
0.1349 \\
0.3648\end{array}$ & 137.363 & $\begin{array}{l}35.592 \\
11.110\end{array}$ & 4.310 & $\begin{array}{c}0.340 \\
1.336 \\
5.846 \\
22.516\end{array}$ & $\begin{array}{c}0.237 \\
1.013 \\
3.901 \\
14.319\end{array}$ \\
\hline $\begin{array}{l}\text { C1A1-1 } \\
\text { C1A1-2 } \\
\text { C1A1-3 } \\
\text { C1A1-4 } \\
\text { C1A1-5 } \\
\text { C1A1-6 }\end{array}$ & $\begin{array}{l}0.0224 \\
0.1223 \\
0.4675\end{array}$ & 57.430 & 12.242 & 3.444 & $\begin{array}{c}0.910 \\
3.348 \\
24.472\end{array}$ & $\begin{array}{c}0.708 \\
2.236 \\
15.198\end{array}$ \\
\hline $\begin{array}{l}\text { C1 A2-1 } \\
\text { C1 A2-2 } \\
\text { C1 A2-3 } \\
\text { C1 A2-4 } \\
\text { C1 A2-5 } \\
\text { C1 A2-6 }\end{array}$ & $\begin{array}{l}0.0589 \\
0.1969 \\
0.3805\end{array}$ & & $\begin{array}{c}24.144 \\
7.537\end{array}$ & 4.152 & $\begin{array}{c}2.626 \\
6.074 \\
16.878\end{array}$ & $\begin{array}{c}1.846 \\
4.093 \\
10.684\end{array}$ \\
\hline $\begin{array}{l}\text { C1A3-1 } \\
\text { C1A3-2 } \\
\text { C1A3-3 } \\
\text { C1 A3-4 } \\
\text { C1A3-5 } \\
\text { C1A3-6 }\end{array}$ & $\begin{array}{l}0.0107 \\
0.0733 \\
0.3805\end{array}$ & 129.068 & 19.886 & 4.152 & $\begin{array}{c}0.387 \\
1.911 \\
14.371\end{array}$ & $\begin{array}{l}0.279 \\
1.312 \\
9.097\end{array}$ \\
\hline $\begin{array}{l}\text { C1A4-2 } \\
\text { C1A4-3 } \\
\text { C1A4-4 } \\
\text { C1A4-5 } \\
\text { C1A4-6 }\end{array}$ & $\begin{array}{l}0.0904 \\
0.3076 \\
0.5706\end{array}$ & & 16.378 & $\begin{array}{l}5.005 \\
2.858\end{array}$ & $\begin{array}{c}4.258 \\
11.990 \\
39.478\end{array}$ & $\begin{array}{c}2.876 \\
7.788 \\
24.210\end{array}$ \\
\hline $\begin{array}{l}C 0-1 \\
C 0-2 \\
C 0-3 \\
C 0-4 \\
C 0-5 \\
C 0-6\end{array}$ & $\begin{array}{l}0.0102 \\
0.0224 \\
0.2470 \\
0.4489\end{array}$ & $\begin{array}{c}146.192 \\
57.430\end{array}$ & 5.913 & 3.576 & $\begin{array}{c}0.336 \\
0.798 \\
13.243 \\
53.353\end{array}$ & $\begin{array}{c}0.224 \\
0.621 \\
9.067 \\
33.243\end{array}$ \\
\hline
\end{tabular}

ICEDF Gas Composition Analysis (page 6)

C. 33 
ICEDF SMF WkSht 6/88 supersedes ICEDF SMF WkSht 9/87

\section{How to use "ICEDF SMF WkSht 6/88"}

1) Open "ICEDF SMF WKSht 6/88".

2) Enter test name at cell $C 2$.

3) Save As "ICEDF testname month/year".

4) Enter data: Test Clock(enter)Sample Duration(enter)...

\section{How this spreadsheet works}

CO flow rate determined by Lookup function: Column H, Cells AB \& AC. Pressure correction added 5/23/89.

Dry gas volume $=\mathrm{CO}$ flow rate * sample duration * pressure correction .

Actual dry gas volume $=\mathrm{VOL}(\mathrm{dry}$, actual $)=$ sample duration ${ }^{*} \mathrm{CO}$ flow rate ${ }^{*}(273+\mathrm{To}) / 293$.

$\mathrm{H} 2 \mathrm{O}$ specific volume $=1.227+0.004712$ (To) for $\mathrm{To} \geq 100^{\circ} \mathrm{C}$.

$\mathrm{H} 2 \mathrm{O}$ saturated steam partial pressure (Psat $/ \mathrm{Po}=$ Formula1) for $\mathrm{T}<100^{\circ} \mathrm{C}$.

Formula1 $=0.0107-3.451^{*} 10^{\wedge}-4^{\star} \mathrm{F} 10+5.359^{\star} 10^{\wedge}-5^{\star} \mathrm{F} 10^{\wedge} 2-5.694^{\star} 10^{\wedge}-7^{\star} \mathrm{F} 10^{\wedge} 3+1.057^{*} 10^{\wedge}-8^{\star} \mathrm{F} 10^{\wedge} 4$

Actual $\mathrm{H} 2 \mathrm{O}$ gas volume:

$\mathrm{T}<100^{\circ} \mathrm{C}: \quad \operatorname{VOL}(\max )=[(\mathrm{Psat} / \mathrm{Po}))^{*}(\mathrm{VOL}($ dry, actual $\left.))\right] /[1$ - (Psat/Po $\left.)\right]$. See BNW 51060, pg 133. $\mathrm{VOL}(\max )=\mathrm{VOL}(\mathrm{H} 2 \mathrm{O}$, saturated, maximum possible at $\mathrm{T})$

Fog Check: compare $\mathrm{H} 2 \mathrm{O}$ mass collected to $\mathrm{H} 2 \mathrm{O}$ mass required for sample saturation $\mathrm{M}(\mathrm{H} 2 \mathrm{O}$, sat) $=[[\mathrm{VOL}($ dry, actual $)+\mathrm{VOL}(\mathrm{H} 2 \mathrm{O}, \max )] / \mathrm{Vs}(\mathrm{H} 2 \mathrm{O}$ vapor, sat $)](1000 / 1000)$ Vs $(\mathrm{H} 2 \mathrm{O}$ vapor, sat $)=$ FormulaA if $\mathrm{T}<25^{\circ} \mathrm{C},=$ FormulaC if $\mathrm{T}>65^{\circ} \mathrm{C}$.

FormulaA $=199.61 * 10^{\wedge}(-2.7052 \theta-2(T))$.

FormulaB $=138.44^{*} 10^{\wedge}(-2.1068 \theta-2(T))$.

FormulaC $=68.411 * 10^{\wedge}(-1.6225 \theta-2(T))$.

1) If condensate mass $<M(\mathrm{H} 2 \mathrm{O}$, sat):

$\operatorname{VOL}(\mathrm{H} 2 \mathrm{O}$, actual $)=(\mathrm{RH}) \bullet(\mathrm{VOL}(\max ))$. Print "Not Sat."

2) If condensate mass $=\mathrm{M}(\mathrm{H} 2 \mathrm{O}$, sat $)$ :

$\mathrm{RH}=$ condensate mass $/ \mathrm{M}(\mathrm{H} 2 \mathrm{O}$, sat $)$.

VOL $(\mathrm{H} 2 \mathrm{O}$, actual $)=$ VOL $(\max )$. Print "Sat." (saturated).

3) If condenate mass $>M(H 2 O$, sat):

VOL $(\mathrm{H} 2 \mathrm{O}$, actual $)=$ VOL (max). Calculate and print fog mass conc.

Fog Conc $=$ condensate mass $-\mathrm{M}(\mathrm{H} 2 \mathrm{O}$, sat $) /$ sample vol. (sample vol $=\left(1000 \mathrm{~m}^{\wedge} 3 / /\right)^{\star} \Sigma$ [actual $\mathrm{H} 2 \mathrm{O}$ \& dry vols])

$\mathrm{T} \geq 100^{\circ} \mathrm{C}: \quad \mathrm{Vol}(\mathrm{H} 2 \mathrm{O})=$ (condensate mass * sat steam spec vol $)^{*}(1000 / 1000)$. Print "S. H. Vap."

SMF = Actual $\mathrm{H} 20$ gas volume / total gas volume (ie., the sum of actual dry and actual $\mathrm{H} 2 \mathrm{O}$ volumes, = sample vol",

Not included: 1) possible temp variations, 2) possible supersaturation.

CO upstream pressure correction factor added to spreadsheet on 6/14/89 (in draft form in 5/89). 
Modifications:

ICEDF SMF WkSht 6/89 superseded ICEDF SMF WkSht 9/87

1) Original date of this version was $6 / 14 / 89$.

2) 1st modification was made 9/14/89:

Crit orifice flow corr. factor formula was changed to print "n if test time was "".

Sample analysis date cell was added to top of page 1.

ICEDF SMF WkSht 10/89 superseded ICEDF SMF WkSht 6/89
1) Changed printer page set-up, and minor editing.
2) Changed SMF column equation to print "n (blank) if no H2O mass is entered.
3) Changed Fog column equation to print "' if no SMF is calculated, and ¿Sat? if SMF is calculated based on assumed saturation when no $\mathrm{H} 2 \mathrm{O}$ mass is entered.
4) Changed Sample ID column 12/1/89 to match new test plan (no C6B1 or C6B2). 


\begin{tabular}{|c|c|c|c|c|c|c|c|c|}
\hline $\begin{array}{c}\text { Prolect: } \\
\text { ICEDF }\end{array}$ & Test: & & & & & $\begin{array}{c}\begin{array}{c}\text { Date of } \\
\text { Analysis }\end{array} \\
12 / 1 / 89\end{array}$ & $\begin{array}{c}\text { Q.A. Verific } \\
\text { Name } \\
\text { WWL }\end{array}$ & $\begin{array}{l}\text { Dation: } \\
\text { Date } \\
1 / 31 / 90\end{array}$ \\
\hline $\begin{array}{l}\text { Sample } \\
\text { ID No. }\end{array}$ & $\begin{array}{c}\text { Test Clock } \\
\text { (min) }\end{array}$ & $\begin{array}{l}\text { Sample } \\
\text { Duration } \\
\Delta t \text { (min) }\end{array}$ & $\begin{array}{l}\text { To } \\
\left({ }^{\circ} \mathrm{C}\right)\end{array}$ & $\begin{array}{c}\text { Critical } \\
\text { Orifice } \\
(\#)\end{array}$ & $\begin{array}{l}C O \\
\Delta P \\
(n \mathrm{Hg})\end{array}$ & $\begin{array}{c}\text { Condensate } \\
\mathrm{H} 2 \mathrm{O} \text { Mass } \\
\text { (a) }\end{array}$ & $\begin{array}{l}\text { Crit. Orifice } \\
\text { Flow Rate } \\
@ 20^{\circ} \mathrm{C} \\
\text { (lpm) }\end{array}$ & $\begin{array}{l}\text { Crit. Orifice } \\
\text { Flow Corr. } \\
\text { Factor } \\
(-)\end{array}$ \\
\hline $\begin{array}{l}\text { C6A-1 } \\
\text { C6A-2 } \\
\text { C6A-3 } \\
\text { C6A-4 } \\
\text { C6A-5 } \\
\text { C6A-6 }\end{array}$ & $\begin{array}{l}11.00 \\
21.00 \\
31.33 \\
41.00 \\
51.33 \\
61.33\end{array}$ & $\begin{array}{l}4.00 \\
4.00 \\
4.00 \\
4.00 \\
4.00 \\
4.00\end{array}$ & $\begin{array}{c}95 \\
100 \\
106 \\
109 \\
110 \\
111\end{array}$ & $\begin{array}{l}80 \\
80 \\
80 \\
80 \\
80 \\
80\end{array}$ & $\begin{array}{l}0.4 \\
0.6 \\
0.6 \\
0.6 \\
0.5 \\
0.5\end{array}$ & $\begin{array}{c}3.80 \\
19.13 \\
19.05 \\
18.32 \\
17.01 \\
19.39\end{array}$ & $\begin{array}{l}1.033 \\
1.033 \\
1.033 \\
1.033 \\
1.033 \\
1.033\end{array}$ & $\begin{array}{l}0.99 \\
0.98 \\
0.98 \\
0.98 \\
0.98 \\
0.98\end{array}$ \\
\hline $\begin{array}{l}\text { C5A1-1 } \\
\text { C5A1-2 } \\
\text { C5A1-3 } \\
\text { C5A1-4 } \\
\text { C5A1-5 } \\
\text { C5A1-6 }\end{array}$ & $\begin{array}{l}11.00 \\
21.00 \\
31.00 \\
41.00 \\
51.00 \\
61.00\end{array}$ & $\begin{array}{l}4.00 \\
2.00 \\
4.00 \\
4.00 \\
2.00 \\
4.00\end{array}$ & $\begin{array}{l}60 \\
55 \\
65 \\
56 \\
69 \\
78\end{array}$ & $\begin{array}{l}65 \\
65 \\
65 \\
65 \\
65 \\
65\end{array}$ & $\begin{array}{l}2.0 \\
2.0 \\
0.0 \\
0.0 \\
0.0 \\
0.0\end{array}$ & $\begin{array}{c}6.95 \\
2.96 \\
8.22 \\
7.11 \\
5.83 \\
26.08\end{array}$ & $\begin{array}{l}6.910 \\
6.910 \\
6.910 \\
6.910 \\
6.910 \\
6.910\end{array}$ & $\begin{array}{l}0.93 \\
0.93 \\
1.00 \\
1.00 \\
1.00 \\
1.00\end{array}$ \\
\hline $\begin{array}{l}\text { C5A2-1 } \\
\text { C5A2-2 } \\
\text { C5A2-3 } \\
\text { C5A2-4 } \\
\text { C5A2-5 } \\
\text { C5A2-6 }\end{array}$ & $\begin{array}{l}11.00 \\
21.00 \\
31.00 \\
41.00 \\
51.00 \\
61.00\end{array}$ & $\begin{array}{l}4.00 \\
2.00 \\
4.00 \\
4.00 \\
2.00 \\
4.00\end{array}$ & $\begin{array}{l}60 \\
72 \\
64 \\
50 \\
53 \\
61\end{array}$ & $\begin{array}{l}65 \\
65 \\
65 \\
65 \\
65 \\
65\end{array}$ & $\begin{array}{l}0.0 \\
2.0 \\
2.0 \\
2.0 \\
2.0 \\
2.0\end{array}$ & $\begin{array}{c}13.93 \\
7.09 \\
4.59 \\
4.89 \\
1.83 \\
7.38\end{array}$ & $\begin{array}{l}6.910 \\
6.910 \\
6.910 \\
6.910 \\
6.910 \\
6.910\end{array}$ & $\begin{array}{l}1.00 \\
0.93 \\
0.93 \\
0.93 \\
0.93 \\
0.93\end{array}$ \\
\hline $\begin{array}{l}\text { C5A3-1 } \\
\text { C5A3-2 } \\
\text { C5A3-3 } \\
\text { C5A3-4 } \\
\text { C5A3-5 } \\
\text { C5A3-6 }\end{array}$ & $\begin{array}{l}11.08 \\
21.04 \\
31.00 \\
41.00 \\
51.00 \\
61.00\end{array}$ & $\begin{array}{l}4.17 \\
4.08 \\
4.00 \\
4.00 \\
4.00 \\
4.00\end{array}$ & $\begin{array}{l}56 \\
57 \\
90 \\
76 \\
86 \\
81\end{array}$ & $\begin{array}{l}65 \\
65 \\
65 \\
65 \\
65 \\
65\end{array}$ & $\begin{array}{l}1.0 \\
2.0 \\
2.0 \\
1.5 \\
2.0 \\
1.2\end{array}$ & $\begin{array}{c}9.06 \\
2.77 \\
28.36 \\
16.24 \\
11.14 \\
5.50\end{array}$ & $\begin{array}{l}6.910 \\
6.910 \\
6.910 \\
6.910 \\
6.910 \\
6.910\end{array}$ & $\begin{array}{l}0.97 \\
0.93 \\
0.93 \\
0.95 \\
0.93 \\
0.96\end{array}$ \\
\hline $\begin{array}{l}\text { C5A4-1 } \\
\text { C5A4-2 } \\
\text { C5A4-3 } \\
\text { C5A4-4 } \\
\text { C5A4-5 } \\
\text { C5A4-6 }\end{array}$ & $\begin{array}{l}11.08 \\
21.04 \\
31.00 \\
41.00 \\
51.00 \\
61.00\end{array}$ & $\begin{array}{l}4.17 \\
4.08 \\
4.00 \\
4.00 \\
4.00 \\
4.00\end{array}$ & $\begin{array}{l}76 \\
76 \\
86 \\
78 \\
82 \\
74\end{array}$ & $\begin{array}{l}65 \\
65 \\
65 \\
65 \\
65 \\
65\end{array}$ & $\begin{array}{l}0.5 \\
2.0 \\
2.0 \\
2.0 \\
2.0 \\
2.0\end{array}$ & $\begin{array}{l}11.40 \\
18.48 \\
17.54 \\
21.65 \\
11.33 \\
10.99\end{array}$ & $\begin{array}{l}6.910 \\
6.910 \\
6.910 \\
6.910 \\
6.910 \\
6.910\end{array}$ & $\begin{array}{l}0.98 \\
0.93 \\
0.93 \\
0.93 \\
0.93 \\
0.93\end{array}$ \\
\hline $\begin{array}{l}C 4 B-1 \\
C 4 B-2 \\
C 4 B-3 \\
C 4 B-4 \\
C 4 B-5 \\
C 4 B-6\end{array}$ & $\begin{array}{l}11.13 \\
21.13 \\
31.13 \\
41.13 \\
51.13 \\
61.13\end{array}$ & $\begin{array}{l}4.00 \\
4.00 \\
4.00 \\
4.00 \\
4.00 \\
4.00\end{array}$ & & $\begin{array}{l}69 \\
69 \\
69 \\
69 \\
69 \\
69\end{array}$ & & $\begin{array}{c}0.07 \\
3.50 \\
4.22 \\
3.99 \\
6.85 \\
17.89\end{array}$ & $\begin{array}{l}5.030 \\
5.030 \\
5.030 \\
5.030 \\
5.030 \\
5.030\end{array}$ & $\begin{array}{l}1.00 \\
1.00 \\
1.00 \\
1.00 \\
1.00 \\
1.00\end{array}$ \\
\hline
\end{tabular}

ICEDF Gas Composition Analysis (page 1) 


\begin{tabular}{|c|c|c|c|c|c|c|c|c|}
\hline $\begin{array}{l}\text { Project: } \\
\text { ICEDF }\end{array}$ & $\begin{array}{l}\text { Test: } \\
16-11 \\
\end{array}$ & & & & & & \begin{tabular}{|c|}
$\begin{array}{c}\text { Q.A. Verific } \\
\text { Name }\end{array}$ \\
$M W L$ \\
\end{tabular} & \begin{tabular}{c|} 
ation: \\
Date \\
$1 / 31 / 90$ \\
\end{tabular} \\
\hline $\begin{array}{l}\text { Sample } \\
\text { ID No. }\end{array}$ & $\begin{array}{c}\text { Test Clock } \\
\text { (min) }\end{array}$ & $\begin{array}{l}\text { Sample } \\
\text { Duration } \\
\Delta t \text { (min) }\end{array}$ & $\begin{array}{c}\text { To } \\
\left({ }^{\circ} \mathrm{C}\right)\end{array}$ & $\begin{array}{c}\text { Critical } \\
\text { Orifice } \\
(\#) \\
\end{array}$ & $\begin{array}{c}C O \\
\Delta P \\
(" \mathrm{Hg})\end{array}$ & $\begin{array}{c}\text { Condensate } \\
\mathrm{H} 2 \mathrm{O} \text { Mass } \\
\text { (g) }\end{array}$ & $\begin{array}{c}\text { Crit. Orifice } \\
\text { Flow Rate } \\
@ 20^{\circ} \mathrm{C} \\
\text { (lpm) } \\
\end{array}$ & $\begin{array}{c}\text { Crit. Orifice } \\
\text { Flow Corr. } \\
\text { Factor } \\
(-)\end{array}$ \\
\hline C2B-1 & 11.00 & 4.00 & & 69 & & 0.11 & 5.030 & 1.00 \\
\hline C2B-2 & 21.00 & 4.00 & & 69 & & 1.18 & 5.030 & 1.00 \\
\hline C2B-3 & 31.00 & 4.00 & & 69 & & 1.04 & 5.030 & 1.00 \\
\hline C2B-4 & 41.00 & 4.00 & & 69 & & 1.36 & 5.030 & 1.00 \\
\hline C2B-5 & 51.00 & 4.00 & & 69 & & 2.00 & 5.030 & 1.00 \\
\hline C2B-6 & 61.00 & 4.00 & & 69 & & 9.18 & 5.030 & 1.00 \\
\hline C1A1-1 & 12.06 & 2.12 & 1 & 65 & 0.3 & 0.10 & 6.910 & 0.99 \\
\hline C1A1-2 & 21.00 & 2.00 & 7 & 65 & 1.3 & 0.02 & 6.910 & 0.96 \\
\hline C1A1-3 & 31.42 & 3.17 & 12 & 65 & 1.2 & 0.71 & 6.910 & 0.96 \\
\hline C1A1-4 & 41.00 & 4.00 & 15 & 65 & 0.7 & 0.75 & 6.910 & 0.98 \\
\hline C1A1-5 & 51.00 & 2.00 & 37 & 65 & 1.3 & 0.37 & 6.910 & 0.96 \\
\hline C1A1-6 & 61.00 & 4.00 & 52 & 65 & 0.6 & 2.78 & 6.910 & 0.98 \\
\hline C1A2-1 & 11.06 & 4.12 & 11 & 65 & 0.7 & 0.12 & 6.910 & 0.98 \\
\hline C1A2-2 & 21.00 & 2.00 & 25 & 65 & 0.7 & 0.29 & 6.910 & 0.98 \\
\hline C1A2-3 & 31.42 & 3.17 & 24 & 65 & 0.7 & 1.02 & 6.910 & 0.98 \\
\hline C1A2-4 & 41.00 & 4.00 & 30 & 65 & 0.6 & 1.07 & 6.910 & 0.98 \\
\hline C1A2-5 & 51.00 & 2.00 & 36 & 65 & 0.6 & 0.38 & 6.910 & 0.98 \\
\hline C1A2-6 & 61.00 & 4.00 & 50 & 65 & 0.6 & 2.24 & 6.910 & 0.98 \\
\hline C1A3-1 & 11.00 & 4.00 & & 65 & & 0.62 & 6.910 & 1.00 \\
\hline C1A3-2 & 21.00 & 2.00 & 5 & 65 & & 0.35 & 6.910 & 1.00 \\
\hline C1A3-3 & 31.00 & 4.00 & 13 & 65 & 1.5 & 0.01 & 6.910 & 0.95 \\
\hline C1A3-4 & 41.00 & 4.00 & 22 & 65 & 1.5 & 0.01 & 6.910 & 0.95 \\
\hline C1A3-5 & 51.00 & 2.00 & 58 & 65 & 3.0 & 2.24 & 6.910 & 0.90 \\
\hline C1A3-6 & 61.00 & 4.00 & 67 & 65 & 1.5 & 8.20 & 6.910 & 0.95 \\
\hline C1A4-1 & 11.00 & 4.00 & & 65 & & 0.25 & 6.910 & 1.00 \\
\hline C1A4-2 & 21.00 & 2.00 & 16 & 65 & & 0.00 & 6.910 & 1.00 \\
\hline C1A4-3 & 31.00 & 4.00 & 30 & 65 & 0.5 & 1.72 & 6.910 & 0.98 \\
\hline C1A4-4 & 41.00 & 4.00 & 55 & 65 & 0.5 & 3.02 & 6.910 & 0.98 \\
\hline C1A4-5 & 51.00 & 2.00 & 60 & 65 & 1.0 & 1.61 & 6.910 & 0.97 \\
\hline C1A4-6 & 61.00 & 4.00 & 60 & 65 & 0.5 & 5.00 & 6.910 & 0.98 \\
\hline$C 0-1$ & 11.00 & 4.00 & 1 & 69 & 0.7 & 0.16 & 5.030 & 0.98 \\
\hline $\mathrm{CO}-2$ & 21.00 & 4.00 & 10 & 69 & 0.7 & 0.30 & 5.030 & 0.98 \\
\hline $\mathrm{CO}-3$ & 31.00 & 4.00 & 15 & 69 & 0.8 & 0.96 & 5.030 & 0.97 \\
\hline $\mathrm{CO}-4$ & 41.00 & 4.00 & 20 & 69 & 0.7 & 1.02 & 5.030 & 0.98 \\
\hline $\mathrm{CO}-5$ & 51.00 & 5.00 & 39 & 69 & 0.7 & 1.73 & 5.030 & 0.98 \\
\hline $\mathrm{CO}-6$ & 61.00 & 4.02 & 60 & 69 & 0.8 & 6.70 & 5.030 & 0.97 \\
\hline
\end{tabular}

ICEDF Gas Composition Analysis (page 2) 


\begin{tabular}{|c|c|c|c|c|c|c|c|c|}
\hline $\begin{array}{l}\text { Project: } \\
\text { ICEDF }\end{array}$ & $\begin{array}{c}\text { Test: } \\
16-11 \\
\end{array}$ & & & & & & & \\
\hline $\begin{array}{l}\text { Sample } \\
\text { ID No. }\end{array}$ & $\begin{array}{c}\text { Dry Gas } \\
\text { Volume } \\
\left(1 @ 20^{\circ} \mathrm{C}\right)\end{array}$ & $\begin{array}{c}\text { Sat. Vapor } \\
\left(\mathrm{T}<100^{\circ} \mathrm{C}\right) \\
\text { (Psat/Po) }\end{array}$ & $\begin{array}{c}\text { H2O Vapor } \\
\text { Spec. Vol. } \\
\left(T<100^{\circ} \mathrm{C}\right) \\
(\mathrm{m} 3 / \mathrm{kg})\end{array}$ & $\begin{array}{c}\text { H2O Vapor } \\
\text { Spec. Vol. } \\
\left(T \geq 100^{\circ} \mathrm{C}\right) \\
(\mathrm{m} 3 / \mathrm{kg})\end{array}$ & $\begin{array}{l}\text { Dry Gas } \\
\text { Volume } \\
(1 @ \text { To })\end{array}$ & $\begin{array}{l}\text { H2O Gas } \\
\text { Volume } \\
\text { (1@ To) }\end{array}$ & $\begin{array}{c}\text { SMF } \\
(-)\end{array}$ & $\begin{array}{c}\text { Fog } \\
@ \text { To } \\
\left(\mathrm{mg} / \mathrm{m}^{\wedge} 3\right)\end{array}$ \\
\hline $\begin{array}{l}\text { C6A-1 } \\
\text { C6A-2 } \\
\text { C6A-3 } \\
\text { C6A-4 } \\
\text { C6A-5 } \\
\text { C6A-6 }\end{array}$ & $\begin{array}{l}4.077 \\
4.049 \\
4.049 \\
4.049 \\
4.063 \\
4.063\end{array}$ & $\begin{array}{c}0.8343 \\
T \geq 100^{\circ} \mathrm{C} \\
T \geq 100^{\circ} \mathrm{C} \\
T \geq 100^{\circ} \mathrm{C} \\
T \geq 100^{\circ} \mathrm{C} \\
T \geq 100^{\circ} \mathrm{C}\end{array}$ & $\begin{array}{c}1.967 \\
T \geq 100^{\circ} \mathrm{C} \\
T \geq 100^{\circ} \mathrm{C} \\
T \geq 100^{\circ} \mathrm{C} \\
T \geq 100^{\circ} \mathrm{C} \\
T \geq 100^{\circ} \mathrm{C}\end{array}$ & $\begin{array}{c}\mathrm{T}<100^{\circ} \mathrm{C} \\
1.698 \\
1.726 \\
1.741 \\
1.745 \\
1.750\end{array}$ & $\begin{array}{l}5.12 \\
5.15 \\
5.24 \\
5.28 \\
5.31 \\
5.33\end{array}$ & $\begin{array}{c}6.24 \\
32.49 \\
32.89 \\
31.89 \\
29.69 \\
33.93\end{array}$ & $\begin{array}{l}0.549 \\
0.863 \\
0.863 \\
0.858 \\
0.848 \\
0.864\end{array}$ & $\begin{array}{l}\text { Not Sat. } \\
\text { S. H. Vap. } \\
\text { S. H. Vap. } \\
\text { S. H. Vap. } \\
\text { S. H. Vap. } \\
\text { S. H. Vap. }\end{array}$ \\
\hline $\begin{array}{l}\text { C5A1-1 } \\
\text { C5A1-2 } \\
\text { C5A1-3 } \\
\text { C5A1-4 } \\
\text { C5A1-5 } \\
\text { C5A1-6 }\end{array}$ & $\begin{array}{l}25.797 \\
12.899 \\
27.640 \\
27.640 \\
13.820 \\
27.640\end{array}$ & $\begin{array}{l}0.1969 \\
0.1558 \\
0.2470 \\
0.1634 \\
0.2946 \\
0.4309\end{array}$ & $\begin{array}{l}7.537 \\
9.606 \\
5.913 \\
9.151 \\
5.195 \\
3.712\end{array}$ & $\begin{array}{l}T<100^{\circ} \mathrm{C} \\
T<100^{\circ} \mathrm{C} \\
T<100^{\circ} \mathrm{C} \\
T<100^{\circ} \mathrm{C} \\
T<100^{\circ} \mathrm{C} \\
T<100^{\circ} \mathrm{C}\end{array}$ & $\begin{array}{l}29.32 \\
14.44 \\
31.89 \\
31.04 \\
16.13 \\
33.11\end{array}$ & $\begin{array}{c}7.19 \\
2.67 \\
10.46 \\
6.06 \\
6.74 \\
25.07\end{array}$ & $\begin{array}{l}0.197 \\
0.156 \\
0.247 \\
0.163 \\
0.295 \\
0.431\end{array}$ & $\begin{array}{c}57.68 \\
68.95 \\
25.02 \\
82.38 \\
62.47 \\
178.86\end{array}$ \\
\hline $\begin{array}{l}\text { C5A2-1 } \\
\text { C5A2-2 } \\
\text { C5A2-3 } \\
\text { C5A2-4 } \\
\text { C5A2-5 } \\
\text { C5A2-6 }\end{array}$ & $\begin{array}{l}27.640 \\
12.899 \\
25.797 \\
25.797 \\
12.899 \\
25.797\end{array}$ & $\begin{array}{l}0.1969 \\
0.3352 \\
0.2362 \\
0.1223 \\
0.1416 \\
0.2062\end{array}$ & $\begin{array}{c}7.537 \\
4.644 \\
6.207 \\
12.242 \\
10.584 \\
7.180\end{array}$ & $\begin{array}{l}T<100^{\circ} \mathrm{C} \\
T<100^{\circ} \mathrm{C} \\
T<100^{\circ} \mathrm{C} \\
T<100^{\circ} \mathrm{C} \\
T<100^{\circ} \mathrm{C} \\
T<100^{\circ} \mathrm{C}\end{array}$ & $\begin{array}{l}31.41 \\
15.19 \\
29.67 \\
28.44 \\
14.35 \\
29.41\end{array}$ & $\begin{array}{l}7.70 \\
7.66 \\
6.73 \\
3.96 \\
2.37 \\
7.64\end{array}$ & $\begin{array}{l}0.197 \\
0.335 \\
0.185 \\
0.122 \\
0.142 \\
0.206\end{array}$ & $\begin{array}{c}223.44 \\
95.03 \\
\text { Not Sat. } \\
69.23 \\
14.98 \\
59.94\end{array}$ \\
\hline $\begin{array}{l}\text { C5A3-1 } \\
\text { C5A3-2 } \\
\text { C5A3-3 } \\
\text { C5A3-4 } \\
\text { C5A3-5 } \\
\text { C5A3-6 }\end{array}$ & $\begin{array}{l}27.854 \\
26.313 \\
25.797 \\
26.258 \\
25.797 \\
26.534\end{array}$ & $\begin{array}{l}0.1634 \\
0.1713 \\
0.6921 \\
0.3967 \\
0.5934 \\
0.4868\end{array}$ & $\begin{array}{l}9.151 \\
8.717 \\
2.371 \\
4.000 \\
2.753 \\
3.318\end{array}$ & $\begin{array}{l}T<100^{\circ} \mathrm{C} \\
T<100^{\circ} \mathrm{C} \\
T<100^{\circ} \mathrm{C} \\
T<100^{\circ} \mathrm{C} \\
T<100^{\circ} \mathrm{C} \\
T<100^{\circ} \mathrm{C}\end{array}$ & $\begin{array}{l}31.28 \\
29.64 \\
31.96 \\
31.28 \\
31.61 \\
32.06\end{array}$ & $\begin{array}{c}6.11 \\
4.14 \\
46.53 \\
20.57 \\
18.20 \\
8.88\end{array}$ & $\begin{array}{l}0.163 \\
0.122 \\
0.593 \\
0.397 \\
0.365 \\
0.217\end{array}$ & $\begin{array}{c}133.06 \\
\text { Not Sat. } \\
\text { Not Sat. } \\
63.24 \\
\text { Not Sat. } \\
\text { Not Sat. }\end{array}$ \\
\hline $\begin{array}{l}\text { C5A4-1 } \\
\text { C5A4-2 } \\
\text { C5A4-3 } \\
\text { C5A4-4 } \\
\text { C5A4-5 } \\
\text { C5A4-6 }\end{array}$ & $\begin{array}{l}28.334 \\
26.313 \\
25.797 \\
25.797 \\
25.797 \\
25.797\end{array}$ & $\begin{array}{l}0.3967 \\
0.3967 \\
0.5934 \\
0.4309 \\
0.5067 \\
0.3648\end{array}$ & $\begin{array}{l}4.000 \\
4.000 \\
2.753 \\
3.712 \\
3.197 \\
4.310\end{array}$ & $\begin{array}{l}\mathrm{T}<100^{\circ} \mathrm{C} \\
T<100^{\circ} \mathrm{C} \\
T<100^{\circ} \mathrm{C} \\
T<100^{\circ} \mathrm{C} \\
T<100^{\circ} \mathrm{C} \\
T<100^{\circ} \mathrm{C}\end{array}$ & $\begin{array}{l}33.75 \\
31.34 \\
31.61 \\
30.90 \\
31.26 \\
30.55\end{array}$ & $\begin{array}{l}18.09 \\
20.61 \\
28.65 \\
23.40 \\
18.35 \\
17.28\end{array}$ & $\begin{array}{l}0.349 \\
0.397 \\
0.475 \\
0.431 \\
0.370 \\
0.361\end{array}$ & $\begin{array}{c}\text { Not Sat. } \\
105.70 \\
\text { Not Sat. } \\
129.30 \\
\text { Not Sat. } \\
\text { Not Sat. }\end{array}$ \\
\hline $\begin{array}{l}C 4 B-1 \\
C 4 B-2 \\
C 4 B-3 \\
C 4 B-4 \\
C 4 B-5 \\
C 4 B-6\end{array}$ & $\begin{array}{l}20.120 \\
20.120 \\
20.120 \\
20.120 \\
20.120 \\
20.120\end{array}$ & & & & $\begin{array}{l}18.75 \\
18.75 \\
18.75 \\
18.75 \\
18.75 \\
18.75\end{array}$ & & & \\
\hline
\end{tabular}

ICEDF Gas Composition Analysis (page 3) 


\begin{tabular}{|c|c|c|c|c|c|c|c|c|}
\hline $\begin{array}{l}\text { Prolect: } \\
\text { ICEDF }\end{array}$ & & $\begin{array}{l}\text { Test: } \\
16-11 \\
\end{array}$ & & & & & & \\
\hline $\begin{array}{l}\text { Sample } \\
\text { ID No. }\end{array}$ & $\begin{array}{c}\text { Dry Gas } \\
\text { Volume } \\
\left(1 @ 20^{\circ} \mathrm{C}\right)\end{array}$ & $\begin{array}{c}\text { Sat. Vapor } \\
\left(\mathrm{T}<100^{\circ} \mathrm{C}\right) \\
\text { (Psat/Po) }\end{array}$ & $\begin{array}{c}\text { H2O Vapor } \\
\text { Spec. Vol. } \\
\left(\mathrm{T}<100^{\circ} \mathrm{C}\right) \\
(\mathrm{m} 3 / \mathrm{kg})\end{array}$ & $\begin{array}{c}\text { H2O Vapor } \\
\text { Spec. Vol. } \\
\left(\mathrm{T} \geq 100^{\circ} \mathrm{C}\right) \\
(\mathrm{m} 3 / \mathrm{kg})\end{array}$ & $\begin{array}{l}\text { Dry Gas } \\
\text { Volume } \\
\text { (1@ @o) }\end{array}$ & $\begin{array}{l}\text { H2O Gas } \\
\text { Volume } \\
(1 @ \text { To })\end{array}$ & $\begin{array}{c}\text { SMF } \\
(-)\end{array}$ & $\begin{array}{c}\text { Fog } \\
@ \text { To } \\
\left(\mathrm{mg} / \mathrm{m}^{\wedge} 3\right)\end{array}$ \\
\hline $\begin{array}{l}\text { C2B-1 } \\
\text { C2B-2 } \\
\text { C2B-3 } \\
\text { C2B-4 } \\
\text { C2B-5 } \\
\text { C2B-6 }\end{array}$ & $\begin{array}{l}20.120 \\
20.120 \\
20.120 \\
20.120 \\
20.120 \\
20.120\end{array}$ & & & & $\begin{array}{l}18.75 \\
18.75 \\
18.75 \\
18.75 \\
18.75 \\
18.75\end{array}$ & & & \\
\hline $\begin{array}{l}\text { C1A1-1 } \\
\text { C1A1-2 } \\
\text { C1A1-3 } \\
\text { C1A1-4 } \\
\text { C1A1-5 } \\
\text { C1A1-6 }\end{array}$ & $\begin{array}{l}14.527 \\
13.221 \\
21.029 \\
26.995 \\
13.221 \\
27.087\end{array}$ & $\begin{array}{l}0.0104 \\
0.0107 \\
0.0135 \\
0.0162 \\
0.0623 \\
0.1349\end{array}$ & $\begin{array}{c}187.556 \\
129.068 \\
94.528 \\
78.416 \\
23.001 \\
11.110\end{array}$ & $\begin{array}{l}\mathrm{T}<100^{\circ} \mathrm{C} \\
\mathrm{T}<100^{\circ} \mathrm{C} \\
\mathrm{T}<100^{\circ} \mathrm{C} \\
\mathrm{T}<100^{\circ} \mathrm{C} \\
\mathrm{T}<100^{\circ} \mathrm{C} \\
T<100^{\circ} \mathrm{C}\end{array}$ & $\begin{array}{l}13.59 \\
12.63 \\
20.45 \\
26.53 \\
13.99 \\
30.05\end{array}$ & $\begin{array}{l}0.14 \\
0.03 \\
0.28 \\
0.44 \\
0.53 \\
4.17\end{array}$ & $\begin{array}{l}0.010 \\
0.002 \\
0.014 \\
0.016 \\
0.036 \\
0.122\end{array}$ & $\begin{array}{c}1.95 \\
\text { Not Sat. } \\
23.66 \\
15.05 \\
\text { Not Sat. } \\
\text { Not Sat. }\end{array}$ \\
\hline $\begin{array}{l}\text { C1A2-1 } \\
\text { C1A2-2 } \\
\text { C1A2-3 } \\
\text { C1A2-4 } \\
\text { C1A2-5 } \\
\text { C1A2-6 }\end{array}$ & $\begin{array}{l}27.805 \\
13.498 \\
21.394 \\
27.087 \\
13.544 \\
27.087\end{array}$ & $\begin{array}{l}0.0128 \\
0.0308 \\
0.0289 \\
0.0418 \\
0.0589 \\
0.1223\end{array}$ & $\begin{array}{c}100.603 \\
41.168 \\
44.765 \\
32.301 \\
24.144 \\
12.242\end{array}$ & $\begin{array}{l}\mathrm{T}<100^{\circ} \mathrm{C} \\
\mathrm{T}<100^{\circ} \mathrm{C} \\
\mathrm{T}<100^{\circ} \mathrm{C} \\
\mathrm{T}<100^{\circ} \mathrm{C} \\
\mathrm{T}<100^{\circ} \mathrm{C} \\
T<100^{\circ} \mathrm{C}\end{array}$ & $\begin{array}{l}26.95 \\
13.73 \\
21.69 \\
28.01 \\
14.28 \\
29.86\end{array}$ & $\begin{array}{l}0.15 \\
0.37 \\
0.65 \\
1.22 \\
0.54 \\
3.35\end{array}$ & $\begin{array}{l}0.006 \\
0.026 \\
0.029 \\
0.042 \\
0.036 \\
0.101\end{array}$ & $\begin{array}{c}\text { Not Sat. } \\
\text { Not Sat. } \\
23.34 \\
5.64 \\
\text { Not Sat. } \\
\text { Not Sat. }\end{array}$ \\
\hline $\begin{array}{l}\text { C1A3-1 } \\
\text { C1A3-2 } \\
\text { C1A3-3 } \\
\text { C1A3-4 } \\
\text { C1A3-5 } \\
\text { C1A3-6 }\end{array}$ & $\begin{array}{l}27.640 \\
13.820 \\
26.258 \\
26.258 \\
12.438 \\
26.258\end{array}$ & $\begin{array}{l}0.0102 \\
0.0143 \\
0.0255 \\
0.1795 \\
0.2699\end{array}$ & $\begin{array}{c}146.192 \\
88.819 \\
50.704 \\
8.305 \\
5.598\end{array}$ & $\begin{array}{l}T<100^{\circ} \mathrm{C} \\
T<100^{\circ} \mathrm{C} \\
T<100^{\circ} \mathrm{C} \\
T<100^{\circ} \mathrm{C} \\
T<100^{\circ} \mathrm{C}\end{array}$ & $\begin{array}{l}25.75 \\
13.11 \\
25.63 \\
26.44 \\
14.05 \\
30.47\end{array}$ & $\begin{array}{c}0.14 \\
0.01 \\
0.01 \\
3.07 \\
11.26\end{array}$ & $\begin{array}{l}0.010 \\
0.000 \\
0.000 \\
0.179 \\
0.270\end{array}$ & $\begin{array}{c}19.58 \\
\text { Not Sat. } \\
\text { Not Sat. } \\
10.39 \\
17.86\end{array}$ \\
\hline $\begin{array}{l}\text { C1A4-1 } \\
\text { C1A4-2 } \\
\text { C1A4-3 } \\
\text { C1A4-4 } \\
\text { C1A4-5 } \\
\text { C1A4-6 }\end{array}$ & $\begin{array}{l}27.640 \\
13.820 \\
27.179 \\
27.179 \\
13.359 \\
27.179\end{array}$ & $\begin{array}{l}0.0173 \\
0.0418 \\
0.1558 \\
0.1969 \\
0.1969\end{array}$ & $\begin{array}{c}73.680 \\
32.301 \\
9.606 \\
7.537 \\
7.537\end{array}$ & $\begin{array}{l}T<100^{\circ} \mathrm{C} \\
T<100^{\circ} \mathrm{C} \\
T<100^{\circ} \mathrm{C} \\
T<100^{\circ} \mathrm{C} \\
T<100^{\circ} \mathrm{C}\end{array}$ & $\begin{array}{l}25.75 \\
13.63 \\
28.11 \\
30.43 \\
15.18 \\
30.89\end{array}$ & $\begin{array}{l}0.00 \\
1.23 \\
4.52 \\
2.39 \\
7.42\end{array}$ & $\begin{array}{l}0.000 \\
0.042 \\
0.129 \\
0.136 \\
0.194\end{array}$ & $\begin{array}{c}\text { Not Sat. } \\
27.68 \\
\text { Not Sat. } \\
\text { Not Sat. } \\
\text { Not Sat. }\end{array}$ \\
\hline $\begin{array}{l}\mathrm{CO}-1 \\
\mathrm{CO}-2 \\
\mathrm{CO}-3 \\
\mathrm{CO}-4 \\
\mathrm{CO}-5 \\
\mathrm{CO}-6\end{array}$ & $\begin{array}{l}19.651 \\
19.651 \\
19.583 \\
19.651 \\
24.563 \\
19.681\end{array}$ & $\begin{array}{l}0.0104 \\
0.0121 \\
0.0162 \\
0.0224 \\
0.0694 \\
0.1969\end{array}$ & $\begin{array}{c}187.556 \\
107.069 \\
78.416 \\
57.430 \\
20.874 \\
7.537\end{array}$ & $\begin{array}{l}T<100^{\circ} \mathrm{C} \\
T<100^{\circ} \mathrm{C} \\
T<100^{\circ} \mathrm{C} \\
T<100^{\circ} \mathrm{C} \\
T<100^{\circ} \mathrm{C} \\
T<100^{\circ} \mathrm{C}\end{array}$ & $\begin{array}{l}18.38 \\
18.98 \\
19.25 \\
19.65 \\
26.16 \\
22.37\end{array}$ & $\begin{array}{l}0.19 \\
0.23 \\
0.32 \\
0.45 \\
1.95 \\
5.48\end{array}$ & $\begin{array}{l}0.010 \\
0.012 \\
0.016 \\
0.022 \\
0.069 \\
0.197\end{array}$ & $\begin{array}{c}3.28 \\
6.27 \\
36.31 \\
33.33 \\
13.64 \\
107.87\end{array}$ \\
\hline
\end{tabular}

ICEDF Gas Composition Analysis (page 4) 
Project: Test:

\begin{tabular}{|l|l|}
\hline ICEDF & $\mathbf{1 6 - 1 1}$ \\
\hline
\end{tabular}

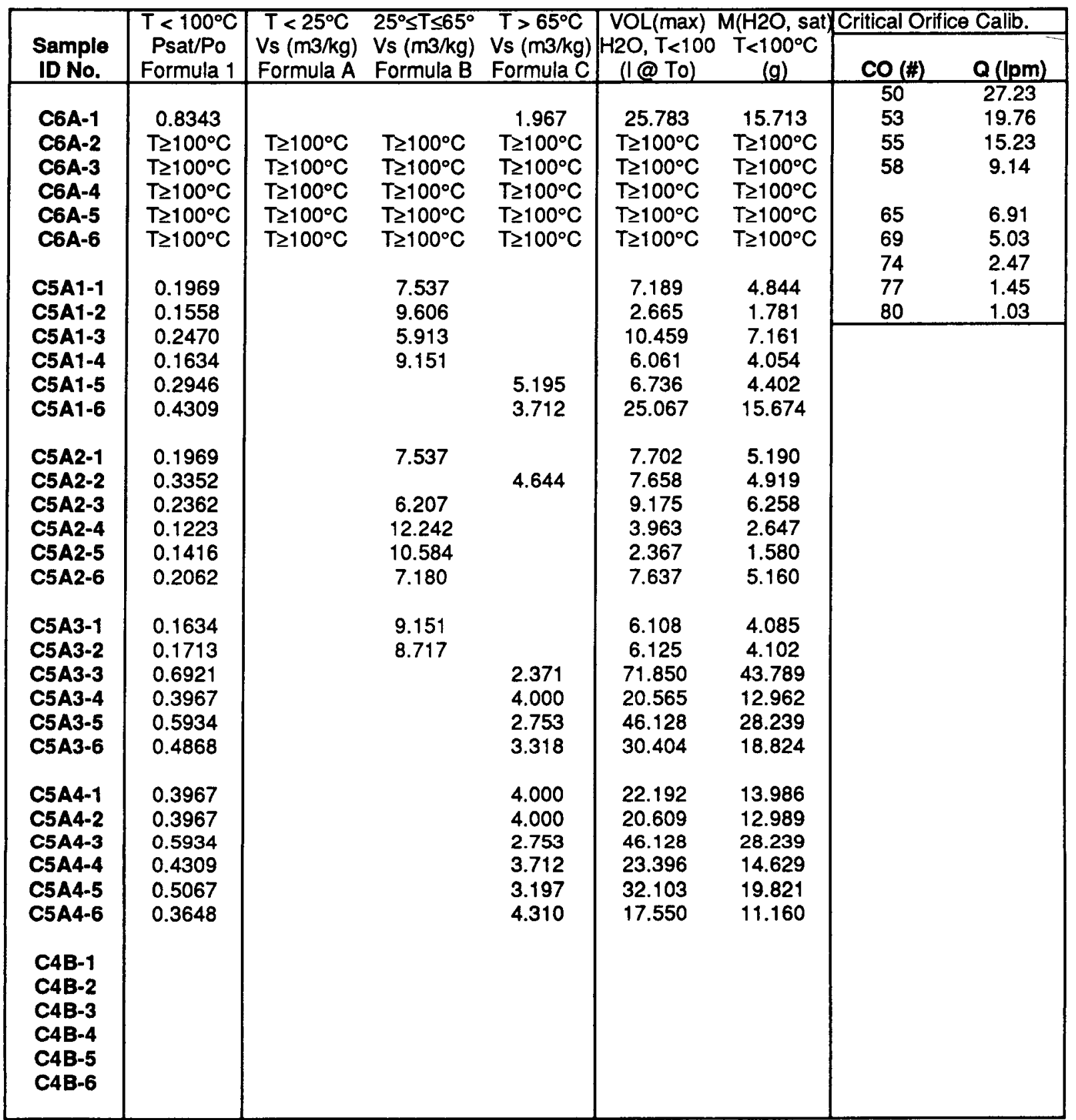

ICEDF Gas Composition Analysis (page 5) 
Prolect: Test:

\begin{tabular}{|l|r|}
\hline ICEDF & $16-11$
\end{tabular}

\begin{tabular}{|c|c|c|c|c|c|c|}
\hline $\begin{array}{l}\text { Sample } \\
\text { ID No. }\end{array}$ & $\begin{array}{l}\mathrm{T}<100^{\circ} \mathrm{C} \\
\text { Psat/Po } \\
\text { Formula } 1\end{array}$ & $\begin{array}{c}\mathrm{T}<25^{\circ} \mathrm{C} \\
\text { Vs }(\mathrm{m} 3 / \mathrm{kg}) \\
\text { Formula } \mathrm{A}\end{array}$ & $\begin{array}{l}25^{\circ} \leq \mathrm{T} \leq 65^{\circ} \\
\text { Vs }(\mathrm{m} 3 / \mathrm{kg}) \\
\text { Formula B }\end{array}$ & $\begin{array}{c}\mathrm{T}>65^{\circ} \mathrm{C} \\
\text { Vs }(\mathrm{m} 3 / \mathrm{kg}) \\
\text { Formula } \mathrm{C}\end{array}$ & $\begin{array}{c}\text { VOL(max) } \\
\mathrm{H} 20, \mathrm{~T}<100 \\
(1 @ \mathrm{To})\end{array}$ & $\begin{array}{c}\mathrm{M}(\mathrm{H} 2 \mathrm{O} \text {, sat }) \\
\mathrm{T}<100^{\circ} \mathrm{C} \\
(\mathrm{g})\end{array}$ \\
\hline $\begin{array}{l}\text { C2B-1 } \\
\text { C2B-2 } \\
\text { C2B-3 } \\
\text { C2B-4 } \\
\text { C2B-5 } \\
\text { C2B-6 }\end{array}$ & & & & & & \\
\hline $\begin{array}{l}\text { C1A1-1 } \\
\text { C1A1-2 } \\
\text { C1A1-3 } \\
\text { C1A1-4 } \\
\text { C1A1-5 } \\
\text { C1A1-6 }\end{array}$ & $\begin{array}{l}0.0104 \\
0.0107 \\
0.0135 \\
0.0162 \\
0.0623 \\
0.1349\end{array}$ & $\begin{array}{c}187.556 \\
129.068 \\
94.528 \\
78.416\end{array}$ & $\begin{array}{l}23.001 \\
11.110\end{array}$ & & $\begin{array}{l}0.143 \\
0.137 \\
0.280 \\
0.437 \\
0.929 \\
4.685\end{array}$ & $\begin{array}{l}0.073 \\
0.099 \\
0.219 \\
0.344 \\
0.649 \\
3.126\end{array}$ \\
\hline $\begin{array}{l}\text { C1A2-1 } \\
\text { C1A2-2 } \\
\text { C1A2-3 } \\
\text { C1A2-4 } \\
\text { C1A2-5 } \\
\text { C1A2-6 }\end{array}$ & $\begin{array}{l}0.0128 \\
0.0308 \\
0.0289 \\
0.0418 \\
0.0589 \\
0.1223\end{array}$ & $\begin{array}{l}100.603 \\
44.765\end{array}$ & $\begin{array}{l}41.168 \\
32.301 \\
24.144 \\
12.242\end{array}$ & & $\begin{array}{l}0.349 \\
0.436 \\
0.646 \\
1.221 \\
0.894 \\
4.161\end{array}$ & $\begin{array}{l}0.271 \\
0.344 \\
0.499 \\
0.905 \\
0.629 \\
2.779\end{array}$ \\
\hline $\begin{array}{l}\text { C1A3-1 } \\
\text { C1A3-2 } \\
\text { C1A3-3 } \\
\text { C1 A3-4 } \\
\text { C1 A3-5 } \\
\text { C1 A3-6 }\end{array}$ & $\begin{array}{l}0.0102 \\
0.0143 \\
0.0255 \\
0.1795 \\
0.2699\end{array}$ & $\begin{array}{l}146.192 \\
88.819 \\
50.704\end{array}$ & 8.305 & 5.598 & $\begin{array}{c}0.136 \\
0.372 \\
0.691 \\
3.074 \\
11.263\end{array}$ & $\begin{array}{l}0.091 \\
0.293 \\
0.535 \\
2.062 \\
7.455\end{array}$ \\
\hline $\begin{array}{l}\text { C1A4-1 } \\
\text { C1A4-2 } \\
\text { C1A4-3 } \\
\text { C1A4-4 } \\
\text { C1A4-5 } \\
\text { C1A4-6 }\end{array}$ & $\begin{array}{l}0.0173 \\
0.0418 \\
0.1558 \\
0.1969 \\
0.1969\end{array}$ & 73.680 & $\begin{array}{c}32.301 \\
9.606 \\
7.537 \\
7.537\end{array}$ & & $\begin{array}{l}0.239 \\
1.225 \\
5.616 \\
3.723 \\
7.574\end{array}$ & $\begin{array}{l}0.188 \\
0.908 \\
3.752 \\
2.509 \\
5.104\end{array}$ \\
\hline $\begin{array}{l}C 0-1 \\
C 0-2 \\
C 0-3 \\
C 0-4 \\
C 0-5 \\
C 0-6\end{array}$ & $\begin{array}{l}0.0104 \\
0.0121 \\
0.0162 \\
0.0224 \\
0.0694 \\
0.1969\end{array}$ & $\begin{array}{c}187.556 \\
107.069 \\
78.416 \\
57.430\end{array}$ & $\begin{array}{c}20.874 \\
7.537\end{array}$ & & $\begin{array}{l}0.193 \\
0.233 \\
0.317 \\
0.450 \\
1.951 \\
5.485\end{array}$ & $\begin{array}{l}0.099 \\
0.179 \\
0.250 \\
0.350 \\
1.347 \\
3.696\end{array}$ \\
\hline
\end{tabular}

ICEDF Gas Composition Analysis (page 6) 
ICEDF SMF WkSht 6/88 supersedes ICEDF SMF WkSht 9/87

\section{How to use "ICEDF SMF WkSht 6/88"}

1) Open "ICEDF SMF WKSht 6/88".

2) Enter test name at cell $C 2$.

3) Save As "ICEDF testname month/year".

4) Enter data: Test Clock(enter)Sample Duration(enter)...

\section{How this spreadsheet works}

CO flow rate determined by Lookup function: Column $\mathrm{H}, \mathrm{Cells} A B$ \& AC. Pressure correction added 5/23/89.

Dry gas volume $=\mathrm{CO}$ flow rate ${ }^{*}$ sample duration * pressure correction.

Actual dry gas volume $=\mathrm{VOL}($ dry, actual $)=$ sample duration ${ }^{*} \mathrm{CO}$ flow rate * $(273+\mathrm{To}) / 293$.

$\mathrm{H} 2 \mathrm{O}$ specific volume $=1.227+0.004712$ (To) for $\mathrm{To} \geq 100^{\circ} \mathrm{C}$.

H2O saturated steam partial pressure (Psat $/ P$ o $=$ Formula 1 ) for $T<100^{\circ} \mathrm{C}$.

Formula1 $=0.0107-3.451^{*} 10^{\wedge}-4^{\star} \mathrm{F} 10+5.359^{*} 10^{\wedge}-5^{\star} \mathrm{F} 10^{\wedge} 2-5.694^{*} 10^{\wedge}-7^{\star} \mathrm{F} 10^{\wedge} 3+1.057^{*} 10^{\wedge}-8^{\star} \mathrm{F} 10^{\wedge} 4$

Actual $\mathrm{H} 2 \mathrm{O}$ gas volume:

$T<100^{\circ} \mathrm{C}: \quad \operatorname{VOL}(\max )=\left[(\right.$ Psat $/ \mathrm{Po}){ }^{*}(\mathrm{VOL}(\mathrm{dry}$, actual $\left.))\right][[1-($ Psat/Po $)]$. See BNW 51060, pg 133. $\operatorname{VOL}(\max )=\operatorname{VOL}(\mathrm{H} 2 \mathrm{O}$, saturated, maximum possible at $\mathrm{T})$

Fog Check: compare $\mathrm{H} 2 \mathrm{O}$ mass collected to $\mathrm{H} 2 \mathrm{O}$ mass required for sample saturation

$\mathrm{M}(\mathrm{H} 2 \mathrm{O}$, sat $)=[[\mathrm{VOL}($ dry, actual $)+\mathrm{VOL}(\mathrm{H} 2 \mathrm{O}, \max )] / \mathrm{Vs}(\mathrm{H} 2 \mathrm{O}$ vapor, sat $)](1000 / 1000)$

Vs $(\mathrm{H} 2 \mathrm{O}$ vapor, sat $)=$ FormulaA if $\mathrm{T}<25^{\circ} \mathrm{C},=$ FormulaC if $\mathrm{T}>65^{\circ} \mathrm{C}$.

FormulaA $=199.61 \cdot 10^{\wedge}(-2.7052 \mathrm{e}-2(\mathrm{~T}))$.

FormulaB $=138.44^{*} 10^{\wedge}(-2.1068 \mathrm{e}-2(\mathrm{~T}))$.

FormulaC $=68.411 \cdot 10^{\wedge}(-1.6225 \mathrm{e}-2(\mathrm{~T}))$.

1) If condensate mass $<M(\mathrm{H} 2 \mathrm{O}$, sat):

VOL $(\mathrm{H} 2 \mathrm{O}$, actual $)=(\mathrm{RH})$ * $(\mathrm{VOL}(\max ))$. Print "Not Sat."

2) If condensate mass $=M(\mathrm{H} 2 \mathrm{O}$, sat $)$ :

$\mathrm{RH}=$ condensate mass $/ \mathrm{M}(\mathrm{H} 2 \mathrm{O}$, sat $)$

VOL(H2O, actual) $=$ VOL (max). Print "Sat." (saturated).

3) If condenate mass $>M(H 2 O$, sat):

$\operatorname{VOL}(\mathrm{H} 2 \mathrm{O}$, actual $)=\mathrm{VOL}(\max )$. Calculate and print fog mass conc.

Fog Conc $=$ condensate mass $-\mathrm{M}(\mathrm{H} 2 \mathrm{O}$, sat $) /$ sample vol.

(sample vol $=\left(1000 \mathrm{~m}^{\wedge} 3 / \mathrm{l}\right)^{\star} \Sigma$ [actual $\mathrm{H} 2 \mathrm{O} \&$ dry vols])

$T \geq 100^{\circ} \mathrm{C}: \quad \operatorname{Vol}(\mathrm{H} 2 \mathrm{O})=($ condensate mass * sat steam spec vol)*(1000/1000). Print "S. H. Vap."

SMF = Actual $\mathrm{H} 20$ gas volume / total gas volume (ie., the sum of actual dry and actual $\mathrm{H} 2 \mathrm{O}$ volumes, = sample vol",

Not included: 1) possible temp variations, 2) possible supersaturation.

CO upstream pressure correction factor added to spreadsheet on 6/14/89 (in draft form in 5/89). 
Modifications:

ICEDF SMF WkSht 6/89 superseded ICEDF SMF WkSht 9/87

1) Original date of this version was 6/14/89.

2) 1st modification was made $9 / 14 / 89$ :

Crit orifice flow corr. factor formula was changed to print " $"$ if test time was ${ }^{n n}$.

Sample analysis date cell was added to top of page 1.

ICEDF SMF WkSht 10/89 superseded ICEDF SMF WkSht 6/89

1) Changed printer page set-up, and minor editing.

2) Changed SMF column equation to print "'" (blank) if no $\mathrm{H} 2 \mathrm{O}$ mass is entered.

3) Changed Fog column equation to print "n if no SMF is calculated, and ¿Sat? if SMF is calculated based on assumed saturation when no $\mathrm{H} 2 \mathrm{O}$ mass is entered.

4) Changed Sample ID column 12/1/89 to match new test plan (no C6B1 or C6B2). 


\begin{tabular}{ll|} 
Project: & Test: \\
\hline ICEDF & $\mathbf{1 7 - 1 2}$ \\
\hline
\end{tabular}

\begin{tabular}{|c|c|c|}
\hline Date of & \multicolumn{2}{|c|}{$\begin{array}{c}\text { A.A. Verification: } \\
\text { Name }\end{array}$} \\
\hline Dalysis & Date \\
\hline $6 / 5 / 90$ & MwL & $7 / 29 / 91$ \\
\hline
\end{tabular}

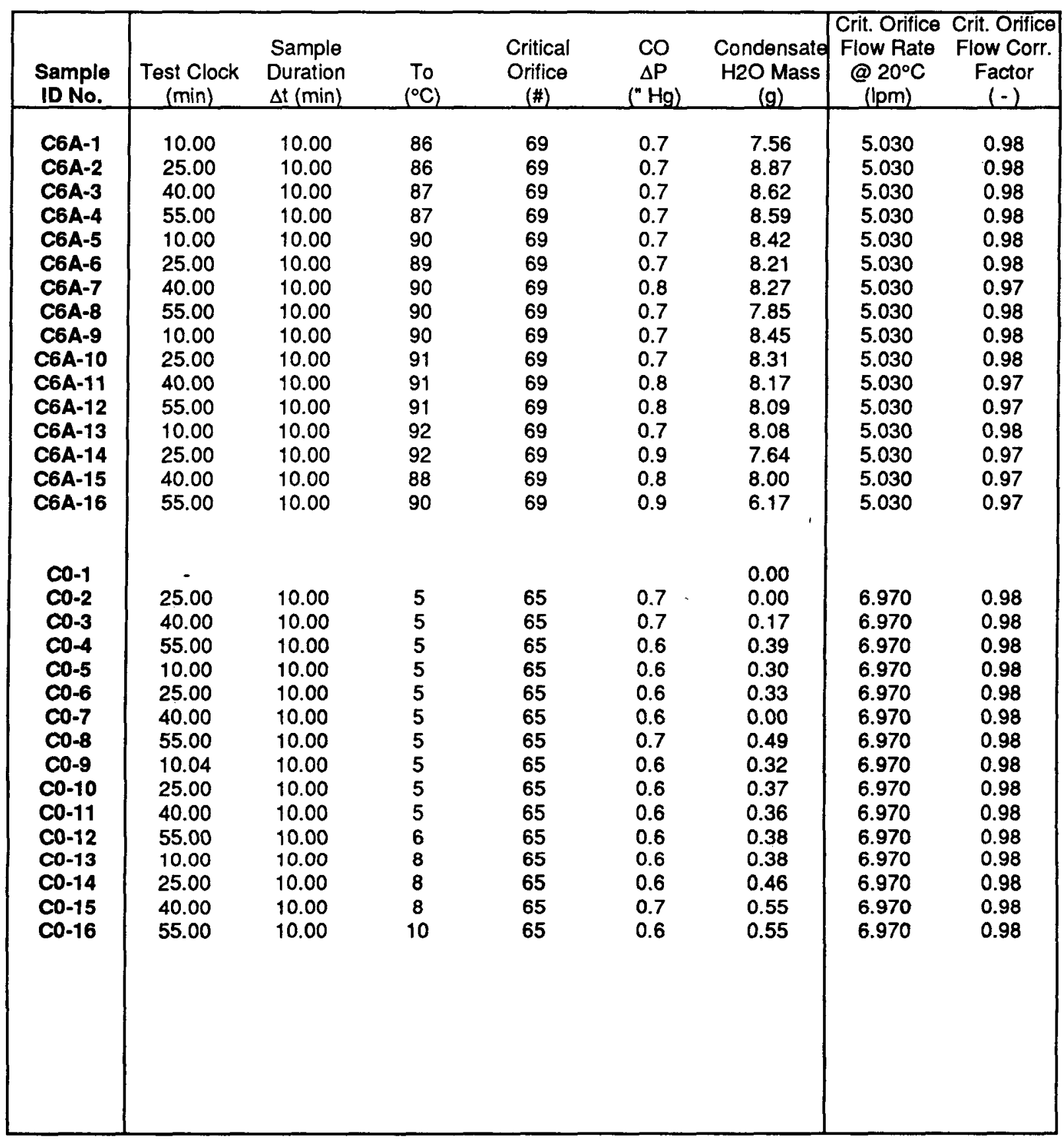

ICEDF Gas Composition Analysis (page 1) 


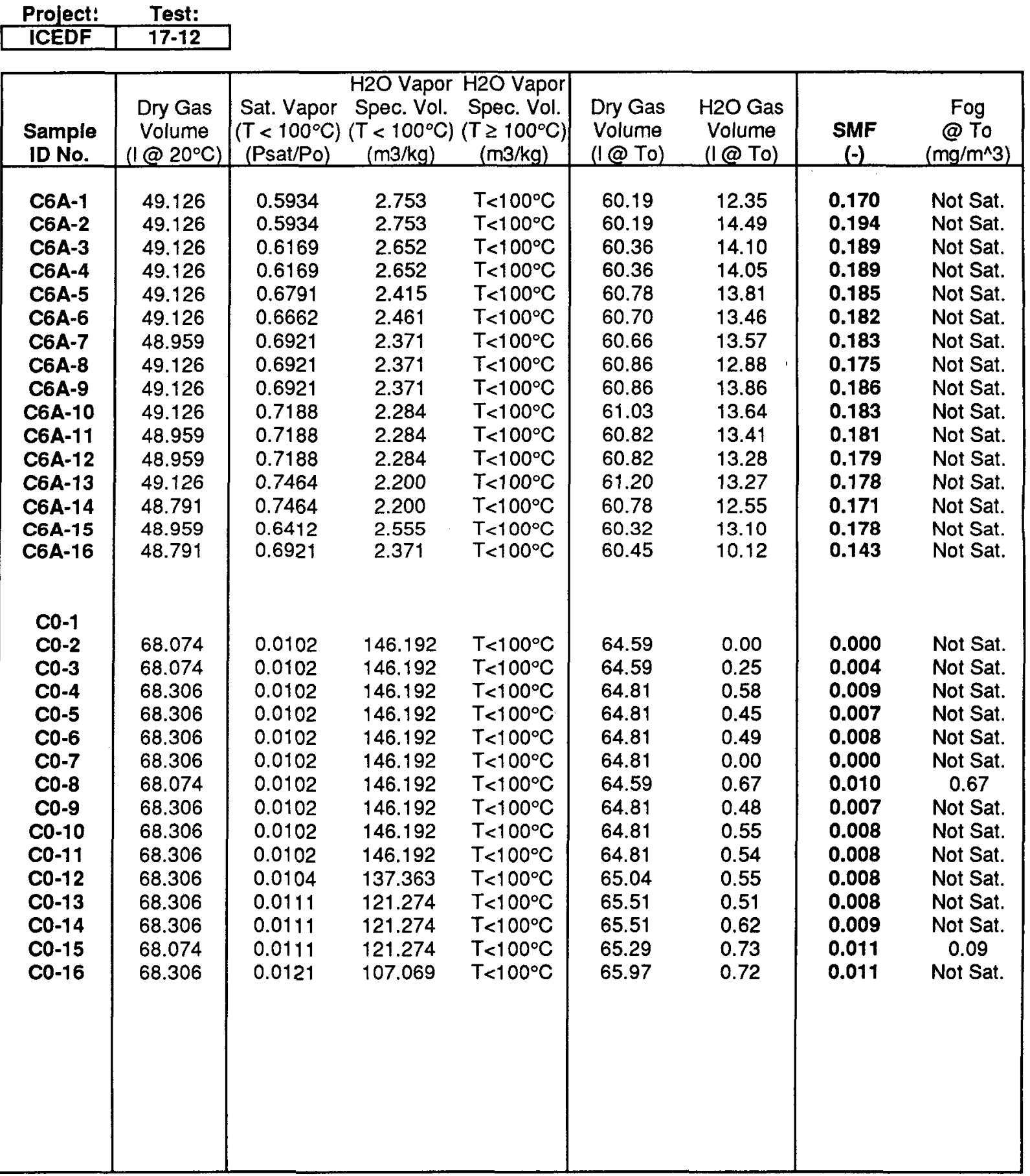




\begin{tabular}{|l|l|} 
Project: & Test: \\
\hline ICEDF & $17-12$ \\
\hline
\end{tabular}

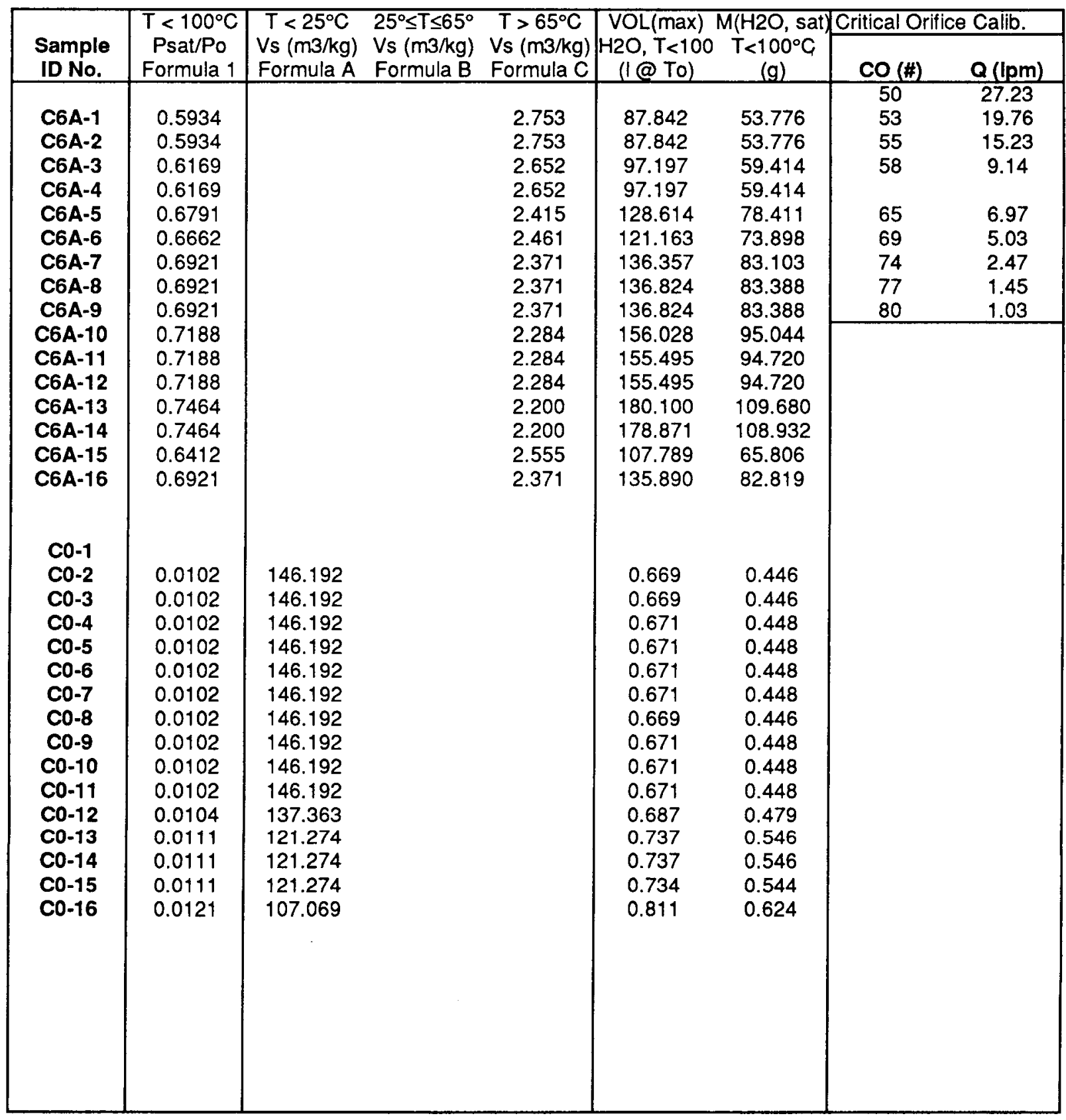

ICEDF Gas Composition Analysis (page 3)

$$
\text { C. } 51
$$




\section{How to use "ICEDF SMF WkSht 6/88"}

1) Open "ICEDF SMF WKSht 6/88".

2) Enter test name at cell $C 2$.

3) Save As "ICEDF testname month/year".

4) Enter data: Test Clock(enter)Sample Duration(enter)...

\section{How this spreadsheet works}

CO flow rate determined by Lookup function: Column H, Cells AB \& AC. Pressure correction added 5/23/89.

Dry gas volume $=\mathrm{CO}$ flow rate * sample duration * pressure correction.

Actual dry gas volume $=\mathrm{VOL}($ dry, actual $)=$ sample duration * CO flow rate ${ }^{\bullet}(273+\mathrm{To}) / 293$.

$\mathrm{H} 2 \mathrm{O}$ specific volume $=1.227+0.004712$ (To) for $\mathrm{To} \geq 100^{\circ} \mathrm{C}$.

H2O saturated steam partial pressure (Psat $/ \mathrm{Po}=$ Formula1) for $\mathrm{T}<100^{\circ} \mathrm{C}$.

Formula1 $=0.0107-3.451^{*} 10^{\wedge}-4^{*} \mathrm{~F} 10+5.359^{*} 10^{\wedge}-5^{\star} \mathrm{F} 10^{\wedge} 2-5.694^{*} 10^{\wedge}-7^{*} \mathrm{~F} 10^{\wedge} 3+1.057^{*} 10^{\wedge}-8^{\star} \mathrm{F} 10^{\wedge} 4$

Actual $\mathrm{H} 2 \mathrm{O}$ gas volume:

$T<100^{\circ} \mathrm{C}: \quad \operatorname{VOL}(\max )=[(\mathrm{Psat} / \mathrm{Po}) \cdot(\mathrm{VOL}($ dry, actual $))] /[1-($ Psat/Po $)]$. See BNW 51060, pg 133. $\operatorname{VOL}(\max )=\operatorname{VOL}(\mathrm{H} 2 \mathrm{O}$, saturated, maximum possible at $\mathrm{T})$

Fog Check: compare $\mathrm{H} 2 \mathrm{O}$ mass collected to $\mathrm{H} 2 \mathrm{O}$ mass required for sample saturation $\mathrm{M}(\mathrm{H} 2 \mathrm{O}$, sat $)=[[\mathrm{VOL}$ (dry, actual) $+\mathrm{VOL}(\mathrm{H} 2 \mathrm{O}, \max )] / \mathrm{Vs}(\mathrm{H} 2 \mathrm{O}$ vapor, sat $)](1000 / 1000)$

Vs $(\mathrm{H} 2 \mathrm{O}$ vapor, sat $)=$ FormulaA if $\mathrm{T}<25^{\circ} \mathrm{C},=$ FormulaC if $\mathrm{T}>65^{\circ} \mathrm{C}$. FormulaA $=199.61^{\bullet} 10^{\wedge}(-2.7052 \theta-2(T))$.

FormulaB $=138.44 * 10^{\wedge}(-2.1068 \theta-2(T))$.

FormulaC $=68.411 \cdot 10^{\wedge}(-1.6225 \theta-2(T))$.

1) If condensate mass $<M(H 2 O$, sat):

VOL(H2O, actual $)=(\mathrm{RH}){ }^{*}(\mathrm{VOL}(\max ))$. Print "Not Sat."

2) If condensate mass $=M(\mathrm{H} 2 \mathrm{O}$, sat $)$ :

$\mathrm{RH}=$ condensate mass $/ \mathrm{M}(\mathrm{H} 2 \mathrm{O}$, sat $)$.

VOL $(\mathrm{H} 2 \mathrm{O}$, actual) $=$ VOL (max). Print "Sat." (saturated).

3) If condenate mass $>M(\mathrm{H} 2 \mathrm{O}$, sat):

VOL $(H 2 O$, actual $)=$ VOL(max). Calculate and print fog mass conc.

Fog Conc $=$ condensate mass $-\mathrm{M}(\mathrm{H} 2 \mathrm{O}$, sat $) /$ sample vol.

(sample vol $=\left(1000 \mathrm{~m}^{\wedge} 3 /\right)^{\star} \Sigma$ [actual $\mathrm{H} 2 \mathrm{O} \&$ dry vols])

$\mathrm{T} \geq 100^{\circ} \mathrm{C}: \quad \operatorname{Vol}(\mathrm{H} 2 \mathrm{O})=($ condensate mass " sat steam spec vol)* $(1000 / 1000)$. Print "S. H. Vap."

SMF = Actual H2O gas volume / total gas volume (ie., the sum of actual dry and actual H2O volumes, = sample vol',

Not included: 1) possible temp variations, 2) possible supersaturation.

CO upstream pressure correction factor added to spreadsheet on 6/14/89 (in draft form in 5/89). 
Modifications:

ICEDF SMF WkSht 6/89 superseded ICEDF SMF WkSht 9/87

1) Original date of this version was $6 / 14 / 89$.

2) 1st modification was made $9 / 14 / 89$ :

Crit orifice flow corr. factor formula was changed to print "n if test time was "n. Sample analysis date cell was added to top of page 1.

ICEDF SMF WkSht 10/89 superseded ICEDF SMF WkSht 6/89

1) Changed printer page set-up, and minor editing.

2) Changed SMF column equation to print "m (blank) if no H2O mass is entered.

3) Changed Fog column equation to print " $"$ if no SMF is calculated, and ¿Sat? if SMF is calculated based on assumed saturation when no $\mathrm{H} 2 \mathrm{O}$ mass is entered.

4) Changed Sample ID column 12/1/89 to match new test plan (no C6B1 or C6B2). 
Project: Test:

\begin{tabular}{l|l} 
ICEDF & 18-13 \\
\hline
\end{tabular}

\begin{tabular}{|c|c|c|}
\hline Date of & \multicolumn{2}{|c|}{ Q.A. Verification: } \\
Analysis & Name & Date \\
\hline $7 / 18 / 90$ & MWL & $8 / 7 / 90$ \\
\hline
\end{tabular}

\begin{tabular}{|c|c|c|c|c|c|c|c|c|}
\hline $\begin{array}{l}\text { Sample } \\
\text { ID No. }\end{array}$ & $\begin{array}{l}\text { Test Clock } \\
\text { (min) }\end{array}$ & $\begin{array}{l}\text { Sample } \\
\text { Duration } \\
\Delta t \text { (min) }\end{array}$ & $\begin{array}{l}\text { To } \\
\left({ }^{\circ} \mathrm{C}\right)\end{array}$ & $\begin{array}{c}\text { Critical } \\
\text { Orifice } \\
(\#) \\
\end{array}$ & $\begin{array}{c}c O \\
\Delta P \\
(" \mathrm{Hg})\end{array}$ & $\begin{array}{c}\text { Condensate } \\
\mathrm{H} 2 \mathrm{O} \text { Mass } \\
\text { (g) }\end{array}$ & $\begin{array}{l}\text { Crit. Orifice } \\
\text { Flow Rate } \\
@ 20^{\circ} \mathrm{C} \\
\text { (lpm) }\end{array}$ & $\begin{array}{c}\text { Crit. Orifice } \\
\text { Flow Corr. } \\
\text { Factor } \\
(-)\end{array}$ \\
\hline C6A-1 & 10.00 & 10.00 & 109 & 69 & 0.7 & 8.97 & 5.030 & 0.98 \\
\hline C6A-2 & 27.50 & 5.00 & 107 & 69 & 0.8 & 4.59 & 5.030 & 0.97 \\
\hline C6A-3 & 37.50 & 5.00 & 106 & 69 & 0.8 & 5.00 & 5.030 & 0.97 \\
\hline C6A-4 & 47.50 & 5.00 & 107 & 69 & 0.8 & 4.50 & 5.030 & $0: 97$ \\
\hline C6A-5 & 57.50 & 5.00 & 107 & 69 & 0.8 & 5.21 & 5.030 & 0.97 \\
\hline C6A-6 & 10.00 & 10.00 & 108 & 69 & 0.8 & 9.63 & 5.030 & 0.97 \\
\hline C6A-7 & 27.50 & 5.00 & 107 & 69 & 0.8 & 4.86 & 5.030 & 0.97 \\
\hline C6A-8 & 37.50 & 5.00 & 107 & 69 & 0.8 & 5.18 & 5.030 & 0.97 \\
\hline C6A-9 & 47.50 & 5.00 & 108 & 69 & 0.8 & 4.92 & 5.030 & 0.97 \\
\hline C6A-10 & 57.50 & 5.00 & 107 & 69 & 0.8 & 4.88 & 5.030 & 0.97 \\
\hline $\mathrm{C} 0-1$ & 10.00 & 10.00 & 5 & 65 & 0.6 & 0.00 & 6.970 & 0.98 \\
\hline $\mathrm{CO}-2$ & 27.50 & 5.00 & 5 & 65 & 0.6 & 0.07 & 6.970 & 0.98 \\
\hline $\mathrm{Co-3}$ & 37.50 & 5.00 & 5 & 65 & 0.6 & 0.12 & 6.970 & 0.98 \\
\hline $\mathrm{CO}-4$ & 47.50 & 5.00 & 5 & 65 & 0.6 & 0.12 & 6.970 & 0.98 \\
\hline $\mathrm{CO}-5$ & 57.50 & 5.00 & 5 & 65 & 0.6 & 0.12 & 6.970 & 0.98 \\
\hline Co-6 & 10.00 & 10.00 & 5 & 65 & 0.6 & 0.40 & 6.970 & 0.98 \\
\hline $\mathrm{Co-7}$ & 27.50 & 5.00 & 5 & 65 & 0.6 & 0.26 & 6.970 & 0.98 \\
\hline $\mathrm{CO}-8$ & 37.50 & 5.00 & 5 & 65 & 0.6 & 0.20 & 6.970 & 0.98 \\
\hline Co-9 & 47.50 & 5.00 & 5 & 65 & 0.6 & 0.30 & 6.970 & 0.98 \\
\hline Co-10 & 57.50 & 5.00 & 5 & 65 & 0.6 & 0.22 & 6.970 & 0.98 \\
\hline C1A1-4 & 47.50 & 5.00 & 0 & 69 & 0.7 & 0.00 & 5.030 & 0.98 \\
\hline C1A2-4 & 47.50 & 5.00 & 3 & 69 & 0.8 & 0.00 & 5.030 & 0.97 \\
\hline C1A3-4 & 47.50 & 5.00 & 0 & 69 & 0.8 & 0.66 & 5.030 & 0.97 \\
\hline C1A4-4 & 47.50 & 5.00 & -1 & 69 & 0.7 & 0.00 & 5.030 & 0.98 \\
\hline C1A1-9 & 47.50 & 5.00 & 1 & 69 & 0.7 & 0.00 & 5.030 & 0.98 \\
\hline C1A2-9 & 47.50 & 5.00 & 6 & 69 & 0.9 & 0.02 & 5.030 & 0.97 \\
\hline C1A3-9 & 47.50 & 5.00 & 1 & 69 & 0.7 & 0.40 & 5.030 & 0.98 \\
\hline C1A4-9 & 47.50 & 5.00 & 1 & 69 & 0.5 & 0.01 & 5.030 & 0.98 \\
\hline C5A1-4 & 47.50 & 5.00 & 28 & 69 & 0.7 & 0.00 & 5.030 & 0.98 \\
\hline C5A2-4 & 47.50 & 5.00 & 44 & 69 & 0.8 & 0.74 & 5.030 & 0.97 \\
\hline C5A3-4 & 47.50 & 5.00 & 13 & 69 & 0.7 & 0.12 & 5.030 & 0.98 \\
\hline C5A4-4 & 47.50 & 5.00 & 38 & 69 & 0.7 & 1.79 & 5.030 & 0.98 \\
\hline C5A1-9 & 47.50 & 5.00 & 22 & 69 & 0.8 & 0.30 & 5.030 & 0.97 \\
\hline C5A2-9 & 47.50 & 5.00 & 29 & 69 & 0.9 & 1.59 & 5.030 & 0.97 \\
\hline C5A3-9 & 47.50 & 5.00 & 23 & 69 & 0.7 & 1.98 & 5.030 & 0.98 \\
\hline C5A4-9 & 47.50 & 5.00 & 35 & 69 & 0.7 & 1.55 & 5.030 & 0.98 \\
\hline
\end{tabular}

ICEDF Gas Composition Analysis (page 1)

$$
\text { C. } 54
$$




\begin{tabular}{|c|c|c|c|c|c|c|c|c|}
\hline $\begin{array}{l}\text { Prolect: } \\
\text { ICEDF }\end{array}$ & $\frac{\text { Test: }}{18-13}$ & & & & & & & \\
\hline $\begin{array}{l}\text { Sample } \\
\text { ID No. }\end{array}$ & $\begin{array}{c}\text { Dry Gas } \\
\text { Volume } \\
\left(1 @ 20^{\circ} \mathrm{C}\right)\end{array}$ & $\begin{array}{c}\text { Sat. Vapor } \\
\left(\mathrm{T}<100^{\circ} \mathrm{C}\right) \\
(\text { Psat/Po) }\end{array}$ & $\begin{array}{c}\text { H2O Vapor } \\
\text { Spec. Vol. } \\
\left(T<100^{\circ} \mathrm{C}\right) \\
(\mathrm{m} 3 / \mathrm{kg})\end{array}$ & $\begin{array}{c}\text { H2O Vapor } \\
\text { Spec. Vol. } \\
\left(T \geq 100^{\circ} \mathrm{C}\right) \\
(\mathrm{m} 3 / \mathrm{kg})\end{array}$ & $\begin{array}{l}\text { Dry Gas } \\
\text { Volume } \\
(1 @ \text { To })\end{array}$ & $\begin{array}{l}\text { H2O Gas } \\
\text { Volume } \\
\text { (1@ To) } \\
\end{array}$ & $\begin{array}{c}\text { SMF } \\
(-)\end{array}$ & $\begin{array}{c}\text { Fog } \\
@ \text { To } \\
\left(\mathrm{mg} / \mathrm{m}^{\wedge} 3\right)\end{array}$ \\
\hline $\begin{array}{l}\text { C6A-1 } \\
\text { C6A-2 } \\
\text { C6A-3 } \\
\text { C6A-4 } \\
\text { C6A-5 } \\
\text { C6A-6 } \\
\text { C6A-7 } \\
\text { C6A-8 } \\
\text { C6A-9 } \\
\text { C6A-10 }\end{array}$ & $\begin{array}{l}49.126 \\
24.479 \\
24.479 \\
24.479 \\
24.479 \\
48.959 \\
24.479 \\
24.479 \\
24.479 \\
24.479\end{array}$ & $\begin{array}{l}T \geq 100^{\circ} \mathrm{C} \\
T \geq 100^{\circ} \mathrm{C} \\
T \geq 100^{\circ} \mathrm{C} \\
T \geq 100^{\circ} \mathrm{C} \\
T \geq 100^{\circ} \mathrm{C} \\
T \geq 100^{\circ} \mathrm{C} \\
T \geq 100^{\circ} \mathrm{C} \\
T \geq 100^{\circ} \mathrm{C} \\
T \geq 100^{\circ} \mathrm{C} \\
T \geq 100^{\circ} \mathrm{C}\end{array}$ & $\begin{array}{l}\mathrm{T} \geq 100^{\circ} \mathrm{C} \\
\mathrm{T} \geq 100^{\circ} \mathrm{C} \\
\mathrm{T} \geq 100^{\circ} \mathrm{C} \\
\mathrm{T} \geq 100^{\circ} \mathrm{C} \\
\mathrm{T} \geq 100^{\circ} \mathrm{C} \\
\mathrm{T} \geq 100^{\circ} \mathrm{C} \\
\mathrm{T} \geq 100^{\circ} \mathrm{C} \\
\mathrm{T} \geq 100^{\circ} \mathrm{C} \\
T \geq 100^{\circ} \mathrm{C} \\
T \geq 100^{\circ} \mathrm{C}\end{array}$ & $\begin{array}{l}1.741 \\
1.731 \\
1.726 \\
1.731 \\
1.731 \\
1.736 \\
1.731 \\
1.731 \\
1.736 \\
1.731\end{array}$ & $\begin{array}{l}64.05 \\
31.75 \\
31.66 \\
31.75 \\
31.75 \\
63.66 \\
31.75 \\
31.75 \\
31.83 \\
31.75\end{array}$ & $\begin{array}{c}15.61 \\
7.95 \\
8.63 \\
7.79 \\
9.02 \\
16.72 \\
8.41 \\
8.97 \\
8.54 \\
8.45\end{array}$ & $\begin{array}{l}0.196 \\
0.200 \\
0.214 \\
0.197 \\
0.221 \\
0.208 \\
0.209 \\
0.220 \\
0.212 \\
0.210\end{array}$ & $\begin{array}{l}\text { S. H. Vap. } \\
\text { S. H. Vap. } \\
\text { S. H. Vap. } \\
\text { S. H. Vap. } \\
\text { S. H. Vap. } \\
\text { S. H. Vap. } \\
\text { S. H. Vap. } \\
\text { S. H. Vap. } \\
\text { S. H. Vap. } \\
\text { S. H. Vap. }\end{array}$ \\
\hline $\begin{array}{l}C 0-1 \\
C 0-2 \\
C 0-3 \\
C 0-4 \\
C 0-5 \\
C 0-6 \\
C 0-7 \\
C 0-8 \\
C 0-9 \\
C 0-10\end{array}$ & $\begin{array}{l}68.306 \\
34.153 \\
34.153 \\
34.153 \\
34.153 \\
68.306 \\
34.153 \\
34.153 \\
34.153 \\
34.153\end{array}$ & $\begin{array}{l}0.0102 \\
0.0102 \\
0.0102 \\
0.0102 \\
0.0102 \\
0.0102 \\
0.0102 \\
0.0102 \\
0.0102 \\
0.0102\end{array}$ & $\begin{array}{l}146.192 \\
146.192 \\
146.192 \\
146.192 \\
146.192 \\
146.192 \\
146.192 \\
146.192 \\
146.192 \\
146.192\end{array}$ & $\begin{array}{l}T<100^{\circ} \mathrm{C} \\
T<100^{\circ} \mathrm{C} \\
T<100^{\circ} \mathrm{C} \\
T<100^{\circ} \mathrm{C} \\
T<100^{\circ} \mathrm{C} \\
T<100^{\circ} \mathrm{C} \\
T<100^{\circ} \mathrm{C} \\
T<100^{\circ} \mathrm{C} \\
T<100^{\circ} \mathrm{C} \\
T<100^{\circ} \mathrm{C}\end{array}$ & $\begin{array}{l}64.81 \\
32.40 \\
32.40 \\
32.40 \\
32.40 \\
64.81 \\
32.40 \\
32.40 \\
32.40 \\
32.40\end{array}$ & $\begin{array}{l}0.00 \\
0.10 \\
0.18 \\
0.18 \\
0.18 \\
0.60 \\
0.34 \\
0.30 \\
0.34 \\
0.33\end{array}$ & $\begin{array}{l}0.000 \\
0.003 \\
0.006 \\
0.006 \\
0.006 \\
0.009 \\
0.010 \\
0.009 \\
0.010 \\
0.010\end{array}$ & $\begin{array}{c}\text { Not Sat. } \\
\text { Not Sat. } \\
\text { Not Sat. } \\
\text { Not Sat. } \\
\text { Not Sat. } \\
\text { Not Sat. } \\
1.10 \\
\text { Not Sat. } \\
2.32 \\
\text { Not Sat. }\end{array}$ \\
\hline $\begin{array}{l}\text { C1A1-4 } \\
\text { C1A2-4 } \\
\text { C1A3-4 } \\
\text { C1A4-4 }\end{array}$ & $\begin{array}{l}24.563 \\
24.479 \\
24.479 \\
24.563\end{array}$ & $\begin{array}{l}0.0107 \\
0.0101 \\
0.0107 \\
T<0^{\circ} \mathrm{C}\end{array}$ & $\begin{array}{l}199.598 \\
165.587 \\
199.598 \\
212.439\end{array}$ & $\begin{array}{l}T<100^{\circ} \mathrm{C} \\
T<100^{\circ} \mathrm{C} \\
T<100^{\circ} \mathrm{C} \\
T<100^{\circ} \mathrm{C}\end{array}$ & $\begin{array}{l}22.89 \\
23.06 \\
22.81 \\
22.80\end{array}$ & $\begin{array}{c}0.00 \\
0.00 \\
0.25 \\
\text { \#VALUE! }\end{array}$ & $\begin{array}{l}0.000 \\
0.000 \\
0.011\end{array}$ & $\begin{array}{c}\text { Not Sat. } \\
\text { Not Sat. } \\
23.62\end{array}$ \\
\hline $\begin{array}{l}\text { C1A1-9 } \\
\text { C1A2-9 } \\
\text { C1A3-9 } \\
\text { C1A4-9 }\end{array}$ & $\begin{array}{l}24.563 \\
24.396 \\
24.563 \\
24.731\end{array}$ & $\begin{array}{l}0.0104 \\
0.0104 \\
0.0104 \\
0.0104\end{array}$ & $\begin{array}{l}187.556 \\
137.363 \\
187.556 \\
187.556\end{array}$ & $\begin{array}{l}T<100^{\circ} \mathrm{C} \\
T<100^{\circ} \mathrm{C} \\
T<100^{\circ} \mathrm{C} \\
T<100^{\circ} \mathrm{C}\end{array}$ & $\begin{array}{l}22.97 \\
23.23 \\
22.97 \\
23.13\end{array}$ & $\begin{array}{l}0.00 \\
0.03 \\
0.24 \\
0.02\end{array}$ & $\begin{array}{l}0.000 \\
0.001 \\
0.010 \\
0.001\end{array}$ & $\begin{array}{c}\text { Not Sat. } \\
\text { Not Sat. } \\
11.90 \\
\text { Not Sat. }\end{array}$ \\
\hline $\begin{array}{l}\text { C5A1-4 } \\
\text { C5A2-4 } \\
\text { C5A3-4 } \\
\text { C5A4-4 }\end{array}$ & $\begin{array}{l}24.563 \\
24.479 \\
24.563 \\
24.563\end{array}$ & $\begin{array}{l}0.0370 \\
0.0904 \\
0.0143 \\
0.0658\end{array}$ & $\begin{array}{l}35.592 \\
16.378 \\
88.819 \\
21.912\end{array}$ & $\begin{array}{l}T<100^{\circ} \mathrm{C} \\
T<100^{\circ} \mathrm{C} \\
T<100^{\circ} \mathrm{C} \\
T<100^{\circ} \mathrm{C}\end{array}$ & $\begin{array}{l}25.23 \\
26.48 \\
23.98 \\
26.07\end{array}$ & $\begin{array}{l}0.00 \\
1.10 \\
0.15 \\
1.84\end{array}$ & $\begin{array}{l}0.000 \\
0.040 \\
0.006 \\
0.066\end{array}$ & $\begin{array}{c}\text { Not Sat. } \\
\text { Not Sat. } \\
\text { Not Sat. } \\
18.50\end{array}$ \\
\hline $\begin{array}{l}\text { C5A1-9 } \\
\text { C5A2-9 } \\
\text { C5A3-9 } \\
\text { C5A4-9 }\end{array}$ & $\begin{array}{l}24.479 \\
24.396 \\
24.563 \\
24.563\end{array}$ & $\begin{array}{l}0.0255 \\
0.0394 \\
0.0271 \\
0.0557\end{array}$ & $\begin{array}{l}50.704 \\
33.907 \\
47.642 \\
25.344\end{array}$ & $\begin{array}{l}T<100^{\circ} \mathrm{C} \\
T<100^{\circ} \mathrm{C} \\
T<100^{\circ} \mathrm{C} \\
T<100^{\circ} \mathrm{C}\end{array}$ & $\begin{array}{l}24.65 \\
25.14 \\
24.81 \\
25.82\end{array}$ & $\begin{array}{l}0.39 \\
1.03 \\
0.69 \\
1.52\end{array}$ & $\begin{array}{l}0.015 \\
0.039 \\
0.027 \\
0.056\end{array}$ & $\begin{array}{c}\text { Not Sat. } \\
31.25 \\
56.64 \\
17.23\end{array}$ \\
\hline
\end{tabular}

ICEDF Gas Composition Analysis (page 2) 
Prolect: Test:

\begin{tabular}{|l|r|}
\hline ICEDF & $18-13$ \\
\hline
\end{tabular}

\begin{tabular}{|c|c|c|c|c|c|c|c|c|}
\hline \multirow[b]{2}{*}{$\begin{array}{l}\text { Sample } \\
\text { ID No. }\end{array}$} & \multirow{2}{*}{$\begin{array}{c}\mathrm{T}<100^{\circ} \mathrm{C} \\
\text { Psat/Po } \\
\text { Formula } 1\end{array}$} & \multirow{2}{*}{$\begin{array}{l}T<25^{\circ} \mathrm{C} \\
\text { Vs (m3/kg) } \\
\text { Formula A }\end{array}$} & \multirow{2}{*}{$\begin{array}{l}25^{\circ} \leq \mathrm{T} \leq 65^{\circ} \\
\text { Vs (m3/kg) } \\
\text { Formula B }\end{array}$} & \multirow{2}{*}{$\begin{array}{c}T>65^{\circ} \mathrm{C} \\
\text { Vs }(\mathrm{m} 3 / \mathrm{kg}) \\
\text { Formula C }\end{array}$} & \multicolumn{4}{|c|}{ VOL(max) $M(H 2 O$, sat) Critical Orifice Calib. } \\
\hline & & & & & $\begin{array}{c}\mathrm{H} 2 \mathrm{O}, \mathrm{T}<100 \\
(1 @ \mathrm{To})\end{array}$ & $\begin{array}{c}\mathrm{T}<100^{\circ} \mathrm{C} \\
(\mathrm{g})\end{array}$ & $\mathrm{CO}(\#)$ & $Q(I p m)$ \\
\hline \multirow{10}{*}{$\begin{array}{l}\text { C6A-1 } \\
\text { C6A-2 } \\
\text { C6A-3 } \\
\text { C6A-4 } \\
\text { C6A-5 } \\
\text { C6A-6 } \\
\text { C6A-7 } \\
\text { C6A-8 } \\
\text { C6A-9 } \\
\text { C6A-10 }\end{array}$} & \multirow{10}{*}{$\begin{array}{l}T \geq 100^{\circ} \mathrm{C} \\
T \geq 100^{\circ} \mathrm{C} \\
T \geq 100^{\circ} \mathrm{C} \\
T \geq 100^{\circ} \mathrm{C} \\
T \geq 100^{\circ} \mathrm{C} \\
T \geq 100^{\circ} \mathrm{C} \\
T \geq 100^{\circ} \mathrm{C} \\
T \geq 100^{\circ} \mathrm{C} \\
T \geq 100^{\circ} \mathrm{C} \\
T \geq 100^{\circ} \mathrm{C}\end{array}$} & \multirow{10}{*}{$\begin{array}{l}T \geq 100^{\circ} \mathrm{C} \\
T \geq 100^{\circ} \mathrm{C} \\
T \geq 100^{\circ} \mathrm{C} \\
T \geq 100^{\circ} \mathrm{C} \\
T \geq 100^{\circ} \mathrm{C} \\
T \geq 100^{\circ} \mathrm{C} \\
T \geq 100^{\circ} \mathrm{C} \\
T \geq 100^{\circ} \mathrm{C} \\
T \geq 100^{\circ} \mathrm{C} \\
T \geq 100^{\circ} \mathrm{C}\end{array}$} & \multirow{10}{*}{$\begin{array}{l}T \geq 100^{\circ} \mathrm{C} \\
T \geq 100^{\circ} \mathrm{C} \\
T \geq 100^{\circ} \mathrm{C} \\
T \geq 100^{\circ} \mathrm{C} \\
T \geq 100^{\circ} \mathrm{C} \\
T \geq 100^{\circ} \mathrm{C} \\
T \geq 100^{\circ} \mathrm{C} \\
T \geq 100^{\circ} \mathrm{C} \\
T \geq 100^{\circ} \mathrm{C} \\
T \geq 100^{\circ} \mathrm{C}\end{array}$} & \multirow{10}{*}{$\begin{array}{l}T \geq 100^{\circ} \mathrm{C} \\
T \geq 100^{\circ} \mathrm{C} \\
T \geq 100^{\circ} \mathrm{C} \\
T \geq 100^{\circ} \mathrm{C} \\
T \geq 100^{\circ} \mathrm{C} \\
T \geq 100^{\circ} \mathrm{C} \\
T \geq 100^{\circ} \mathrm{C} \\
T \geq 100^{\circ} \mathrm{C} \\
T \geq 100^{\circ} \mathrm{C} \\
T \geq 100^{\circ} \mathrm{C}\end{array}$} & \multirow{10}{*}{$\begin{array}{l}\mathrm{T} \geq 100^{\circ} \mathrm{C} \\
\mathrm{T} \geq 100^{\circ} \mathrm{C} \\
\mathrm{T} \geq 100^{\circ} \mathrm{C} \\
\mathrm{T} \geq 100^{\circ} \mathrm{C} \\
\mathrm{T} \geq 100^{\circ} \mathrm{C} \\
\mathrm{T} \geq 100^{\circ} \mathrm{C} \\
\mathrm{T} \geq 100^{\circ} \mathrm{C} \\
\mathrm{T} \geq 100^{\circ} \mathrm{C} \\
\mathrm{T} \geq 100^{\circ} \mathrm{C} \\
\mathrm{T} \geq 100^{\circ} \mathrm{C}\end{array}$} & $\mathrm{T} \geq 100^{\circ} \mathrm{C}$ & \multirow{4}{*}{$\begin{array}{l}50 \\
53 \\
55 \\
58\end{array}$} & \multirow{2}{*}{$\begin{array}{l}27.23 \\
19.76\end{array}$} \\
\hline & & & & & & $T \geq 100^{\circ} \mathrm{C}$ & & \\
\hline & & & & & & $\mathrm{T} \geq 100^{\circ} \mathrm{C}$ & & 9.14 \\
\hline & & & & & & $T \geq 100^{\circ} \mathrm{C}$ & & \\
\hline & & & & & & $T \geq 100^{\circ} \mathrm{C}$ & 65 & 6.97 \\
\hline & & & & & & $T \geq 100^{\circ} \mathrm{C}$ & 69 & 5.03 \\
\hline & & & & & & $T \geq 100^{\circ} \mathrm{C}$ & 74 & 2.47 \\
\hline & & & & & & $T \geq 100^{\circ} \mathrm{C}$ & 77 & 1.45 \\
\hline & & & & & & $T \geq 100^{\circ} \mathrm{C}$ & 80 & 1.03 \\
\hline & & & & & & $T \geq 100^{\circ} \mathrm{C}$ & & \\
\hline Co-1 & 0.0102 & 146.192 & & & 0.671 & 0.448 & & \\
\hline $\mathrm{CO}-2$ & 0.0102 & 146.192 & & & 0.336 & 0.224 & & \\
\hline Co-3 & 0.0102 & 146.192 & & & 0.336 & 0.224 & & \\
\hline $\mathrm{CO}-4$ & 0.0102 & 146.192 & & & 0.336 & 0.224 & & \\
\hline Co-5 & 0.0102 & 146.192 & & & 0.336 & 0.224 & & \\
\hline C0-6 & 0.0102 & 146.192 & & & 0.671 & 0.448 & & \\
\hline $\mathrm{Co-7}$ & 0.0102 & 146.192 & & & 0.336 & 0.224 & & \\
\hline $\mathrm{CO}-8$ & 0.0102 & 146.192 & & & 0.336 & 0.224 & & \\
\hline $\mathrm{CO}-9$ & 0.0102 & 146.192 & & & 0.336 & 0.224 & & \\
\hline$C 0-10$ & 0.0102 & 146.192 & & & 0.336 & 0.224 & & \\
\hline C1A1-4 & 0.0107 & 199.588 & & & 0.248 & 0.116 & & \\
\hline C1A2-4 & 0.0101 & 165.587 & & & 0.236 & 0.141 & & \\
\hline C1A3-4 & 0.0107 & 199.598 & & & 0.247 & 0.116 & & \\
\hline C1A4-4 & $\mathrm{T} \leq 0^{\circ} \mathrm{C}$ & 212.439 & & & & \#VALUE! & & \\
\hline C1A1-9 & 0.0104 & 187.556 & & & 0.242 & 0.124 & & \\
\hline C1A2-9 & 0.0104 & 137.363 & & & 0.245 & 0.171 & & \\
\hline C1A3-9 & 0.0104 & $\begin{array}{l}187.556 \\
187556\end{array}$ & & & $\begin{array}{l}0.242 \\
0.243\end{array}$ & $\begin{array}{l}0.124 \\
0.125\end{array}$ & & \\
\hline & & & & & 0.243 & 0.125 & & \\
\hline C5A1-4 & 0.0370 & & 35.592 & & 0.971 & 0.736 & & \\
\hline C5A2-4 & 0.0904 & & 16.378 & & 2.631 & 1.778 & & \\
\hline C5A3-4 & 0.0143 & 88.819 & & & 0.348 & 0.274 & & \\
\hline C5A4-4 & 0.0658 & & 21.912 & & 1.835 & 1.274 & & \\
\hline C5A1-9 & 0.0255 & 50.704 & & & 0.644 & 0.499 & & \\
\hline C5A2-9 & 0.0394 & & 33.907 & & 1.030 & 0.772 & & \\
\hline C5A3-9 & 0.0271 & 47.642 & & & 0.692 & 0.535 & & \\
\hline C5A4-9 & 0.0557 & & 25.344 & & 1.524 & 1.079 & & \\
\hline
\end{tabular}

ICEDF Gas Composition Analysis (page 3)

$$
\text { C. } 56
$$


ICEDF SMF WkSht 6/88 supersedes ICEDF SMF WkSht 9/87 ICEDF SMF SkSht 10/89 supersedes ICEDF SMF WkSht 6/88

1) Open "ICEDF SMF WkSht 10/89". 2) Enter test name. 3) Save as "ICEDF testname month/year".

\section{How this spreadsheet works}

CO flow rate determined by Lookup function: Column H, Cells AB \& AC. Pressure correction added 5/23/89.

Dry gas volume $=\mathrm{CO}$ flow rate ${ }^{*}$ sample duration ${ }^{*}$ pressure correction

Actual dry gas volume $=\mathrm{VOL}(\mathrm{dry}$, actual $)=$ sample duration ${ }^{*} \mathrm{CO}$ flow rate ${ }^{*}(273+\mathrm{To}) / 293$.

$\mathrm{H} 2 \mathrm{O}$ specific volume $=1.227+0.004712(\mathrm{To})$ for To $\geq 100^{\circ} \mathrm{C}$.

H2O saturated steam partial pressure (Psat $/ \mathrm{Po}=$ Formula1) for $\mathrm{T}<100^{\circ} \mathrm{C}$.

Formula1 $=0.0107-3.451^{*} 10^{\wedge}-4^{\star} \mathrm{F} 10+5.359^{*} 10^{\wedge}-5^{*} \mathrm{~F} 10^{\wedge} 2-5.694^{*} 10^{\wedge}-7^{\star} \mathrm{F} 10^{\wedge} 3+1.057^{\star} 10^{\wedge}-8^{*} \mathrm{~F} 10^{\wedge} 4$

Actual $\mathrm{H} 2 \mathrm{O}$ gas volume:

$\mathrm{T}<100^{\circ} \mathrm{C}: \quad \operatorname{VOL}(\max )=[($ Psat $/ \mathrm{Po}) \cdot(\mathrm{VOL}($ dry, actual $))] /[1-($ Psat/Po $)]$. See BNW 51060,pg 133. $\mathrm{VOL}(\max )=\mathrm{VOL}(\mathrm{H} 2 \mathrm{O}$, saturated, maximum possible at $\mathrm{T})$

Fog Check: compare $\mathrm{H} 2 \mathrm{O}$ mass collected to $\mathrm{H} 2 \mathrm{O}$ mass required for sample saturation $\mathrm{M}(\mathrm{H} 2 \mathrm{O}, \mathrm{sat})=[\mathrm{VOL}(\mathrm{dry}$, actual $)+\mathrm{VOL}(\mathrm{H} 2 \mathrm{O}, \max )] \mathrm{Vs}(\mathrm{H} 2 \mathrm{O}$ vapor, sat $)](1000 / 1000)$

$\mathrm{Vs}(\mathrm{H} 2 \mathrm{O}$ vapor, sat $)=$ FormulaA if $\mathrm{T}<25^{\circ} \mathrm{C},=$ FormulaC if $\mathrm{T}>65^{\circ} \mathrm{C}$.

FormulaA $=199.61 \cdot 10^{\wedge}(-2.7052 \theta-2(T))$.

FormulaB $=138.44 * 10^{\wedge}(-2.1068 \theta-2(T))$.

FormulaC $=68.411 * 10^{\wedge}(-1.6225 \mathrm{e}-2(\mathrm{~T}))$.

1) If condensate mass $<M(\mathrm{H} 2 \mathrm{O}$, sat):

$\operatorname{VOL}(\mathrm{H} 2 \mathrm{O}$, actual $)=(\mathrm{RH}) \cdot(\mathrm{VOL}(\max ))$. Print "Not Sat."

$\mathrm{RH}=$ condensate mass $/ \mathrm{M}(\mathrm{H} 2 \mathrm{O}$, sat).

2) If condensate mass $=M(\mathrm{H} 2 \mathrm{O}$, sat $)$ :

VOL $(\mathrm{H} 2 \mathrm{O}$, actual) $=\mathrm{VOL}(\max )$. Print "Sat." (saturated).

3) If condenate mass $>M(\mathrm{H} 2 \mathrm{O}$, sat):

$\operatorname{VOL}(\mathrm{H} 2 \mathrm{O}$, actual $)=\mathrm{VOL}(\max )$. Calculate and print fog mass conc.

Fog Conc $=$ condensate mass $-\mathrm{M}(\mathrm{H} 2 \mathrm{O}$, sat $)$ / sample vol.

(sample vol $=\left(1000 \mathrm{~m}^{\wedge} 3 /\right)^{*} \Sigma$ [actual $\mathrm{H} 2 \mathrm{O}$ \& dry vols])

$\mathrm{T} \geq 100^{\circ} \mathrm{C}: \quad \operatorname{Vol}(\mathrm{H} 2 \mathrm{O})=\left(\right.$ condensate mass ${ }^{*}$ sat steam spec vol)* $(1000 / 1000)$. Print "S. H. Vap."

SMF = Actual H2O gas volume / total gas volume (ie., the sum of actual dry and actual $\mathrm{H} 2 \mathrm{O}$ volumes, = sample vol'

Not included: 1) possible temp variations, 2) possible supersaturation.

CO upstream pressure correction factor added to spreadsheet on 6/14/89 (in draft form in 5/89).

Modifications: ICEDF SMF WkSht 6/89 superseded ICEDF SMF WkSht 9/87

1) Original date of this version was $6 / 14 / 89$.

2) Ist modification was made 9/14/89:

Crit orifice flow corr. factor formula was changed to print "n if test time was "n.

Sample analysis date cell was added to top of page 1.

ICEDF SMF WkSht 10/89 superseded ICEDF SMF WkSht 6/89

1) Changed printer page set-up, and minor editing. 2) Changed SMF col eq to print "n if no H2O mass is entered.

3) Changed Fog column equation to print " $"$ if no SMF is calculated, and iSat? if SMF is calculated

based on assumed saturation when no $\mathrm{H} 2 \mathrm{O}$ mass is entered.

4) Changed Sample ID column 12/1/89 to match new test plan (no C6B1 or C6B2). 
Prolect: Test:

ICEDF $19-14$

\begin{tabular}{|c|c|c|}
\hline Date of & \multicolumn{2}{|c|}{ Q. Veriflcatlon: } \\
Analysis & Name & Date \\
\hline $7 / 13 / 90$ & MuL & $8 / 7 / 90$ \\
\hline
\end{tabular}

\begin{tabular}{|c|c|c|c|c|c|c|c|c|}
\hline $\begin{array}{l}\text { Sample } \\
\text { ID No. }\end{array}$ & $\begin{array}{c}\text { Test Clock } \\
\text { (min) }\end{array}$ & $\begin{array}{c}\text { Sample } \\
\text { Duration } \\
\Delta t \text { (min) }\end{array}$ & $\begin{array}{l}\text { To } \\
\left({ }^{\circ} \mathrm{C}\right) \\
\end{array}$ & $\begin{array}{c}\text { Critical } \\
\text { Orifice } \\
\text { (\#) }\end{array}$ & $\begin{array}{c}C O \\
\Delta P \\
(" \mathrm{Hg}) \\
\end{array}$ & $\begin{array}{c}\text { Condensate } \\
\text { H2O Mass } \\
\text { (g) }\end{array}$ & $\begin{array}{l}\text { Crit. Orifice } \\
\text { Flow Rate } \\
@ 20^{\circ} \mathrm{C} \\
(\text { lpm) }\end{array}$ & $\begin{array}{l}\text { Crit. Orifice } \\
\text { Flow Corr. } \\
\text { Factor } \\
(-)\end{array}$ \\
\hline C6A-1 & 11.00 & 8.08 & 110 & 69 & 0.8 & 11.36 & 5.030 & 0.97 \\
\hline C6A-2 & 27.50 & 5.00 & 113 & 69 & 0.7 & 4.02 & 5.030 & 0.98 \\
\hline C6A-3 & 38.25 & 3.50 & 114 & 69 & 0.8 & 2.54 & 5.030 & 0.97 \\
\hline C6A-4 & 47.50 & 5.00 & 114 & 69 & 0.8 & 4.45 & 5.030 & 0.97 \\
\hline C6A-5 & 57.50 & 5.00 & 115 & 69 & 0.8 & 3.92 & 5.030 & 0.97 \\
\hline C6A-6 & 10.00 & 10.00 & 117 & 69 & 1.2 & 55.64 & 5.030 & 0.96 \\
\hline C6A-7 & 27.50 & 5.00 & 119 & 69 & 1.2 & & 5.030 & 0.96 \\
\hline C6A-8 & 37.50 & 5.00 & 120 & 69 & 1.2 & 28.61 & 5.030 & 0.96 \\
\hline C6A-9 & 47.50 & 5.00 & 120 & 69 & 1.2 & 28.15 & 5.030 & 0.96 \\
\hline C6A-10 & 57.50 & 5.00 & 121 & 69 & 1.2 & 28.86 & 5.030 & 0.96 \\
\hline Co-1 & 11.00 & 8.00 & 0 & 65 & 1.0 & 0.10 & 6.970 & 0.97 \\
\hline $\mathrm{Co-2}$ & 27.50 & 5.00 & 0 & 65 & 1.0 & 0.23 & 6.970 & 0.97 \\
\hline $\mathrm{Co-3}$ & 37.50 & 5.00 & 0 & 65 & 1.0 & 0.26 & 6.970 & 0.97 \\
\hline Co-4 & 47.50 & 5.00 & 0 & 65 & 2.0 & 0.23 & 6.970 & 0.93 \\
\hline C0-5 & 57.50 & 5.00 & 0 & 65 & 2.0 & 0.19 & 6.970 & 0.93 \\
\hline C0-6 & 10.00 & 10.00 & 5 & 65 & 2.0 & 1.13 & 6.970 & 0.93 \\
\hline$C 0-7$ & 27.50 & 5.00 & 5 & 65 & 2.0 & 0.69 & 6.970 & 0.93 \\
\hline C0-8 & 37.50 & 5.00 & 6 & 65 & 2.0 & 0.67 & 6.970 & 0.93 \\
\hline Co-9 & 47.50 & 5.00 & 10 & 65 & 2.0 & 0.75 & 6.970 & 0.93 \\
\hline C0-10 & 57.50 & 5.00 & 15 & 65 & 2.0 & 0.90 & 6.970 & 0.93 \\
\hline C1A1-4 & 47.50 & 5.00 & 0 & 69 & 0.7 & 0.19 & 5.030 & 0.98 \\
\hline C1A2-4 & 47.50 & 5.00 & 8 & 69 & 0.7 & 0.01 & 5.030 & 0.98 \\
\hline C1A3-4 & 47.50 & 5.00 & 1 & 69 & 0.6 & 0.06 & 5.030 & 0.98 \\
\hline C1A4-4 & 47.50 & 5.00 & 2 & 69 & 0.7 & 0.00 & 5.030 & 0.98 \\
\hline C1A1-9 & 47.50 & 5.00 & 14 & 69 & 0.9 & 0.10 & 5.030 & 0.97 \\
\hline C1A2-9 & 47.50 & 5.00 & 23 & 69 & 0.8 & 0.33 & 5.030 & 0.97 \\
\hline C1A3-9 & 47.50 & 5.00 & 4 & 69 & 0.7 & 0.34 & 5.030 & 0.98 \\
\hline C1A4-9 & 47.50 & 5.00 & 9 & 69 & 0.7 & 0.00 & 5.030 & 0.98 \\
\hline C5A1-4 & 47.50 & 5.00 & 27 & 69 & 0.8 & 0.33 & 5.030 & 0.97 \\
\hline C5A2-4 & 47.50 & 5.00 & 46 & 69 & 0.8 & 0.95 & 5.030 & 0.97 \\
\hline C5A3-4 & 47.50 & 5.00 & 23 & 69 & 0.6 & 0.02 & 5.030 & 0.98 \\
\hline C5A4-4 & 47.50 & 5.00 & 41 & 69 & 0.7 & 0.75 & 5.030 & 0.98 \\
\hline C5A1-9 & 47.50 & 5.00 & 33 & 69 & 0.8 & 0.87 & 5.030 & 0.97 \\
\hline C5A2-9 & 47.50 & 5.00 & 61 & 69 & 0.8 & 3.97 & 5.030 & 0.97 \\
\hline C5A3-9 & 47.50 & 5.00 & 28 & 69 & 0.6 & 0.49 & 5.030 & 0.98 \\
\hline C5A4-9 & 47.50 & 5.00 & 47 & 69 & 0.8 & 2.56 & 5.030 & 0.97 \\
\hline
\end{tabular}




\begin{tabular}{|c|c|c|c|c|c|c|c|c|}
\hline $\begin{array}{l}\text { Prolect: } \\
\text { ICEDF }\end{array}$ & $\begin{array}{l}\text { Test: } \\
19-14\end{array}$ & & & & & & & \\
\hline $\begin{array}{l}\text { Sample } \\
\text { ID No. }\end{array}$ & $\begin{array}{c}\text { Dry Gas } \\
\text { Volume } \\
\left(1 @ 20^{\circ} \mathrm{C}\right)\end{array}$ & $\begin{array}{c}\text { Sat. Vapor } \\
\left(T<100^{\circ} \mathrm{C}\right) \\
(\mathrm{Psat} / \mathrm{Po})\end{array}$ & $\begin{array}{c}\text { H2O Vapor } \\
\text { Spec. Vol. } \\
\left(\mathrm{T}<100^{\circ} \mathrm{C}\right) \\
(\mathrm{m} 3 / \mathrm{kg})\end{array}$ & $\begin{array}{c}\text { H2O Vapor } \\
\text { Spec. Vol. } \\
\left(T \geq 100^{\circ} \mathrm{C}\right) \\
(\mathrm{m} 3 / \mathrm{kg})\end{array}$ & $\begin{array}{l}\text { Dry Gas } \\
\text { Volume } \\
\text { (1@ To) }\end{array}$ & $\begin{array}{l}\text { H2O Gas } \\
\text { Volume } \\
\text { (1@ To) }\end{array}$ & $\begin{array}{c}\text { SMF } \\
(-) \\
\end{array}$ & $\begin{array}{c}\text { Fog } \\
@ \text { To } \\
\left(m g / m^{\wedge} 3\right)\end{array}$ \\
\hline $\begin{array}{l}\text { C6A-1 } \\
\text { C6A-2 } \\
\text { C6A-3 } \\
\text { C6A-4 } \\
\text { C6A-5 } \\
\text { C6A-6 } \\
\text { C6A-7 } \\
\text { C6A-8 } \\
\text { C6A-9 } \\
\text { C6A-10 }\end{array}$ & $\begin{array}{l}39.559 \\
24.563 \\
17.136 \\
24.479 \\
24.479 \\
48.288 \\
24.144 \\
24.144 \\
24.144 \\
24.144\end{array}$ & $\begin{array}{l}T \geq 100^{\circ} \mathrm{C} \\
T \geq 100^{\circ} \mathrm{C} \\
T \geq 100^{\circ} \mathrm{C} \\
T \geq 100^{\circ} \mathrm{C} \\
T \geq 100^{\circ} \mathrm{C} \\
T \geq 100^{\circ} \mathrm{C} \\
T \geq 100^{\circ} \mathrm{C} \\
T \geq 100^{\circ} \mathrm{C} \\
T \geq 100^{\circ} \mathrm{C} \\
T \geq 100^{\circ} \mathrm{C}\end{array}$ & $\begin{array}{l}T \geq 100^{\circ} \mathrm{C} \\
T \geq 100^{\circ} \mathrm{C} \\
T \geq 100^{\circ} \mathrm{C} \\
T \geq 100^{\circ} \mathrm{C} \\
T \geq 100^{\circ} \mathrm{C} \\
T \geq 100^{\circ} \mathrm{C} \\
T \geq 100^{\circ} \mathrm{C} \\
T \geq 100^{\circ} \mathrm{C} \\
T \geq 100^{\circ} \mathrm{C} \\
T \geq 100^{\circ} \mathrm{C}\end{array}$ & $\begin{array}{l}1.745 \\
1.759 \\
1.764 \\
1.764 \\
1.769 \\
1.778 \\
1.788 \\
1.792 \\
1.792 \\
1.797\end{array}$ & $\begin{array}{l}51.71 \\
32.36 \\
22.63 \\
32.33 \\
32.42 \\
64.27 \\
32.30 \\
32.38 \\
32.38 \\
32.47\end{array}$ & $\begin{array}{c}19.83 \\
7.07 \\
4.48 \\
7.85 \\
6.93 \\
98.94 \\
0.00 \\
51.28 \\
50.46 \\
51.87\end{array}$ & $\begin{array}{l}0.277 \\
0.179 \\
0.165 \\
0.195 \\
0.176 \\
0.606 \\
\\
0.613 \\
0.609 \\
0.615\end{array}$ & $\begin{array}{l}\text { S. H. Vap. } \\
\text { S. H. Vap. } \\
\text { S. H. Vap. } \\
\text { S. H. Vap. } \\
\text { S. H. Vap. } \\
\text { S. H. Vap. } \\
\\
\text { S. H. Vap. } \\
\text { S. H. Vap. } \\
\text { S. H. Vap. }\end{array}$ \\
\hline $\begin{array}{l}C 0-1 \\
C 0-2 \\
C 0-3 \\
C 0-4 \\
C 0-5 \\
C 0-6 \\
C 0-7 \\
C 0-8 \\
C 0-9 \\
C 0-10\end{array}$ & $\begin{array}{l}53.901 \\
33.688 \\
33.688 \\
32.527 \\
32.527 \\
65.053 \\
32.527 \\
32.527 \\
32.527 \\
32.527\end{array}$ & $\begin{array}{l}0.0107 \\
0.0107 \\
0.0107 \\
0.0107 \\
0.0107 \\
0.0102 \\
0.0102 \\
0.0104 \\
0.0121 \\
0.0162\end{array}$ & $\begin{array}{l}198.371 \\
198.371 \\
198.371 \\
198.371 \\
198.371 \\
146.192 \\
146.192 \\
137.363 \\
107.069 \\
78.416\end{array}$ & $\begin{array}{l}\mathrm{T}<100^{\circ} \mathrm{C} \\
\mathrm{T}<100^{\circ} \mathrm{C} \\
\mathrm{T}<100^{\circ} \mathrm{C} \\
\mathrm{T}<100^{\circ} \mathrm{C} \\
\mathrm{T}<100^{\circ} \mathrm{C} \\
T<100^{\circ} \mathrm{C} \\
\mathrm{T}<100^{\circ} \mathrm{C} \\
T<100^{\circ} \mathrm{C} \\
T<100^{\circ} \mathrm{C} \\
T<100^{\circ} \mathrm{C}\end{array}$ & $\begin{array}{l}50.24 \\
31.40 \\
31.40 \\
30.32 \\
30.32 \\
61.72 \\
30.86 \\
30.97 \\
31.42 \\
31.97\end{array}$ & $\begin{array}{l}0.21 \\
0.34 \\
0.34 \\
0.33 \\
0.33 \\
0.64 \\
0.32 \\
0.33 \\
0.39 \\
0.53\end{array}$ & $\begin{array}{l}0.004 \\
0.011 \\
0.011 \\
0.011 \\
0.011 \\
0.010 \\
0.010 \\
0.010 \\
0.012 \\
0.016\end{array}$ & $\begin{array}{c}\text { Not Sat. } \\
2.21 \\
3.15 \\
2.46 \\
1.16 \\
11.28 \\
15.29 \\
14.13 \\
14.24 \\
14.94\end{array}$ \\
\hline $\begin{array}{l}\text { C1A1-4 } \\
\text { C1A2-4 } \\
\text { C1A3-4 } \\
\text { C1A4-4 }\end{array}$ & $\begin{array}{l}24.563 \\
24.563 \\
24.647 \\
24.563\end{array}$ & $\begin{array}{l}0.0107 \\
0.0111 \\
0.0104 \\
0.0102\end{array}$ & $\begin{array}{l}198.371 \\
121.274 \\
187.556 \\
176.229\end{array}$ & $\begin{array}{l}T<100^{\circ} \mathrm{C} \\
T<100^{\circ} \mathrm{C} \\
T<100^{\circ} \mathrm{C} \\
T<100^{\circ} \mathrm{C}\end{array}$ & $\begin{array}{l}22.89 \\
23.56 \\
23.05 \\
23.05\end{array}$ & $\begin{array}{l}0.25 \\
0.01 \\
0.12 \\
0.00\end{array}$ & $\begin{array}{l}0.011 \\
0.001 \\
0.005 \\
0.000\end{array}$ & $\begin{array}{c}3.17 \\
\text { Not Sat. } \\
\text { Not Sat. } \\
\text { Not Sat. }\end{array}$ \\
\hline $\begin{array}{l}\text { C1A1-9 } \\
\text { C1A2-9 } \\
\text { C1A3-9 } \\
\text { C1A4-9 }\end{array}$ & $\begin{array}{l}24.396 \\
24.479 \\
24.563 \\
24.563\end{array}$ & $\begin{array}{l}0.0152 \\
0.0271 \\
0.0101 \\
0.0116\end{array}$ & $\begin{array}{c}83.455 \\
47.642 \\
155.587 \\
113.950\end{array}$ & $\begin{array}{l}\mathrm{T}<100^{\circ} \mathrm{C} \\
\mathrm{T}<100^{\circ} \mathrm{C} \\
T<100^{\circ} \mathrm{C} \\
T<100^{\circ} \mathrm{C}\end{array}$ & $\begin{array}{l}23.90 \\
24.73 \\
23.22 \\
23.64\end{array}$ & $\begin{array}{l}0.13 \\
0.43 \\
0.24 \\
0.00\end{array}$ & $\begin{array}{l}0.005 \\
0.017 \\
0.010 \\
0.000\end{array}$ & $\begin{array}{c}\text { Not Sat. } \\
\text { Not Sat. } \\
8.07 \\
\text { Not Sat. }\end{array}$ \\
\hline $\begin{array}{l}\text { C5A1-4 } \\
\text { C5A2-4 } \\
\text { C5A3-4 } \\
\text { C5A4-4 }\end{array}$ & $\begin{array}{l}24.479 \\
24.479 \\
24.647 \\
24.563\end{array}$ & $\begin{array}{l}0.0349 \\
0.1001 \\
0.0271 \\
0.0773\end{array}$ & $\begin{array}{l}37.362 \\
14.864 \\
47.642 \\
18.944\end{array}$ & $\begin{array}{l}T<100^{\circ} \mathrm{C} \\
T<100^{\circ} \mathrm{C} \\
T<100^{\circ} \mathrm{C} \\
T<100^{\circ} \mathrm{C}\end{array}$ & $\begin{array}{l}25.06 \\
26.65 \\
24.90 \\
26.32\end{array}$ & $\begin{array}{l}0.43 \\
1.41 \\
0.03 \\
1.10\end{array}$ & $\begin{array}{l}0.017 \\
0.050 \\
0.001 \\
0.040\end{array}$ & $\begin{array}{l}\text { Not Sat. } \\
\text { Not Sat. } \\
\text { Not Sat. } \\
\text { Not Sat. }\end{array}$ \\
\hline $\begin{array}{l}\text { C5A1-9 } \\
\text { C5A2-9 } \\
\text { C5A3-9 } \\
\text { C5A4-9 }\end{array}$ & $\begin{array}{l}24.479 \\
24.479 \\
24.647 \\
24.479\end{array}$ & $\begin{array}{l}0.0497 \\
0.2062 \\
0.0370 \\
0.1053\end{array}$ & $\begin{array}{c}27.927 \\
7.180 \\
35.592 \\
14.160\end{array}$ & $\begin{array}{l}T<100^{\circ} \mathrm{C} \\
T<100^{\circ} \mathrm{C} \\
T<100^{\circ} \mathrm{C} \\
T<100^{\circ} \mathrm{C}\end{array}$ & $\begin{array}{l}25.57 \\
27.90 \\
25.32 \\
26.74\end{array}$ & $\begin{array}{l}1.21 \\
5.88 \\
0.65 \\
3.15\end{array}$ & $\begin{array}{l}0.045 \\
0.174 \\
0.025 \\
0.105\end{array}$ & $\begin{array}{c}\text { Not Sat. } \\
\text { Not Sat. } \\
\text { Not Sat. } \\
15.05\end{array}$ \\
\hline
\end{tabular}




\begin{tabular}{l|l|}
\hline Prolect: & Test: \\
\hline ICEDF & $19-14$ \\
\hline
\end{tabular}

\begin{tabular}{|c|c|c|c|c|c|c|c|c|}
\hline \multirow[b]{2}{*}{$\begin{array}{l}\text { Sample } \\
\text { ID No. }\end{array}$} & \multirow{2}{*}{$\begin{array}{c}\mathrm{T}<100^{\circ} \mathrm{C} \\
\text { Psat } / P \circ \\
\text { Formula } 1 \\
\end{array}$} & \multirow{2}{*}{$\begin{array}{l}\mathrm{T}<25^{\circ} \mathrm{C} \\
\text { Vs }(\mathrm{m} 3 / \mathrm{kg}) \\
\text { Formula A }\end{array}$} & \multirow{2}{*}{$\begin{array}{l}25^{\circ} \leq \mathrm{T} \leq 65^{\circ} \\
\text { Vs }(\mathrm{m} 3 / \mathrm{kg}) \\
\text { Formula B }\end{array}$} & \multirow{2}{*}{$\begin{array}{l}\mathrm{T}>65^{\circ} \mathrm{C} \\
\text { Vs }(\mathrm{m} 3 / \mathrm{kg}) \\
\text { Formula } \mathrm{C}\end{array}$} & \multirow{2}{*}{\multicolumn{2}{|c|}{$\begin{array}{cc}\text { VOL(max) } & M(\mathrm{H} 2 \mathrm{O} \text {, sat) } \\
\mathrm{H} 2 \mathrm{O}, \mathrm{T}<100 & \mathrm{~T}<100^{\circ} \mathrm{C} \\
\text { (I@ @o) } & \text { (g) }\end{array}$}} & \multicolumn{2}{|c|}{ Critical Orifice Calib. } \\
\hline & & & & & & & & Q (Ipm) \\
\hline \multirow{10}{*}{$\begin{array}{l}\text { C6A-1 } \\
\text { C6A-2 } \\
\text { C6A-3 } \\
\text { C6A-4 } \\
\text { C6A-5 } \\
\text { C6A-6 } \\
\text { C6A-7 } \\
\text { C6A-8 } \\
\text { C6A-9 } \\
\text { C6A-10 }\end{array}$} & \multirow{10}{*}{$\begin{array}{l}T \geq 100^{\circ} \mathrm{C} \\
T \geq 100^{\circ} \mathrm{C} \\
T \geq 100^{\circ} \mathrm{C} \\
T \geq 100^{\circ} \mathrm{C} \\
T \geq 100^{\circ} \mathrm{C} \\
T \geq 100^{\circ} \mathrm{C} \\
T \geq 100^{\circ} \mathrm{C} \\
T \geq 100^{\circ} \mathrm{C} \\
T \geq 100^{\circ} \mathrm{C} \\
T \geq 100^{\circ} \mathrm{C}\end{array}$} & \multirow{10}{*}{$\begin{array}{l}T \geq 100^{\circ} \mathrm{C} \\
T \geq 100^{\circ} \mathrm{C} \\
T \geq 100^{\circ} \mathrm{C} \\
T \geq 100^{\circ} \mathrm{C} \\
T \geq 100^{\circ} \mathrm{C} \\
T \geq 100^{\circ} \mathrm{C} \\
T \geq 100^{\circ} \mathrm{C} \\
T \geq 100^{\circ} \mathrm{C} \\
T \geq 100^{\circ} \mathrm{C} \\
T \geq 100^{\circ} \mathrm{C}\end{array}$} & \multirow{10}{*}{$\begin{array}{l}T \geq 100^{\circ} \mathrm{C} \\
T \geq 100^{\circ} \mathrm{C} \\
T \geq 100^{\circ} \mathrm{C} \\
T \geq 100^{\circ} \mathrm{C} \\
T \geq 100^{\circ} \mathrm{C} \\
T \geq 100^{\circ} \mathrm{C} \\
T \geq 100^{\circ} \mathrm{C} \\
T \geq 100^{\circ} \mathrm{C} \\
T \geq 100^{\circ} \mathrm{C} \\
T \geq 100^{\circ} \mathrm{C}\end{array}$} & \multirow{10}{*}{$\begin{array}{l}T \geq 100^{\circ} \mathrm{C} \\
T \geq 100^{\circ} \mathrm{C} \\
T \geq 100^{\circ} \mathrm{C} \\
T \geq 100^{\circ} \mathrm{C} \\
T \geq 100^{\circ} \mathrm{C} \\
T \geq 100^{\circ} \mathrm{C} \\
T \geq 100^{\circ} \mathrm{C} \\
T \geq 100^{\circ} \mathrm{C} \\
T \geq 100^{\circ} \mathrm{C} \\
T \geq 100^{\circ} \mathrm{C}\end{array}$} & \multirow{10}{*}{$\begin{array}{l}T \geq 100^{\circ} \mathrm{C} \\
T \geq 100^{\circ} \mathrm{C} \\
T \geq 100^{\circ} \mathrm{C} \\
T \geq 100^{\circ} \mathrm{C} \\
T \geq 100^{\circ} \mathrm{C} \\
T \geq 100^{\circ} \mathrm{C} \\
T \geq 100^{\circ} \mathrm{C} \\
T \geq 100^{\circ} \mathrm{C} \\
T \geq 100^{\circ} \mathrm{C} \\
T \geq 100^{\circ} \mathrm{C}\end{array}$} & \multirow{10}{*}{$\begin{array}{l}\mathrm{T} \geq 100^{\circ} \mathrm{C} \\
\mathrm{T} \geq 100^{\circ} \mathrm{C} \\
\mathrm{T} \geq 100^{\circ} \mathrm{C} \\
\mathrm{T} \geq 100^{\circ} \mathrm{C} \\
\mathrm{T} \geq 100^{\circ} \mathrm{C} \\
\mathrm{T} \geq 100^{\circ} \mathrm{C} \\
\mathrm{T} \geq 100^{\circ} \mathrm{C} \\
T \geq 100^{\circ} \mathrm{C} \\
T \geq 100^{\circ} \mathrm{C} \\
T \geq 100^{\circ} \mathrm{C}\end{array}$} & \multirow{4}{*}{$\begin{array}{l}50 \\
53 \\
55 \\
58\end{array}$} & \multirow{4}{*}{$\begin{array}{c}27.23 \\
19.76 \\
15.23 \\
9.14\end{array}$} \\
\hline & & & & & & & & \\
\hline & & & & & & & & \\
\hline & & & & & & & & \\
\hline & & & & & & & 65 & 6.97 \\
\hline & & & & & & & 69 & 5.03 \\
\hline & & & & & & & 74 & 2.47 \\
\hline & & & & & & & 77 & 1.45 \\
\hline & & & & & & & 80 & 1.03 \\
\hline & & & & & & & & \\
\hline Co-1 & 0.0107 & 198.371 & & & 0.542 & 0.256 & & \\
\hline $\mathrm{CO-2}$ & 0.0107 & 198.371 & & & 0.339 & 0.160 & & \\
\hline $\mathrm{Co-3}$ & 0.0107 & 198.371 & & & 0.339 & 0.160 & & \\
\hline $\mathrm{CO}-4$ & 0.0107 & 198.371 & & & 0.327 & 0.154 & & \\
\hline$C 0.5$ & 0.0107 & 198.371 & & & 0.327 & 0.154 & & \\
\hline Co-6 & 0.0102 & 146.192 & & & 0.639 & 0.427 & & \\
\hline $\mathrm{Co-7}$ & 0.0102 & 146.192 & & & 0.320 & 0.213 & & \\
\hline Co-8 & 0.0104 & 137.363 & & & 0.327 & 0.228 & & \\
\hline $\mathrm{CO}-9$ & 0.0121 & 107.069 & & & 0.386 & 0.297 & & \\
\hline $\mathrm{Co}-10$ & 0.0162 & 78.416 & & & 0.526 & 0.414 & & \\
\hline C1A1-4 & 0.0107 & 198.371 & & & 0.247 & 0.117 & & \\
\hline C1A2-4 & 0.0111 & 121.274 & & & 0.265 & 0.196 & & \\
\hline C1A3-4 & 0.0104 & 187.556 & & & 0.242 & 0.124 & & \\
\hline C1A4-4 & 0.0102 & 176.229 & & & 0.238 & 0.132 & & \\
\hline C1A1-9 & 0.0152 & 83.455 & & & 0.369 & 0.291 & & \\
\hline C1A2-9 & 0.0271 & 47.642 & & & 0.690 & 0.534 & & \\
\hline C1 A3-9 & 0.0101 & 155.587 & & & 0.238 & 0.151 & & \\
\hline C1 A4-9 & 0.0116 & 113.950 & & & 0.277 & 0.210 & & \\
\hline C5A1-4 & 0.0349 & & 37.362 & & 0.905 & 0.695 & & \\
\hline C5A2-4 & 0.1001 & & 14.864 & & 2.965 & 1.993 & & \\
\hline C5A3-4 & 0.0271 & 47.642 & & & 0.695 & 0.537 & & \\
\hline C5A4-4 & 0.0773 & & 18.944 & & 2.204 & 1.506 & & \\
\hline C5A1-9 & 0.0497 & & 27.927 & & 1.338 & 0.963 & & \\
\hline C5A2-9 & 0.2062 & & 7.180 & & 7.247 & 4.896 & & \\
\hline C5A3-9 & 0.0370 & & 35.592 & & 0.974 & 0.739 & & \\
\hline C5A4-9 & 0.1053 & & 14.160 & & 3.147 & 2.110 & & \\
\hline
\end{tabular}

ICEDF Gas Composition Analysis (page 3)

$$
\text { C. } 60
$$


ICEDF SMF WkSht 6/88 supersedes ICEDF SMF WkSht 9/87 ICEDF SMF SkSht 10/89 supersedes ICEDF SMF WkSht 6/88

1) Open "ICEDF SMF WkSht 10/89". 2) Enter test name. 3) Save as "ICEDF testname month/year".

\section{How thls spreadsheet works}

CO flow rate determined by Lookup function: Column $\mathrm{H}$, Cells AB \& AC. Pressure correction added 5/23/89.

Dry gas volume $=\mathrm{CO}$ flow rate ${ }^{*}$ sample duration ${ }^{*}$ pressure correction .

Actual dry gas volume $=$ VOL $(d r y$, actual $)=$ sample duration * CO flow rate * $(273+$ To $) / 293$.

$\mathrm{H} 2 \mathrm{O}$ specific volume $=1.227+0.004712(\mathrm{To})$ for To $\geq 100^{\circ} \mathrm{C}$.

H2O saturated steam partial pressure (Psat/Po $=$ Formula1) for $T<100^{\circ} \mathrm{C}$

Formula1 $=0.0107-3.451^{*} 10^{\wedge}-4^{*} \mathrm{~F} 10+5.359^{\star} 10^{\wedge}-5^{\star} \mathrm{F} 10^{\wedge} 2-5.694^{*} 10^{\wedge}-7^{\star} \mathrm{F} 10^{\wedge} 3+1.057^{*} 10^{\wedge}-8^{*} \mathrm{~F} 10^{\wedge} 4$

Actual $\mathrm{H} 2 \mathrm{O}$ gas volume:

$T<100^{\circ} \mathrm{C}: \quad \operatorname{VOL}(\max )=[($ Psat/Po $) \cdot($ VOL $(d r y$, actual $))][1$ - (Psat/Po $\left.)\right]$. See BNW 51060, pg 133. $\mathrm{VOL}(\max )=\mathrm{VOL}(\mathrm{H} 2 \mathrm{O}$, saturated, maximum possible at $\mathrm{T})$

Fog Check: compare $\mathrm{H} 2 \mathrm{O}$ mass collected to $\mathrm{H} 2 \mathrm{O}$ mass required for sample saturation $\mathrm{M}(\mathrm{H} 2 \mathrm{O}$, sat $)=[\mathrm{VOL}(\mathrm{dry}$, actual $)+\mathrm{VOL}(\mathrm{H} 2 \mathrm{O}, \max )] \mathrm{Vs}(\mathrm{H} 2 \mathrm{O}$ vapor, sat $)](1000 / 1000)$ $\mathrm{Vs}(\mathrm{H} 2 \mathrm{O}$ vapor, sat $)=$ FormulaA if $\mathrm{T}<25^{\circ} \mathrm{C},=$ FormulaC if $\mathrm{T}>65^{\circ} \mathrm{C}$. FormulaA $=199.61^{*} 10^{\wedge}(-2.7052 \theta-2(\mathrm{~T}))$. FormulaB $=138.44^{*} 10^{\wedge}(-2.1068 \theta-2(T))$. FormulaC $=68.411 \cdot 10^{\wedge}(-1.6225 \theta-2(T))$.

1) If condensate mass $<M\left(\mathrm{H}_{2} \mathrm{O}\right.$, sat $)$ : $\operatorname{VOL}(\mathrm{H} 2 \mathrm{O}$, actual $)=(\mathrm{RH})$ " $(\mathrm{VOL}(\max ))$. Print "Not Sat."

2) If condensate mass $=\mathrm{M}(\mathrm{H} 2 \mathrm{O}$, sat $)$ :

$\mathrm{RH}=$ condensate mass $/ \mathrm{M}(\mathrm{H} 2 \mathrm{O}$, sat $)$. VOL $(H 2 O$, actual) $=$ VOL(max). Print "Sat." (saturated).

3) If condenate mass $>\mathrm{M}(\mathrm{H} 2 \mathrm{O}$, sat): VOL(H2O, actual) $=$ VOL(max). Calculate and print fog mass conc. Fog Conc $=$ condensate mass $\cdot \mathrm{M}(\mathrm{H} 2 \mathrm{O}$, sat $) /$ sample vol. (sample vol $=\left(1000 \mathrm{~m}^{\wedge} 3 /\right)^{*} \Sigma$ [actual $\mathrm{H} 2 \mathrm{O} \&$ dry vols])

$\mathrm{T} \geq 100^{\circ} \mathrm{C}: \quad \operatorname{Vol}(\mathrm{H} 2 \mathrm{O})=(\text { condensate mass " sat steam spec vol })^{*}(1000 / 1000)$. Print "S. H. Vap."

SMF = Actual $\mathrm{H} 20$ gas volume / total gas volume (ie., the sum of actual dry and actual $\mathrm{H} 2 \mathrm{O}$ volumes, = sample vol:

Not included: 1) possible temp variations, 2) possible supersaturation.

CO upstream pressure correction factor added to spreadsheet on 6/14/89 (in draft form in 5/89).

Modifications: ICEDF SMF WkSht 6/89 superseded ICEDF SMF WkSht 9/87

1) Originall date of this version was $6 / 14 / 89$.

2) 1st modification was made 9/14/89:

Crit orifice flow corr. factor formula was changed to print "n if test time was "

Sample analysis date cell was added to top of page 1.

ICEDF SMF WkSht 10/89 superseded ICEDF SMF WkSht 6/89

1) Changed prịnter päge set-up, and minor editing. 2) Changed SMF col eq to print "n if no H2O mass is entered.

3) Changed Fog column equation to print "m" it no SMF is calculated, and iSat? if SMF is calculated based on assumed saturation when no $\mathrm{H} 2 \mathrm{O}$ mass is entered.

4) Changed Sample ID column 12/1/89 to match new test plan (no C6B1 or C6B2). 
APPENDIX D

AEROSOL PARTICLE SIZE DISTRIBUTION 


\section{AEROSOL PARTICLE SIZE DISTRIBUTION}

Results of measured aerosol particle size distributions are shown graphically for Test 2 and each aerosol test performed with ice present in the baskets. The results are plotted on log-probability scales and represent the aerodynamic mass distributions of suspended particles. On the selected scales, a straight-line fit is an indication that the particle size distribution is log-normal. The aerodynamic mass median diameter (AMMD) and the geometric standard deviation (GSD) of the aerosols measured at various locations within the test section are listed on each figure in the appendix (on the figures, MMAD is equivalent to AMMD). AMMD was determined using data from all impactor stages and the mass collected on the top of Stage 0 . Because of the non-ideal nature of the cascade impactors, log-normal particle size distributions were generally determined neglecting the two largest particle sizes in each data set or the data from stages cumulatively collecting less than about 5 or $10 \%$ of the total sampled particulate mass on both extremes of the size distributions. This only influenced the determination of GSD.

Other information presented on the figures include the time when samples were obtained (particle size was measured twice during most tests), the type of analysis method used (gravimetric or chemical), and the location from which samples were obtained. While symbols used to plot data were generally selected to represent the location of the sample, results for Test 11 (Alternate Test No. 16-11) were plotted by analysis method to show a comparison of gravimetric ( $m$, representing mass analysis) and chemical ( $z$, representing zinc analysis) analyses of the same samples. The location from which samples were obtained was listed in the figure title. For the other tests, the symbol "I" was used to plot data from samples obtained at the inlet (Station 6A), and the symbol " 0 " was used to plot data from samples obtained at the outlet (Station 0). The symbols "B" and " $T$ " were used for samples obtained near the bottom and top of the ice-basket region (Stations 5A and 1A1 or 1B), respectively. Finally, the symbol "E" was used for the few samples obtained between the inlet turning vanes and the bottom of the ice baskets (Station 6B). 
Test $18-1,22 \mathrm{~min}$

T) MMAD $=05.66$

T) GSD- 2.59

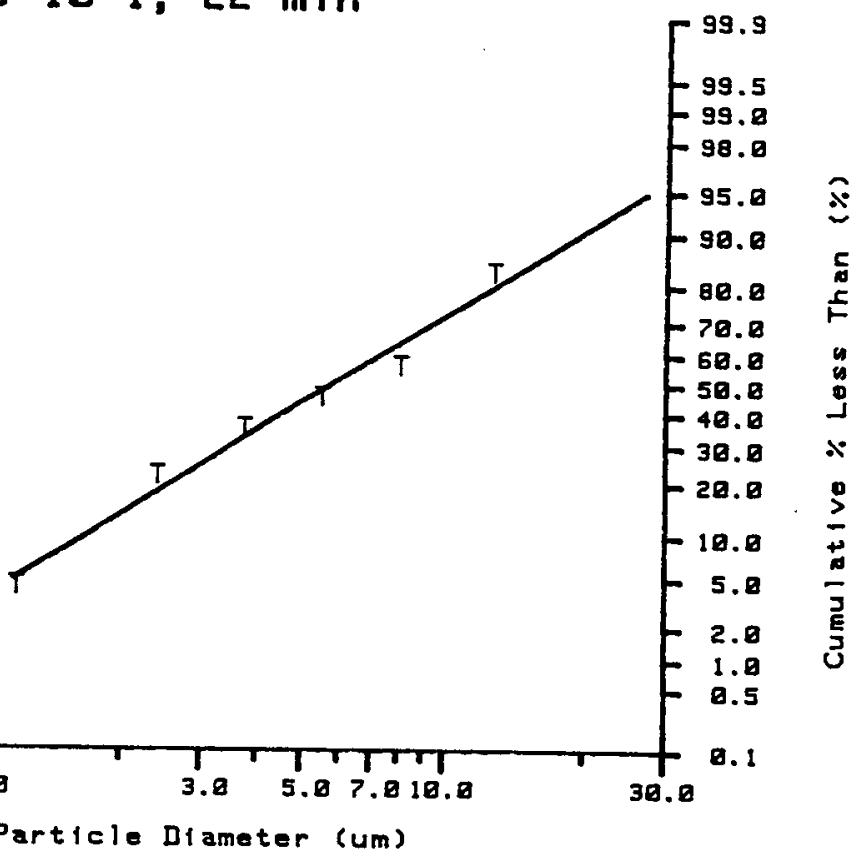

\section{Test 1Q-1, $52 \mathrm{~min}$}
B) MMAD= 03.86
B) $G 5 D=2.59$
T) MMAD= 86.86
T) GSD 2.33

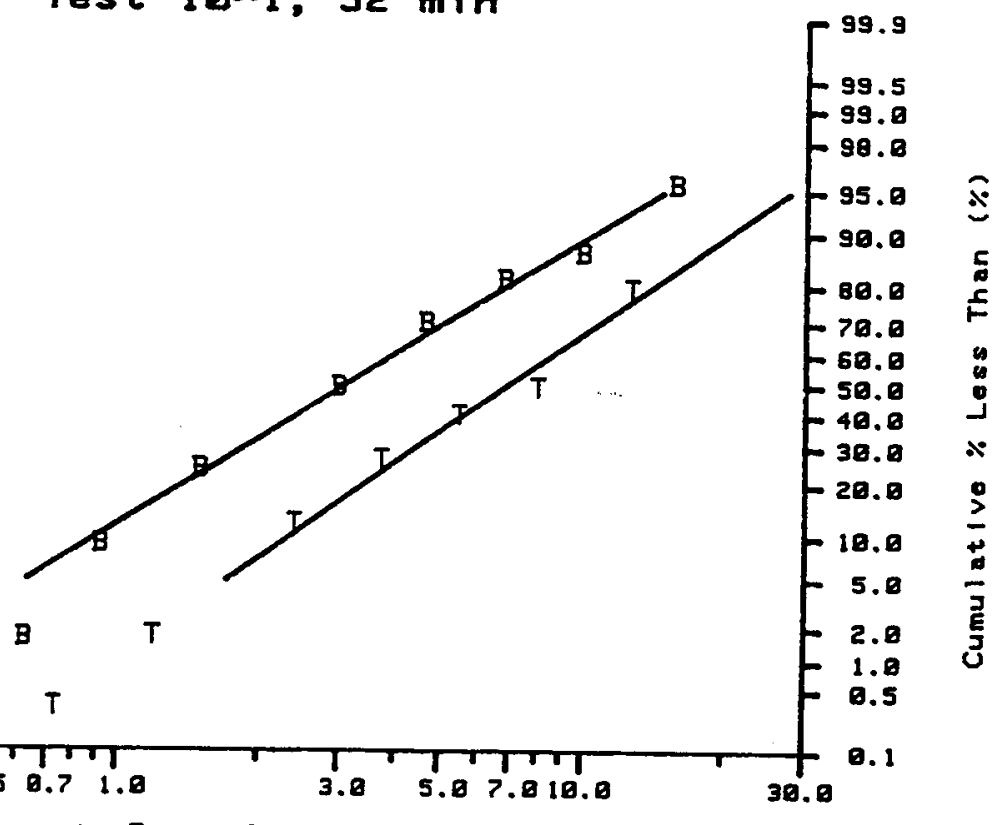

Aerodynamic Particle Diameter (um) 
Test $15-2,32 \mathrm{~min}$

B) MMAD- 05.98

B) G5D- 2.62

T) MMAD- 05.77

T) GSD- 2.62

$-99.9$

$-99.5$

$-99.0$

$-98.0$

$-95.8 \hat{x}$

$-90.0$

$-80.0$

$-78.0$

$-68.0$

$-58.0$

49.8

$-30.0$

$-20.8$

$-10.9$

$-5.8$

甲

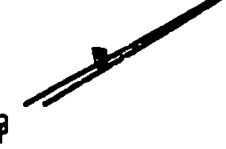

T

$-2.0$

1.9

0.5

a.

e. 1

B) MMAD- 05.78

B) GSD- 2.68

T) MMAD $=86.18$

T) GSD $=2.63$

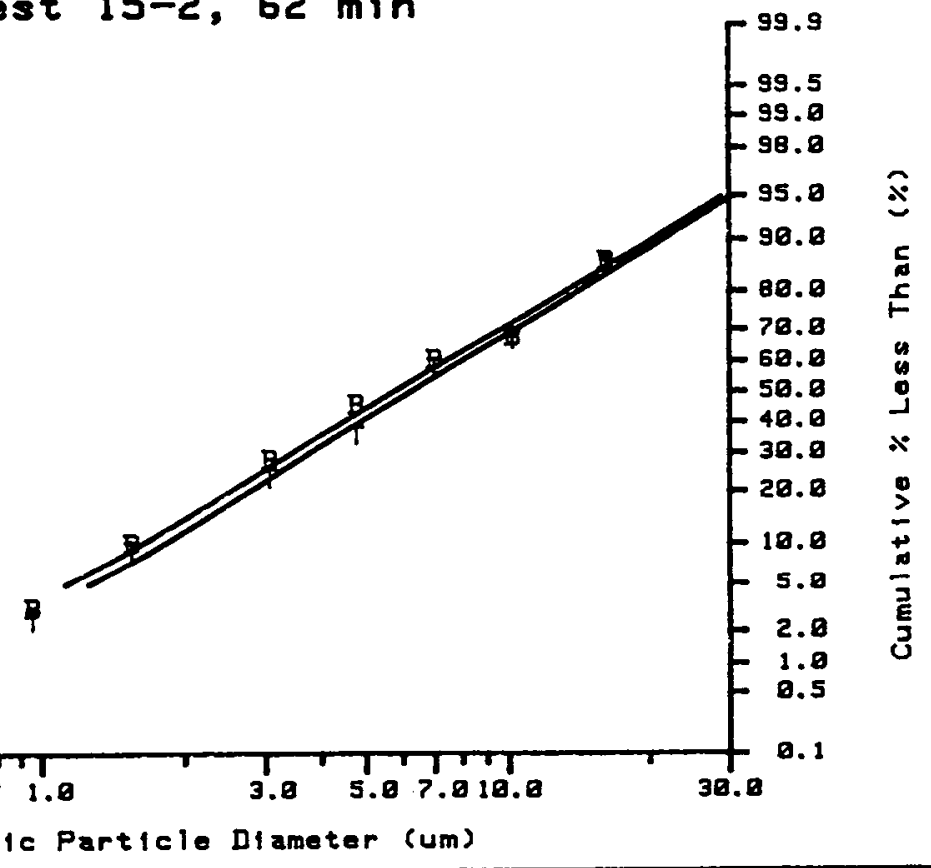

D. 3 
I) MAD- 25.35

I) $650-4.91$

B) MMAD- 18.86

घ) $\operatorname{csp}=3.45$

T) Mrap- 65.33

T) 6SD- 2.87

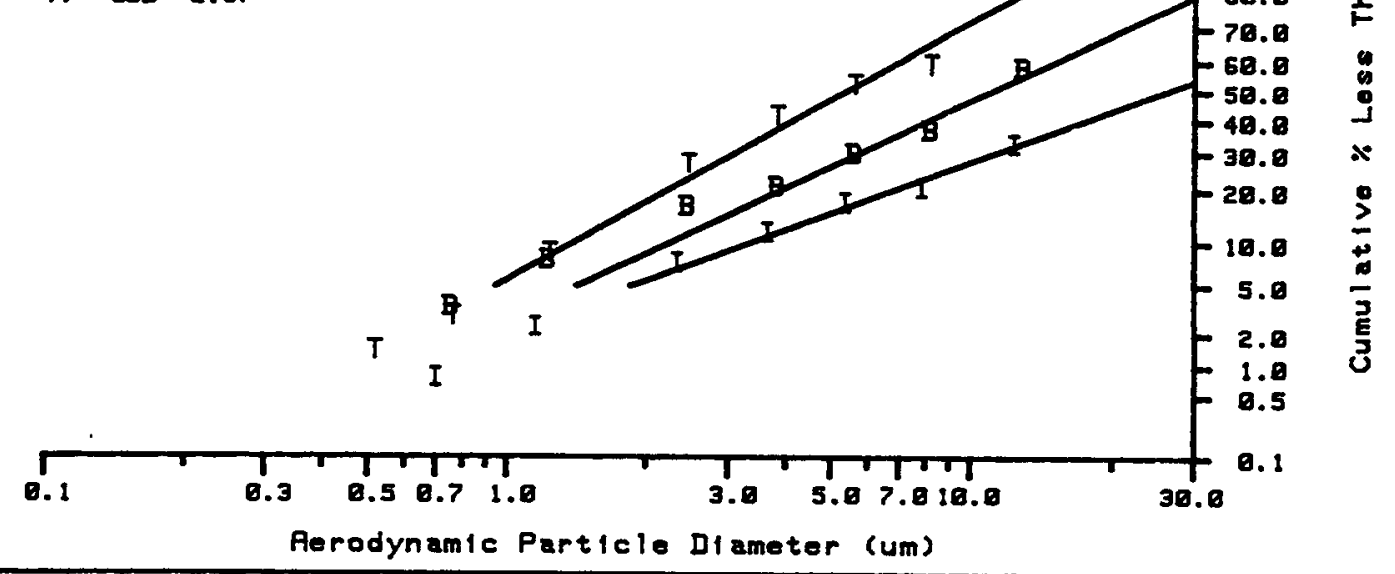

\section{Test $2-3,47 \mathrm{~min}$}

I) MARDo 49.92

I) $\mathrm{GSD}=7.41$

B) MMAD 06.98

B) GSD 2.97

T) MAD- 84.49

T) CSD 3.17

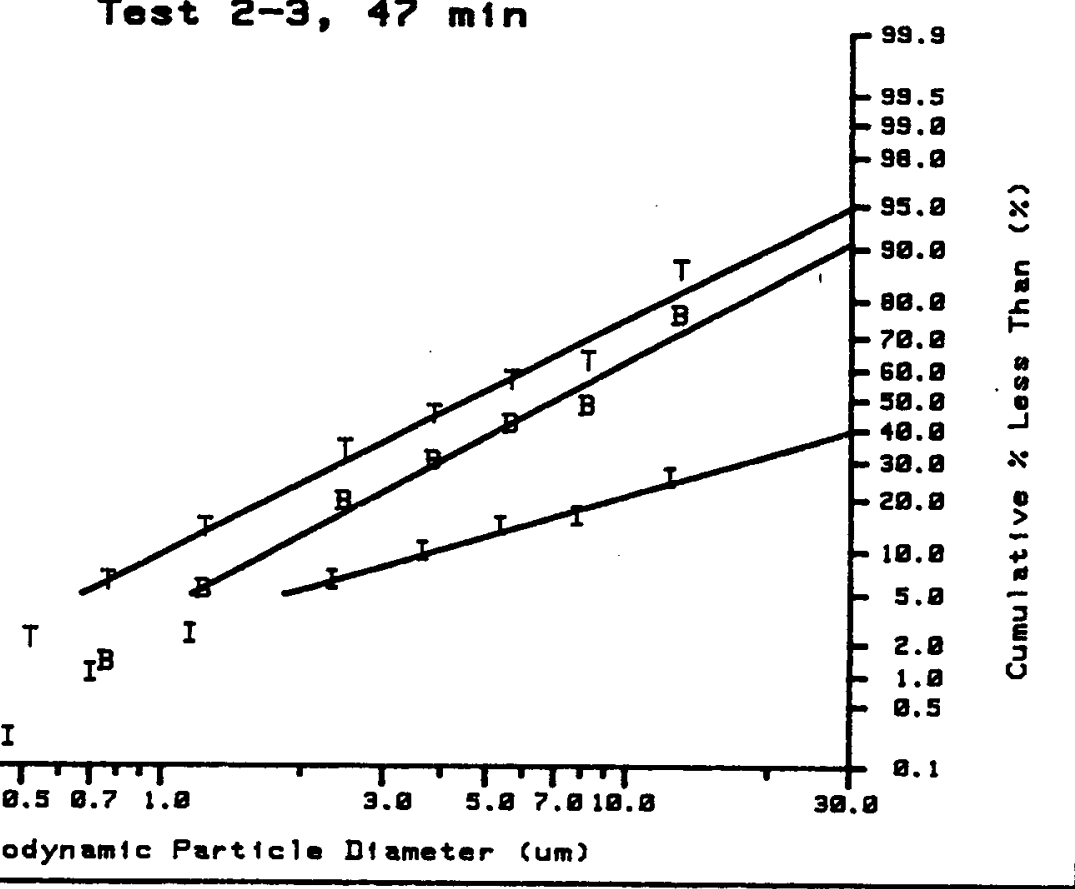


I) MMAD- 88.00

I) GSD $=3.17$

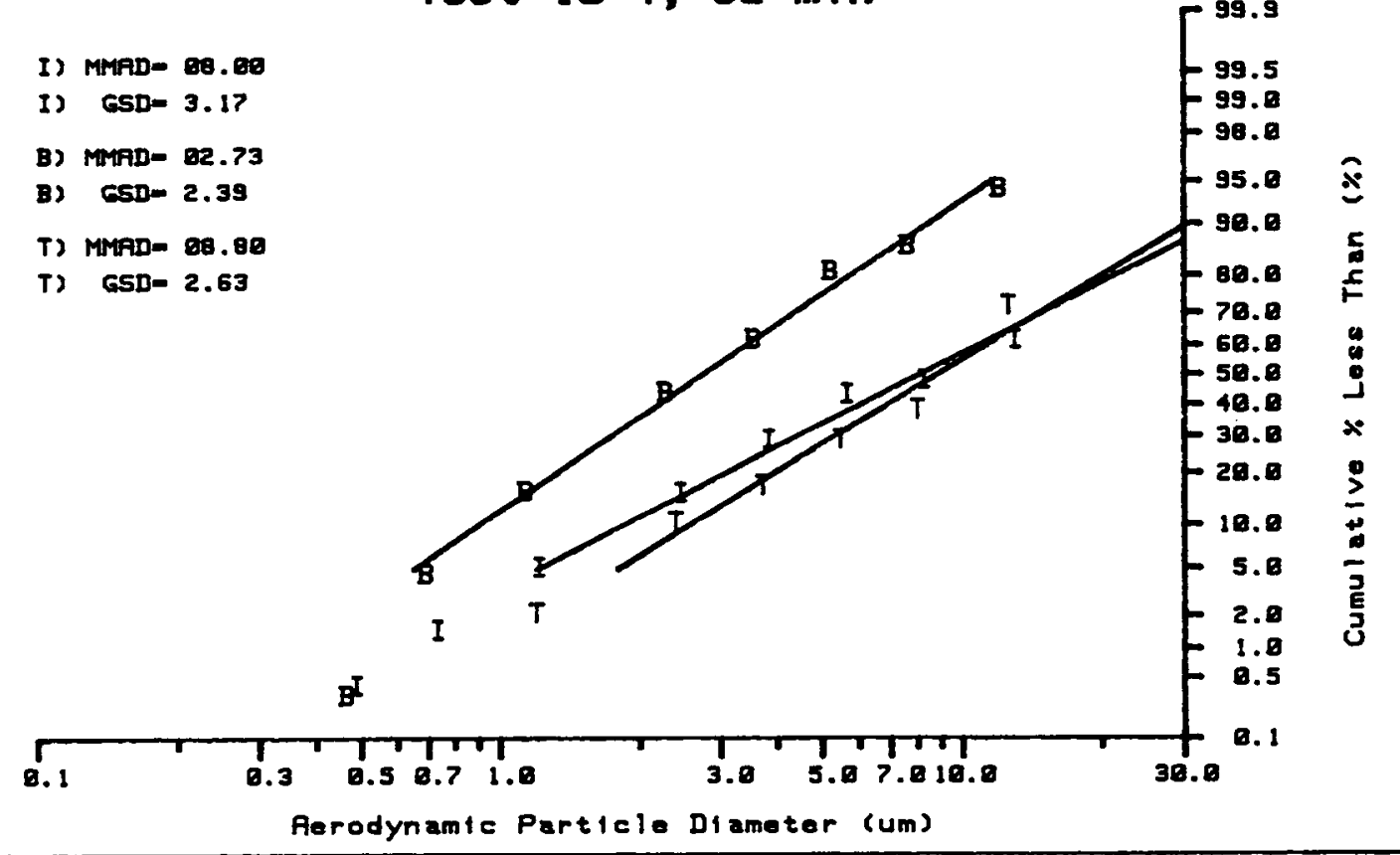

B) MADD- 92.73

B) 650- 2.39

T) MMAD- 88.80

T) G5D- 2.63

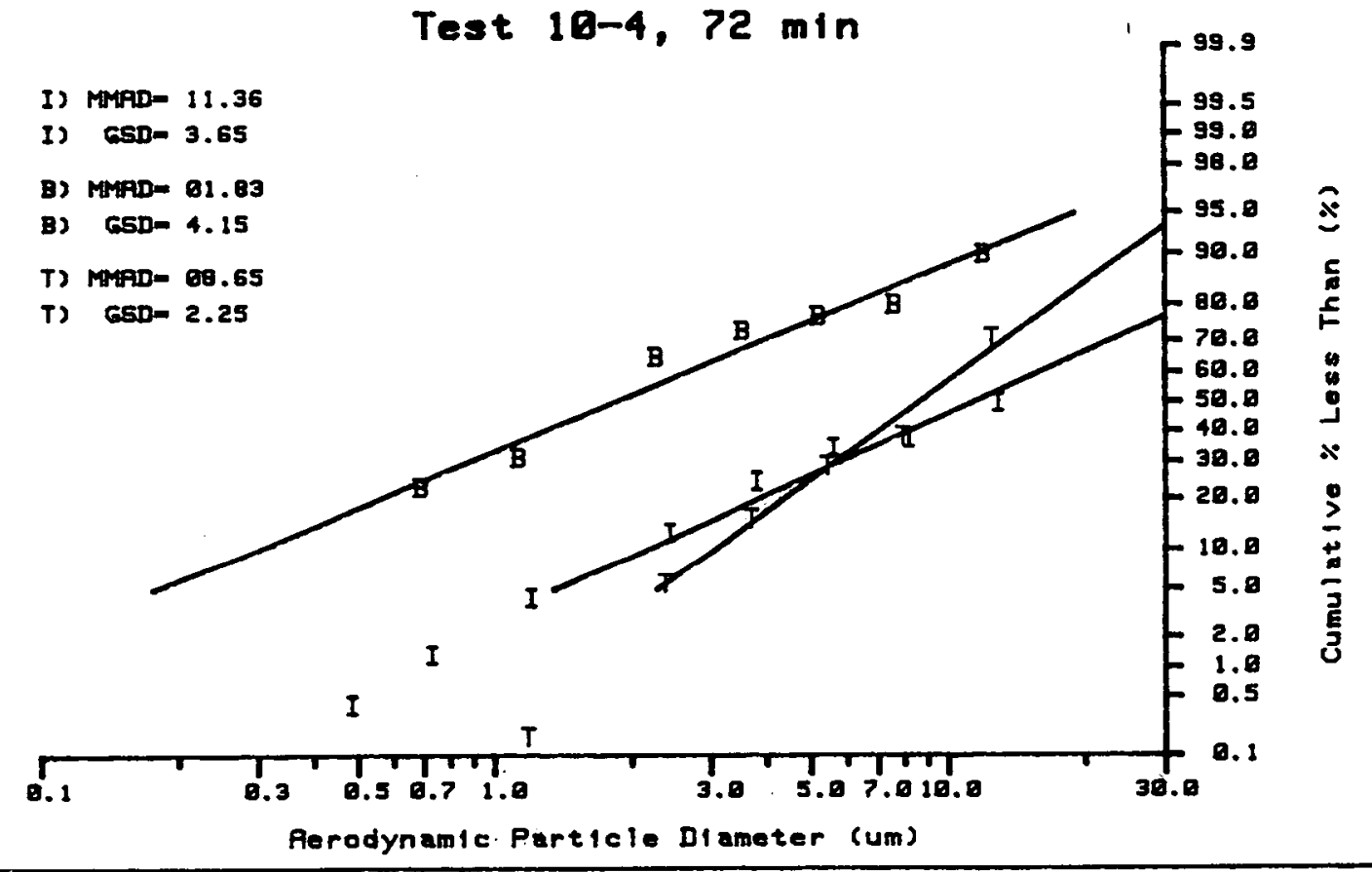


1) MMAD- 83.83

I) $65 \mathrm{D}=2.69$

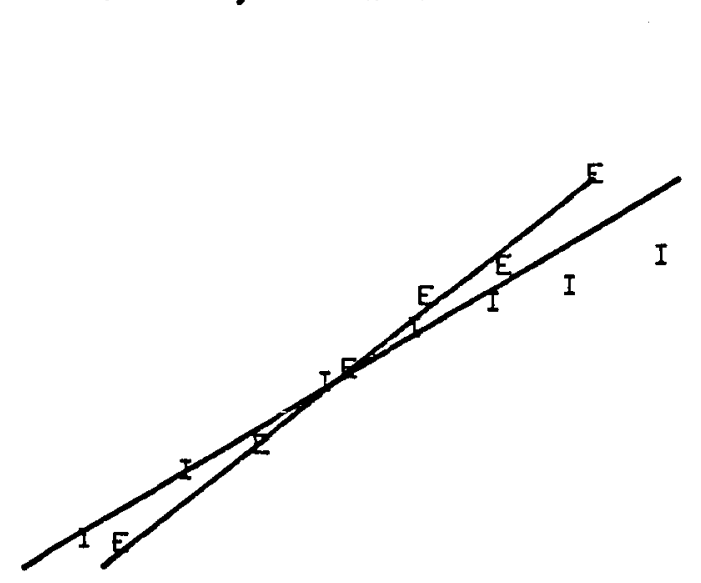

99.9

E) MMAD= 03.73

E) GSD $=2.89$

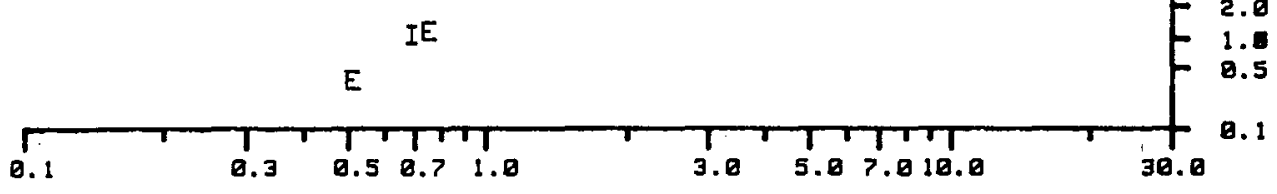

Ferodynamic Particle Dlamoter (um)

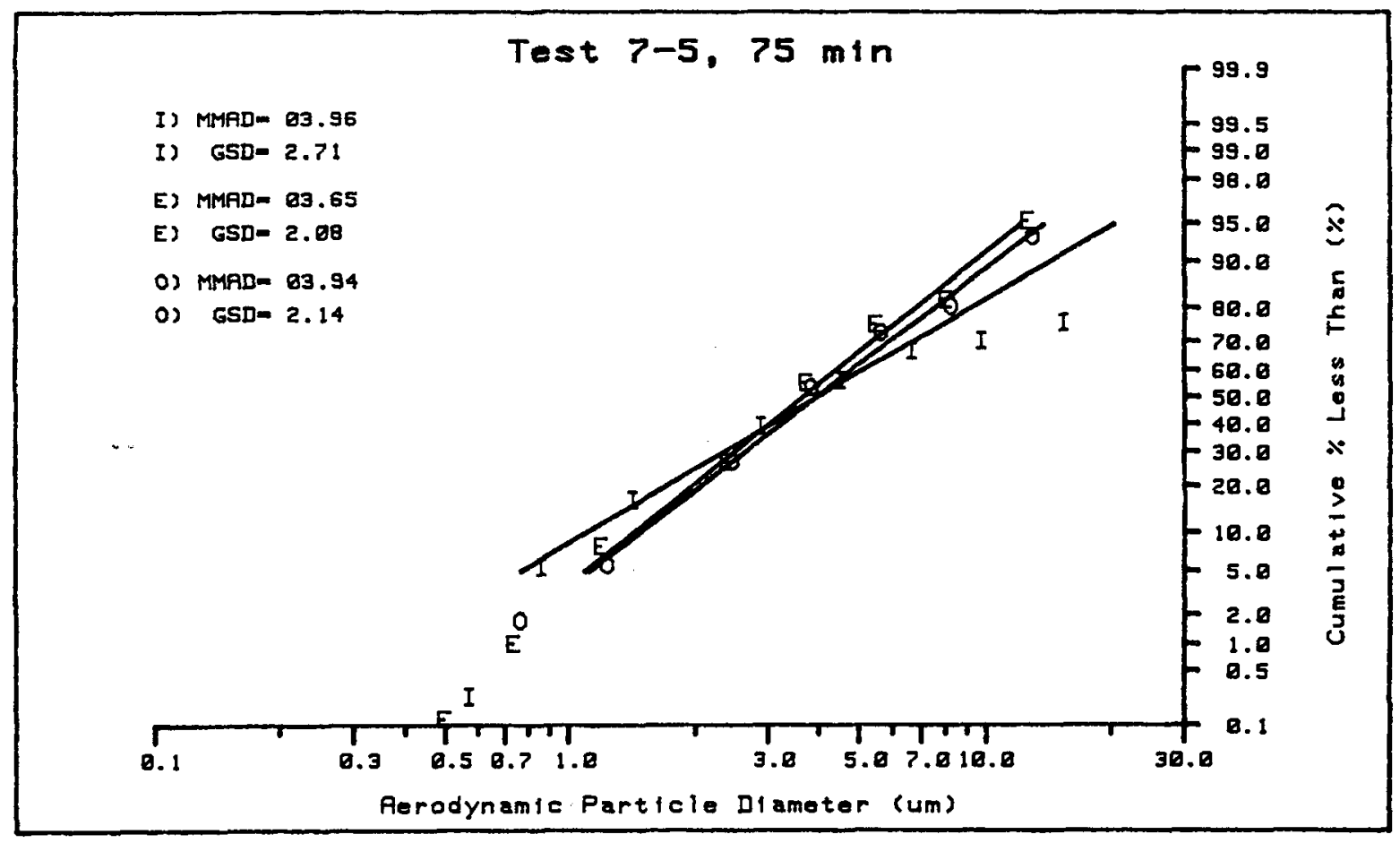




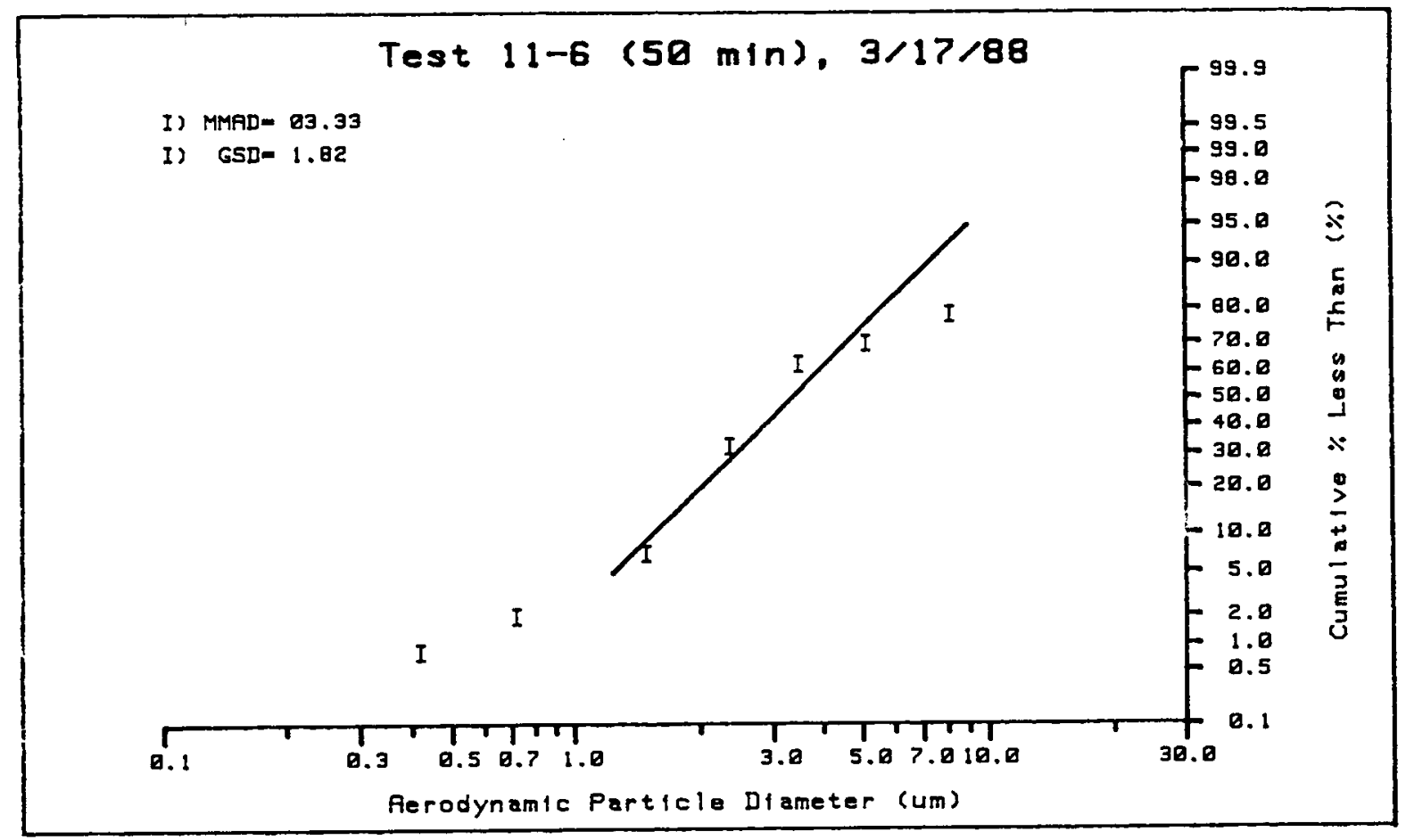

I) MMAD- 03.69

I) $6 S D=2.22$

E) MMAD $=03.65$

E) $65 D=1.76$

T) MMAD $=9.21$

T) GSD $=1.98$

\section{Test $11-6(118 \mathrm{~m} / \mathrm{n}), 3 / 17 / 88$}

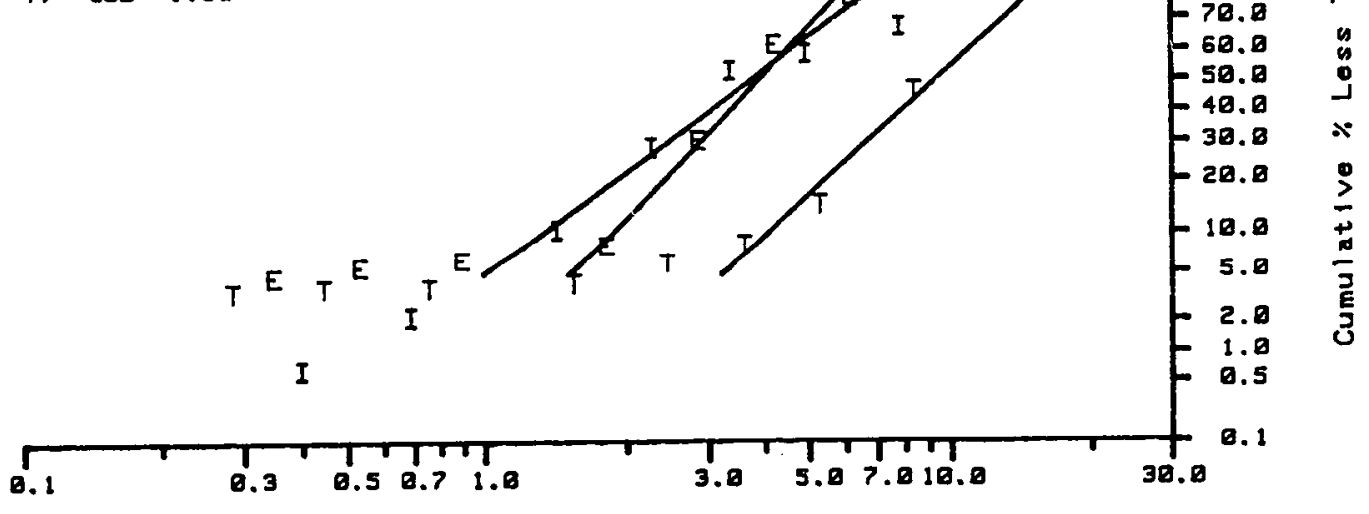

Aerodynamic Particle Dlameter (um) 
Test $9-7,39 \mathrm{~min}$

I) MMAD- 03.26

I) $65 D=2.69$

99.9

E) MAD- 01.67

E) 6SD- 2.39

T) MAB- 81.58

T) 6SD- 2.22

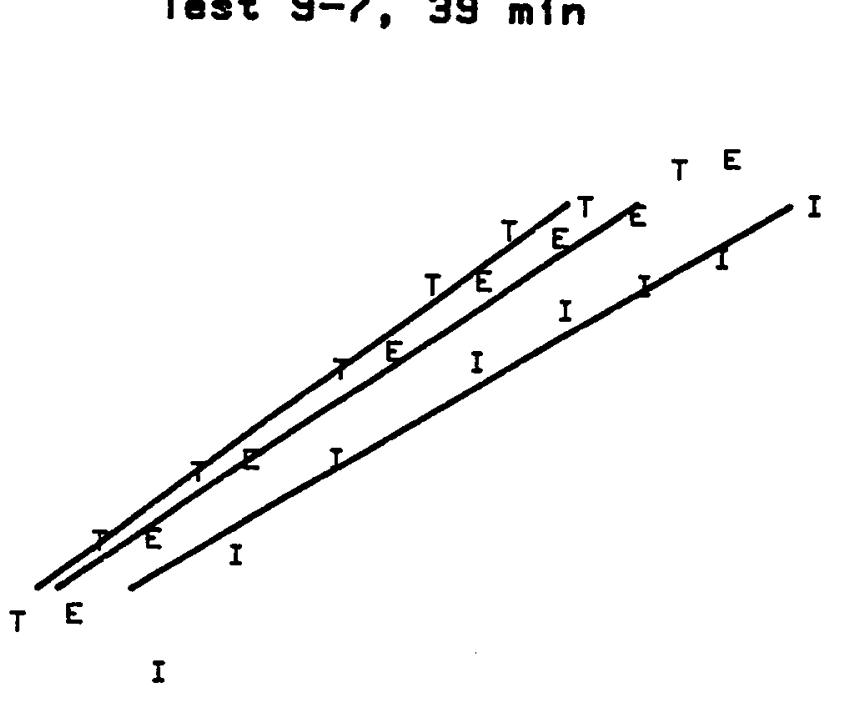

$-99.5$

$-99.8$

- 98.0

-95.8 ख̃

- 90.0

$-80.0$

$-70.8$

$-69.0$

$-50.0$

$-40.8$

$-30.0$

- 20.8

$-10.0$

5.8

- 2.0

- 1.0

- .5

อ.

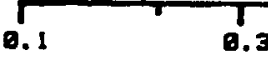

$0.3 \quad 0.50 .7 \quad 1.8$

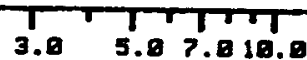

0.1

Perodynamic Particle Diameter (um)

I) MARD- 99.39

I) $\mathrm{GDO}=2.35$

\section{Test 9-7, $78 \mathrm{~min}$}

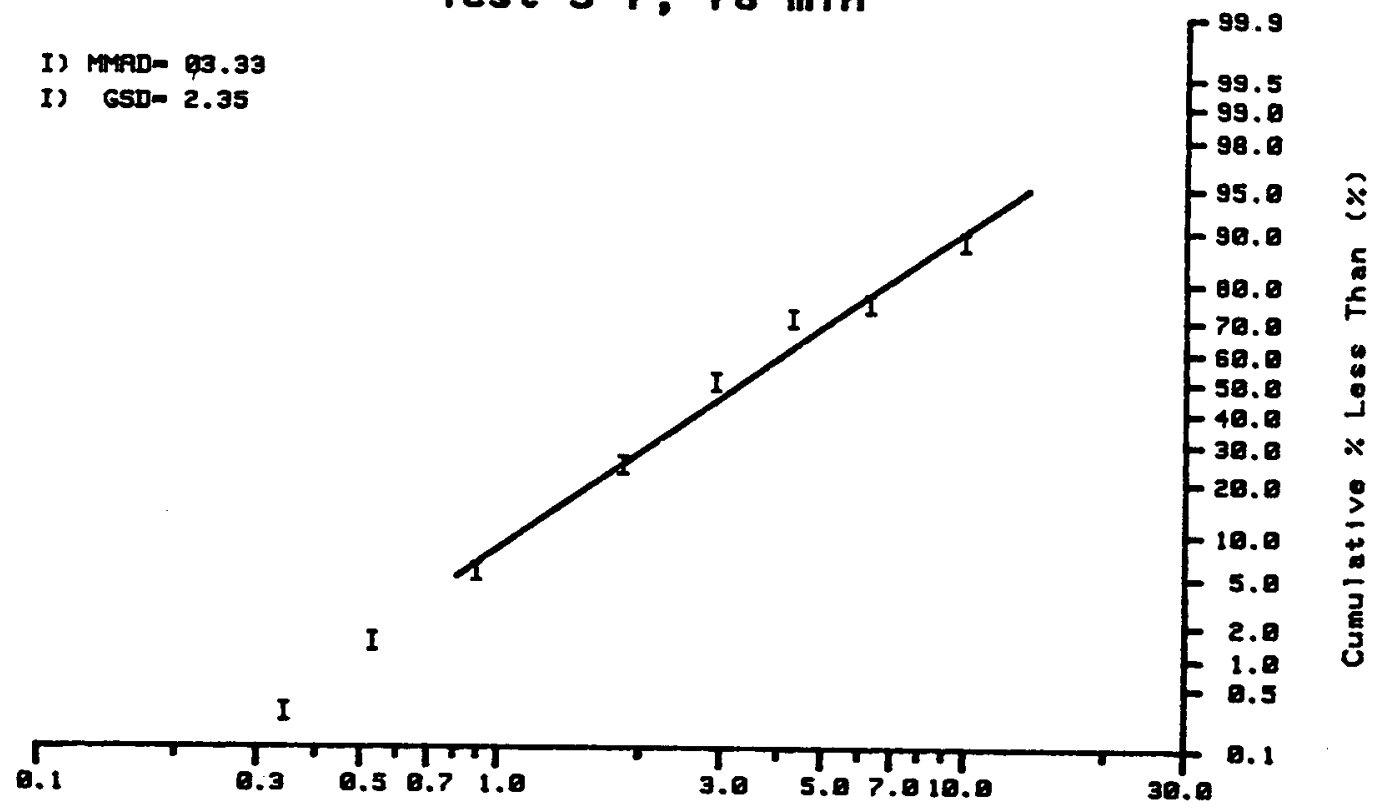

I

ferodynamic Particle Dianeter (um) 
I) MMAD- 67.05

I) $C S D=2.38$

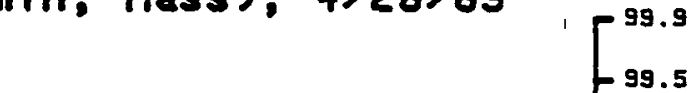

0) MAD- 15.45

D) $65 D-1.89$

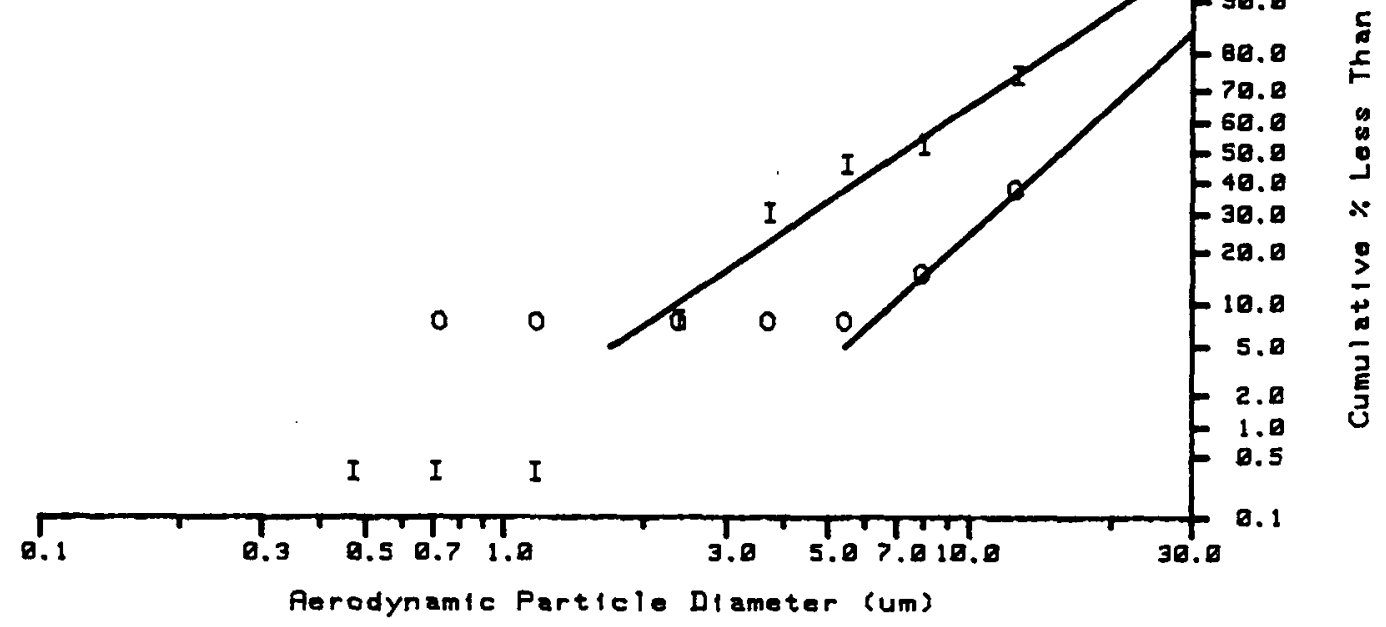

Test 14-8 (27 $\mathrm{min}, \mathrm{KCl}), 4 / 28 / 89$

0) MMPD- 16.75

0) GSD 1.91

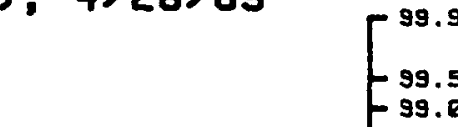

- 99.0

$-98.8$

-95.8 X

$-98.9$

$-80.0$

$->0.0$

$-60.9$

- 50.

$-40.8$

$-30.8$

- 28.8

$-10.0$

00

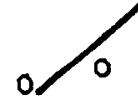

$-5.0$

2.0

0

00

$-1.0$

0.5

a. 1

0.3 0.5 0.7 1.8

3.05 .07917

- 0.1

Perodynamtc Particle Diameter (um) 
I) MMAD= 03.78

I) GSD- 2.30

0) MMAD $=16.68$

a) GSD- 2.93

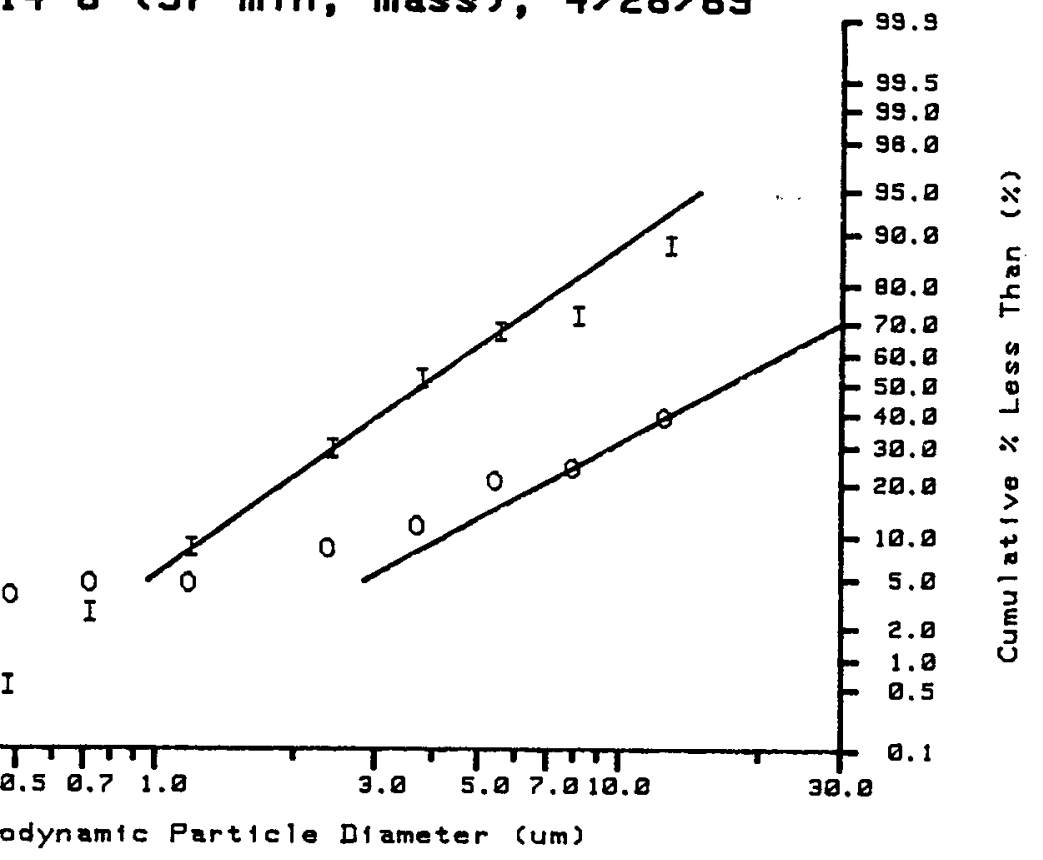

Test 14-8 (57 $\mathrm{m} / \mathrm{n}, \mathrm{KCl}), 4 / 28 / 89$

I) MMAD= 03.73

I) $6 S D-2.30$

0) MMAD- 12.48

o) GSD $=2.56$

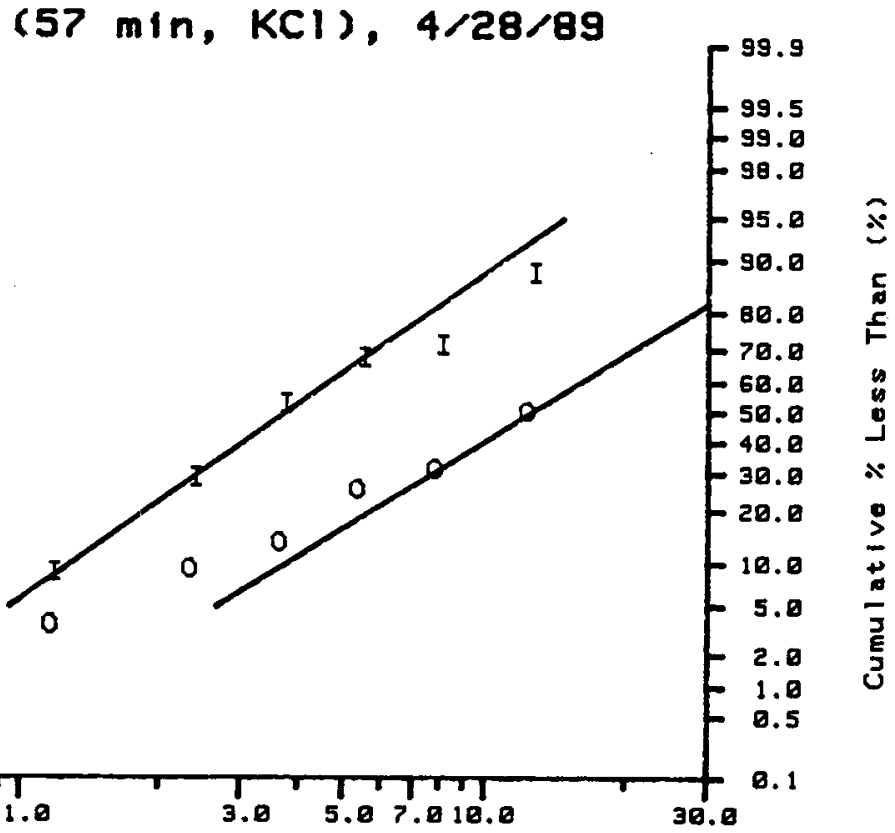

Ferodynamic Particle Diameter (um) 
Test 5-9 (25 $\mathrm{min}, \mathrm{KCl}), 6 / 1 / 89$

I) MMAD- 68.39

I) $\mathrm{GSD}=2.03$

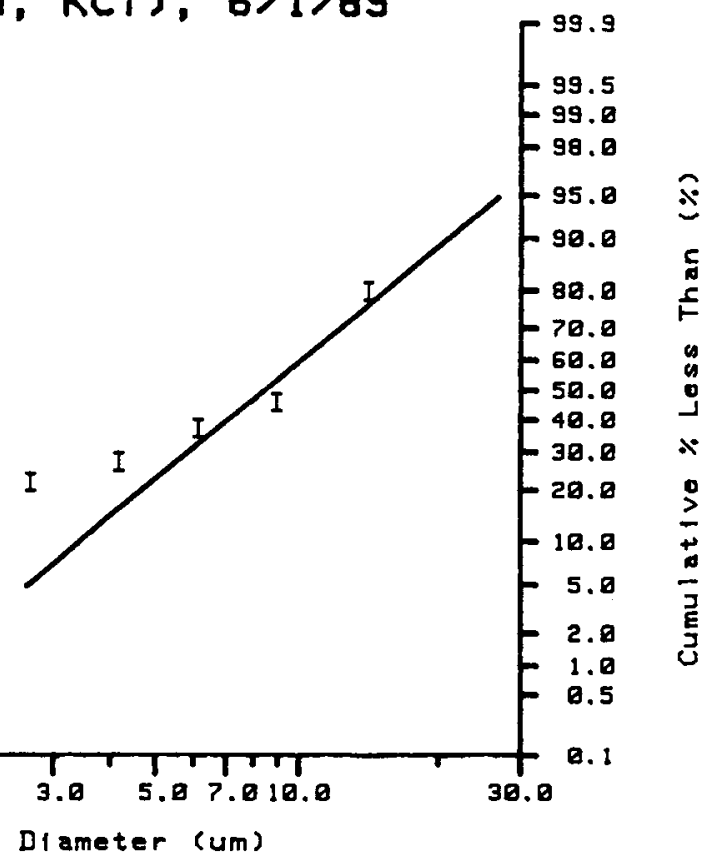

D. 11 


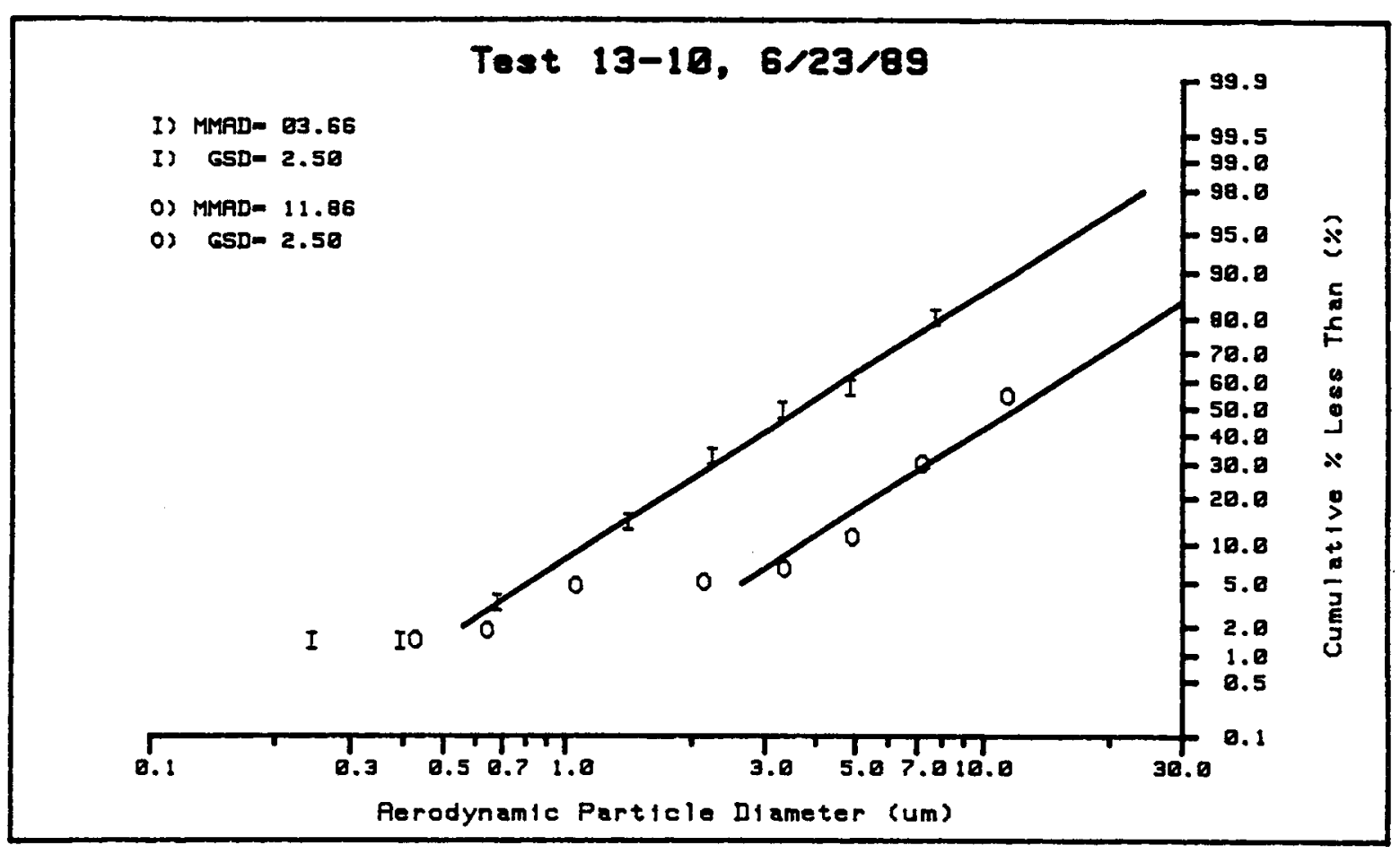


Test 16-11, Sta $0,21 \mathrm{~min}, 11 / 2 / 89$

M) MMAD- 04.19

M) GSD- 2.41

Z) MMAD- 83.80

Z) $C S D=2.53$

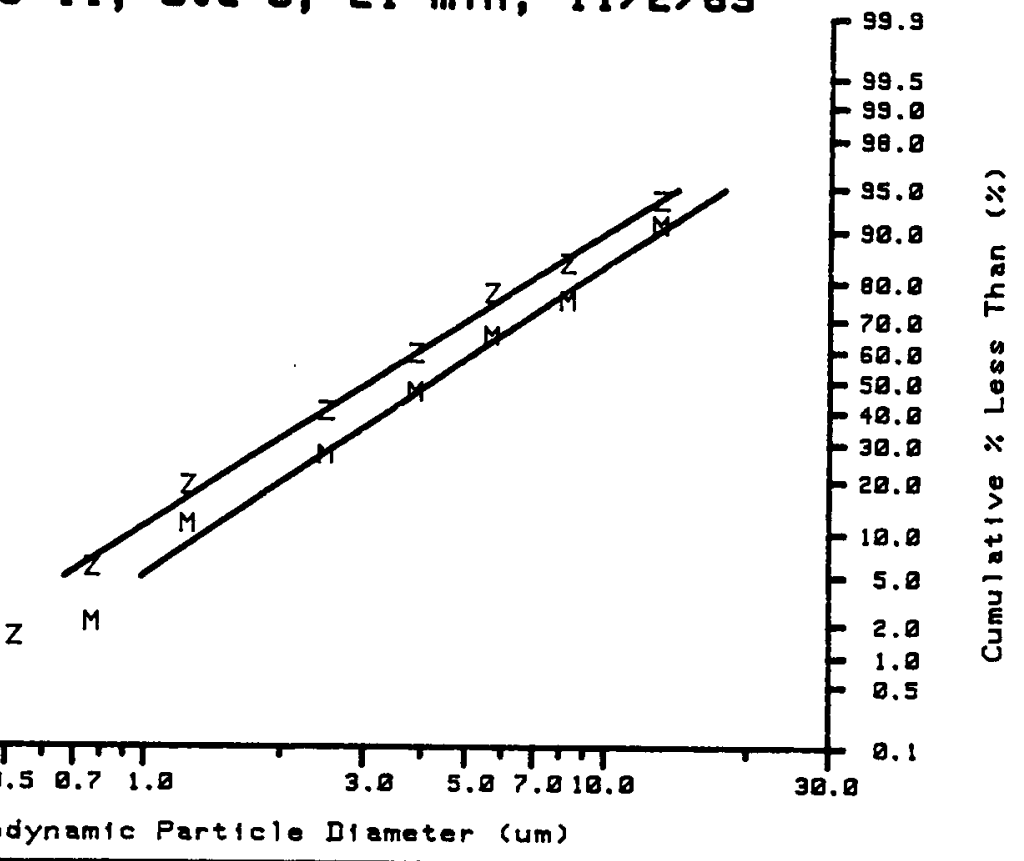

\section{Test $16-11$, Sta $0,51 \mathrm{~m} / \mathrm{n}, 11 / 2 / 89$}

M) MMAD $=92.22$

M) GSD 2.76

z) MMAD- 81.39

z) GSD $=2.81$

2) GSD 2.81
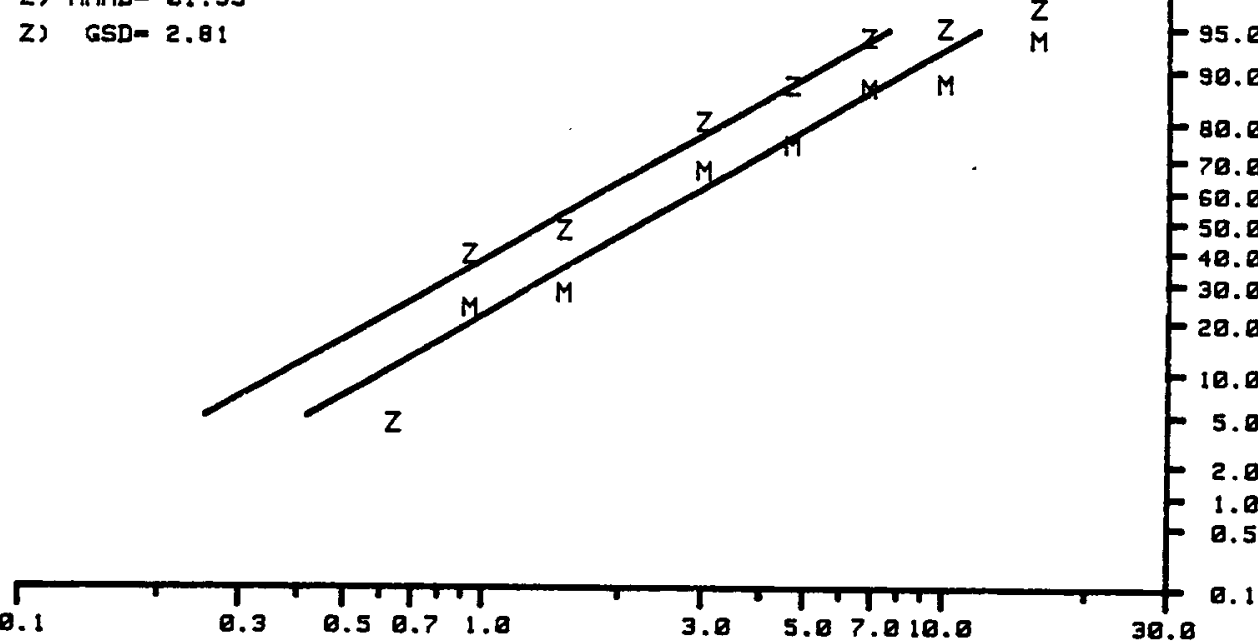

Aerodynamic Particle Diameter (um) 
Test $17-12 a, 5 / 2 / 90$

I) $M M R D=98.98$

I) $G 5 D=1.23$

o) MMAD $=01.32$

o) GSD- 2.18
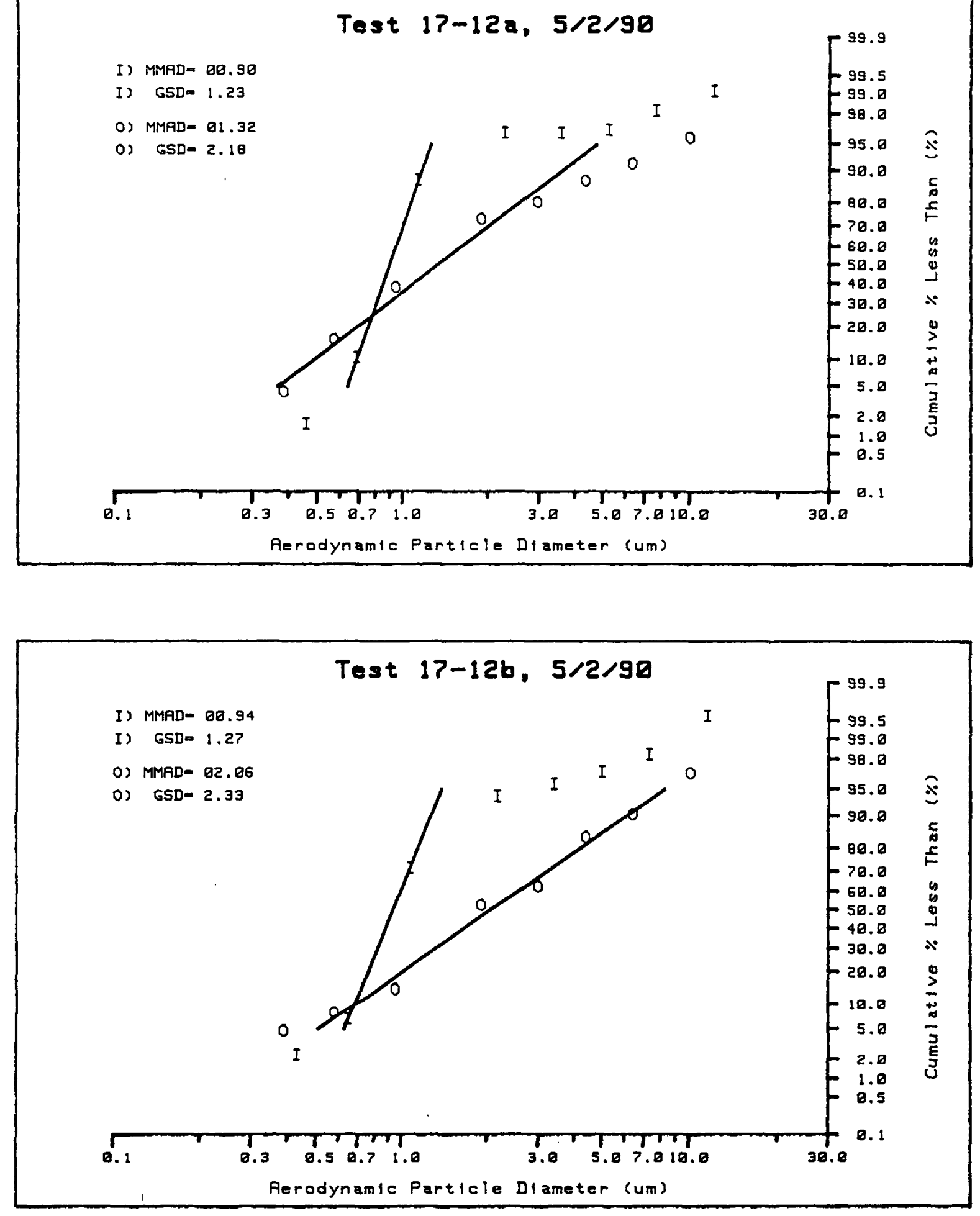


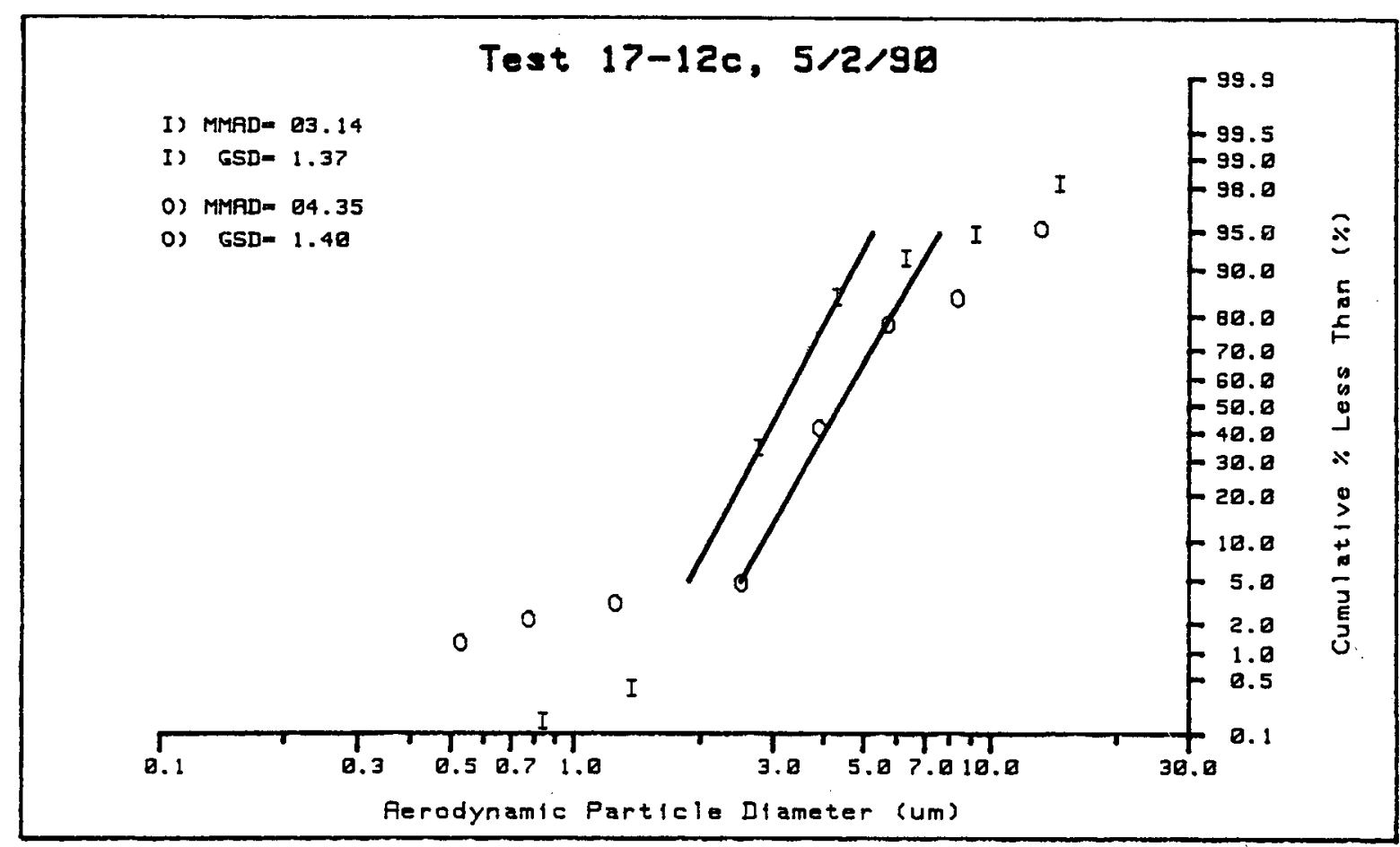

\section{Test 17-12d, 5/2/90}

I) MMAD $=12.26$

I) $\mathrm{GSD}=1.37$

0) MMAD- 10.49

()) $G S D=2.22$

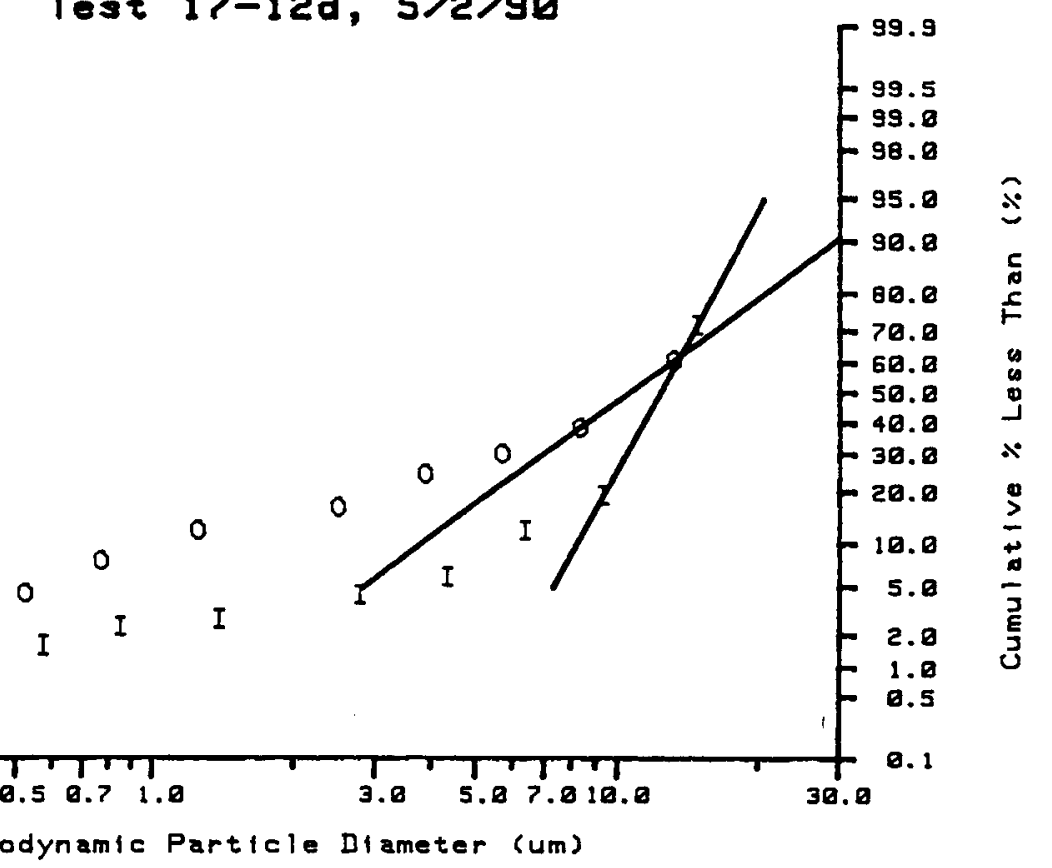


I) MMAD= 81.53

I) $\mathrm{GSD}=1.96$

0) MMAD= 03.36

o) GSD 3.83
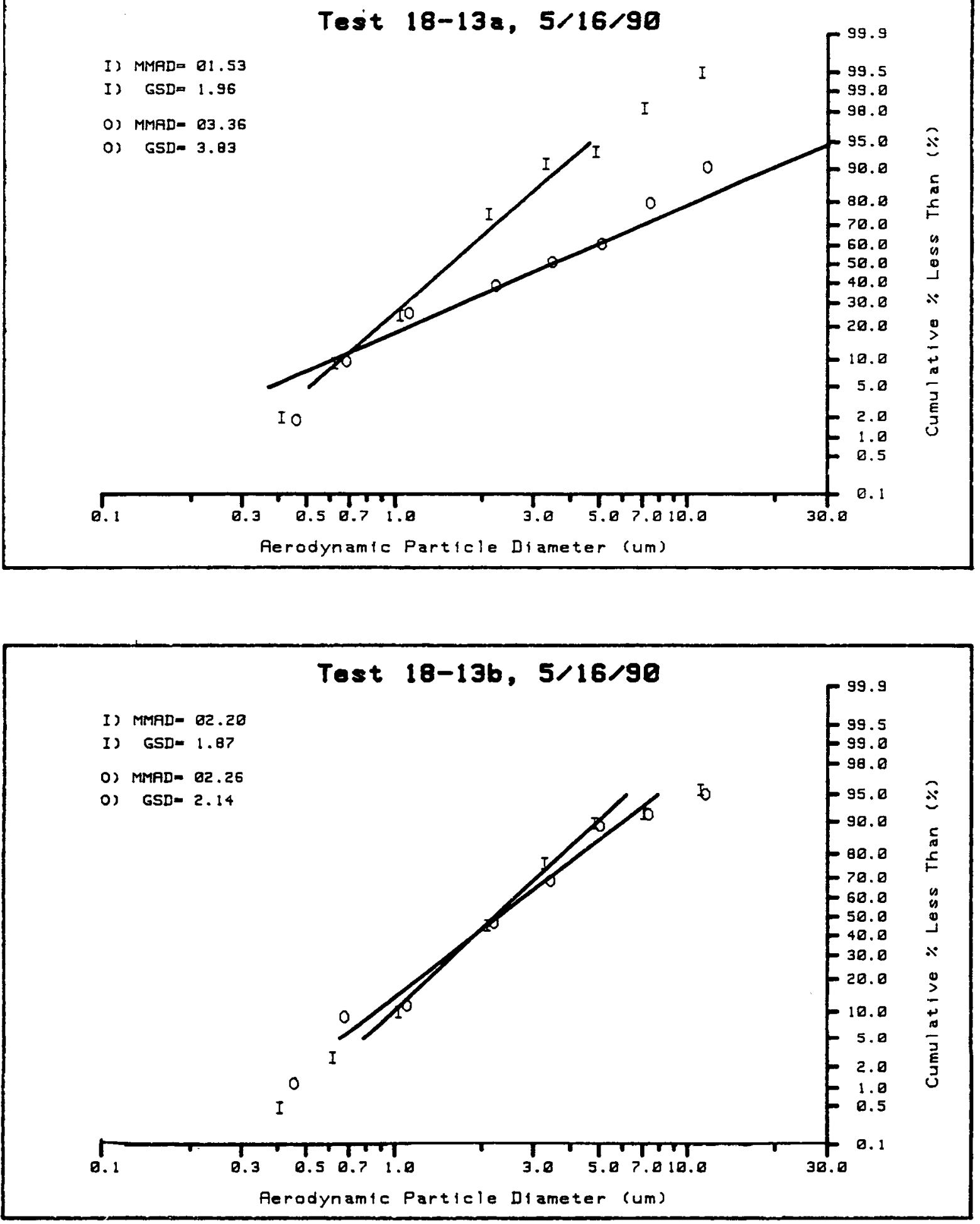
I) MMAD- 02.04

I) $65 \mathrm{D}=1.79$

0) MMAD = 82.78

o) GSD- 2.65

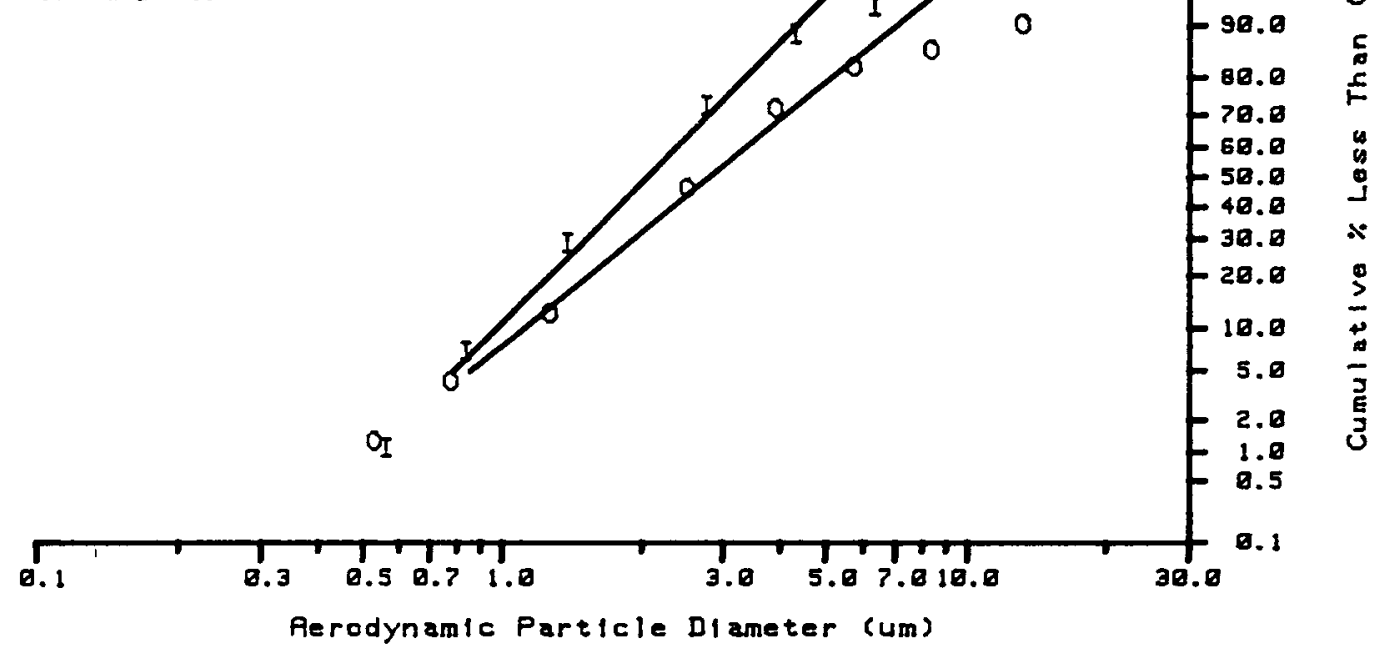

\section{Test $19-14 b, 5 / 31 / 90$}

I) MMAD 02.49

I) GSD - 1.86

0) MMAD- 84.86

o) 6SD- 2.38

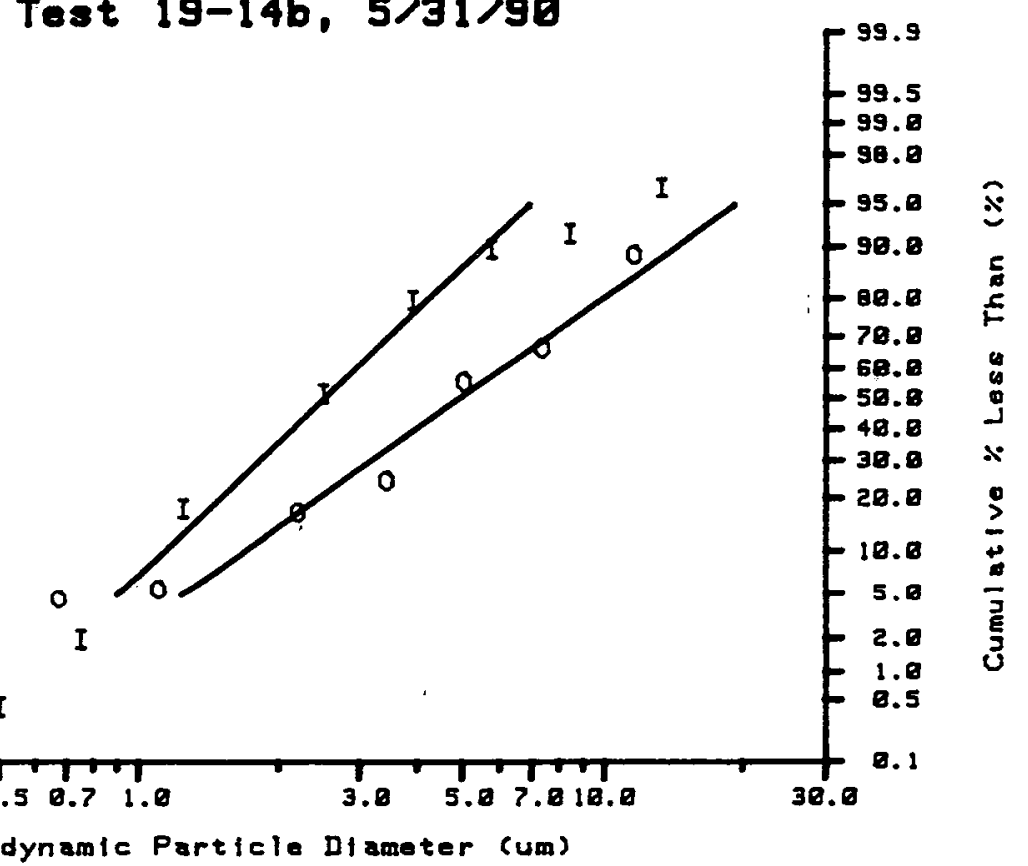




\section{APPENDIX E}

PARTICLE CONCENTRATION AND MASS FLOW RATE WORKSHEETS 


\begin{tabular}{|c|c|c|c|c|c|c|c|c|}
\hline Test & $10-1$ & \multicolumn{4}{|c|}{ 1A1: assumed to be well-mixed } & QA Check: & \multirow{2}{*}{$\begin{array}{l}\text { MwL } \\
\text { Name }\end{array}$} & $/ 29 / 91$ \\
\hline $\begin{array}{r}\text { SMF_I }= \\
\text { GasFlow }= \\
\text { Temp }=\end{array}$ & $\frac{0.205}{0.21}$ & \multicolumn{4}{|c|}{$\left(\mathrm{m}^{\wedge} 3 / \mathrm{s} @ \mathrm{To}\right)$} & $\begin{array}{r}\text { Test Compound }= \\
\text { Chemical Analyzed }= \\
\text { ChemFrac }(1-100 \%)=\end{array}$ & & $\frac{\mathrm{KCl}}{-}$ \\
\hline $\begin{array}{l}\text { Sample } \\
\text { ID No. }\end{array}$ & $\begin{array}{c}\text { Test Time } \\
\text { (min) }\end{array}$ & $\begin{array}{c}\Delta t \\
(\min ) \\
\end{array}$ & $\begin{array}{l}\text { Temp. } \\
\left({ }^{\circ} \mathrm{C}\right)\end{array}$ & $\begin{array}{l}\text { Critical } \\
\text { Orifice } \\
(\#)\end{array}$ & $\begin{array}{c}\mathrm{CO} \\
\Delta \mathrm{P} \\
\text { (in. }-\mathrm{Hg}) \\
\end{array}$ & $\begin{array}{l}\text { SMF } \\
(-)\end{array}$ & $\begin{array}{c}\text { Gravimetric } \\
\Delta M(m g) \\
\end{array}$ & $\begin{array}{l}\text { Chemical } \\
\Delta M(m g)\end{array}$ \\
\hline $\begin{array}{l}\text { F6A-1 } \\
\text { F6A-2 } \\
\text { F6A-3 } \\
\text { F6A-4 } \\
\text { F6A-5 }\end{array}$ & $\begin{array}{c}7.0 \\
23.0 \\
38.0 \\
53.0 \\
67.0\end{array}$ & $\begin{array}{l}3.00 \\
4.00 \\
4.00 \\
4.00 \\
4.00\end{array}$ & $\begin{array}{l}115 \\
120 \\
125 \\
125 \\
122\end{array}$ & $\begin{array}{l}69 \\
69 \\
69 \\
69 \\
69\end{array}$ & & $\begin{array}{l}0.183 \\
0.199 \\
0.210 \\
0.228 \\
0.228\end{array}$ & $\begin{array}{l}19.36 \\
21.72 \\
70.78 \\
77.10 \\
88.38\end{array}$ & \\
\hline $\begin{array}{l}\text { F1A1-1 } \\
\text { F1A1-2 } \\
\text { F1A1-3 }\end{array}$ & $\begin{array}{c}7.0 \\
37.0 \\
67.7\end{array}$ & $\begin{array}{l}4.00 \\
4.00 \\
4.00\end{array}$ & $\begin{array}{l}22 \\
32 \\
35\end{array}$ & $\begin{array}{l}58 \\
58 \\
58\end{array}$ & & $\begin{array}{l}0.000 \\
0.012 \\
0.023\end{array}$ & $\begin{array}{c}7.11 \\
16.79 \\
18.86\end{array}$ & \\
\hline $\begin{array}{l}\text { ACl-5A1 } \\
\text { ACl-5A1 } \\
\text { ACl-1A1 } \\
\text { ACl-1A1 }\end{array}$ & $\begin{array}{l}21.5 \\
51.5 \\
21.5 \\
51.5\end{array}$ & $\begin{array}{l}3.00 \\
3.00 \\
3.00 \\
3.00\end{array}$ & $\begin{array}{l}53 \\
51 \\
25 \\
30\end{array}$ & $\begin{array}{l}58 \\
58 \\
55 \\
55\end{array}$ & & $\begin{array}{l}0.040 \\
0.060 \\
0.009 \\
0.014\end{array}$ & $\begin{array}{c}33.54 \\
9.87 \\
12.52\end{array}$ & \\
\hline $\begin{array}{l}\text { F5A1-1 } \\
\text { F5A1-2 } \\
\text { F5A1-3 }\end{array}$ & $\begin{array}{c}7.0 \\
37.0 \\
67.0\end{array}$ & $\begin{array}{l}4.00 \\
4.00 \\
4.00\end{array}$ & $\begin{array}{l}50 \\
42 \\
44\end{array}$ & $\begin{array}{l}69 \\
58 \\
58\end{array}$ & & $\begin{array}{l}0.030 \\
0.049 \\
0.036\end{array}$ & $\begin{array}{l}23.89 \\
42.78 \\
17.97\end{array}$ & \\
\hline $\begin{array}{l}F 4 B-1 \\
F 4 B-2 \\
F 4 B-3 \\
F 4 B-4 \\
F 4 B-5\end{array}$ & $\begin{array}{l}7.0 \\
22.0 \\
37.0 \\
52.0 \\
67.0\end{array}$ & $\begin{array}{l}4.00 \\
4.00 \\
4.00 \\
4.00 \\
4.00\end{array}$ & $\begin{array}{l}25 \\
31 \\
34 \\
35 \\
32\end{array}$ & $\begin{array}{l}58 \\
58 \\
58 \\
58 \\
58\end{array}$ & & $\begin{array}{l}0.000 \\
0.000 \\
0.000 \\
0.002 \\
0.006\end{array}$ & $\begin{array}{c}4.31 \\
7.92 \\
9.48 \\
12.45 \\
11.60\end{array}$ & \\
\hline $\begin{array}{l}\text { F2B-1 } \\
\text { F2B-2 } \\
\text { F2B-3 } \\
\text { F2B-4 } \\
\text { F2B-5 }\end{array}$ & $\begin{array}{c}7.0 \\
22.0 \\
37.0 \\
52.0 \\
67.0\end{array}$ & $\begin{array}{l}4.00 \\
4.00 \\
4.00 \\
4.00 \\
4.00\end{array}$ & $\begin{array}{l}26 \\
28 \\
37 \\
36 \\
35\end{array}$ & $\begin{array}{l}69 \\
69 \\
69 \\
69 \\
69\end{array}$ & & $\begin{array}{l}0.003 \\
0.007 \\
0.018 \\
0.018 \\
0.009\end{array}$ & $\begin{array}{c}7.17 \\
10.51 \\
17.41 \\
15.71 \\
10.92\end{array}$ & . \\
\hline
\end{tabular}




Test $10-1$

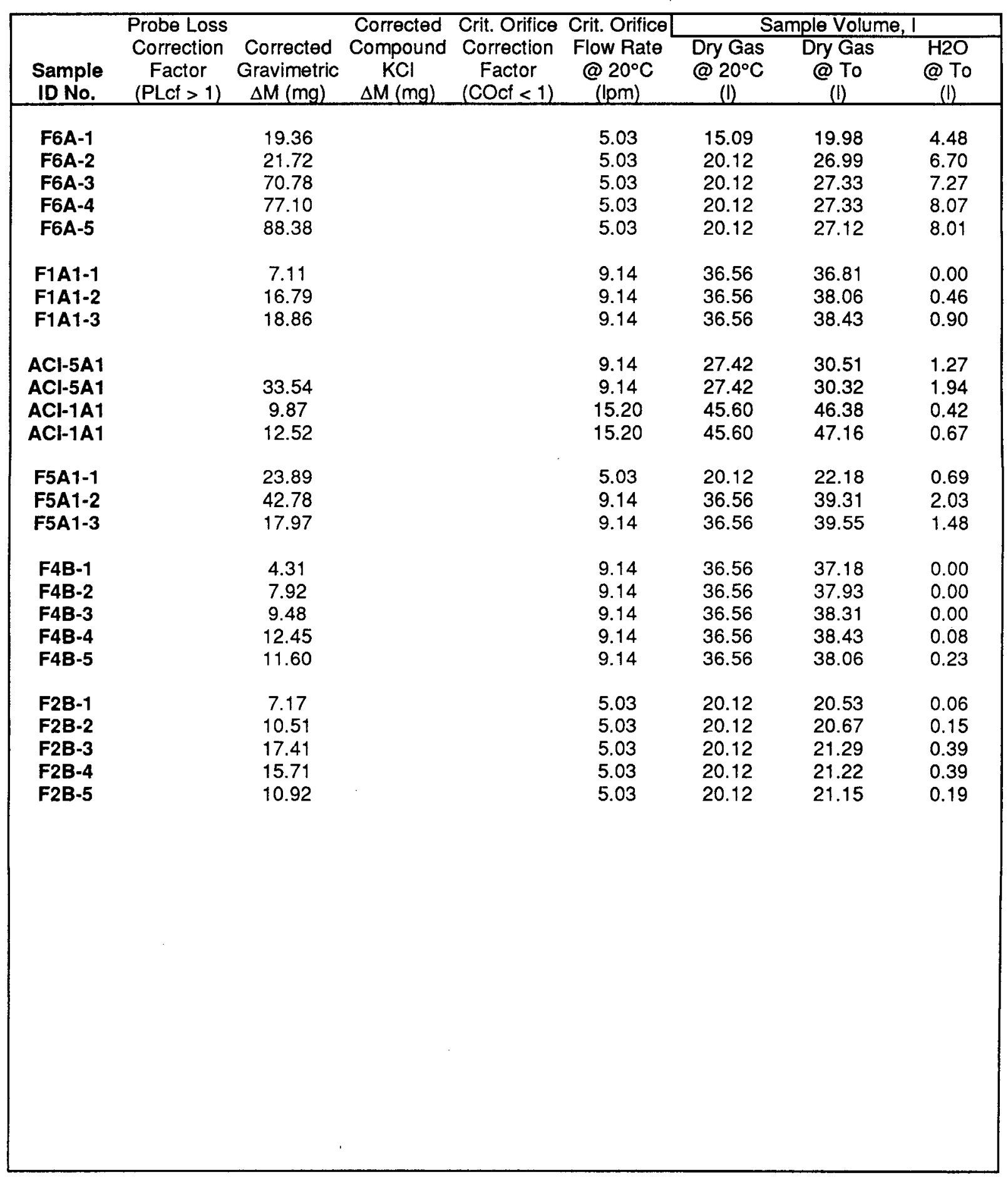

ICEDF DF WorkSheet (page 2) 


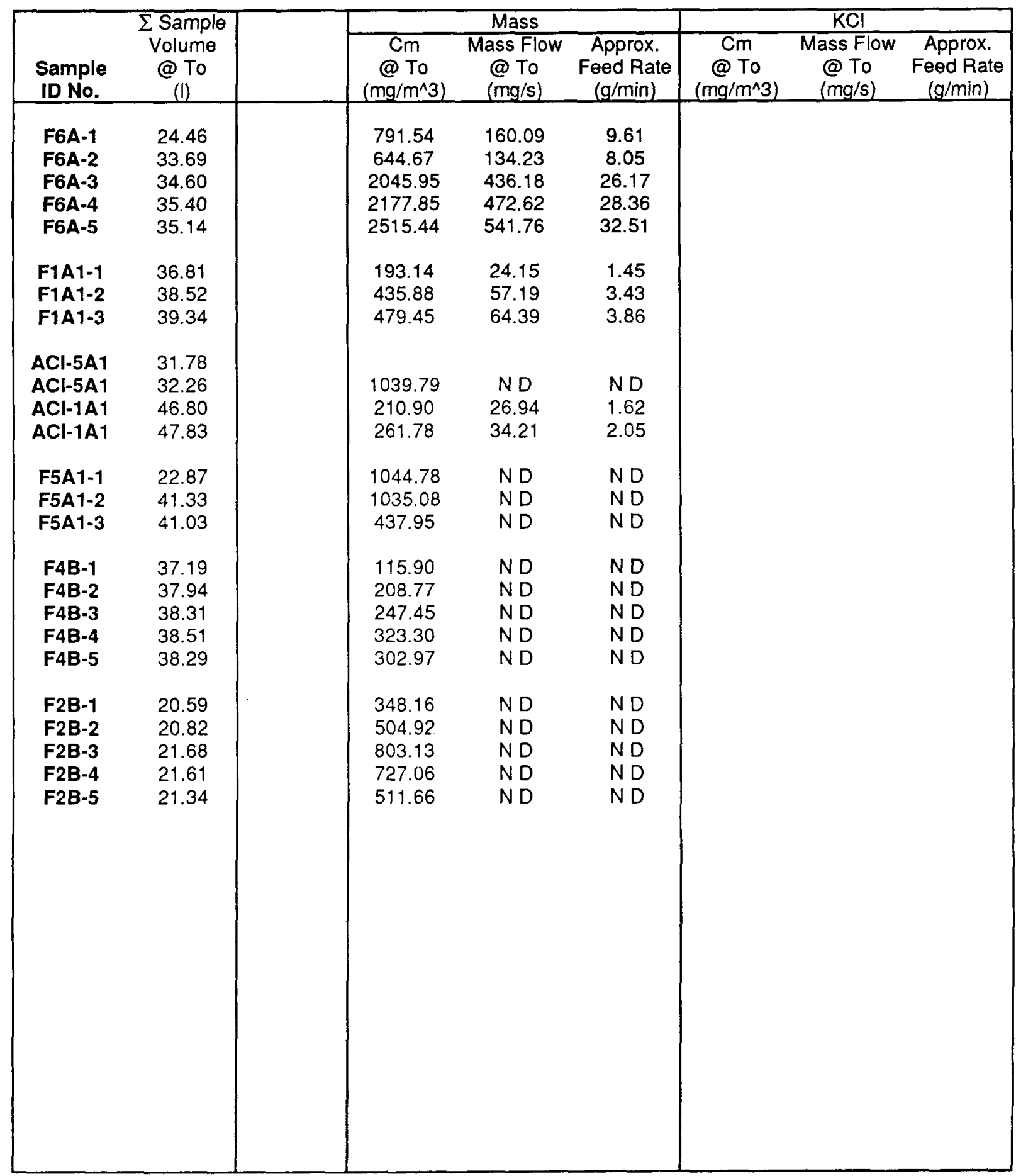

ICEDF DF WorkSheet (page 3)

E. 3 
How to use "ICEDF DF WkSht 8/89"

1) Open "ICEDF DF WkSht $8 / 89$ "

2) Enter test name and other constants.

3) Save As "ICEDF testname DF month/year".

4) Enter data on page 1 (change sample ID's if req'd)

WorkSheet Updates:

10/5/89: Added correction for $\triangle P$ upstream of critical orifice, changed sample ID No. listing.

10/5/89: Removed aerosol mass flow rate calculations for quad stations.

\begin{tabular}{|cc|}
\hline \multicolumn{2}{|c|}{ Critical Orifice Calib. } \\
\hline & \\
CO (\#) & Q (lpm) \\
\hline 50 & 27.2 \\
53 & 19.8 \\
55 & 15.2 \\
58 & 9.14 \\
65 & 6.97 \\
69 & 5.03 \\
74 & 2.47 \\
77 & 1.45 \\
80 & 1.03 \\
\hline
\end{tabular}




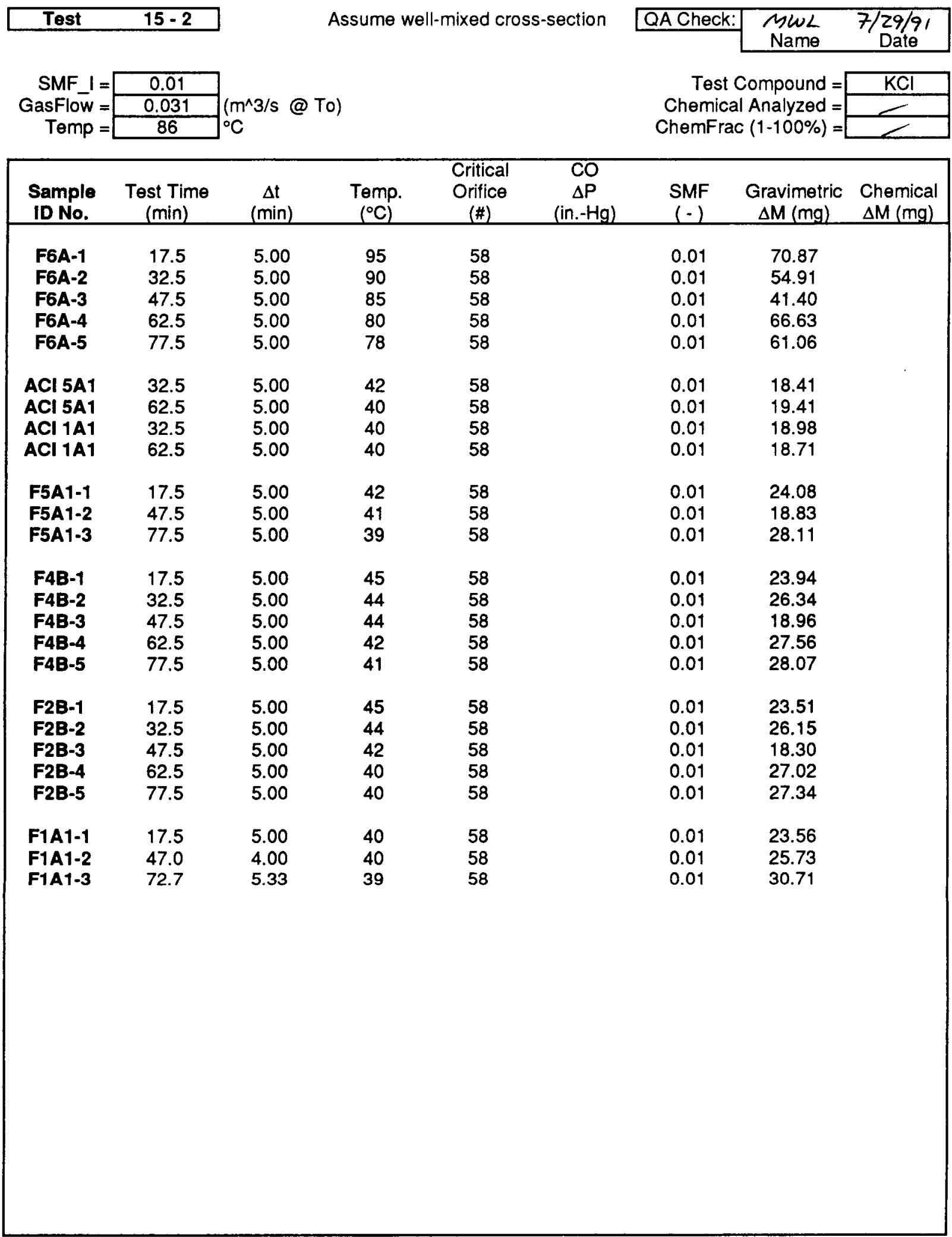




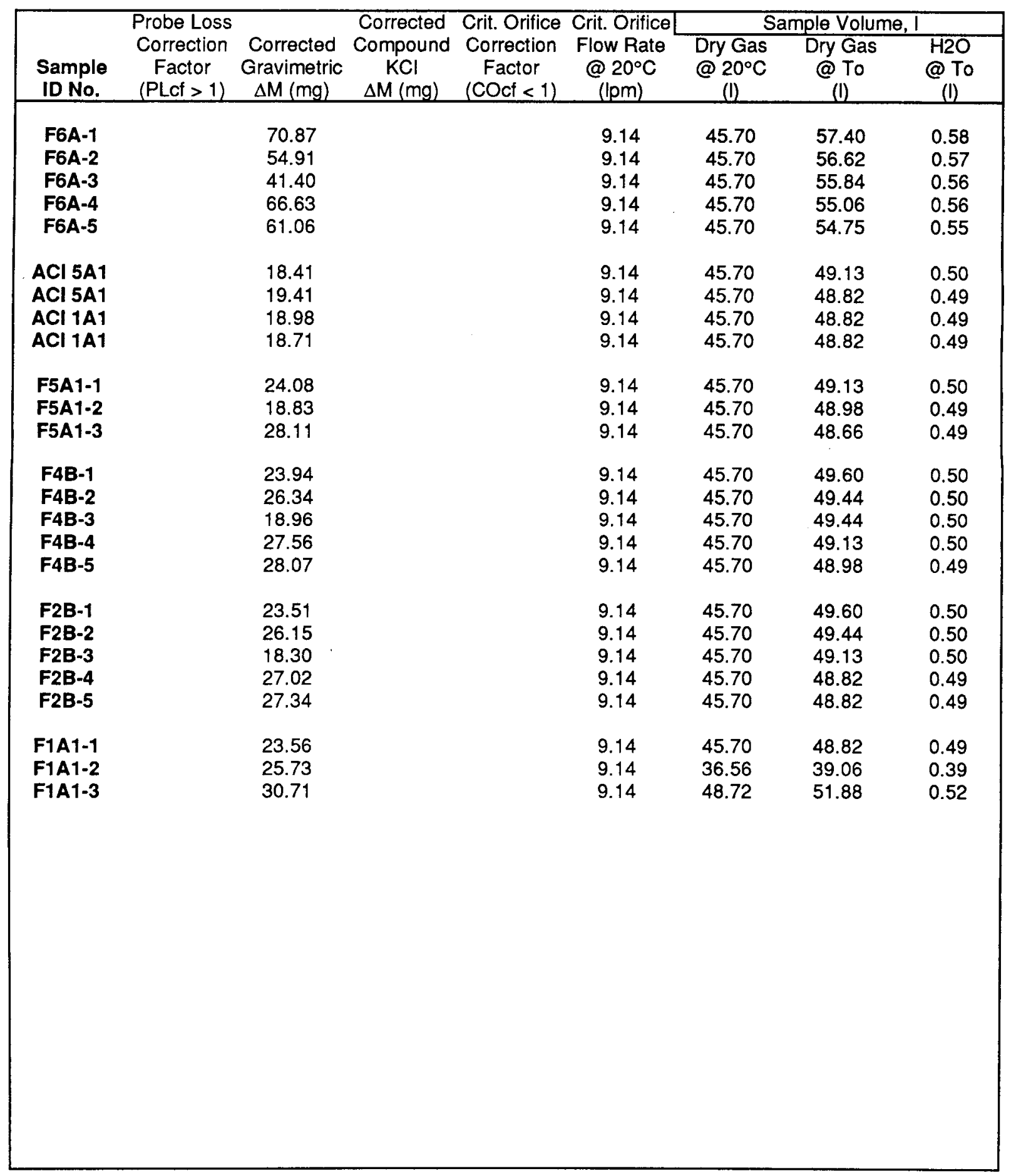

ICEDF DF WorkSheet (page 2)

E. 6 


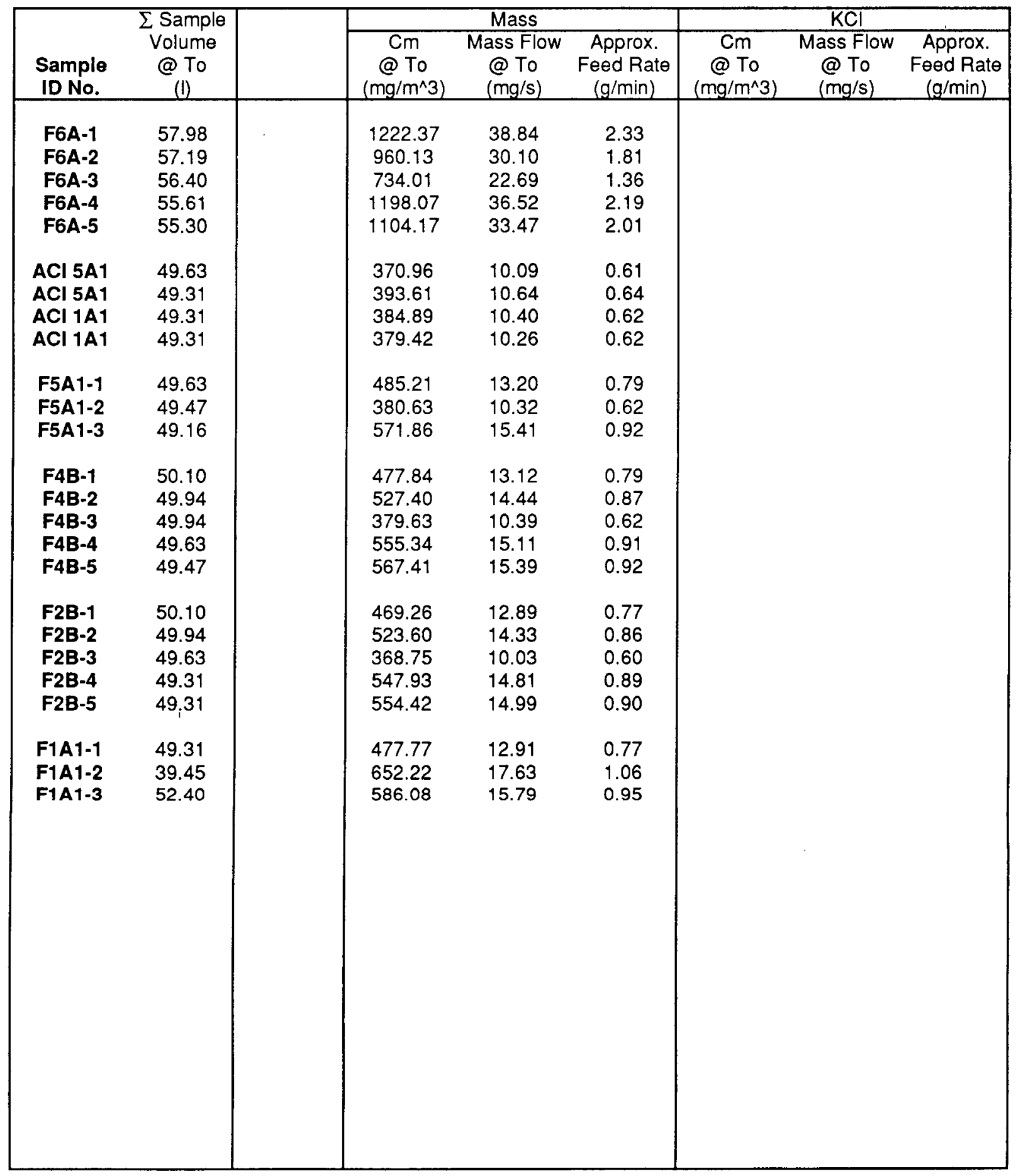


How to use "ICEDF DF WkSht 8/89"

1) Open "ICEDF DF WkSht 8/89"

2) Enter test name and other constants.

3) Save As "ICEDF testname DF month/year".

4) Enter data on page 1 (change sample ID's if req'd)

WorkSheet Updates:

10/5/89: Added correction for $\Delta \mathrm{P}$ upstream of critical orifice, changed sample ID No. listing. 10/5/89: Removed aerosol mass flow rate calculations for quad stations.

\begin{tabular}{|cc|}
\hline \multicolumn{2}{|c|}{ Critical Orifice Calib. } \\
\hline & \\
CO (\#) & Q(lpm) \\
\hline 50 & 27.2 \\
53 & 19.8 \\
55 & 15.2 \\
58 & 9.14 \\
65 & 6.97 \\
69 & 5.03 \\
74 & 2.47 \\
77 & 1.45 \\
80 & 1.03 \\
\hline
\end{tabular}

ICEDF DF WorkSheet (page 4)

E.8 


\begin{tabular}{|c|c|c|c|c|c|c|c|c|}
\hline Test & $2-3$ & \multicolumn{4}{|c|}{$\begin{array}{l}\text { Assume SMF } ~ 0.01 \\
1 \mathrm{A1}: \text { assume well-mixed }\end{array}$} & QA Check: & MouL & $\begin{array}{c}7 / 29 / 91 \\
\text { Date }\end{array}$ \\
\hline $\begin{array}{r}\text { SMF_I }= \\
\text { GasFlow }= \\
\text { Temp }=\end{array}$ & \begin{tabular}{|c|}
0.01 \\
0.029 \\
85 \\
\end{tabular} & \multicolumn{2}{|c|}{$\left.\int_{{ }^{\circ} \mathrm{C}}^{\wedge} 3 / \mathrm{s} @ \mathrm{To}\right)$} & \multirow[b]{2}{*}{$\begin{array}{l}\text { Critical } \\
\text { Orifice } \\
\text { (\#) }\end{array}$} & & \multicolumn{2}{|c|}{$\begin{array}{r}\text { Test Compound }= \\
\text { Chemical Analyzed }= \\
\text { ChemFrac }(1-100 \%)=\end{array}$} & $\stackrel{\mathrm{SiO} 2}{\sim}$ \\
\hline $\begin{array}{l}\text { Sample } \\
\text { ID No. }\end{array}$ & $\begin{array}{c}\text { Test Time } \\
\text { (min) }\end{array}$ & $\begin{array}{c}\Delta t \\
(\min )\end{array}$ & $\begin{array}{c}\text { Temp. } \\
\left({ }^{\circ} \mathrm{C}\right)\end{array}$ & & $\begin{array}{c}\mathrm{CO} \\
\Delta \mathrm{P} \\
\text { (in.-Hg) }\end{array}$ & $\begin{array}{l}\text { SMF } \\
(-)\end{array}$ & $\begin{array}{c}\text { Gravimetric } \\
\Delta \mathrm{M}(\mathrm{mg})\end{array}$ & $\begin{array}{l}\text { Chemical } \\
\Delta M(\mathrm{mg})\end{array}$ \\
\hline $\begin{array}{l}\text { F6A-1 } \\
\text { F6A-2 } \\
\text { F6A-3 }\end{array}$ & $\begin{array}{l}17.5 \\
37.5 \\
61.1\end{array}$ & $\begin{array}{l}5.00 \\
5.00 \\
7.25\end{array}$ & $\begin{array}{l}88 \\
86 \\
82\end{array}$ & $\begin{array}{l}58 \\
58 \\
58\end{array}$ & $\begin{array}{l}1.7 \\
1.7 \\
1.6\end{array}$ & $\begin{array}{l}0.01 \\
0.01 \\
0.01\end{array}$ & $\begin{array}{l}26.62 \\
26.92 \\
34.52\end{array}$ & \\
\hline $\begin{array}{l}\text { ACI 6A } \\
A C I 6 A \\
A C I 5 A 1 \\
A C I 5 A 1 \\
A C I 1 A 1 \\
A C I 1 A 1\end{array}$ & $\begin{array}{l}27.5 \\
46.5 \\
27.5 \\
47.5 \\
27.5 \\
47.5\end{array}$ & $\begin{array}{l}5.00 \\
5.00 \\
5.00 \\
5.00 \\
5.05 \\
5.02\end{array}$ & $\begin{array}{c}86 \\
85 \\
11 \\
10 \\
0 \\
0\end{array}$ & $\begin{array}{l}55 \\
55 \\
55 \\
55 \\
55 \\
55\end{array}$ & $\begin{array}{l}1.7 \\
1.7 \\
1.7 \\
1.7 \\
1.9 \\
1.8\end{array}$ & $\begin{array}{l}0.01 \\
0.01 \\
0.01 \\
0.01 \\
0.01 \\
0.01\end{array}$ & $\begin{array}{c}22.77 \\
32.76 \\
6.08 \\
6.01 \\
2.79 \\
3.26\end{array}$ & \\
\hline $\begin{array}{l}\text { F5A1-1 } \\
\text { F5AT-2 } \\
\text { F5A1-3 }\end{array}$ & $\begin{array}{l}17.5 \\
37.5 \\
62.5\end{array}$ & $\begin{array}{c}5.00 \\
5.00 \\
15.00\end{array}$ & $\begin{array}{c}11 \\
10 \\
9\end{array}$ & $\begin{array}{l}58 \\
58 \\
58\end{array}$ & & $\begin{array}{l}0.01 \\
0.01 \\
0.01\end{array}$ & $\begin{array}{c}5.53 \\
5.41 \\
20.93\end{array}$ & \\
\hline $\begin{array}{l}F 4 B-1 \\
F 4 B-2 \\
F 4 B-3 \\
F 4 B-4 \\
F 4 B-5\end{array}$ & $\begin{array}{l}17.5 \\
27.5 \\
37.5 \\
47.5 \\
62.5\end{array}$ & $\begin{array}{c}5.00 \\
5.00 \\
5.00 \\
5.00 \\
15.00\end{array}$ & $\begin{array}{c}6 \\
6 \\
8 \\
10 \\
8\end{array}$ & $\begin{array}{l}58 \\
58 \\
58 \\
58 \\
58\end{array}$ & & $\begin{array}{l}0.01 \\
0.01 \\
0.01 \\
0.01 \\
0.01\end{array}$ & $\begin{array}{c}4.61 \\
5.41 \\
5.72 \\
7.32 \\
21.30\end{array}$ & \\
\hline $\begin{array}{l}\text { F2B-1 } \\
\text { F2B-2 } \\
\text { F2B-3 } \\
\text { F2B-4 } \\
\text { F2B-5 }\end{array}$ & $\begin{array}{l}17.5 \\
27.5 \\
37.5 \\
47.5 \\
62.5\end{array}$ & $\begin{array}{c}5.00 \\
5.00 \\
5.00 \\
5.00 \\
15.00\end{array}$ & $\begin{array}{l}0 \\
0 \\
0 \\
0 \\
0\end{array}$ & $\begin{array}{l}58 \\
58 \\
58 \\
58 \\
58\end{array}$ & & $\begin{array}{l}0.01 \\
0.01 \\
0.01 \\
0.01 \\
0.01\end{array}$ & $\begin{array}{c}2.59 \\
3.13 \\
2.84 \\
3.14 \\
10.32\end{array}$ & \\
\hline $\begin{array}{l}\text { F1A1-1 } \\
\text { F1A1-2 } \\
\text { F1A1-3 }\end{array}$ & $\begin{array}{l}17.5 \\
37.5 \\
62.5\end{array}$ & $\begin{array}{c}5.00 \\
5.00 \\
15.00\end{array}$ & $\begin{array}{l}0 \\
0 \\
0\end{array}$ & $\begin{array}{l}58 \\
58 \\
58\end{array}$ & & $\begin{array}{l}0.01 \\
0.01 \\
0.01\end{array}$ & $\begin{array}{l}2.51 \\
2.71 \\
9.82\end{array}$ & \\
\hline
\end{tabular}


Test $2-3$

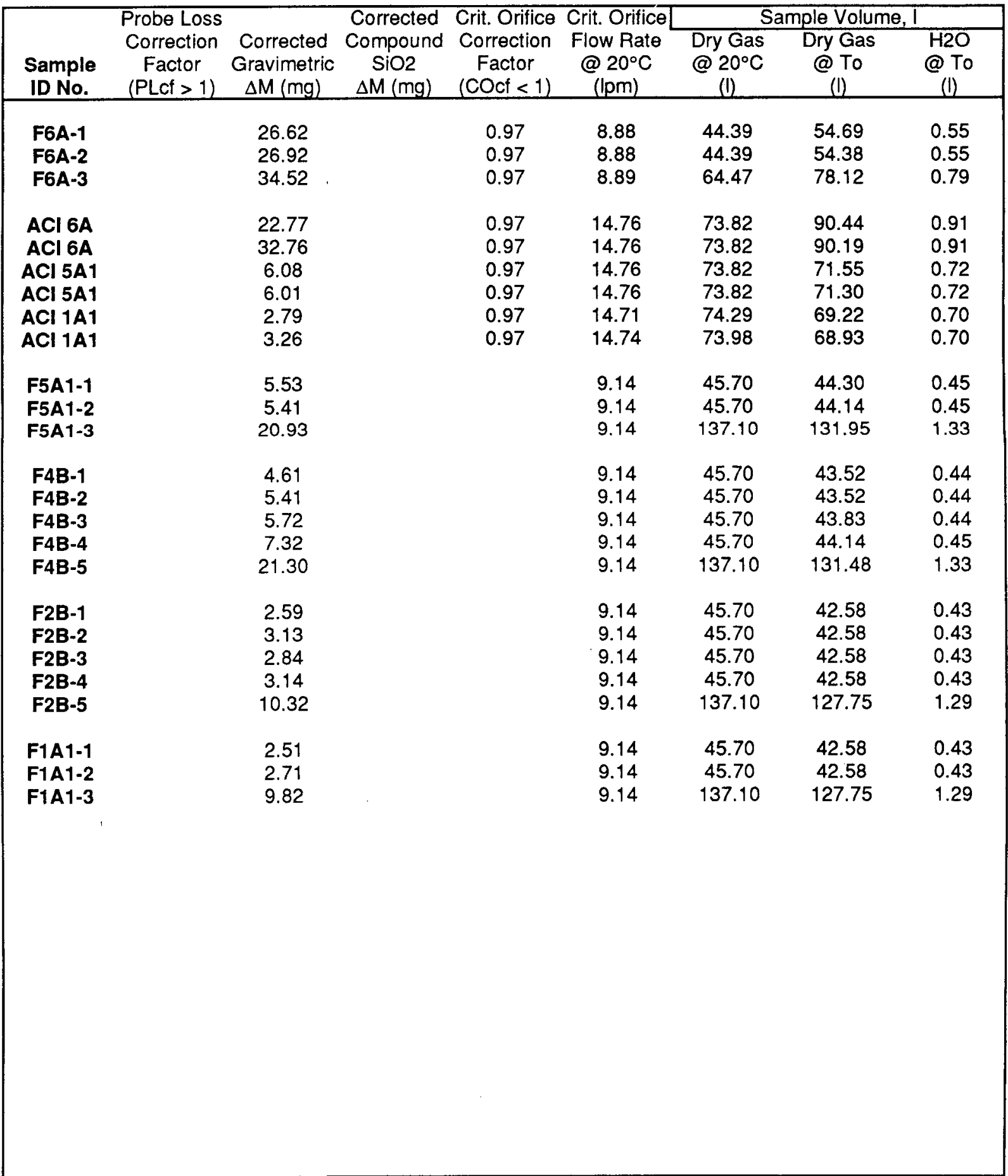

ICEDF DF WorkSheet (page 2)

E. 10 


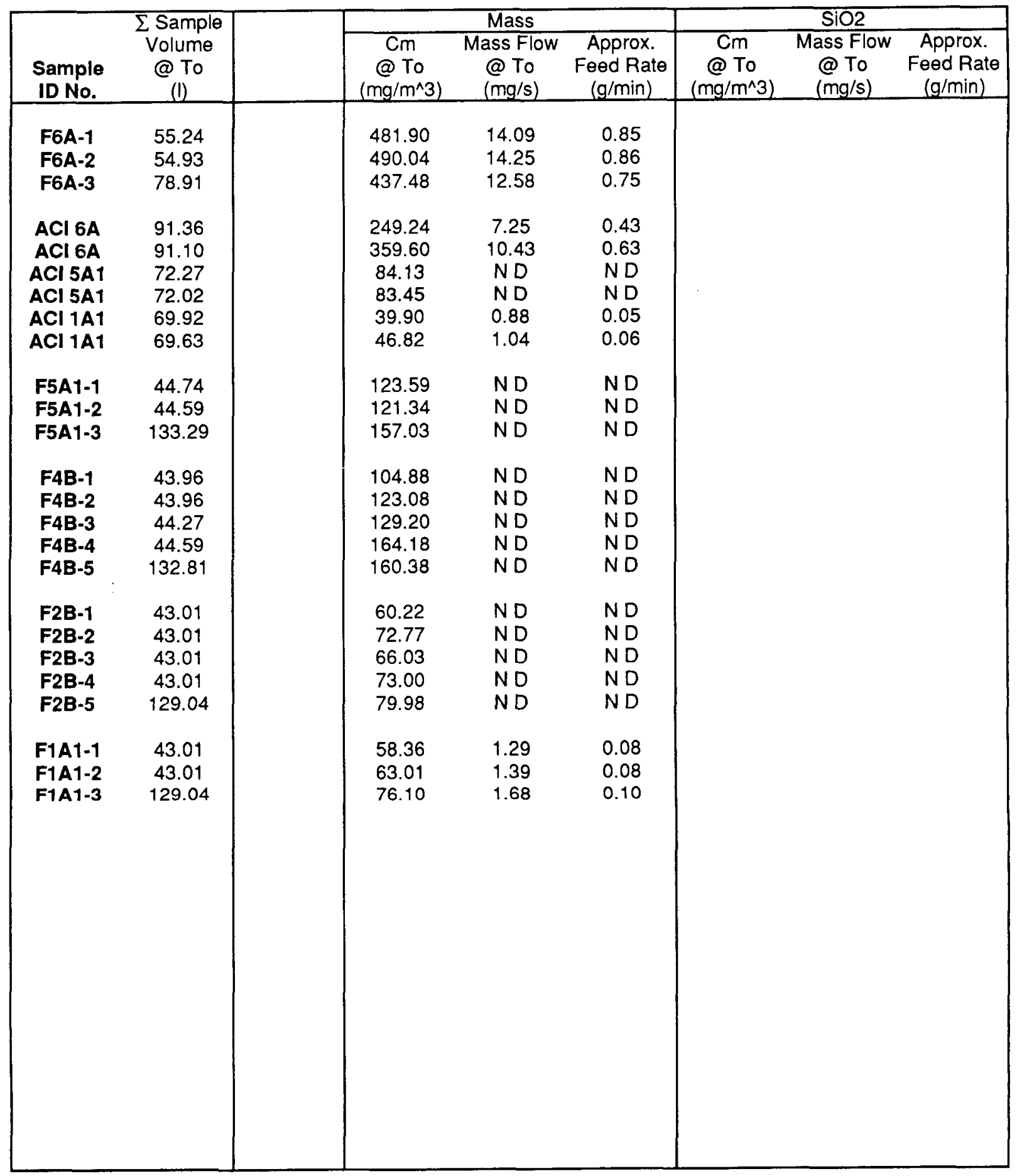

ICEDF DF WorkSheet (page 3)

$$
\text { E. } 11
$$




\section{How to use "ICEDF DF WkSht B/89"}

1) Open "ICEDF DF WkSht 8/89"

2) Enter test name and other constants.

3) Save As "ICEDF testname DF month/year".

4) Enter data on page 1 (change sample ID's if req'd)

WorkSheet Updates:

10/5/89: Added correction for $\Delta P$ upstream of critical orifice, changed sample ID No. listing.

10/5/89: Removed aerosol mass flow rate calculations for quad stations.

\begin{tabular}{|cc|}
\hline Critical & Orifice Calib. \\
\hline & \\
CO (\#) & Q (lpm) \\
\hline 50 & 27.2 \\
53 & 19.8 \\
55 & 15.2 \\
58 & 9.14 \\
65 & 6.97 \\
69 & 5.03 \\
74 & 2.47 \\
77 & 1.45 \\
80 & 1.03 \\
\hline
\end{tabular}




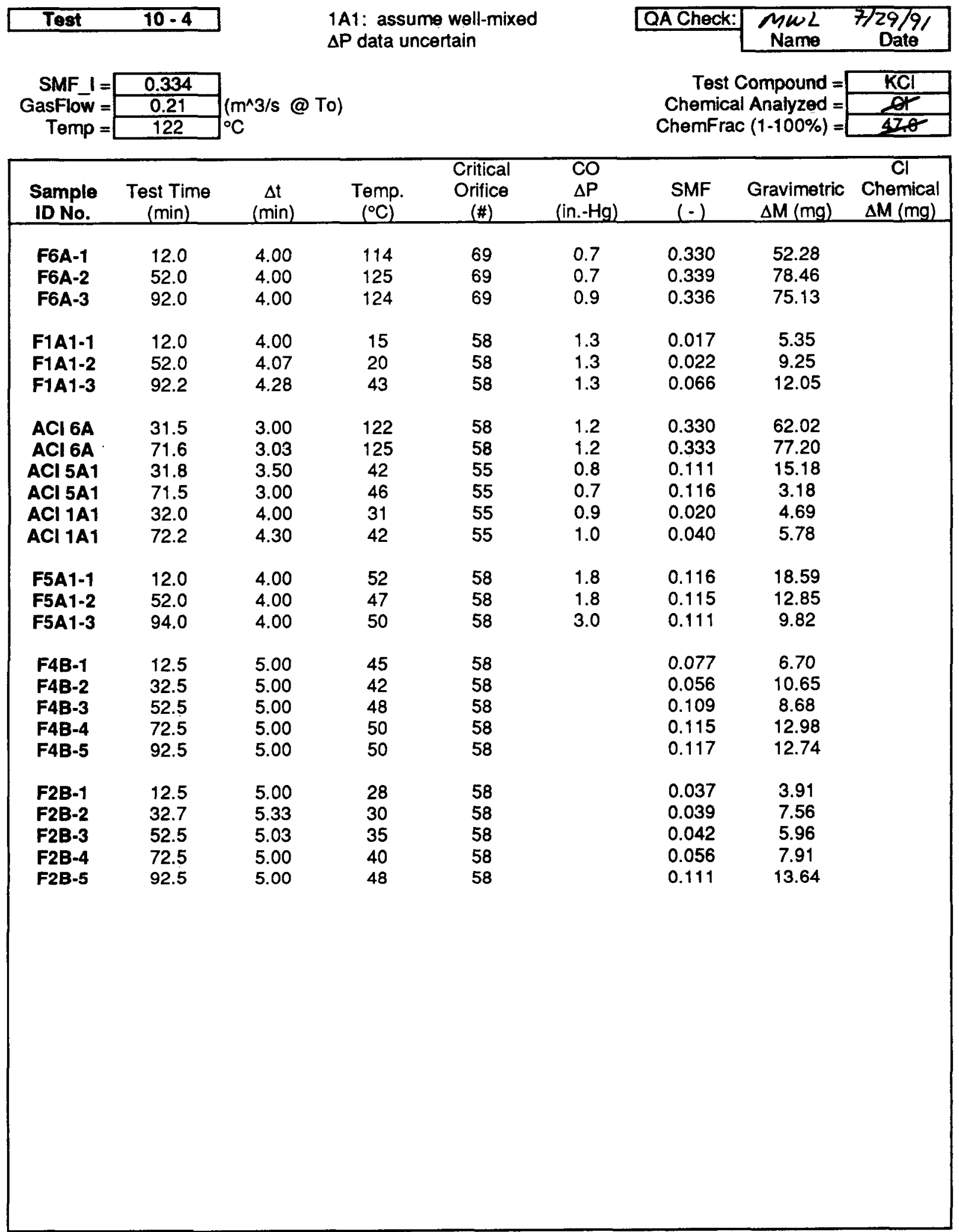


Test $10-4$

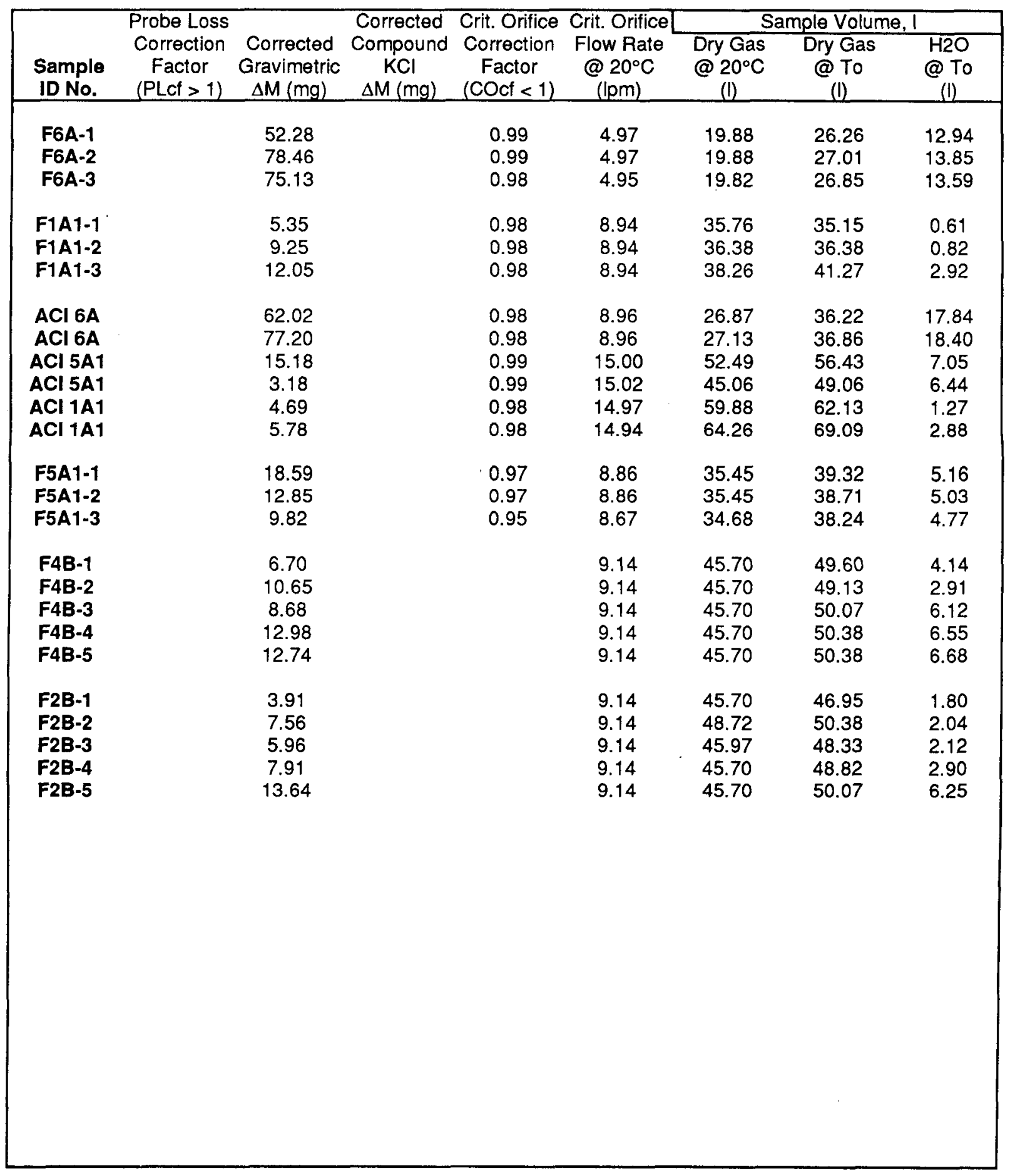

ICEDF DF WorkSheet (page 2)

$$
\text { E. } 14
$$




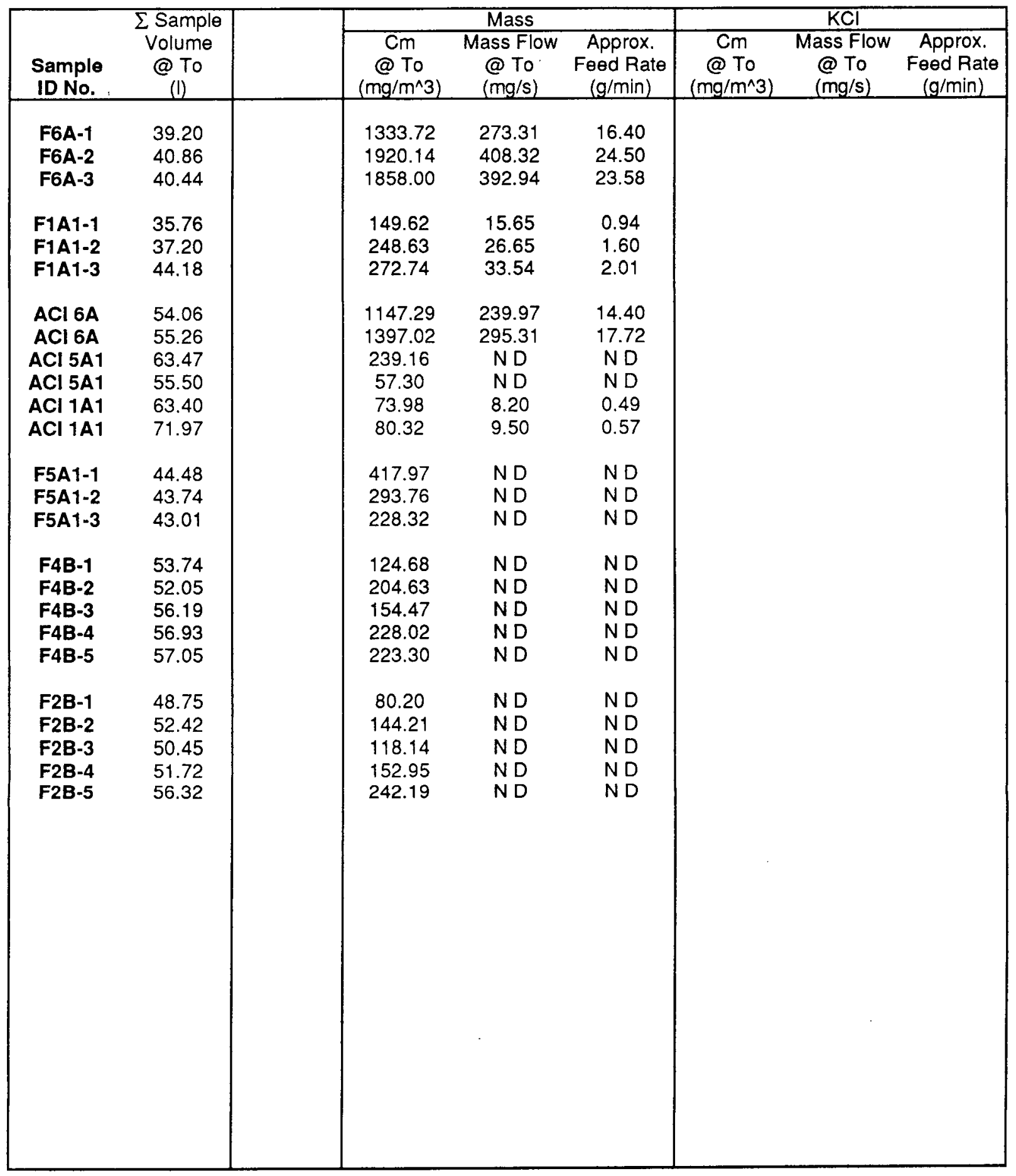




\section{How to use "ICEDF DF WkSht 8/89"}

1) Open "ICEDF DF WkSht $8 / 89$ "

2) Enter test name and other constants.

3) Save As "ICEDF testname DF month/year".

4) Enter data on page 1 (change sample ID's if req'd)

\section{WorkSheet Updates:}

10/5/89: Added correction for $\triangle P$ upstream of critical orifice, changed sample ID No. listing. 10/5/89: Removed aerosol mass flow rate calculations for quad stations.

\begin{tabular}{|cc|}
\hline \multicolumn{2}{|c|}{ Critical Orifice Calib. } \\
\hline & \\
CO (\#) & Q (lpm) \\
\hline 50 & 27.2 \\
53 & 19.8 \\
55 & 15.2 \\
58 & 9.14 \\
65 & 6.97 \\
69 & 5.03 \\
74 & 2.47 \\
77 & 1.45 \\
80 & 1.03 \\
\hline
\end{tabular}




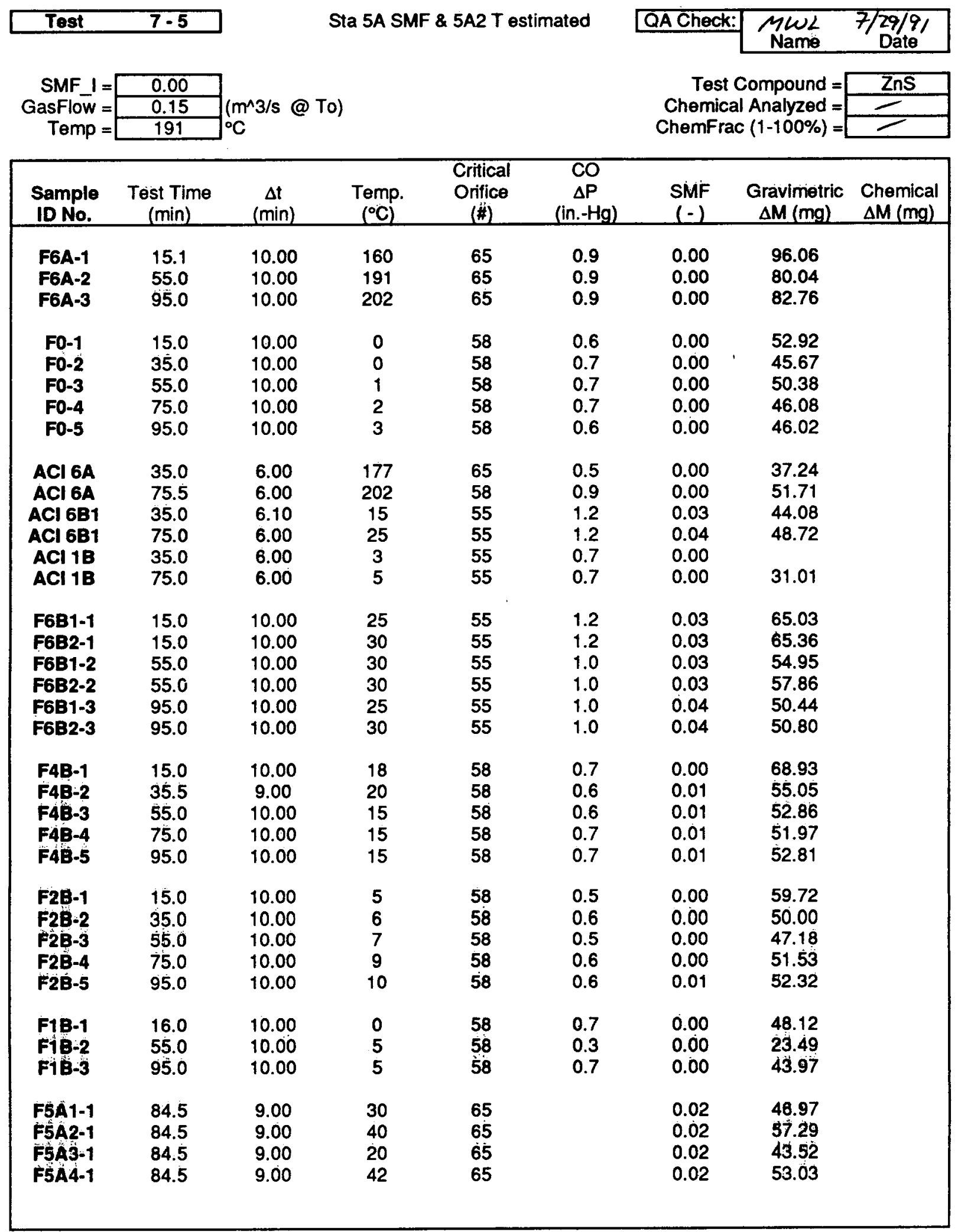


Test 7.5

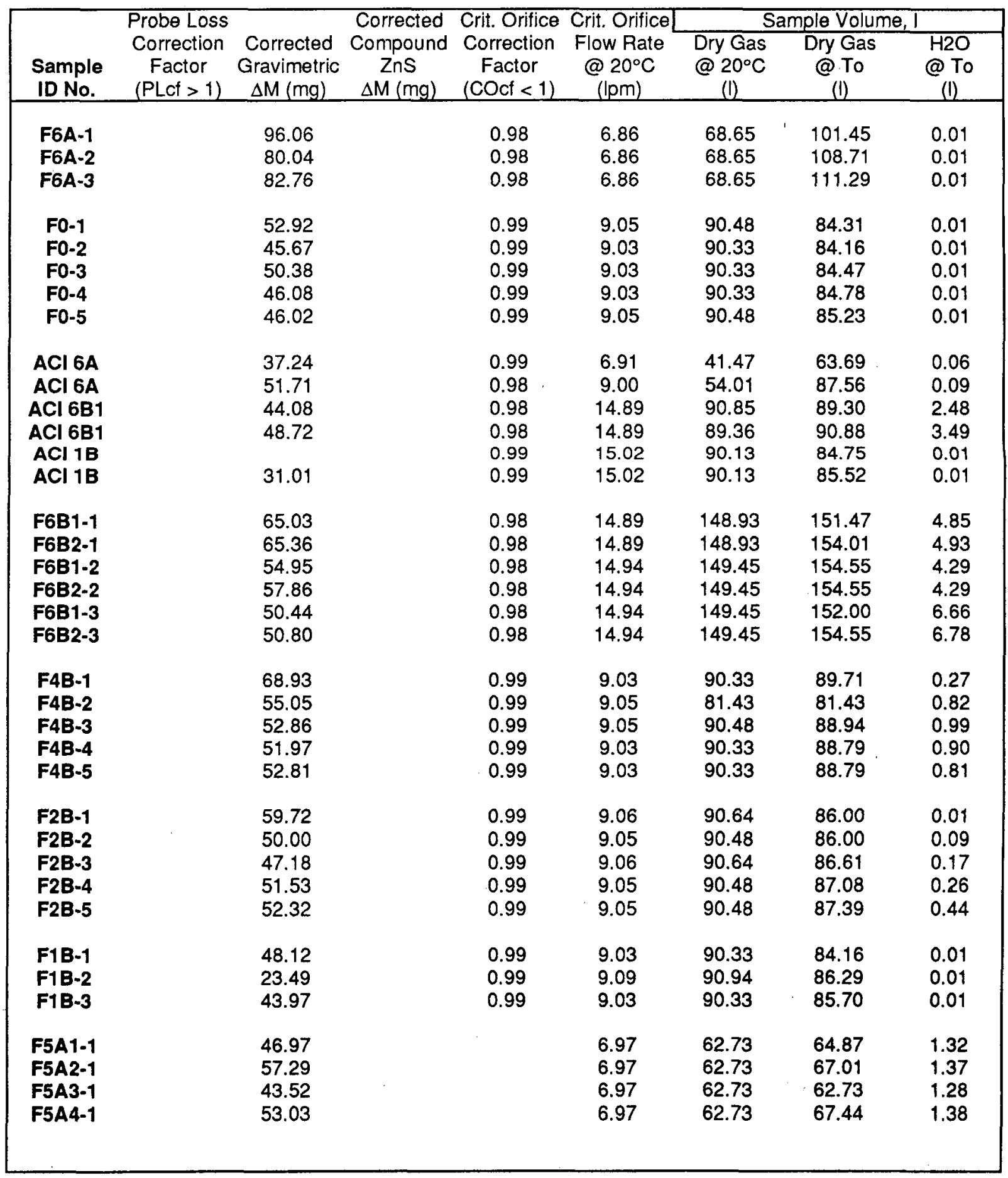

ICEDF DF WorkSheet (page 2)

E.18 


\section{Test}

$7-5$

\begin{tabular}{|c|c|c|c|c|c|c|c|}
\hline & $\sum$ Sample & & Mass & & & $\mathrm{ZnS}$ & \\
\hline $\begin{array}{l}\text { Sample } \\
\text { ID No. }\end{array}$ & $\begin{array}{c}\text { Volume } \\
\text { @ To } \\
\text { (I) }\end{array}$ & $\begin{array}{c}\mathrm{Cm} \\
@ \mathrm{To} \\
\left(\mathrm{mg} / \mathrm{m}^{\wedge} 3\right)\end{array}$ & $\begin{array}{c}\text { Mass Flow } \\
\text { @ To } \\
\text { (mg/s) }\end{array}$ & $\begin{array}{c}\text { Approx. } \\
\text { Feed Rate } \\
\text { (g/min) }\end{array}$ & $\begin{array}{c}\mathrm{Cm} \\
@ \mathrm{To} \\
\left(\mathrm{mg} / \mathrm{m}^{\wedge} 3\right)\end{array}$ & $\begin{array}{c}\text { Mass Flow } \\
\text { @ To } \\
(\mathrm{mg} / \mathrm{s}) \\
\end{array}$ & $\begin{array}{l}\text { Approx. } \\
\text { Feed Rate } \\
\text { (g/min) }\end{array}$ \\
\hline $\begin{array}{l}\text { F6A-1 } \\
\text { F6A-2 } \\
\text { F6A-3 }\end{array}$ & $\begin{array}{l}101.46 \\
108.72 \\
111.30\end{array}$ & $\begin{array}{l}946.80 \\
736.20 \\
743.59\end{array}$ & $\begin{array}{l}132.55 \\
110.44 \\
114.19\end{array}$ & $\begin{array}{l}7.95 \\
6.63 \\
6.85\end{array}$ & & & \\
\hline $\begin{array}{l}\text { F0-1 } \\
\text { F0-2 } \\
\text { F0-3 } \\
\text { F0-4 } \\
\text { F0-5 }\end{array}$ & $\begin{array}{l}84.31 \\
84.17 \\
84.48 \\
84.79 \\
85.24\end{array}$ & $\begin{array}{l}627.65 \\
542.59 \\
596.37 \\
543.48 \\
539.89\end{array}$ & $\begin{array}{l}55.42 \\
47.91 \\
52.85 \\
48.34 \\
48.19\end{array}$ & $\begin{array}{l}3.32 \\
2.87 \\
3.17 \\
2.90 \\
2.89\end{array}$ & & & \\
\hline $\begin{array}{c}A C l 6 A \\
A C l 6 A \\
A C l 6 B 1 \\
A C l 6 B 1 \\
A C l 1 B \\
A C l 1 B\end{array}$ & $\begin{array}{l}63.75 \\
87.65 \\
91.77 \\
94.37 \\
84.76 \\
85.52\end{array}$ & $\begin{array}{l}584.11 \\
589.97 \\
480.31 \\
516.24 \\
\\
362.59\end{array}$ & $\begin{array}{l}85.06 \\
90.68 \\
\text { ND } \\
\text { ND } \\
\text { ND } \\
\text { ND }\end{array}$ & $\begin{array}{l}5.10 \\
5.44 \\
\text { ND } \\
\text { ND } \\
\text { ND } \\
\text { ND }\end{array}$ & & $\begin{array}{l}\text { ND } \\
\text { ND } \\
\text { ND } \\
\text { ND }\end{array}$ & $\begin{array}{l}\text { ND } \\
\text { ND } \\
\text { ND } \\
\text { ND }\end{array}$ \\
\hline $\begin{array}{l}\text { F6B1-1 } \\
\text { F6B2-1 } \\
\text { F6B1-2 } \\
\text { F6B2-2 } \\
\text { F6B1-3 } \\
\text { F6B2-3 }\end{array}$ & $\begin{array}{l}156.32 \\
158.94 \\
158.83 \\
158.83 \\
158.66 \\
161.32\end{array}$ & $\begin{array}{l}416.02 \\
411.23 \\
345.96 \\
364.28 \\
317.91 \\
314.90\end{array}$ & $\begin{array}{l}\text { ND } \\
\text { ND } \\
\text { ND } \\
\text { ND } \\
\text { ND } \\
\text { ND }\end{array}$ & $\begin{array}{l}\text { ND } \\
\text { ND } \\
\text { ND } \\
\text { ND } \\
\text { ND } \\
\text { ND }\end{array}$ & & $\begin{array}{l}\text { ND } \\
\text { ND } \\
\text { ND } \\
\text { ND } \\
\text { ND } \\
\text { ND }\end{array}$ & $\begin{array}{l}\text { ND } \\
\text { ND } \\
\text { ND } \\
\text { ND } \\
\text { ND } \\
\text { ND }\end{array}$ \\
\hline $\begin{array}{l}\text { F4B-1 } \\
\text { F4B-2 } \\
\text { F4B-3 } \\
\text { F4B-4 } \\
\text { F4B-5 }\end{array}$ & $\begin{array}{l}89.98 \\
82.26 \\
89.93 \\
89.68 \\
89.59\end{array}$ & $\begin{array}{l}766.05 \\
669.25 \\
587.81 \\
579.49 \\
589.45\end{array}$ & $\begin{array}{l}N D \\
N D \\
N D \\
N D \\
N D\end{array}$ & $\begin{array}{l}N D \\
N D \\
N D \\
N D \\
N D\end{array}$ & & $\begin{array}{l}N D \\
N D \\
N D \\
N D \\
N D\end{array}$ & $\begin{array}{l}\text { ND } \\
N D \\
N D \\
N D \\
N D\end{array}$ \\
\hline $\begin{array}{l}\text { F2B-1 } \\
\text { F2B-2 } \\
\text { F2B-3 } \\
\text { F2B-4 } \\
\text { F2B-5 }\end{array}$ & $\begin{array}{l}86.00 \\
86.09 \\
86.79 \\
87.35 \\
87.83\end{array}$ & $\begin{array}{l}694.39 \\
580.79 \\
543.63 \\
589.95 \\
595.68\end{array}$ & $\begin{array}{l}N D \\
N D \\
N D \\
N D \\
N D\end{array}$ & $\begin{array}{l}N D \\
N D \\
N D \\
N D \\
N D\end{array}$ & & $\begin{array}{l}N D \\
N D \\
N D \\
N D \\
N D\end{array}$ & $\begin{array}{l}\text { ND } \\
\text { ND } \\
\text { ND } \\
\text { ND } \\
\text { ND }\end{array}$ \\
\hline $\begin{array}{l}\text { F1B-1 } \\
\text { F1B-2 } \\
\text { F1B-3 }\end{array}$ & $\begin{array}{l}84.17 \\
86.29 \\
85.71\end{array}$ & $\begin{array}{l}571.70 \\
272.21 \\
513.00\end{array}$ & $\begin{array}{l}\text { ND } \\
\text { ND } \\
\text { ND }\end{array}$ & $\begin{array}{l}\text { ND } \\
\text { ND } \\
\text { ND }\end{array}$ & & $\begin{array}{l}\text { ND } \\
\text { ND } \\
\text { ND }\end{array}$ & $\begin{array}{l}\text { ND } \\
\text { ND } \\
\text { ND }\end{array}$ \\
\hline $\begin{array}{l}\text { F5A1-1 } \\
\text { F5A2-1 } \\
\text { F5A3-1 } \\
\text { F5A4-1 }\end{array}$ & $\begin{array}{l}66.19 \\
68.38 \\
64.01 \\
68.82\end{array}$ & $\begin{array}{l}709.57 \\
837.82 \\
679.89 \\
770.60\end{array}$ & $\begin{array}{l}\text { ND } \\
\text { ND } \\
\text { ND } \\
\text { ND }\end{array}$ & $\begin{array}{l}\text { ND } \\
\text { ND } \\
\text { ND } \\
\text { ND }\end{array}$ & & $\begin{array}{l}\text { ND } \\
\text { ND } \\
\text { ND } \\
\text { ND }\end{array}$ & $\begin{array}{l}\text { ND } \\
\text { ND } \\
\text { ND } \\
\text { ND }\end{array}$ \\
\hline
\end{tabular}

ICEDF DF WorkSheet (page 3)

E.19 
How to use "ICEDF DF WkSht 8/89"

1) Open "ICEDF DF WkSht 8/89"

2) Enter test name and other constants.

3) Save As "ICEDF testname DF month/year".

4) Enter data on page 1 (change sample ID's if req'd)

WorkSheet Updates:

10/5/89: Added correction for $\Delta P$ upstream of critical orifice, changed sample ID No. listing. 10/5/89: Removed aerosol mass flow rate calculations for quad stations.

\begin{tabular}{|cc|}
\hline \multicolumn{2}{|c|}{ Critical Orifice Calib. } \\
\hline & \\
CO (if) & Q(lpm) \\
\hline 50 & 27.2 \\
53 & 19.8 \\
55 & 15.2 \\
58 & 9.14 \\
65 & 6.97 \\
69 & 5.03 \\
74 & 2.47 \\
77 & 1.45 \\
80 & 1.03 \\
\hline
\end{tabular}

ICEDF DF WorkSheet (page 4)

E. 20 


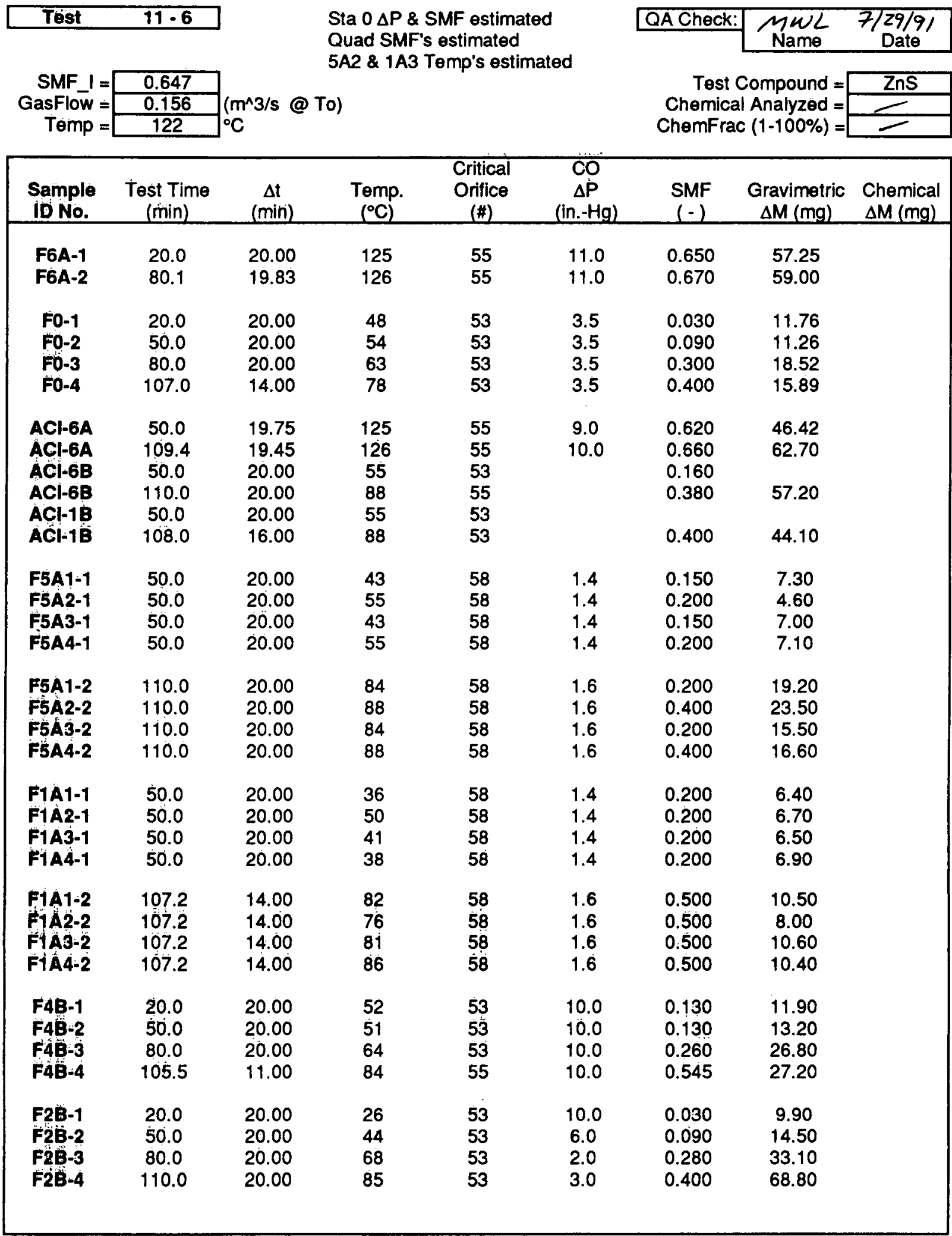


Test $11-6$

\begin{tabular}{|c|c|c|c|c|c|c|c|c|}
\hline \multirow[b]{2}{*}{$\begin{array}{l}\text { Sample } \\
\text { ID No. }\end{array}$} & \multirow{2}{*}{$\begin{array}{l}\text { Probe Loss } \\
\text { Correction } \\
\text { Factor } \\
(P L C f>1)\end{array}$} & \multirow{2}{*}{$\begin{array}{c}\text { Corrected } \\
\text { Gravimetric } \\
\Delta \mathrm{M}(\mathrm{mg}) \\
\end{array}$} & \multirow{2}{*}{$\begin{array}{c}\text { Corrected } \\
\text { Compound } \\
\text { ZnS } \\
\Delta \mathrm{M}(\mathrm{mg}) \\
\end{array}$} & \multirow{2}{*}{$\begin{array}{l}\text { Crit. Orifice } \\
\text { Correction } \\
\text { Factor } \\
(\text { COcf }<1) \\
\end{array}$} & \multirow{2}{*}{$\begin{array}{l}\text { Crit. Orifice } \\
\text { Flow Rate } \\
@ 20^{\circ} \mathrm{C} \\
\text { (lpm) }\end{array}$} & \multicolumn{3}{|c|}{ Sample Volume, I } \\
\hline & & & & & & $\begin{array}{c}\text { Dry Gas } \\
@ 20^{\circ} \mathrm{C} \\
\text { (1) }\end{array}$ & $\begin{array}{c}\text { Dry Gas } \\
@ \text { To } \\
\text { (1) }\end{array}$ & $\begin{array}{c}\mathrm{H} 2 \mathrm{O} \\
@ \mathrm{To} \\
(1)\end{array}$ \\
\hline $\begin{array}{l}\text { F6A-1 } \\
\text { F6A-2 }\end{array}$ & & $\begin{array}{l}57.25 \\
59.00\end{array}$ & & $\begin{array}{l}0.80 \\
0.80\end{array}$ & $\begin{array}{l}12.10 \\
12.10\end{array}$ & $\begin{array}{l}241.93 \\
239.87\end{array}$ & $\begin{array}{l}328.63 \\
326.65\end{array}$ & $\begin{array}{l}610.31 \\
663.21\end{array}$ \\
\hline F0-1 & & 11.76 & & 0.94 & 18.61 & 372.18 & 407.75 & 12.61 \\
\hline F0-2 & & 11.26 & & 0.94 & 18.61 & 372.18 & 415.37 & 41.08 \\
\hline F0-3 & & 18.52 & & 0.94 & 18.61 & 372.18 & 426.80 & 182.92 \\
\hline F0-4 & & 15.89 & & 0.94 & 18.61 & 260.53 & 312.10 & 208.07 \\
\hline ACI-6A & & 46.42 & & 0.84 & 12.72 & 251.17 & 341.17 & 556.65 \\
\hline ACl-6A & & 62.70 & & 0.82 & 12.41 & 241.39 & 328.72 & 638.10 \\
\hline ACl-6B & & & & & 19.80 & 396.00 & 443.30 & 84.44 \\
\hline ACl-6B & & 57.20 & & & 15.20 & 304.00 & 374.55 & 229.56 \\
\hline $\mathrm{ACl}-1 \mathrm{~B}$ & & & & & 19.80 & 396.00 & 443.30 & \\
\hline $\mathrm{ACl}-1 \mathrm{~B}$ & & 44.10 & & & 19.80 & 316.80 & 390.32 & 260.22 \\
\hline F5A1-1 & & 7.30 & & 0.98 & 8.92 & 178.48 & 192.49 & 33.97 \\
\hline F5A2-1 & & 4.60 & & 0.98 & 8.92 & 178.48 & 199.80 & 49.95 \\
\hline F5A3-1 & & 7.00 & & 0.98 & 8.92 & 178.48 & 192.49 & 33.97 \\
\hline F5A4-1 & & 7.10 & & 0.98 & 8.92 & 178.48 & 199.80 & 49.95 \\
\hline F5A1-2 & & 19.20 & & 0.97 & 8.89 & 177.86 & 216.71 & 54.18 \\
\hline F5A2-2 & & 23.50 & & 0.97 & 8.89 & 177.86 & 219.14 & 146.09 \\
\hline F5A3-2 & & 15.50 & & 0.97 & 8.89 & 177.86 & 216.71 & 54.18 \\
\hline F5A4-2 & & 16.60 & & 0.97 & 8.89 & 177.86 & 219.14 & 146.09 \\
\hline F1A1-1 & & 6.40 & & 0.98 & $8: 92$ & 178.48 & 188.23 & 47.06 \\
\hline F1A2-1 & & 6.70 & & 0.98 & 8.92 & 178.48 & 196.76 & 49.19 \\
\hline F1A3-1 & & 6.50 & & 0.98 & 8.92 & 178.48 & 191.28 & 47.82 \\
\hline F1A4-1 & & 6.90 & & 0.98 & 8.92 & 178.48 & 189.45 & 47.36 \\
\hline F1A1-2 & & 10.50 & & 0.97 & 8.89 & 124.50 & 150.85 & 150.85 \\
\hline F1A2-2 & & 8.00 & & 0.97 & 8.89 & 124.50 & 148.30 & 148.30 \\
\hline F1A3-2 & & 10.60 & & 0.97 & 8.89 & 124.50 & 150.42 & 150.42 \\
\hline F1A4-2 & & 10.40 & & 0.97 & 8.89 & 124.50 & 152.55 & 152.55 \\
\hline F4B-1 & & 11.90 & & 0.82 & 16.17 & 323.33 & 358.65 & 53.59 \\
\hline F4B-2 & & 13.20 & & 0.82 & 16.17 & 323.33 & 357.54 & 53.43 \\
\hline F4B-3 & & 26.80 & & 0.82 & 16.17 & 323.33 & 371.89 & 130.66 \\
\hline F4B-4 & & 27.20 & & 0.82 & 12.41 & 136.52 & 166.34 & 199.24 \\
\hline F2B-1 & & 9.90 & & 0.82 & 16.17 & 323.33 & 329.95 & 10.20 \\
\hline F2B-2 & & 14.50 & & 0.89 & 17.71 & 354.19 & 383.21 & 37.90 \\
\hline F2B-3 & & 33.10 & & 0.97 & 19.13 & 382.57 & 445.25 & 173.15 \\
\hline F2B-4 & & 68.80 & & 0.95 & 18.78 & 375.68 & 459.02 & 306.01 \\
\hline
\end{tabular}

ICEDF DF WorkSheet (page 2)

E.22 
Test $11 \cdot 6$

\begin{tabular}{|c|c|c|c|c|c|c|c|}
\hline & $\sum$ Sample & & Mass & & & ZnS & \\
\hline $\begin{array}{l}\text { Sample } \\
\text { ID No. }\end{array}$ & $\begin{array}{l}\text { Volume } \\
\text { @ To } \\
\text { (I) }\end{array}$ & $\begin{array}{c}\mathrm{Cm} \\
@ \text { To } \\
\left(\mathrm{mg} / \mathrm{m}^{\wedge} 3\right)\end{array}$ & $\begin{array}{c}\text { Mass Flow } \\
@ \text { To } \\
\text { (mg/s) }\end{array}$ & $\begin{array}{c}\text { Approx. } \\
\text { Feed Rate } \\
\text { (g/min) }\end{array}$ & $\begin{array}{c}\mathrm{Cm} \\
@ \mathrm{To} \\
\left(\mathrm{mg} / \mathrm{m}^{\wedge} 3\right)\end{array}$ & $\begin{array}{c}\text { Mass Flow } \\
\text { @ To } \\
\text { (mg/s) } \\
\end{array}$ & $\begin{array}{l}\text { Approx. } \\
\text { Fe日d Rate } \\
\text { (g/min) }\end{array}$ \\
\hline $\begin{array}{l}\text { F6A-1 } \\
\text { F6A-2 }\end{array}$ & $\begin{array}{l}938.94 \\
989.86\end{array}$ & $\begin{array}{l}60.97 \\
59.60\end{array}$ & $\begin{array}{l}9.61 \\
9.61\end{array}$ & $\begin{array}{l}0.58 \\
0.58\end{array}$ & & & \\
\hline F0-1 & 420.36 & 27.98 & 1.36 & 0.08 & & & \\
\hline F0-2 & 456.45 & 24.67 & 1.41 & 0.08 & & & \\
\hline F0-3 & 609.72 & 30.37 & 2.63 & 0.16 & & & \\
\hline F0-4 & 520.17 & 30.55 & 3.19 & 0.19 & & & \\
\hline ACl-6A & 897.82 & 51.70 & 7.91 & 0.47 & & & \\
\hline ACl-6A & 966.82 & 64.85 & 10.35 & 0.62 & & & \\
\hline ACI-6B & 527.74 & & & & & & \\
\hline $\begin{array}{l}\mathrm{ACl}-6 \mathrm{~B} \\
\mathrm{ACl}-1 \mathrm{~B}\end{array}$ & 604.12 & 94.68 & 9.90 & 0.59 & & & \\
\hline ACl-1B & 650.54 & 67.79 & 7.28 & 0.44 & & & \\
\hline F5A1-1 & 226.46 & 32.23 & ND & ND & & ND & ND \\
\hline F5A2-1 & 249.76 & 18.42 & ND & ND & & ND & ND \\
\hline F5A3-1 & 226.46 & 30.91 & ND & ND & & ND & ND \\
\hline F5A4-1 & 249.76 & 28.43 & ND & ND & & ND & ND \\
\hline F5A1-2 & 270.89 & 70.88 & ND & ND & & ND & ND \\
\hline F5A2-2 & 365.23 & 64.34 & ND & ND & & ND & ND \\
\hline F5A3.2 & 270.89 & 57.22 & ND & N D & & ND & ND \\
\hline F5A4-2 & 365.23 & 45.45 & ND & ND & & ND & ND \\
\hline F1A1-1 & 235.29 & 27.20 & ND & ND & & ND & ND \\
\hline F1A2-1 & 245.95 & 27.24 & ND & ND & & ND & ND \\
\hline F1A3-1 & 239.10 & 27.19 & ND & ND & & ND & ND \\
\hline F1A4-1 & 236.81 & 29.14 & ND & ND & & ND & ND \\
\hline F1A1-2 & 301.69 & 34.80 & ND & ND & & ND & ND \\
\hline F1A2-2 & 296.59 & 26.97 & ND & ND & & ND & ND \\
\hline F1A3-2 & 300.84 & 35.23 & ND & ND & & ND & ND \\
\hline F1A4-2 & 305.09 & 34.09 & ND & ND & & ND & ND \\
\hline F4B-1 & 412.24 & 28.87 & ND & ND & & ND & ND \\
\hline F4B-2 & 410.97 & 32.12 & ND & ND & & ND & ND \\
\hline F4B-3 & 502.55 & 53.33 & ND & ND & & ND & ND \\
\hline F4B-4 & 365.58 & 74.40 & ND & ND & & ND & ND \\
\hline F2B-1 & 340.16 & 29.10 & ND & ND & & ND & ND \\
\hline F2B-2 & 421.11 & 34.43 & ND & ND & & ND & ND \\
\hline F2B-3 & 618.40 & 53.53 & ND & ND & & ND & ND \\
\hline F2B-4 & 765.03 & 89.93 & ND & ND & & ND & ND \\
\hline
\end{tabular}




\section{How to use "ICEDF DF WkSht B/89"}

1) Open "ICEDF DF WkSht 8/89"

2) Enter test name and other constants.

3) Save As "ICEDF testname DF month/year".

4) Enter data on page 1 (change sample ID's if req'd)

WorkSheet Updates:

10/5/89: Added correction for $\Delta \mathrm{P}$ upstream of critical orifice, changed sample ID No. listing.

10/5/89: Removed aerosol mass flow rate calculations for quad stations.

\begin{tabular}{|cc|}
\hline \multicolumn{2}{|c|}{ Critical Orifice Calib. } \\
\hline & \\
Co (\#) & Q (lpm) \\
\hline 50 & 27.2 \\
53 & 19.8 \\
55 & 15.2 \\
58 & 9.14 \\
65 & 6.97 \\
69 & 5.03 \\
74 & 2.47 \\
77 & 1.45 \\
80 & 1.03 \\
\hline
\end{tabular}




\begin{tabular}{|c|c|c|c|c|c|c|c|c|}
\hline Test & 9.7 & \multicolumn{4}{|c|}{$\begin{array}{l}\text { F5A2 Temps approximated. } \\
\text { Quad SMF's estimated }(0.01-0.08)\end{array}$} & QA Check: & $\begin{array}{c}\text { Mame } \\
\text { Name }\end{array}$ & $\begin{array}{c}7 / 29 / 91 \\
\text { Date }\end{array}$ \\
\hline $\begin{array}{r}\text { SMFI }= \\
\text { GasFlow }= \\
\text { Temp }=\end{array}$ & $\begin{array}{c}0.596 \\
0.058 \\
146 \\
\end{array}$ & $\left(\mathrm{~m}^{\wedge} 3 / \mathrm{s} @\right.$ & & & & $\begin{array}{r}\text { Test } \\
\text { Chemica } \\
\text { ChemFrac }\end{array}$ & $\begin{array}{l}\text { Lompound }= \\
\text { Analyzed }= \\
(1-100 \%)=\end{array}$ & $\begin{array}{c}\text { CsI } \\
\text { Cs } \\
51.2 \\
\end{array}$ \\
\hline $\begin{array}{l}\text { Sample } \\
\text { ID No. }\end{array}$ & $\begin{array}{l}\text { Test Time } \\
\text { (min) }\end{array}$ & $\begin{array}{c}\Delta t \\
(\min )\end{array}$ & $\begin{array}{l}\text { Temp. } \\
\left({ }^{\circ} \mathrm{C}\right)\end{array}$ & $\begin{array}{c}\text { Critical } \\
\text { Orifice } \\
(\#) \\
\end{array}$ & $\begin{array}{c}C O \\
\Delta P \\
\text { (in. }-H g) \\
\end{array}$ & $\begin{array}{c}\text { SMF } \\
(-)\end{array}$ & $\begin{array}{l}\text { Gravimetric } \\
\Delta \mathrm{M}(\mathrm{mg})\end{array}$ & $\begin{array}{c}\text { Cs } \\
\text { Chemical } \\
\Delta M \text { (mg) }\end{array}$ \\
\hline $\begin{array}{l}\text { F6A-1 } \\
\text { F6A-2 } \\
\text { F6A-3 } \\
\text { F6A-4 }\end{array}$ & $\begin{array}{l}27.5 \\
48.5 \\
67.5 \\
87.5\end{array}$ & $\begin{array}{l}5.00 \\
5.00 \\
5.00 \\
5.00\end{array}$ & $\begin{array}{l}142 \\
144 \\
147 \\
150\end{array}$ & $\begin{array}{l}74 \\
74 \\
74 \\
65\end{array}$ & $\begin{array}{l}0.4 \\
0.4 \\
0.7 \\
1.6\end{array}$ & $\begin{array}{l}0.608 \\
0.603 \\
0.593 \\
0.581\end{array}$ & & $\begin{array}{l}0.0414 \\
0.0312 \\
0.0485 \\
0.0974\end{array}$ \\
\hline $\begin{array}{l}\text { F0-1 } \\
\text { FO-2 } \\
\text { F0-3 } \\
\text { F0-4 } \\
\text { F0-5 } \\
\text { F0-6 }\end{array}$ & $\begin{array}{l}27.5 \\
37.5 \\
48.3 \\
67.5 \\
77.5 \\
87.5\end{array}$ & $\begin{array}{l}5.00 \\
5.00 \\
6.58 \\
5.00 \\
5.00 \\
5.00\end{array}$ & $\begin{array}{c}7 \\
7 \\
6 \\
19 \\
25 \\
30\end{array}$ & $\begin{array}{l}55 \\
55 \\
55 \\
55 \\
55 \\
55\end{array}$ & $\begin{array}{l}1.0 \\
0.9 \\
1.0 \\
1.0 \\
1.0 \\
1.0\end{array}$ & $\begin{array}{l}0.000 \\
0.000 \\
0.005 \\
0.011 \\
0.021 \\
0.042\end{array}$ & & $\begin{array}{l}0.00069 \\
0.0029 \\
0.0013 \\
0.0064 \\
0.0066 \\
0.0063\end{array}$ \\
\hline $\begin{array}{l}A C l 6 A 1 \\
A C I 6 A 2 \\
A C I 6 B 1 \\
A C I 6 B 2 \\
A C I 1 B 1 \\
A C I 1 B 2\end{array}$ & $\begin{array}{l}39.5 \\
77.5 \\
39.5 \\
39.5 \\
37.5 \\
77.5\end{array}$ & $\begin{array}{l}5.00 \\
5.00 \\
5.00 \\
5.00 \\
5.00 \\
5.00\end{array}$ & $\begin{array}{c}144 \\
148 \\
42 \\
45 \\
5 \\
25\end{array}$ & $\begin{array}{l}74 \\
58 \\
50 \\
50 \\
50 \\
50\end{array}$ & $\begin{array}{l}0.3 \\
2.3 \\
>1.5 \\
>1.5 \\
1.6 \\
1.5\end{array}$ & $\begin{array}{l}0.605 \\
0.590 \\
0.070 \\
0.070 \\
0.005 \\
0.020\end{array}$ & & $\begin{array}{l}0.0318 \\
0.1125 \\
0.0048 \\
0.0054 \\
0.0008\end{array}$ \\
\hline $\begin{array}{c}\text { F6B1-1 } \\
\text { F6B2-1 } \\
\text { F6B1-2 } \\
\text { F6B2-2 } \\
\text { F6B1-3 } \\
\text { F6B2-3 } \\
\text { F1B-1 } \\
\text { F1B-2 } \\
\text { F1B-3 } \\
\text { F1B-4 }\end{array}$ & $\begin{array}{l}29.0 \\
29.0 \\
48.8 \\
48.8 \\
69.0 \\
69.0 \\
27.5 \\
47.5 \\
67.5 \\
87.8\end{array}$ & $\begin{array}{l}5.00 \\
5.00 \\
5.00 \\
5.00 \\
5.00 \\
5.00 \\
5.00 \\
5.00 \\
5.00 \\
5.50\end{array}$ & $\begin{array}{c}35 \\
44 \\
31 \\
43 \\
13 \\
17 \\
5 \\
7 \\
20 \\
31\end{array}$ & $\begin{array}{l}50 \\
50 \\
50 \\
50 \\
50 \\
50 \\
55 \\
55 \\
55 \\
55\end{array}$ & $\begin{array}{l}>1.5 \\
>1.5 \\
>1.5 \\
>1.5 \\
>1.5 \\
>1.5 \\
1.0 \\
1.0 \\
1.1 \\
1.1\end{array}$ & $\begin{array}{l}0.069 \\
0.069 \\
0.062 \\
0.062 \\
0.040 \\
0.040 \\
0.004 \\
0.005 \\
0.017 \\
0.022\end{array}$ & & $\begin{array}{c}0.0041 \\
0.0043 \\
0.0030 \\
0.0027 \\
0.0060 \\
0.0047 \\
0.0013 \\
0.00091 \\
0.0032 \\
0.0026\end{array}$ \\
\hline $\begin{array}{l}\text { F5A1-1 } \\
\text { F5A2-1 } \\
\text { F5A3-1 } \\
\text { F5A4-1 } \\
\text { F5A1-2 } \\
\text { F5A2-2 } \\
\text { F5A3-2 } \\
\text { F5A4-2 } \\
\text { F1A1-1 } \\
\text { F1A2-1 } \\
\text { F1A3-1 } \\
\text { F1A4-1 } \\
\text { F1A1-2 } \\
\text { F1A2-2 } \\
\text { F1A3-2 } \\
\text { F1A4-2 }\end{array}$ & $\begin{array}{l}22.5 \\
22.5 \\
22.5 \\
22.5 \\
57.5 \\
57.5 \\
57.5 \\
57.5 \\
22.5 \\
22.5 \\
22.5 \\
22.5 \\
57.5 \\
57.5 \\
57.5 \\
57.5\end{array}$ & $\begin{array}{l}5.00 \\
5.00 \\
5.00 \\
5.00 \\
5.00 \\
5.00 \\
5.00 \\
5.00 \\
5.00 \\
5.00 \\
5.00 \\
5.00 \\
5.00 \\
5.00 \\
5.00 \\
5.00\end{array}$ & $\begin{array}{c}32 \\
44 \\
32 \\
47 \\
28 \\
42 \\
32 \\
45 \\
6 \\
-2 \\
5 \\
5 \\
4 \\
7 \\
5 \\
15 \\
\end{array}$ & $\begin{array}{l}65 \\
65 \\
65 \\
65 \\
65 \\
65 \\
65 \\
65 \\
58 \\
58 \\
58 \\
58 \\
58 \\
58 \\
58 \\
58 \\
\end{array}$ & & $\begin{array}{l}0.040 \\
0.040 \\
0.040 \\
0.040 \\
0.040 \\
0.040 \\
0.040 \\
0.040 \\
0.040 \\
0.040 \\
0.040 \\
0.040 \\
0.040 \\
0.040 \\
0.040 \\
0.040 \\
\end{array}$ & & $\begin{array}{l}0.00094 \\
0.0112 \\
0.0042 \\
0.0098 \\
0.0020 \\
0.0086 \\
0.0037 \\
0.0139 \\
0.0017 \\
0.0014 \\
0.0017 \\
0.0015 \\
0.0024 \\
0.0029 \\
0.0021 \\
0.0026 \\
\end{array}$ \\
\hline
\end{tabular}


Test $9 \cdot 7$

\begin{tabular}{|c|c|c|c|c|c|c|c|c|}
\hline $\begin{array}{l}\text { Sample } \\
\text { ID No. }\end{array}$ & $\begin{array}{c}\text { Probe Loss } \\
\text { Correction } \\
\text { Factor } \\
(\text { PLcf }>1)\end{array}$ & $\begin{array}{l}\text { Corrected } \\
\text { Gravimetric } \\
\Delta \mathrm{M}(\mathrm{mg})\end{array}$ & $\begin{array}{c}\text { Corrected } \\
\text { Compound } \\
\text { Csl } \\
\Delta M(\mathrm{mg})\end{array}$ & $\begin{array}{c}\text { Crit. Orifice } \\
\text { Correction } \\
\text { Factor } \\
(\text { COct }<1)\end{array}$ & $\begin{array}{c}\text { Crit. Orifice } \\
\text { Flow Rate } \\
@ 20^{\circ} \mathrm{C} \\
\text { (lpm) }\end{array}$ & $\begin{array}{c}\text { S } \\
\text { Dry Gas } \\
@ 20^{\circ} \mathrm{C} \\
\text { (1) }\end{array}$ & $\begin{array}{c}\text { iple Volur } \\
\text { Dry Gas } \\
@ \text { To } \\
\text { (1) }\end{array}$ & $\begin{array}{c}\mathrm{H} 2 \mathrm{O} \\
@ \text { To } \\
\text { (I) }\end{array}$ \\
\hline $\begin{array}{l}\text { F6A-1 } \\
\text { F6A-2 } \\
\text { F6A-3 } \\
\text { F6A-4 }\end{array}$ & & & $\begin{array}{l}0.08 \\
0.06 \\
0.09 \\
0.19\end{array}$ & $\begin{array}{l}0.99 \\
0.99 \\
0.99 \\
0.97\end{array}$ & $\begin{array}{l}2.45 \\
2.45 \\
2.44 \\
6.78\end{array}$ & $\begin{array}{l}12.27 \\
12.27 \\
12.21 \\
33.91\end{array}$ & $\begin{array}{l}17.38 \\
17.46 \\
17.50 \\
48.95\end{array}$ & $\begin{array}{l}26.95 \\
26.52 \\
25.49 \\
67.88\end{array}$ \\
\hline $\begin{array}{l}\text { F0-1 } \\
\text { F0-2 } \\
\text { F0-3 } \\
\text { F0-4 } \\
\text { F0-5 } \\
\text { F0-6 }\end{array}$ & & & $\begin{array}{l}0.00 \\
0.01 \\
0.00 \\
0.01 \\
0.01 \\
0.01\end{array}$ & $\begin{array}{l}0.98 \\
0.98 \\
0.98 \\
0.98 \\
0.98 \\
0.98\end{array}$ & $\begin{array}{l}14.94 \\
14.97 \\
14.94 \\
14.94 \\
14.94 \\
14.94\end{array}$ & $\begin{array}{l}74.72 \\
74.85 \\
98.33 \\
74.72 \\
74.72 \\
74.72\end{array}$ & $\begin{array}{l}71.41 \\
71.53 \\
93.64 \\
74.47 \\
76.00 \\
77.27\end{array}$ & $\begin{array}{l}0.01 \\
0.01 \\
0.47 \\
0.83 \\
1.63 \\
3.39\end{array}$ \\
\hline $\begin{array}{l}A C l 6 A 1 \\
A C l 6 A 2 \\
A C l 6 B 1 \\
A C l 6 B 2 \\
A C l 1 B 1 \\
A C l 1 B 2\end{array}$ & & & $\begin{array}{l}0.06 \\
0.22 \\
0.01 \\
0.01 \\
0.00\end{array}$ & $\begin{array}{l}0.97 \\
0.97\end{array}$ & $\begin{array}{c}2.46 \\
8.78 \\
27.20 \\
27.20 \\
26.46 \\
26.51\end{array}$ & $\begin{array}{c}12.29 \\
43.91 \\
136.00 \\
136.00 \\
132.32 \\
132.56\end{array}$ & $\begin{array}{c}17.49 \\
63.10 \\
146.21 \\
147.60 \\
125.55 \\
134.82\end{array}$ & $\begin{array}{c}26.79 \\
90.80 \\
11.01 \\
11.11 \\
0.63 \\
2.75\end{array}$ \\
\hline $\begin{array}{c}\text { F6B1-1 } \\
\text { F6B2-1 } \\
\text { F6B1-2 } \\
\text { F6B2-2 } \\
\text { F6B1-3 } \\
\text { F6B2-3 } \\
\text { F1B-1 } \\
\text { F1B-2 } \\
\text { F1B-3 } \\
\text { F1B-4 }\end{array}$ & & & $\begin{array}{l}0.01 \\
0.01 \\
0.01 \\
0.01 \\
0.01 \\
0.01 \\
0.00 \\
0.00 \\
0.01 \\
0.01\end{array}$ & $\begin{array}{l}0.98 \\
0.98 \\
0.98 \\
0.98\end{array}$ & $\begin{array}{l}27.20 \\
27.20 \\
27.20 \\
27.20 \\
27.20 \\
27.20 \\
14.94 \\
14.94 \\
14.92 \\
14.92\end{array}$ & $\begin{array}{c}136.00 \\
136.00 \\
136.00 \\
136.00 \\
136.00 \\
136.00 \\
74.72 \\
74.72 \\
74.59 \\
82.05\end{array}$ & $\begin{array}{c}142.96 \\
147.14 \\
141.11 \\
146.68 \\
132.75 \\
134.61 \\
70.90 \\
71.41 \\
74.59 \\
85.13\end{array}$ & $\begin{array}{l}10.60 \\
10.91 \\
9.33 \\
9.69 \\
5.53 \\
5.61 \\
0.28 \\
0.36 \\
1.29 \\
1.92\end{array}$ \\
\hline $\begin{array}{l}\text { F5A1-1 } \\
\text { F5A2-1 } \\
\text { F5A3-1 } \\
\text { F5A4-1 } \\
\text { F5A1-2 } \\
\text { F5A2-2 } \\
\text { F5A3-2 } \\
\text { F5A4-2 } \\
\text { F1A1-1 } \\
\text { F1A2-1 } \\
\text { F1A3-1 } \\
\text { F1A4-1 } \\
\text { F1A1-2 } \\
\text { F1A2-2 } \\
\text { F1A3-2 } \\
\text { F1A4-2 }\end{array}$ & & & $\begin{array}{l}0.00 \\
0.02 \\
0.01 \\
0.02 \\
0.00 \\
0.02 \\
0.01 \\
0.03 \\
0.00 \\
0.00 \\
0.00 \\
0.00 \\
0.00 \\
0.01 \\
0.00 \\
0.01\end{array}$ & & $\begin{array}{l}6.97 \\
6.97 \\
6.97 \\
6.97 \\
6.97 \\
6.97 \\
6.97 \\
6.97 \\
9.14 \\
9.14 \\
9.14 \\
9.14 \\
9.14 \\
9.14 \\
9.14 \\
9.14 \\
\end{array}$ & $\begin{array}{l}34.85 \\
34.85 \\
34.85 \\
34.85 \\
34.85 \\
34.85 \\
34.85 \\
34.85 \\
45.70 \\
45.70 \\
45.70 \\
45.70 \\
45.70 \\
45.70 \\
45.70 \\
45.70 \\
\end{array}$ & $\begin{array}{l}36.28 \\
37.70 \\
36.28 \\
38.06 \\
35.80 \\
37.47 \\
36.28 \\
37.82 \\
43.52 \\
42.27 \\
43.36 \\
43.36 \\
43.20 \\
43.67 \\
43.36 \\
44.92 \\
\end{array}$ & $\begin{array}{l}1.51 \\
1.57 \\
1.51 \\
1.59 \\
1.49 \\
1.56 \\
1.51 \\
1.58 \\
1.81 \\
1.76 \\
1.81 \\
1.81 \\
1.80 \\
1.82 \\
1.81 \\
1.87 \\
\end{array}$ \\
\hline
\end{tabular}

ICEDF DF WorkSheet (page 2)

$$
\text { E. } 26
$$




\begin{tabular}{|c|c|c|c|c|c|c|c|}
\hline & $\Sigma$ Sample & & Mass & & & Csl & \\
\hline $\begin{array}{l}\text { Sample } \\
\text { ID No. }\end{array}$ & $\begin{array}{c}\text { Volume } \\
\text { @ To } \\
\text { (1) }\end{array}$ & $\begin{array}{c}\mathrm{Cm} \\
@ \mathrm{To} \\
\left(\mathrm{mg} / \mathrm{m}^{\wedge} 3\right)\end{array}$ & $\begin{array}{c}\text { Mass Flow } \\
@ \text { To } \\
(\mathrm{mg} / \mathrm{s}) \\
\end{array}$ & $\begin{array}{l}\text { Approx. } \\
\text { Feed Rate } \\
\text { (g/min) }\end{array}$ & $\begin{array}{c}\mathrm{Cm} \\
@ \text { To } \\
\left(\mathrm{mg} / \mathrm{m}^{\wedge} 3\right)\end{array}$ & $\begin{array}{c}\text { Mass Flow } \\
\text { @ To } \\
\text { (mg/s) } \\
\end{array}$ & $\begin{array}{c}\text { Approx. } \\
\text { Feød Rate } \\
\text { (g/min) }\end{array}$ \\
\hline $\begin{array}{l}\text { F6A-1 } \\
\text { F6A-2 } \\
\text { F6A-3 } \\
\text { F6A-4 }\end{array}$ & $\begin{array}{c}44.32 \\
43.98 \\
42.99 \\
116.83\end{array}$ & & & & $\begin{array}{l}1.82 \\
1.39 \\
2.20 \\
1.63\end{array}$ & $\begin{array}{l}0.106 \\
0.081 \\
0.128 \\
0.094\end{array}$ & $\begin{array}{l}0.0064 \\
0.0048 \\
0.0077 \\
0.0056\end{array}$ \\
\hline $\begin{array}{l}\text { F0-1 } \\
\text { F0-2 } \\
\text { F0-3 } \\
\text { F0-4 } \\
\text { F0-5 } \\
\text { FO-6 }\end{array}$ & $\begin{array}{l}71.41 \\
71.54 \\
94.11 \\
75.30 \\
77.63 \\
80.66\end{array}$ & & & & $\begin{array}{l}0.019 \\
0.079 \\
0.027 \\
0.166 \\
0.166 \\
0.153\end{array}$ & $\begin{array}{l}0.00030 \\
0.00124 \\
0.00043 \\
0.00279 \\
0.00291 \\
0.00285\end{array}$ & $\begin{array}{l}0.00002 \\
0.00007 \\
0.00003 \\
0.00017 \\
0.00017 \\
0.00017\end{array}$ \\
\hline $\begin{array}{l}A C I 6 A 1 \\
A C I 6 A 2 \\
A C I 6 B 1 \\
A C I 6 B 2 \\
A C I 1 B 1 \\
A C I 1 B 2\end{array}$ & $\begin{array}{c}44.27 \\
153.90 \\
157.22 \\
158.71 \\
126.18 \\
137.57\end{array}$ & & & & $\begin{array}{l}1.403 \\
1.428 \\
0.059 \\
0.066 \\
0.012\end{array}$ & $\begin{array}{c}0.08170 \\
0.08271 \\
\text { ND } \\
\text { ND } \\
\text { ND } \\
\text { ND }\end{array}$ & $\begin{array}{c}0.00490 \\
0.00496 \\
\text { ND } \\
\text { ND } \\
\text { ND } \\
\text { ND }\end{array}$ \\
\hline $\begin{array}{c}\text { F6B1-1 } \\
\text { F6B2-1 } \\
\text { F6B1-2 } \\
\text { F6B2-2 } \\
\text { F6B1-3 } \\
\text { F6B2-3 } \\
\text { F1B-1 } \\
\text { F1B-2 } \\
\text { F1B-3 } \\
\text { F1B-4 }\end{array}$ & $\begin{array}{l}153.56 \\
158.05 \\
150.43 \\
156.37 \\
138.28 \\
140.22 \\
71.18 \\
71.77 \\
75.88 \\
87.05\end{array}$ & & & & $\begin{array}{l}0.052 \\
0.053 \\
0.039 \\
0.034 \\
0.085 \\
0.065 \\
0.036 \\
0.025 \\
0.082 \\
0.058\end{array}$ & $\begin{array}{l}\text { ND } \\
\text { ND } \\
\text { ND } \\
\text { ND } \\
\text { ND } \\
\text { ND } \\
\text { ND } \\
\text { ND } \\
\text { ND } \\
\text { ND }\end{array}$ & $\begin{array}{l}\text { ND } \\
N D \\
N D \\
N D \\
N D \\
N D \\
N D \\
N D \\
N D \\
N D\end{array}$ \\
\hline $\begin{array}{l}\text { F5A1-1 } \\
\text { F5A2-1 } \\
\text { F5A3-1 } \\
\text { F5A4-1 } \\
\text { F5A1-2 } \\
\text { F5A2-2 } \\
\text { F5A3-2 } \\
\text { F5A4-2 } \\
\text { F1A1-1 } \\
\text { F1A2-1 } \\
\text { F1A3-1 } \\
\text { F1A4-1 } \\
\text { F1A1-2 } \\
\text { F1A2-2 } \\
\text { F1A3-2 } \\
\text { F1A4-2 }\end{array}$ & $\begin{array}{l}37.79 \\
39.28 \\
37.79 \\
39.65 \\
37.29 \\
39.03 \\
37.79 \\
39.40 \\
45.33 \\
44.03 \\
45.17 \\
45.17 \\
45.00 \\
45.49 \\
45.17 \\
46.79 \\
\end{array}$ & & & & $\begin{array}{l}0.049 \\
0.557 \\
0.217 \\
0.483 \\
0.105 \\
0.430 \\
0.191 \\
0.689 \\
0.073 \\
0.062 \\
0.074 \\
0.065 \\
0.104 \\
0.125 \\
0.091 \\
0.109 \\
\end{array}$ & $\begin{array}{l}N D \\
N D \\
N D \\
N D \\
N D \\
N D \\
N D \\
N D \\
N D \\
N D \\
N D \\
N D \\
N D \\
N D \\
N D \\
N D \\
\end{array}$ & $\begin{array}{l}N D \\
N D \\
N D \\
N D \\
N D \\
N D \\
N D \\
N D \\
N D \\
N D \\
N D \\
N D \\
N D \\
N D \\
N D \\
N D \\
\end{array}$ \\
\hline
\end{tabular}


How to use "ICEDF DF WkSht 8/89"

1) Open "ICEDF DF WkSht $8 / 89$ "

2) Enter test name and other constants.

3) Save As "ICEDF testname DF month/year".

4) Enter data on page 1 (change sample ID's if req'd)

WorkSheet Updates:

10/5/89: Added correction for $\Delta P$ upstream of critical orifice, changed sample ID No. listing.

10/5/89: Removed aerosol mass flow rate calculations for quad stations.

\begin{tabular}{|cc|}
\hline \multicolumn{2}{|c|}{ Critical Orifice Calib. } \\
\hline & \\
CO (\#) & Q (lpm) \\
\hline 50 & 27.2 \\
53 & 19.8 \\
55 & 15.2 \\
58 & 9.14 \\
65 & 6.97 \\
69 & 5.03 \\
74 & 2.47 \\
77 & 1.45 \\
80 & 1.03 \\
\hline
\end{tabular}




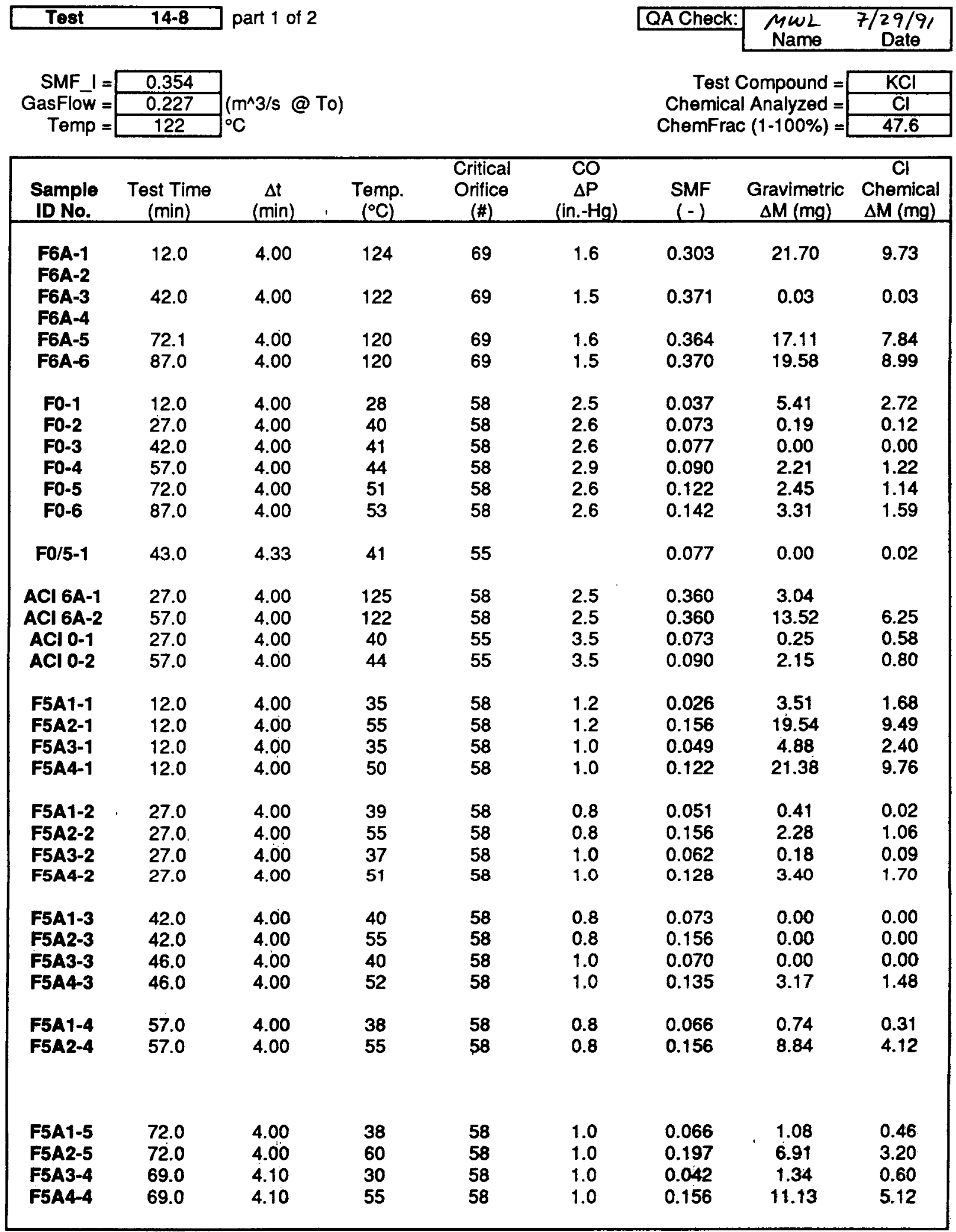




\begin{tabular}{|c|c|c|c|c|c|c|c|c|}
\hline \multirow{2}{*}{$\begin{array}{l}\text { Sample } \\
\text { ID No. }\end{array}$} & \multirow{2}{*}{$\begin{array}{l}\text { Probe Loss } \\
\text { Correction } \\
\text { Factor } \\
(P L c f>1)\end{array}$} & \multirow[b]{2}{*}{$\begin{array}{c}\text { Corrected } \\
\text { Gravimetric } \\
\Delta M(m g)\end{array}$} & \multirow{2}{*}{$\begin{array}{c}\text { Corrected } \\
\text { Compound } \\
\mathrm{KCl} \\
\Delta \mathrm{M}(\mathrm{mg})\end{array}$} & \multirow{2}{*}{$\begin{array}{c}\text { Crit. Orifice } \\
\text { Correction } \\
\text { Factor } \\
(\text { COcf }<1)\end{array}$} & \multirow{2}{*}{$\begin{array}{l}\text { Crit. Orifice } \\
\text { Flow Rate } \\
@ 20^{\circ} \mathrm{C} \\
(1 \mathrm{pm})\end{array}$} & \multicolumn{3}{|c|}{ Sample Volume, I } \\
\hline & & & & & & $\begin{array}{c}\text { Dry Gas } \\
\text { @ } 20^{\circ} \mathrm{C} \\
\text { (1) }\end{array}$ & $\begin{array}{c}\text { Dry Gas } \\
@ \text { To } \\
(1)\end{array}$ & $\begin{array}{c}\mathrm{H} 2 \mathrm{O} \\
@ \mathrm{To} \\
\text { (1) }\end{array}$ \\
\hline $\begin{array}{l}\text { F6A-1 } \\
\text { F6A-2 }\end{array}$ & & 21.70 & 20.44 & 0.97 & 4.89 & 19.58 & 26.52 & 11.53 \\
\hline $\begin{array}{l}\text { F6A-3 } \\
\text { F6A-4 }\end{array}$ & & 0.03 & 0.06 & 0.97 & 4.90 & 19.61 & 26.44 & 15.59 \\
\hline $\begin{array}{l}\text { F6A-5 } \\
\text { F6A-6 }\end{array}$ & & $\begin{array}{l}17.11 \\
19.58\end{array}$ & $\begin{array}{l}16.47 \\
18.89\end{array}$ & $\begin{array}{l}0.97 \\
0.97\end{array}$ & $\begin{array}{l}4.89 \\
4.90\end{array}$ & $\begin{array}{l}19.58 \\
19.61\end{array}$ & $\begin{array}{l}26.26 \\
26.30\end{array}$ & $\begin{array}{l}15.03 \\
15.45\end{array}$ \\
\hline F0-1 & & 5.41 & 5.71 & 0.96 & 8.75 & 35.00 & 35.96 & 1.38 \\
\hline F0-2 & & 0.19 & 0.25 & 0.96 & 8.73 & 34.94 & 37.32 & 2.94 \\
\hline F0-3 & & 0.00 & 0.00 & 0.96 & 8.73 & 34.94 & 37.44 & 3.12 \\
\hline F0-4 & & 2.21 & 2.56 & 0.95 & 8.69 & 34.75 & 37.59 & 3.72 \\
\hline F0-5 & & 2.45 & 2.39 & 0.96 & 8.73 & 34.94 & 38.64 & 5.37 \\
\hline F0-6 & & 3.31 & 3.34 & 0.96 & 8.73 & 34.94 & 38.88 & 6.43 \\
\hline Fo/5-1 & & 0.00 & 0.04 & & 15.20 & 65.82 & 70.53 & 5.88 \\
\hline ACl 6A-1 & & 3.04 & & 0.96 & 8.75 & 35.00 & 47.55 & 26.75 \\
\hline ACl 6A-2 & & 13.52 & 13.13 & 0.96 & 8.75 & 35.00 & 47.19 & 26.54 \\
\hline $\mathrm{ACl} 0-1$ & & 0.25 & 1.23 & 0.94 & 14.29 & 57.14 & 61.04 & 4.81 \\
\hline ACl 0-2 & & 2.15 & 1.68 & 0.94 & 14.29 & 57.14 & 61.82 & 6.11 \\
\hline F5A1-1 & & 3.51 & 3.53 & 0.98 & 8.96 & 35.82 & 37.66 & 1.01 \\
\hline F5A2-1 & & 19.54 & 19.94 & 0.98 & 8.96 & 35.82 & 40.10 & 7.41 \\
\hline F5A3-1 & & 4.88 & 5.04 & 0.98 & 8.99 & 35.95 & 37.79 & 1.95 \\
\hline F5A4-1 & & 21.38 & 20.50 & 0.98 & 8.99 & 35.95 & 39.63 & 5.51 \\
\hline F5A1-2 & & 0.41 & 0.04 & 0.99 & 9.02 & 36.07 & 38.41 & 2.06 \\
\hline F5A2-2 & & 2.28 & 2.23 & 0.99 & 9.02 & 36.07 & 40.38 & 7.46 \\
\hline F5A3-2 & & 0.18 & 0.18 & 0.98 & 8.99 & 35.95 & 38.03 & 2.51 \\
\hline F5A4-2 & & 3.40 & 3.57 & 0.98 & 8.99 & 35.95 & 39.75 & 5.83 \\
\hline F5A1-3 & & 0.00 & 0.00 & 0.99 & 9.02 & 36.07 & 38.53 & 3.03 \\
\hline F5A2-3 & & 0.00 & 0.00 & 0.99 & 9.02 & 36.07 & 40.38 & 7.46 \\
\hline F5A3-3 & & 0.00 & 0.00 & 0.98 & 8.99 & 35.95 & 38.40 & 2.89 \\
\hline F5A4-3 & & 3.17 & 3.11 & 0.98 & 8.99 & 35.95 & 39.87 & 6.22 \\
\hline $\begin{array}{l}\text { F5A1-4 } \\
\text { F5A2-4 }\end{array}$ & & $\begin{array}{l}0.74 \\
8.84\end{array}$ & $\begin{array}{l}0.64 \\
8.66\end{array}$ & $\begin{array}{l}0.99 \\
0.99\end{array}$ & $\begin{array}{l}9.02 \\
9.02\end{array}$ & $\begin{array}{l}36.07 \\
36.07\end{array}$ & $\begin{array}{l}38.29 \\
40.38\end{array}$ & $\begin{array}{l}2.71 \\
7.46\end{array}$ \\
\hline F5A1-5 & & 1.08 & 0.96 & 0.98 & 8.99 & 35.95 & 38.15 & 2.70 \\
\hline F5A2-5 & & 6.91 & 6.72 & 0.98 & 8.99 & 35.95 & 40.85 & 10.02 \\
\hline F5A3-4 & & 1.34 & 1.27 & 0.98 & 8.99 & 36.84 & 38.10 & 1.67 \\
\hline F5A4-4 & & 11.13 & 10.76 & 0.98 & 8.99 & 36.84 & 41.25 & 7.62 \\
\hline
\end{tabular}

ICEDF DF WorkSheet (page 2)

$$
\text { E. } 30
$$




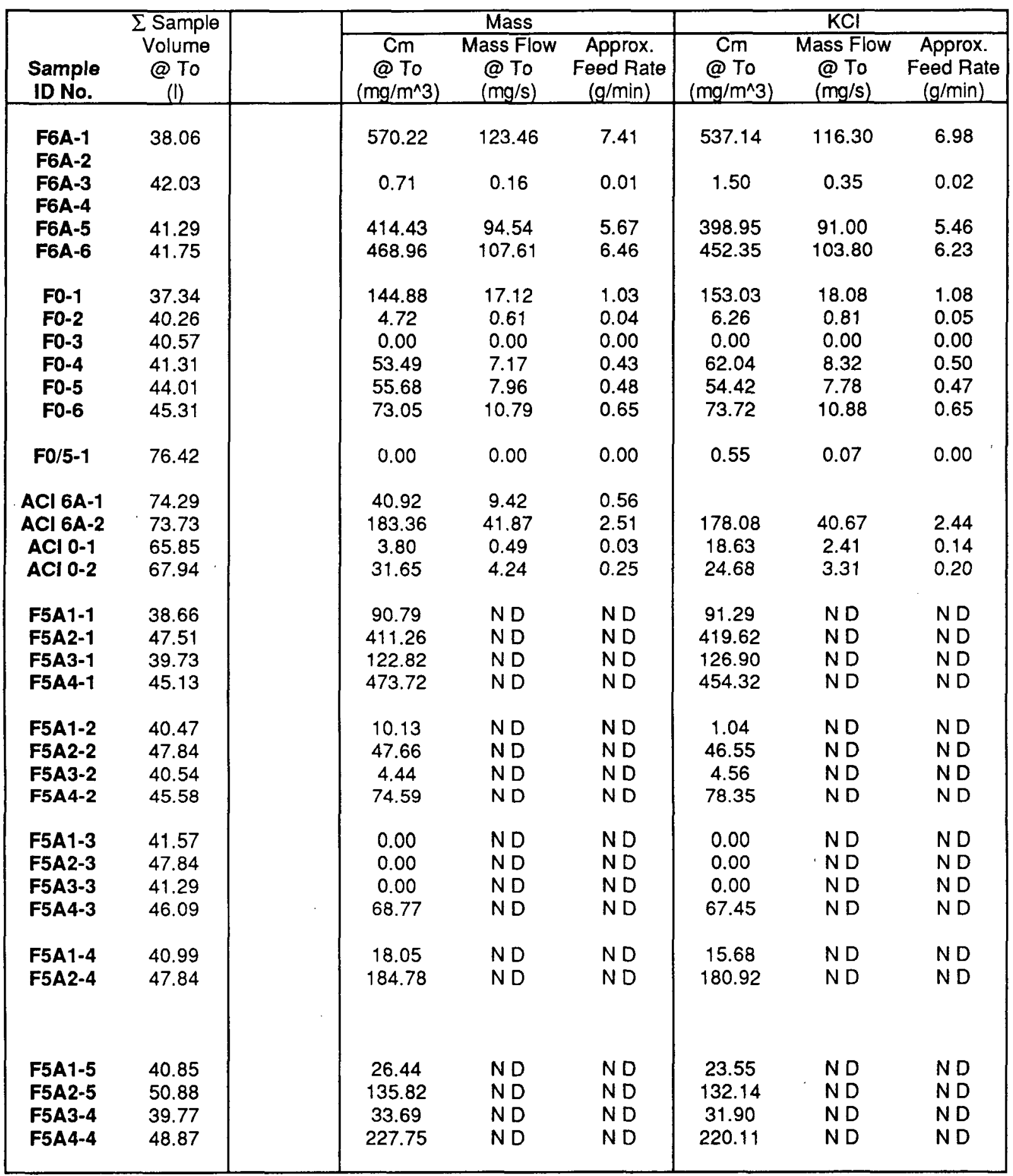




\section{How to use "ICEDF DF WkSht 8/89"}

1) Open "ICEDF DF WkSht $8 / 89$ "

2) Enter test name and other constants.

3) Save As "ICEDF testname DF month/year".

4) Enter data on page 1 (change sample ID's if req'd)

WorkSheet Updates:

10/5/89: Added correction for $\triangle P$ upstream of critical orifice, changed sample ID No. listing.

10/5/89: Removed aerosol mass flow rate calculations for quad stations.

\begin{tabular}{|cc|}
\hline \multicolumn{2}{|c|}{ Critical Orifice Calib. } \\
\hline & \\
CO (\#) & Q (lpm) \\
\hline 50 & 27.2 \\
53 & 19.8 \\
55 & 15.2 \\
58 & 9.14 \\
65 & 6.97 \\
69 & 5.03 \\
74 & 2.47 \\
77 & 1.45 \\
80 & 1.03 \\
\hline
\end{tabular}




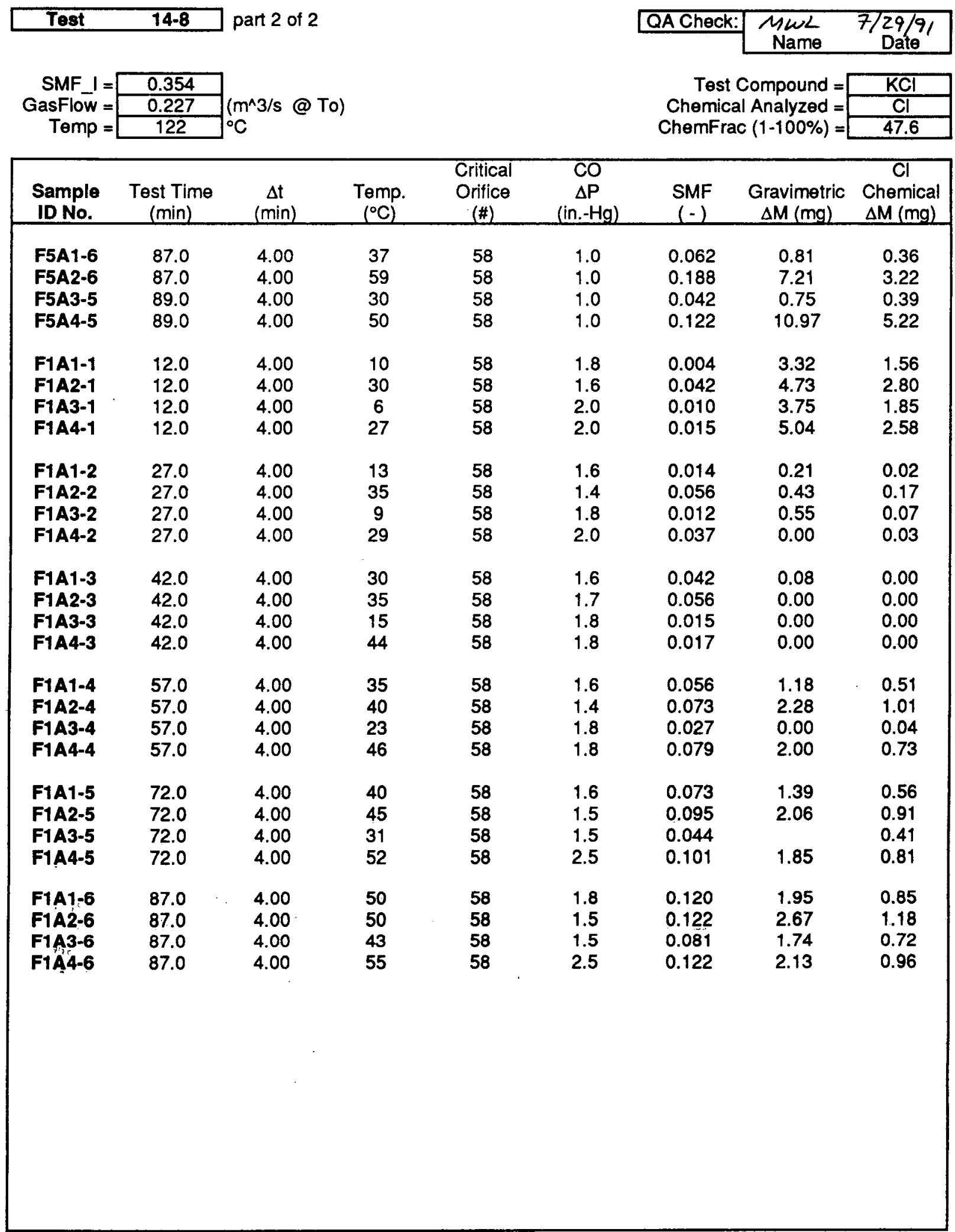

ICEDF DF WorkSheet (page 1) 


\begin{tabular}{|c|c|c|c|c|c|c|c|c|}
\hline & Probe Loss & & Corrected & Crit. Orifice & Crit. Orifice & & mple Volun & \\
\hline $\begin{array}{l}\text { Sample } \\
\text { ID No. }\end{array}$ & $\begin{array}{l}\text { Correction } \\
\text { Factor } \\
(\text { PLCf }>1)\end{array}$ & $\begin{array}{c}\text { Corrected } \\
\text { Gravimetric } \\
\Delta M(m g)\end{array}$ & $\begin{array}{c}\text { Compound } \\
\mathrm{KCl} \\
\Delta \mathrm{M}(\mathrm{mg})\end{array}$ & $\begin{array}{l}\text { Correction } \\
\text { Factor } \\
\text { (Cocf < 1) }\end{array}$ & $\begin{array}{c}\text { Flow Rate } \\
@ 20^{\circ} \mathrm{C} \\
(\mathrm{lpm})\end{array}$ & $\begin{array}{c}\text { Dry Gas } \\
@ 20^{\circ} \mathrm{C} \\
\text { (I) }\end{array}$ & $\begin{array}{c}\text { Dry Gas } \\
@ \text { To } \\
(1)\end{array}$ & $\begin{array}{c}\mathrm{H} 2 \mathrm{O} \\
\text { @ To } \\
(1)\end{array}$ \\
\hline F5A1-6 & & 0.81 & 0.76 & 0.98 & 8.99 & 35.95 & 38.03 & 2.51 \\
\hline F5A2-6 & & 7.21 & 6.76 & 0.98 & 8.99 & 35.95 & 40.73 & 9.43 \\
\hline F5A3-5 & & 0.75 & 0.82 & 0.98 & 8.99 & 35.95 & 37.17 & 1.63 \\
\hline F5A4-5 & & 10.97 & 10.97 & 0.98 & 8.99 & 35.95 & 39.63 & 5.51 \\
\hline F1A1-1 & & 3.32 & 3.28 & 0.97 & 8.86 & 35.45 & 34.24 & 0.14 \\
\hline F1A2-1 & & 4.73 & 5.88 & 0.97 & 8.89 & 35.57 & 36.79 & 1.61 \\
\hline F1A3-1 & & 3.75 & 3.89 & 0.97 & 8.83 & 35.32 & 33.63 & 0.34 \\
\hline F1A4-1 & & 5.04 & 5.42 & 0.97 & 8.83 & 35.32 & 36.16 & 0.55 \\
\hline F1A1-2 & & 0.21 & 0.04 & 0.97 & 8.89 & 35.57 & 34.72 & 0.49 \\
\hline F1A2-2 & & 0.43 & 0.36 & 0.98 & 8.92 & 35.70 & 37.52 & 2.23 \\
\hline F1A3-2 & & 0.55 & 0.16 & 0.97 & 8.86 & 35.45 & 34.12 & 0.41 \\
\hline F1A4-2 & & 0.00 & 0.06 & 0.97 & 8.83 & 35.32 & 36.41 & 1.40 \\
\hline F1A1-3 & & 0.08 & 0.00 & 0.97 & 8.89 & 35.57 & 36.79 & 1.61 \\
\hline F1A2-3 & & 0.00 & 0.00 & 0.97 & 8.88 & 35.51 & 37.33 & 2.21 \\
\hline F1A3-3 & & 0.00 & 0.00 & 0.97 & 8.86 & 35.45 & 34.84 & 0.53 \\
\hline F1A4-3 & & 0.00 & 0.00 & 0.97 & 8.86 & 35.45 & 38.35 & 0.66 \\
\hline F1A1-4 & & 1.18 & 1.08 & 0.97 & 8.89 & 35.57 & 37.39 & 2.22 \\
\hline F1A2-4 & & 2.28 & 2.12 & 0.98 & 8.92 & 35.70 & 38.13 & 3.00 \\
\hline F1A3-4 & & 0.00 & 0.08 & 0.97 & 8.86 & 35.45 & 35.81 & 0.99 \\
\hline F1A4-4 & & 2.00 & 1.53 & 0.97 & 8.86 & 35.45 & 38.59 & 3.31 \\
\hline F1A1-5 & & 1.39 & 1.17 & 0.97 & 8.89 & 35.57 & 38.00 & 2.99 \\
\hline F1A2-5 & & 2.06 & 1.90 & 0.97 & 8.91 & 35.63 & 38.67 & 4.06 \\
\hline F1A3-5 & & & 0.85 & 0.97 & 8.91 & 35.63 & 36.97 & 1.70 \\
\hline F1A4-5 & & 1.85 & 1.70 & 0.96 & 8.75 & 35.00 & 38.83 & 4.36 \\
\hline F1A1-6 & & 1.95 & 1.78 & 0.97 & 8.86 & 35.45 & 39.08 & 5.33 \\
\hline F1A2-6 & & 2.67 & 2.48 & 0.97 & 8.91 & 35.63 & 39.28 & 5.46 \\
\hline F1A3-6 & & 1.74 & 1.51 & 0.97 & 8.91 & 35.63 & 38.43 & 3.39 \\
\hline F1A4-6 & & 2.13 & 2.02 & 0.96 & 8.75 & 35.00 & 39.18 & 5.44 \\
\hline & & & & & & & & \\
\hline & & & & & & & & \\
\hline & & & & & & & & \\
\hline & & & & & & & & \\
\hline & & & & & & & & \\
\hline & & & & & & & & \\
\hline
\end{tabular}

ICEDF DF WorkSheet (page 2)

$$
\text { E. } 34
$$




\begin{tabular}{|c|c|c|c|c|c|c|c|}
\hline & $\sum$ Sample & & Mass & & & $\mathrm{KCl}$ & \\
\hline $\begin{array}{l}\text { Sample } \\
\text { ID No. }\end{array}$ & $\begin{array}{c}\text { Volume } \\
\text { @ To } \\
\text { (l) }\end{array}$ & $\begin{array}{c}\mathrm{Cm} \\
@ \text { To }^{\circ} \\
\left(\mathrm{mg} / \mathrm{m}^{\wedge} 3\right)\end{array}$ & $\begin{array}{c}\text { Mass Flow } \\
\text { @ To } \\
(\mathrm{mg} / \mathrm{s})\end{array}$ & $\begin{array}{c}\text { Approx. } \\
\text { Feed Rate } \\
(\mathrm{g} / \mathrm{min})\end{array}$ & $\begin{array}{c}\mathrm{Cm} \\
@ \text { To } \\
\left(\mathrm{mg} / \mathrm{m}^{\wedge} 3\right)\end{array}$ & $\begin{array}{c}\text { Mass Flow } \\
\text { @ To } \\
\text { (mg/s) }\end{array}$ & $\begin{array}{c}\text { Approx. } \\
\text { Feed Rate } \\
\text { (g/min) }\end{array}$ \\
\hline $\begin{array}{l}\text { F5A1-6 } \\
\text { F5A2-6 } \\
\text { F5A3-5 } \\
\text { F5A4-5 }\end{array}$ & $\begin{array}{l}40.54 \\
50.16 \\
38.80 \\
45.13\end{array}$ & $\begin{array}{c}19.98 \\
143.74 \\
19.33 \\
243.06\end{array}$ & $\begin{array}{l}\text { ND } \\
\text { ND } \\
\text { ND } \\
\text { ND }\end{array}$ & $\begin{array}{l}N D \\
N D \\
N D \\
N D\end{array}$ & $\begin{array}{c}18.65 \\
134.86 \\
21.12 \\
242.98\end{array}$ & $\begin{array}{l}\text { ND } \\
\text { ND } \\
\text { ND } \\
\text { ND }\end{array}$ & $\begin{array}{l}\text { ND } \\
\text { ND } \\
\text { ND } \\
\text { ND }\end{array}$ \\
\hline $\begin{array}{l}\text { F1A1-1 } \\
\text { F1A2-1 } \\
\text { F1A3-1 } \\
\text { F1A4-1 }\end{array}$ & $\begin{array}{l}34.37 \\
38.40 \\
33.97 \\
36.71\end{array}$ & $\begin{array}{c}96.58 \\
123.18 \\
110.38 \\
137.27\end{array}$ & $\begin{array}{l}\text { ND } \\
\text { ND } \\
\text { ND } \\
\text { ND }\end{array}$ & $\begin{array}{l}\text { ND } \\
\text { ND } \\
N D \\
N D\end{array}$ & $\begin{array}{c}95.34 \\
153.19 \\
114.40 \\
147.63\end{array}$ & $\begin{array}{l}\text { ND } \\
\text { ND } \\
\text { ND } \\
\text { ND }\end{array}$ & $\begin{array}{l}\text { ND } \\
\text { ND } \\
\text { ND } \\
\text { ND }\end{array}$ \\
\hline $\begin{array}{l}\text { F1A1-2 } \\
\text { F1A2-2 } \\
\text { F1A3-2 } \\
\text { F1A4-2 }\end{array}$ & $\begin{array}{l}35.21 \\
39.75 \\
34.53 \\
37.80\end{array}$ & $\begin{array}{c}5.96 \\
10.82 \\
15.93 \\
0.00\end{array}$ & $\begin{array}{l}\text { ND } \\
\text { ND } \\
\text { ND } \\
\text { ND }\end{array}$ & $\begin{array}{l}\text { N D } \\
N D \\
N D \\
N D\end{array}$ & $\begin{array}{l}1.19 \\
8.98 \\
4.50 \\
1.67\end{array}$ & $\begin{array}{l}\text { ND } \\
\text { ND } \\
\text { ND } \\
\text { ND }\end{array}$ & $\begin{array}{l}\text { ND } \\
\text { ND } \\
\text { ND } \\
\text { ND }\end{array}$ \\
\hline $\begin{array}{l}\text { F1A1-3 } \\
\text { F1A2-3 } \\
\text { F1A3-3 } \\
\text { F1A4-3 }\end{array}$ & $\begin{array}{l}38.40 \\
39.54 \\
35.37 \\
39.01\end{array}$ & $\begin{array}{l}2.08 \\
0.00 \\
0.00 \\
0.00\end{array}$ & $\begin{array}{l}\text { ND } \\
\text { ND } \\
\text { ND } \\
\text { ND }\end{array}$ & $\begin{array}{l}\text { ND } \\
N D \\
N D \\
N D\end{array}$ & $\begin{array}{l}0.00 \\
0.00 \\
0.00 \\
0.00\end{array}$ & $\begin{array}{l}\text { ND } \\
\text { ND } \\
\text { ND } \\
\text { ND }\end{array}$ & $\begin{array}{l}\text { ND } \\
N D \\
N D \\
N D\end{array}$ \\
\hline $\begin{array}{l}\text { F1A1-4 } \\
\text { F1A2-4 } \\
\text { F1A3-4 } \\
\text { F1A4-4 }\end{array}$ & $\begin{array}{l}39.61 \\
41.14 \\
36.80 \\
41.90\end{array}$ & $\begin{array}{c}29.79 \\
55.43 \\
0.00 \\
47.73\end{array}$ & $\begin{array}{l}\text { ND } \\
\text { ND } \\
\text { ND } \\
\text { ND }\end{array}$ & $\begin{array}{l}\text { ND } \\
N D \\
N D \\
N D\end{array}$ & $\begin{array}{c}27.26 \\
51.58 \\
2.28 \\
36.60\end{array}$ & $\begin{array}{l}\text { ND } \\
N D \\
N D \\
N D\end{array}$ & $\begin{array}{l}\text { ND } \\
\text { ND } \\
\text { ND } \\
\text { ND }\end{array}$ \\
\hline $\begin{array}{l}\text { F1A1-5 } \\
\text { F1A2-5 } \\
\text { F1A3-5 } \\
\text { F1A4-5 }\end{array}$ & $\begin{array}{l}40.99 \\
42.73 \\
38.67 \\
43.19\end{array}$ & $\begin{array}{l}33.91 \\
48.20 \\
42.84\end{array}$ & $\begin{array}{l}\text { ND } \\
N D \\
N D \\
N D\end{array}$ & $\begin{array}{l}\text { ND } \\
\text { ND } \\
\text { ND } \\
\text { ND }\end{array}$ & $\begin{array}{l}28.60 \\
44.54 \\
22.05 \\
39.30\end{array}$ & $\begin{array}{l}\text { ND } \\
\text { ND } \\
\text { ND } \\
\text { ND }\end{array}$ & $\begin{array}{l}\text { ND } \\
\text { ND } \\
\text { ND } \\
\text { ND }\end{array}$ \\
\hline $\begin{array}{l}\text { F1A1-6 } \\
\text { F1A2-6 } \\
\text { F1A3-6 } \\
\text { F1A4-6 }\end{array}$ & $\begin{array}{l}44.40 \\
44.74 \\
41.82 \\
44.63\end{array}$ & $\begin{array}{l}43.91 \\
59.68 \\
41.61 \\
47.73\end{array}$ & $\begin{array}{l}\text { ND } \\
N D \\
N D \\
N D\end{array}$ & $\begin{array}{l}\text { ND } \\
N D \\
N D \\
N D\end{array}$ & $\begin{array}{l}40.12 \\
55.41 \\
36.17 \\
45.19\end{array}$ & $\begin{array}{l}\text { ND } \\
\text { ND } \\
\text { ND } \\
\text { ND }\end{array}$ & $\begin{array}{l}\text { ND } \\
N D \\
N D \\
N D\end{array}$ \\
\hline
\end{tabular}

ICEDF DF WorkSheet (page 3) 


\section{How to use "ICEDF DF WkSht 8/89"}

1) Open "ICEDF DF WkSht $8 / 89$ "

2) Enter test name and other constants.

3) Save As "ICEDF testname DF month/year".

4) Enter data on page 1 (change sample ID's if req'd)

WorkSheet Updates:

10/5/89: Added correction for $\Delta P$ upstream of critical orifice, changed sample ID No. listing.

10/5/89: Removed aerosol mass flow rate calculations for quad stations.

\begin{tabular}{|cc|}
\hline \multicolumn{2}{|c|}{ Critical Orifice Calib. } \\
\hline & \\
CO (\#) & Q(lpm) \\
\hline 50 & 27.2 \\
53 & 19.8 \\
55 & 15.2 \\
58 & 9.14 \\
65 & 6.97 \\
69 & 5.03 \\
74 & 2.47 \\
77 & 1.45 \\
80 & 1.03 \\
\hline
\end{tabular}


Test 5.9

SMF I $=0.872$
GasFlow $=0.396 \quad\left(\mathrm{~m}^{\wedge} 3 / \mathrm{s} @\right.$ To $)$

QA Check: \begin{tabular}{cc|} 
MwL \\
Name
\end{tabular} $\begin{gathered}7 / 29 / 91 \\
\text { Date }\end{gathered}$

Test Compound $=$ Chemical Analyzed $=$ ChemFrac $(1-100 \%)=$

\begin{tabular}{l}
$=\mathrm{KCl}$ \\
$=\mathrm{Cl}$ \\
\hline 47.6 \\
\hline
\end{tabular}

\begin{tabular}{|c|c|c|c|c|c|c|c|c|}
\hline $\begin{array}{l}\text { Sample } \\
\text { ID No. }\end{array}$ & $\begin{array}{c}\text { Test Time } \\
\text { (min) }\end{array}$ & $\begin{array}{c}\Delta t \\
(\min )\end{array}$ & $\begin{array}{l}\text { Temp. } \\
\left({ }^{\circ} \mathrm{C}\right) .\end{array}$ & $\begin{array}{c}\text { Critical } \\
\text { Orifice } \\
(\#) \\
\end{array}$ & $\begin{array}{c}\mathrm{CO} \\
\Delta \mathrm{P} \\
\text { (in. }-\mathrm{Hg} \text { ) } \\
\end{array}$ & $\begin{array}{l}\text { SMF } \\
(-)\end{array}$ & $\begin{array}{c}\text { Gravimetric } \\
\Delta \mathrm{M}(\mathrm{mg})\end{array}$ & $\begin{array}{c}\mathrm{Cl} \\
\text { Chemical } \\
\Delta \mathrm{M}(\mathrm{mg})\end{array}$ \\
\hline $\begin{array}{l}\text { F6A-1 } \\
\text { F6A-2 } \\
\text { F6A-3 }\end{array}$ & $\begin{array}{c}8.5 \\
16.5\end{array}$ & $\begin{array}{l}3.00 \\
3.00\end{array}$ & $\begin{array}{l}106 \\
101\end{array}$ & $\begin{array}{l}77 \\
77\end{array}$ & $\begin{array}{l}4.4 \\
3.5\end{array}$ & $\begin{array}{l}0.867 \\
0.873\end{array}$ & & $\begin{array}{l}0.100 \\
0.530\end{array}$ \\
\hline F6A-4 & 32.5 & 3.00 & 104 & 77 & 3.9 & 0.871 & & 0.330 \\
\hline $\begin{array}{l}F 0-1 \\
F 0-2 \\
F 0-3 \\
F 0-4\end{array}$ & $\begin{array}{c}8.5 \\
16.8 \\
25.2 \\
32.5\end{array}$ & $\begin{array}{l}3.00 \\
3.00 \\
3.00 \\
3.00\end{array}$ & $\begin{array}{c}2 \\
8 \\
15 \\
29\end{array}$ & $\begin{array}{l}58 \\
58 \\
58 \\
58\end{array}$ & $\begin{array}{c}8.0 \\
7.0 \\
12.0 \\
5.0\end{array}$ & $\begin{array}{l}0.000 \\
0.011 \\
0.016 \\
0.039\end{array}$ & & $\begin{array}{l}0.030 \\
0.150 \\
0.022 \\
0.028\end{array}$ \\
\hline $\begin{array}{c}\text { Fo/5-1 } \\
\text { ACl } 6 A-1 \\
\text { ACl } 0-1\end{array}$ & $\begin{array}{l}16.8 \\
25.3 \\
25.2\end{array}$ & $\begin{array}{l}3.00 \\
3.00 \\
3.00\end{array}$ & $\begin{array}{c}8 \\
100 \\
15\end{array}$ & $\begin{array}{l}55 \\
77 \\
55\end{array}$ & $\begin{array}{l}3.5 \\
1.9 \\
3.7\end{array}$ & $\begin{array}{l}0.011 \\
0.877 \\
0.016\end{array}$ & & $\begin{array}{l}0.078 \\
0.858 \\
0.022\end{array}$ \\
\hline $\begin{array}{l}A C I \text { 5A-1 } \\
A C I 5 A-2\end{array}$ & $\begin{array}{l}24.8 \\
24.8\end{array}$ & $\begin{array}{l}3.00 \\
3.00\end{array}$ & $\begin{array}{l}60 \\
52\end{array}$ & $\begin{array}{l}65 \\
65\end{array}$ & $\begin{array}{l}2.5 \\
2.0\end{array}$ & $\begin{array}{l}0.124 \\
0.135\end{array}$ & & \\
\hline $\begin{array}{l}\text { F5A1-2 } \\
\text { F5A2-2 } \\
\text { F5A3-2 } \\
\text { F5A4-2 }\end{array}$ & $\begin{array}{l}16.5 \\
16.5 \\
16.5 \\
16.5\end{array}$ & $\begin{array}{l}3.00 \\
3.00 \\
3.00 \\
3.00\end{array}$ & $\begin{array}{l}45 \\
70 \\
32 \\
62\end{array}$ & $\begin{array}{l}65 \\
65 \\
65 \\
65\end{array}$ & $\begin{array}{l}2.5 \\
2.9\end{array}$ & $\begin{array}{l}0.044 \\
0.306 \\
0.004 \\
0.216\end{array}$ & & $\begin{array}{l}0.044 \\
0.182 \\
0.038 \\
0.214\end{array}$ \\
\hline $\begin{array}{l}\text { F5A1-3 } \\
\text { F5A2-3 } \\
\text { F5A3-3 } \\
\text { F5A4-3 }\end{array}$ & $\begin{array}{l}24.5 \\
24.5\end{array}$ & $\begin{array}{l}3.00 \\
3.00\end{array}$ & $\begin{array}{l}50 \\
52\end{array}$ & $\begin{array}{l}65 \\
65\end{array}$ & $\begin{array}{l}1.0 \\
1.0\end{array}$ & $\begin{array}{l}0.083 \\
0.135\end{array}$ & & $\begin{array}{l}0.056 \\
0.086\end{array}$ \\
\hline $\begin{array}{l}\text { F5A1-4 } \\
\text { F5A2-4 } \\
\text { F5A3-4 } \\
\text { F5A4-4 }\end{array}$ & $\begin{array}{l}32.5 \\
32.5 \\
32.5 \\
32.5\end{array}$ & $\begin{array}{l}3.00 \\
3.00 \\
3.00 \\
3.00\end{array}$ & $\begin{array}{l}65 \\
65 \\
48 \\
55\end{array}$ & $\begin{array}{l}65 \\
65 \\
65 \\
65\end{array}$ & $\begin{array}{l}2.9 \\
2.9 \\
0.3 \\
0.7\end{array}$ & $\begin{array}{l}0.190 \\
0.247 \\
0.110 \\
0.156\end{array}$ & & $\begin{array}{l}0.124 \\
0.158 \\
0.106 \\
0.270\end{array}$ \\
\hline $\begin{array}{l}\text { F1A1-2 } \\
\text { F1A2-2 } \\
\text { F1A3-2 } \\
\text { F1A4-2 }\end{array}$ & $\begin{array}{l}16.5 \\
16.5 \\
16.5 \\
16.5\end{array}$ & $\begin{array}{l}3.00 \\
3.00 \\
3.00 \\
3.00\end{array}$ & $\begin{array}{c}5 \\
1 \\
5 \\
34\end{array}$ & $\begin{array}{l}58 \\
58 \\
58 \\
58\end{array}$ & $\begin{array}{c}4.4 \\
4.4 \\
10.0 \\
10.0\end{array}$ & $\begin{array}{l}0.010 \\
0.010 \\
0.010 \\
0.030\end{array}$ & & $\begin{array}{l}0.130 \\
0.028 \\
0.064 \\
0.023\end{array}$ \\
\hline $\begin{array}{l}\text { F1A1-3 } \\
\text { F1A2-3 } \\
\text { F1A3-3 } \\
\text { F1A4-3 }\end{array}$ & $\begin{array}{l}25.5 \\
25.5 \\
25.5 \\
25.5\end{array}$ & $\begin{array}{l}3.00 \\
3.00 \\
3.00 \\
3.00\end{array}$ & $\begin{array}{l}15 \\
30 \\
15 \\
38\end{array}$ & $\begin{array}{l}58 \\
58 \\
58 \\
58\end{array}$ & $\begin{array}{l}12.0 \\
12.0 \\
10.0 \\
10.0\end{array}$ & $\begin{array}{l}0.016 \\
0.042 \\
0.016 \\
0.066\end{array}$ & & $\begin{array}{l}0.036 \\
0.026 \\
0.090 \\
0.040\end{array}$ \\
\hline $\begin{array}{l}\text { F1A1-4 } \\
\text { F1A2-4 } \\
\text { F1A3-4 } \\
\text { F1A4-4 }\end{array}$ & $\begin{array}{l}32.6 \\
32.6 \\
32.6 \\
32.6 \\
\end{array}$ & $\begin{array}{l}3.00 \\
3.00 \\
3.00 \\
3.00\end{array}$ & $\begin{array}{l}25 \\
40 \\
15 \\
55\end{array}$ & $\begin{array}{l}58 \\
58 \\
58 \\
58\end{array}$ & $\begin{array}{c}12.0 \\
12.0 \\
10.0 \\
2.0 \\
\end{array}$ & $\begin{array}{l}0.031 \\
0.073 \\
0.016 \\
0.000 \\
\end{array}$ & & $\begin{array}{l}0.020 \\
0.114 \\
0.030 \\
0.022 \\
\end{array}$ \\
\hline
\end{tabular}

ICEDF DF WorkSheet (page 1)

E. 37 
Test $\quad 5-9$

\begin{tabular}{|c|c|c|c|c|c|c|c|c|}
\hline & Probe Loss & & Corrected & Crit. Orifice & Crit. Orifice & & ple Volun & \\
\hline $\begin{array}{l}\text { Sample } \\
\text { ID No. }\end{array}$ & $\begin{array}{l}\text { Correction } \\
\text { Factor } \\
(P L C f>1)\end{array}$ & $\begin{array}{c}\text { Corrected } \\
\text { Gravimetric } \\
\Delta \mathrm{M}(\mathrm{mg})\end{array}$ & $\begin{array}{c}\text { Compound } \\
\mathrm{KCl} \\
\Delta \mathrm{M}(\mathrm{mg}) \\
\end{array}$ & $\begin{array}{l}\text { Correction } \\
\text { Factor } \\
(\text { COcf }<1)\end{array}$ & $\begin{array}{c}\text { Flow Rate } \\
@ 20^{\circ} \mathrm{C} \\
(\text { lpm) }\end{array}$ & $\begin{array}{c}\text { Dry Gas } \\
@ 20^{\circ} \mathrm{C} \\
\text { (l) }\end{array}$ & $\begin{array}{c}\text { Dry Gas } \\
\text { @ To } \\
\text { (I) }\end{array}$ & $\begin{array}{l}\text { H2O } \\
\text { @ To } \\
\text { (1) }\end{array}$ \\
\hline $\begin{array}{l}\text { F6A-1 } \\
\text { F6A-2 } \\
\text { F6A-3 }\end{array}$ & & & $\begin{array}{l}0.21 \\
1.11\end{array}$ & $\begin{array}{l}0.92 \\
0.94\end{array}$ & $\begin{array}{l}1.34 \\
1.36\end{array}$ & $\begin{array}{l}4.02 \\
4.09\end{array}$ & $\begin{array}{l}5.20 \\
5.22\end{array}$ & $\begin{array}{l}33.88 \\
35.87\end{array}$ \\
\hline F6A-4 & & & 0.69 & 0.93 & 1.35 & 4.06 & 5.22 & 35.25 \\
\hline F0-1 & & & 0.06 & 0.86 & 7.83 & 23.48 & 22.04 & 0.00 \\
\hline F0-2 & & & 0.32 & 0.88 & 8.00 & 24.01 & 23.03 & 0.26 \\
\hline Fo-3 & & & 0.05 & 0.77 & 7.08 & 21.24 & 20.88 & 0.34 \\
\hline Fo-4 & & & 0.06 & 0.91 & 8.34 & 25.03 & 25.80 & 1.05 \\
\hline F0/5-1 & & & 0.16 & 0.94 & 14.29 & 42.86 & 41.10 & 0.46 \\
\hline$A C I 6 A-1$ & & & 1.80 & 0.97 & 1.40 & 4.21 & 5.36 & 38.21 \\
\hline ACI 0-1 & & & 0.05 & 0.94 & 14.23 & 42.70 & 41.97 & 0.68 \\
\hline ACI 5A-1 & & & & 0.96 & 6.67 & 20.02 & 22.75 & 3.22 \\
\hline $\mathrm{ACl} 5 \mathrm{~A}-2$ & & & & 0.97 & 6.73 & 20.20 & 22.41 & 3.50 \\
\hline F5A1-2 & & & 0.09 & 0.96 & 6.67 & 20.02 & 21.73 & 1.00 \\
\hline F5A2-2 & & & 0.38 & 0.95 & 6.62 & 19.87 & 23.27 & 10.26 \\
\hline F5A3-2 & & & 0.08 & & 6.97 & 20.91 & 21.77 & 0.09 \\
\hline F5A4-2 & & & 0.45 & & 6.97 & 20.91 & 23.91 & 6.59 \\
\hline F5A1-3 & & & & & & & & \\
\hline $\begin{array}{l}\text { F5A2-3 } \\
\text { F5A3-3 }\end{array}$ & & & 0.12 & 098 & 6.85 & 20.56 & 22.66 & 205 \\
\hline F5A4-3 & & & 0.18 & 0.98 & 6.85 & 20.56 & 22.80 & 3.56 \\
\hline F5A1-4 & & & 0.26 & 0.95 & 6.62 & 19.87 & 22.93 & 5.38 \\
\hline F5A2-4 & & & 0.33 & 0.95 & 6.62 & 19.87 & 22.93 & 7.52 \\
\hline F5A3-4 & & & 0.22 & 0.99 & 6.94 & 20.81 & 22.79 & 2.82 \\
\hline F5A4-4 & & & 0.57 & 0.99 & 6.89 & 20.66 & 23.13 & 4.28 \\
\hline F1A1-2 & & & 0.27 & 0.92 & 8.44 & 25.33 & 24.03 & 0.24 \\
\hline F1A2-2 & & & 0.06 & 0.92 & 8.44 & 25.33 & 23.69 & 0.24 \\
\hline F1A3-2 & & & 0.13 & 0.82 & 7.46 & 22.39 & 21.24 & 0.21 \\
\hline F1A4-2 & & & 0.05 & 0.82 & 7.46 & 22.39 & 23.46 & 0.73 \\
\hline F1A1-3 & & & 0.08 & 0.77 & 7.08 & 21.24 & 20.88 & 0.34 \\
\hline F1A2-3 & & & 0.05 & 0.77 & 7.08 & 21.24 & 21.96 & 0.96 \\
\hline F1A3-3 & & & 0.19 & 0.82 & 7.46 & 22.39 & 22.01 & 0.36 \\
\hline F1A4-3 & & & 0.08 & 0.82 & 7.46 & 22.39 & 23.76 & 1.68 \\
\hline F1A1-4 & & & 0.04 & 0.77 & 7.08 & 21.24 & 21.60 & 0.69 \\
\hline F1A2-4 & & & 0.24 & 0.77 & 7.08 & 21.24 & 22.69 & 1.79 \\
\hline F1A3-4 & & & 0.06 & 0.82 & 7.46 & 22.39 & 22.01 & 0.36 \\
\hline F1A4-4 & & & 0.05 & 0.97 & 8.83 & 26.49 & 29.65 & 0.00 \\
\hline
\end{tabular}

ICEDF DF WorkSheet (page 2)

E.38 


\begin{tabular}{|c|c|c|c|c|c|c|c|}
\hline & $\bar{\Sigma}$ Sample & & Mass & & & $\mathrm{KCl}$ & \\
\hline $\begin{array}{c}\text { Sample } \\
\text { ID No. }\end{array}$ & $\begin{array}{c}\text { Volume } \\
\text { @ To } \\
\text { (I) }\end{array}$ & $\begin{array}{c}\mathrm{Cm} \\
@ \mathrm{To} \\
\left(\mathrm{mg} / \mathrm{m}^{\wedge} 3\right)\end{array}$ & $\begin{array}{c}\text { Mass Flow } \\
@ \text { To } \\
(\mathrm{mg} / \mathrm{s}) \\
\end{array}$ & $\begin{array}{c}\text { Approx. } \\
\text { Feed Rate } \\
\text { (g/min) }\end{array}$ & $\begin{array}{c}\mathrm{Cm} \\
@ \mathrm{To} \\
\left(\mathrm{mg} / \mathrm{m}^{\wedge} 3\right)\end{array}$ & $\begin{array}{c}\text { Mass Flow } \\
\text { @ To } \\
\text { (mg/s) } \\
\end{array}$ & $\begin{array}{c}\text { Approx. } \\
\text { Feed Rate } \\
\text { (g/min) }\end{array}$ \\
\hline $\begin{array}{l}\text { F6A-1 } \\
\text { F6A-2 } \\
\text { F6A-3 } \\
\text { F6A-4 }\end{array}$ & $\begin{array}{l}39.08 \\
41.09 \\
40.47\end{array}$ & & & & $\begin{array}{c}5.38 \\
27.10 \\
\\
17.13\end{array}$ & $\begin{array}{c}2.14 \\
10.71 \\
\\
6.81\end{array}$ & $\begin{array}{l}0.13 \\
0.64 \\
0.41\end{array}$ \\
\hline $\begin{array}{l}\text { F0-1 } \\
\text { FO-2 } \\
\text { F0-3 } \\
\text { FO-4 }\end{array}$ & $\begin{array}{l}22.04 \\
23.28 \\
21.22 \\
26.85\end{array}$ & & & & $\begin{array}{c}2.86 \\
13.54 \\
2.18 \\
2.19\end{array}$ & $\begin{array}{l}0.11 \\
0.56 \\
0.10 \\
0.12\end{array}$ & $\begin{array}{l}0.01 \\
0.03 \\
0.01 \\
0.01\end{array}$ \\
\hline $\begin{array}{c}\text { FO/5-1 } \\
\text { ACl 6A-1 } \\
\text { ACl 0-1 }\end{array}$ & $\begin{array}{l}41.56 \\
43.57 \\
42.65\end{array}$ & & & & $\begin{array}{c}3.94 \\
41.37 \\
1.08\end{array}$ & $\begin{array}{c}0.16 \\
16.38 \\
0.047\end{array}$ & $\begin{array}{l}0.01 \\
0.98 \\
0.00\end{array}$ \\
\hline $\begin{array}{l}A C I \text { 5A-1 } \\
A C I 5 A-2\end{array}$ & $\begin{array}{l}25.97 \\
25.90\end{array}$ & & & & & $\begin{array}{l}\text { ND } \\
\text { ND }\end{array}$ & $\begin{array}{l}\text { ND } \\
\text { ND }\end{array}$ \\
\hline $\begin{array}{l}\text { F5A1-2 } \\
\text { F5A2-2 } \\
\text { F5A3-2 } \\
\text { F5A4-2 }\end{array}$ & $\begin{array}{l}22.73 \\
33.52 \\
21.85 \\
30.49\end{array}$ & & & & $\begin{array}{c}4.07 \\
11.41 \\
3.65 \\
14.74\end{array}$ & $\begin{array}{l}\text { ND } \\
\text { ND } \\
\text { ND } \\
\text { ND }\end{array}$ & $\begin{array}{l}\text { ND } \\
\text { ND } \\
\text { ND } \\
\text { ND }\end{array}$ \\
\hline $\begin{array}{l}\text { F5A1-3 } \\
\text { F5A2-3 } \\
\text { F5A3-3 } \\
\text { F5A4-3 }\end{array}$ & $\begin{array}{l}24.71 \\
26.36\end{array}$ & & & & $\begin{array}{l}4.76 \\
6.85\end{array}$ & $\begin{array}{l}\text { ND } \\
\text { ND }\end{array}$ & $\begin{array}{l}\text { ND } \\
\text { ND }\end{array}$ \\
\hline $\begin{array}{l}\text { F5A1-4 } \\
\text { F5A2-4 } \\
\text { F5A3-4 } \\
\text { F5A4-4 }\end{array}$ & $\begin{array}{l}28.30 \\
30.45 \\
25.61 \\
27.41\end{array}$ & & & & $\begin{array}{c}9.20 \\
10.90 \\
8.70 \\
20.70\end{array}$ & $\begin{array}{l}\text { ND } \\
\text { ND } \\
\text { ND } \\
\text { ND }\end{array}$ & $\begin{array}{l}\text { ND } \\
\text { ND } \\
\text { ND } \\
\text { ND }\end{array}$ \\
\hline $\begin{array}{l}\text { F1A1-2 } \\
\text { F1A2-2 } \\
\text { F1A3-2 } \\
\text { F1A4-2 }\end{array}$ & $\begin{array}{l}24.28 \\
23.93 \\
21.46 \\
24.18\end{array}$ & & & & $\begin{array}{l}11.25 \\
2.46 \\
6.27 \\
2.00\end{array}$ & $\begin{array}{l}N D \\
N D \\
N D \\
N D\end{array}$ & $\begin{array}{l}N D \\
N D \\
N D \\
N D\end{array}$ \\
\hline $\begin{array}{l}\text { F1A1-3 } \\
\text { F1A2-3 } \\
\text { F1A3-3 } \\
\text { F1A4-3 }\end{array}$ & $\begin{array}{l}21.22 \\
22.93 \\
22.36 \\
25.44\end{array}$ & & & & $\begin{array}{l}3.56 \\
2.38 \\
8.45 \\
3.30\end{array}$ & $\begin{array}{l}\text { ND } \\
\text { ND } \\
\text { ND } \\
\text { ND }\end{array}$ & $\begin{array}{l}\text { ND } \\
\text { ND } \\
\text { ND } \\
\text { ND }\end{array}$ \\
\hline $\begin{array}{l}\text { F1A1-4 } \\
\text { F1A2-4 } \\
\text { F1A3-4 } \\
\text { F1A4-4 }\end{array}$ & $\begin{array}{l}22.29 \\
24.48 \\
22.36 \\
29.66\end{array}$ & & & & $\begin{array}{l}1.88 \\
9.78 \\
2.82 \\
1.56 \\
\end{array}$ & $\begin{array}{l}\text { ND } \\
\text { ND } \\
\text { ND } \\
\text { ND } \\
\end{array}$ & $\begin{array}{l}\text { ND } \\
\text { ND } \\
\text { ND } \\
\text { ND } \\
\end{array}$ \\
\hline
\end{tabular}




\section{How to use "ICEDF DF WkSht B/89"}

1) Open "ICEDF DF WkSht 8/89"

2) Enter test name and other constants.

3) Save As "ICEDF testname DF month/year".

4) Enter data on page 1 (change sample ID's if req'd)

WorkSheet Updates:

10/5/89: Added correction for $\triangle \mathrm{P}$ upstream of critical orifice, changed sample ID No. listing. 10/5/89: Removed aerosol mass flow rate calculations for quad stations.

\begin{tabular}{|cc|}
\hline \multicolumn{2}{|c|}{ Critical Orifice Calib. } \\
\hline & \\
CO (\#) & Q (lpm) \\
\hline 50 & 27.2 \\
53 & 19.8 \\
55 & 15.2 \\
58 & 9.14 \\
65 & 6.97 \\
69 & 5.03 \\
74 & 2.47 \\
77 & 1.45 \\
80 & 1.03 \\
\hline
\end{tabular}




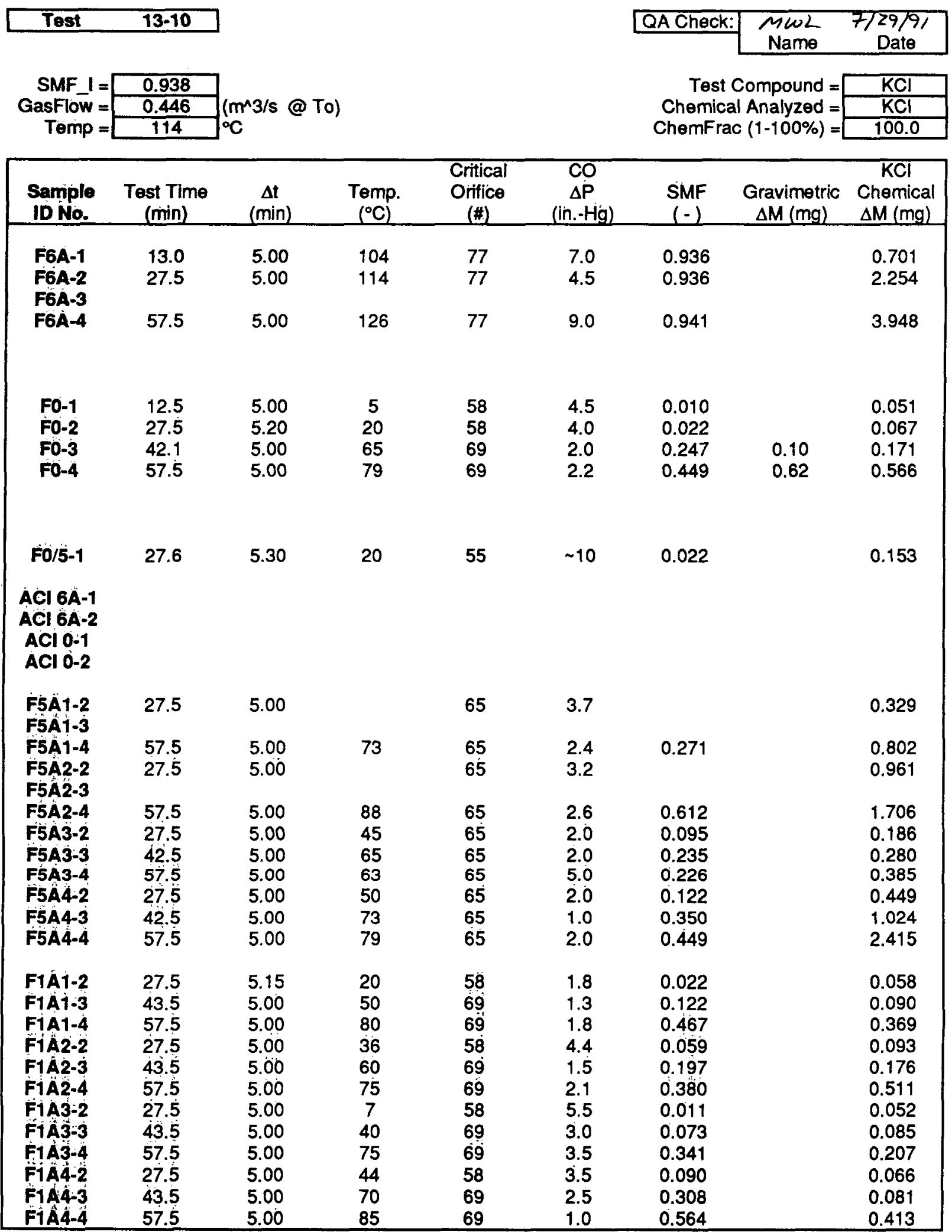




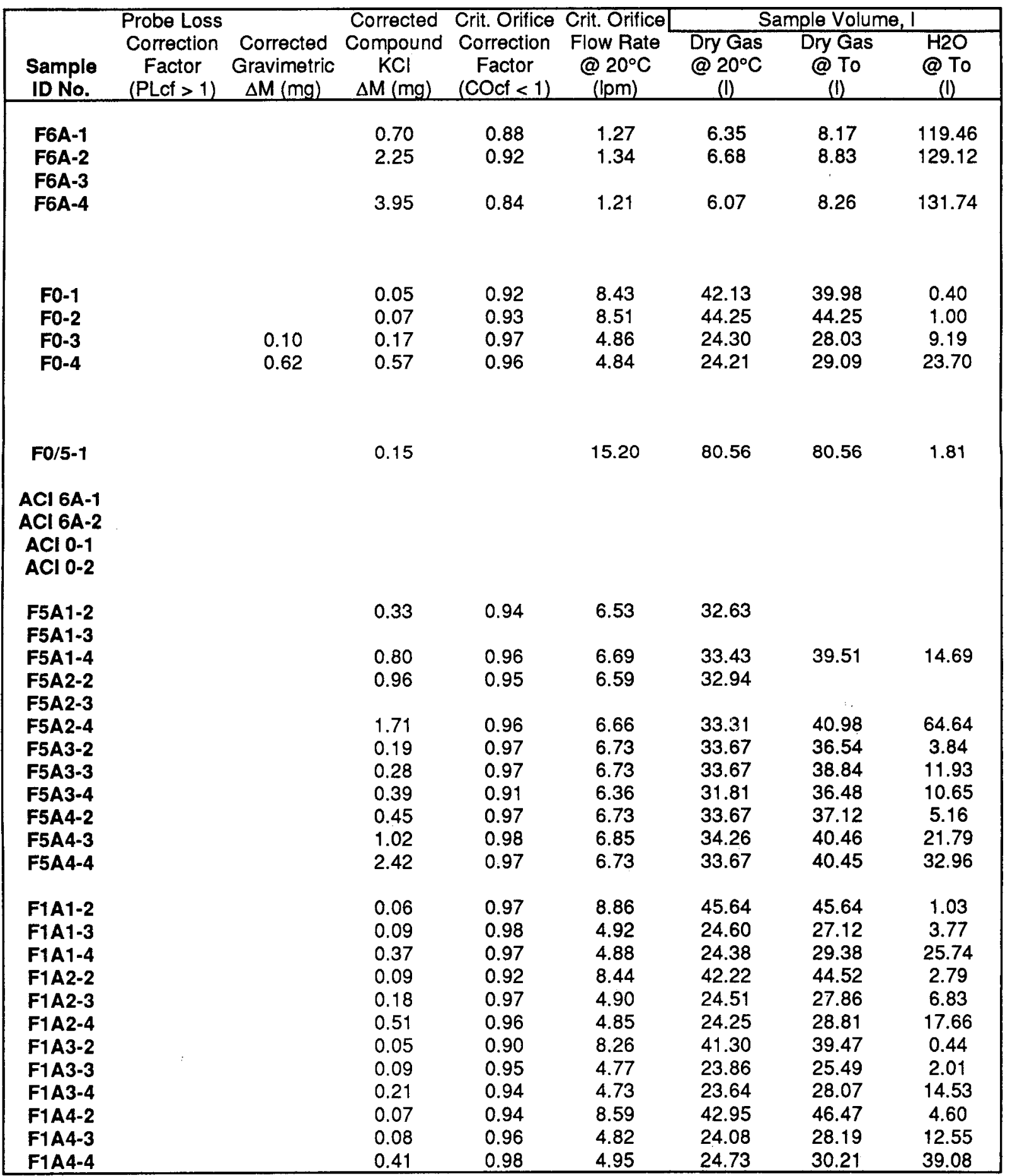

ICEDF DF WorkSheet (page 2)

$$
\text { E. } 42
$$




\begin{tabular}{|c|c|c|c|c|c|c|c|}
\hline & $\overline{\Sigma S \text { Sample }}$ & & Mass & & & $\mathrm{KCl}$ & \\
\hline $\begin{array}{l}\text { Sample } \\
\text { ID No. }\end{array}$ & $\begin{array}{l}\text { Volume } \\
\text { @ To } \\
\text { (1) }\end{array}$ & $\begin{array}{c}\mathrm{Cm} \\
@ \mathrm{To} \\
\left(\mathrm{mg} / \mathrm{m}^{\wedge} 3\right)\end{array}$ & $\begin{array}{c}\text { Mass Flow } \\
@ \text { To } \\
\text { (mg/s) }\end{array}$ & $\begin{array}{c}\text { Approx. } \\
\text { Feed Rate } \\
\text { (g/min) }\end{array}$ & $\begin{array}{c}\mathrm{Cm} \\
\text { @ To } \\
\left(\mathrm{mg} / \mathrm{m}^{\wedge} 3\right)\end{array}$ & $\begin{array}{c}\text { Mass Flow } \\
@ \text { To } \\
\text { (mg/s) } \\
\end{array}$ & $\begin{array}{c}\text { Approx. } \\
\text { Feed Rate } \\
\text { (g/min) }\end{array}$ \\
\hline $\begin{array}{l}\text { F6A-1 } \\
\text { F6A-2 } \\
\text { F6A-3 } \\
\text { F6A-4 }\end{array}$ & $\begin{array}{l}127.62 \\
137.95 \\
140.00\end{array}$ & & & & $\begin{array}{c}5.49 \\
16.34 \\
28.20\end{array}$ & $\begin{array}{r}2.38 \\
7.27 \\
13.01\end{array}$ & $\begin{array}{l}0.14 \\
0.44\end{array}$ \\
\hline $\begin{array}{l}\text { F0-1 } \\
\text { F0-2 } \\
\text { F0-3 } \\
\text { F0-4 }\end{array}$ & $\begin{array}{l}40.38 \\
45.24 \\
37.22 \\
52.79\end{array}$ & $\begin{array}{c}2.69 \\
11.75\end{array}$ & $\begin{array}{l}0.32 \\
2.43\end{array}$ & $\begin{array}{l}0.02 \\
0.15\end{array}$ & $\begin{array}{c}1.26 \\
1.48 \\
4.59 \\
10.72\end{array}$ & $\begin{array}{l}0.029 \\
0.042 \\
0.553 \\
2.223\end{array}$ & $\begin{array}{l}0.00 \\
0.00 \\
0.03 \\
0.13\end{array}$ \\
\hline $\begin{array}{c}\text { Fo/5-1 } \\
\text { ACI 6A-1 } \\
\text { ACI 6A-2 } \\
\text { ACI 0-1 } \\
\text { ACI 0-2 }\end{array}$ & 82.37 & & & & 1.86 & 0.053 & 0.00 \\
\hline $\begin{array}{l}\text { F5A1-2 } \\
\text { F5A1-3 } \\
\text { F5A1-4 } \\
\text { F5A2-2 } \\
\text { F5A2-3 } \\
\text { F5A2-4 } \\
\text { F5A3-2 } \\
\text { F5A3-3 } \\
\text { F5A3-4 } \\
\text { F5A4-2 } \\
\text { F5A4-3 } \\
\text { F5A4-4 }\end{array}$ & $\begin{array}{c}54.19 \\
\\
105.61 \\
40.38 \\
50.77 \\
47.13 \\
42.27 \\
62.25 \\
73.41\end{array}$ & & $\begin{array}{l}N D \\
N \\
N \\
N D \\
N D \\
N D \\
N D \\
N D \\
N D \\
N D \\
N D \\
N D \\
N D \\
N \\
D\end{array}$ & $\begin{array}{l}N D \\
N D \\
N D \\
N D \\
N D \\
N D \\
N D \\
N D \\
N D \\
N D \\
N D \\
N D\end{array}$ & $\begin{array}{c}\text { Flow? } \\
\\
14.80 \\
\text { Flow? } \\
16.15 \\
4.61 \\
5.52 \\
8.17 \\
10.62 \\
16.45 \\
32.90\end{array}$ & $\begin{array}{l}N D \\
N D \\
N D \\
N D \\
N D \\
N D \\
N D \\
N D \\
N D \\
N D \\
N D \\
N D\end{array}$ & 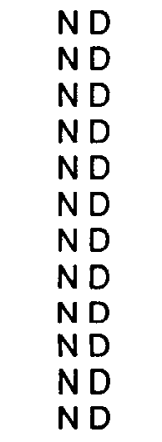 \\
\hline $\begin{array}{l}\text { F1A1-2 } \\
\text { F1A1-3 } \\
\text { F1A1-4 } \\
\text { F1A2-2 } \\
\text { F1A2-3 } \\
\text { F1A2-4 } \\
\text { F1A3-2 } \\
\text { F1A3-3 } \\
\text { F1A3-4 } \\
\text { F1A4-2 } \\
\text { F1A4-3 } \\
\text { F1A4-4 }\end{array}$ & $\begin{array}{l}46.66 \\
30.89 \\
55.12 \\
47.31 \\
34.69 \\
46.46 \\
39.91 \\
27.50 \\
42.60 \\
51.07 \\
40.73 \\
69.30\end{array}$ & & 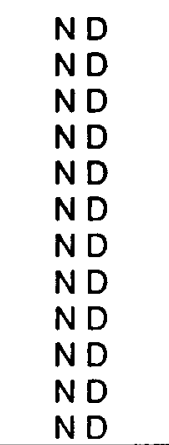 & 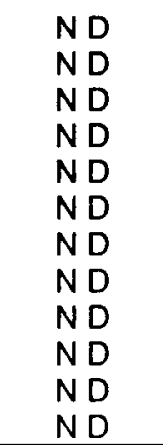 & $\begin{array}{c}1.24 \\
2.91 \\
6.69 \\
1.97 \\
5.07 \\
11.00 \\
1.30 \\
3.09 \\
4.86 \\
1.29 \\
1.99 \\
5.96\end{array}$ & $\begin{array}{l}N D \\
N D \\
N D \\
N D \\
N D \\
N D \\
N D \\
N D \\
N D \\
N D \\
N D \\
N D\end{array}$ & 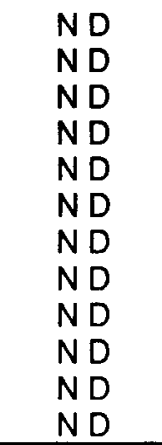 \\
\hline
\end{tabular}




\section{How to use "ICEDF DF WkSht 8/89"}

1) Open "ICEDF DF WkSht 8/89"

2) Enter test name and other constants.

3) Save As "ICEDF testname DF month/year".

4) Enter data on page 1 (change sample ID's if req'd)

\section{WorkSheet Updates:}

10/5/89: Added correction for $\triangle \mathrm{P}$ upstream of critical orifice, changed sample ID No. listing. 10/5/89: Removed aerosol mass flow rate calculations for quad stations.

\begin{tabular}{|cc|}
\hline Critical Orifice Calib. \\
\hline & \\
& \\
\hline (\#) & Q (lpm) \\
\hline 50 & 27.2 \\
53 & 19.8 \\
55 & 15.2 \\
58 & 9.14 \\
65 & 6.97 \\
69 & 5.03 \\
74 & 2.47 \\
77 & 1.45 \\
80 & 1.03 \\
\hline
\end{tabular}




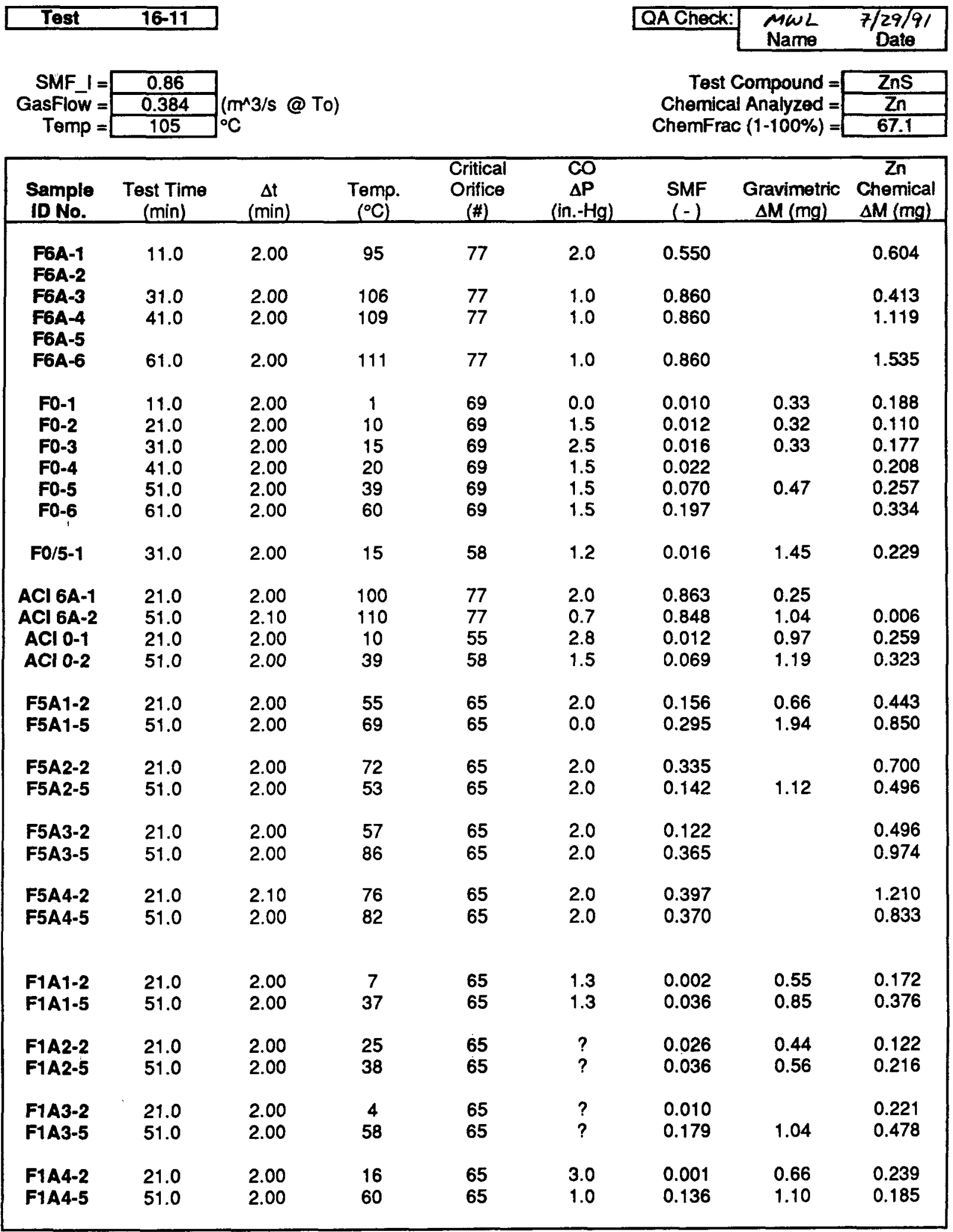

ICEDF DF WorkSheet (page 1) 


\begin{tabular}{|c|c|c|c|c|c|c|c|c|}
\hline $\begin{array}{l}\text { Sample } \\
\text { ID No. }\end{array}$ & $\begin{array}{l}\text { Probe Loss } \\
\text { Correction } \\
\text { Factor } \\
(\text { PLcf }>1) \\
\end{array}$ & $\begin{array}{l}\text { Corrected } \\
\text { Gravimetric } \\
\Delta \mathrm{M}(\mathrm{mg})\end{array}$ & $\begin{array}{c}\text { Corrected } \\
\text { Compound } \\
\text { ZnS } \\
\Delta \mathrm{M}(\mathrm{mg}) \\
\end{array}$ & $\begin{array}{l}\text { Crit. Orifice } \\
\text { Correction } \\
\text { Factor } \\
(\text { COcf }<1) \\
\end{array}$ & $\begin{array}{l}\text { Crit. Orifice } \\
\text { Flow Rate } \\
@ 20^{\circ} \mathrm{C} \\
\text { (lpm) }\end{array}$ & $\begin{array}{c}\text { S } \\
\text { Dry Gas } \\
@ 20^{\circ} \mathrm{C} \\
\text { (1) }\end{array}$ & $\begin{array}{c}\text { pple Volun } \\
\text { Dry Gas } \\
@ \text { To } \\
\text { (I) }\end{array}$ & $\begin{array}{c}\mathrm{H} 2 \mathrm{O} \\
\text { @ To } \\
(1)\end{array}$ \\
\hline $\begin{array}{l}\text { F6A-1 } \\
\text { F6A-2 }\end{array}$ & & & 0.90 & 0.97 & 1.40 & 2.80 & 3.52 & 4.30 \\
\hline F6A-3 & & & 0.62 & 0.98 & 1.43 & 2.85 & 3.69 & 22.66 \\
\hline $\begin{array}{l}\text { F6A-4 } \\
\text { F6A-5 }\end{array}$ & & & 1.67 & 0.98 & 1.43 & 2.85 & 3.72 & 22.84 \\
\hline F6A-6 & & & 2.29 & 0.98 & 1.43 & 2.85 & 3.74 & 22.95 \\
\hline F0-1 & & 0.33 & 0.28 & & 5.03 & 10.06 & 9.41 & 0.10 \\
\hline F0-2 & & 0.32 & 0.16 & 0.97 & 4.90 & 9.81 & 9.47 & 0.12 \\
\hline Fo-3 & & 0.33 & 0.26 & 0.96 & 4.82 & 9.63 & 9.47 & 0.15 \\
\hline F0-4 & & & 0.31 & 0.97 & 4.90 & 9.81 & 9.81 & 0.22 \\
\hline F0-5 & & 0.47 & 0.38 & 0.97 & 4.90 & 9.81 & 10.44 & 0.79 \\
\hline F0-6 & & & 0.50 & 0.97 & 4.90 & 9.81 & 11.14 & 2.73 \\
\hline F0/5-1 & & 1.45 & 0.34 & 0.98 & 8.96 & 17.91 & 17.61 & 0.29 \\
\hline$A C I 6 A-1$ & & 0.25 & & 0.97 & 1.40 & 2.80 & 3.57 & 22.47 \\
\hline ACl 6A-2 & & 1.04 & 0.01 & 0.99 & 1.43 & 3.01 & 3.93 & 21.95 \\
\hline $\mathrm{ACl} 0-1$ & & 0.97 & 0.39 & 0.95 & 14.47 & 28.95 & 27.96 & 0.34 \\
\hline ACl $0-2$ & & 1.19 & 0.48 & 0.97 & 8.91 & 17.82 & 18.97 & 1.41 \\
\hline F5A1-2 & & 0.66 & 0.66 & 0.97 & 6.68 & 13.35 & 14.95 & 2.76 \\
\hline F5A1-5 & & 1.94 & 1.27 & & 6.91 & 13.82 & 16.13 & 6.75 \\
\hline F5A2-2 & & & 1.04 & 0.97 & 6.68 & 13.35 & 15.72 & 7.92 \\
\hline F5A2-5 & & 1.12 & 0.74 & 0.97 & 6.68 & 13.35 & 14.86 & 2.46 \\
\hline F5A3-2 & & & 0.74 & 0.97 & 6.68 & 13.35 & 15.04 & 2.09 \\
\hline F5A3-5 & & & 1.45 & 0.97 & 6.68 & 13.35 & 16.36 & 9.40 \\
\hline F5A4-2 & & & 1.80 & 0.97 & 6.68 & 14.02 & 16.70 & 10.99 \\
\hline F5A4-5 & & & 1.24 & 0.97 & 6.68 & 13.35 & 16.18 & 9.50 \\
\hline F1A1-2 & & 0.55 & 0.26 & 0.98 & 6.76 & 13.52 & 12.92 & 0.03 \\
\hline F1A1-5 & & 0.85 & 0.56 & 0.98 & 6.76 & 13.52 & 14.30 & 0.53 \\
\hline F1A2-2 & & 0.44 & 0.18 & & 6.91 & 13.82 & 14.06 & 0.38 \\
\hline F1A2-5 & & 0.56 & 0.32 & & 6.91 & 13.82 & 14.67 & 0.55 \\
\hline F1A3-2 & & & 0.33 & & 6.91 & 13.82 & 13.07 & 0.13 \\
\hline F1A3-5 & & 1.04 & 0.71 & & 6.91 & 13.82 & 15.61 & 3.40 \\
\hline F1A4-2 & & 0.66 & 0.36 & 0.95 & 6.56 & 13.11 & 12.93 & 0.01 \\
\hline F1A4-5 & & 1.10 & 0.28 & 0.98 & 6.79 & 13.59 & 15.44 & 2.43 \\
\hline
\end{tabular}

ICEDF DF WorkSheet (page 2) 


\begin{tabular}{|c|c|c|c|c|c|c|c|}
\hline & ¿ Sample & & Mass & & & Znis & \\
\hline $\begin{array}{l}\text { Sample } \\
\text { ID No. }\end{array}$ & $\begin{array}{c}\text { Volume } \\
\text { @ To } \\
\text { (I) }\end{array}$ & $\begin{array}{c}\mathrm{cm} \\
@ \mathrm{To} \\
\left(\mathrm{mg} / \mathrm{m}^{\wedge} 3\right)\end{array}$ & $\begin{array}{c}\text { Mass Flow } \\
\text { @ To } \\
\text { (mg/s) }\end{array}$ & $\begin{array}{c}\text { Approx. } \\
\text { Feed Rate } \\
\text { (g/min) }\end{array}$ & $\begin{array}{c}\mathrm{Cm} \\
@ \mathrm{To} \\
\left(\mathrm{mg} / \mathrm{m}^{\wedge} 3\right)\end{array}$ & $\begin{array}{c}\text { Mass Flow } \\
@ \text { To } \\
(\mathrm{mg} / \mathrm{s})\end{array}$ & $\begin{array}{c}\text { Approx. } \\
\text { Feed Rate } \\
\text { (g/min) }\end{array}$ \\
\hline $\begin{array}{l}\text { F6A-1 } \\
\text { F6A-2 }\end{array}$ & 7.82 & & & & 115.11 & 29.69 & 1.78 \\
\hline $\begin{array}{l}\text { F6A-3 } \\
\text { F6A-4 } \\
\text { F6A-5 }\end{array}$ & $\begin{array}{l}26.34 \\
26.55\end{array}$ & & & & $\begin{array}{l}23.36 \\
62.81\end{array}$ & $\begin{array}{c}9.00 \\
24.37\end{array}$ & $\begin{array}{l}0.54 \\
1.46\end{array}$ \\
\hline F6A-6 & 26.69 & & & & 85.71 & 33.43 & 2.01 \\
\hline F0-1 & 9.50 & 34.73 & 1.45 & 0.09 & 29.48 & 1.23 & 0.07 \\
\hline F0-2 & 9.59 & 33.38 & 1.46 & 0.09 & 17.10 & 0.75 & 0.04 \\
\hline F0-3 & 9.62 & 34.30 & 1.57 & 0.09 & 27.42 & 1.25 & 0.08 \\
\hline F0-4 & 10.03 & & & & 30.92 & 1.49 & 0.09 \\
\hline F0-5 & 11.23 & 41.86 & 2.79 & 0.17 & 34.12 & 2.27 & 0.14 \\
\hline F0-6 & 13.88 & & & & 35.87 & 4.09 & 0.25 \\
\hline F0/5-1 & 17.89 & 81.05 & 3.70 & 0.22 & 19.08 & 0.87 & 0.05 \\
\hline$A C l$ 6A-1 & 26.03 & 9.60 & 3.65 & 0.22 & & & \\
\hline $\mathrm{ACl} 6 \mathrm{~A}-2$ & 25.88 & 40.19 & 15.45 & 0.93 & 0.35 & 0.13 & 0.01 \\
\hline $\mathrm{ACl} 0-1$ & 28.30 & 34.28 & 1.50 & 0.09 & 13.64 & 0.60 & 0.04 \\
\hline ACl $0-2$ & 20.38 & 58.39 & 3.87 & 0.23 & 23.62 & 1.56 & 0.09 \\
\hline F5A1-2 & 17.71 & 37.27 & ND & ND & 37.28 & ND & ND \\
\hline F5A1-5 & 22.88 & 84.79 & ND & ND & 55.36 & ND & ND \\
\hline F5A2-2 & 23.64 & & ND & ND & 44.13 & ND & ND \\
\hline F5A2-5 & 17.31 & 64.69 & ND & ND & 42.69 & ND & ND \\
\hline $\begin{array}{l}\text { F5A3-2 } \\
\text { F5A3-5 }\end{array}$ & $\begin{array}{l}17.13 \\
25.76\end{array}$ & & $\begin{array}{l}\text { ND } \\
\text { ND }\end{array}$ & $\begin{array}{l}\text { ND } \\
\text { ND }\end{array}$ & $\begin{array}{l}43.16 \\
56.35\end{array}$ & $\begin{array}{l}\text { ND } \\
\text { ND }\end{array}$ & $\begin{array}{l}\text { ND } \\
\text { ND }\end{array}$ \\
\hline $\begin{array}{l}\text { F5A4-2 } \\
\text { F5A4-5 }\end{array}$ & $\begin{array}{l}27.69 \\
25.68\end{array}$ & & $\begin{array}{l}\text { ND } \\
\text { ND }\end{array}$ & $\begin{array}{l}\text { ND } \\
\text { ND }\end{array}$ & $\begin{array}{l}65.12 \\
48.35\end{array}$ & $\begin{array}{l}\text { ND } \\
\text { ND }\end{array}$ & $\begin{array}{l}\text { ND } \\
\text { ND }\end{array}$ \\
\hline $\begin{array}{l}\text { F1A1-2 } \\
\text { F1A1-5 }\end{array}$ & $\begin{array}{l}12.94 \\
14.84\end{array}$ & $\begin{array}{l}42.49 \\
57.29\end{array}$ & $\begin{array}{l}\text { ND } \\
\text { ND }\end{array}$ & $\begin{array}{l}\text { ND } \\
\text { ND }\end{array}$ & $\begin{array}{l}19.80 \\
37.77\end{array}$ & $\begin{array}{l}\text { ND } \\
\text { ND }\end{array}$ & $\begin{array}{l}\text { ND } \\
\text { ND }\end{array}$ \\
\hline F1A2-2 & 14.43 & 30.49 & ND & ND & 12.60 & ND & ND \\
\hline F1A2-5 & 15.22 & 36.80 & ND & & 21.15 & & \\
\hline $\begin{array}{l}\text { F1A3-2 } \\
\text { F1A3-5 }\end{array}$ & $\begin{array}{l}13.20 \\
19.02\end{array}$ & 54.69 & $\begin{array}{l}\text { ND } \\
\text { ND }\end{array}$ & $\begin{array}{l}\text { ND } \\
\text { ND }\end{array}$ & $\begin{array}{l}24.96 \\
37.46\end{array}$ & $\begin{array}{l}\text { ND } \\
\text { ND }\end{array}$ & $\begin{array}{l}\text { ND } \\
\text { ND }\end{array}$ \\
\hline $\begin{array}{l}\text { F1A4-2 } \\
\text { F1A4-5 }\end{array}$ & $\begin{array}{l}12.94 \\
17.87\end{array}$ & $\begin{array}{l}50.99 \\
61.54\end{array}$ & $\begin{array}{l}\text { ND } \\
\text { ND }\end{array}$ & $\begin{array}{l}\text { ND } \\
\text { ND }\end{array}$ & $\begin{array}{l}27.52 \\
15.43\end{array}$ & $\begin{array}{l}\text { ND } \\
\text { ND }\end{array}$ & $\begin{array}{l}\text { ND } \\
\text { ND }\end{array}$ \\
\hline
\end{tabular}




\section{How to use "ICEDF DF WkSht 8/89"}

1) Open "ICEDF DF WkSht 8/89"

2) Enter test name and other constants.

3) Save As "ICEDF testname DF month/year".

4) Enter data on page 1 (change sample ID's if req'd)

\section{WorkSheet Updates:}

10/5/89: Added correction for $\Delta P$ upstream of critical orifice, changed sample ID No. listing. 10/5/89: Removed aerosol mass flow rate calculations for quad stations.

\begin{tabular}{|cc|}
\hline \multicolumn{2}{|c|}{ Critical Orifice Calib. } \\
\hline & \\
CO (\#) & Q (lpm) \\
\hline 50 & 27.2 \\
53 & 19.8 \\
55 & 15.2 \\
58 & 9.14 \\
65 & 6.91 \\
69 & 5.03 \\
74 & 2.47 \\
77 & 1.45 \\
80 & 1.03 \\
\hline
\end{tabular}




\begin{tabular}{|c|c|c|c|c|c|c|c|c|}
\hline Test & $17-12$ & & & & & QA Check: & $\begin{array}{l}\text { MwL } \\
\text { Name }\end{array}$ & $\begin{array}{c}7 / 29 / 91 \\
\text { Date }\end{array}$ \\
\hline $\begin{array}{r}\text { SMF_I }= \\
\text { GasFlow }= \\
\text { Temp }=\end{array}$ & $\begin{array}{c}0.18 \\
0.079 \\
89 \\
\end{array}$ & $\begin{array}{l}\left(m^{\wedge} 3 / s @ T c\right. \\
{ }^{\circ} \mathrm{C}\end{array}$ & & & & $\begin{array}{r}\text { Test } C \\
\text { Chemical } \\
\text { ChemFrac }\end{array}$ & $\begin{array}{l}\text { Compound }= \\
\text { inalyzed }= \\
(1-100 \%)=\end{array}$ & $\begin{array}{c}\text { DOP\&FL } \\
\text { FI (dp) } \\
100.0\end{array}$ \\
\hline $\begin{array}{l}\text { Sample } \\
\text { ID No. }\end{array}$ & $\begin{array}{l}\text { Test Time } \\
\text { (min) }\end{array}$ & $\begin{array}{c}\Delta t \\
(\min )\end{array}$ & $\begin{array}{c}\text { Temp. } \\
\left({ }^{\circ} \mathrm{C}\right)\end{array}$ & $\begin{array}{c}\text { Critical } \\
\text { Orifice } \\
(\#) \\
\end{array}$ & $\begin{array}{c}C O \\
\Delta P \\
\text { (in. }-\mathrm{Hg} \text { ) }\end{array}$ & $\begin{array}{l}\text { SMF } \\
(-)\end{array}$ & $\begin{array}{c}\text { Gravimetric } \\
\Delta M(m g)\end{array}$ & $\begin{array}{c}F l(d p) \\
\text { Chemical } \\
\Delta M(\mu g)\end{array}$ \\
\hline $\begin{array}{l}\text { F6A-1 } \\
\text { F6A-2 }\end{array}$ & $\begin{array}{l}25.0 \\
55.0\end{array}$ & $\begin{array}{l}10.00 \\
10.00\end{array}$ & $\begin{array}{l}86 \\
87\end{array}$ & $\begin{array}{l}69 \\
69\end{array}$ & $\begin{array}{l}1.1 \\
1.1\end{array}$ & $\begin{array}{l}0.180 \\
0.180\end{array}$ & & $\begin{array}{l}0.143 \\
0.150\end{array}$ \\
\hline $\begin{array}{l}\text { F6A-3 } \\
\text { F6A-4 }\end{array}$ & $\begin{array}{l}25.0 \\
55.0\end{array}$ & $\begin{array}{l}10.00 \\
10.00\end{array}$ & $\begin{array}{l}89 \\
90\end{array}$ & $\begin{array}{l}69 \\
69\end{array}$ & $\begin{array}{l}1.2 \\
1.1\end{array}$ & $\begin{array}{l}0.180 \\
0.180\end{array}$ & & $\begin{array}{l}1.650 \\
1.500\end{array}$ \\
\hline $\begin{array}{l}\text { F6A-5 } \\
\text { F6A-6 }\end{array}$ & $\begin{array}{l}25.0 \\
55.0\end{array}$ & $\begin{array}{l}10.00 \\
10.00\end{array}$ & $\begin{array}{l}91 \\
91\end{array}$ & $\begin{array}{l}69 \\
69\end{array}$ & $\begin{array}{l}1.2 \\
1.2\end{array}$ & $\begin{array}{l}0.180 \\
0.180\end{array}$ & & $\begin{array}{l}14.600 \\
14.400\end{array}$ \\
\hline $\begin{array}{l}\text { F6A-7 } \\
\text { F6A-8 }\end{array}$ & $\begin{array}{l}25.0 \\
55.0\end{array}$ & $\begin{array}{l}10.00 \\
10.00\end{array}$ & $\begin{array}{l}92 \\
90\end{array}$ & $\begin{array}{l}69 \\
69\end{array}$ & $\begin{array}{l}1.1 \\
1.1\end{array}$ & $\begin{array}{l}0.180 \\
0.180\end{array}$ & & $\begin{array}{l}113.000 \\
127.000\end{array}$ \\
\hline $\begin{array}{l}\text { FO-1 } \\
\text { F0-2 } \\
\text { Fo-3 }\end{array}$ & $\begin{array}{l}25.0 \\
40.0 \\
55.0\end{array}$ & $\begin{array}{l}10.00 \\
10.00 \\
10.00\end{array}$ & $\begin{array}{l}5 \\
5 \\
5\end{array}$ & $\begin{array}{l}58 \\
58 \\
58\end{array}$ & $\begin{array}{l}2.0 \\
2.0 \\
2.0\end{array}$ & $\begin{array}{l}0.010 \\
0.010 \\
0.010\end{array}$ & & $\begin{array}{l}0.023 \\
0.025 \\
0.031\end{array}$ \\
\hline $\begin{array}{l}F 0-4 \\
F 0-5 \\
F 0-6\end{array}$ & $\begin{array}{l}25.0 \\
40.0 \\
55.0\end{array}$ & $\begin{array}{l}10.00 \\
10.00 \\
10.00\end{array}$ & $\begin{array}{l}5 \\
5 \\
5\end{array}$ & $\begin{array}{l}58 \\
58 \\
58\end{array}$ & $\begin{array}{l}2.5 \\
2.5 \\
2.5\end{array}$ & $\begin{array}{l}0.010 \\
0.010 \\
0.010\end{array}$ & & $\begin{array}{l}0.328 \\
0.347 \\
0.629\end{array}$ \\
\hline $\begin{array}{l}F 0-7 \\
F 0-8 \\
F 0-9\end{array}$ & $\begin{array}{l}25.0 \\
40.0 \\
55.0\end{array}$ & $\begin{array}{l}10.00 \\
10.00 \\
10.00\end{array}$ & $\begin{array}{l}5 \\
5 \\
6\end{array}$ & $\begin{array}{l}58 \\
58 \\
58\end{array}$ & $\begin{array}{l}2.5 \\
2.5 \\
2.5\end{array}$ & $\begin{array}{l}0.010 \\
0.010 \\
0.010\end{array}$ & & $\begin{array}{l}4.678 \\
5.582 \\
4.963\end{array}$ \\
\hline $\begin{array}{l}\text { FO-10 } \\
\text { Fo-11 } \\
\text { F0-12 }\end{array}$ & $\begin{array}{l}25.0 \\
40.0 \\
55.0\end{array}$ & $\begin{array}{l}10.00 \\
10.00 \\
10.00\end{array}$ & $\begin{array}{c}8 \\
8 \\
10\end{array}$ & $\begin{array}{l}58 \\
58 \\
58\end{array}$ & $\begin{array}{l}2.5 \\
2.5 \\
2.5\end{array}$ & $\begin{array}{l}0.010 \\
0.010 \\
0.010\end{array}$ & & $\begin{array}{l}15.810 \\
12.165 \\
12.503\end{array}$ \\
\hline $\begin{array}{l}\text { IMP-1(a) } \\
\text { IMP-2(c) } \\
\text { IMP-3(d) }\end{array}$ & $\begin{array}{l}55.0 \\
55.0 \\
55.0\end{array}$ & $\begin{array}{l}10.00 \\
10.00 \\
10.00\end{array}$ & $\begin{array}{c}5 \\
6 \\
10\end{array}$ & & & $\begin{array}{l}0.010 \\
0.010 \\
0.010\end{array}$ & & $\begin{array}{l}0.000 \\
1.500 \\
7.064\end{array}$ \\
\hline $5 / 0$ (c) & 55.0 & 10.00 & 6 & 50 & & 0.010 & & 3.530 \\
\hline $\begin{array}{l}\text { ACla } \\
\text { Aclib } \\
\text { Ací } \\
\text { Acid } \\
\text { Aćló } \\
\text { Acli } \\
\text { Acig } \\
\text { Acih }\end{array}$ & $\begin{array}{l}40.0 \\
40.0 \\
40.0 \\
40.0 \\
40.0 \\
40.0 \\
40.0 \\
40.0\end{array}$ & $\begin{array}{l}10.00 \\
10.00 \\
10.00 \\
10.00 \\
10.00 \\
10.00 \\
10.00 \\
10.00\end{array}$ & $\begin{array}{l}88 \\
90 \\
91 \\
88 \\
5 \\
5 \\
5 \\
8\end{array}$ & $\begin{array}{l}55 \\
58 \\
58 \\
58 \\
50 \\
50 \\
55 \\
55\end{array}$ & $\begin{array}{l}3.3 \\
4.2 \\
2.1 \\
2.2 \\
5.5 \\
6.5 \\
3.1 \\
3.0\end{array}$ & $\begin{array}{l}0.189 \\
0.183 \\
0.181 \\
0.178 \\
0.004 \\
0.000 \\
0.008 \\
0.011\end{array}$ & & $\begin{array}{c}0.327 \\
3.642 \\
20.390 \\
20.369 \\
0.071 \\
1.004 \\
5.223 \\
7.289\end{array}$ \\
\hline
\end{tabular}




\section{Test 17-12}

\begin{tabular}{|c|c|c|c|c|c|c|c|c|}
\hline $\begin{array}{l}\text { Sample } \\
\text { ID No. }\end{array}$ & $\begin{array}{l}\text { Probe Loss } \\
\text { Correction } \\
\text { Factor } \\
(P L C f>1)\end{array}$ & $\begin{array}{c}\text { Corrected } \\
\text { Gravimetric } \\
\Delta \mathrm{M}(\mathrm{mg})\end{array}$ & $\begin{array}{c}\text { Corrected } \\
\text { Compound } \\
\text { DOP\&FL } \\
\Delta \mathrm{M}(\mu \mathrm{g})\end{array}$ & $\begin{array}{l}\text { Crit. Orifice } \\
\text { Correction } \\
\text { Factor } \\
(\mathrm{COcf}<1) \\
\end{array}$ & $\begin{array}{c}\text { Crit. Orifice } \\
\text { Flow Rate } \\
@ 20^{\circ} \mathrm{C} \\
(1 \mathrm{pm}) \\
\end{array}$ & $\begin{array}{c}\text { Dry Gas } \\
@ 20^{\circ} \mathrm{C} \\
\text { (l) }\end{array}$ & $\begin{array}{c}\text { mple Volun } \\
\text { Dry Gas } \\
@ \text { To } \\
\text { (I) }\end{array}$ & $\begin{array}{c}\text { H2O } \\
\text { @ To } \\
(1)\end{array}$ \\
\hline $\begin{array}{l}\text { F6A-1 } \\
\text { F6A-2 }\end{array}$ & & & $\begin{array}{l}0.14 \\
0.15\end{array}$ & $\begin{array}{l}0.98 \\
0.98\end{array}$ & $\begin{array}{l}4.94 \\
4.94\end{array}$ & $\begin{array}{l}49.37 \\
49.37\end{array}$ & $\begin{array}{l}60.49 \\
60.66\end{array}$ & $\begin{array}{l}13.28 \\
13.32\end{array}$ \\
\hline $\begin{array}{l}\text { F6A-3 } \\
\text { F6A-4 }\end{array}$ & & & $\begin{array}{l}16.50 \\
15.00\end{array}$ & $\begin{array}{l}0.98 \\
0.98\end{array}$ & $\begin{array}{l}4.93 \\
4.94\end{array}$ & $\begin{array}{l}49.28 \\
49.37\end{array}$ & $\begin{array}{l}60.89 \\
61.16\end{array}$ & $\begin{array}{l}13.37 \\
13.43\end{array}$ \\
\hline $\begin{array}{l}\text { F6A-5 } \\
\text { F6A-6 }\end{array}$ & & & $\begin{array}{l}146.00 \\
144.00\end{array}$ & $\begin{array}{l}0.98 \\
0.98\end{array}$ & $\begin{array}{l}4.93 \\
4.93\end{array}$ & $\begin{array}{l}49.28 \\
49.28\end{array}$ & $\begin{array}{l}61.23 \\
61.23\end{array}$ & $\begin{array}{l}13.44 \\
13.44\end{array}$ \\
\hline $\begin{array}{l}\text { F6A-7 } \\
\text { F6A-8 }\end{array}$ & & & $\begin{array}{l}5650.00 \\
6350.00\end{array}$ & $\begin{array}{l}0.98 \\
0.98\end{array}$ & $\begin{array}{l}4.94 \\
4.94\end{array}$ & $\begin{array}{l}49.37 \\
49.37\end{array}$ & $\begin{array}{l}61.50 \\
61.16\end{array}$ & $\begin{array}{l}13.50 \\
13.43\end{array}$ \\
\hline $\begin{array}{l}\text { F0-1 } \\
\text { F0-2 } \\
\text { F0-3 }\end{array}$ & & & $\begin{array}{l}0.02 \\
0.03 \\
0.03\end{array}$ & $\begin{array}{l}0.97 \\
0.97 \\
0.97\end{array}$ & $\begin{array}{l}8.83 \\
8.83 \\
8.83\end{array}$ & $\begin{array}{l}88.30 \\
88.30 \\
88.30\end{array}$ & $\begin{array}{l}83.78 \\
83.78 \\
83.78\end{array}$ & $\begin{array}{l}0.85 \\
0.85 \\
0.85\end{array}$ \\
\hline $\begin{array}{l}F 0-4 \\
F 0-5 \\
\text { F0-6 }\end{array}$ & & & $\begin{array}{l}3.28 \\
3.47 \\
6.29\end{array}$ & $\begin{array}{l}0.96 \\
0.96 \\
0.96\end{array}$ & $\begin{array}{l}8.75 \\
8.75 \\
8.75\end{array}$ & $\begin{array}{l}87.51 \\
87.51 \\
87.51\end{array}$ & $\begin{array}{l}83.03 \\
83.03 \\
83.03\end{array}$ & $\begin{array}{l}0.84 \\
0.84 \\
0.84\end{array}$ \\
\hline $\begin{array}{l}F 0-7 \\
\text { F0-8 } \\
\text { F0-9 }\end{array}$ & & & $\begin{array}{l}46.78 \\
55.82 \\
49.63\end{array}$ & $\begin{array}{l}0.96 \\
0.96 \\
0.96\end{array}$ & $\begin{array}{l}8.75 \\
8.75 \\
8.75\end{array}$ & $\begin{array}{l}87.51 \\
87.51 \\
87.51\end{array}$ & $\begin{array}{l}83.03 \\
83.03 \\
83.33\end{array}$ & $\begin{array}{l}0.84 \\
0.84 \\
0.84\end{array}$ \\
\hline $\begin{array}{l}F 0-10 \\
F 0-11 \\
F 0-12\end{array}$ & & & $\begin{array}{l}790.50 \\
608.25 \\
625.15\end{array}$ & $\begin{array}{l}0.96 \\
0.96 \\
0.96\end{array}$ & $\begin{array}{l}8.75 \\
8.75 \\
8.75\end{array}$ & $\begin{array}{l}87.51 \\
87.51 \\
87.51\end{array}$ & $\begin{array}{l}83.92 \\
83.92 \\
84.52\end{array}$ & $\begin{array}{l}0.85 \\
0.85 \\
0.85\end{array}$ \\
\hline $\begin{array}{l}\text { IMP-1(a) } \\
\text { IMP-2(c) } \\
\text { IMP-3(d) }\end{array}$ & & & $\begin{array}{c}0.00 \\
15.00 \\
353.20\end{array}$ & & & & & \\
\hline $5 / 0$ (c) & & & 35.30 & & 27.20 & 272.00 & 259.00 & 2.62 \\
\hline $\begin{array}{l}\text { ACla } \\
\text { AClb } \\
\text { AClc } \\
\text { ACld } \\
\text { ACle } \\
\text { AClf } \\
\text { AClg } \\
\text { AClh }\end{array}$ & & & $\begin{array}{c}0.33 \\
3.64 \\
20.39 \\
20.37 \\
0.07 \\
1.00 \\
5.22 \\
7.29\end{array}$ & $\begin{array}{l}0.94 \\
0.93 \\
0.96 \\
0.96 \\
0.90 \\
0.89 \\
0.95 \\
0.95\end{array}$ & $\begin{array}{c}14.34 \\
8.48 \\
8.81 \\
8.80 \\
24.58 \\
24.07 \\
14.39 \\
14.42\end{array}$ & $\begin{array}{c}143.40 \\
84.76 \\
88.14 \\
87.98 \\
245.81 \\
240.74 \\
143.93 \\
144.20\end{array}$ & $\begin{array}{l}176.68 \\
105.01 \\
109.50 \\
108.40 \\
233.22 \\
228.41 \\
136.56 \\
138.29\end{array}$ & $\begin{array}{c}41.17 \\
23.52 \\
24.20 \\
23.47 \\
0.94 \\
0.00 \\
1.10 \\
1.54\end{array}$ \\
\hline
\end{tabular}

ICEDF DF WorkSheet (page 2)

$$
\text { E. } 50
$$




\begin{tabular}{|c|c|c|c|c|c|c|c|}
\hline & $\sum$ Sample & & Mass & & & DOP\&FL & \\
\hline $\begin{array}{l}\text { Sample } \\
\text { ID No. }\end{array}$ & $\begin{array}{c}\text { Volume } \\
\text { @ To } \\
\text { (I) }\end{array}$ & $\begin{array}{c}\mathrm{Cm} \\
@ \mathrm{To}^{-} \\
\left(\mathrm{mg} / \mathrm{m}^{\wedge} 3\right)\end{array}$ & $\begin{array}{c}\text { Mass Flow } \\
@ \text { To } \\
\text { (mg/s) } \\
\end{array}$ & $\begin{array}{c}\text { Approx. } \\
\text { Feed Rate } \\
\text { (g/min) }\end{array}$ & $\begin{array}{c}\mathrm{Cm} \\
@ \mathrm{To} \\
\left(\mu \mathrm{g} / \mathrm{m}^{\wedge} 3\right)\end{array}$ & $\begin{array}{c}\text { Mass Flow } \\
@ \text { To } \\
(\mu \mathrm{g} / \mathrm{s}) \\
\end{array}$ & $\begin{array}{c}\text { Approx. } \\
\text { Feed Rate } \\
\text { (mg/min) }\end{array}$ \\
\hline $\begin{array}{l}\text { F6A-1 } \\
\text { F6A-2 }\end{array}$ & $\begin{array}{l}73.77 \\
73.97\end{array}$ & & & & $\begin{array}{l}1.94 \\
2.03\end{array}$ & $\begin{array}{l}0.15 \\
0.16\end{array}$ & $\begin{array}{l}0.01 \\
0.01\end{array}$ \\
\hline $\begin{array}{l}\text { F6A-3 } \\
\text { F6A-4 }\end{array}$ & $\begin{array}{l}74.26 \\
74.59\end{array}$ & & & & $\begin{array}{l}222.20 \\
201.10\end{array}$ & $\begin{array}{l}17.55 \\
15.93\end{array}$ & $\begin{array}{l}1.05 \\
0.96\end{array}$ \\
\hline $\begin{array}{l}\text { F6A-5 } \\
\text { F6A-6 }\end{array}$ & $\begin{array}{l}74.67 \\
74.67\end{array}$ & & & & $\begin{array}{l}1955.37 \\
1928.59\end{array}$ & $\begin{array}{l}155.33 \\
153.20\end{array}$ & $\begin{array}{l}9.32 \\
9.19\end{array}$ \\
\hline $\begin{array}{l}\text { F6A-7 } \\
\text { F6A-8 }\end{array}$ & $\begin{array}{l}75.00 \\
74.59\end{array}$ & & & & $\begin{array}{l}75332.22 \\
85131.89\end{array}$ & $\begin{array}{l}6000.54 \\
6743.99\end{array}$ & $\begin{array}{l}360.03 \\
404.64\end{array}$ \\
\hline $\begin{array}{l}F 0-1 \\
F 0-2 \\
F 0-3\end{array}$ & $\begin{array}{l}84.63 \\
84.63 \\
84.63\end{array}$ & & & & $\begin{array}{l}0.27 \\
0.30 \\
0.37\end{array}$ & $\begin{array}{l}0.014 \\
0.015 \\
0.018\end{array}$ & $\begin{array}{l}0.00 \\
0.00 \\
0.00\end{array}$ \\
\hline $\begin{array}{l}F 0-4 \\
F 0-5 \\
\text { F0-6 }\end{array}$ & $\begin{array}{l}83.87 \\
83.87 \\
83.87\end{array}$ & & & & $\begin{array}{l}39.11 \\
41.37 \\
75.00\end{array}$ & $\begin{array}{l}1.97 \\
2.08 \\
3.78\end{array}$ & $\begin{array}{l}0.12 \\
0.13 \\
0.23\end{array}$ \\
\hline $\begin{array}{l}F 0-7 \\
F 0-8 \\
\text { F0-9 }\end{array}$ & $\begin{array}{l}83.87 \\
83.87 \\
84.17\end{array}$ & & & & $\begin{array}{l}557.78 \\
665.57 \\
589.65\end{array}$ & $\begin{array}{l}28.09 \\
33.52 \\
29.80\end{array}$ & $\begin{array}{l}1.69 \\
2.01 \\
1.79\end{array}$ \\
\hline $\begin{array}{l}F 0-10 \\
F 0-11 \\
F 0-12\end{array}$ & $\begin{array}{l}84.77 \\
84.77 \\
85.38\end{array}$ & & & & $\begin{array}{l}9324.95 \\
7175.08 \\
7322.32\end{array}$ & $\begin{array}{l}474.70 \\
365.26 \\
375.40\end{array}$ & $\begin{array}{l}28.48 \\
21.92 \\
22.52\end{array}$ \\
\hline $\begin{array}{l}\text { IMP-1(a) } \\
\text { IMP-2(c) } \\
\text { IMP-3(d) }\end{array}$ & & & & & $\begin{array}{l}\text { Flow? } \\
\text { Flow? } \\
\text { Flow? }\end{array}$ & & \\
\hline $5 / 0(c)$ & 261.62 & & & & 134.93 & 6.82 & 0.41 \\
\hline $\begin{array}{l}\text { ACla } \\
\text { AClb } \\
\text { AClc } \\
\text { ACld } \\
\text { ACle } \\
\text { ACli } \\
\text { AClg } \\
\text { AClh }\end{array}$ & $\begin{array}{l}190.00 \\
128.53 \\
133.70 \\
131.88 \\
234.16 \\
228.41 \\
137.67 \\
139.83\end{array}$ & & & & $\begin{array}{c}1.72 \\
28.34 \\
152.50 \\
154.45 \\
0.30 \\
4.40 \\
37.94 \\
52.13\end{array}$ & $\begin{array}{c}0.137 \\
2.25 \\
12.13 \\
12.14 \\
0.015 \\
0.22 \\
1.91 \\
2.66\end{array}$ & $\begin{array}{l}0.01 \\
0.14 \\
0.73 \\
0.73 \\
0.00 \\
0.01 \\
0.11 \\
0.16\end{array}$ \\
\hline
\end{tabular}

ICEDF DF WorkSheet (page 3)

$$
\text { E. } 51
$$


How to use "ICEDF DF WkSht 8/89"

1) Open "ICEDF DF WkSht $8 / 89$ "

2) Enter test name and other constants.

3) Save As "ICEDF testname DF month/year".

4) Enter data on page 1 (change sample ID's if req'd)

WorkSheet Updates:

10/5/89: Added correction for $\Delta P$ upstream of critical orifice, changed sample ID No. listing.

10/5/89: Removed aerosol mass flow rate calculations for quad stations.

6/13/90: Entered specific chemfrac into column M equations (this test only)

This Test!!!!!! Q for $\mathrm{ACl}$ a was set at $19 \mathrm{lpm}$ (see data sheet)

\begin{tabular}{|cc|}
\hline \multicolumn{2}{|c|}{ Critical Orifice Calib. } \\
\hline & \\
CO (\#) & Q(lpm) \\
\hline 50 & 27.2 \\
53 & 19.8 \\
55 & 15.2 \\
58 & 9.14 \\
65 & 6.91 \\
69 & 5.03 \\
74 & 2.47 \\
77 & 1.45 \\
80 & 1.03 \\
\hline
\end{tabular}

ICEDF DF WorkSheet (page 4)

E. 52 


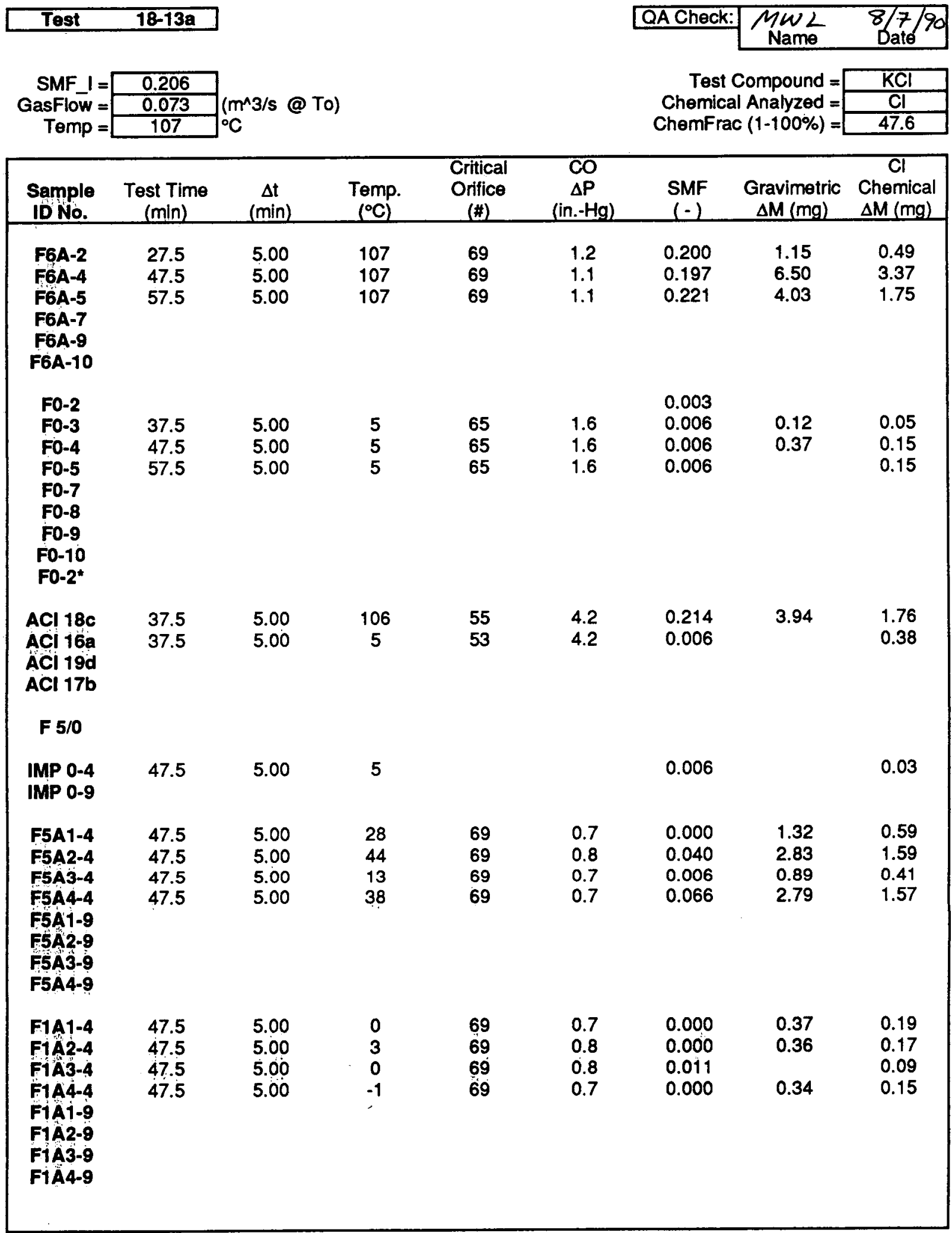


Test 18-13a

\begin{tabular}{|c|c|c|c|c|c|c|c|c|}
\hline $\begin{array}{l}\text { Sample } \\
\text { ID No. }\end{array}$ & $\begin{array}{l}\text { Probe Loss } \\
\text { Correction } \\
\text { Factor } \\
(\text { PLCf }>1)\end{array}$ & $\begin{array}{l}\text { Corrected } \\
\text { Gravimetric } \\
\Delta \mathrm{M}(\mathrm{mg})\end{array}$ & $\begin{array}{c}\text { Corrected } \\
\text { Compound } \\
\mathrm{KCl} \\
\Delta \mathrm{M}(\mathrm{mg})\end{array}$ & $\begin{array}{l}\text { Crit. Orifice } \\
\text { Correction } \\
\text { Factor } \\
(\text { COcf }<1)\end{array}$ & $\begin{array}{c}\text { Crit. Orifice } \\
\text { Flow Rate } \\
@ 20^{\circ} \mathrm{C} \\
\text { (lpm) }\end{array}$ & $\begin{array}{c}\text { S } \\
\text { Dry Gas } \\
@ 20^{\circ} \mathrm{C} \\
\text { (l) }\end{array}$ & $\begin{array}{c}\text { nple Volum } \\
\text { Dry Gas } \\
@ \text { To } \\
\text { (I) }\end{array}$ & $\begin{array}{c}\mathrm{H} 2 \mathrm{O} \\
@ \mathrm{To} \\
\text { (I) }\end{array}$ \\
\hline $\begin{array}{c}\text { F6A-2 } \\
\text { F6A-4 } \\
\text { F6A-5 } \\
\text { F6A-7 } \\
\text { F6A-9 } \\
\text { F6A-10 }\end{array}$ & & $\begin{array}{l}1.15 \\
6.50 \\
4.03\end{array}$ & $\begin{array}{l}1.03 \\
7.08 \\
3.68\end{array}$ & $\begin{array}{l}0.98 \\
0.98 \\
0.98\end{array}$ & $\begin{array}{l}4.93 \\
4.94 \\
4.94\end{array}$ & $\begin{array}{l}24.64 \\
24.68 \\
24.68\end{array}$ & $\begin{array}{l}31.96 \\
32.01 \\
32.01\end{array}$ & $\begin{array}{l}7.99 \\
7.85 \\
9.08\end{array}$ \\
\hline $\begin{array}{c}\text { FO-2 } \\
\text { FO-3 } \\
\text { F0-4 } \\
\text { F0-5 } \\
\text { F0-7 } \\
\text { F0-8 } \\
\text { F0-9 } \\
\text { F0-10 } \\
\text { F0-2 }\end{array}$ & & $\begin{array}{l}0.12 \\
0.37\end{array}$ & $\begin{array}{l}0.11 \\
0.32 \\
0.32\end{array}$ & $\begin{array}{l}0.97 \\
0.97 \\
0.97\end{array}$ & $\begin{array}{l}6.78 \\
6.78 \\
6.78\end{array}$ & $\begin{array}{l}33.91 \\
33.91 \\
33.91\end{array}$ & $\begin{array}{l}32.17 \\
32.17 \\
32.17\end{array}$ & $\begin{array}{l}0.19 \\
0.19 \\
0.19\end{array}$ \\
\hline $\begin{array}{l}A C l 18 c \\
A C l 16 a \\
A C l 19 d \\
A C l 17 b\end{array}$ & & 3.94 & $\begin{array}{l}\text { '3.69 } \\
0.79\end{array}$ & $\begin{array}{l}0.93 \\
0.93\end{array}$ & $\begin{array}{l}14.10 \\
18.36\end{array}$ & $\begin{array}{l}70.48 \\
91.81\end{array}$ & $\begin{array}{l}91.17 \\
87.11\end{array}$ & $\begin{array}{c}24.82 \\
0.53\end{array}$ \\
\hline$F 5 / 0$ & & & & & & & & \\
\hline $\begin{array}{l}\text { IMP 0-4 } \\
\text { IMP 0-9 }\end{array}$ & & & 0.06 & & & & & \\
\hline $\begin{array}{l}\text { F5A1-4 } \\
\text { F5A2-4 } \\
\text { F5A3-4 } \\
\text { F5A4-4 } \\
\text { F5A1-9 } \\
\text { F5A2-9 } \\
\text { F5A3-9 } \\
\text { F5A4-9 }\end{array}$ & & $\begin{array}{l}1.32 \\
2.83 \\
0.89 \\
2.79\end{array}$ & $\begin{array}{l}1.24 \\
3.34 \\
0.86 \\
3.30\end{array}$ & $\begin{array}{l}0.99 \\
0.99 \\
0.99 \\
0.99\end{array}$ & $\begin{array}{l}4.97 \\
4.96 \\
4.97 \\
4.97\end{array}$ & $\begin{array}{l}24.85 \\
24.81 \\
24.85 \\
24.85\end{array}$ & $\begin{array}{l}25.53 \\
26.84 \\
24.26 \\
26.38\end{array}$ & $\begin{array}{l}0.00 \\
1.12 \\
0.15 \\
1.86\end{array}$ \\
\hline $\begin{array}{l}\text { F1A1-4 } \\
\text { F1A2-4 } \\
\text { F1A3-4 } \\
\text { F1A4-4 } \\
\text { F1A1-9 } \\
\text { F1A2-9 } \\
\text { F1A3-9 } \\
\text { F1A4-9 }\end{array}$ & & $\begin{array}{l}0.37 \\
0.36 \\
0.34\end{array}$ & $\begin{array}{l}0.40 \\
0.36 \\
0.19 \\
0.32\end{array}$ & $\begin{array}{l}0.99 \\
0.99 \\
0.99 \\
0.99\end{array}$ & $\begin{array}{l}4.97 \\
4.96 \\
4.96 \\
4.97\end{array}$ & $\begin{array}{l}24.85 \\
24.81 \\
24.81 \\
24.85\end{array}$ & $\begin{array}{l}23.16 \\
23.37 \\
23.12 \\
23.07\end{array}$ & $\begin{array}{l}0.00 \\
0.00 \\
0.26 \\
0.00\end{array}$ \\
\hline
\end{tabular}

ICEDF DF WorkSheet (page 2)

$$
\text { E. } 54
$$




\section{Test 18-13a}

\begin{tabular}{|c|c|c|c|c|c|c|c|}
\hline & $\overline{\Sigma \text { Sample }}$ & & Mass & & & $\mathrm{KCl}$ & \\
\hline $\begin{array}{l}\text { Sample } \\
\text { ID No. }\end{array}$ & $\begin{array}{l}\text { Volume } \\
\text { @ To } \\
\text { (1) }\end{array}$ & $\begin{array}{c}\mathrm{Cm} \\
@ \mathrm{To} \\
\left(\mathrm{mg} / \mathrm{m}^{\wedge} 3\right)\end{array}$ & $\begin{array}{c}\text { Mass Flow } \\
\text { @ To } \\
\text { (mg/s) } \\
\end{array}$ & $\begin{array}{c}\text { Approx. } \\
\text { Feed Rate } \\
\text { (g/min) }\end{array}$ & $\begin{array}{c}\mathrm{Cm} \\
@ \mathrm{To} \\
\left(\mathrm{mg} / \mathrm{m}^{\wedge} 3\right)\end{array}$ & $\begin{array}{c}\text { Mass Flow } \\
@ \text { To } \\
\text { (mg/s) }\end{array}$ & $\begin{array}{c}\text { Approx. } \\
\text { Feed Rate } \\
\text { (g/min) }\end{array}$ \\
\hline $\begin{array}{c}\text { F6A-2 } \\
\text { F6A-4 } \\
\text { F6A-5 } \\
\text { F6A-7 } \\
\text { F6A-9 } \\
\text { F6A-10 }\end{array}$ & $\begin{array}{l}39.95 \\
39.87 \\
41.10\end{array}$ & $\begin{array}{c}28.79 \\
163.04 \\
98.06\end{array}$ & $\begin{array}{c}2.09 \\
11.79 \\
7.27\end{array}$ & $\begin{array}{l}0.13 \\
0.71 \\
0.44\end{array}$ & $\begin{array}{c}25.77 \\
177.58 \\
89.46\end{array}$ & $\begin{array}{c}1.87 \\
12.85 \\
6.63\end{array}$ & $\begin{array}{l}0.11 \\
0.77 \\
0.40\end{array}$ \\
\hline $\begin{array}{c}\text { F0-2 } \\
\text { FO-3 } \\
\text { FO-4 } \\
\text { F0-5 } \\
\text { F0-7 } \\
\text { FO-8 } \\
\text { FO-9 } \\
\text { FO-10 } \\
\text { FO-2* }\end{array}$ & $\begin{array}{l}32.37 \\
32.37 \\
32.37\end{array}$ & $\begin{array}{c}3.71 \\
11.43\end{array}$ & $\begin{array}{l}0.16 \\
0.49\end{array}$ & $\begin{array}{l}0.01 \\
0.03\end{array}$ & $\begin{array}{l}3.25 \\
9.74 \\
9.74\end{array}$ & $\begin{array}{l}0.14 \\
0.42 \\
0.42\end{array}$ & $\begin{array}{l}0.01 \\
0.02 \\
0.02\end{array}$ \\
\hline $\begin{array}{l}A C l 18 c \\
A C l 16 a \\
A C l 19 d \\
A C l 17 b\end{array}$ & $\begin{array}{c}115.99 \\
87.63\end{array}$ & 33.97 & 2.49 & 0.15 & $\begin{array}{c}31.81 \\
9.04\end{array}$ & $\begin{array}{l}2.33 \\
0.39\end{array}$ & $\begin{array}{l}0.14 \\
0.02\end{array}$ \\
\hline $\begin{array}{c}\text { F 5/0 } \\
\text { IMP 0-4 } \\
\text { IMP 0-9 }\end{array}$ & & & & & Flow? & & \\
\hline $\begin{array}{l}\text { F5A1-4 } \\
\text { F5A2-4 } \\
\text { F5A3-4 } \\
\text { F5A4-4 } \\
\text { F5A1-9 } \\
\text { F5A2-9 } \\
\text { F5A3-9 } \\
\text { F5A4-9 }\end{array}$ & $\begin{array}{l}25.53 \\
27.96 \\
24.41 \\
28.25\end{array}$ & $\begin{array}{c}51.70 \\
101.20 \\
36.46 \\
98.78\end{array}$ & $\begin{array}{l}N D \\
N D \\
N D \\
N D \\
N D \\
N D \\
N D \\
N D\end{array}$ & $\begin{array}{l}N D \\
N D \\
N D \\
N D \\
N D \\
N D \\
N D \\
N D\end{array}$ & $\begin{array}{c}48.54 \\
119.45 \\
35.29 \\
116.77\end{array}$ & 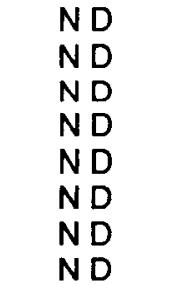 & $\begin{array}{l}\text { ND } \\
N D \\
N D \\
N D \\
N D \\
N D \\
N D \\
N D\end{array}$ \\
\hline $\begin{array}{l}\text { F1A1-4 } \\
\text { F1A2-4 } \\
\text { F1A3-4 } \\
\text { F1A4-4 } \\
\text { F1A1-9 } \\
\text { F1A2-9 } \\
\text { F1A3-9 } \\
\text { F1A4-9 }\end{array}$ & $\begin{array}{l}23.16 \\
23.37 \\
23.38 \\
23.07\end{array}$ & $\begin{array}{l}15.98 \\
15.40 \\
\\
14.74\end{array}$ & $\begin{array}{l}N D \\
N D \\
N D \\
N D \\
N D \\
N D \\
N D \\
N D\end{array}$ & $\begin{array}{l}\text { ND } \\
N D \\
N D \\
N D \\
N D \\
N D \\
N D \\
N D\end{array}$ & $\begin{array}{c}17.24 \\
15.28 \\
8.09 \\
13.66\end{array}$ & $\begin{array}{l}N D \\
N D \\
N D \\
N D \\
N D \\
N D \\
N D \\
N D\end{array}$ & $\begin{array}{l}N D \\
N D \\
N D \\
N D \\
N D \\
N D \\
N D \\
N D\end{array}$ \\
\hline
\end{tabular}


How to use "ICEDF DF WkSht 8/89"

1) Open "ICEDF DF WkSht $8 / 89$ "

2) Enter test name and other constants.

3) Save As "ICEDF testhame DF month/year".

4) Enter data on page 1 (change sample ID's if req'd)

WorkSheet Updates:

10/5/89: Added correction for $\Delta \mathrm{P}$ upstream of critical orifice, changed sample ID No. listing. 10/5/89: Removed aerosol mass flow rate calculations for quad stations.

\begin{tabular}{|cc|}
\hline \multicolumn{2}{|c|}{ Critical Orifice Calib. } \\
\hline & \\
Co (\#) & Q(lpm) \\
\hline 50 & 27.2 \\
53 & 19.8 \\
55 & 15.2 \\
58 & 9.14 \\
65 & 6.97 \\
69 & 5.03 \\
74 & 2.47 \\
77 & 1.45 \\
80 & 1.03 \\
\hline
\end{tabular}




\begin{tabular}{|c|c|c|c|c|c|c|c|c|}
\hline \multicolumn{2}{|c|}{ Test $18-13 b$} & & & & & QA Check: & $\begin{array}{l}M w L \\
\text { Name }\end{array}$ & $8 / 7 / 90$ \\
\hline $\begin{aligned} \text { SMF_I } & = \\
\text { GasFlow } & = \\
\text { Temp } & =\end{aligned}$ & $\begin{array}{c}\frac{0.212}{0.073} \\
107 \\
\end{array}$ & \multicolumn{4}{|c|}{$\left(\mathrm{m}^{\wedge} 3 / \mathrm{s} @ \mathrm{To}\right)$} & \multicolumn{2}{|c|}{$\begin{array}{r}\text { Test Compound }= \\
\text { Chemical Analyzed }= \\
\text { ChemFrac }(1-100 \%)=\end{array}$} & $\frac{2 n S}{\frac{Z n}{67.1}}$ \\
\hline $\begin{array}{l}\text { Sample } \\
\text { ID No. }\end{array}$ & $\begin{array}{c}\text { Test Time } \\
\text { (min) }\end{array}$ & $\begin{array}{c}\Delta t \\
(m i n)\end{array}$ & $\begin{array}{l}\text { Temp. } \\
\left({ }^{\circ} \mathrm{C}\right)\end{array}$ & $\begin{array}{l}\text { Critical } \\
\text { Orifice } \\
(\#)\end{array}$ & $\begin{array}{c}C O \\
\Delta P \\
\text { (in. }-H g)\end{array}$ & $\begin{array}{l}\text { SMF } \\
(-) \\
\end{array}$ & $\begin{array}{c}\text { Gravimetric } \\
\Delta M(\mathrm{mg})\end{array}$ & $\begin{array}{c}\mathrm{Zn} \\
\text { Chemical } \\
\Delta \mathrm{M}(\mathrm{mg})\end{array}$ \\
\hline \multicolumn{9}{|l|}{$\begin{array}{l}\text { F6A-2 } \\
\text { F6A-4 } \\
\text { F6A-5 }\end{array}$} \\
\hline $\begin{array}{l}\text { F6A-7 } \\
\text { F6A-9 } \\
\text { F6A-10 }\end{array}$ & $\begin{array}{l}27.5 \\
47.5 \\
57.5\end{array}$ & $\begin{array}{l}5.00 \\
5.00 \\
5.00\end{array}$ & $\begin{array}{l}107 \\
108 \\
107\end{array}$ & $\begin{array}{l}69 \\
69 \\
69\end{array}$ & $\begin{array}{l}1.2 \\
1.2 \\
1.2\end{array}$ & $\begin{array}{l}0.209 \\
0.212 \\
0.210\end{array}$ & $\begin{array}{l}5.52 \\
6.25 \\
6.12\end{array}$ & $\begin{array}{l}2.96 \\
3.64 \\
3.31\end{array}$ \\
\hline \multicolumn{9}{|l|}{$\begin{array}{l}\text { FO-2 } \\
\text { FO-3 } \\
\text { FO-4 } \\
\text { FO-5 }\end{array}$} \\
\hline $\begin{array}{l}F 0-7 \\
F 0-8 \\
F 0-9 \\
F 0-10 \\
F 0-2^{*}\end{array}$ & $\begin{array}{l}27.5 \\
37.5 \\
47.5 \\
57.5 \\
67.5\end{array}$ & $\begin{array}{l}5.00 \\
5.00 \\
5.00 \\
5.00 \\
5.00\end{array}$ & $\begin{array}{l}5 \\
5 \\
5 \\
5 \\
5\end{array}$ & $\begin{array}{l}65 \\
65 \\
65 \\
65 \\
65\end{array}$ & $\begin{array}{l}1.6 \\
1.5 \\
1.6 \\
1.8 \\
1.6\end{array}$ & $\begin{array}{l}0.010 \\
0.009 \\
0.010 \\
0.010 \\
0.010\end{array}$ & $\begin{array}{l}2.28 \\
2.42 \\
2.03 \\
2.80\end{array}$ & $\begin{array}{l}1.42 \\
1.44 \\
1.30 \\
1.66\end{array}$ \\
\hline \multicolumn{9}{|l|}{$\begin{array}{l}\mathrm{ACl} 18 \mathrm{c} \\
\mathrm{ACl} 16 a\end{array}$} \\
\hline $\begin{array}{l}\text { ACl 19d } \\
\text { ACl 17b }\end{array}$ & $\begin{array}{l}37.5 \\
37.5\end{array}$ & $\begin{array}{l}5.00 \\
5.00\end{array}$ & $\begin{array}{c}107 \\
5\end{array}$ & $\begin{array}{l}55 \\
53\end{array}$ & $\begin{array}{l}4.1 \\
4.2\end{array}$ & $\begin{array}{l}0.220 \\
0.009\end{array}$ & $\begin{array}{l}15.65 \\
3.47\end{array}$ & $\begin{array}{l}7.36 \\
1.59\end{array}$ \\
\hline$F 0 / 5$ & 47.5 & 5.00 & 5 & 50 & 6.5 & 0.010 & 5.94 & 3.54 \\
\hline $\begin{array}{l}\text { IMP 0-4 } \\
\text { IMP 0-9 }\end{array}$ & IMP 0-4 & 5.00 & 5 & & & 0.010 & & \\
\hline $\begin{array}{l}\text { F5A1-4 } \\
\text { F5A2-4 } \\
\text { F5A3-4 } \\
\text { F5A4-4 } \\
\text { F5A1-9 } \\
\text { F5A2-9 } \\
\text { F5A3-9 } \\
\text { F5A4-9 }\end{array}$ & \multicolumn{7}{|c|}{$\begin{array}{l}\text { F5A1-4 } \\
\text { F5A2-4 } \\
\text { F5A3-4 } \\
\text { F5A4-4 }\end{array}$} & $\begin{array}{l}1.75 \\
2.28 \\
1.80 \\
2.23\end{array}$ \\
\hline $\begin{array}{l}\text { F1A1-4 } \\
\text { F1A2-4 } \\
\text { F1A3-4 } \\
\text { F1A4-4 } \\
\text { F1A1-9 } \\
\text { F1A2-9 } \\
\text { F1A3-9 } \\
\text { F1A4-9 }\end{array}$ & \multicolumn{8}{|c|}{$\begin{array}{l}\text { F1A1-4 } \\
\text { F1A2-4 } \\
\text { F1A3-4 } \\
\text { F1A4-4 }\end{array}$} \\
\hline
\end{tabular}




\begin{tabular}{|c|c|c|c|c|c|c|c|c|}
\hline $\begin{array}{l}\text { Sample } \\
\text { ID No. }\end{array}$ & $\begin{array}{l}\text { Probe Loss } \\
\text { Correction } \\
\text { Factor } \\
(P L c f>1)\end{array}$ & $\begin{array}{l}\text { Corrected } \\
\text { Gravimetric } \\
\Delta \mathrm{M}(\mathrm{mg})\end{array}$ & $\begin{array}{c}\text { Corrected } \\
\text { Compound } \\
\text { ZnS } \\
\Delta M(\mathrm{mg})\end{array}$ & $\begin{array}{l}\text { Crit. Orifice } \\
\text { Correction } \\
\text { Factor } \\
(\text { COcf }<1)\end{array}$ & $\begin{array}{c}\text { Crit. Orifice } \\
\text { Flow Rate } \\
@ 20^{\circ} \mathrm{C} \\
(1 \mathrm{pm})\end{array}$ & $\begin{array}{c}\text { S } \\
\text { Dry Gas } \\
@ 20^{\circ} \mathrm{C} \\
\text { (l) }\end{array}$ & $\begin{array}{c}\text { nple Volur } \\
\text { Dry Gas } \\
\text { @ To } \\
\text { (I) }\end{array}$ & $\begin{array}{c}\mathrm{H} 2 \mathrm{O} \\
@ \text { To } \\
\text { (I) }\end{array}$ \\
\hline \multicolumn{9}{|l|}{$\begin{array}{l}\text { F6A-2 } \\
\text { F6A-4 } \\
\text { F6A-5 }\end{array}$} \\
\hline $\begin{array}{l}\text { F6A-7 } \\
\text { F6A-9 } \\
\text { F6A-10 }\end{array}$ & & $\begin{array}{l}5.52 \\
6.25 \\
6.12\end{array}$ & $\begin{array}{l}4.41 \\
5.42 \\
4.93\end{array}$ & $\begin{array}{l}0.98 \\
0.98 \\
0.98\end{array}$ & $\begin{array}{l}4.93 \\
4.93 \\
4.93\end{array}$ & $\begin{array}{l}24.64 \\
24.64 \\
24.64\end{array}$ & $\begin{array}{l}31.96 \\
32.04 \\
31.96\end{array}$ & $\begin{array}{l}8.44 \\
8.62 \\
8.50\end{array}$ \\
\hline \multicolumn{9}{|l|}{$\begin{array}{l}\text { F0-2 } \\
\text { F0-3 } \\
\text { F0-4 } \\
\text { F0-5 }\end{array}$} \\
\hline $\begin{array}{l}\text { F0-7 } \\
\text { F0-8 } \\
\text { F0-9 } \\
\text { F0-10 } \\
\text { F0-2 }\end{array}$ & & $\begin{array}{l}2.28 \\
2.42 \\
2.03 \\
2.80\end{array}$ & $\begin{array}{l}2.12 \\
2.15 \\
1.94 \\
2.47\end{array}$ & $\begin{array}{l}0.97 \\
0.97 \\
0.97 \\
0.97 \\
0.97\end{array}$ & $\begin{array}{l}6.78 \\
6.79 \\
6.78 \\
6.76 \\
6.78\end{array}$ & $\begin{array}{l}33.91 \\
33.97 \\
33.91 \\
33.79 \\
33.91\end{array}$ & $\begin{array}{l}32.17 \\
32.23 \\
32.17 \\
32.06 \\
32.17\end{array}$ & $\begin{array}{l}0.32 \\
0.29 \\
0.32 \\
0.32 \\
0.32\end{array}$ \\
\hline \multicolumn{9}{|l|}{$\begin{array}{l}A C l 18 c \\
A C l 16 a\end{array}$} \\
\hline $\begin{array}{l}A C l 19 d \\
A C l 17 b\end{array}$ & & $\begin{array}{c}15.65 \\
3.47\end{array}$ & $\begin{array}{c}10.97 \\
2.37\end{array}$ & $\begin{array}{l}0.93 \\
0.93\end{array}$ & $\begin{array}{l}14.12 \\
18.36\end{array}$ & $\begin{array}{l}70.62 \\
91.81\end{array}$ & $\begin{array}{l}91.58 \\
87.11\end{array}$ & $\begin{array}{c}25.83 \\
0.79\end{array}$ \\
\hline$F 0 / 5$ & & 5.94 & 5.28 & 0.89 & 24.07 & 120.37 & 114.21 & 1.15 \\
\hline \multicolumn{9}{|l|}{ IMP 0-4 } \\
\hline \multicolumn{9}{|l|}{$\begin{array}{l}\text { F5A1-4 } \\
\text { F5A2-4 } \\
\text { F5A3-4 } \\
\text { F5A4-4 }\end{array}$} \\
\hline $\begin{array}{l}\text { F5A1-9 } \\
\text { F5A2-9 } \\
\text { F5A3-9 } \\
\text { F5A4-9 }\end{array}$ & & $\begin{array}{l}2.79 \\
4.01 \\
2.88 \\
3.55\end{array}$ & $\begin{array}{l}2.61 \\
3.40 \\
2.68 \\
3.32\end{array}$ & $\begin{array}{l}0.99 \\
0.98 \\
0.99 \\
0.99\end{array}$ & $\begin{array}{l}4.96 \\
4.95 \\
4.97 \\
4.97\end{array}$ & $\begin{array}{l}24.81 \\
24.77 \\
24.85 \\
24.85\end{array}$ & $\begin{array}{l}24.98 \\
25.53 \\
25.11 \\
26.13\end{array}$ & $\begin{array}{l}0.38 \\
1.04 \\
0.70 \\
1.55\end{array}$ \\
\hline \multicolumn{9}{|l|}{$\begin{array}{l}\text { F1A1-4 } \\
\text { F1A2-4 } \\
\text { F1A3-4 } \\
\text { F1A4-4 }\end{array}$} \\
\hline $\begin{array}{l}\text { F1A1-9 } \\
\text { F1A2-9 } \\
\text { F1A3-9 } \\
\text { F1A4-9 }\end{array}$ & & $\begin{array}{l}1.81 \\
1.71 \\
1.52 \\
0.54 \\
\end{array}$ & $\begin{array}{l}1.76 \\
1.73 \\
1.27 \\
0.75 \\
\end{array}$ & $\begin{array}{l}0.99 \\
0.98 \\
0.99 \\
0.99 \\
\end{array}$ & $\begin{array}{l}4.97 \\
4.95 \\
4.97 \\
4.99 \\
\end{array}$ & $\begin{array}{l}24.85 \\
24.77 \\
24.85 \\
24.94 \\
\end{array}$ & $\begin{array}{l}23.24 \\
23.59 \\
23.24 \\
23.32 \\
\end{array}$ & $\begin{array}{l}0.00 \\
0.02 \\
0.23 \\
0.02 \\
\end{array}$ \\
\hline
\end{tabular}

ICEDF DF WorkSheet (page 2)

$$
\text { E. } 58
$$




\begin{tabular}{|c|c|c|c|c|c|c|c|}
\hline \multirow{2}{*}{\multicolumn{2}{|c|}{$\begin{array}{lc} & \sum \text { Sample } \\
\text { Volume } \\
\text { Sample } & @ \text { To } \\
\text { ID No. } & \text { (1) } \\
\end{array}$}} & \multicolumn{3}{|c|}{ Mass } & \multicolumn{3}{|c|}{$\mathrm{ZnS}$} \\
\hline & & $\begin{array}{c}\mathrm{Cm} \\
@ \mathrm{To} \\
\left(\mathrm{mg} / \mathrm{m}^{\wedge} 3\right)\end{array}$ & $\begin{array}{c}\text { Mass Flow } \\
\text { @ To } \\
\text { (mg/s) }\end{array}$ & $\begin{array}{l}\text { Approx. } \\
\text { Feed Rate } \\
\text { (g/min) }\end{array}$ & $\begin{array}{c}\text { Cm } \\
\text { @ To } \\
\left(\mathrm{mg} / \mathrm{m}^{\wedge} 3\right)\end{array}$ & $\begin{array}{c}\text { Mass Flow } \\
@ \text { To } \\
(\mathrm{mg} / \mathrm{s})\end{array}$ & $\begin{array}{c}\text { Approx. } \\
\text { Fe日d Rate } \\
\text { (g/min) }\end{array}$ \\
\hline $\begin{array}{l}\text { F6A-2 } \\
\text { F6A-4 } \\
\text { F6A-5 }\end{array}$ & & & & & & & \\
\hline $\begin{array}{c}\text { F6A-7 } \\
\text { F6A-9 } \\
\text { F6A-10 }\end{array}$ & $\begin{array}{l}40.40 \\
40.66 \\
40.45\end{array}$ & $\begin{array}{l}136.62 \\
153.70 \\
151.28\end{array}$ & $\begin{array}{c}9.94 \\
11.25 \\
11.02\end{array}$ & $\begin{array}{l}0.60 \\
0.67 \\
0.66\end{array}$ & $\begin{array}{l}109.18 \\
133.41 \\
121.94\end{array}$ & $\begin{array}{l}7.95 \\
9.76 \\
8.88\end{array}$ & $\begin{array}{l}0.48 \\
0.59 \\
0.53\end{array}$ \\
\hline $\begin{array}{l}F 0-2 \\
F 0-3 \\
F 0-4 \\
F 0-5\end{array}$ & & & & & & & \\
\hline $\begin{array}{l}F 0-7 \\
F 0-8 \\
F 0-9 \\
F 0-10 \\
F 0-2\end{array}$ & $\begin{array}{l}32.50 \\
32.52 \\
32.50 \\
32.38 \\
32.50\end{array}$ & $\begin{array}{l}70.16 \\
74.41 \\
62.47 \\
86.47\end{array}$ & $\begin{array}{l}2.99 \\
3.17 \\
2.66 \\
3.69\end{array}$ & $\begin{array}{l}0.18 \\
0.19 \\
0.16 \\
0.22\end{array}$ & $\begin{array}{l}65.12 \\
65.99 \\
59.62 \\
76.40\end{array}$ & $\begin{array}{l}2.78 \\
2.81 \\
2.54 \\
3.26\end{array}$ & $\begin{array}{l}0.17 \\
0.17 \\
0.15 \\
0.20\end{array}$ \\
\hline $\begin{array}{l}A C I 18 c \\
A C l 16 a \\
A C I 19 d \\
A C I 17 b\end{array}$ & $\begin{array}{c}117.42 \\
87.90\end{array}$ & $\begin{array}{c}133.29 \\
39.48\end{array}$ & $\begin{array}{l}9.81 \\
1.68\end{array}$ & $\begin{array}{l}0.59 \\
0.10\end{array}$ & $\begin{array}{l}93.42 \\
26.96\end{array}$ & $\begin{array}{l}6.87 \\
1.15\end{array}$ & $\begin{array}{l}0.41 \\
0.07\end{array}$ \\
\hline $\begin{array}{c}\text { F 0/5 } \\
\text { IMP 0-4 } \\
\text { IMP 0-9 }\end{array}$ & 115.36 & 51.49 & 2.19 & 0.13 & 45.73 & 1.95 & 0.12 \\
\hline $\begin{array}{l}\text { F5A1-4 } \\
\text { F5A2-4 } \\
\text { F5A3-4 } \\
\text { F5A4-4 } \\
\text { F5A1-9 } \\
\text { F5A2-9 } \\
\text { F5A3-9 } \\
\text { F5A4-9 }\end{array}$ & $\begin{array}{l}25.36 \\
26.57 \\
25.81 \\
27.68\end{array}$ & $\begin{array}{l}110.01 \\
150.94 \\
111.60 \\
128.26\end{array}$ & $\begin{array}{l}\text { ND } \\
\text { ND } \\
\text { ND } \\
\text { ND } \\
\text { ND } \\
\text { ND } \\
\text { ND } \\
\text { ND }\end{array}$ & $\begin{array}{l}\text { ND } \\
\text { ND } \\
\text { ND } \\
\text { ND } \\
\text { ND } \\
\text { ND } \\
\text { ND } \\
\text { ND }\end{array}$ & $\begin{array}{l}102.83 \\
127.90 \\
103.95 \\
120.08\end{array}$ & $\begin{array}{l}\text { ND } \\
\text { ND } \\
\text { ND } \\
\text { ND } \\
\text { ND } \\
\text { ND } \\
\text { ND } \\
\text { ND }\end{array}$ & $\begin{array}{l}\text { ND } \\
\text { ND } \\
\text { ND } \\
\text { ND } \\
\text { ND } \\
\text { ND } \\
\text { ND } \\
\text { ND }\end{array}$ \\
\hline $\begin{array}{l}\text { F1A1-4 } \\
\text { F1A2-4 } \\
\text { F1A3-4 } \\
\text { F1A4-4 } \\
\text { F1A1-9 } \\
\text { F1A2-9 } \\
\text { F1A3-9 } \\
\text { F1A4-9 }\end{array}$ & $\begin{array}{l}23.24 \\
23.61 \\
23.48 \\
23.35\end{array}$ & $\begin{array}{l}77.87 \\
72.43 \\
64.74 \\
23.13\end{array}$ & $\begin{array}{l}\text { ND } \\
\text { ND } \\
\text { ND } \\
\text { ND } \\
\text { ND } \\
N D \\
N D \\
N D \\
N D\end{array}$ & $\begin{array}{l}N D \\
N D \\
N D \\
N D \\
N D \\
N D \\
N D \\
N D\end{array}$ & $\begin{array}{l}75.66 \\
73.22 \\
53.96 \\
31.92 \\
\end{array}$ & $\begin{array}{l}\text { ND } \\
\text { ND } \\
\text { ND } \\
\text { ND } \\
\text { ND } \\
\text { ND } \\
\text { ND } \\
\text { ND }\end{array}$ & $\begin{array}{l}\text { ND } \\
\text { ND } \\
\text { ND } \\
\text { ND } \\
\text { ND } \\
\text { ND } \\
\text { ND } \\
\text { ND }\end{array}$ \\
\hline
\end{tabular}


How to use "ICEDF DF WkSht 8/89"

1) Open "ICEDF DF WkSht 8/89"

2) Enter test name and other constants.

3) Save As "ICEDF testname DF month/year".

4) Enter data on page 1 (change sample ID's if req'd)

\section{WorkSheet Updates:}

10/5/89: Added correction for $\triangle P$ upstream of critical orifice, changed sample ID No. listing.

10/5/89: Removed aerosol mass flow rate calculations for quad stations.

\begin{tabular}{|cc|}
\hline \multicolumn{2}{|c|}{ Critical Orifice Calib. } \\
\hline & \\
CO (\#) & Q (lpm) \\
\hline 50 & 27.2 \\
53 & 19.8 \\
55 & 15.2 \\
58 & 9.14 \\
65 & 6.97 \\
69 & 5.03 \\
74 & 2.47 \\
77 & 1.45 \\
80 & 1.03 \\
\hline
\end{tabular}




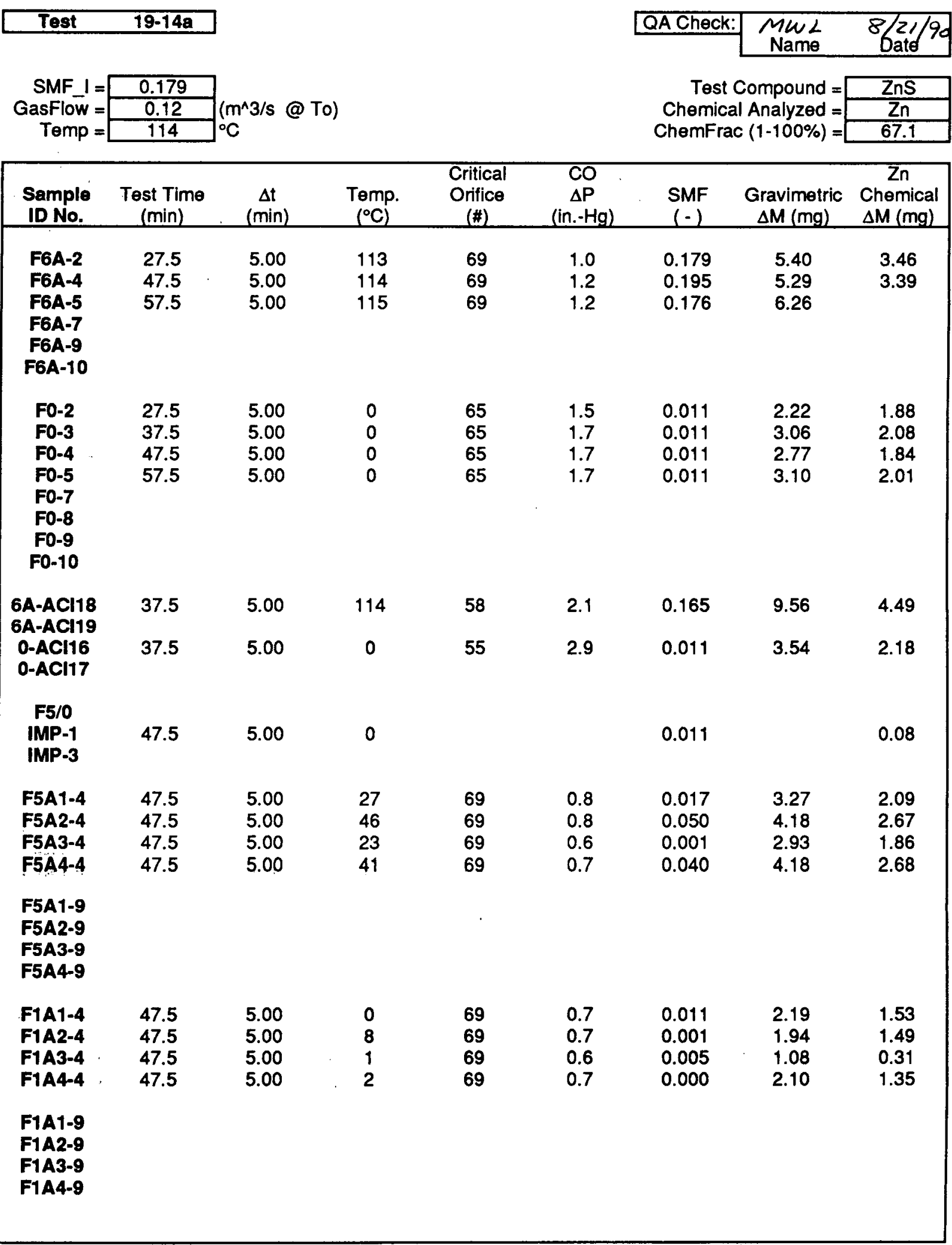




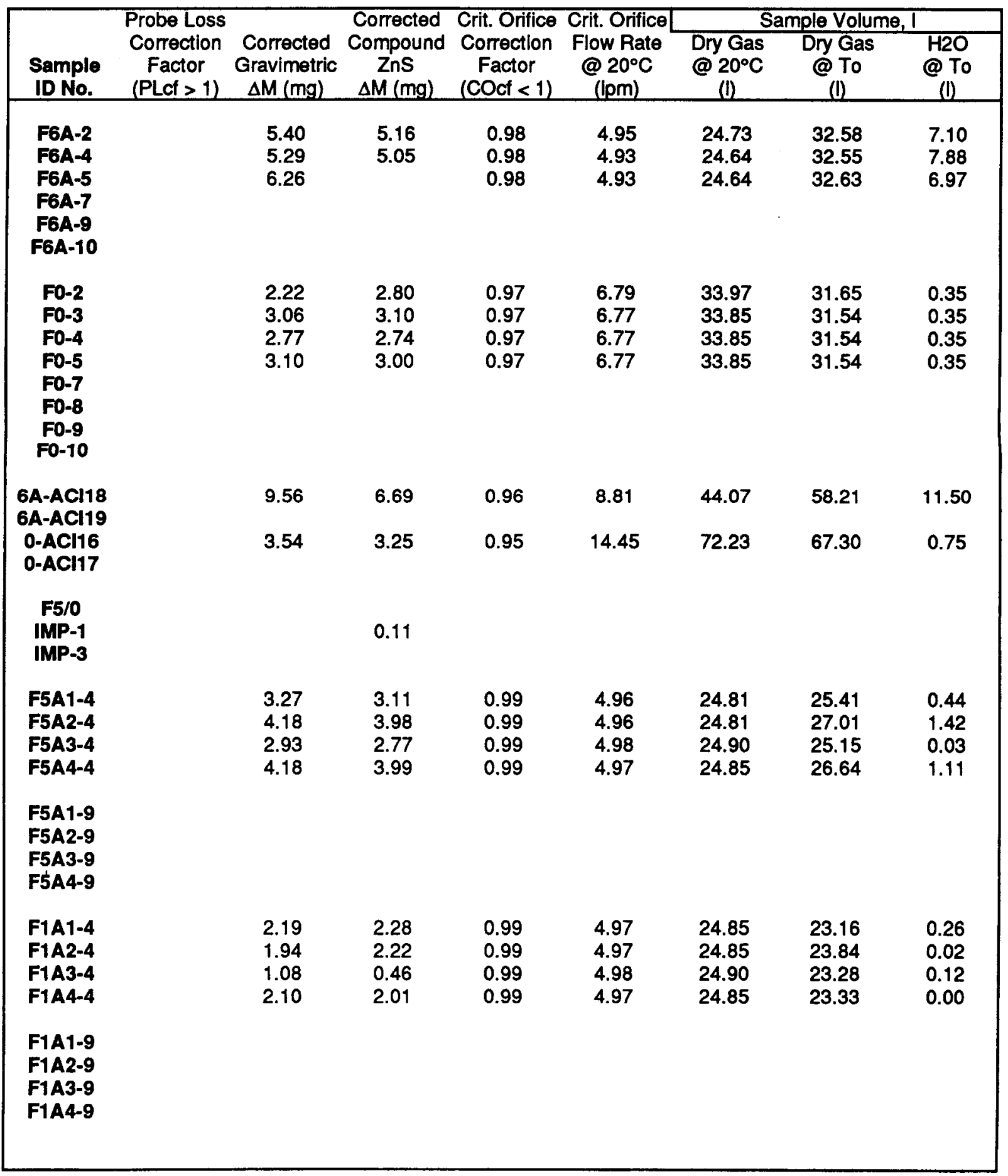




\begin{tabular}{|c|c|c|c|c|c|c|c|}
\hline & E Sample & & Mass & & & $\mathrm{ZnS}$ & \\
\hline $\begin{array}{l}\text { Sample } \\
\text { ID No. }\end{array}$ & $\begin{array}{c}\text { Volume } \\
\text { @ To } \\
\text { (I) }\end{array}$ & $\begin{array}{c}\mathrm{Cm} \\
@ \text { To } \\
\left(\mathrm{mg} / \mathrm{m}^{\wedge} 3\right)\end{array}$ & $\begin{array}{c}\text { Mass Flow } \\
@ \text { To } \\
(\mathrm{mg} / \mathrm{s})\end{array}$ & $\begin{array}{c}\text { Approx. } \\
\text { Feed Rate } \\
\text { (g/min) }\end{array}$ & $\begin{array}{c}\text { Cm } \\
@ \text { To } \\
\left(\mathrm{mg} / \mathrm{m}^{\wedge} 3\right)\end{array}$ & $\begin{array}{c}\text { Mass Flow } \\
@ \text { To } \\
(\mathrm{mg} / \mathrm{s})\end{array}$ & $\begin{array}{c}\text { Approx. } \\
\text { Feed Rate } \\
\text { (g/min) }\end{array}$ \\
\hline $\begin{array}{l}\text { F6A-2 } \\
\text { F6A-4 } \\
\text { F6A-5 } \\
\text { F6A-7 } \\
\text { F6A-9 } \\
\text { F6A-10 }\end{array}$ & $\begin{array}{l}39.68 \\
40.43 \\
39.60\end{array}$ & $\begin{array}{l}136.09 \\
130.84 \\
158.08\end{array}$ & $\begin{array}{l}16.29 \\
15.95 \\
18.96\end{array}$ & $\begin{array}{l}0.98 \\
0.96 \\
1.14\end{array}$ & $\begin{array}{l}129.96 \\
124.96\end{array}$ & $\begin{array}{l}15.55 \\
15.23\end{array}$ & $\begin{array}{l}0.93 \\
0.91\end{array}$ \\
\hline $\begin{array}{c}\text { F0-2 } \\
\text { F0-3 } \\
\text { F0-4 } \\
\text { F0-5 } \\
\text { F0-7 } \\
\text { F0-8 } \\
\text { F0-9 } \\
\text { F0-10 }\end{array}$ & $\begin{array}{l}32.00 \\
31.89 \\
31.89 \\
31.89\end{array}$ & $\begin{array}{l}69.37 \\
95.96 \\
86.87 \\
97.21\end{array}$ & $\begin{array}{l}4.89 \\
6.76 \\
6.12 \\
6.85\end{array}$ & $\begin{array}{l}0.29 \\
0.41 \\
0.37 \\
0.41\end{array}$ & $\begin{array}{l}87.55 \\
97.21 \\
85.99 \\
93.94\end{array}$ & $\begin{array}{l}6.17 \\
6.85 \\
6.06 \\
6.62\end{array}$ & $\begin{array}{l}0.37 \\
0.41 \\
0.36 \\
0.40\end{array}$ \\
\hline $\begin{array}{c}\text { 6A-ACI18 } \\
\text { 6A-ACl19 } \\
0-A C l 16 \\
0-A C l 17\end{array}$ & $\begin{array}{l}69.71 \\
68.05\end{array}$ & $\begin{array}{l}137.13 \\
52.02\end{array}$ & $\begin{array}{l}16.23 \\
3.66\end{array}$ & $\begin{array}{l}0.97 \\
0.22\end{array}$ & $\begin{array}{l}95.99 \\
47.74\end{array}$ & $\begin{array}{l}11.36 \\
3.36\end{array}$ & $\begin{array}{l}0.68 \\
0.20\end{array}$ \\
\hline $\begin{array}{l}\text { F5/0 } \\
\text { IMP-1 } \\
\text { IMP-3 }\end{array}$ & & & & & Flow? & & \\
\hline $\begin{array}{l}\text { F5A1-4 } \\
\text { F5A2-4 } \\
\text { F5A3-4 } \\
\text { F5A4-4 }\end{array}$ & $\begin{array}{l}25.84 \\
28.44 \\
25.18 \\
27.75\end{array}$ & $\begin{array}{l}126.53 \\
147.00 \\
116.37 \\
150.65\end{array}$ & $\begin{array}{l}\text { ND } \\
\text { ND } \\
\text { ND } \\
\text { ND }\end{array}$ & $\begin{array}{l}\text { ND } \\
\text { ND } \\
\text { ND } \\
\text { ND }\end{array}$ & $\begin{array}{l}120.52 \\
139.93 \\
110.10 \\
143.95\end{array}$ & $\begin{array}{l}\text { ND } \\
\text { ND } \\
\text { ND } \\
\text { ND }\end{array}$ & $\begin{array}{l}\text { ND } \\
\text { ND } \\
\text { ND } \\
\text { ND }\end{array}$ \\
\hline $\begin{array}{l}\text { F5A1-9 } \\
\text { F5A2-9 } \\
\text { F5A3-9 } \\
\text { F5A4-9 }\end{array}$ & & & & & & & \\
\hline $\begin{array}{l}\text { F1A1-4 } \\
\text { F1A2-4 } \\
\text { F1A3-4 } \\
\text { F1A4-4 }\end{array}$ & $\begin{array}{l}23.42 \\
23.86 \\
23.40 \\
23.33\end{array}$ & $\begin{array}{l}93.53 \\
81.31 \\
46.15 \\
90.01\end{array}$ & $\begin{array}{l}\text { ND } \\
\text { ND } \\
\text { ND } \\
\text { ND }\end{array}$ & $\begin{array}{l}\text { ND } \\
\text { ND } \\
\text { N D } \\
\text { N D }\end{array}$ & $\begin{array}{l}97.38 \\
93.06 \\
19.74 \\
86.24\end{array}$ & $\begin{array}{l}\text { ND } \\
\text { ND } \\
\text { ND } \\
\text { ND }\end{array}$ & $\begin{array}{l}\text { ND } \\
\text { ND } \\
\text { ND } \\
\text { ND }\end{array}$ \\
\hline $\begin{array}{l}\text { F1A1-9 } \\
\text { F1A2-9 } \\
\text { F1A3-9 } \\
\text { F1A4-9 }\end{array}$ & & & & & & & \\
\hline
\end{tabular}

ICEDF DF WorkSheet (page 3)

$$
\text { E. } 63
$$




\section{How to use "ICEDF DF WkSht 8/89"}

1) Open "ICEDF DF WkSht 8/89"

2) Enter test name and other constants.

3) Save As "ICEDF testname DF month/year".

4) Enter data on page 1 (change sample ID's if req'd)

WorkSheet Updates:

10/5/89: Added correction for $\triangle \mathrm{P}$ upstream of critical orifice, changed sample ID No. listing. 10/5/89: Removed aerosol mass flow rate calculations for quad stations.

\begin{tabular}{|cc|}
\hline \multicolumn{2}{|c|}{ Critical Orifice Calib. } \\
\hline & \\
CO (\#) & Q (lpm) \\
\hline 50 & 27.2 \\
53 & 19.8 \\
55 & 15.2 \\
58 & 9.14 \\
65 & 6.97 \\
69 & 5.03 \\
74 & 2.47 \\
77 & 1.45 \\
80 & 1.03 \\
\hline
\end{tabular}




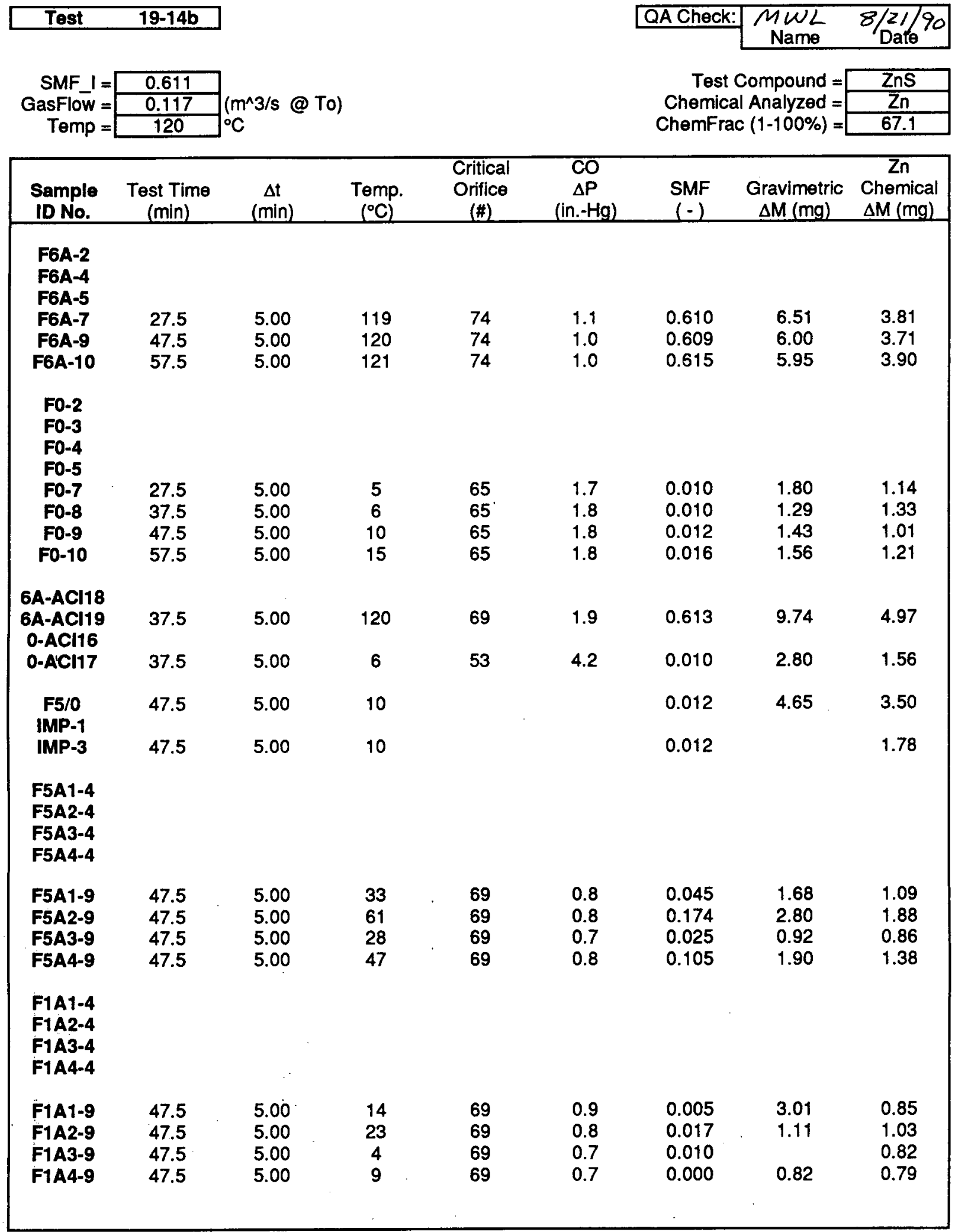

ICEDF DF WorkShe日t (page 1)

E. 65 
Test 19-14b

\begin{tabular}{|c|c|c|c|c|c|c|c|c|}
\hline $\begin{array}{l}\text { Sample } \\
\text { ID No. }\end{array}$ & $\begin{array}{l}\text { Probe Loss } \\
\text { Correction } \\
\text { Factor } \\
(\text { PLcf }>1)\end{array}$ & $\begin{array}{l}\text { Corrected } \\
\text { Gravimetric } \\
\Delta M(\mathrm{mg})\end{array}$ & $\begin{array}{c}\text { Corrected } \\
\text { Compoind } \\
\text { ZnS } \\
\Delta \mathrm{M}(\mathrm{mg})\end{array}$ & $\begin{array}{l}\text { Crit. Orifice } \\
\text { Correction } \\
\text { Factor } \\
(\text { COcf }<1)\end{array}$ & $\begin{array}{l}\text { Crit. Orifice } \\
\text { Flow Rate } \\
@ 20^{\circ} \mathrm{C} \\
\text { (lpm) }\end{array}$ & $\begin{array}{c}\text { S } \\
\text { Dry Gas } \\
@ 20^{\circ} \mathrm{C} \\
(1)\end{array}$ & $\begin{array}{c}\text { nple Volum } \\
\text { Dry Gas } \\
@ \text { To } \\
\text { (I) }\end{array}$ & $\begin{array}{l}\mathrm{H} 2 \mathrm{O} \\
@ \text { To } \\
\text { (l) }\end{array}$ \\
\hline $\begin{array}{c}\text { F6A-2 } \\
\text { F6A-4 } \\
\text { F6A-5 } \\
\text { F6A-7 } \\
\text { F6A-9 } \\
\text { F6A-10 }\end{array}$ & & $\begin{array}{l}6.51 \\
6.00 \\
5.95\end{array}$ & $\begin{array}{l}5.68 \\
5.53 \\
5.81\end{array}$ & $\begin{array}{l}0.98 \\
0.98 \\
0.98\end{array}$ & $\begin{array}{l}2.42 \\
2.43 \\
2.43\end{array}$ & $\begin{array}{l}12.12 \\
12.14 \\
12.14\end{array}$ & $\begin{array}{l}16.22 \\
16.29 \\
16.33\end{array}$ & $\begin{array}{l}25.37 \\
25.37 \\
26.08\end{array}$ \\
\hline \multicolumn{9}{|l|}{$\begin{array}{l}\text { F0-2 } \\
\text { F0-3 } \\
\text { F0-4 } \\
\text { F0-5 }\end{array}$} \\
\hline $\begin{array}{c}6 A-A C l 18 \\
6 A-A C l 19 \\
0-A C l 16 \\
0-A C l 17\end{array}$ & & $\begin{array}{l}9.74 \\
2.80\end{array}$ & $\begin{array}{l}7.41 \\
2.32\end{array}$ & 0.97 & $\begin{array}{r}4.87 \\
18.36\end{array}$ & $\begin{array}{l}24.34 \\
91.81\end{array}$ & $\begin{array}{l}32.65 \\
87.42\end{array}$ & 51.71 \\
\hline $\begin{array}{c}\text { F5/0 } \\
\text { IMP-1 } \\
\text { IMP-3 }\end{array}$ & & 4.65 & $\begin{array}{l}5.22 \\
2.65\end{array}$ & & & & & \\
\hline \multicolumn{9}{|l|}{$\begin{array}{l}\text { F5A1-4 } \\
\text { F5A2-4 } \\
\text { F5A3-4 } \\
\text { F5A4-4 }\end{array}$} \\
\hline $\begin{array}{l}\text { F5A1-9 } \\
\text { F5A2-9 } \\
\text { F5A3-9 } \\
\text { F5A4-9 }\end{array}$ & & $\begin{array}{l}1.68 \\
2.80 \\
0.92 \\
1.90\end{array}$ & $\begin{array}{l}1.62 \\
2.80 \\
1.28 \\
2.06\end{array}$ & $\begin{array}{l}0.99 \\
0.99 \\
0.99 \\
0.99\end{array}$ & $\begin{array}{l}4.96 \\
4.96 \\
4.97 \\
4.96\end{array}$ & $\begin{array}{l}24.81 \\
24.81 \\
24.85 \\
24.81\end{array}$ & $\begin{array}{l}25.91 \\
28.28 \\
25.53 \\
27.10\end{array}$ & $\begin{array}{l}1.22 \\
5.96 \\
0.65 \\
3.18\end{array}$ \\
\hline \multicolumn{9}{|l|}{$\begin{array}{l}\text { F1A1-4 } \\
\text { F1A2-4 } \\
\text { F1A3-4 } \\
\text { F1A4-4 }\end{array}$} \\
\hline $\begin{array}{l}\text { F1A1-9 } \\
\text { F1A2-9 } \\
\text { F1A3-9 } \\
\text { F1A4-9 }\end{array}$ & & $\begin{array}{l}3.01 \\
1.11 \\
0.82\end{array}$ & $\begin{array}{l}1.27 \\
1.54 \\
1.22 \\
1.18\end{array}$ & $\begin{array}{l}0.98 \\
0.99 \\
0.99 \\
0.99\end{array}$ & $\begin{array}{l}4.95 \\
4.96 \\
4.97 \\
4.97\end{array}$ & $\begin{array}{l}24.77 \\
24.81 \\
24.85 \\
24.85\end{array}$ & $\begin{array}{l}24.26 \\
25.07 \\
23.50 \\
23.92\end{array}$ & $\begin{array}{l}0.12 \\
0.43 \\
0.24 \\
0.00\end{array}$ \\
\hline
\end{tabular}

ICEDF DF WorkSheet (page 2)

$$
\text { E. } 66
$$




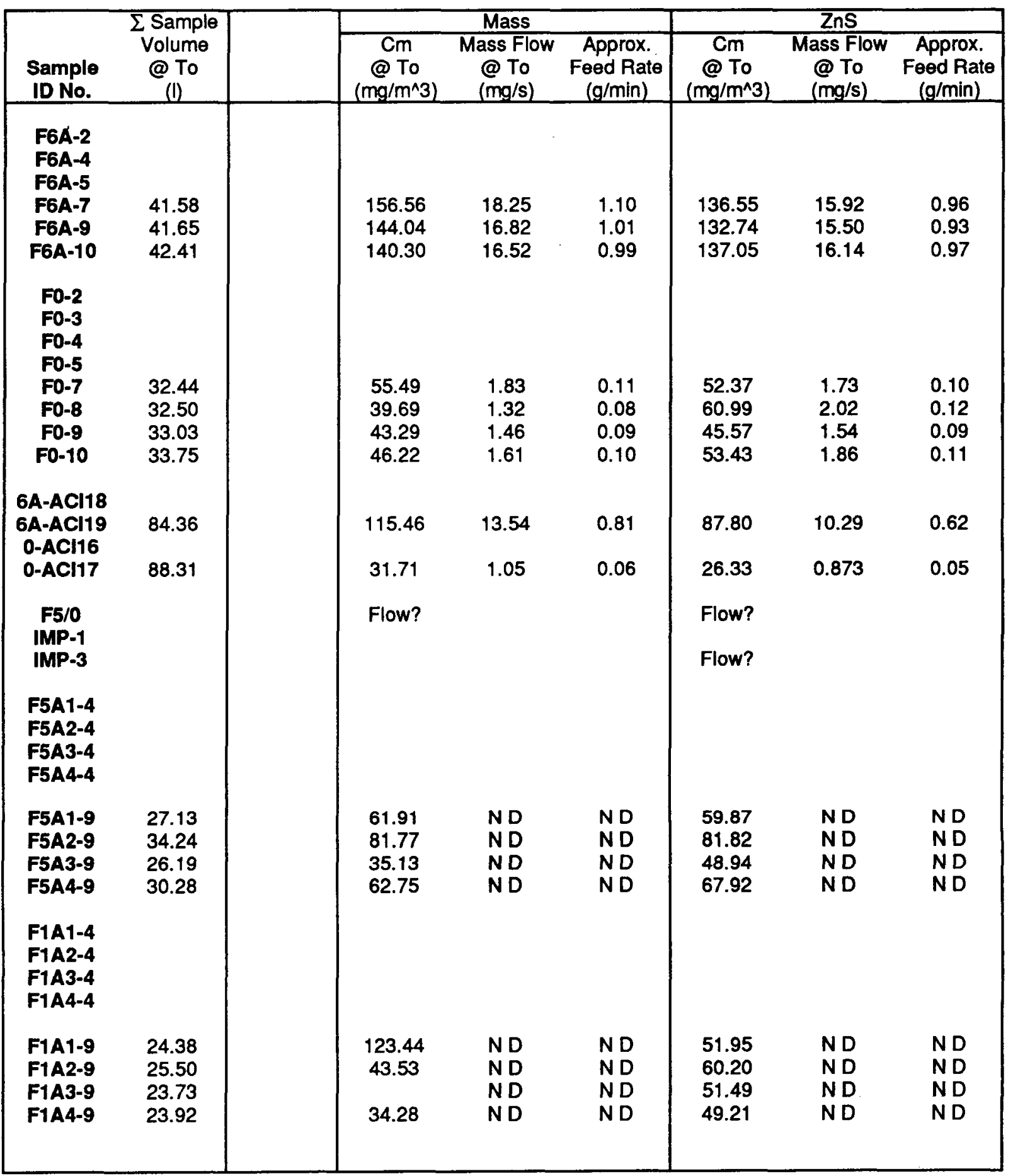

ICEDF DF WorkSheet (page 3)

$$
\text { E. } 67
$$




\section{How to use "ICEDF DF WkSht 8/89"}

1) Open "ICEDF DF WkSht $8 / 89$ "

2) Enter test name and other constants.

3) Save As "ICEDF testname DF month/year".

4) Enter data on page 1 (change sample ID's if req'd)

\section{WorkSheet Updates:}

10/5/89: Added correction for $\triangle P$ upstream of critical orifice, changed sample ID No. listing. 10/5/89: Removed aerosol mass flow rate calculations for quad stations.

\begin{tabular}{|cc|}
\hline \multicolumn{2}{|c|}{ Critical Orifice Calib. } \\
\hline & \\
CO (\#) & Q (lpm) \\
\hline 50 & 27.2 \\
53 & 19.8 \\
55 & 15.2 \\
58 & 9.14 \\
65 & 6.97 \\
69 & 5.03 \\
74 & 2.47 \\
77 & 1.45 \\
80 & 1.03 \\
\hline
\end{tabular}


APPENDIX $\mathbf{F}$

ICE-BASKET REGGION PARTICLE MASS CONCENTRATION 


\section{APPENDIX $\mathbf{F}$ \\ ICE-BASKET REGION PARTICLE MASS CONCENTRATION}

Aerosol concentrations present in the ice-basket region provided information on the spatial distribution of particles as influenced by thermalhydraulic conditions. The results of aerosol mass concentration distributions are shown for tests with ice present in the test section. The figures were prepared using data listed in Appendix E. The first test performed using a quad station was 5 (Alternate Test No. 7-5). Data were obtained for all subsequent tests except 12. Quad Stations $5 \mathrm{~A}$ and $1 \mathrm{~A}$ provided data from the centerline of each open flow channel between ice baskets. 


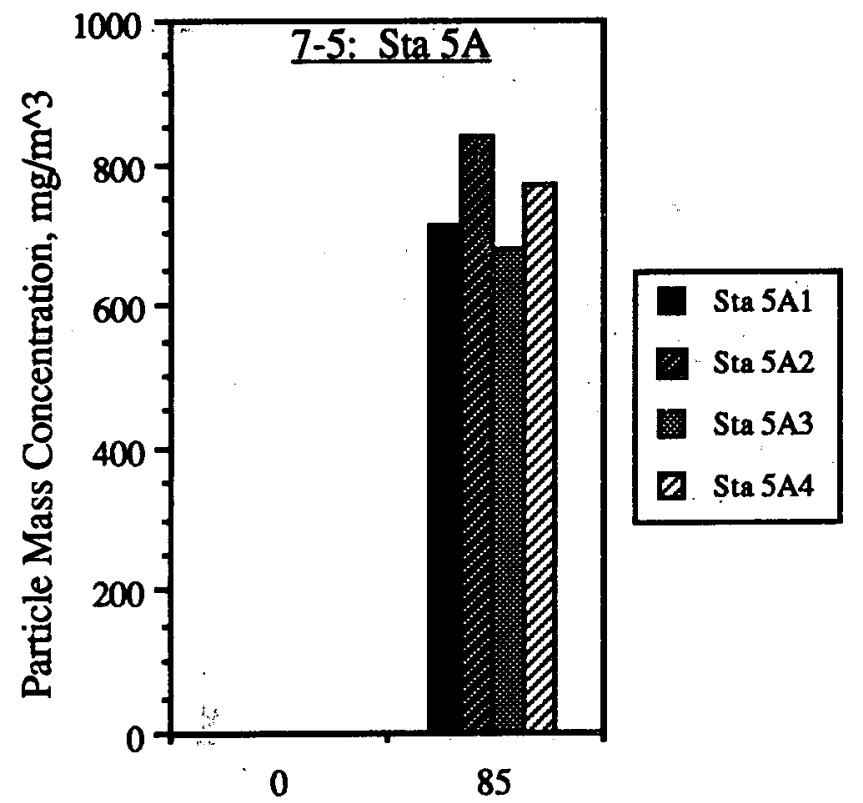

Time, $\min$

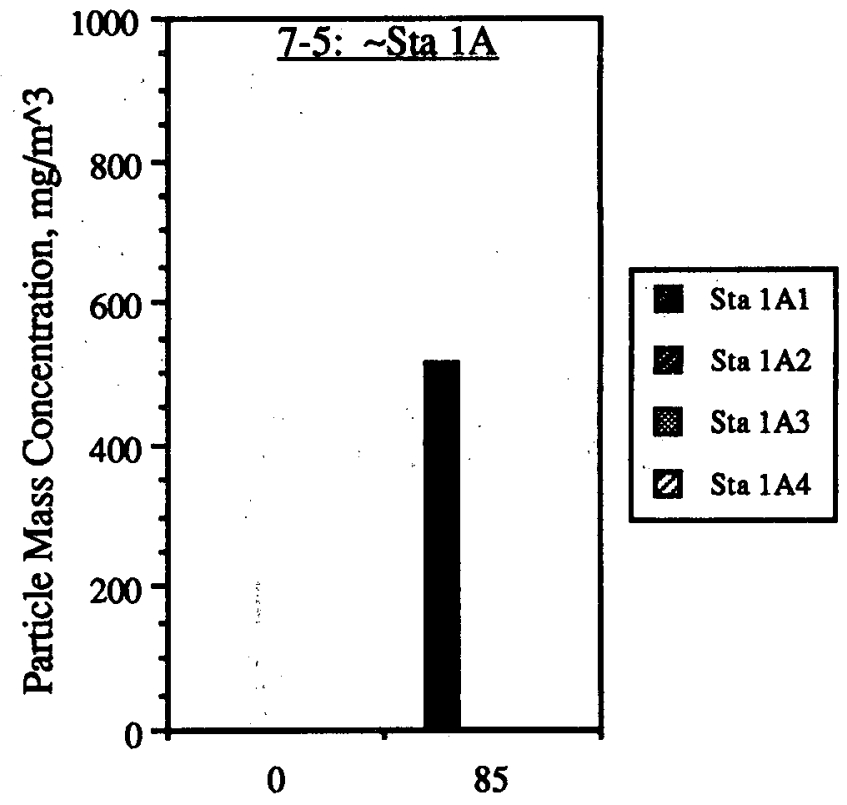

Time, $\min$
7-5 Guad Data 9/90

Data $=\mathrm{cm}$

3 (mg Żns/m^3)

5 Ouad Sta 1 A

5 Ouad Sta 1A

7

8 Sample @ 85'
Mon, Sep 3, 1990 10:50 AM

\begin{tabular}{|c|c|c|c|c|c|c|c|c|}
\hline Time, min & Sta $5 A 1$ & Sta $5 A 2$ & Sta $5 A 3$ & Sta $5 A 4$ & Sta $1 \mathrm{~A} 1$ & Sta $1 A 2$ & Sta $1 \mathrm{A3}$ & Sta $1 \mathrm{A4}$ \\
\hline $\begin{array}{c}0 \\
85\end{array}$ & $\begin{array}{c}0.000 \\
710.000\end{array}$ & $\begin{array}{c}0.000 \\
838.000\end{array}$ & $\begin{array}{c}0.000 \\
680.000\end{array}$ & $\begin{array}{c}0.000 \\
771.000\end{array}$ & $\begin{array}{c}0.000 \\
513.000\end{array}$ & $\begin{array}{l}0.000 \\
0.000\end{array}$ & $\begin{array}{l}0.000 \\
0.000\end{array}$ & $\begin{array}{l}0.000 \\
0.000\end{array}$ \\
\hline
\end{tabular}




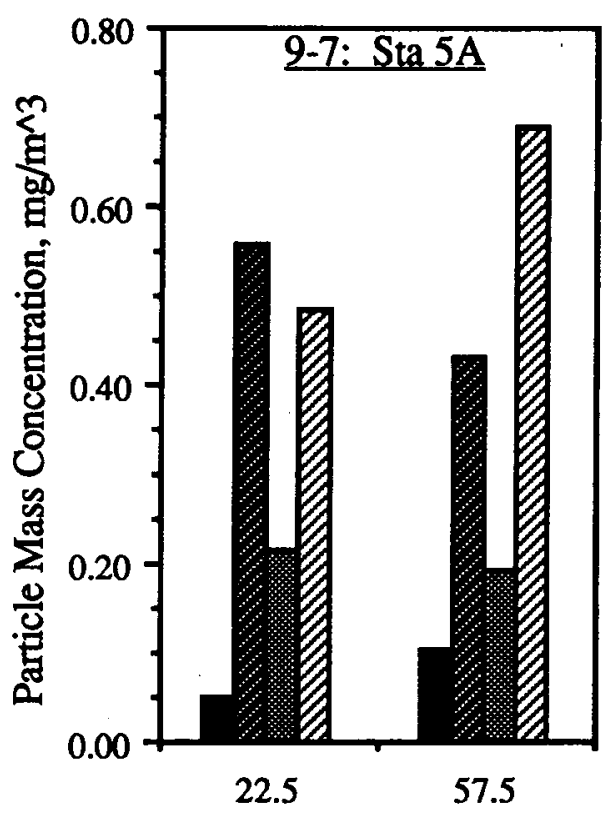

Time, $\min$

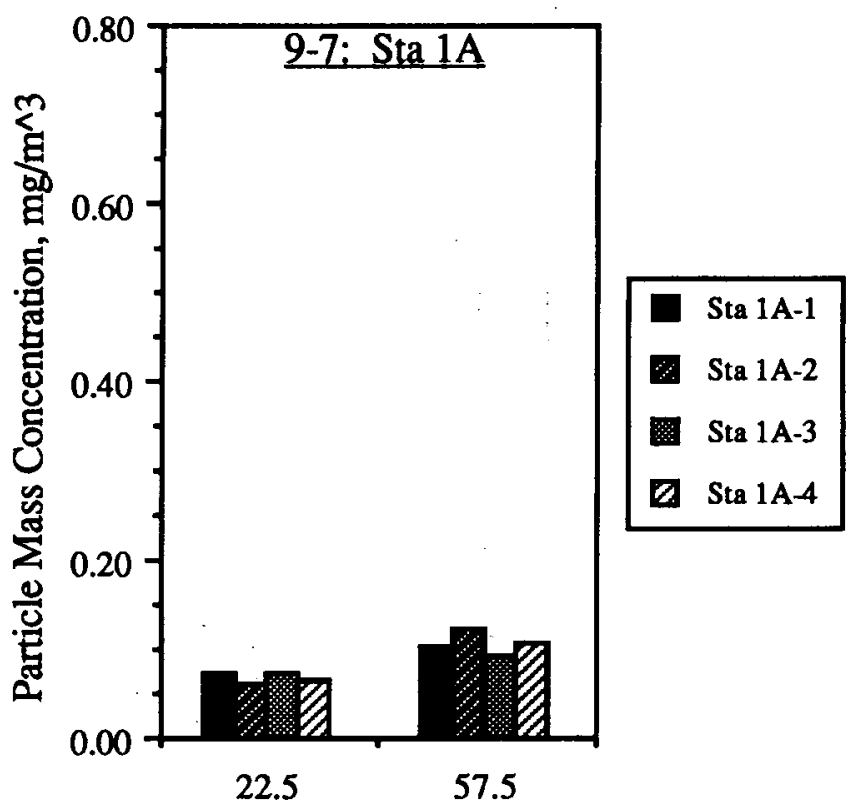

Time, $\min$

9-7 Qued Data 8/80

Tue, Aug 28, 1990 2:45 PM

$\begin{array}{cccccccccc}\text { Test 9-7 } & \text { Time, } m i n & \text { Sta } 5 A-1 & \text { Sta 5A-2 } & \text { Sta 5A-3 } & \text { Sta } 5 A-4 & \text { Sta 1A-1 } & \text { Sta 1A-2 } & \text { Sta 1A-3 } & \text { Sta 1A-4 } \\ & 22.5 & 0.048 & 0.557 & 0.217 & 0.483 & 0.073 & 0.062 & 0.074 & 0.065 \\ \text { Data = Cm } & 57.5 & 0.105 & 0.430 & 0.191 & 0.689 & 0.104 & 0.125 & 0.091 & 0.109\end{array}$

3 (mg Csl/m^3)

F5A2 data is

approximate 


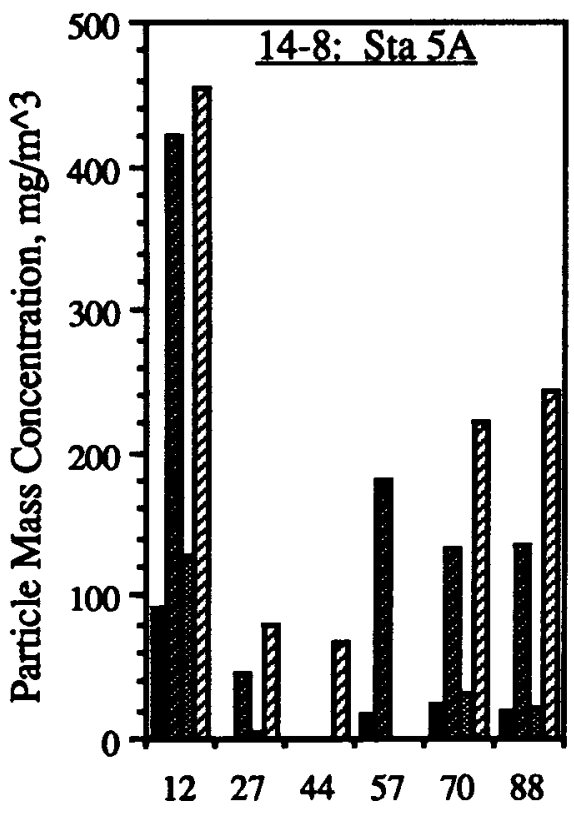

Time, $\min$

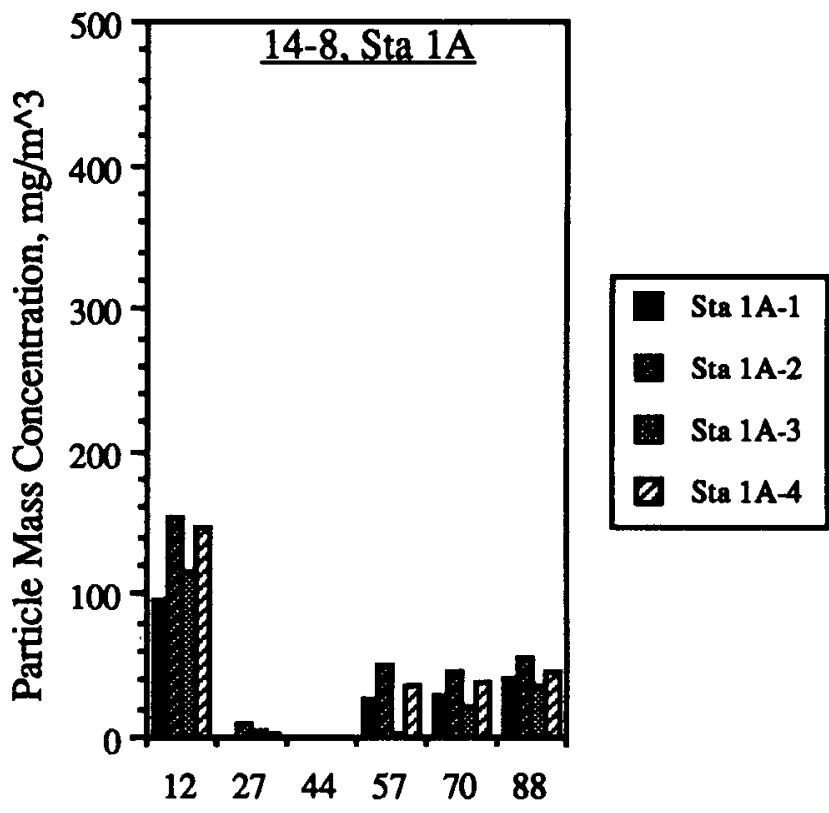

Time, $\min$
14-8 Quad Data 8reo

$\begin{array}{lcc} & \text { Test 14-8 } & \text { Time, min } \\ 1 & & 12 \\ 2 \quad \text { Data }=\mathrm{Cm} & 27 \\ 3 \text { (mg KCl/m^3) } & 44 \\ 4 & 57 \\ 50.0=2 e r 0, \text { or } & 70 \\ 6 \text { no data (lor } & 88 \\ 757,54384) & \end{array}$

$\begin{array}{cc}\text { Sta } 5 A-1 & \text { Sta } 5 A-2 \\ 81.3 & 419.6 \\ 1.0 & 46.5 \\ 0.0 & 0.0 \\ 15.7 & 180.8 \\ 23.6 & 132.1 \\ 18.6 & 134.9\end{array}$

Sta $5 A-3$
126.9
4.6
0.0
0.0
31.9
21.1

Ste $5 A-4$
454.3
78.3
67.4
0.0
220.1
243.0

Sta $1 A-1$
95.3
1.2
0.0
27.3
28.6
40.1
Sta 1A-2
153.2
9.0
0.0
51.6
44.5
55.4

Based on $\mathrm{KCl}$

Mon, Aug 27, $1990 \quad 4: 02$

$\begin{array}{cc}\text { Sta 1A-3 } & \text { Sta } 1 A-4 \\ 114.4 & 147.6 \\ 4.5 & 1.7 \\ 0.0 & 0.0 \\ 2.3 & 36.6 \\ 22.0 & 39.3 \\ 36.2 & 45.2\end{array}$




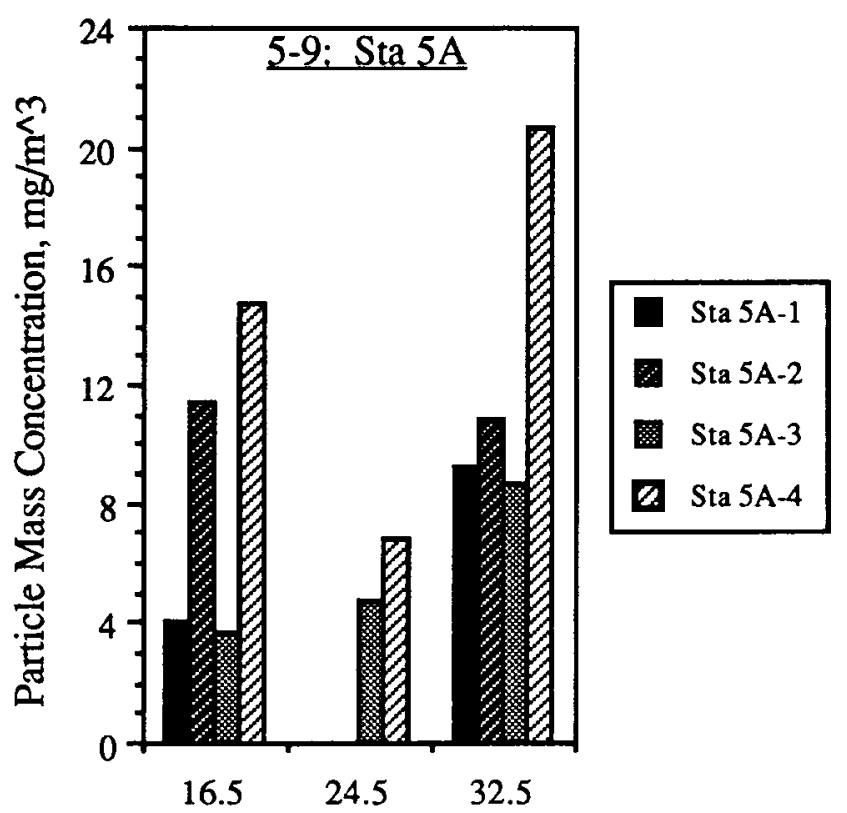

Time, $\min$

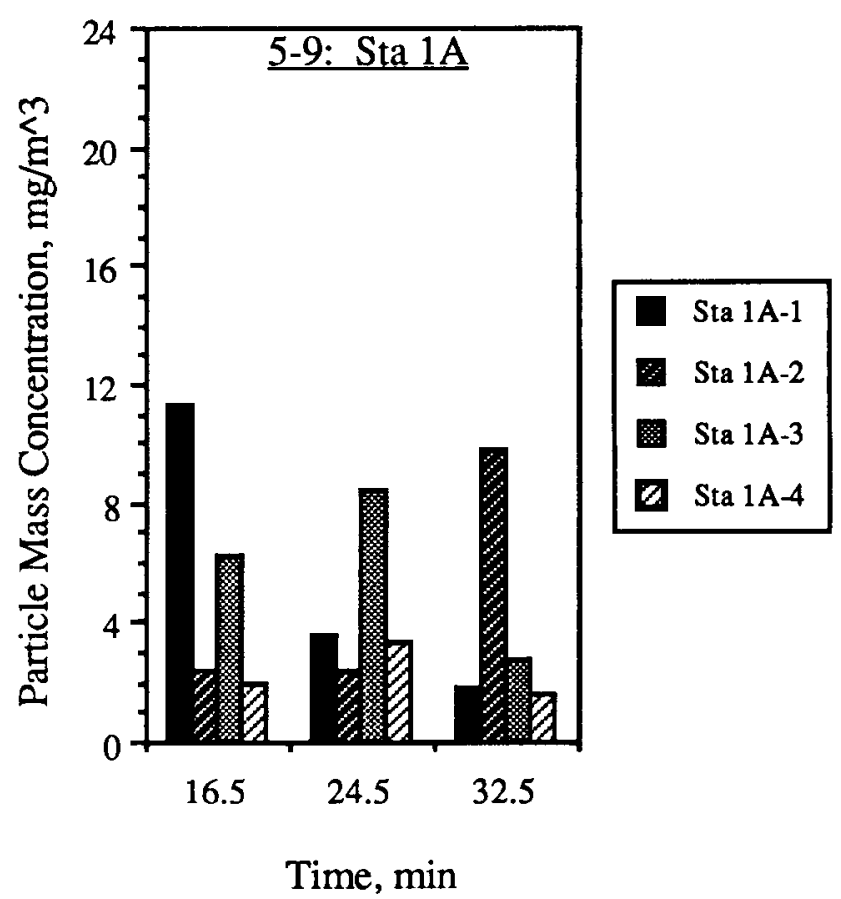

5-9 Qued Data 8/90

$\begin{array}{cccc}\text { Sta } 1 A-1 & \text { Sta } 1 A-2 & \text { Sta } 1 A-3 & \text { Sta } 1 A-4 \\ 11.2 & 2.5 & 6.3 & 2.0 \\ 3.6 & 2.4 & 8.4 & 3.3 \\ 1.9 & 9.8 & 2.8 & 1.6\end{array}$

Based on $\mathrm{KCl}$ 


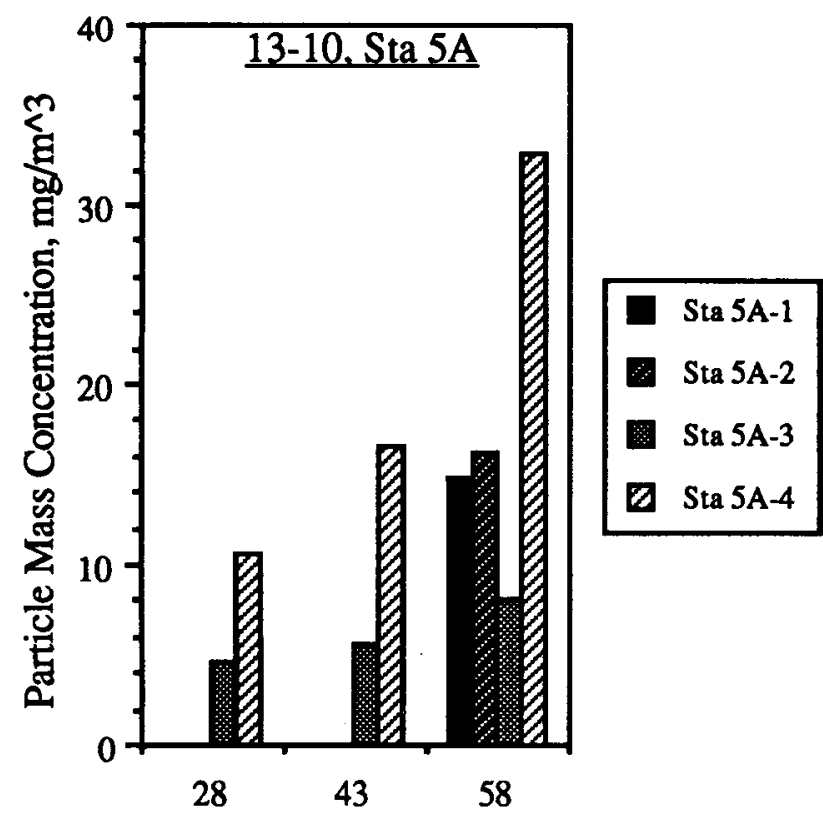

Time, $\min$

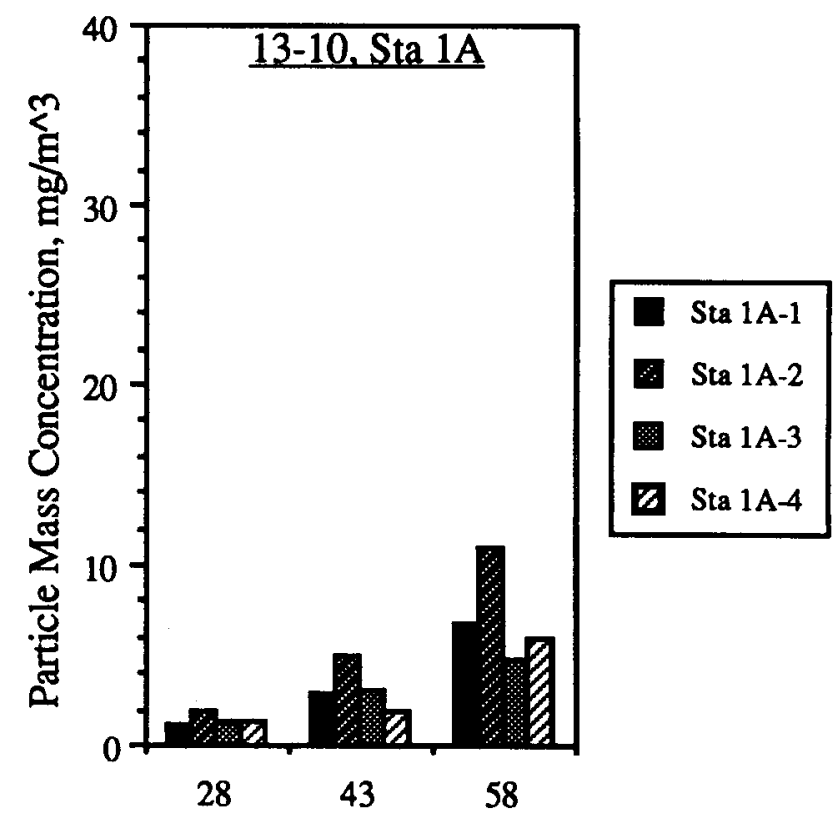

Time, $\min$
13-10 Quad Data 8/90

Test $13-10$
$1 \quad$
2 Data $=\mathrm{Cm}$
$3\left(\mathrm{mg} \mathrm{KCl} / \mathrm{m}^{\wedge} 3\right)$
$40.00=$ no data

Time, min

$$
\begin{aligned}
& 28 \\
& 43 \\
& 58
\end{aligned}
$$

Sta $5 A-1$

0.00

0.00

14.80
Sta $5 A-3$
4.61
5.52

8.17

Sta $5 A-4$
10.62
16.45
32.90
Sta 1A-1
1.24
2.81
6.69

Sat, Aug 25, 1990 5:20 PM

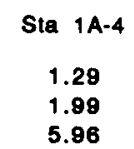




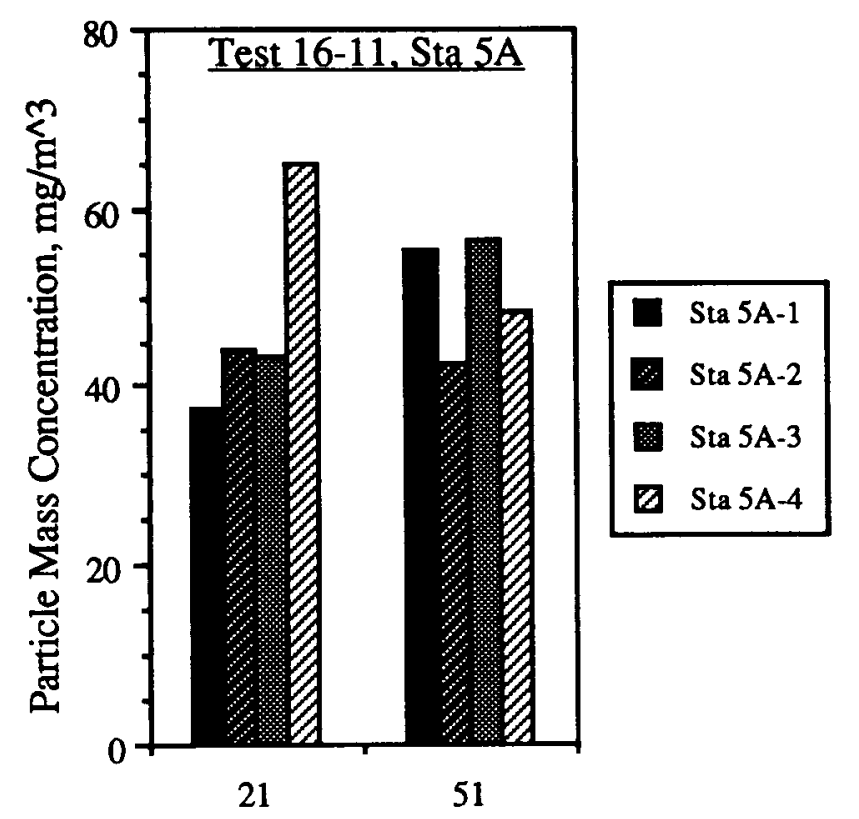

Time, $\min$

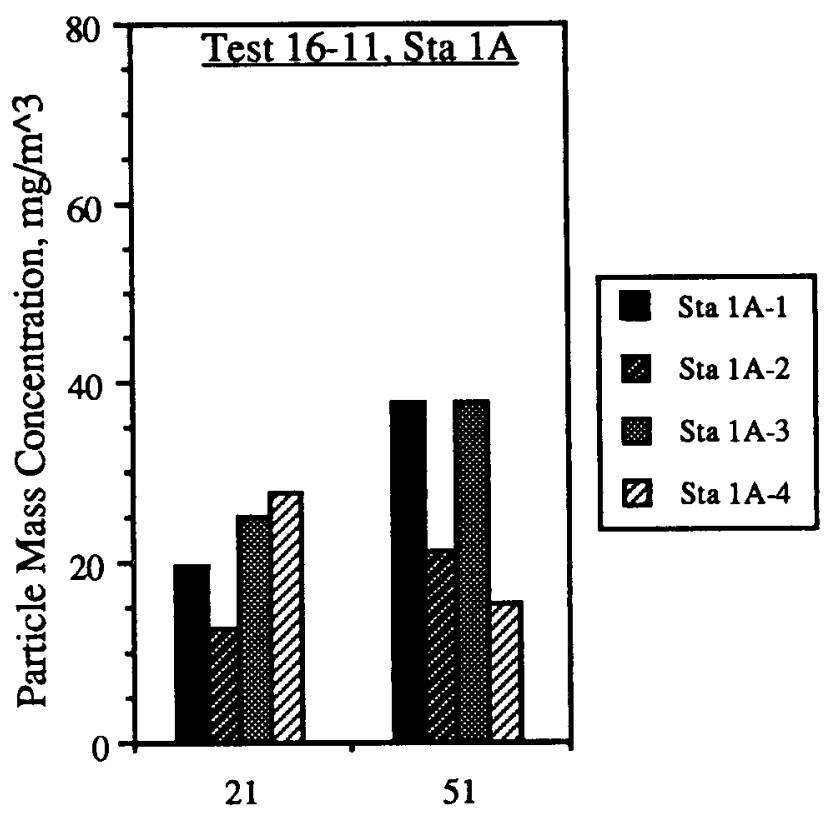

Time, $\min$
16-11 Quad Data 8/80

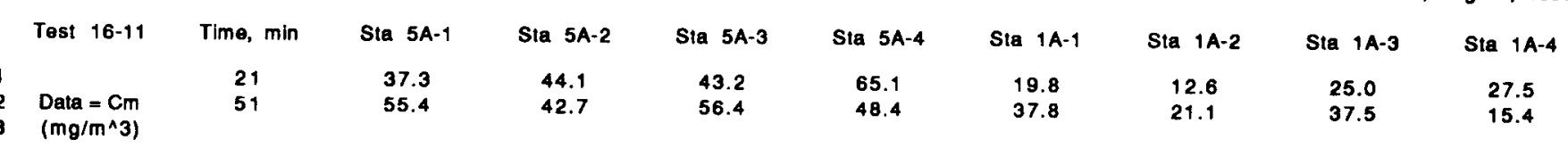




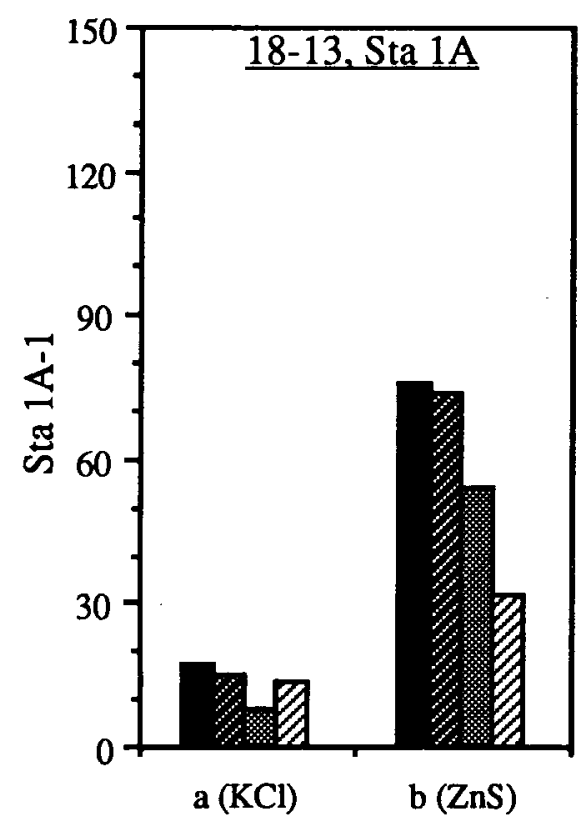

Test Sequence

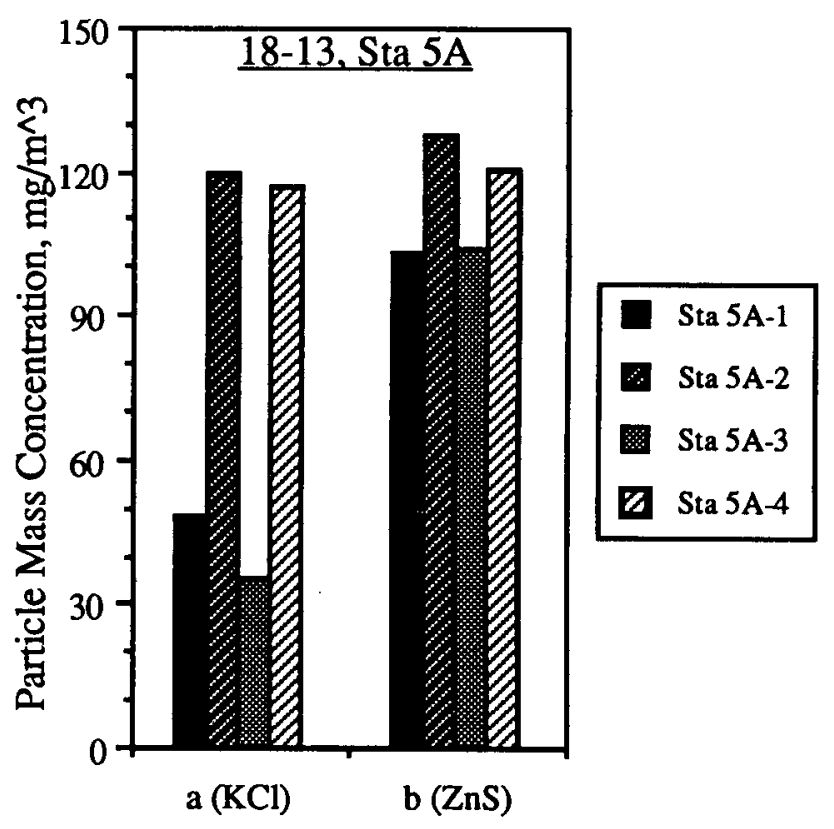

Test Sequence
18-13 Quad Data 8/90

\begin{tabular}{|c|c|c|c|c|c|c|c|c|c|}
\hline Test $18-13$ & Test Sequence & Sta $5 A-1$ & Sta $5 A-2$ & Sta $5 A-3$ & Sta $5 A-4$ & Sta $1 A-1$ & Sta 1A-2 & Sta 1A-3 & Sta 1A-4 \\
\hline & $\mathrm{a}(\mathrm{KCl})$ & 48.5 & 119.4 & 35.3 & 116.8 & 17.2 & 15.3 & 8.1 & 13.7 \\
\hline 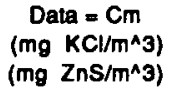 & $b(\mathrm{ZnS})$ & 102.8 & 127.9 & 104.0 & 120.1 & 75.7 & 73.2 & 54.0 & 31.8 \\
\hline
\end{tabular}




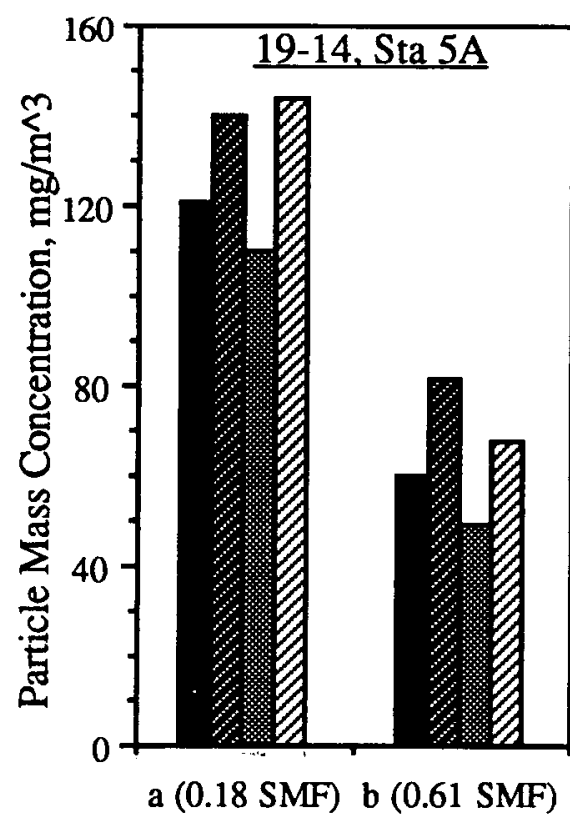

Test Sequence

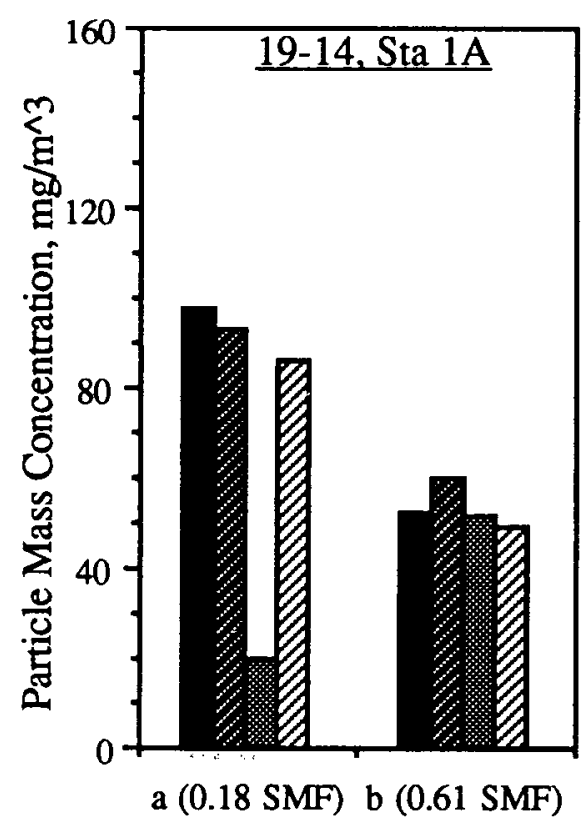

Test Sequence
19-14 Quad Data 8/90

Test 19-14 Test Sequence

a (0.18 SMF)

Data $=\mathrm{Cm} \quad$ o $(0.61$ SMF) $\left(\mathrm{mg} / \mathrm{m}^{\wedge} 3\right)$
Sta 5A-1

120.5

59.9
Sta 5A-2

139.9

81.8
Sta $5 A-4$

144.0

110.1

48.9
Sta 1A-1

97.4
Thu, Aug 23, 1990 12:25 PM

Sta $1 A-$

93.1

60.2

Sta $1 \mathrm{~A}-3$

19.7

51.5
3 Sta 1 A-4

86.2
Sta 1A-1

Sta 1A-2

Sta 1A-3

B Sta $1 \mathrm{~A}-4$ 
APPENDIX G

INLET AND OUTLET PARTICLE MASS FLOW RATES 


\section{APPENDIX G}

\section{INLET AND OUTLET PARTICLE MASS FLOW RATES}

Figures show particle mass flow rate versus time at the inlet and outlet of the test section for each test. Particle mass flow rates in the figures represent values determined in Appendix E. Sampling was not performed during the early periods of each test to allow the test section to be purged about five times by the inlet gases. The duration of this delay varied and was based on the thermal-hydraulic characteristics of each test. In the figures, straight lines connect data obtained from the same station and do not represent instantaneous particle mass flow rate information. Solid lines connecting the data points represent results based on gravimetric analys is of the aerosol samples, and dashed lines represent those based on chemical analyses. Tests $12 \mathrm{a}$ and $12 \mathrm{~b}$, and Tests $12 \mathrm{c}$ and $12 \mathrm{~d}$ were plotted on the same figures, with data from one test connected using solid lines, and the other using dashed lines. All data from Test $12 \mathrm{a}$ through $12 \mathrm{~d}$ were analyzed using a fluoroscopic method. Where particle mass flow rates were available based on gravimetric and chemical methods of analysis, both sets of results are plotted on the same scales. Results based on both types of analyses were similar, as shown in the figures for Tests $8,10,11,13 a, 13 b, 14 a$, and 14b. 


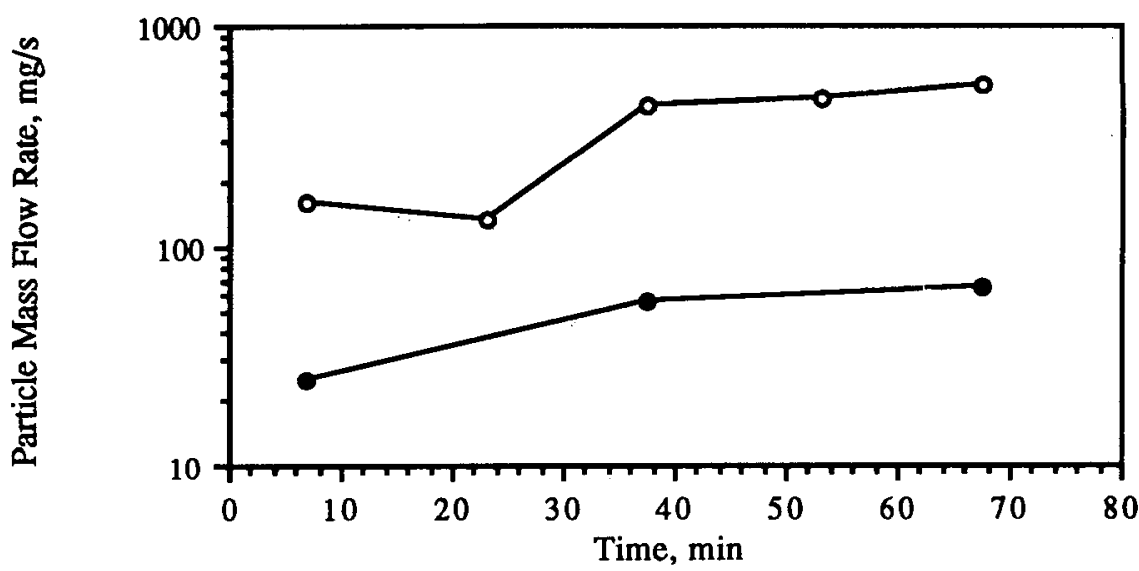

Test 10-1

吕

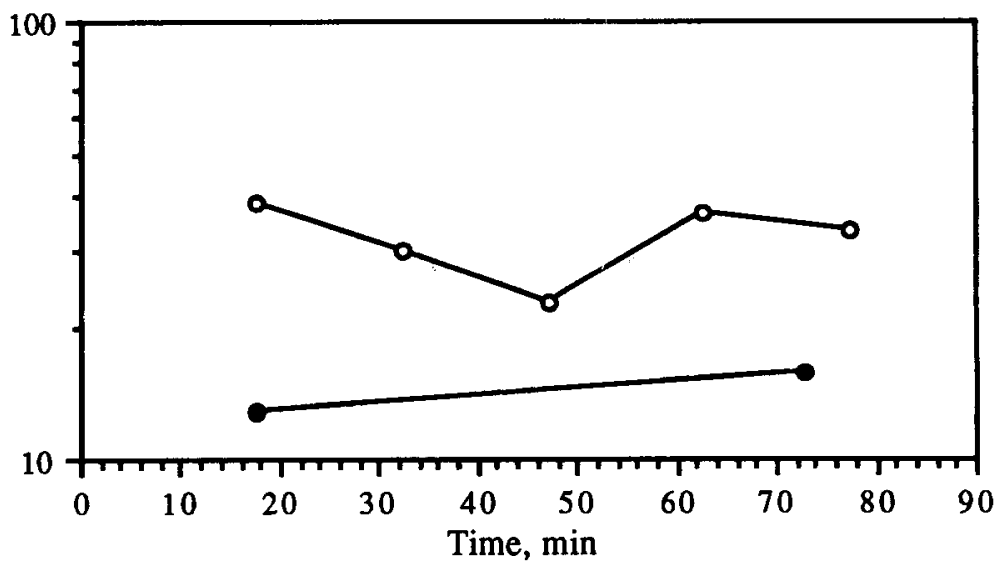

Test 15-2

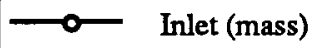

$\longrightarrow$ Outlet (mass)

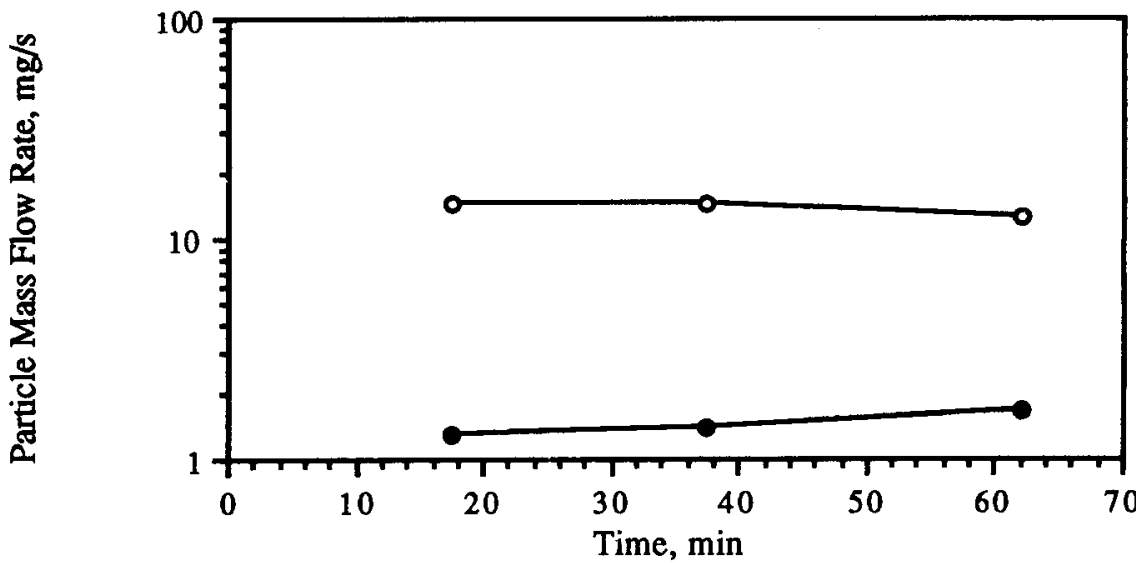

Test 2-3 


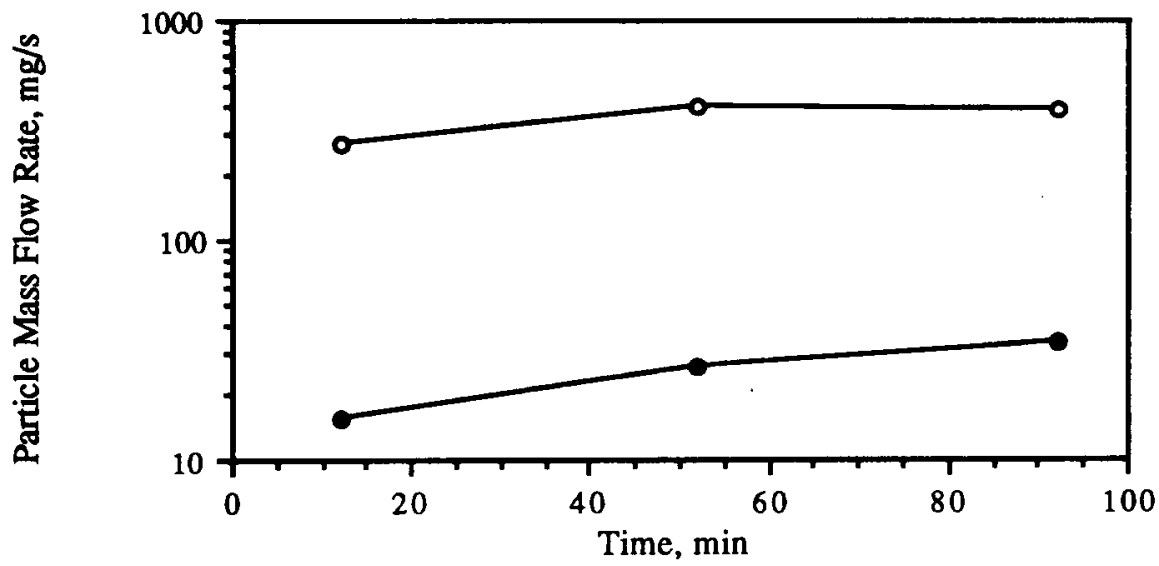

Test 10-4

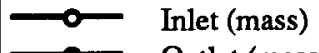

Outlet (mass)

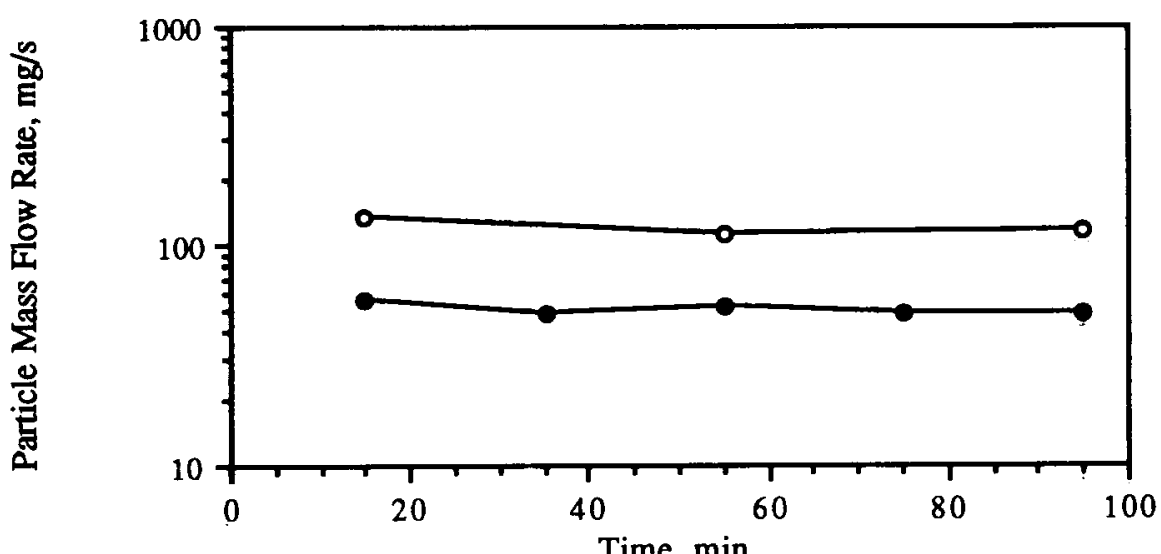

Test 7.5

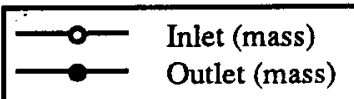

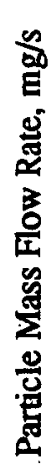

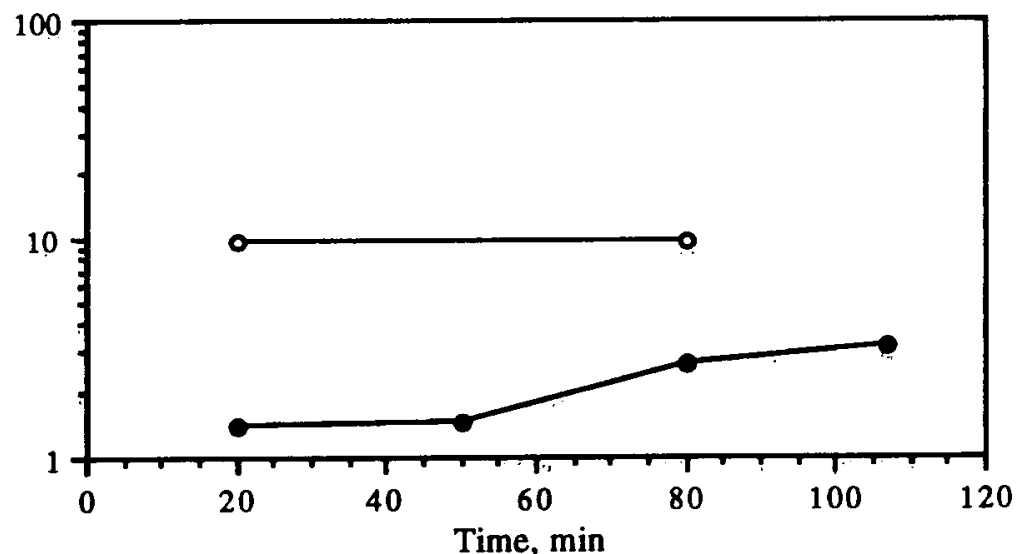

Test 11-6

Inlet (mass)

$\begin{array}{ll}\longrightarrow & \text { Onlet (mass) } \\ & \text { Outlet (mass) }\end{array}$

G.3 


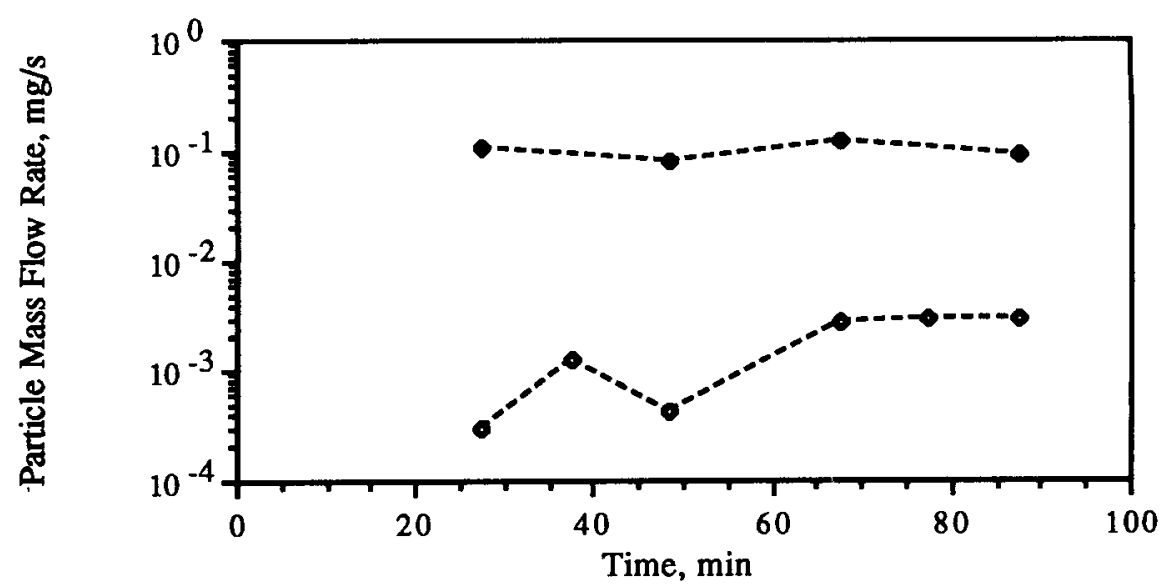

Test 9-7

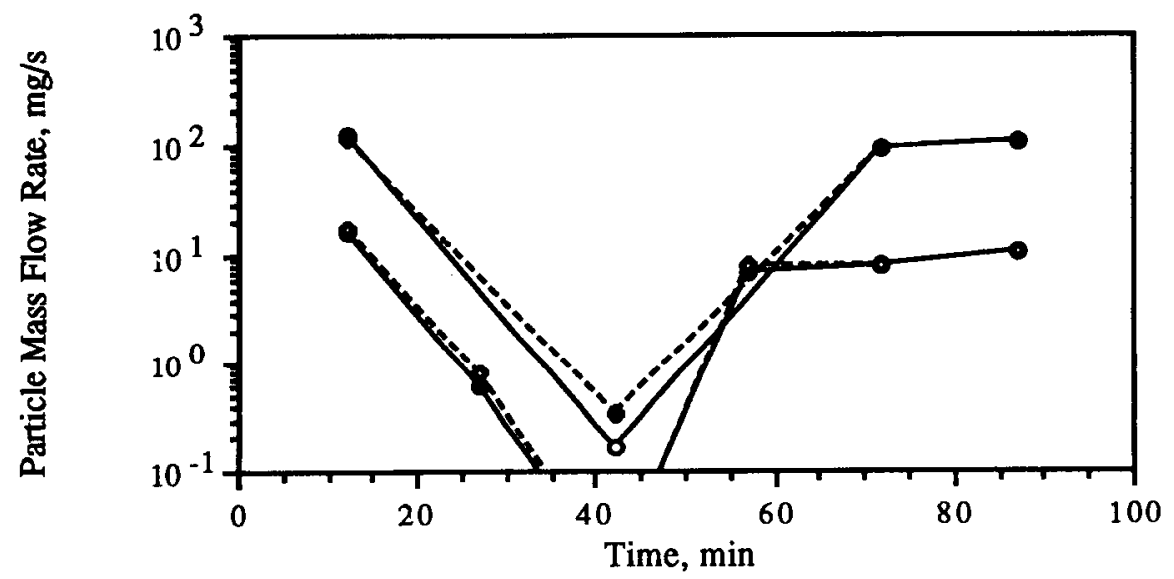

Test 14-8

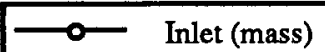

$\longrightarrow$ Outlet (mass)

---.. Inlet (chem)

---০-- Outlet (chem)

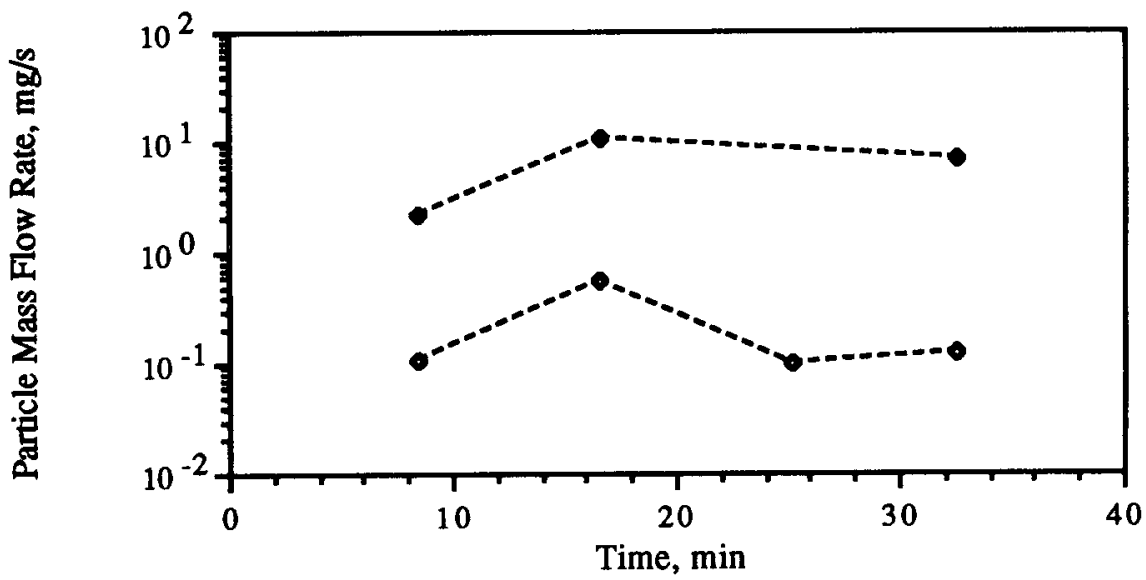

Test 5-9 


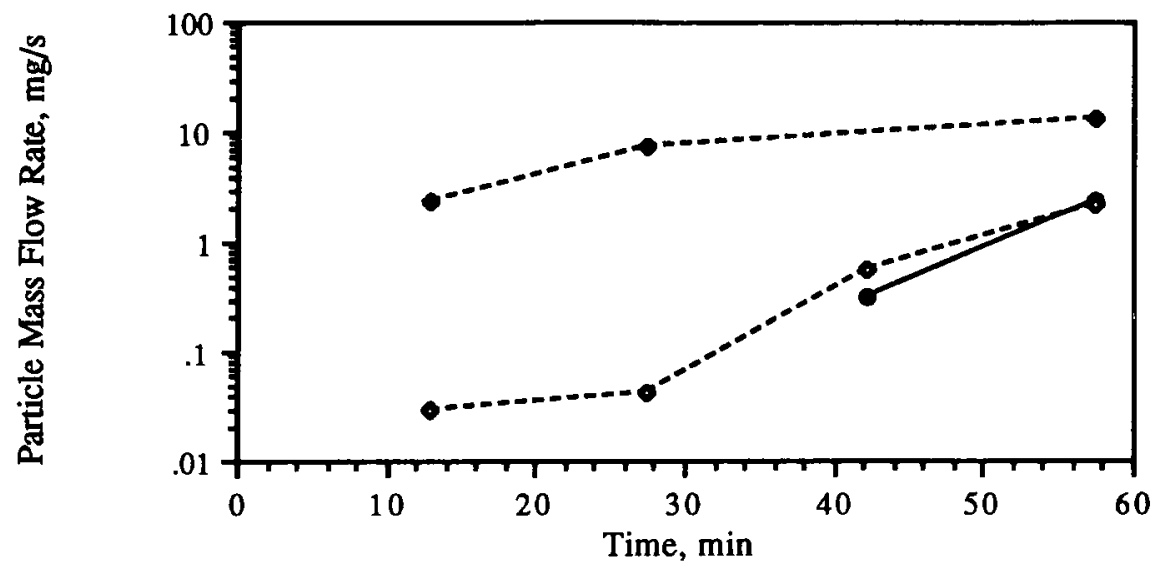

Test 13-10

$\longrightarrow$ Outlet (mass)

- - -.. Inlet (chem)

----- Outlet (chem)

No Inlet (mass) data was obtained

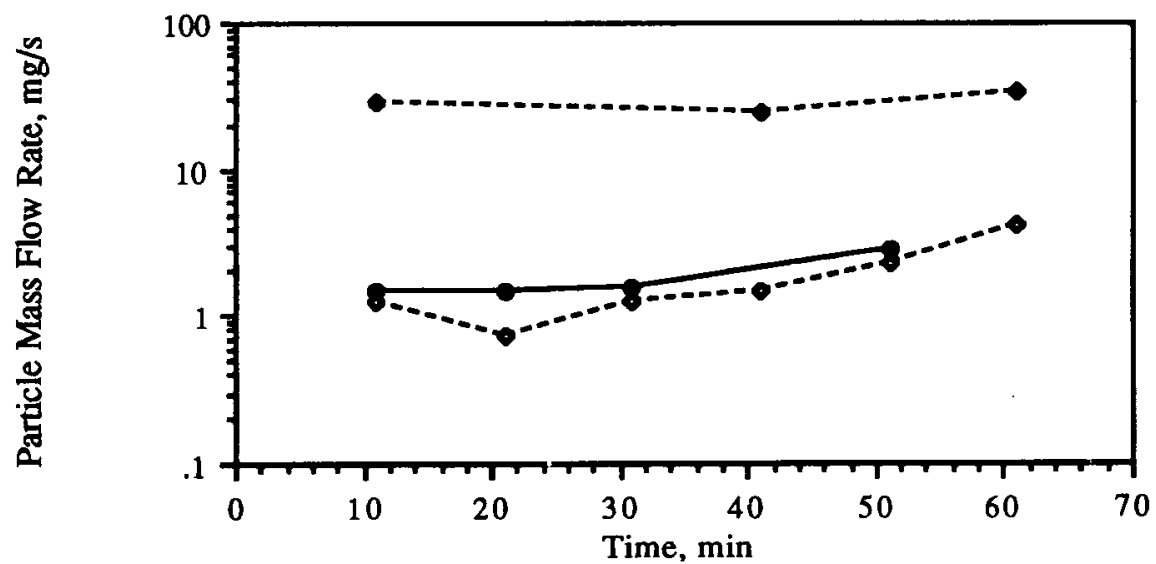

Test 16-11

$\longrightarrow$ Outlet (mass)

---- Inlet (chem)

- Outlet (chem) 


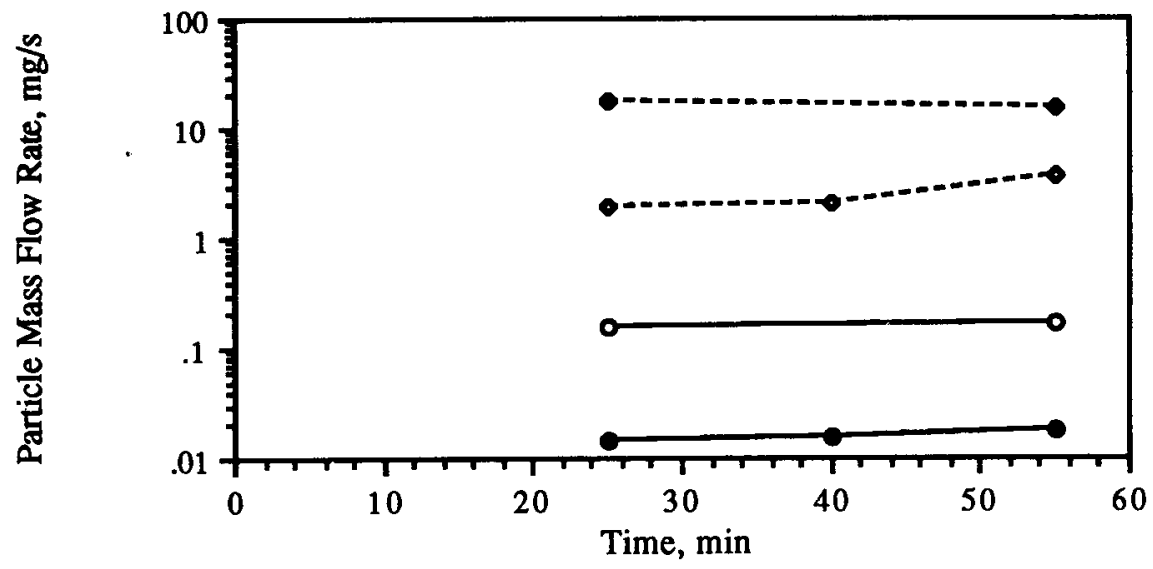

Tests $17-12 a$ \& $17-12 b$

- $12 \mathrm{a}$ Inlet

$\longrightarrow 12 \mathrm{a}$ Outlet

-. $12 \mathrm{~b}$ Inlet

---4 12b Outlet

告

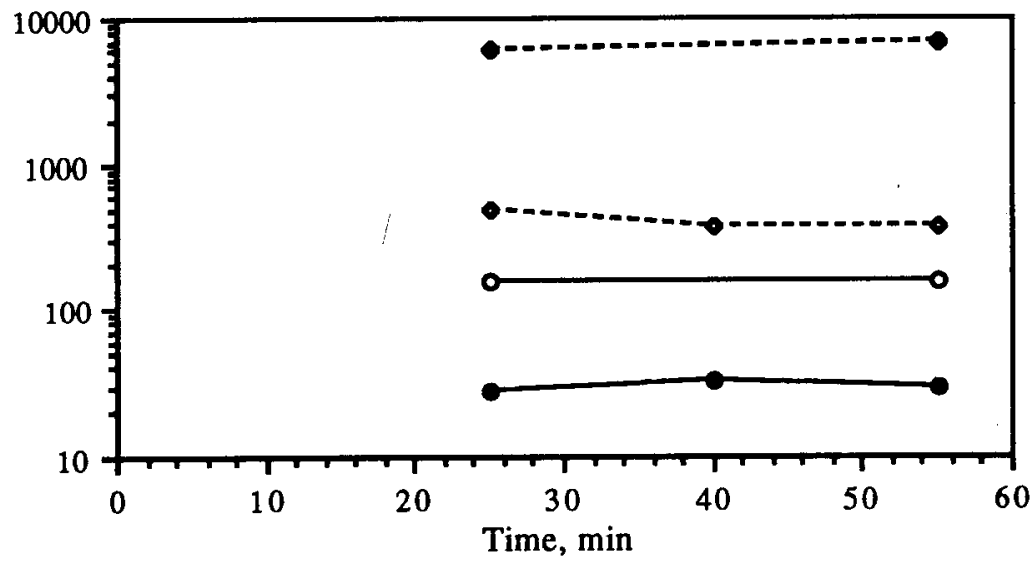

Tests $17-12 \mathrm{c} \& 17-12 \mathrm{~d}$

- $12 \mathrm{c}$ Inlet $\longrightarrow \quad 12 \mathrm{c}$ Outlet

-m-4--12d Inlet

---๑-- 12d Outlet 

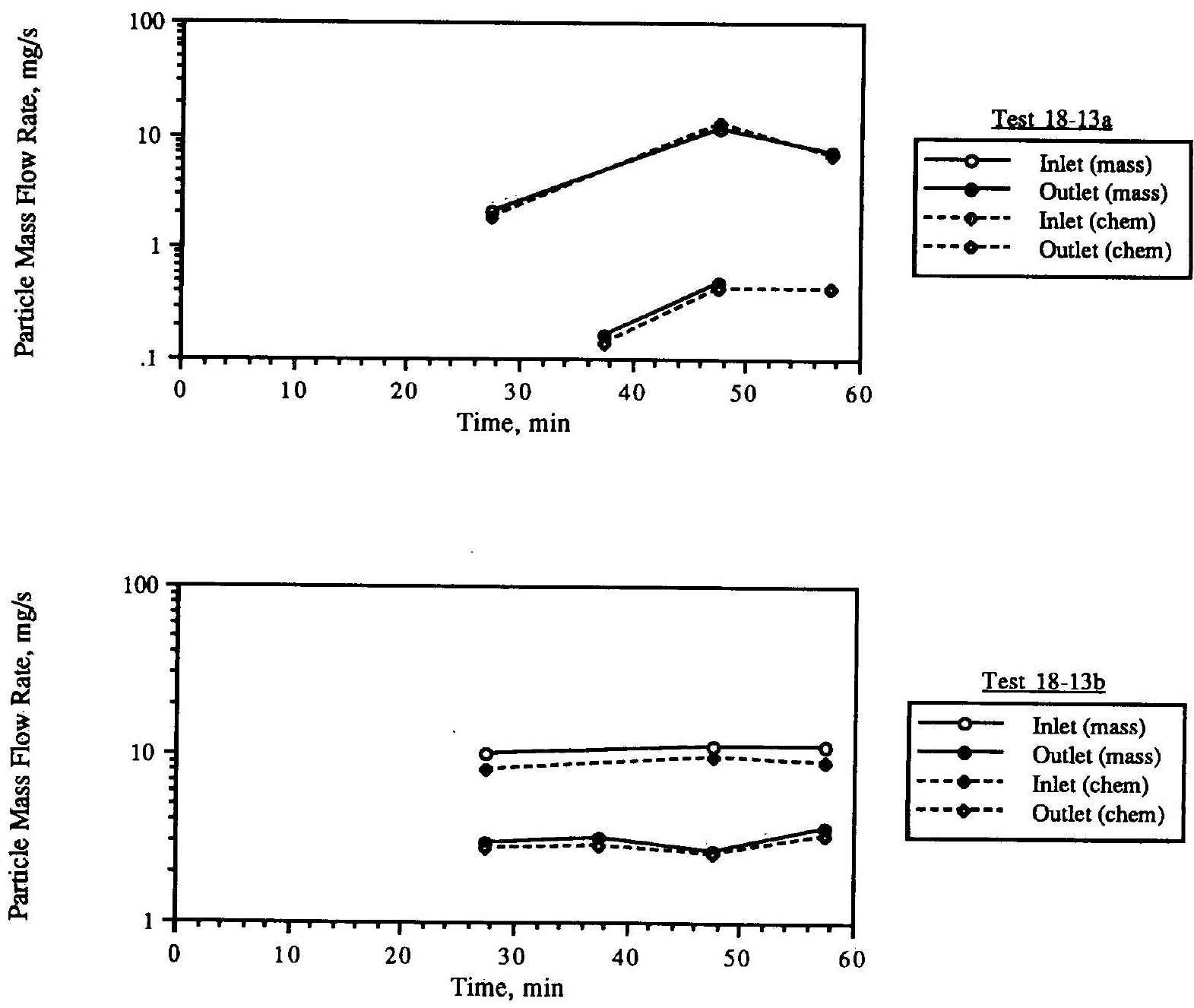


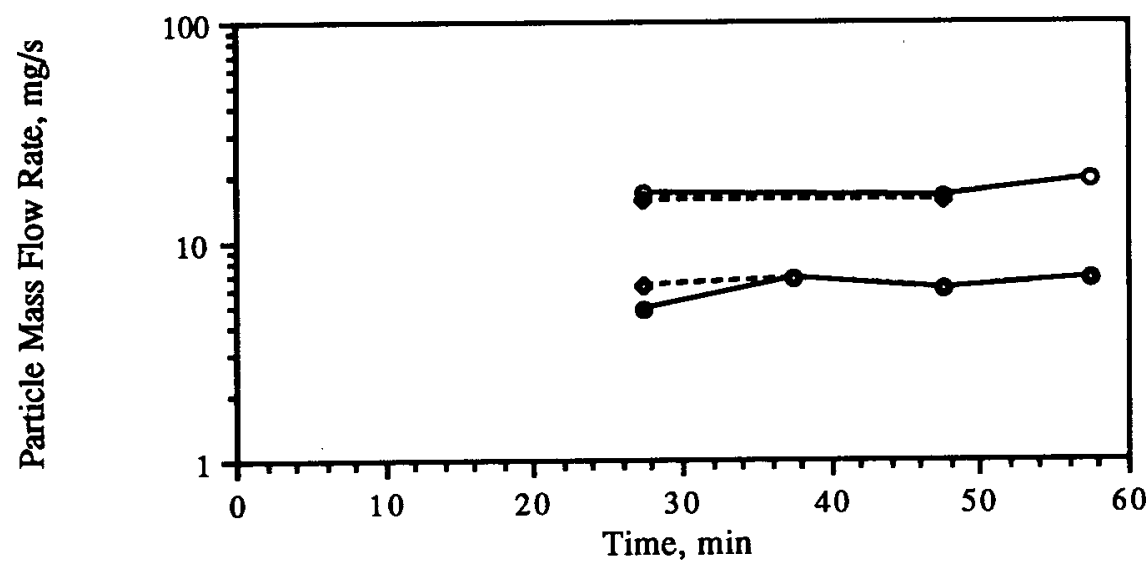

Test 19-14a

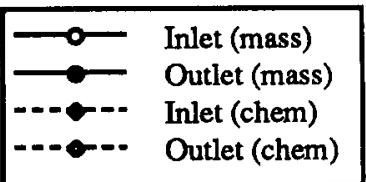

告

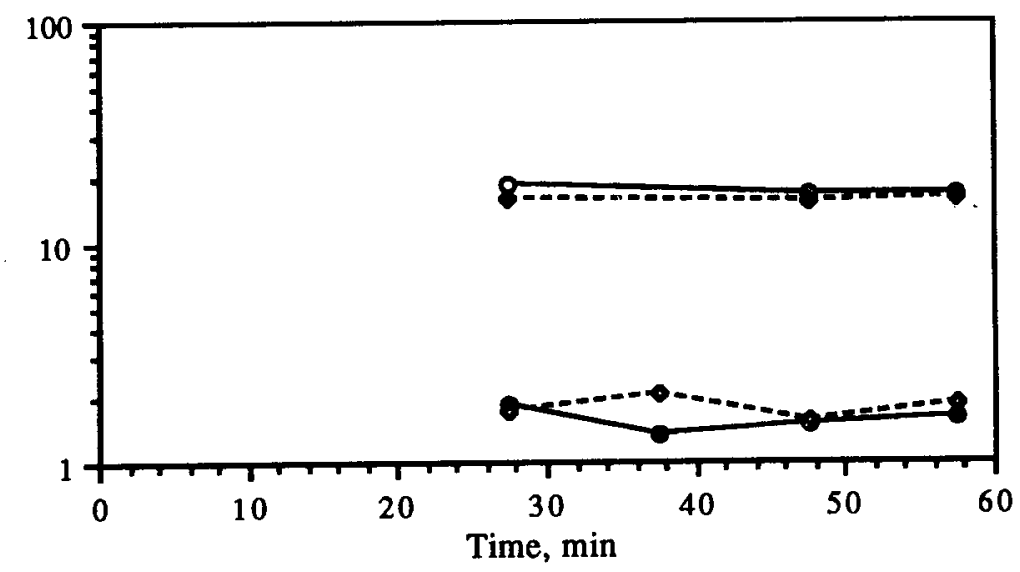

Test 19-14b

$\longrightarrow$ Inlet (mass)

$\longrightarrow$ Outlet (mass)

---0-. Inlet (chem)

---๑-- Outlet (chem) 
$19-14$ 2 ICEDF particle 3 mass flow 4 rate figures 5 (mg/s) 6 19-14a: 2-6 7 19-14b: 7-10 8 9
Time, min

$$
\begin{aligned}
& 27.5 \\
& 37.5 \\
& 47.5
\end{aligned}
$$

Inlet (mass)

Outlet (mass)

Inlet (chem)

Outlet (chem) Inlet (mass)

$\begin{array}{ll}15.6 & 6.17 \\ & 6.85 \\ 15.2 & 6.06 \\ & 6.62\end{array}$

$$
\begin{aligned}
& 4.89 \\
& 6.76 \\
& 6.12
\end{aligned}
$$

6.85

\section{2 \\ 16.8 \\ 16.5}

Outlet (mass) Inlet (chem) Outlet (chem)

$\begin{array}{lll}1.83 & 15.9 & 1.73 \\ 1.32 & & 2.02 \\ 1.46 & 15.5 & 1.54 \\ 1.61 & 16.1 & 1.86\end{array}$

ICEDF $m$ Data 1/91

$18-13$ 2 ICEDF particle

3 mass flow 4 rate figures $5 \quad(\mathrm{mg} / \mathrm{s})$ 6 18-13a:13-16 7 18-13b:17-20 8

9

\section{Time, min}

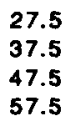

47.5

57.5
Inlet (mass)

2.09
11.79
7.27

Outlet (mass)

\subsection{6}

0.49

1.87
12.85
6.63

Outlet (chem)

Inlet (mass)

Outlet (mass) Inlet (chem)

Sal, Jan 19, $1991 \quad$ 11:58 AM

KCEF m Data 1/91

Time, min
25.00
40.00
55.00

12a Inlet

12a Outlet

$12 b$ Inlet

12b Outlet

12c Inlet

12c Outle

17.55

1.97

0.15

0.014

0.16

0.018

15.93

2.08

3.78

155.33

28.09

33.52

153.20

$\begin{array}{ll}7.95 & 2.78 \\ & 2.81 \\ 9.76 & 2.54 \\ 8.88 & 3.26\end{array}$

mass flow

( $\mathrm{mg} / \mathrm{s}$ )

6 17-12a:23-24

7 17-12b:25-26

8 17-12c:27-28

9 17-12d:29-30

ICEDF m Data 1/91

16-11

1

2 ICEDF particle

3 mass flow

rate llgures

( $\mathrm{mg} / \mathrm{s}$ )

6 no Inlet (mass)

$731 \mathrm{~min}$ inlet

8 datum is bad
Time, min

11.00

21.00

31.00

41.00

51.00

61.00
Outlet (mass) Inlet (chem) Outlet (chem)

1.45
1.46
1.57

2.79
29.69

24.37

33.43
$13-10$

ICEDF particle

mass flow

rate figures

( $\mathrm{mg} / \mathrm{s}$ )

no Inlet (mass)
Sat, Jan 19, $1991 \quad 11: 58$ AM

$\begin{array}{cc}12 d \text { Inlet } & 12 d \text { Outlet } \\ 6000.54 & 474.70 \\ & 365.26 \\ 6743.99 & 375.40\end{array}$




$$
5 \cdot 9
$$

Time, $\mathrm{mln}$ 8.50 16.60 25.20

ICEDF particle

mass flow

rate flgures

( $\mathrm{mg} / \mathrm{s})$

No (mass)
Inlet (chem) Outlet (chem)

2.14

10.71

0.11

0.56

0.10

6.81
14-8 Time, min

ICEDF particle
mass flow

12.00

27.00

42.00

rate figures

( $\mathrm{mg} / \mathrm{s}$ )

$42 \mathrm{~min}$ data

57.00

72.00

87.00

Inlet (mass)

123.46

17.12

17.12
0.61

Inlet (chem)

Outlet (chem)

0.16

0.01

7.17

94.54

107.61

10.79

116.30

18.08

0.35

0.01

91.00

8.32

103.80
ICEDF m Dala $1 / 91$

9-7 Time, min

27.5

37.5

48.4

67.5

77.5

87.5
Inlet (chem) Oullet (chem)

0.106

0.081

0.128

0.094

0.00030

0.00124

0.00043

0.00279

0.00291

0.00285
11-6

Time, min

ICEDF particle

mass flow

rate figures

( $\mathrm{mg} / \mathrm{s}$ )

No (chem)

50.0

80.0

107.0
Sat, Jan 19, $1991^{\circ} \quad 11: 58$ AM

Inlet (mass)

9.61

9.61

1

Outlet (mass)

$\begin{array}{cc}7-5 & \text { Time, mIn } \\ & 15.0 \\ \text { ICEDF particle } & 35.0 \\ \text { mass flow } & 55.0 \\ \text { rate flgures } & 75.0 \\ \text { (mg/s) } & 95.0 \\ \text { No (chem) } & \end{array}$

ICEDF m Data $1 / 81$

Inlei (mass) Outlet (mass)

$\begin{array}{ll}132.55 & 55.42 \\ & 47.91 \\ 110.44 & 52.85 \\ & 48.34 \\ 114.19 & 48.19\end{array}$

$10-4$

Time, $\min$

Inlet (mass)

Outlet (mass)

2-3

15.65

12.0
52.0
92.1

273.31

408.32

26.65

ICEDF particle

mass flow

rate figures

( $\mathrm{mg} / \mathrm{s})$

No (chem)

Outlet at

Station $1 \mathrm{~A} 1$

33.54

ICEDF particle
mass flow

mass flow

( $\mathrm{mg} / \mathrm{s})$

No (chem)

Outlel at

Station $1 \mathrm{~A} 1$

Time, min

Inlet (mass)

Sat, Jan 19, $1991 \quad$ 11:58 AM

17.5
37.5
62.0

14.09

14.25

12.58

62.0

ICEDF m Data $1 / 81$

1.29

1.39

Sat, Jan 19, $1991 \quad$ 11:58 AM

\begin{tabular}{|c|c|c|c|c|c|c|c|c|}
\hline & $15-2$ & Time, $\min$ & Inlet (mass) & Outlet (mass) & $10-1$ & Time, $\operatorname{mln}$ & Inlet (mass) & Outlet (mass) \\
\hline 1 & & 17.5 & 38.84 & 12.91 & & 7.00 & 160.09 & 24.15 \\
\hline 2 & ICEDF particle & 32.5 & 30.10 & & ICEDF particle & 23.00 & 134.23 & \\
\hline 3 & mass flow & 47.2 & 22.69 & & mass flow & 37.50 & 436.18 & 57.19 \\
\hline 4 & rate figures & 62.5 & 36.52 & & rate figures & 53.00 & 472.62 & \\
\hline 5 & $(\mathrm{mg} / \mathrm{s})$ & 72.7 & & 15.79 & (mg/s) & 67.35 & 541.76 & 64.39 \\
\hline 6 & No (chem) & 77.5 & 33.47 & & No (chem) & & & \\
\hline 7 & Outlet atiAi & & & & Outlet at & & & \\
\hline 8 & 47 min outlet & & & & Station $1 \mathrm{A1}$ & & & \\
\hline
\end{tabular}




\section{DISTRIBUTION}

No. of

Copies

\section{OFFSITE}

U.S. Nuclear Regulatory

$$
\text { Commission }
$$

Division of Technical

Information and Document

Control

7920 Norfolk Avenue

Bethesda, MD 20014

5 C. W. Nilsen

Office of Nuclear Regulatory Research

U.S. Nuclear Regulatory Commission

Washington, DC 20555

D. A. Cool

Office of Nuclear Regulatory Research

U.S. Nuclear Regulatory Commission

Washington, DC 20555

R. 0. Meyer

Office of Nuclear Regulatory Research

U.S. Nuclear Regulatory Commission

Washington, DC 20555

J. A. Mitcheili

U.S. Nuclear Regulatory Commission

Washington, DC 20555

K. G. Steyer

Office of Nuclear Regulatory Rèsearch

U.S. Nuic lear Regulatory

Cominission

Wastingtion, DC 20555
No. of

Copies

T. F. Zanin

American Electric Power Service Corporation

1 Riverside Plaza

Columbus, $\mathrm{OH} 43215$

G. B. Swindlehurst

Duke Power Company

422 S. Church Street

Charlotte, NC 28242

N. A. Smith

Duke Power Company

McGuire Nuclear Station

12700 Hagers Ferry Road

Huntersville, NC 28078

W. K. Lifsey

Duke Power Company

Catawba Nuclear Station

PO Box 256

Clover, SC 29710

R. DeVault

Tennessee Valley Authority

$400 \mathrm{~W}$. Summit Hill Drive

Mail Stop $W-8 D 200 C-K$

Knoxville, TN 37902

J. A. Gieseke

Battelle Columbus Laboratories

$505 \mathrm{King}$ Àve.

Colutibus, OH 43201

K. W: Lee

Battèlie Columibús Laboratories

505 King Ave.

Columbus, $\mathrm{OH} \quad 43201$

0. R. Moss

Chèmical Industry Institute of Toxicology (CIIT)

6 Davis Drive

PO Box 12137

Research Triangle Park, NC 27709 
No. of

Copies

M. Merilo

Electric Power Research Inst. PO Box 10412

Palo Alto, CA 94303

A. K. Postma

Route 1

Box 46A

Halfway, OR 97834

J. E. Brockmann

Sandia National Laboratories

PO Box 5800

Albuquerque, NM 87185

N. A. Russell

Sandia National Laboratories

Containment Modeling Div 6429

Albuquerque, NM 87185

B. A. Ross

Stirling Technology Company

2952 George Washington Way

Richland, WA 99352

International

M. W. Jankowski

International Atomic Energy Agency

Wagramerstrasse 5

PO Box 100

A-1400 Vienna, Austria

H. Tuomisto

Nuclear Power Engineering Dept.

Imatran Voima Oy

PO Box 112

SF-01601 Vantaa

Finland
No. of

Copies

P. Lundstrom

Imatran Voima $0 y$

PO Box 112

SF-01601 Vantaa

Finland

0 . Hongisto

Research and Development

Imatran Voima oy

Viikintie 3

SF-00560 Helsinki

Finland

L. Wolf

Battelle-Institut e.V.

Am Römerhof 35

D-6000 Frankfurt am Main 90

Germany

\section{ONSITE}

1 Westinghouse Hanford

J. D. McCormack, L5-31

29 Pacific Northwest Laboratory

R. T. Allemann, K7-15

J. M. Bates, K7-15

M. K. Drost, K5-19

E. J. Eschbach, K7-15 (3)

L. D. Kannberg, K5-02

M. W. Ligotke, P7-54

R. L. Moffitt, K6-46

P. C. Owczarski, K6-08

E. W. Pearson, K7-15

G. F. Piepel, K7-34

L. E. Rogers, P7-54

W. K. Winegardner, K5-19 (4)

Technical Report Files (5)

Publishing Coordination 


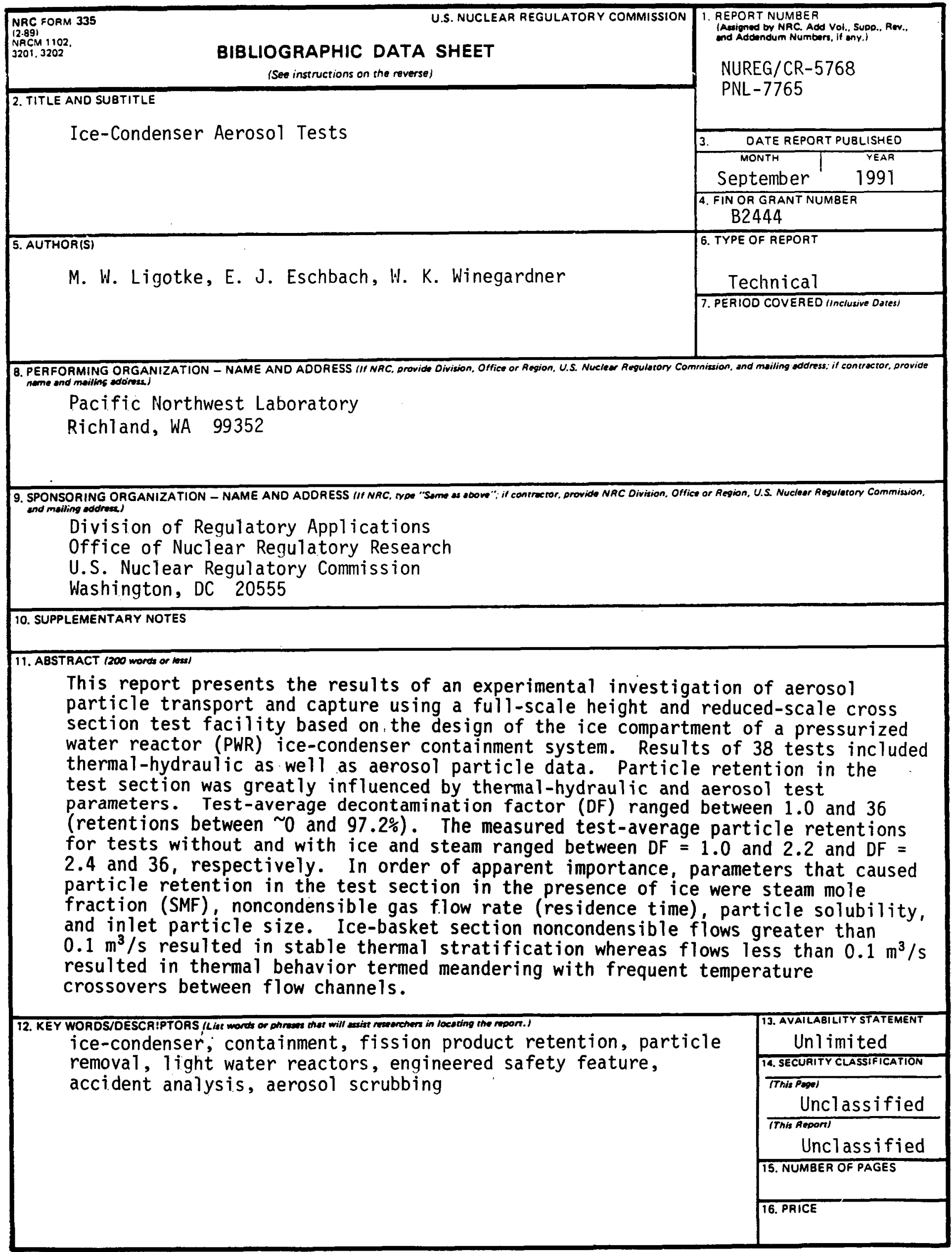

